\title{
RESULTS OF THE 2008/2009 KNOWLEDGE AND OPINIONS SURVEYS CONDUCTED FOR THE U.S. DEPARTMENT OF ENERGY HYDROGEN PROGRAM
}

\author{
R. L. Schmoyer \\ Tykey Truett \\ Oak Ridge National Laboratory \\ Christy Cooper \\ Andrea Chew \\ U.S. Department of Energy
}

April 2010

\author{
Prepared by the \\ OAK RIDGE NATIONAL LABORATORY \\ Oak Ridge, Tennessee 37831-6073 \\ Managed by \\ UT-BATTELLE, LLC \\ For the \\ U.S., DEPARTMENT OF ENERGY \\ Under contract No. DE-AC05-00OR22725
}

Prepared for the

U.S. DEPARTMENT OF ENERGY

Washington, D.C. 



\section{CONTENTS}

LIST OF TABLES .......................................................................................................... iv

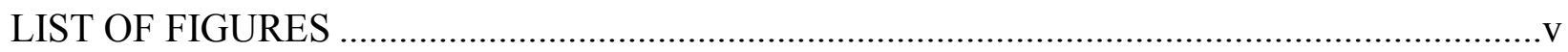

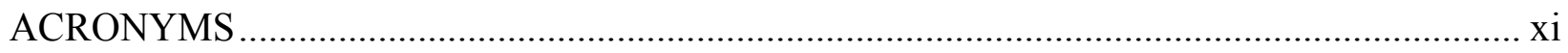

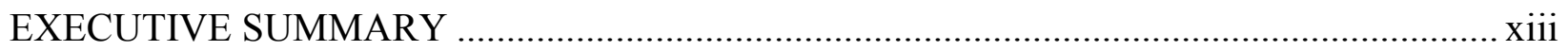

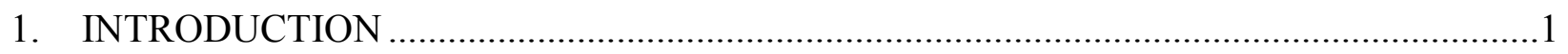

1.1 Background and the 2004 Baseline Assessment .........................................................

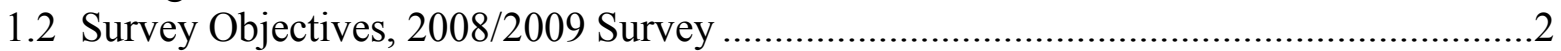

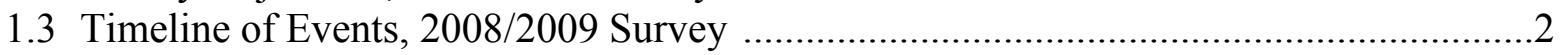

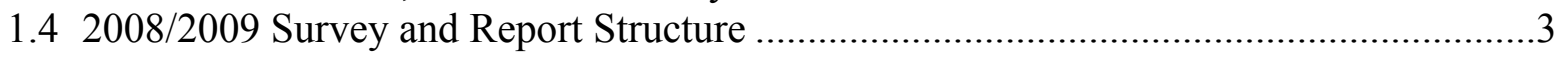

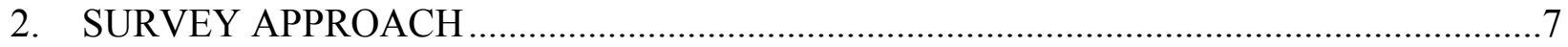

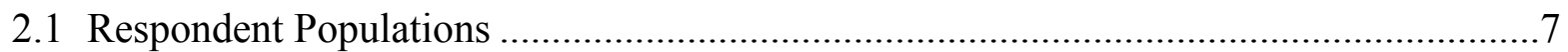

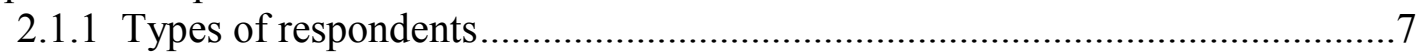

2.1.2 Estimated number of respondents ...............................................................

2.1.3 Coverage and response rates .................................................................8

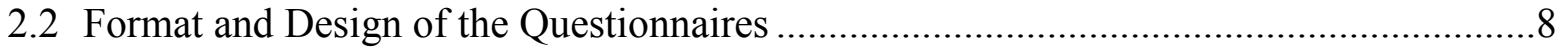

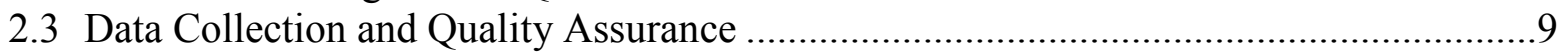

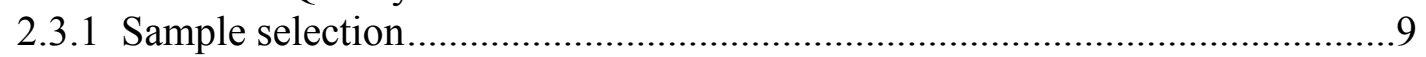

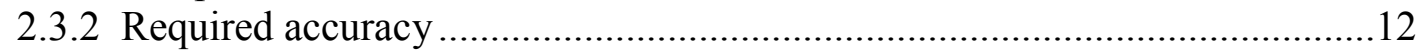

2.3.3 Coverage

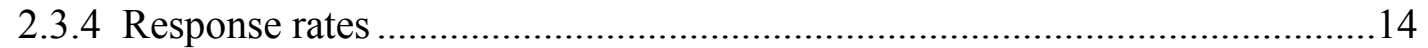

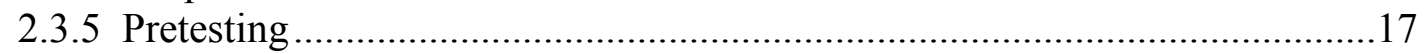

2.3.6 Quality assurance in the data analysis ..........................................................17

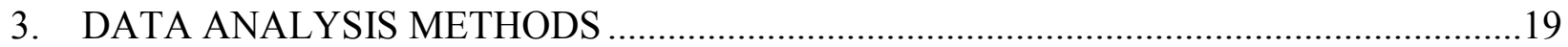

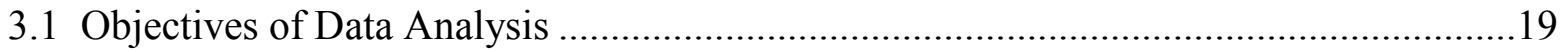

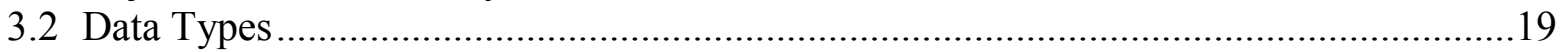

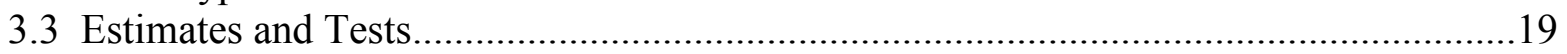

3.4 Comparison of 2008/2009 Results with the Baseline..................................................20

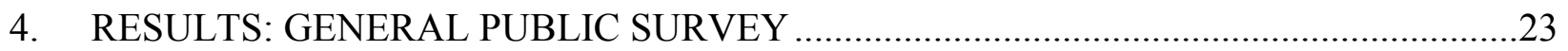

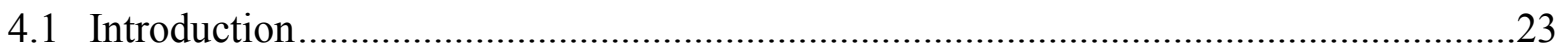

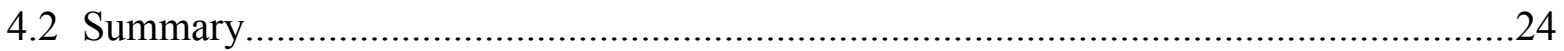

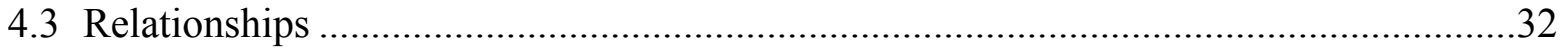

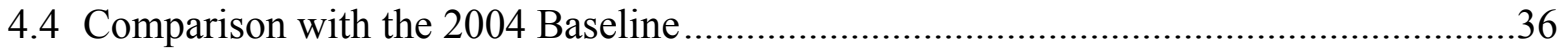

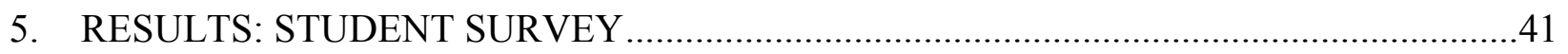

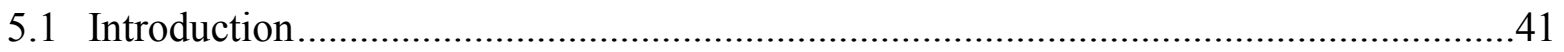

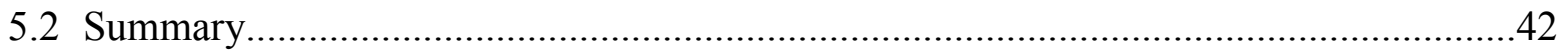

$\begin{array}{lll}\text { Hydrogen Knowledge and Opinions Surveys } & \text { i } & \text { April 21, } 2010\end{array}$ 


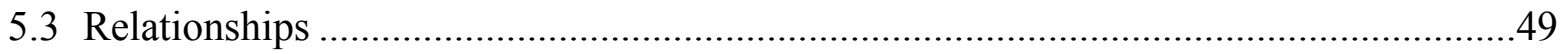

5.4 Comparison with 2004 Baseline ..........................................................................5

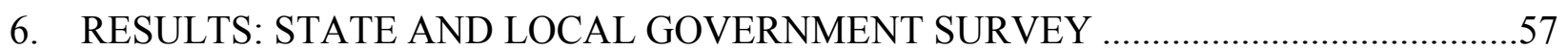

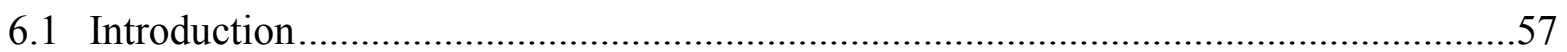

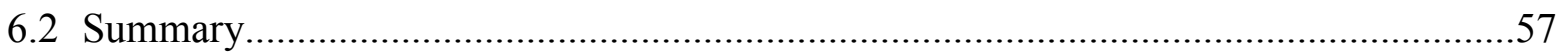

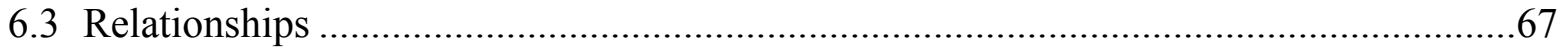

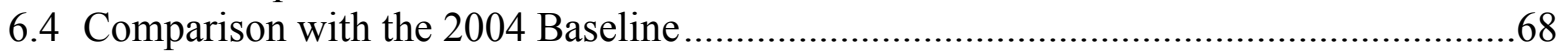

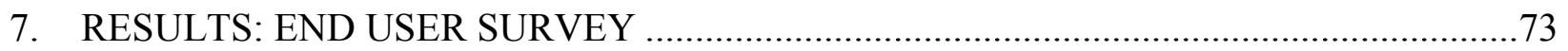

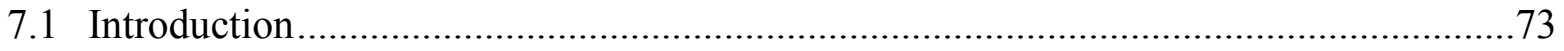

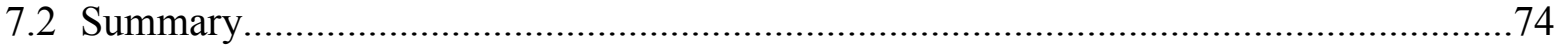

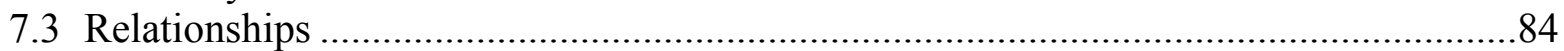

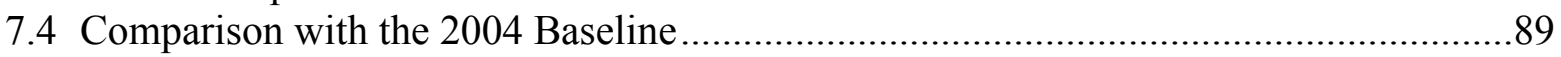

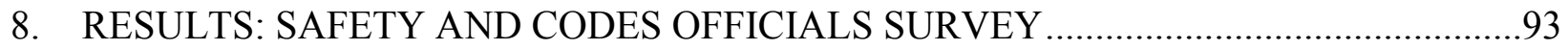

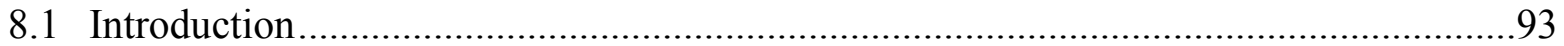

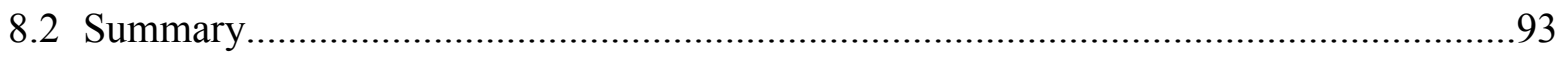

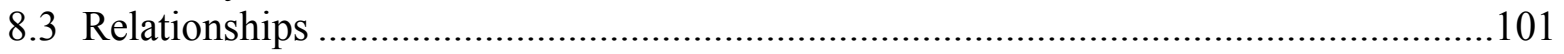

9. COMPARISON OF RESULTS FOR THE FIVE POPULATIONS ……………..................105

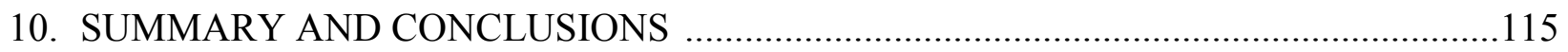

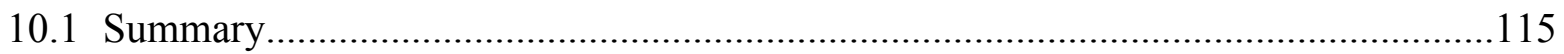

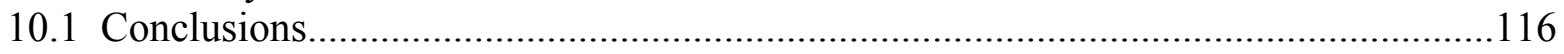

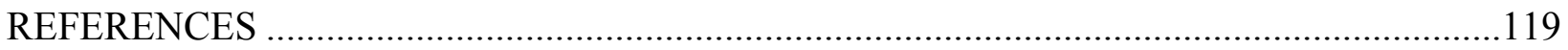

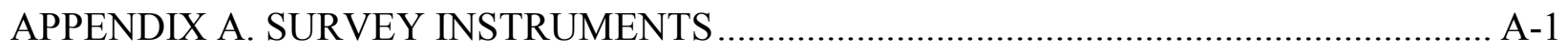

A.1 Hydrogen - General Public ………................................................................ A-2

A.2 Hydrogen - Students ........................................................................................... A-11

A.3 Hydrogen - State and Local Government Agencies ................................................ A-2

A.4 Hydrogen - Potential Large-scale End Users.................................................. A-31

A.5 Hydrogen - Safety and Codes Officials ................................................................... A-40

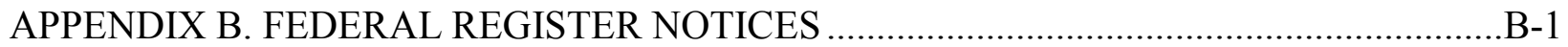

B.1 Federal Register, November 17, 2006 .................................................................

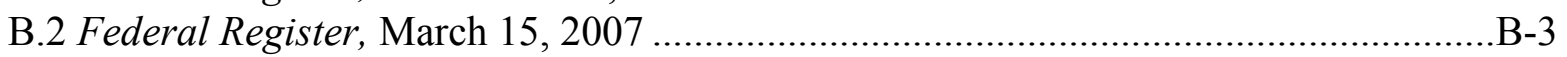

B.3 Federal Register, January 3, 2008 ............................................................................

B.4 Federal Register, April 30, 2008 ...........................................................................

APPENDIX C. TOTAL COUNTS FOR EACH SURVEY QUESTION

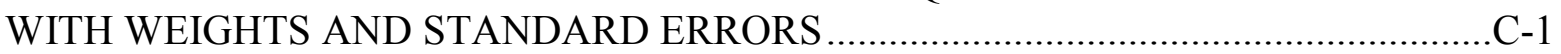

C.1 Summary of Responses to the General Public Survey ...................................................

C.2 Summary of Responses to the Student Survey ………………………………........... -20

C.3 Summary of Responses to the State and Local Government Survey..............................37 
C.4 Summary of Responses to the End User Survey....................................................53

C.5 Summary of Responses to the Safety and Codes Officials Survey..............................

APPENDIX D. NOTIFICATION LETTERS …........................................................... D-1

D.1 State and Local Government Agencies................................................................ D-2

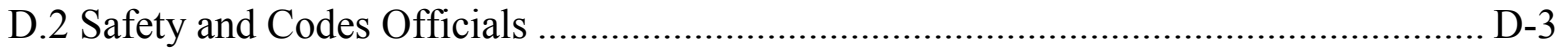

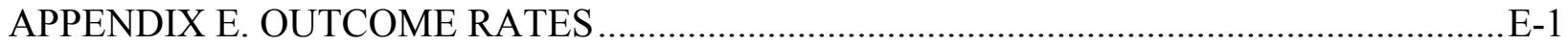

E.1. General Public Survey Outcome Rates ..................................................................E-2

E.2. Student Survey Outcome Rates........................................................................ E-3

E.3. State and Local Government Survey Outcome Rates .............................................E-4

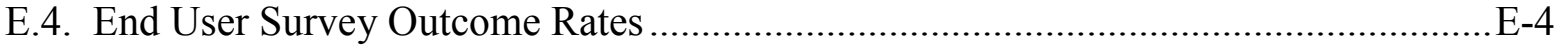

E.5. Safety and Codes Officials Survey Outcome Rates .................................................. E-5 


\section{LIST OF TABLES}

$\underline{\text { Table }}$

$\underline{\text { Page }}$

ES.1 Response rates by population, 2004 and 2008/2009 surveys ..................................... xiv

ES.2 Average technical scores by population for the 2004 and 2008/2009 surveys ................. Xvi

1.1 Number of responses and average score for each of the four survey populations included in the 2004 hydrogen survey

2.1 Number of responses expected for each of the five survey populations in the 2008/2009 hydrogen survey

2.2 Populations and interview plans for the three sectors in the end user population group .....12

4.1 Summary of results on the technical knowledge questions (correct/incorrect), general public

4.2 Summary of importance ranking, general public.....

5.1 Summary of results on the technical knowledge questions (correct/incorrect), students.

6.1 Summary of results on the technical knowledge questions (correct/incorrect), state and local governments

6.2 Summary of importance ranking, state and local governments

6.3 Time frames for implementation for government agencies planning to use hydrogen or fuel cells in the future

7.1 Summary of results on the technical knowledge questions (correct/incorrect), end users

7.2 Time frames for implementation for end users planning to use hydrogen or fuel cells in the future

8.1 Summary of results on the technical knowledge questions (correct/incorrect), safety and codes officials

8.2 Summary of importance ranking, safety and codes officials

8.3 Sources that would be used if additional information were needed to review an application for a stationary fuel cell or hydrogen refueling station, Question 35, safety and codes officials

9.1 Sample sizes and response rates by population for the 2004 and 2008/2009 surveys .......105

9.2 Average technical scores by population for the 2004 and 2008/2009 surveys ................108

10.1 Response rates by population, 2004 and 2008/2009 surveys ........................................116

E.1 Outcome frequencies for the general public survey ...............................................

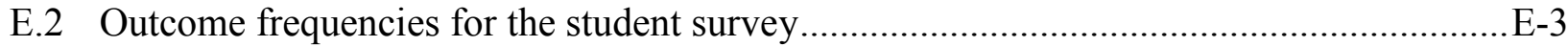

E.3 Outcome frequencies for the state and local government survey ...................................

E.4 Outcome frequencies for the end user survey .....................................................

E.5 Outcome frequencies for the survey of safety and codes officials................................. E-5 


\section{LIST OF FIGURES}

Figure

ES.1 Responses by technical score above/below average to Question 8, "How would you feel if your local gas station also sold hydrogen," general public survey....

$\underline{\text { Page }}$

Comparison of results of the 2004 and 2008/2009 surveys regarding opinions about the availability of hydrogen at a local gas station, Question 8, student survey ............... xvii

ES.3 The percentage of respondents in each population who agreed with statements about the advantages and safety of hydrogen as a vehicle fuel, 2008/2009 surveys ................ xvii

ES.4 Percentages of negative responses to "Hydrogen is too dangerous for everyday use by the general public" and positive responses to "Hydrogen is as safe to use in my car as gasoline and diesel fuels".

ES.5 Responses to Questions 24-25 concerning plans to use hydrogen and fuel cell technologies, state and local government survey.... xix

ES.6 The use of mass media for obtaining energy information, by population group, 2009/2009 surveys. xix

ES.7 The self-rated levels of familiarity with hydrogen and fuel cell technologies for each of the five population groups, 2008/2009 surveys .. XX

ES.8 Responses by gender to Question 10C, "Hydrogen is as safe to use in my car as gasoline and diesel fuels," general public survey xxi

1.1 List of eight technical knowledge questions used in the 2008/2009 hydrogen surveys ........5

4.1 Weighted percent of correct, incorrect, and "Don't know" responses for the technical knowledge questions, general public survey.....

4.2 Distribution of the number of correct answers to the eight technical knowledge questions, general public survey

4.3 Distribution of responses to the question about familiarity with hydrogen and fuel cell technologies, Question 1, general public survey

4.4 Mean of preference rankings of cost, safety, environment, convenience, and performance, Question 7, general public survey....

4.5 Share of respondents who would purchase a fuel cell vehicle if it were available at the same price as a gasoline-fueled vehicle, Question 11, general public survey....

4.6 Responses to statements about the potential benefits of the use of hydrogen as a vehicle fuel, Questions 10A and 10B, general public survey ....

4.7 Responses to the statement, "Hydrogen is as safe to use in my car as gasoline and diesel fuels," Question 10C, general public survey

4.8 Reactions to the possibility of sales of hydrogen at a local gas station, Question 8, general public survey

4.9 Reactions to the possible onsite use of a fuel cell to provide power for a public building, Question 12, general public survey....

4.10 Weighted counts of responses regarding the frequency of use of information sources when making decisions about energy costs and safety, Question 14, general public survey

4.11 Weighted counts of responses regarding the frequency of use of different types of mass media for obtaining energy information, Question 15, general public survey....

4.12 Responses by technical score above/below average to Question 1 (familiarity of 
respondents to hydrogen and fuel cell technologies), general public survey.....

4.13 Responses by technical score above/below average to Question 8, "How would you feel if your local gas station also sold hydrogen," general public survey

4.14 Responses by technical score above/below average to Question 9, "Please tell me if the following statement is true, if it is false, or if you don't know: 'Hydrogen is too dangerous for everyday use by the general public,"' general public survey

4.15 Responses by gender to Question 8, "How would you feel if your local gas station also sold hydrogen," general public survey.....

4.16 Responses by gender to Question 12, "How would you feel if a school, hospital, or other building in your neighborhood was powered by a fuel cell located on its property," general public survey

4.17 Responses by gender to Question 10C, "Hydrogen is as safe to use in my car as gasoline and diesel fuels," general public survey....

4.18 Responses by age to Question 8, "How would you feel if your local gas station also sold hydrogen" general public survey.

4.19 Differences between the 2008 and 2004 average percentage correct for each technical question and overall, general public survey.....

4.20 Mean of the general public's 2004 preference rankings of cost, safety, environment, and convenience

4.21 Comparison of results of the 2004 and 2008 surveys regarding opinions about the everyday use of hydrogen, Question 9, general public survey....

4.22 Comparison of results of the 2004 and 2008 surveys regarding opinions about the availability of hydrogen at a local gas station, Question 8, general public survey ....

4.23 Comparison of results of the 2004 and 2008 surveys regarding opinions about the safety of hydrogen as a vehicle fuel, Question 10C, general public survey

5.1 Distribution of students by grade level, Question 25, student survey.

5.2 Weighted percent of correct, incorrect, and "Don't know" responses for the technical knowledge questions, student survey.

5.3 Distribution of the number of correct answers to the eight technical knowledge questions, student survey....

5.4 Distribution of responses to the question about familiarity with hydrogen and fuel cell technologies, Question 1, student survey....

5.5 Importance of six specific characteristics of a new automobile, Question 20, student survey.

5.6 Responses to statements about the potential benefits of the use of hydrogen as a vehicle fuel, Questions 10A and 10B, student survey....

5.7 Responses to statements about the uses of fuel cells, Question 3, student survey.....

5.8 Responses to the statement, "Hydrogen is as safe to use in my car as gasoline and diesel fuels," Question 10C, student survey....

5.9 Reactions to the possibility of sales of hydrogen at a local gas station, Question 8, student survey.....

5.10 Reactions to the possibility of using a fuel cell to provide electricity and heat for the respondent's school, Question 8A, student survey

5.11 Weighted counts of responses regarding the frequency of use of different types of mass media for obtaining energy information, Question 24, student survey....

5.12 Responses by technical score above/below average to Question 1 (familiarity of 
respondents to hydrogen and fuel cell technologies), student survey.....

5.13 Responses by technical score above/below average to Question 8, "How would you feel if your local gas station also sold hydrogen," student survey ....

5.14 Response percentages by familiarity to Question 8, "How would you feel if your local gas station also sold hydrogen," student survey.

5.15 Responses by technical score above/below average to Question 8A, "How would you feel if your school's electricity and heat were provided by a fuel cell located on school grounds," student survey.....

5.16 Response percentages by familiarity to Question 10A, "Using hydrogen will reduce U.S. dependence on foreign oil," student survey

5.17 Response percentages by gender to Question 8A, "How would you feel if your school's electricity and heat were provided by a fuel cell located on school grounds," student survey

5.18 Differences between the 2008 and 2004 average percentage correct for each technical question and overall, student survey

5.19 Comparison of results of the 2004 and 2008 surveys regarding opinions about the everyday use of hydrogen, Question 9, student survey.....

5.20 Comparison of results of the 2004 and 2008 surveys regarding opinions about the availability of hydrogen at a local gas station, Question 8, student survey ....

5.21 Comparison of results of the 2004 and 2008 surveys regarding opinions about the safety of hydrogen as a vehicle fuel, Question 10C, student survey....

6.1 Weighted percent of correct, incorrect, and "Don't know" responses for the technical knowledge questions, state and government agencies

6.2 Distribution of the number of correct answers to the eight technical knowledge questions, state and local government agencies

6.3 Distribution of responses to the question about familiarity with hydrogen and fuel cell technologies, Question 1, state and local government agencies.....

6.4 Mean of preference rankings of cost, safety, environment, convenience, and performance, Question 7, state and local government agencies.

6.5 Share of respondents who would recommend purchasing a fuel cell vehicle for their organization's vehicle fleet if the cost were comparable to that of a gasoline vehicle, Question 13G, state and local government agencies....

6.6 Share of respondents who would recommend purchasing a stationary fuel cell to help meet the power needs of their facility if stationary fuel cells were available at a cost comparable to that of traditional power systems, Question 13H, state and local government agencies

6.7 Opinions of government officials about using hydrogen and fuel cell technologies to meet their organization's energy needs, Question 13I, state and local government agencies

6.8 Weighted counts of responses regarding the frequency of use of information sources when making decisions about energy costs and safety, Question 14, state and local government agencies

6.9 Weighted counts of responses regarding the frequency of use of different types of mass media for obtaining energy information, Question 15, state and local government agencies

6.10 Percentages of officials who responded "Yes" to Questions 20-24 about hydrogen and 
fuel cell technology penetration, state and local government survey....

6.11 Responses to Questions 24-25 concerning plans to use hydrogen and fuel cell technologies, state and local government agencies

6.12 Percentages of "Yes" responses concerning possession of information about hydrogen and/or fuel cells and desire to attend a class, Questions 26-29, state and local government agencies

6.13 Responses by technical score above/below average to Question 1 (familiarity of respondents to hydrogen and fuel cell technologies), state and local government agencies

6.14 Responses by functional group to Question 2B (technical question on fuel cells), state and local government agencies

6.15 Differences between the 2008 and 2004 average percentage correct for each technical question and overall, state and local government agencies....

6.16 Comparison of results of the 2004 and 2008 surveys regarding the statement, "Hydrogen is too dangerous for everyday use by the general public," Question 9, state and local government survey

6.17 Comparison of results of the 2004 and 2008 surveys regarding opinions about the availability of hydrogen at a local gas station, Question 8, state and local government survey

6.18 Comparison of results of the 2004 and 2008 surveys regarding opinions about the safety of hydrogen as a vehicle fuel, Question 10C, state and local government survey ....71

7.1 Distribution of respondents by business subcategory, end user survey ...........................73

7.2 Weighted percent of correct, incorrect, and "Don't know" responses for the technical knowledge questions, end user survey

7.3 Distribution of the number of correct answers to the eight technical knowledge questions, end user survey.... . .76

7.4 Distribution of responses to the question about familiarity with hydrogen and fuel cell technologies, Question 1, end user survey

7.5 Importance of sever specific characteristics of fuels or p9ower supplies, end user survey.77

7.6 Share of respondents who would recommend purchasing a fuel cell vehicle for their organization's vehicle fleet if the cost were comparable to that of a gasoline vehicle, Question 15, end user survey .....

7.7 Share of respondents who would recommend purchasing a stationary fuel cell to help meet the power needs of their facility if stationary fuel cells were available at a cost comparable to that of traditional power systems, Question 16, end user survey ................79

7.8 Opinions of end users about using hydrogen and fuel cell technologies to meet their organization's energy needs, Question 17, end user survey .....

7.9 Responses to statements about the potential benefits of the use of hydrogen as a vehicle fuel, Questions 13A and 13B, end user survey

7.10 Responses to the statement, "Hydrogen is as safe to use in my car as gasoline and diesel fuels," Question 13C, end user survey....

7.11 Reactions to the possibility of sales of hydrogen at a local gas station, Question 11, End user survey

7.12 Reactions to the statement, "Hydrogen is too dangerous for everyday use by the general public," Question 12, end user survey

7.13 Weighted counts of responses regarding the frequency of use of information sources 
when making decisions about energy costs and safety, Question 18, end user survey........83

7.14 Weighted counts of responses regarding the frequency of use of different types of mass media for obtaining energy information, Question 19, end user survey....

7.15 Percentages of "Yes" responses to Questions 20-22 concerning receiving information about hydrogen and/or fuel cells and the desire to attend a class, end user survey ............84

7.16 Responses by technical score above/below average to Question 1 (familiarity of respondents to hydrogen and fuel cell technologies), end user survey

7.17 Responses by technical score above/below average to Question 13C, "Hydrogen is as safe to use in my car as gasoline and diesel fuels," end user survey

7.18 Percent of responses by gender to Question 13C, "Hydrogen is as safe to use in my car as gasoline and diesel fuels," end user survey

7.19 Percent of responses by familiarity to Question 12, "Hydrogen is too dangerous for everyday use by the general public," end user survey

7.20 Response percentages by gender to Question 13B, "Using hydrogen will reduce emissions and improve air quality," end user survey

7.21 Business categories of the end user respondents who correctly answered fewer than three and at least three of the eight technical questions, end user survey

7.22 Response percentages to "How would you feel if your local gas station also sold hydrogen" by whether or not respondents correctly answered at least three of the eight technical questions, end user survey

7.23 Differences between the 2008 and 2004 average percentage correct for each technical question and overall, end user survey

7.24 Comparison of results of the 2004 and 2008 surveys regarding the statement, "Hydrogen is too dangerous for everyday use by the general public," Question 12, end user survey ...90

7.25 Comparison of results of the 2004 and 2008 surveys regarding opinions about the safety of hydrogen as a vehicle fuel, Question 13C, end user survey

7.26 Comparison of results of the 2004 and 2008 surveys regarding opinions about the availability of hydrogen at a local gas station, Question 11, end user survey

8.1 Weighted percent of correct, incorrect, and "Don't know" responses for the technical knowledge questions, safety and code officials

8.2 Distribution of the number of correct answers to the eight technical knowledge questions, safety and codes officials

8.3 Distribution of responses to the question about familiarity with hydrogen and fuel cell technologies, Question 1, safety and codes officials

8.4 Mean of preference rankings of cost, safety, environment, convenience, and performance, Question 7, safety and codes officials

8.5 Responses to statements about the uses of fuel cells, Question 3, safety and codes officials.

8.6 Responses to statement, "Hydrogen is as safe to use in my car as gasoline and diesel fuels," Question 10C, safety and codes officials

8.7 Responses to the possibility of sales of hydrogen at a local gas station, Question 8, safety and codes officials

8.8 Weighted counts of responses regarding the frequency of use of information sources when making decisions about energy costs and safety, Question 14, safety and codes officials.....

8.9 Weighted counts of responses regarding the frequency of use of different types of 
mass media for obtaining energy information, Question 15, safety and codes officials....101

8.10 Responses by technical score above/below average to Question 1 (familiarity of respondents to hydrogen and fuel cell technologies), safety and codes officials.

8.11 Responses by technical score above/below average concerning the safety relative to technology in use today of small portable devices such as laptop computers or cell phones, Question 13D, safety and codes officials.

9.1 The self-rated levels of familiarity with hydrogen and fuel cell technologies for each of the five population groups, 2008/2009 survey.

9.2 Distribution of the average percentage of correct responses to the eight technical questions by population, for fuel cell questions (Questions 2B and 5 of the general public survey) and all eight technical questions, 2008/2009 survey....

9.3 Distribution of the average percentage of correct, incorrect, and "Don't know" responses to the eight technical questions by population, 2008/2009 survey.

9.4 Percentage of respondents in each population that answered "Don't know" to the eight technical questions assessing knowledge of hydrogen and fuel cells ....

9.5 Comparison of average preference rankings of cost, safety, environment, convenience, and performance for the general public, government officials, and safety and codes officials, 2008/2009 survey .....

9.6 Percentage of respondents in each population that agreed with statements about the advantages and safety of hydrogen as a vehicle fuel, 2008/2009 survey

9.7 For each survey population and for six applications, the percentages of respondents answering that hydrogen and fuel cells are equally as safe as other technologies in use today.

9.8 Percentages of respondents who disagreed with the statement "Hydrogen is too dangerous for everyday use by the general public" and percentages who agreed with the statement "Hydrogen is as safe to use in my car as gasoline and diesel fuels"....

9.9 Percentage, by population group, of respondents that indicated they would be pleased or at ease with sales of hydrogen at a local gas station, 2004 and 2008/2009 surveys ......112

9.10 Percentages of respondents indicating frequent use of various mass media for obtaining energy information, by population group. 


\section{ACRONYMS}

$\begin{array}{ll}\text { AAPOR } & \text { American Association for Public Opinion Research } \\ \text { BTS } & \text { Bureau of Transportation Statistics } \\ \text { CASRO } & \text { Council of American Survey Research Organizations } \\ \text { CATI } & \text { Computer assisted telephone interview } \\ \text { CD } & \text { Compact disk } \\ \text { D\&B } & \text { Dun \& Bradstreet } \\ \text { DEP } & \text { Department of Environmental Protection } \\ \text { DOE } & \text { Department of Energy } \\ \text { DOT } & \text { Department of Transportation } \\ \text { FCT } & \text { Fuel Cell Technologies } \\ \text { HFCIT } & \text { Hydrogen, Fuel Cells, and Infrastructure Technologies } \\ \text { IAFC } & \text { International Association of State Fire Chiefs } \\ \text { ICC } & \text { International Code Council } \\ \text { ID } & \text { Identification } \\ \text { OMB } & \text { Office of Management and Budget } \\ \text { ORC } & \text { Opinion Research Corporation } \\ \text { ORNL } & \text { Oak Ridge National Laboratory } \\ \text { NAICS } & \text { North American Industry Classifications System } \\ \text { NASFM } & \text { National Association of State Fire Marshalls } \\ \text { NFPA } & \text { National Fire Protection Association } \\ \text { RDD } & \text { Random digit dialing } \\ \text { SAS } & \text { Statistical Analysis System } \\ \text { SEO } & \text { State Energy Office } \\ \text { URL } & \text { Uniform Resource Locator }\end{array}$




\section{EXECUTIVE SUMMARY}

Background. The U.S. Department of Energy (DOE) Fuel Cell Technologies Program (FCT) ${ }^{1}$ conducts comprehensive efforts to enable the widespread commercialization of fuel cells in diverse sectors of the economy-with emphasis on applications that will most effectively strengthen our nation's energy security and improve our stewardship of the environment.

Expanding the use of fuel cells requires a sustained education effort to lay the foundation for future commercial market introduction. The FCT education subprogram seeks to facilitate fuel cell demonstrations and support future commercialization by providing technically accurate and objective information to key target audiences both directly and indirectly involved in the use of fuel cells today. These key target audiences include a public that is familiar and comfortable with using a new fuel, state and local government officials who understand the near-term realities and long-term potential of the technology, an educated business and industry component, and trained safety and codes officials. With this in mind, the DOE FCT program established an education key activity to address the training and informational needs of target audiences that have a role in the near-term transition and the long-term development of a hydrogen economy.

Whether or not changes can be attributed to the program, designing and maintaining an effective education program entails measuring baseline awareness and periodically measuring what has been learned. The purpose of this report is to document the data and results of statistical surveys undertaken in 2008 and 2009 to measure and establish changes in understanding and awareness about hydrogen and fuel cell technologies since a baseline survey was conducted in 2004 . This report is essentially a data book, a digest of the survey data and an exposition of changes in knowledge of and opinions about hydrogen and fuel cell technology since 2004. Many conclusions can be made from the survey data. However, the purpose here is not to draw the conclusions, but rather to summarize the data in a way that facilitates drawing them. It is envisioned that the same statistical surveys will be fielded again in approximately three years

Methods. Scientific sampling was used to survey five populations: (1) the general public, ages 18 and over; (2) students, ages 12-17; (3) state and local government officials from state departments of transportation and environmental protection, state energy offices, and functionally similar personnel from cities and counties; (4) potential hydrogen end users in three business categories: transportation, businesses requiring uninterrupted power supplies, and industries with large power requirements; and (5) safety and codes officials in four organizations: International Association of State Fire Chiefs (IAFC), International Code Council (ICC), National Association of State Fire Marshalls (NASFM), and National Fire Protection Association (NFPA). ${ }^{2}$ The surveys were designed to obtain 1,000 sample responses from each of the general public and student categories, and to sample 246 state and local officials, 600 largescale end users, and 200 safety and codes officials.

The survey questions were designed to accomplish specific objectives. Technical questions were posed to measure technical understanding and awareness of hydrogen technology. Opinion

\footnotetext{
${ }^{1}$ Previously the Hydrogen, Fuel Cells, and Infrastructure Technologies Program.

${ }^{2}$ In 2004, the population of safety and codes officials was not surveyed.
} 
questions measured attitudes about the relative importance of safety, cost, the environment, performance, and convenience for a vehicle fuel or power supply for a home or business.

Questions were posed to assess visions about the likelihood of various future applications of hydrogen technology. For most of the questions, "I don't know" or "I have no opinion" were perfectly acceptable answers. Questions about information sources (teachers, friends, government, etc.) and media (radio, Internet, magazines, etc.) were posed to assess how energy technology information is received.

At various stages in their development the survey questionnaires were reviewed by National Hydrogen Association and U.S. Fuel Cell Council personnel and by management at the DOE FCT office. Federal Register notices were published, and Office of Management and Budget approval to conduct the surveys was obtained, per the Paperwork Reduction Act of 1995.

The general public and student survey samples were selected by random digit dialing. Potential large-scale end users were selected by random sampling. Surveys of state and local government officials and safety and codes officials were of their entire target populations (i.e., except for nonresponse, they are complete samples). All five surveys were administered by computerassisted telephone interviewing (CATI). The general public and student surveys were administered in either English or Spanish, at the option of the respondents. For all populations except the safety and codes officials, the length of the survey was less than 15 minutes, including the introduction, screening process, and general information and demographic questions. The average interview length of safety and codes officials was 17 minutes.

Limitations. The biggest data quality limitation of the hydrogen survey data is nonresponse bias. Table ES. 1 shows 2004 and 2008/2009 response rates (percentages) by survey component population. Response rates were for the most part very slightly lower for the 2008/2009 surveys. This is consistent with trends toward cell-phone-only households and increasing use of caller ID.

\begin{tabular}{|l|c|c|}
\hline \multicolumn{3}{|c|}{$\begin{array}{c}\text { Table ES.1. Response Rates by Population, } \\
\mathbf{2 0 0 4} \text { and 2008/2009 Surveys }\end{array}$} \\
\hline Population & $\mathbf{2 0 0 4}$ & $\mathbf{2 0 0 8} / \mathbf{2 0 0 9}$ \\
\hline General public & $24.8 \%$ & $23.0 \%$ \\
\hline Students & $27.5 \%$ & $29.5 \%$ \\
\hline Government agencies & $95.9 \%$ & $89.4 \%$ \\
\hline End Users & $29.1 \%$ & $17.0 \%$ \\
\hline Safety and codes officials & NA* & $77.2 \%$ \\
\hline$*$ In 2004, the population of safety and codes officials was not surveyed. \\
\hline
\end{tabular}

We are willing to accept nonresponse bias because we believe that it is not severe enough to invalidate the survey and because all reasonable measures were taken to minimize it (careful and aggressive callbacks, adjustments to sampling weights). We also expect that changes in response rates will not obscure measurements of changes in knowledge of, awareness of, and attitudes toward hydrogen. An issue involving telephone surveys is the possibility of undercoverage because of cell-phone-only households. While sampling weights provide a partial correction, it was not feasible to fully address the cell-phone-only issue in the 2008/2009 hydrogen surveys. Results. The data analysis focuses on the main data endpoints and survey objectives. Answers to the technical questions are compiled into technical knowledge scores. Opinions about safety 
are summarized as proportions of target population individuals responding in the various possible ways. Preference rankings are summarized as mean ranks. Relationships between endpoints such as technology acceptance and technical awareness are tested with chi-square tests. The likelihood of future use of hydrogen and fuel cell technologies, sources of energy information, interest in training are summarized as class proportions. Changes in the 2008/2009 results relative to the 2004 baseline are estimated (when applicable). The following questions were addressed in comparisons with the baseline:

- For each population group, how have the average numbers of correct, incorrect, and don't know responses to the technical questions changed?

- For each population group, have opinions about the safety of hydrogen and fuel cell technologies changed? If so, how? Is the change statistically significant?

- Have there been changes in the media sources used by respondents to obtain energy information?

- How have respondent concepts of time frames for implementing hydrogen technologies changed? (state and local government agencies and end user populations only)

- Have response rates for the surveys changed?

The data analysis incorporates necessary adjustments for the sampling design (sampling probabilities and stratification) and sampling weights, which are used to adjust for a priori unequal sampling probabilities as well as nonresponse. Otherwise the data analysis mostly involves straightforward estimation of proportions of the respondents providing various answers to the questions. However, sample-weight-adjusted contingency table chi-square tests were also computed to further identify differences between demographic groups.

Several of the more significant results of the 2008/2009 hydrogen knowledge and opinions survey are as follows:

- The average technical knowledge scores for each of the populations surveyed in both 2004 and 2008/2009 increased slightly, although, except for students, the increases were not statistically significant. For students, the average technical score increased 4.5 percentage points, a difference that is statistically significant $(\mathrm{p}<0.0001)^{3}$. As in the 2004 survey, state and local government officials had the highest average score on the technical knowledge questions (Table ES.2).

- When choosing a vehicle fuel or power source, the general public, on average, consider the following in decreasing order of importance: cost, safety, environmental impact, performance, convenience. State and local officials had exactly the same preferences. Safety and codes officials had the same preferences also with the exception that environmental impact was ranked as least important. (Preference ranking questions were not asked of end users or students.)

\footnotetext{
${ }^{3}$ Significance levels (p) are expressed in this report either as " $p=$ value," or, for values less than 0.0001, , $p<0.0001$."
} 


\begin{tabular}{|l|c|c|c|c|c|}
\hline \multirow{2}{*}{ Table ES.2. Average Technical Scores by Population for the 2004 and 2008/2009 Surveys } \\
\hline & \multicolumn{2}{|c|}{ Sample size } & \multicolumn{2}{|c|}{$\begin{array}{c}\text { Average technical } \\
\text { score (\% correct) }\end{array}$} & $\begin{array}{c}\text { Score difference } \\
\text { (percentage } \\
\text { points) }\end{array}$ \\
\cline { 2 - 5 } & $\mathbf{2 0 0 4}$ & $\mathbf{2 0 0 8 - 0 9}$ & $\mathbf{2 0 0 4}$ & $\mathbf{2 0 0 8 - 0 9}$ & \\
\hline General public & 889 & 1,000 & 35.2 & 35.2 & +0.0 \\
\hline Students & 1,000 & 1,004 & 35.3 & 39.8 & +4.5 \\
\hline Government agencies & 236 & 220 & 66.6 & 66.6 & +0.1 \\
\hline End users & 99 & 601 & 46.3 & 47.9 & +1.6 \\
\hline Safety and codes officials & NA & 193 & NA & 51.5 & NA \\
\hline
\end{tabular}

- For the general public, students, and end users, hydrogen technology acceptance is strongly associated with hydrogen technical awareness (chi-square test; $p<.0001$ ). This relationship, which was evident in both the 2004 and 2008/2009 surveys, is shown in Figure ES.1 for the general public. For state and local government officials and safety and codes officials, this relationship was not statistically significant.

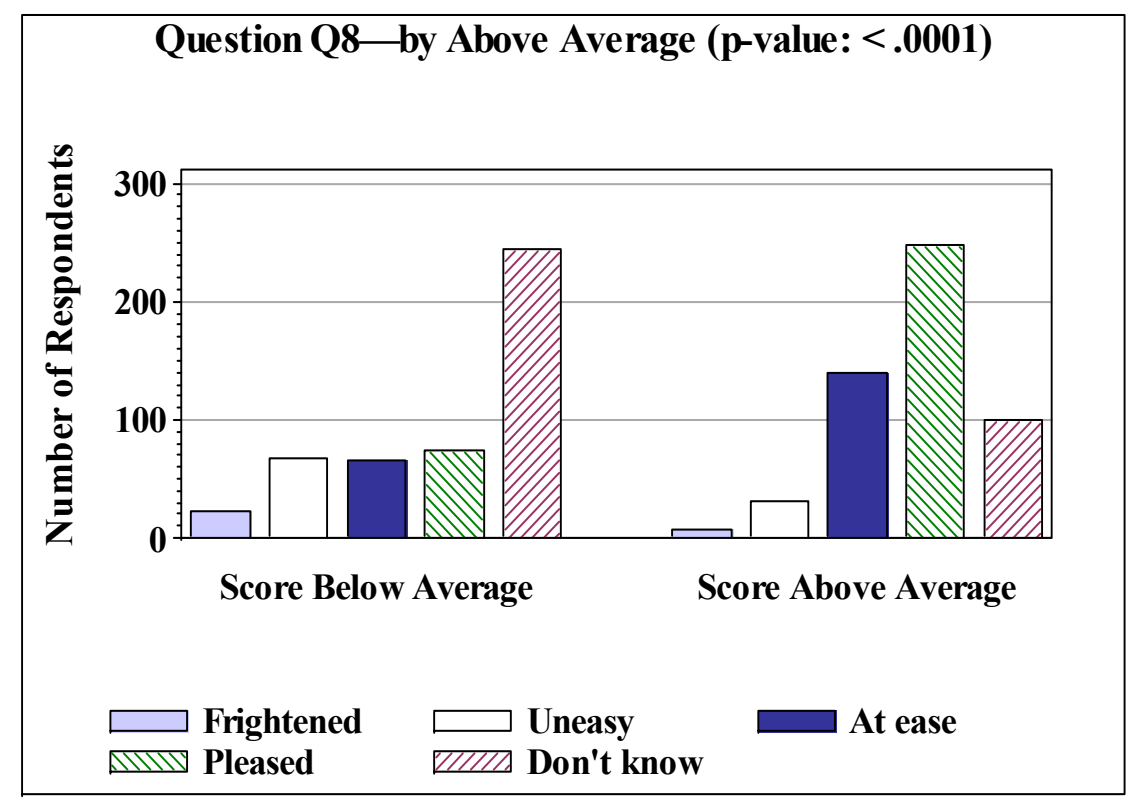

Figure ES.1. Responses by technical score above/below average to Question 8, "How would you feel if your local gas station also sold hydrogen," general public survey.

- Despite having only small increases in average technical scores, all four populations surveyed in both 2004 and 2008/2009 expressed greater confidence in the safety of hydrogen technologies in 2008/2009 than in 2004. Figure ES. 2 shows that in 2008 fewer students indicated that they would be "Frightened" or "Uneasy" with the availability of hydrogen at a local gas station and that more students indicated that they would be "At ease" or "Pleased." Similar trends are evident for the general public, state and local officials, and end users. For state and local government officials and end users, the proportions of respondents who indicated they would be "Pleased" if hydrogen were available at their local gas station increased by over 15 percentage points. 


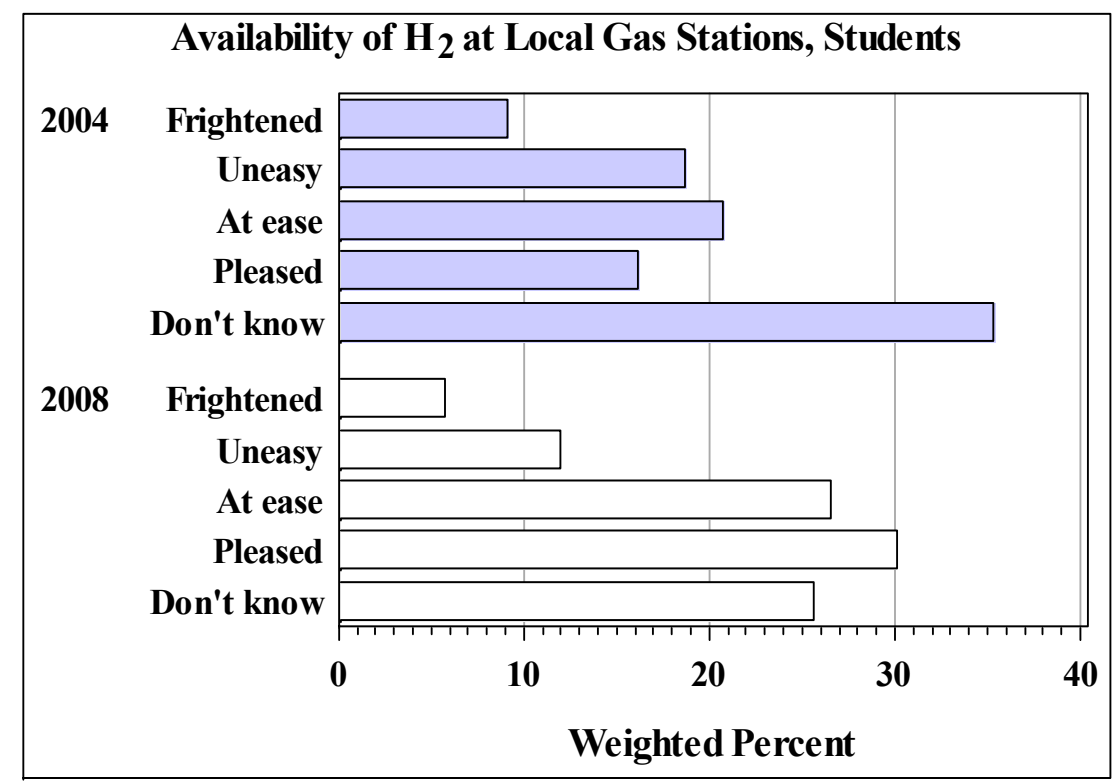

Figure ES.2. Comparison of results of the 2004 and 2008/2009 surveys regarding opinions about the availability of hydrogen at a local gas station, Question 8, student survey.

- All five survey groups agreed that the use of hydrogen as a vehicle fuel would reduce U.S. dependence on foreign oil and would reduce emissions and improve air quality (Figure ES.3)

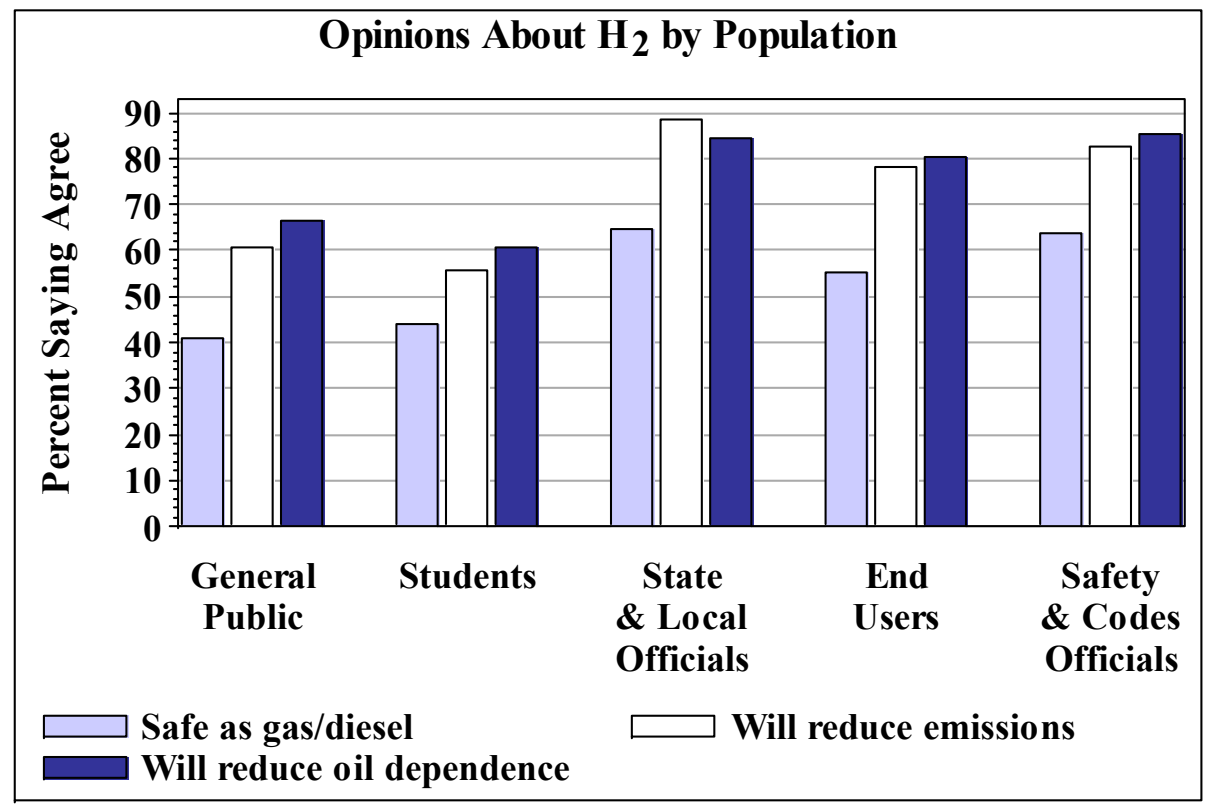

Figure ES.3. The percentage of respondents in each population who agreed with statements about the advantages and safety of hydrogen as a vehicle fuel, 2008/2009 surveys. 
- Over $60 \%$ of the government officials, over $60 \%$ of the safety and codes officials, and over $50 \%$ of end user respondents believe that hydrogen is as safe as gasoline or diesel fuel. Corresponding percentages for the general public and students, though lower, have increased since 2004. In all five populations, greater proportions feel that hydrogen is not too dangerous for everyday use by the general public (Figure ES.4).

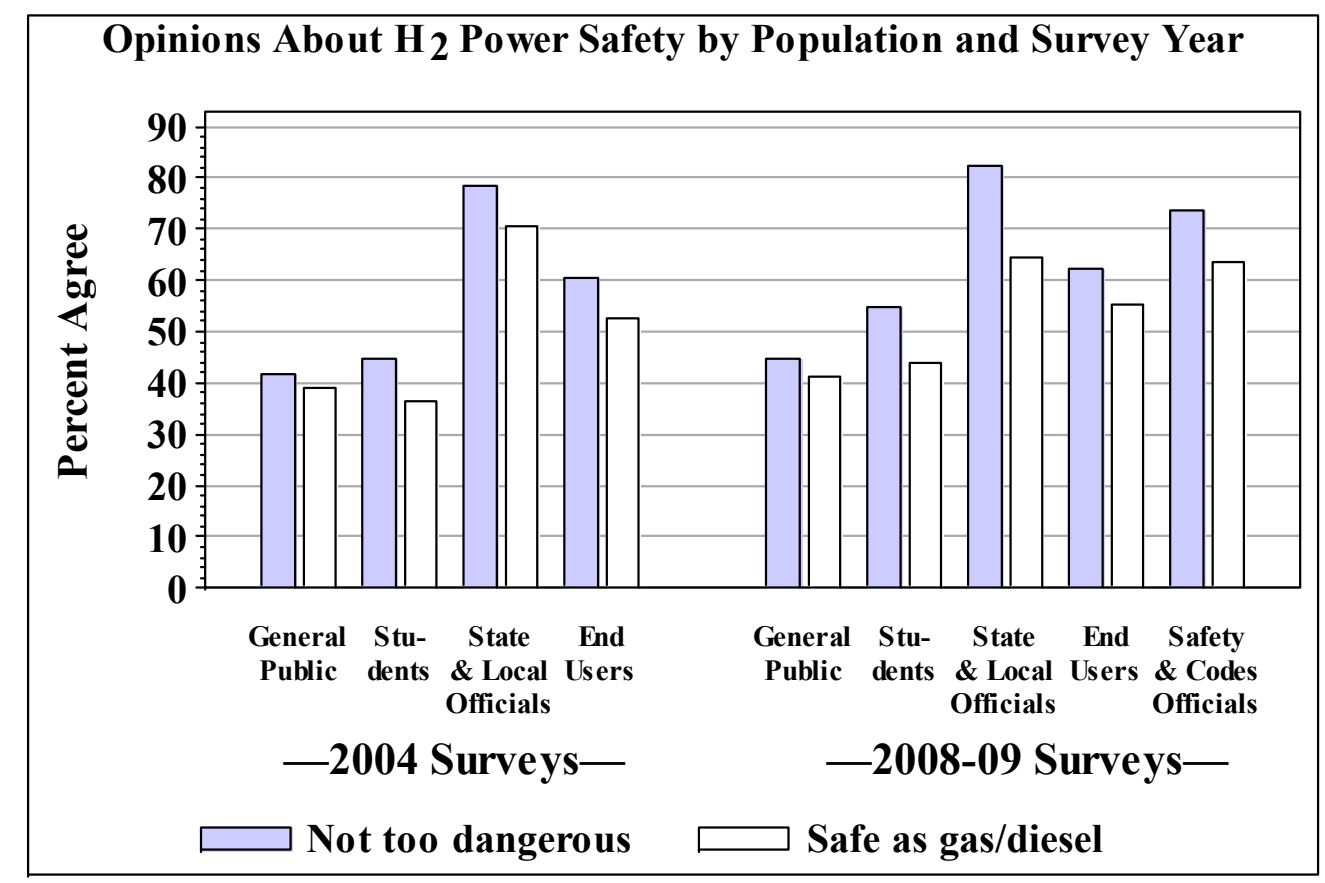

Figure ES.4. Percentages of negative responses to "Hydrogen is too dangerous for everyday use by the general public" and positive responses to "Hydrogen is as safe to use in my car as gasoline and diesel fuels."

- About $21 \%$ of the state and local agencies surveyed in 2008 have plans to use hydrogen and fuel cell technologies within the next five years (Figure ES.5). This is essentially the same as in 2004.

- When asked about implementing hydrogen and fuel cell technologies to meet their organizations' energy needs, almost half (48.8\%) of end users stated their position as "wait and see how the market develops," and 30\% stated their position as "considering it but need more information." State and local government officials expressed similar opinions.

- According to the 2008/2009 surveys, the Internet is an important source for obtaining energy information for state and local officials, end users, and safety and codes officials; television is the primary source of energy information for the general public and students (Figure ES.6). These results are very similar to findings in 2004. 


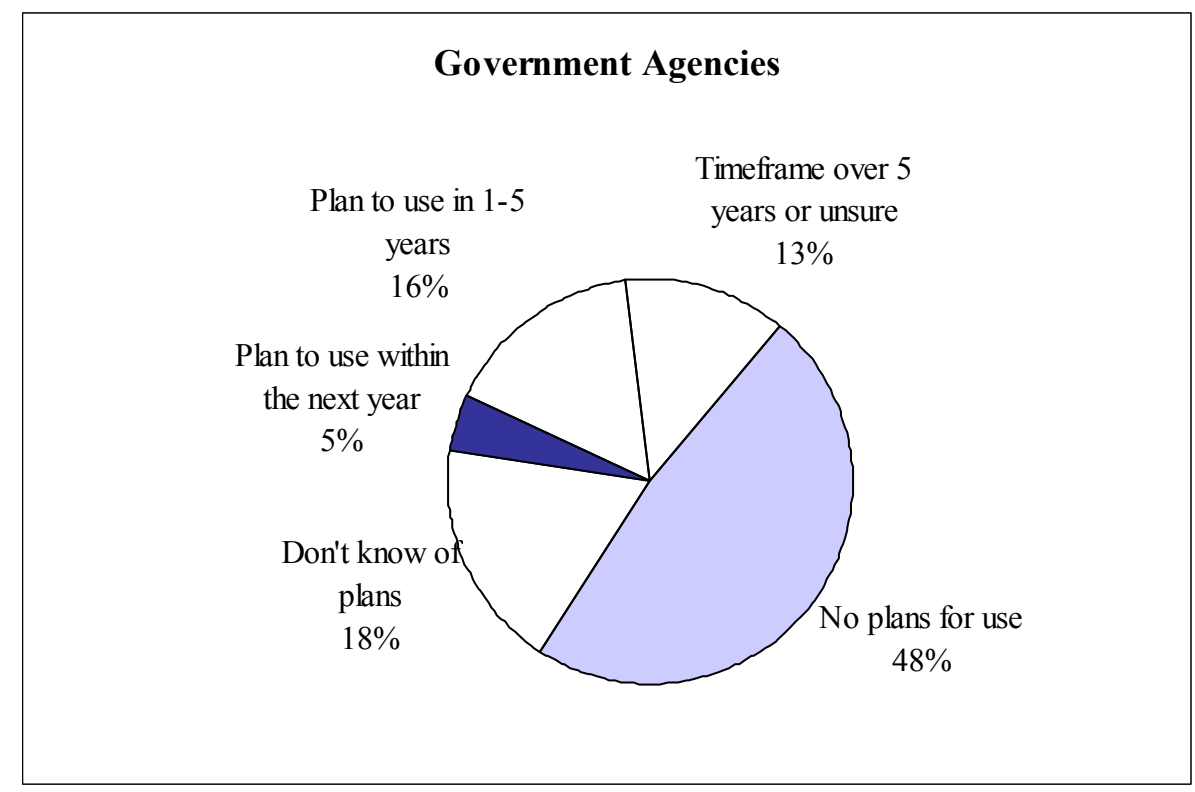

Figure ES.5. Responses to Questions 24-25 concerning plans to use hydrogen and fuel cell technologies, state and local government survey.

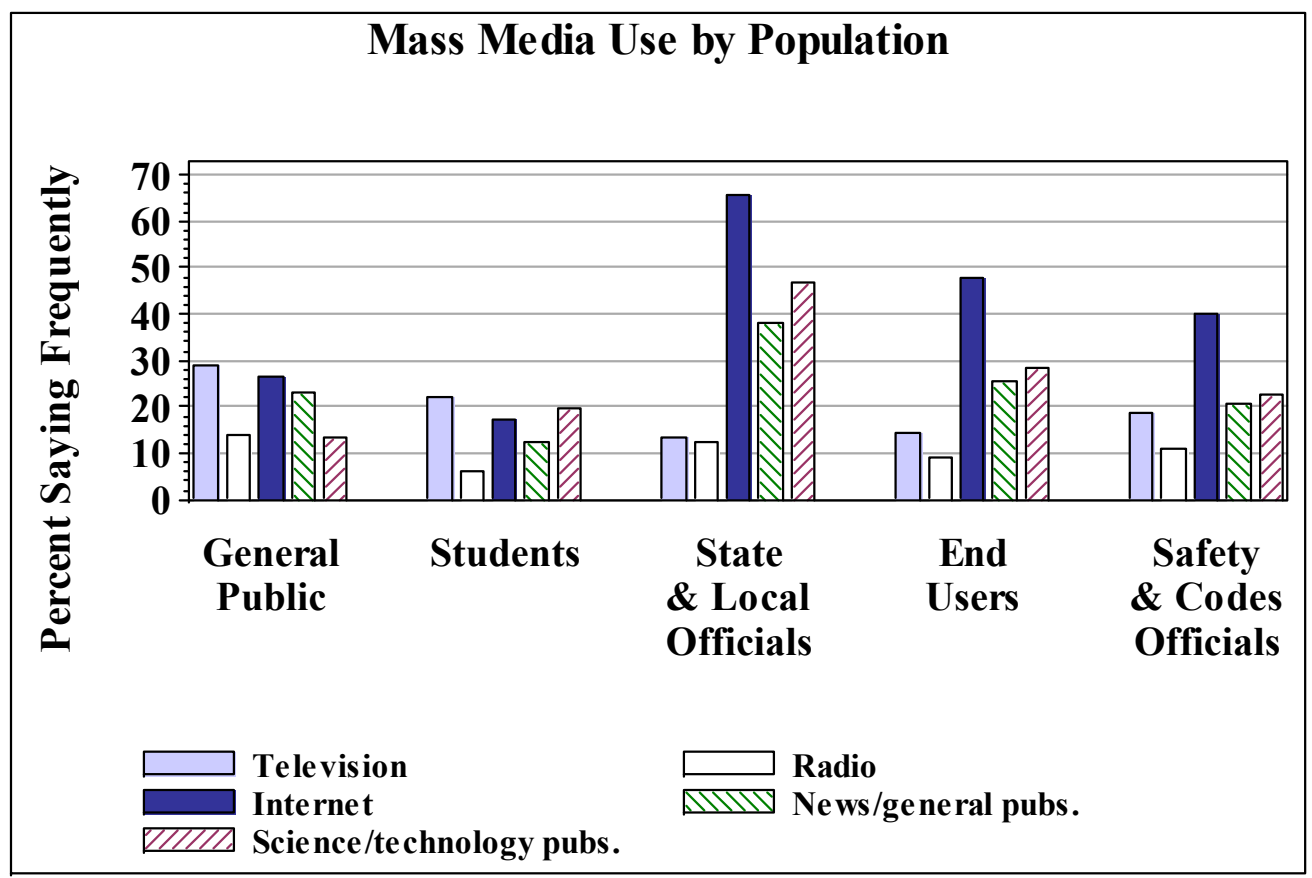

Figure ES.6. The use of mass media for obtaining energy information, by population group, 2008/2009 surveys. 
- When asked about training, $69 \%$ of state and local agency officials, $71 \%$ of end users, and $78 \%$ of safety and codes officials said they would like to participate in a class on hydrogen or fuel cell technologies.

- State and local officials were most likely to rate themselves as either "Familiar" or "Very familiar" with hydrogen and fuel cell technologies, followed by safety and codes officials (41.8\% for state and local officials; $22.8 \%$ for by safety and codes officials. See Figure ES.7).

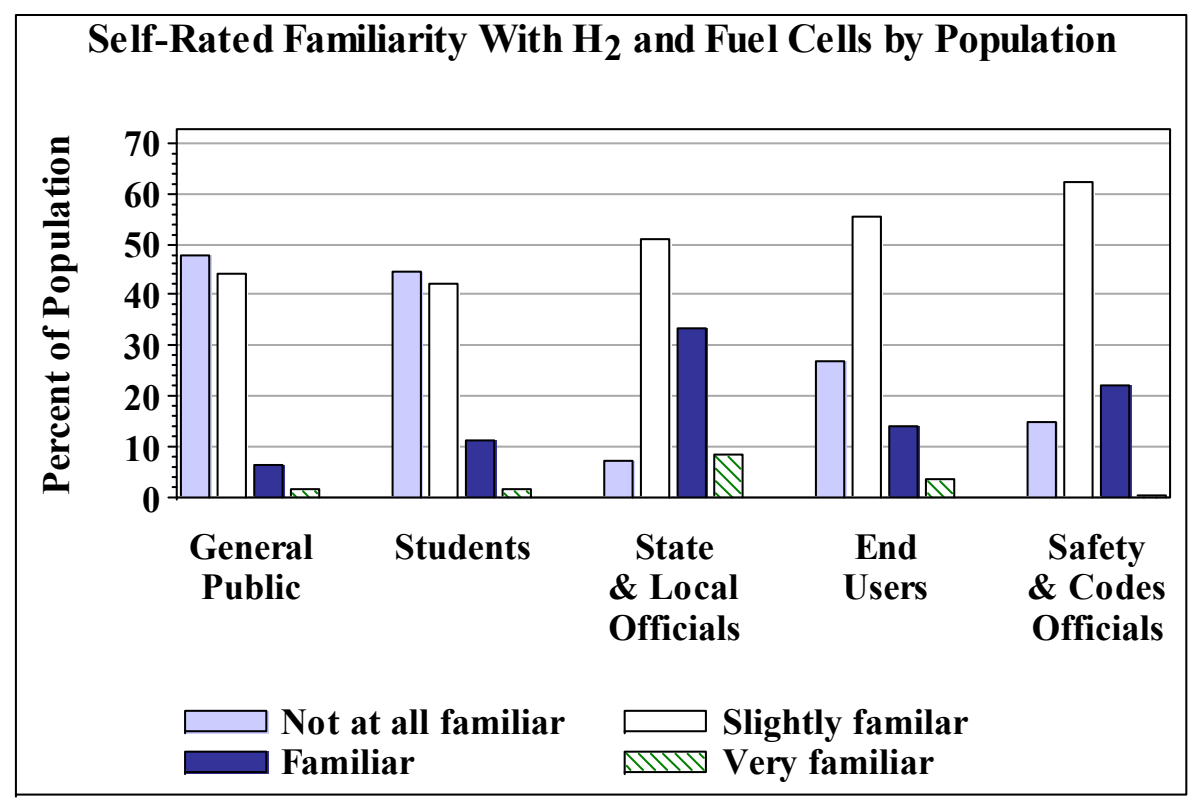

Figure ES.7. The self-rated levels of familiarity with hydrogen and fuel cell technologies for each of the five population groups, 2008/2009 surveys.

- Statistically significance differences between genders were observed in responses to several of the opinion questions about safety and technology acceptance, in the general public, student, and end user populations. Males tended to be more positive, whereas females were more likely to respond that they don't know. For example, Figure ES.8 shows differences between the sexes in responses (agree/disagree/are neutral/don't know) to the statement "Hydrogen is as safe to use in my car as gasoline and diesel fuels." 


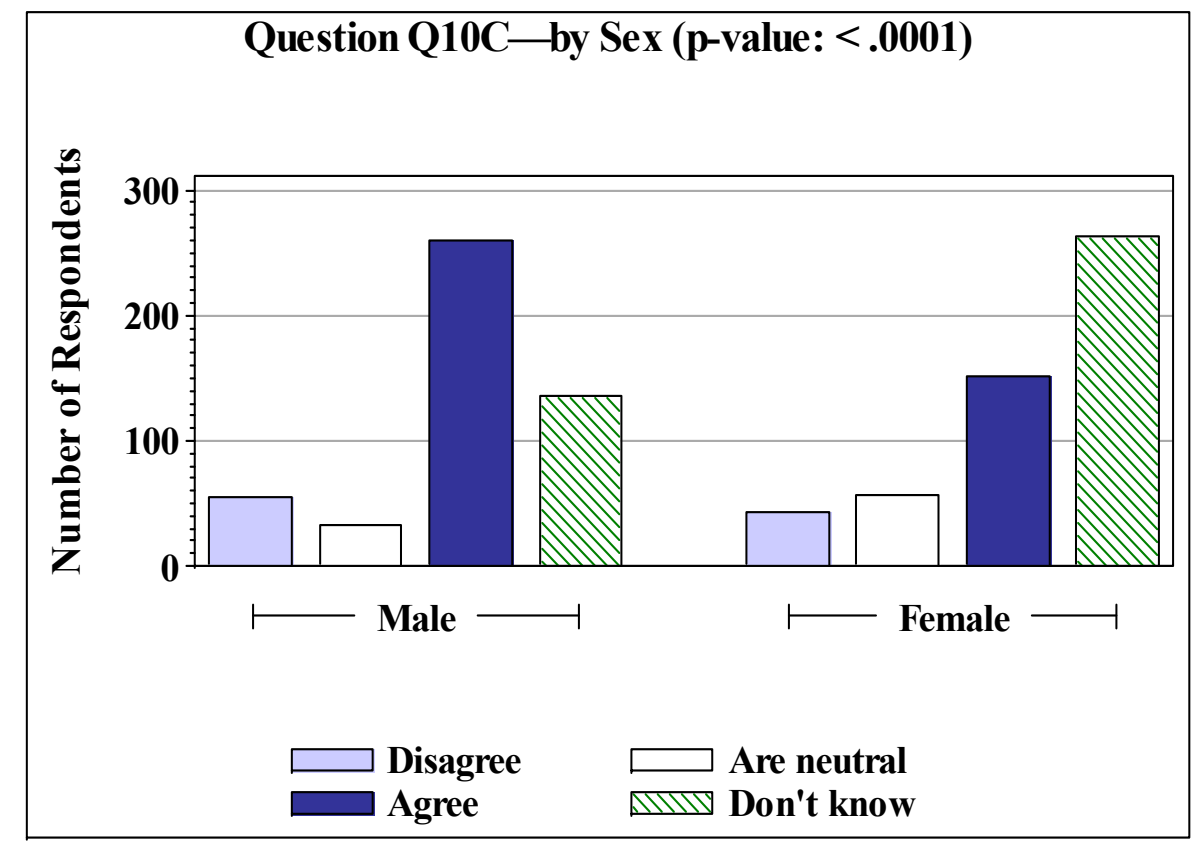

Figure ES.8. Responses by gender to Question 10C, "Hydrogen is as safe to use in my car as gasoline and diesel fuels," general public survey.

In summary, when the 2008/2009 findings are compared with the 2004 survey results, the following conclusions are evident:

- For each population group surveyed in both 2004 and 2009/2009, average technical knowledge scores increased slightly, but, except for student, not significantly. For students the average score increased 4.5 percentage points, a statistically significant change $(\mathrm{p}<0.0001)$.

- Opinions about the safety of hydrogen and fuel cell technologies have become more positive, and respondents expressed greater confidence in the safety of hydrogen technologies in 2008/2009 than in 2004.

- Statistically significance differences between genders were observed in responses to several of the questions about safety and technology acceptance, in the general public, student, and end user populations.

- There have been no statistically significant changes in the media sources used by respondents to obtain energy information.

- No statistically significant changes since 2004 were observed in respondent concepts (state and local government agencies and end user populations only) of time frames for implementing hydrogen technologies.

- Response rates were slightly lower in 2008/2009 than they were in 2004 for all except the student population. 


\section{INTRODUCTION}

The U.S. Department of Energy (DOE) Fuel Cell Technologies Program (FCT) ${ }^{4}$ conducts comprehensive efforts to overcome the technological, economic, and institutional obstacles to the widespread commercialization of fuel cells and related technologies. The program works with partners in industry, academia, non-profit institutions, and the national labs, and coordinates closely with other programs in four DOE offices - Energy Efficiency and Renewable Energy, Science, Fossil Energy, and Nuclear Energy. The mission of the program is to enable the widespread commercialization of fuel cells in diverse sectors of the economy - with emphasis on applications that will most effectively strengthen our nation's energy security and improve our stewardship of the environment.

Expanding the use of fuel cells requires a sustained education effort to lay the foundation for future commercial market introduction. The FCT education subprogram seeks to facilitate fuel cell demonstrations and support future commercialization by providing technically accurate and objective information to key target audiences both directly and indirectly involved in the use of fuel cells today.

\subsection{BACKGROUND AND THE 2004 BASELINE ASSESSMENT}

For DOE's hydrogen education program to be effective, it needs a well-defined starting point - a characterization, at a particular point in time, of knowledge and opinions about hydrogen and fuel cell technology and safety. Thus, in the early stages of developing the education program, a literature review was conducted to attempt to characterize this knowledge level. ${ }^{5,6}$ The literature review concluded, however, that very few scientific surveys had been conducted to ascertain knowledge levels about hydrogen.

In response to the above finding, statistically designed surveys of four different populations in the United States - the general public, students, state and local government agencies, and potential end users - were conducted in 2004 to measure the level of awareness and understanding of hydrogen and fuel cell technologies. ${ }^{7}$ The results of these surveys provided a baseline that described the level of knowledge and opinions about hydrogen and fuel cells in 2004. An analysis of the results was documented in a technical report, ${ }^{8}$ and plans were made to use the baseline for comparison with future knowledge and opinions surveys.

\footnotetext{
${ }^{4}$ Previously the Hydrogen, Fuel Cells, and Infrastructure Technologies Program.

${ }^{5}$ Truett, Tykey, Literature Review for the Baseline Knowledge Assessment of the Hydrogen, Fuel Cells, and Infrastructure Technologies Program, ORNL/TM-2003/258, http://cta.ornl.gov/cta/Publications/Reports/ORNL_TM_2003_258.pdf, October 2003.

${ }^{6}$ The literature review was updated during 2008; the current citation is Truett, Tykey, Rick Schmoyer, and Christy Cooper, Compendium: Surveys Evaluating Knowledge and Opinions of Hydrogen and Fuel Cell Technologies, ORNL/TM-2008/151, http://www-cta.ornl.gov/cta/Publications/Reports/ORNL_TM 2008 151.pdf, October 2008. 7 Approval to conduct the surveys was obtained from the Office of Management and Budget (OMB).

${ }^{8}$ Schmoyer, R. L., Tykey Truett, and Christy Cooper, Results of the 2004 Knowledge and Opinions Surveys for the Baseline Knowledge Assessment of the U.S. Department of Energy Hydrogen Program, ORNL/TM-2006/417, http://cta.ornl.gov/cta/Publications/Reports/ORNL_TM_2006_417.pdf, April 2006.
} 
Table 1.1 shows the number of respondents in each population group in the 2004 survey. The table also shows the composite average percentage of correct responses to eleven technical questions that were asked as part of each of the four surveys. The highest average score was for state and local government officials.

\begin{tabular}{|l|c|c|}
\hline \multicolumn{3}{|c|}{$\begin{array}{c}\text { Table 1.1. Number of Responses and Average Score for Each of the Four Survey } \\
\text { Populations Included in the 2004 Hydrogen Survey }\end{array}$} \\
\hline \multicolumn{1}{|c|}{ Population } & $\begin{array}{c}\text { Total } \\
\text { completed interviews }\end{array}$ & $\begin{array}{c}\text { Average \% correct on } \\
\text { technical questions }\end{array}$ \\
\hline General public & 889 & 32.8 \\
\hline Students & 1,000 & 32.2 \\
\hline State and local government officials & 246 & 65.8 \\
\hline Potential end users & 99 & 44.4 \\
\hline
\end{tabular}

Analysis of the 2004 survey showed that, for every population group, technical understanding appeared to influence opinions about safety. For the general public, student, and end user surveys, respondents with above-average scores on the eleven technical questions were more likely to have an opinion about hydrogen technology safety, and for those respondents who expressed an opinion, their opinion was more likely to be positive. These differences were statistically significant. The 2004 survey findings also indicated that all four of the populations knew more about hydrogen than about fuel cells.

\subsection{SURVEY OBJECTIVES, 2008/2009 SURVEY}

The 2008/2009 Knowledge and Opinions Survey is intended to measure the levels of awareness and understanding of hydrogen and fuel cell technologies in the same four populations that were surveyed during 2004, plus one additional population group. The four original populations were (1) the general public, (2) students, (3) personnel in state and local governments, and (4) potential end users of hydrogen and fuel cell technologies in business and industry; the additional group, which was not surveyed in 2004, is (5) safety and code officials. The ultimate goal of the hydrogen surveys is a statistically valid, nationally based assessment of awareness and understanding of hydrogen and fuel cells for each of these target populations. The same processes used for data collection in 2004 were used for the 2008/2009 surveys, and the same methods were used for the data analysis of individual surveys. In addition, the 2008/2009 findings were also compared with the 2004 findings to assess changes in knowledge levels and opinions from the 2004 baseline. The information from the current assessment will be used to decide whether hydrogen education strategies should be modified and, if so, how.

\subsection{TIMELINE OF EVENTS OF 2008/2009 SURVEY}

The Paperwork Reduction Act (44 United States Code 3501 et seq.) requires approval by the Office of Management and Budget (OMB) to conduct the surveys. Federal Register notices were published in November 2006 and March 2007 to announce the information collections of the first four surveys; these were the same populations that were surveyed in 2004. Copies of these 
notices are included in Appendix B. OMB approval for conducting the follow-on surveys of these four populations was received on July 11, 2007.

A contract was let with Opinion Research Corporation (ORC, a public opinion research firm) in December 2007. The first survey was initiated in January 2008, and the first four surveys (general public, students, government agencies, and end users) were completed by the end of July 2008.

In January and April 2008, Federal Register notices were published concerning the information collection request for the survey of safety and codes officials. Copies of these notices are included in Appendix B. Application was made to OMB to conduct this survey in June 2008. Additional information was requested by and submitted to OMB in November 2008. OMB approved this survey on March 23, 2009. ORC completed the telephone surveys on June 26, 2009.

A draft report including a draft analysis of the first four surveys was submitted to DOE in January 2009. This report (September 2009) provides an analysis of the results of all five surveys.

\section{4. $2008 / 2009$ SURVEY AND REPORT STRUCTURE}

Section 2 of this report is about the general approach taken in conducting the four surveys, including definitions of the four populations, questionnaire design, and survey methodology. Methods used for analysis of the data are discussed in Section 3. In addition to technical knowledge questions, the surveys include questions about sources of information and opinions of interviewees about the safety of hydrogen and fuel cell technologies. Some questions varied by the population being interviewed; for example, the general public, state and local officials, and safety and codes officials` (but not students or end users) were asked to rank the importance of safety, cost, the environment, performance, and convenience for a vehicle fuel or power supply for a home or business; students were asked about experience with science activities; government agency personnel were asked to predict future usage of hydrogen or fuel cell technologies in their respective geographic jurisdiction; end users were asked about power usage at the place of business; safety and codes officials were asked about their experiences in reviewing hydrogen or fuel cell permitting applications. Demographic questions were also included for statistical purposes (e.g., weighting).

Because measuring changes is one of the most important purposes of the 2008 surveys, an attempt was made to keep the survey questions and methods as consistent as possible with the questions and methods used in 2004. In a few case, however, hindsight suggested revisions. In particular, three of the eleven technical questions asked in the 2004 surveys were dropped in 2008. Comparisons of the 2008 technical score results with the 2004 baseline are therefore based on the 2004 results for eight questions only.

Sections 4-8 of the report contain the results of the analyses of the survey of each population, including comparisons with the 2004 results for each population. Charts are provided for "one- 
way" statistics; that is, summaries defined in terms of one survey variable, for example sex or response to a specific question. Weighted frequencies and weighted means are used for the summaries (to adjust for possible under-coverage or nonresponse), and standard deviations and confidence bounds (that account for the sampling weights) are also given to quantify the statistical variability of the frequencies and means.

Obviously there are also myriad relationships and interactions between the survey variables that could be investigated (for example, whether a respondent's sex or geographic region affects his/her responses to a particular question). Although no such interactions were of particular interest a priori, a few of the more statistically significant interactions are investigated in Sections 4-8.

Sections 4-8 also include discussions of outcome rates - particularly, response rates. Response rates are of interest in all sample surveys, because low response rates suggest the possibility of nonresponse bias. Response rates are also of interest in the sense that interest in and awareness of hydrogen can affect response rates in this and future hydrogen surveys.

Finally, Sections 4-8 also include discussions of changes seen in the 2008/2009 survey results, relative to the 2004 baseline. These include changes in technical knowledge as well as opinions.

Section 9 focuses on comparisons across the five populations, including, in a few cases, comparisons of cross-populations over time. Section 10 is an overall summary of the results.

For the sake of simplicity, several variables are reduced to a simpler form in some analyses in Sections 4-9. The thirteen age categories are sometimes also considered in terms of just two categories: 18-44 and 45+ (divides population in approximate halves). "Degree" is defined as associate degree or higher. A variable "Above Average?" indicates whether respondents scored above or below the mean for all respondents on the eight technical knowledge questions.

Appendix A contains copies of the survey instruments. The eight technical questions that are common to all surveys are provided below (Figure 1.1), based on the question numbers from Appendix A.1 (the general public survey). The specific question numbers may differ among the survey instruments; however, the questions are the same.

Appendix C contains the main data summary tables. Both weighted and unweighted frequencies of the various responses (called response values) to the various questions are provided. Unweighted frequencies are raw respondent counts. Weighted frequencies are adjusted (because of possible under-coverage or nonresponse) to more accurately reflect actual U.S. demographic characteristics. A standard deviation of the weighted frequency measures the statistical variability of the frequency. (The range defined by taking plus or minus two standard deviations from the frequency is an approximate $95 \%$ confidence interval for the expected frequency.) The weighted frequencies are also expressed as percentages, with standard errors similarly reflecting statistical variability.

Appendix D contains copies of notification letters that were sent to state and local government agencies or to safety and codes officials. 
True or false questions (Responses include "true," "false," or "don't know/no opinion.")

Q2A. Hydrogen gas is toxic (false)

Q2B. Fuel cells produce electricity through hydrogen combustion (false)

Q2C. Hydrogen is lighter than air (true)

Q2D. Hydrogen has a distinct odor (false)

Q12. Hydrogen is too dangerous for everyday use by the general public (false)

Multiple choice questions

Q4. In which state or condition can hydrogen be stored?

- Chemical compound

- $\quad$ Liquid

- Both of these (correct answer)

- Or, neither of these

- Don't know/No opinion

Q5. When using pure hydrogen, fuel cell vehicles generate electricity, water, and what else?

- Carbon dioxide

- Nitrous oxides

- Heat (correct answer)

- Or, all of these

- Don't know/No opinion

Q6. Hydrogen can be produced using which of the following sources of energy?

- Natural gas

- Sunlight

- Organic matter

- All of these (correct answer)

- Don't know

Figure 1.1. List of eight technical knowledge questions used in the 2008/2009 hydrogen surveys. 


\section{SURVEY APPROACH}

This section is about the general approach to conducting the five surveys. How the survey populations are defined is considered in Section 2.1. Questionnaire design is discussed in Section 2.2. Data collection methodology is considered in Section 2.3. Distinct information collections were employed for each of the five target populations. All questions were in a closed-end format, and all collections were conducted using computer-assisted telephone interviews (CATI). Copies of the survey questionnaires are included in Appendix A. In 2011/2012, each population group will be surveyed again using the same survey instrument and methodology.

\subsection{RESPONDENT POPULATION}

\subsubsection{Types of respondents}

As in 2004, all 2008 surveys were conducted by telephone interviewing. The general public was surveyed first. The general public survey was a random digit dialing (RDD) survey of adults, age 18 and over. The student sample (students ages 12-17) was also selected by RDD. The third population, state and local government agencies, consisted of three state-level offices in all 50 states, plus government officials in the twelve largest cities and counties in each of the four Census regions. The population of state and local government agencies was also surveyed by telephone interview, but completely rather than by statistical sampling. Potential end users of hydrogen and fuel cells (the fourth population) were also interviewed by telephone. End users were sampled randomly from three strata based on usage characteristics: transportation agencies, users needing uninterrupted power, and potential hydrogen and fuel cell users. The population of safety and codes officials was chosen from four organizations (see Section 2.3.1).

\subsubsection{Estimated number of respondents}

The number of desired respondents differed for each of the populations. The general public survey consisted of interviews with 1,000 adults; the student survey included 1,000 students; the total number of contacts with state and local agencies was approximately 250; about 600 interviews with end users and about 200 interviews with safety and codes officials were planned. The number of respondents in each population group is shown in Table 2.1; the rationale for these sample sizes is discussed in Section 2.3.

\begin{tabular}{|l|c|}
\hline \multicolumn{2}{|c|}{$\begin{array}{c}\text { Table 2.1. Number of Responses Expected for Each of the Five Survey } \\
\text { Populations in the 2008/2009 Hydrogen Survey }\end{array}$} \\
\hline \multicolumn{1}{|c|}{ Population } & Total planned responses \\
\hline General public & 1,000 \\
\hline Students & 1,000 \\
\hline State and local government officials & 246 \\
\hline Potential end users & 600 \\
\hline Safety and code officials & 193 \\
\hline
\end{tabular}




\subsubsection{Coverage and Response Rates}

In recent studies about hydrogen knowledge and opinions, methodologies for collecting data have included CATI surveys, face-to-face interviews, computer-based questionnaires completed electronically, and focus groups. ${ }^{9}$ The CATI RDD survey methodology used to conduct the DOE hydrogen knowledge assessment surveys has been employed for many years. Its strengths and weaknesses have been studied, and telephone survey researchers (and OMB) are aware of them. For example, over the last thirty years, coverage rates (the proportion of the target populations from which samples are drawn) have been high in CATI RDD surveys because nearly all of the target populations have had landline telephones. On the other hand, response rates in CATI surveys have often been low (e.g., less than 25\%). Despite low response rates, however, because of inherent efficiency and low costs, CATI surveys have been a popular method used in survey research.

In the last few years, however, there has been a sudden decline in the coverage rate in landline telephone surveys because of steep increases in the proportion of "cell-phone-only" individuals. This issue is discussed in several recent publications. ${ }^{10,11,12,13}$ In fact, the Associated Press reported in December 2008 that more than one-sixth of all households have cell phones only. ${ }^{14}$ The cell-phone-only problem is thus becoming substantial.

Coverage and response rates are discussed further in Sections 2.3.3 and 2.3.4, respectively.

\subsection{FORMAT AND DESIGN OF THE QUESTIONNAIRES}

Copies of the survey instruments (questionnaires) in their final format are found in Appendix A. To facilitate data analysis, the survey questionnaires were prepared in closed-end format. For every question, answer options were read to the interviewee, who was asked to choose one of the options. In every case, one of the options was "I don't know" or "I have no opinion." Prior to asking any questions, respondents were assured that there were no trick questions and that an "I don't know" response was perfectly acceptable.

\footnotetext{
${ }^{9}$ See Truett, Tykey, Rick Schmoyer, and Christy Cooper, Compendium: Surveys Evaluating Knowledge and Opinions Concerning Hydrogen and Fuel Cell Technologies, Oak Ridge National Laboratory Technical Report, ORNL/TM-2008/151, http://www-cta.ornl.gov/cta/Publications/Reports/ORNL_TM_2008_151.pdf, October 2008. ${ }^{10}$ Blumberg, Stephen J., Julian V. Luke, and Marcie L. Cynamon, "Telephone Coverage and Health Survey Estimates: Evaluating the Need for Concern About Wireless Substitution," American Journal of Public Health, 96(5), May 2006.

${ }^{11}$ Lavrakas, Paul J., Charles D. Shuttles, Charlotte Steeh, and Howard Fienberg, "The State of Surveying Cell Phone Numbers in the United States, 2007 and Beyond," Public Opinion Quarterly, 71(5), 840-854, 2007.

${ }^{12}$ Link, Michael W., et al. "Practicability of Including Cell Phone Numbers in Random Digit Dialed Surveys: Pilot Study Results from the Behavioral Risk Factor Surveillance System," http://www.fcsm.gov/07papers/Link.II-C.pdf, accessed 2008.

${ }^{13}$ ZuWallack, Randal S. "Piloting Data Collection via Cellular Phones: Results, Experiences, and Lessons Learned," Macro International Inc. (white paper), http://www.orcmacro.com/Survey/CellPhone/Cell\%20phone\%20white\%20paper.pdf, September 2007.

${ }_{14}$ Associated Press, "More Than One-Sixth of Households Have Only Cell Phones," http://www.ohio.com/business/36313319.html, Posted 01:28 p.m. EST, Dec 17, 2008.
} 
Two sections of each of the survey questionnaires contain technical knowledge questions. These include questions about general properties of hydrogen as well as questions about fuel cells. One of the technical knowledge sections is a true-false section, the other, a multiple choice section. Another section contains opinion questions ("How do you feel about ...?"). This section is also common to all of the surveys. Questions about the relative safety of hydrogen and fuel cells are included in every section of the survey. In each survey, one section is specific to the population being surveyed.

The questionnaires for the public and student surveys were translated into Spanish prior to the start of each survey period. The Spanish version was coded into the computer system of the opinion research firm conducting the interviews. Respondents to these two surveys had the option of completing the interview in either English or Spanish.

For all populations except safety and codes officials, the length of each of the surveys was under 15 minutes (averaging 10-15 minutes), including the introduction, screening process, and demographic questions (age, etc.). The average interview length for safety and codes officials was 17 minutes.

\subsection{DATA COLLECTION AND QUALITY ASSURANCE}

This section deals with statistical and quality assurance procedures implemented to ensure correctness in data collection and analysis.

\subsubsection{Sample Selection}

The respondent universe for the general public survey was non-institutionalized U.S. adults (ages 18 and over), slightly under 230 million people. ${ }^{15}$ The sampling method was RDD using the Genesys system for generating samples. ${ }^{16}$ This approach to public opinion surveys is standard and widely used. For example, it was used by the Bureau of Transportation Statistics for their Omnibus Household Survey. ${ }^{17}$ Genesys samples are implicitly stratified by Census Division and Metropolitan Statistical Area size (i.e., they are sorted by these variables before systematic sampling). The samples include both listed and unlisted residential telephone numbers. The system is updated twice a year. For purposes involving statistical sampling, the general public population is essentially infinite. ${ }^{18}$

Households for the general public survey were contacted using CATI methods. Random selection of adults within a given household was according to most recent birthday. One thousand completed interviews was the target sample size for the public survey.

\footnotetext{
${ }^{15}$ U.S. Census Bureau, "Projected Population by Single Year of Age, Sex, Race, and Hispanic Origin for the United States: July 1, 2000 to July 1, 2050," http://www.census.gov/population/www/projections/downloadablefiles.html, released 2008 .

${ }^{16}$ Marketing Systems Group, “GENESYS,” http://www.m-s-g.com/genesys/genesyshme.htm .

${ }^{17}$ Bureau of Transportation Statistics, "Omnibus Survey, Household Survey Results," http://www.bts.gov/omnibus/household/general methodology.html.

${ }^{18}$ That is, there is no need for making finite population corrections.
} 
For students, a national sample of telephone numbers was randomly generated as described for the general public survey. A much lower proportion of these numbers was eligible, however, because only students age 12-17 were eligible for interviewing. If a household contained multiple teenagers, random selection of the interviewee within the household was according to most recent birthday. The sample size for the student survey was also 1,000 completed interviews. An OMB requirement of the student surveys was that parental permission had to be obtained before interviews with students. This requirement was a serious obstacle in conducting the student survey because it increased the nonresponse rate.

The targeted sample size for the state and local government agencies was 246 completed interviews. The state agencies were State Energy Offices (SEOs), Departments of Environmental Protection (DEPs), ${ }^{19}$ and Departments of Transportation (DOTs) for a total of 150 state responses (one per state for each of the three state agencies).

Functionally similar personnel working for cities or counties (local governments) were interviewed. Because small cities or counties were not expected to be able to respond to the survey now or in the near future, the target population was taken as the 12 largest cities and 12 largest counties in each of the Northeast, Midwest, South, and West Census Regions. For each Census Region, all 12 of the largest cities and counties were sampled. A total of 96 local responses was expected. If county and city governments were combined into a single government entity, only one call was made to that office, and the next largest county in that census region was selected for interviewing. Contact lists were generated by examination of the website of each of the largest city and county entities to identify an appropriate person to interview in each office.

Potential hydrogen end users were defined as businesses and industries with potential commercial uses of hydrogen and/or fuel cells. However, respondents to the end user survey did not need to be using hydrogen or fuel cells at the time of the survey interview. Although respondents could have global corporate operations, it was required that they have facilities in the United States, and only personnel in the United States were interviewed. Potential persons to be interviewed included chief executive officers, chief financial officers, facility managers, energy managers, fleet managers, and information/security managers.

As in the 2004 survey, eligible businesses were identified according to the North American Industry Classification System (NAICS) and stratified into three sectors of hydrogen usage or potential hydrogen usage:

- Transportation. Examples include private and public fleets that use trucks, buses, or other ground-based vehicle types; these are the end users (not developers) of hydrogenpowered vehicles.

\footnotetext{
${ }^{19}$ For the purposes of this document, state environmental offices are called Departments of Environmental Protection. The agency name, however, varies by state. Equivalent agency names include Department of Environmental Quality, Department of Environment, or Department of Natural Resources.
} 
- Business types for which energy usage is primarily for facility heating/cooling and localized power requirements and for which on-site power generation is important because of the need for an uninterrupted power supply. These business types include large agricultural productions, hospitals and other healthcare institutions, education institutions, financial institutions, and others.

- Industrial sectors that have large power requirements. Examples include processing, manufacturing, and fabrication plants; mills and refineries; and industrial machinery and equipment plants.

Component population numbers for each of these three categories are shown in Table 2.2. Lists of businesses meeting the above criteria were purchased from Dun $\&$ Bradstreet. ${ }^{20}$ In addition to NAICS code, the lists included numbers of employees and revenues for each listed business. The purchased lists were the most recent available for this type of data.

For each NAICS category, businesses in the compiled lists were ranked by either number of employees or revenue, depending on which was considered more appropriate for the category. For the transportation stratum and for the stratum of businesses needing uninterrupted power supplies, the number of employees was used primarily as the ranking criterion for NAICS categories (revenue was used for a few subcategories); for the stratum of industrial businesses with large power requirements, revenue was used for all categories. The largest $0.3 \%$ of businesses were then selected from each category and used as the sampling frames from which interviewees were chosen. The largest businesses were selected because they represent the greatest potential for hydrogen usage. For each stratum, these largest businesses were then sampled randomly to obtain 200 respondents, as indicated in Table 2.2.

In the 2004 study, 488 phone numbers were used to get 99 respondents, for an overall response rate of approximately $20 \%$ (response totals were not identified by sector). For the 2008 survey, the target was 600 respondents, 200 in each of the three sectors. Under the assumption that the response rate would be the same in 2008 as in 2004, approximately 1,000 interviews would have to be attempted in each sector to get the required number of completions. Given the number of businesses in the top $0.3 \%$ of each component population (see Table 2.2 ), there would be just enough (i.e., 1,001) in transportation and extras in the other two sectors. As a precaution, reserve pools consisting of the next largest $0.3 \%$ of businesses in each component population were also identified, to be used in the event that the top $0.3 \%$ was exhausted before the 200 interviews were completed. (The reserve pool was in fact used. See Section 7.4.)

The population of safety and codes officials to be surveyed was derived from memberships in four groups: International Association of State Fire Chiefs (IAFC), 50 contacts; International Code Council (ICC), 49 contacts; National Association of State Fire Marshalls (NASFM), 50 contacts; and National Fire Protection Association (NFPA), 44 contacts. There were, therefore, a total of 193 contacts on the master list.

${ }^{20}$ Specifically the D\&B Market Place database. 


\begin{tabular}{|l|c|c|c|c|}
\hline \multicolumn{5}{|c|}{ Table 2.2. Populations and Interview Plans for the Three Sectors } \\
in the End User Population Group \\
\hline & $\begin{array}{c}\text { Number in } \\
\text { component } \\
\text { population* }\end{array}$ & $\begin{array}{c}\text { Number } \\
\text { in top } \\
\mathbf{0 . 3 \%} \text { of } \\
\text { population }\end{array}$ & $\begin{array}{c}\text { Desired } \\
\text { number of } \\
\text { completed } \\
\text { interviews }\end{array}$ & $\begin{array}{c}\text { Expected number } \\
\text { of attempted } \\
\text { interviews** }\end{array}$ \\
\hline Transportation & 333,623 & 1,001 & 200 & $\approx 1,000$ \\
\hline $\begin{array}{l}\text { Businesses needing } \\
\text { uninterrupted power } \\
\text { supplies }\end{array}$ & 877,549 & 2,633 & 200 & $\approx 1,000$ \\
\hline $\begin{array}{l}\text { Industrial sectors with large } \\
\text { power requirements }\end{array}$ & 657,810 & 1,973 & 200 & $\approx 1,000$ \\
\hline Total & $\mathbf{1 , 5 1 8 , 8 7 1}$ & $\mathbf{5 , 6 0 7}$ & $\mathbf{6 0 0}$ & $\approx \mathbf{3 , 0 0 0}$ \\
\hline $\begin{array}{l}\text { *Based on the Census Bureau's 2002 Economic Census. Note that sampling will be restricted to } \\
\text { the largest 0.3\% of these populations, if possible. } \\
\text { **Expected number based on 20\% response rate obtained in } 2004 \text { survey. The actual response } \\
\text { rate was slightly lower, and the actual number of attempts was higher (see Section 7.4). }\end{array}$ \\
\hline
\end{tabular}

\subsubsection{Required Accuracy}

Although RDD methods are complex, the general public and student surveys are simple enough that a reasonable approximation in reckoning necessary sample sizes (given the more complicated development needed to account exactly for the stratification and probability sampling) is to treat the sampling as simple random sampling. ${ }^{21} \mathrm{~A}$ standard approximation in deciding necessary simple random sample sizes is the normal approximation to the binomial, under which confidence limits for an observed proportion $\hat{p}$ are approximately $\hat{p} \pm$ $\mathrm{Z} \times[\hat{p}(1-\hat{p}) / \mathrm{n}]^{1 / 2}$, where $\mathrm{n}$ is the number of respondents and $\mathrm{Z}$ is a quantile of the standard normal distribution. This approximation is known to be good when $\mathrm{n}$ is large (e.g., $\mathrm{n}>100$ ), and $\hat{p}$ is between 0.1 and 0.9 . Under these conditions, a sample size of 1,000 respondents leads to the \pm three percentage point margin of error with $95 \%$ confidence (i.e., when $Z=1.96$ ), which is the often-quoted margin of error for surveys with respondents numbering around $1,000{ }^{22}$

The state and local government survey was a census (i.e., not a random sample). However some nonresponse did occur and was modeled (in the data analysis) as random. As the sample was thus not complete, estimates computed for this survey does have statistical error, though the error is generally smaller than for the other survey components.

${ }^{21}$ The actual data analysis properly accounted for stratification and the sample weights.

${ }^{22}$ An unusual feature of the hydrogen surveys is the possibility of high frequencies of responses such as "Don't know" or "Have no opinion" on some of the survey questions. For example, if $95 \%$ of responses are in the "Don't know" category, then the usual confidence limits based on the normal approximation to the binomial distribution are most likely not a good approximation. In these cases, exact confidence limits based on the binomial distribution can be used, rather than the normal approximation to the binomial. For example, suppose every response in a sample of 1,000 is a "Don't know." Then a $97.5 \%$ exact lower confidence bound (i.e., lower $95 \%$ two-sided confidence bound) for the true proportion of "Don't know" responses is 0.996 (as opposed to 1.0 on the basis of the normal approximation). If, instead, 950 responses are "Don't know," then the lower confidence bound is 0.935 . If 900 responses are "Don't know," then the lower confidence bound is 0.880 . This approach also demonstrates that a sample size of 1,000 is adequate in these extreme cases. 
The end user survey was a smaller sample (600 total respondents) than either the student or general public surveys. Using the approximation discussed above, but with a sample size of 600 (rather than 1,000), the margin of error is $\pm 4 \%$. Although this is slightly larger than the margins for the general public and student surveys, it was still considered adequate.

The survey of safety and codes officials was also a census, similar to the survey of state and local government officials. Analysis and modeling was similar to that of the government agencies.

\subsubsection{Coverage}

For the general public and student surveys, coverage (i.e., the proportion of the population included in the sampling frame) is imperfect because not every individual in the target populations can be reached by telephone. As discussed in Section 2.1.3, however, coverage has not been considered an important issue in most traditional RDD surveys conducted in the last thirty years, because, in fact, only a small proportion of individuals could not be reached by traditional landline telephone. Recently, however, the advent of individuals who have a cell phone but no traditional landline telephone has begun to threaten the good coverage of traditional RDD surveys.

According to the sources listed in Section 2.1.3, cell-phone-only individuals are most frequently in the 20-35 age bracket. For the general public and student surveys, corrections for undersampling this age bracket are made in the survey data analysis by assigning higher poststratification weights (a weighting adjustment in the data analysis) to individuals in this age group. However, age-based weighting corrections cannot be used to properly adjust for inherent differences (e.g., in awareness or opinions about hydrogen) between cell-phone-only and landline individuals of the same age. It is reasonable to speculate that cell-phone-only individuals could be more aware of technology in general (and thus hydrogen technology in particular) than individuals with landline phones only or even both landline and cell phones. Failure to address the cell-phone-only coverage deficiency in traditional landline surveys could thus be a concern in the DOE hydrogen technology awareness survey, particularly the RDD surveys of the general public and students.

An obvious remedy to the cell-phone-only coverage issue would be to supplement traditional CATI RDD landline phone surveys with cell-phone components. However, obstacles to cellphone supplements include (1) imposition on respondents, who bear cell phone usage costs in "minutes," (2) laws such as the federal Telephone Consumer Protection Act, which requires that unsolicited calls to cell phones have to be dialed by hand rather than a computer, and (3) the administrative difficulty of obtaining OMB approval for a supplemented. How to properly weight cell-phone-only, cell-and-landline, and landline-only respondents in a combined survey is also the subject of current research.

These issues are being addressed by survey research firms and in big survey studies such as the Behavioral Risk Factor Surveillance System, ${ }^{23}$ which is the world's largest ongoing public health telephone survey. Sampling weights provide a partial correction. It is not feasible, however, to

\footnotetext{
${ }^{23}$ Link, Michael W., et al., op cit.
} 
fully address the cell-phone-only issue in the 2008 DOE Hydrogen Knowledge and Opinion Surveys. It is very likely, however, that methods for dealing with this problem will have been developed by 2011. Because of continued increases in the number of cell-phone-only individuals, the issue will have to be addressed for the 2011/2012 DOE surveys.

\subsubsection{Response Rates}

\section{Definition of nonresponse}

Various outcome rates are of interest in characterizing survey data results. The response rate is the proportion of sampled eligible subjects for whom complete survey interview information was obtained. The refusal rate is the proportion of sampled eligible subjects who refused to be interviewed or who terminated their interviews before completion. The contact rate is the proportion of sampled eligible subjects that were contacted at all. In general the number of eligible subjects must be estimated, and there are various ways to estimate this number and to define, in turn, estimates of the rates. The American Association for Public Opinion Research (AAPOR) gives various definitions for the rates and provides a spreadsheet calculator for computing them. ${ }^{24}$ In this report we focus on response rates according to just one of the AAPOR definitions. The response category frequencies will all be archived, however, should a need arise to analyze refusal or contact rates or response rates according to one of the other definitions.

The Council of American Survey Research Organizations (CASRO) definition of response rate ${ }^{25}$ is as follows:

Response Rate $=$

Number of Complete Interviews

$($ Number Sampled Eligible $)+[($ Number Sampled but Eligibility Undetermined $) * \mathrm{e}]$

where e $=($ Number Known Eligible $) \div($ Number Known Eligible + Number Known Ineligible $)$.

This is the "RR3" definition of response rate used by AAPOR. ${ }^{26}$ AAPOR has also extended this definition to allow for partially completed interviews. However, because nearly all of the survey questions could be answered with a simple "Don't know" or "No opinion" response, partially complete interviews were not counted as responses in the hydrogen surveys. Thus we have used the AAPOR RR3 response rate definition. These adjustments were used to calculate response rates for all survey components except the surveys of state and local government agencies and

\footnotetext{
${ }^{24}$ AAPOR, Standard Definitions: Final Dispositions of Case Codes and Outcome Rates for Surveys, The American Association for Public Opinion Research, Lenexa, Kansas, http://www.aapor.org/uploads/Standard Definitions 0708 Final.pdf, revised 2008.

${ }^{25}$ Frankel, Lester R. "The Report of the CASRO Task Force on Response Rates," in Improving Data Quality in a Sample Survey, 1983.

${ }^{26}$ AAPOR, Standard Definitions: Final Dispositions of Case Codes and Outcome Rates for Surveys, The American Association for Public Opinion Research, Lenexa, Kansas, http://www.aapor.org/uploads/Standard_Definitions_07 08_Final.pdf, revised 2008.
} 
safety and codes officials. For these two populations, the nonresponse rate was minimal and was estimated simply as (Number of Complete Interviews) $\div$ (Number of Interviews Targeted).

Methods for estimating nonresponse rates and call disposition frequencies were the same for both the 2004 and the 2008/2009 surveys. Thus, nonresponse rates can be compared, as they are themselves relevant in the context of public interest in hydrogen, as well as survey sampling.

\section{Nonresponse bias}

The approach to dealing with nonresponse in the hydrogen surveys is similar to approaches taken in similar surveys, for example, the Omnibus Household Survey (see Section 2.3.1).

Nonresponse was minimized through careful and aggressive callbacks. Sampling weights (general public and student surveys) were used to adjust for nonresponse (in the sense that undersampled demographic groups are given more weight in the analyses). However, further follow-ups, for example by mail or in-person interviews, were not made. Although following up a sample of "first-stage" nonresponders (those who do not complete the survey despite repeated call-backs) with an aggressive second-stage (via mail or in-person visits) does allow survey estimates to be computed for the first-stage nonresponders, such approaches are expensive and were considered beyond the scope of the hydrogen surveys.

In lieu of statistical estimates for first-stage nonresponders (or other assumptions), some nonresponse bias must be tolerated, and nonresponse bias is probably the major data quality limitation of the hydrogen survey data. Because the 2008/2009 fielding of the survey was implemented with exactly the same methods as those used in 2004, some of the nonresponse or coverage bias is accounted for (i.e., subtracts out) in the cross-time differences. Nevertheless, even the cross-time comparisons could be biased:

- Changes among responders could be different from changes among nonresponders.

- Changes in telephone technology because of the frequency of use of call blocking and caller ID technologies could affect comparisons over time. (Note that unlisted numbers are, in fact, sampled in RDD surveys.)

- Changes over time in general attitudes, such as willingness to participate in phone surveys, could adversely affect comparison over time.

These issues are important; however, their importance should not be overestimated. A study of increasing nonresponse rates in telephone surveys reports "more numbers out of scope (including mobile phones, fax/modems/ pagers) ... 27.4 percent in 1995 versus 35.1 percent in 2000 pretest," and "more numbers with the scope not determined ...6.8 percent of the numbers in sample had scope not determined in 1995 versus 8.6 percent in 2000."27 Although these changes are substantial, they do not appear to be overwhelming. Furthermore, because of the relatively recent introduction of state and federal telemarketer no-call lists, which will reduce the number of nuisance phone calls, it is possible that response rates might even be increasing. (Note that firms conducting survey research are exempt from no-call lists.)

\footnotetext{
${ }^{27}$ McGuckin, Nancy, Mary Ann Keyes, and Susan Liss, "Hang-ups - Looking at Nonresponse in Telephone Surveys," International Conference on Travel Survey Methods, http://www.fhwa.dot.gov/ohim/hang ups.htm, 2002.
} 
Considering the expense of the alternatives (e.g., mail or in-person follow-up surveys), all reasonable measures (CATI methods for scheduled call backs, adjustment of sampling weights to account for nonresponse, etc.) were taken to minimize nonresponse bias in the hydrogen surveys.

\section{Maximizing response rates}

"CATI" refers to methodology by which telephone numbers are dialed (e.g., using the Genesys system) and by which responses are recorded using programmed computer formats. In the hydrogen surveys, the actual interviews are conducted by individuals who have been well-trained in interviewing techniques ${ }^{28}$ to avoid "hang-ups" and otherwise minimize nonresponse.

Procedures used in the hydrogen surveys for maximizing response rates exceeded usual standards for CATI surveys. Interviewers made a minimum of 15 attempts before giving up trying to reach eligible households. Each call attempt used a minimum of five rings. For the general public and student surveys, the CATI software cycled the attempts in the following order: weekday day, weekday evening, Saturday day, and Sunday evening to maximize coverage of the residential population. Sample allocation and scheduling of interview sessions assured a minimum of three attempts in each day part (e.g., weekday day, weekday evening, weekend). For surveys of government agencies, end users, and safety and codes officials, calls were made during normal business hours for the time zone being called.

For all surveys, lines that were busy were called back a minimum of five times at 10-minute intervals. If the line was still busy after the fifth attempt, the number was attempted again on different calling occasions. If the line was still busy after the fifth calling occasion, the CATI system attempted to contact the phone company to ascertain whether the number was actually in service.

The 2004 baseline general public survey was conducted to accommodate the special feature that relatively large proportions of "Don't know" and "No opinion" responses were expected. Respondents were assured that "Don't know" and "No opinion" were perfectly acceptable answers to the survey questions. This helped to minimize item nonresponse rates for the 2004 survey. The same assurances were provided to interviewees in 2008/2009.

CATI surveys accurately handle large numbers of scheduled call back appointments. When a scheduled appointment time arrives, the CATI system finds the next available station and delivers the appropriate phone number for the next call. Ensuring that appointments are kept helps to maximize response rates (and to minimize imposition on study participants). The CATI system also allows for callbacks to rescheduled interviews and to restart interrupted interviews (for example, if a respondent wants to finish an interview later). Scheduled call backs can be either casual (general time) or definite (exact time) depending on the respondent's request. The CATI system also automatically handles callbacks for no-answer, busy, and answering machines. Call backs for busy signals are retried at several minute intervals; callbacks for no-answer and answering machines are scheduled to ensure coverage at different times of day.

${ }^{28}$ AAPOR, "Best Practices for Survey and Public Opinion Research,” http://www.aapor.org/bestpractices . 
Another step that was taken to maximize response rates was to route each initial refusal to special survey staff trained and experienced at converting initial refusals to responses. How initial refusals were handled was decided on the basis of each particular case and the experience by the special staff member. One technique that was used when appropriate was to switch from an English to a Spanish-speaking interviewer.

\section{Statistical adjustments for nonresponse}

For the general public and student surveys, sampling weights were computed to adjust for variable selection probabilities in the random sampling. These weights were further adjusted to account for households with multiple phones (including transfers), number of eligible household members, and for response rate (and coverage rate) differences over various demographic subgroups. (Weights were adjusted upwards for groups with lower response rates.) Surveys of state and local government agencies, end users, and safety and codes officials were not weighted, because, for these surveys, selection probabilities were uniform across the target populations. Weights are discussed further in Section 3.

\subsubsection{Pretesting}

For the 2004 general public survey, a formal pilot study of 50 respondents was conducted as a part of the OMB-approved information collection. This pilot study was used as a basis for final adjustments to the questions, served as a check on response rate estimates and the CATI system, and served as a quality assurance check for the methods of data analysis. Results of these 50 respondents in the pretest were not included in the analysis of the general public survey since changes had been made to the survey instrument. As the surveys of the other populations were similar to the general public survey, pretests were not used for those surveys.

Similarly, because the 2008/2009 surveys are nearly the same as their 2004 counterpart, the 2004 surveys serve as pretests, and additional pretesting of the 2008/2009 surveys was unnecessary.

\subsubsection{Quality Assurance in the Data Analysis}

CATI technology and the multiple-choice nature of the survey questions precluded out-of range data entries. As with the 2004 surveys, 2008 survey data and all programs written to analyze the results for the 2008 surveys were carefully logic-checked and "sanity-checked" through examination of the output (tables, charts, etc.).

While performing the data analysis, all project materials, including survey design documentation, results of the survey, and data analysis programs and results were backed up to secondary storage media. After the analysis of the 2008 surveys and issue of the final report, this information will also be archived to compact disks (CDs) and stored at multiple locations. 


\section{DATA ANALYSIS METHODS}

\subsection{OBJECTIVES OF DATA ANALYSIS}

At any point in time, for each possible response to each survey question, there is a proportion of individuals in the survey target population who would give that response. The primary endpoints of the statistical analysis of the 2008/2009 survey data were estimates of these proportions for the survey questions (except for the standard demographic questions used to weight the results) in 2008 and 2009, and standard errors and confidence limits for these estimates. Certain composite results, such as the average proportion of correct answers to the survey technical questions, are also of primary interest, as are the changes in these endpoints relative to the 2004 baseline.

In addition to the primary findings, the survey results were also analyzed for secondary information, including differences in the primary endpoints across ages, genders, and geographic regions, and cross tabulations of pairs of primary endpoints. (These demographic variables were not recorded for the state and local government agencies nor for the safety and codes officials surveys.) Cross tabulations of interest are of knowledge levels with attitudes and opinions; knowledge levels with sources of energy information; and attitudes and opinions with sources of energy information. ${ }^{29}$ Though secondary, much of this information is of great interest and relevance to the hydrogen education program.

\subsection{DATA TYPES}

Responses to the survey questions will be of several different data types. Responses to the multiple choice questions as well as true/false/don't know questions are simple (unordered) multinomial data. With the exception of a "Don't know/no opinion" response, responses to the rating questions are ordinal (ordered) multinomial data. Because of the "Don't know/no opinion" category, however, responses to the rating questions are only partially ordered. Finally, for the general public, government agencies, and safety and codes officials surveys, there is also a ranking question, in which five items are ranked in importance (in the context of a hydrogen economy) by the respondent. The items are (a) safety, (b) cost, (c) the environment, (d) convenience, and (e) performance.

\subsection{ESTIMATES AND TESTS}

In addition to data types, another important consideration in the data analysis is the application of sampling weights (general public and student surveys only), which are used to adjust estimates and tests for variable selection probabilities as well as nonresponse and under-coverage. Proper adjustment with sampling weights is necessary but restricts the set of appropriate software

\footnotetext{
${ }^{29}$ See also Schmoyer, R. L., Tykey Truett, and Susan Diegel, Data Collection, Quality Assurance, and Analysis Plan for the 2008/2009 Hydrogen and Fuel Cells Knowledge and Opinions Surveys, ORNL/TM-2008/113, http://cta.ornl.gov/cta/Publications/Reports/ORNL_TM_2008_113.pdf, September 2008.
} 
available for the data analysis. Estimates and tests computed for the data analysis account for survey stratification as well as sampling weights. Sampling weights were computed from selection probabilities adjusted for nonresponse, households with multiple telephone numbers, and (by iterative proportional fitting) post-stratification by age, sex, and region. Weights were computed for the general public and student surveys only; surveys of state and local government agencies, end users, and safety and codes officials were stratified but not weighted (or, equivalently, they were analyzed with weights, but all of them equal).

The following general approach was taken in the data analysis. Results for each of the survey questions were analyzed with the Statistical Analysis System (SAS) Surveyfreq procedure to produce one-way (i.e., specific by exactly one classification variable) summary tables of frequencies, percentages, and standard errors for the various response categories. These statistics are weighted (as appropriate) and account for the design stratification. The one-way statistics were explored by examining charts for each survey question, and additional charts were computed to illustrate various features of interest observed for multiple questions in the one-way tables.

Results for the survey technical questions were combined to form overall scores. In the overall scores, "credit" was given only for correct answers; no credit was given for either incorrect answers or "Don't knows." Percentages of "Don't knows" were also of interest and were analyzed separately. The overall scores were charted and analyzed with the SAS Surveymeans procedures, which handles continuous (as opposed to categorical) data such as the test scores. The preference ranking results for safety, cost, environment, convenience, and performance were analyzed with the Surveymeans procedure. (The pairwise preference results, components of the ranking, were also analyzed as part of the one-way analyses.) Like the Surveyfreq procedure for categorical data, the Surveymeans procedure also properly accounts for sampling weights and stratification.

Relationships were explored between the question responses and various demographic variables such as sex, census region, age category, educational degree, and whether the respondent's overall technical question score is above or below average. The SAS Surveyfreq procedure (also used to compute the one-way tables) was used to compute statistical significance levels for the association between question responses and the demographic variables. ${ }^{30}$

Response rates were determined using the formula in Section 2.3.4 and compared with the rates computed for the 2004 survey results

\subsection{COMPARISON OF 2008/2009 RESULTS WITH THE 2004 BASELINE}

The results of the 2008/2009 surveys are statistically independent of the 2004 baseline survey. Hence, once results are obtained, statistical tests about changes can be made in the usual way: the variance of each difference is the sum of the variances of the differenced quantities, and tests

\footnotetext{
${ }^{30}$ Many of the most highly significant relationships for the 2004 surveys were discussed in the report by Schmoyer, Truett, and Cooper.
} 
(e.g., t-tests) about each difference can be computed by relating estimated difference to its standard error (i.e., square root of the variance of the difference). Once the 2004 and 2008/2009 estimates and standard errors are computed (the technically more difficult step, particularly for the surveys with sampling weights), cross-survey comparisons are thus relatively straightforward. ${ }^{31}$

The following questions were addressed in the comparison of the 2008/2009 findings with the 2004 baseline.

- For each population group, how have the average numbers of correct, incorrect, and don't know responses to the technical questions changed?

- For each population group, have opinions about the safety of hydrogen and fuel cell technologies changed? If so, how? Is the change statistically significant?

- Have there been changes in the media sources used by respondents to obtain energy information?

- How have respondent concepts of time frames for implementing hydrogen technologies changed? (state and local government agencies and end user populations only)

- Have response rates for the surveys changed?

It should be noted that for the 2004 survey, there were 11 technical questions. On the basis of the 2004 analysis, three of these questions were eliminated from the 2008/2009 surveys. The comparison of technical "scores" is, therefore, based only on the eight technical questions that are common to both the 2004 and the 2008/2009 surveys.

\footnotetext{
${ }^{31}$ Because the survey of safety and code officials was not fielded in 2004, the 2008/2009 survey of this group will establish the baseline of knowledge and opinions for this population. Changes with respect to this baseline will be measured when the survey is fielded again in 2011/2012.
} 


\section{RESULTS: GENERAL PUBLIC SURVEY}

\subsection{INTRODUCTION}

This section summarizes the results of the general public survey. A copy of the survey is provided in Appendix A.1. A total of 1,000 interviews with the general public were completed during the period of January 8-28, 2008. Interviews were by telephone survey conducted among a national probability sample of adults (500 men and 500 women) 18 years of age and older, living in private households in the continental United States. The total average interview length was slightly less than 11.4 minutes, broken down into a screening time of 2.5 minutes and a main interview length of 8.8 minutes. A summary of responses to this survey, by question number, is in Appendix C.1.

If the person who answered the telephone answered in Spanish or requested that the interview be conducted in Spanish, the interview was conducted in Spanish. If the person who answered the telephone was not proficient in either English or Spanish, the interview was terminated.

Section 4.2 is a general summary of the general public responses. Relationships between the response variables are discussed in Section 4.3. Differences between the 2008 and 2004 survey results are discussed in Section 4.5.

For the sake of simplicity, the responses "Don't know," "No opinion," and "Don't know/no opinion" are all treated equivalently and generally as "Don't know" in this report.

The response rate for the General Public Survey is discussed in Appendix E.1. The response rate is .2301, which is just slightly lower than the response rate of .2480 calculated for the 2004 hydrogen survey ${ }^{32}$. It is reasonable to assume that the more enthusiastic or at least knowledgeable people are about hydrogen technology, the more likely they would be (all else equal) to respond if sampled in the survey. Thus response rates are of interest from the perspective of hydrogen technology awareness itself. On the other hand, it is well known that telephone survey response rates have been declining in recent years. ${ }^{33}$ Reasons include the volume of surveys conducted, other forms of telephone solicitation, people spending more time away from home, and the use of answering machines and caller ID. In view of the general decline in response rates, the difference in response rate between the 2004 and 2008 surveys is probably unimportant.

\footnotetext{
${ }^{32}$ Schmoyer, R. L., Tykey Truett, and Christy Cooper, Results of the 2004 Knowledge and Opinions Surveys for the Baseline Knowledge Assessment of the U.S. Department of Energy Hydrogen Program, ORNL/TM-2006/417, http://cta.ornl.gov/cta/Publications/Reports/ORNL_TM_2006 417.pdf, April 2006.

${ }^{33}$ Keeter, S., C. Kennedy, M. Dimock, J. Best, and P. Craighill, "Gauging the Impact of Growing Nonresponse on Estimates from a National RDD Telephone Survey,” Public Opinion Quarterly, 70(5), 759-779, http://poq.oxfordjournals.org/cgi/reprint/70/5/759.pdf, Special Issue, 2006.
} 


\subsection{SUMMARY}

The section summarizes the responses to the individual questions in the general public survey. Most of the questions are summarized as proportions of respondents in each of the respective multiple choice categories. Preference ranks are summarized as means. Answers to the technical questions are summarized individually and are also compiled into an overall technical score. Relationships between responses to different questions and comparisons with the 2004 survey results are considered in Section 4.3 and 4.4.

Table 4.1 summarizes the technical questions in terms of whether they were answered correctly or incorrectly with "Don't know" treated as an incorrect response.

\begin{tabular}{|l|r|r|r|r|}
\hline \multicolumn{1}{|c|}{ Table 4.1. Summary of Results on the Technical Knowledge Questions (correct/incorrect), } \\
Question & $\begin{array}{c}\text { Number } \\
\text { of } \\
\text { responses }\end{array}$ & $\begin{array}{c}\text { Weighted } \\
\text { percent } \\
\text { correct }\end{array}$ & $\begin{array}{c}\text { Lower 95\% } \\
\text { confidence } \\
\text { bound }\end{array}$ & $\begin{array}{c}\text { Upper 95\% } \\
\text { confidence } \\
\text { bound }\end{array}$ \\
\hline & 1,000 & 42.87 & 38.92 & 46.82 \\
\hline 2A. Hydrogen gas is toxic (false) & 1,000 & 11.25 & 9.05 & 13.45 \\
\hline $\begin{array}{l}\text { 2B. Fuel cells produce electricity through } \\
\text { hydrogen combustion (false) }\end{array}$ & 1,000 & 51.83 & 47.83 & 55.83 \\
\hline 2C. Hydrogen is lighter than air (true) & 1,000 & 49.62 & 45.61 & 53.63 \\
\hline 2D. Hydrogen has a distinct odor (false) & 1,000 & 29.20 & 25.64 & 32.77 \\
\hline $\begin{array}{l}\text { 4. In which state or condition can hydrogen } \\
\text { be stored? (chemical compound, liquid) }\end{array}$ & 1,000 & 22.13 & 19.07 & 25.20 \\
\hline $\begin{array}{l}\text { 5. When using pure hydrogen, fuel cell } \\
\text { vehicles generate electricity, water, and what } \\
\text { else? (heat) }\end{array}$ & & & & \\
\hline $\begin{array}{l}\text { 6. Hydrogen can be produced using which of } \\
\text { the following sources of energy? (natural } \\
\text { gas, sunlight, organic matter) }\end{array}$ & 1,000 & 29.65 & 26.23 & 33.06 \\
\hline $\begin{array}{l}\text { 9. Hydrogen is too dangerous for everyday } \\
\text { use by the general public (false) }\end{array}$ & 1,000 & 44.95 & 41.05 & 48.85 \\
\hline \begin{tabular}{l} 
Overall average \\
\hline
\end{tabular} & 1,000 & 35.2 & 33.17 & 37.21 \\
\hline
\end{tabular}

The greatest percentage of correct responses is 51.8\%, for Question 2C (Hydrogen is lighter than air...), followed by 49.6\% for Question 2D (Hydrogen has a distinct odor...). The smallest percentage of correct responses is $11.3 \%$ for Question 2B (Fuel cells produce electricity through...), followed by $22.1 \%$ for Question 5 (When using pure hydrogen...). Questions 2B, 4, 5, and 6 were all answered correctly by less than $30 \%$ of respondents.

The correct/incorrect perspective used in Table 4.1 is conventional, since "Don't know" is generally considered an incorrect response. However, "Don't know" was a very common response to the survey technical questions. Figure 4.1 shows the responses broken down according to type: Correct, Incorrect, and "Don't know." On average, 35.2\% of the technical questions were answered correctly, 19.4\% were answered incorrectly, and 45.4\% were answered with "Don't know." 
Figure 4.2 shows the distribution of the number of correct responses. The dispersion about the mean score (35.3\% or 2.8 correct) is substantial, as might be expected, given the varied backgrounds of general public respondents. The distribution is right skewed, with over $16 \%$ of respondents answering zero technical questions correctly but fewer than $1 \%$ of respondents answering all eight technical questions correctly.

The first question in the survey asked respondents to gauge their familiarity with hydrogen and fuel cell technologies. Figure 4.3 shows the distribution of responses. Almost half of all respondents considered themselves not at all familiar.

Table 4.2 summarizes the rank scores for the question (Question 7) asking respondents to rank the importance of safety, cost, environment, convenience, and performance when selecting a fuel for your vehicle or power supply for your home or business. The table shows weighted averages of the ranks (1-5) assigned by each survey subject and confidence bounds for the average. In this ranking, "1" ranks as more important than " 2 ," etc. Therefore, the lower the weighted average rank, the more important the "Value" to the respondent. On average, "Cost" was considered most important, followed in order by "Safety," "Environment," "Performance," and "Convenience." Of course many individuals departed from this exact order. The last ten "Value" entries in Appendix C.1 are for pairwise comparisons based on the safety, cost, environment, convenience, and preference rankings, with each possible pair (e.g., safety and cost) considered separately.

\begin{tabular}{|l|c|c|c|c|}
\hline \multicolumn{5}{|c|}{ Table 4.2. Summary of Importance Ranking, General Public } \\
\hline Question & $\begin{array}{c}\text { Number of } \\
\text { responses }\end{array}$ & $\begin{array}{c}\text { Weighted } \\
\text { average } \\
\text { rank }\end{array}$ & $\begin{array}{c}\text { Lower 95\% } \\
\text { confidence } \\
\text { bound }\end{array}$ & $\begin{array}{c}\text { Upper 95\% } \\
\text { confidence } \\
\text { bound }\end{array}$ \\
\hline Cost & 982 & 2.23 & 2.13 & 2.33 \\
\hline Safety & 978 & 2.50 & 2.40 & 2.59 \\
\hline Environment & 966 & 3.10 & 3.00 & 3.21 \\
\hline Performance & 973 & 3.40 & 3.30 & 3.51 \\
\hline Convenience & 971 & 3.73 & 3.63 & 3.83 \\
\hline
\end{tabular}

Figure 4.4 also illustrates the pattern shown in Table 4.2.

Respondents were asked to imagine that they were shopping for a new car. They were asked whether they would buy a fuel cell vehicle if they could purchase it at the same price as a comparable gasoline vehicle model. As shown in Figure 4.5, over $60 \%$ of the respondents indicated that they would purchase a fuel cell vehicle.

Related to the preference ranking question, Figure 4.6 shows that the general public generally agree that the use of hydrogen will reduce U.S. dependence on foreign oil and will reduce emissions and improve air quality. 


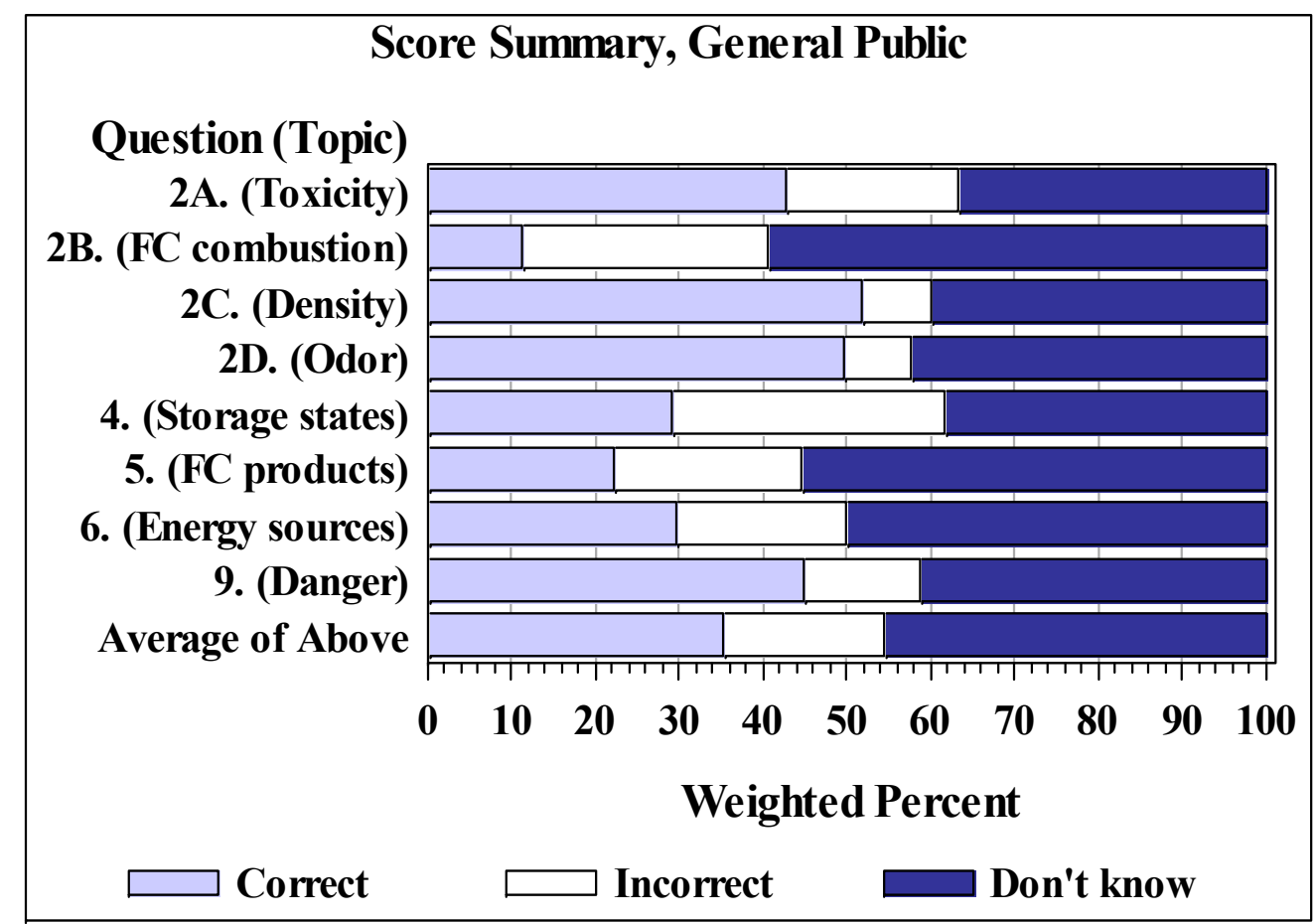

Figure 4.1. Weighted percent of correct, incorrect, and "Don't know" responses for the technical knowledge questions, general public survey.

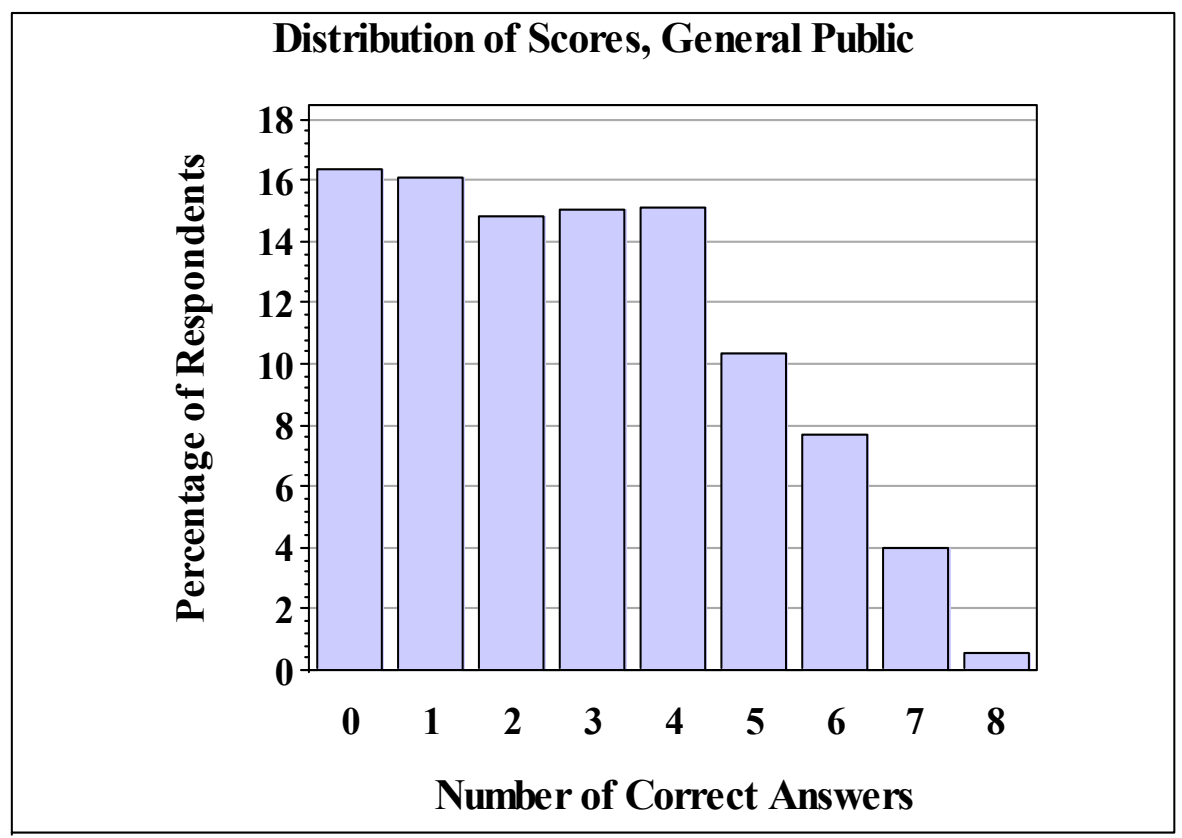

Figure 4.2. Distribution of the number of correct answers to the eight technical knowledge questions, general public survey. 


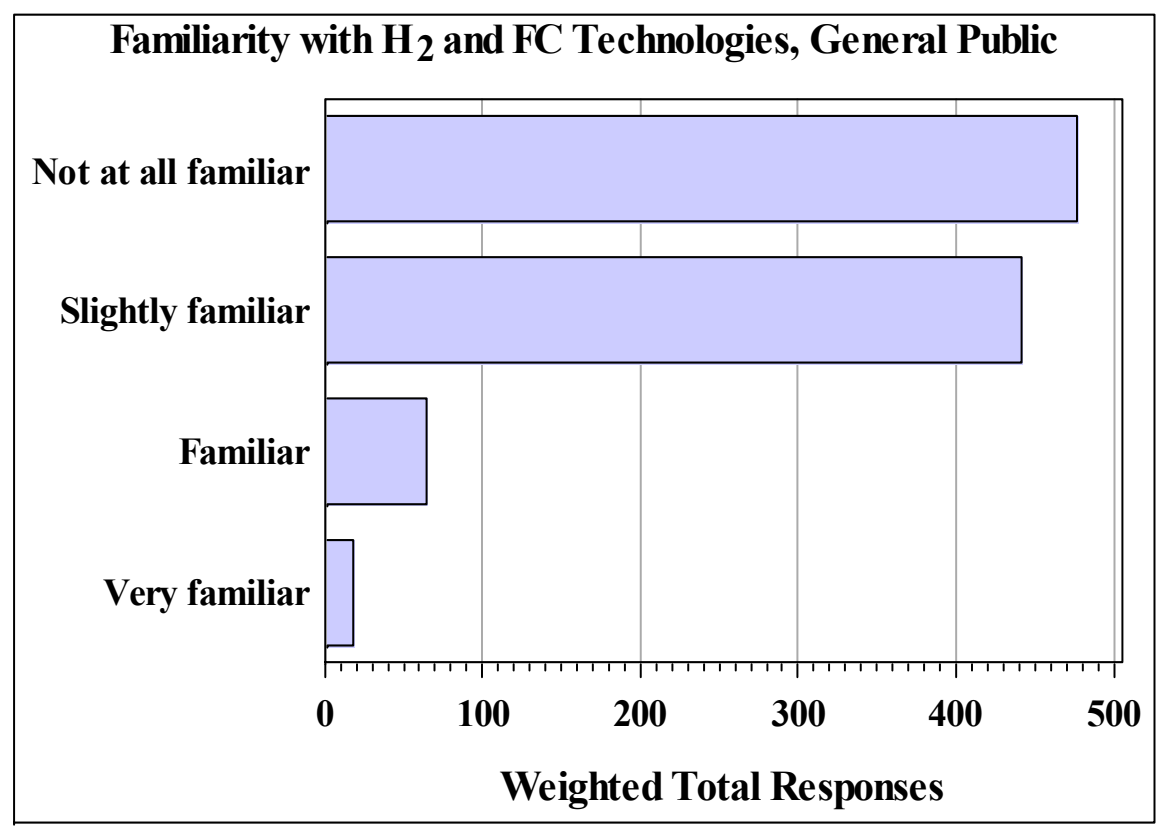

Figure 4.3. Distribution of responses to the question about familiarity with hydrogen and fuel cell technologies, Question 1, general public survey.

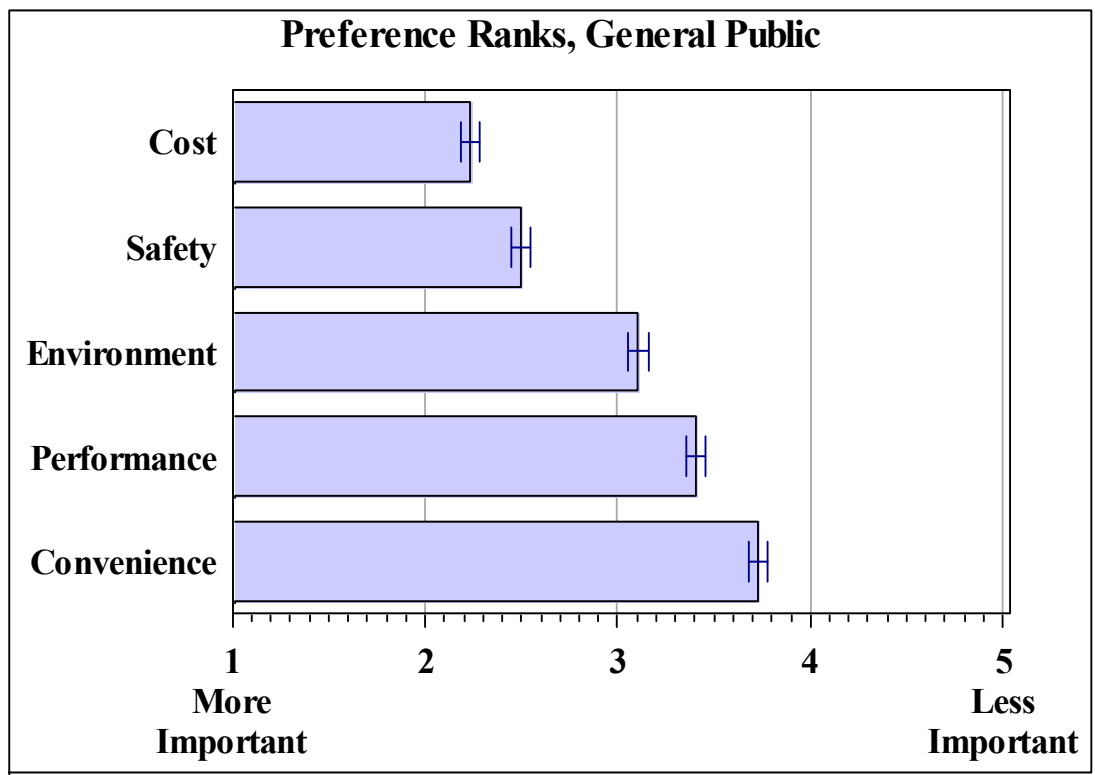

Figure 4.4. Mean of preference rankings of cost, safety, environment, convenience, and performance, Question 7, general public survey. (Rank=1 for first choice, 2 for second choice, etc.) The error bar on each chart bar shows $95 \%$ confidence limits for the mean rank. 


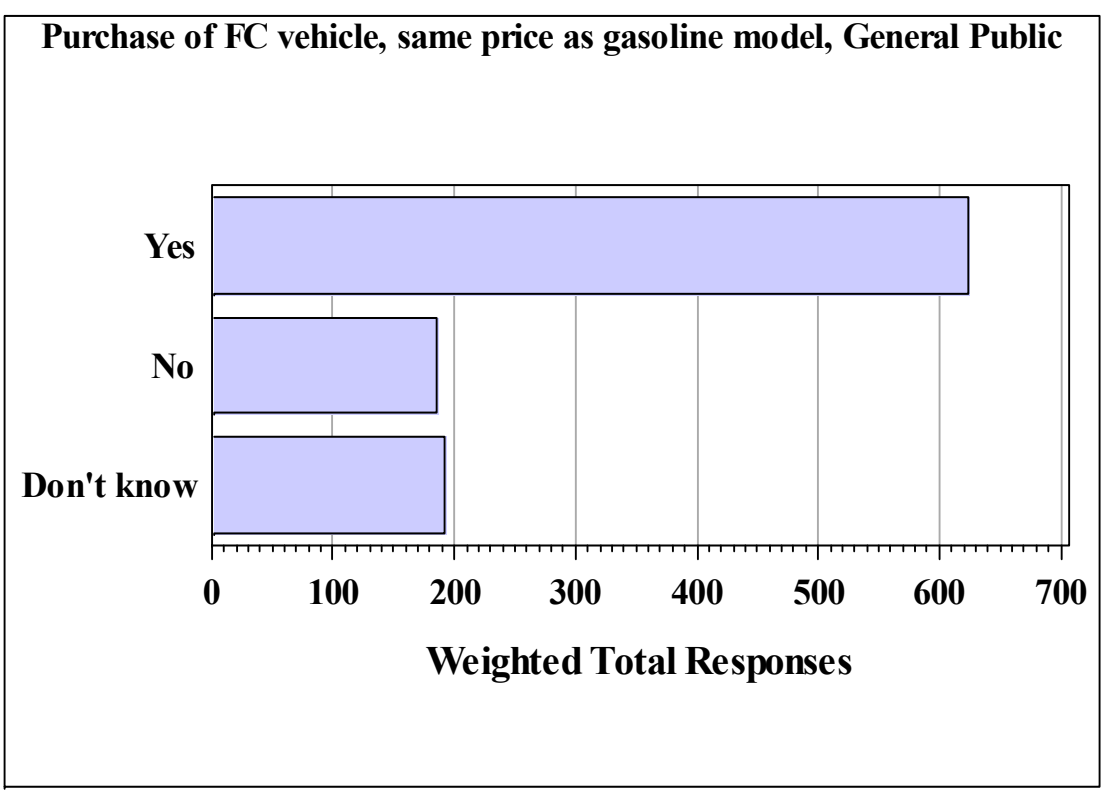

Figure 4.5. Share of respondents who would purchase a fuel cell vehicle if it were available at the same price as a gasoline-fueled vehicle, Question 11, general public survey.

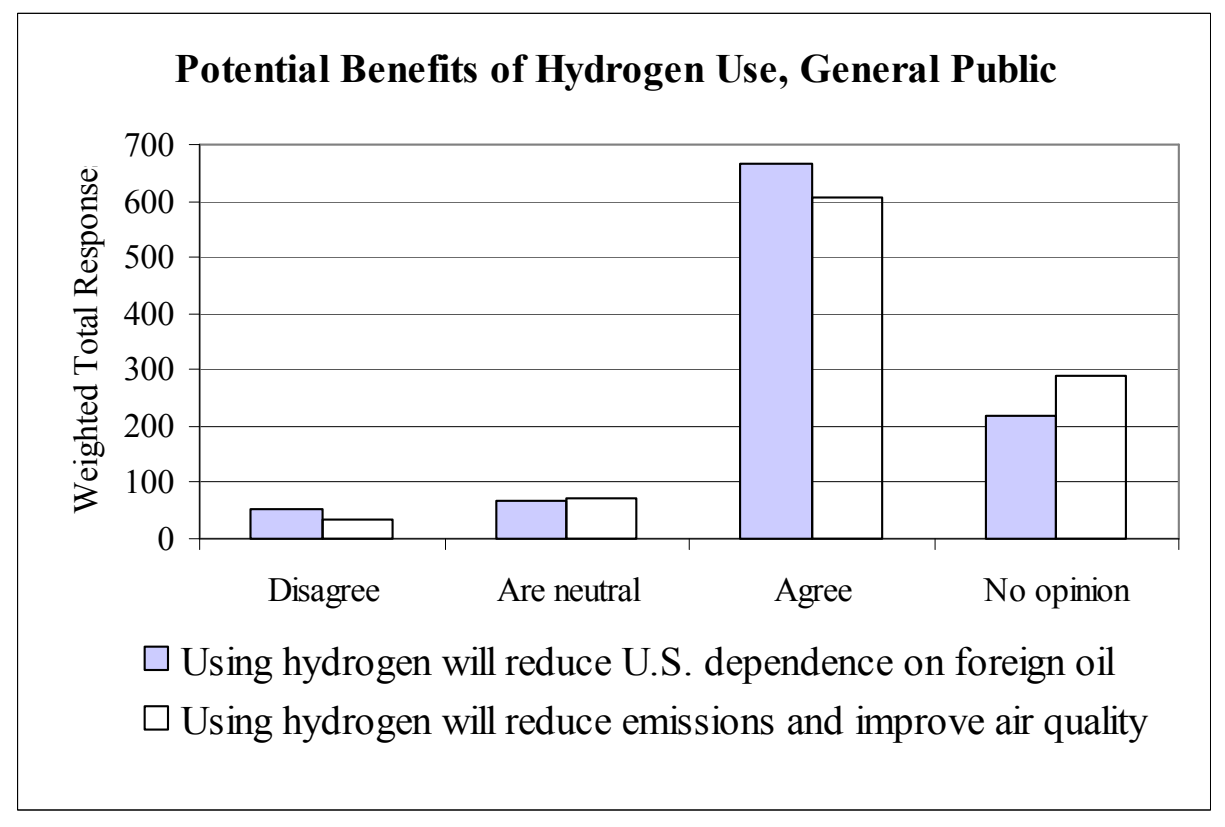

Figure 4.6. Responses to statements about the potential benefits of the use of hydrogen as a vehicle fuel, Questions 10A and 10B, general public survey.

Figure 4.7 shows that more than $40 \%$ of respondents agree with the statement "Hydrogen is as safe to use in my car as gasoline and diesel fuels." At the same time, however, nearly $40 \%$ of respondents provided a "Don't know/No opinion" response to this question. 


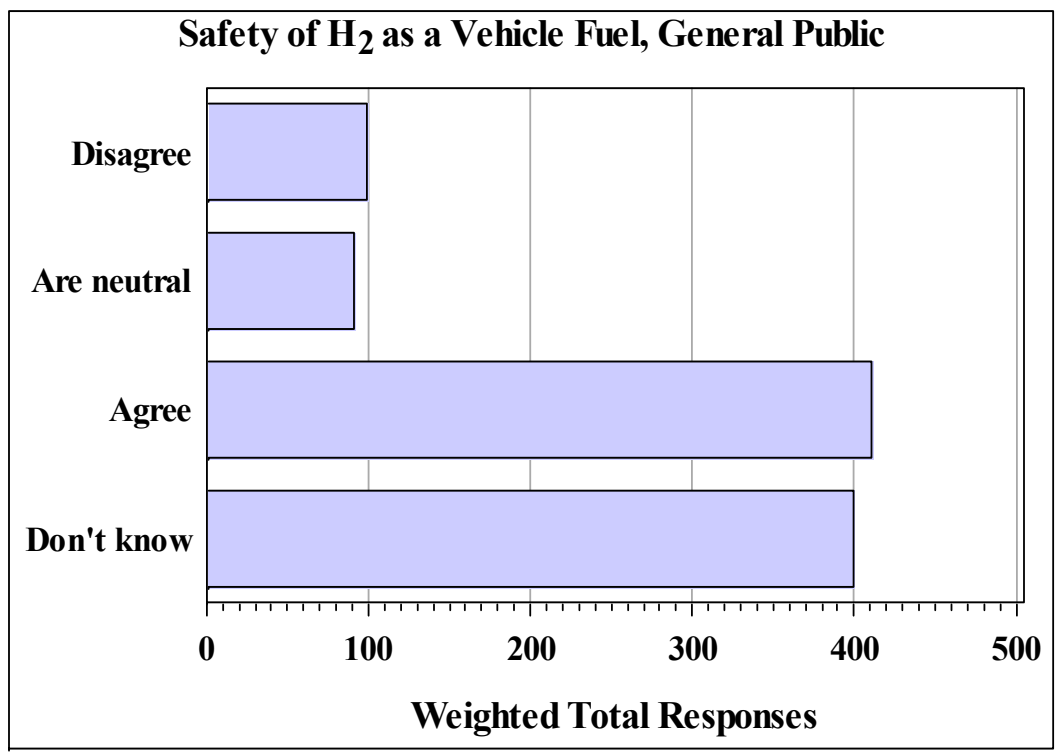

Figure 4.7. Responses to the statement, "Hydrogen is as safe to use in my car as gasoline and diesel fuels," Question 10C, general public survey.

Respondents were asked how they would feel if their local gas station also sold hydrogen. Figure 4.8 shows their responses to this question. Over half of the respondents indicated that they would be either "At ease" or "Pleased."

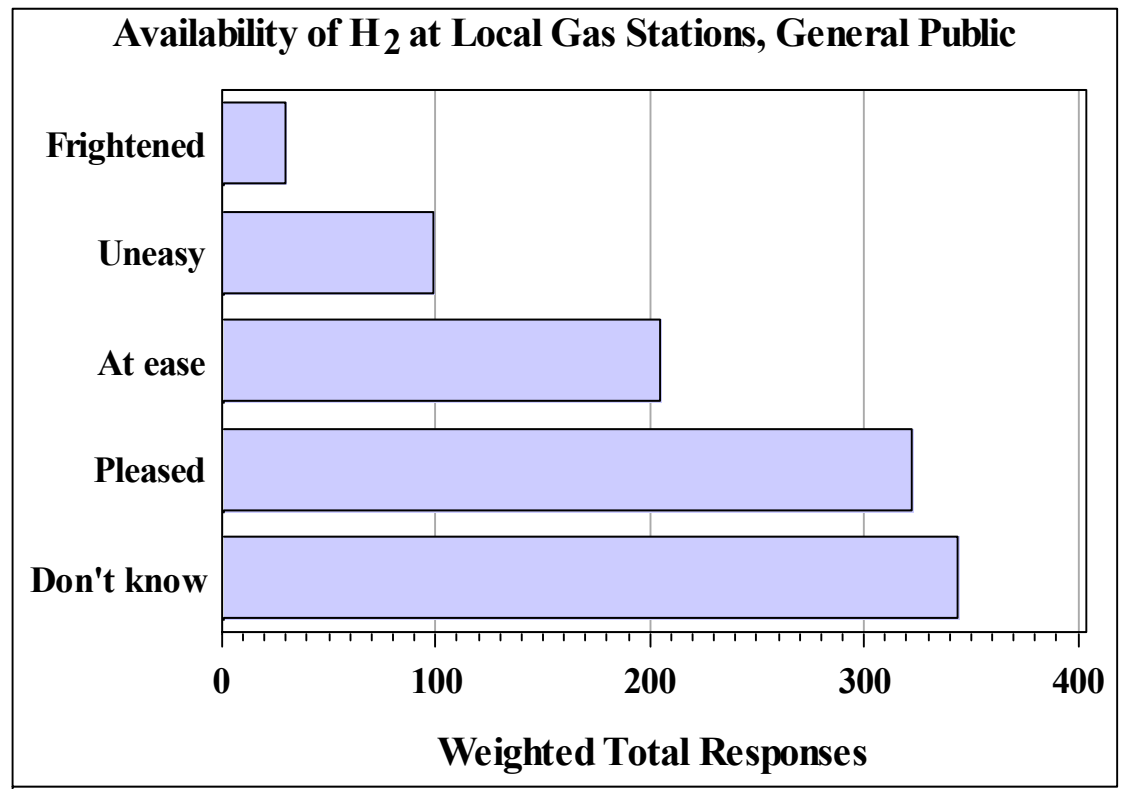

Figure 4.8. Reactions to the possibility of sales of hydrogen at a local gas station, Question 8, general public survey.

A similar question asked respondents how they would feel if a school, hospital, or other building in their neighborhood was powered by a fuel cell located on its property. Figure 4.9 shows the 
results to this question, which indicate that over half of the general public respondents would feel either "At ease" or "Pleased" about the use of a fuel cell to provide power at a public building.

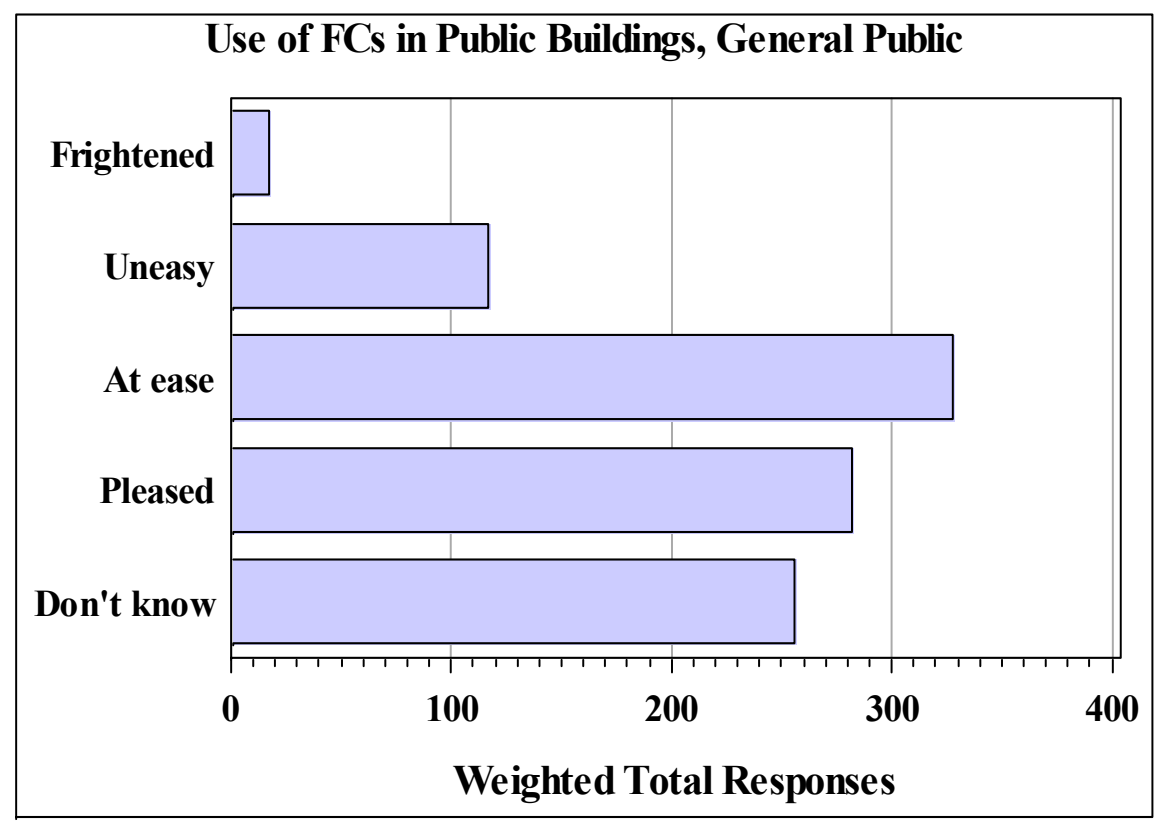

Figure 4.9. Reactions to the possible onsite use of a fuel cell to provide power for a public building, Question 12, general public survey

The population-wide response profiles in Figures 4.8 and 4.9 are similar. For individual respondents, the responses to the two questions (Questions 8 and 12) also tended to be the same. More than $40 \%$ of respondents gave exactly the same ordinal response (frightened, uneasy, at ease, or pleased) to both questions, and $15 \%$ of respondents differed by only one place on this scale. Only $5 \%$ of respondents differed by more than one place, the remaining $40 \%$ or respondents answering "Don't know" to either one or both questions.

The adults responding to the general public survey were asked two questions about information sources. Question 14 asked about the frequency ("Never," "Sometimes," "Frequently") of use of information sources to make decisions about energy costs and safety. As shown in Figure 4.10, the source marked "Frequently" most often was friends and family members $(22.3 \%$ of respondents indicated frequent use of this source). On the other hand, "Never" was the most common response (followed by "Sometimes"). In fact, the only information sources for which "Never" was not the most frequent were friends and family members and utility companies or brokers. The responses of the general public to this question were very similar to those recorded in the 2004 survey.

Question 15 also asked about information sources, but from the perspective of media sources, that is, information vectors (television, radio, internet, etc.) for obtaining energy information. As shown in Figure 4.11, general public respondents indicated that they rarely used science and technology journals and trade magazines; their most frequent media source for obtaining energy information was television. 


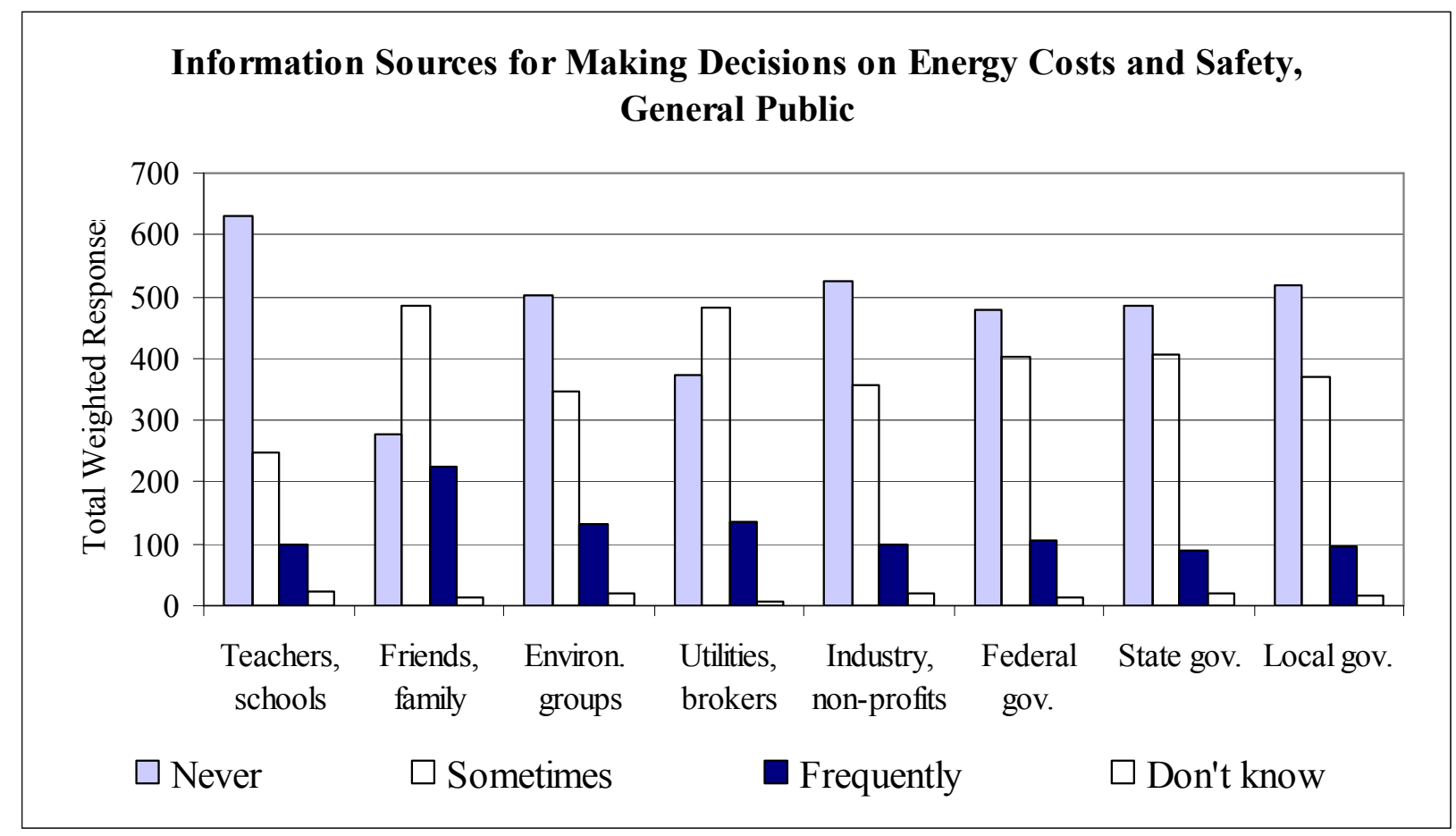

Figure 4.10. Weighted counts of responses regarding the frequency of use of information sources when making decisions about energy costs and safety, Question 14, general public survey.

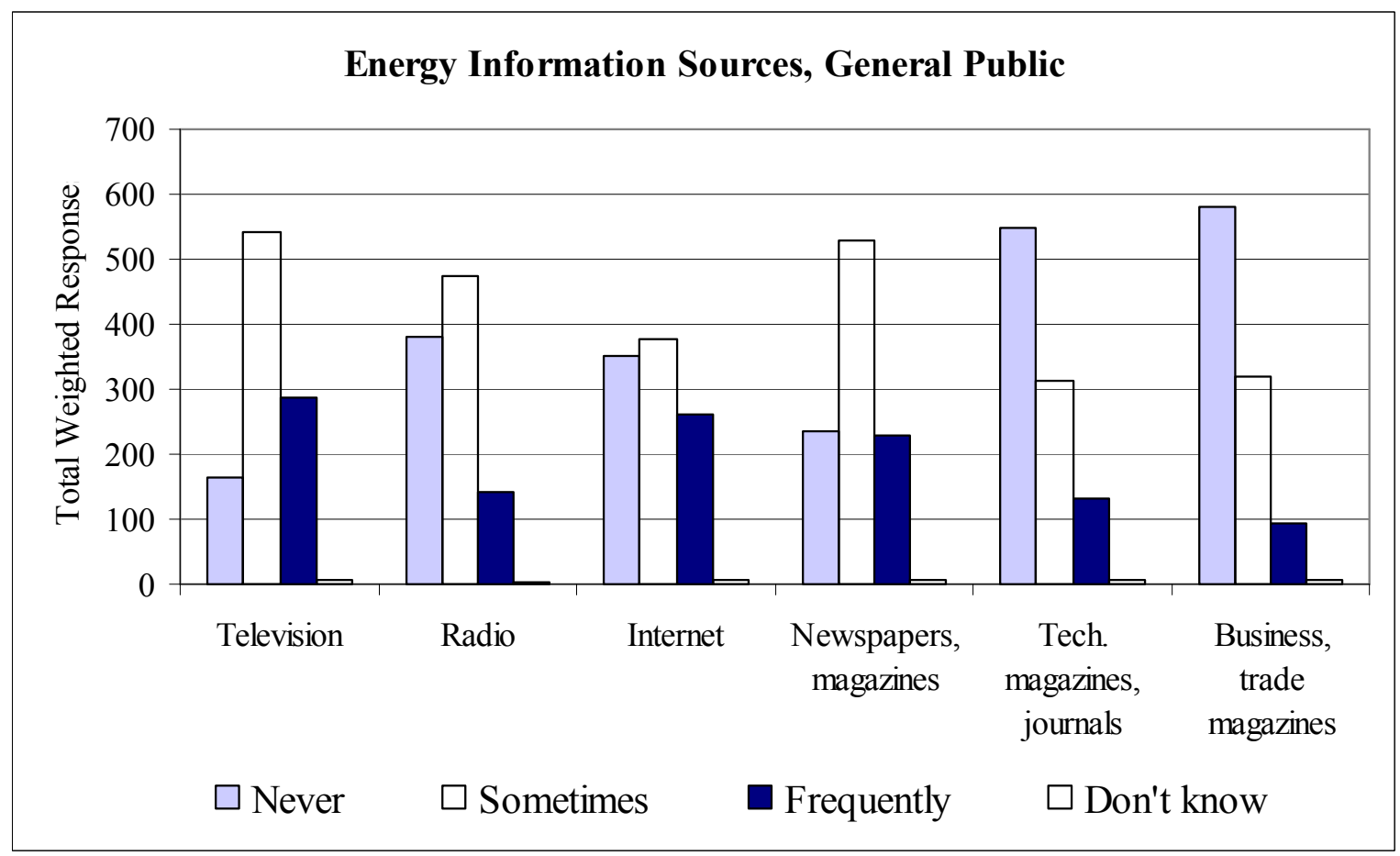

Figure 4.11. Weighted counts of responses regarding the frequency of use of different types of mass media for obtaining energy information, Question 15, general public survey. 


\subsection{RELATIONSHIPS}

The summary statistics discussed in Section 4.2 are "one-way" statistics in the sense that the response categories are defined in terms of one variable such as the response to an opinion question such as "Hydrogen is as safe to use in my car as gasoline and diesel fuels." However, relationships in the responses determined by two or more variables are also of interest. Although no relationships were of particular interest a priori, a few of the more statistically significant twoway relationships are illustrated in this section. Interactions that were considered were between survey variables and sex, age (18-44, and 45+; divides population in approximate halves), region, urban/non-urban, degree (no degree/associate or above), the individual assessment of familiarity with hydrogen and fuel cell technologies, and whether or not the score on the technical questions was above the average for the sample. The statistical significance criterion here is the significance level $(\mathrm{p})^{34}$ of a chi-square test that accounts for the sampling weights. ${ }^{35}$

As shown in Figure 4.12, respondents who scored below average on the technical questions were more likely to assess their familiarity as "Not at all familiar," and respondents who scored above average were more likely to claim a higher familiarity with hydrogen and fuel cell technologies. Thus, the familiarity self-assessments are consistent with the technical awareness scores.

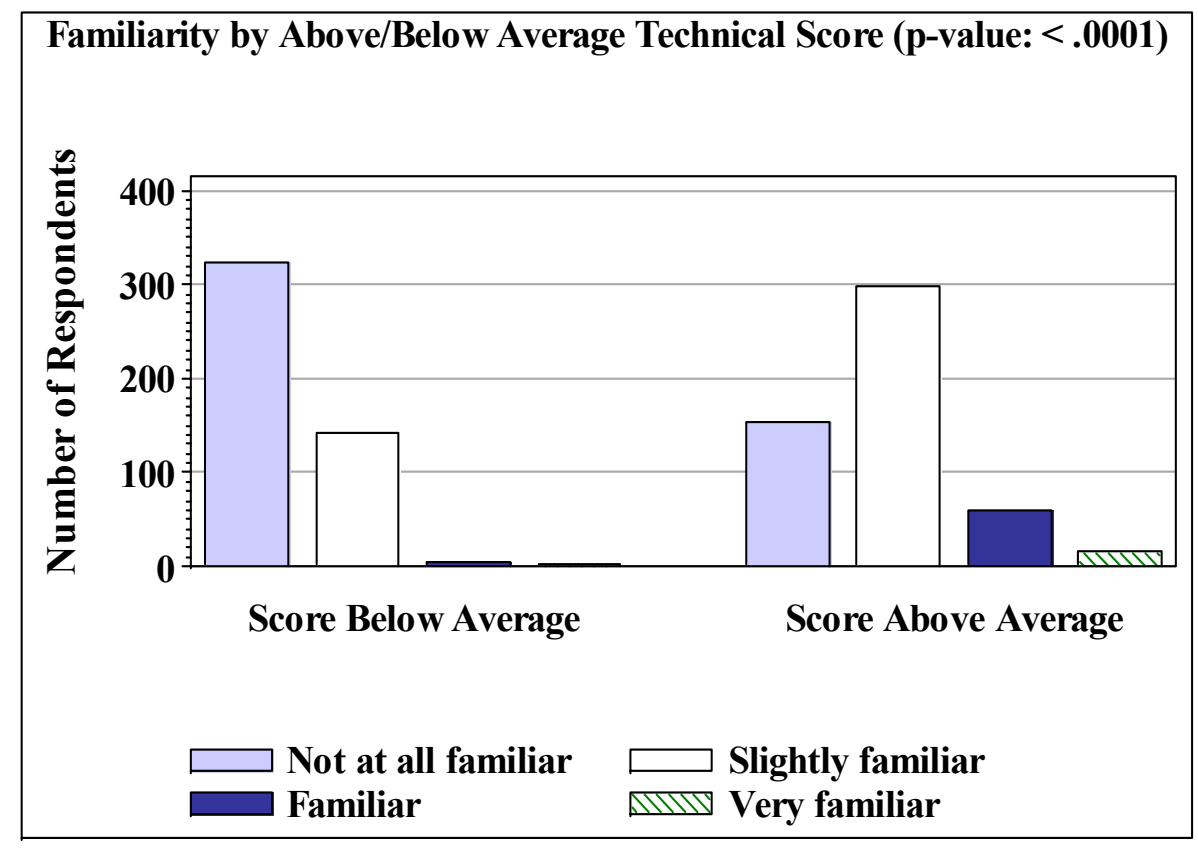

Figure 4.12. Responses by technical score above/below average to Question 1 (familiarity of respondents to hydrogen and fuel cell technologies), general public survey.

\footnotetext{
${ }^{34}$ Significance levels (p) are expressed in this report either as " $p=$ value" or, for values less than 0.0001 , " $p<0.0001$." Significance levels for relationships, which are for chi-square tests, are printed at the tops of the figures.

${ }^{35}$ Measures could also be based on odds ratios or combinations of odd ratios and significance levels as well as other metrics. Significance levels alone were used for simplicity and because sample sizes are essentially the same for all survey questions.
} 
In the 2004 general public survey results, an interesting and statistically significant finding was that respondents who did better on the technical knowledge questions were much more likely to say that they would be comfortable with a local hydrogen gas station. As shown in Figure 4.13, this finding was also evident in the 2008 survey results.

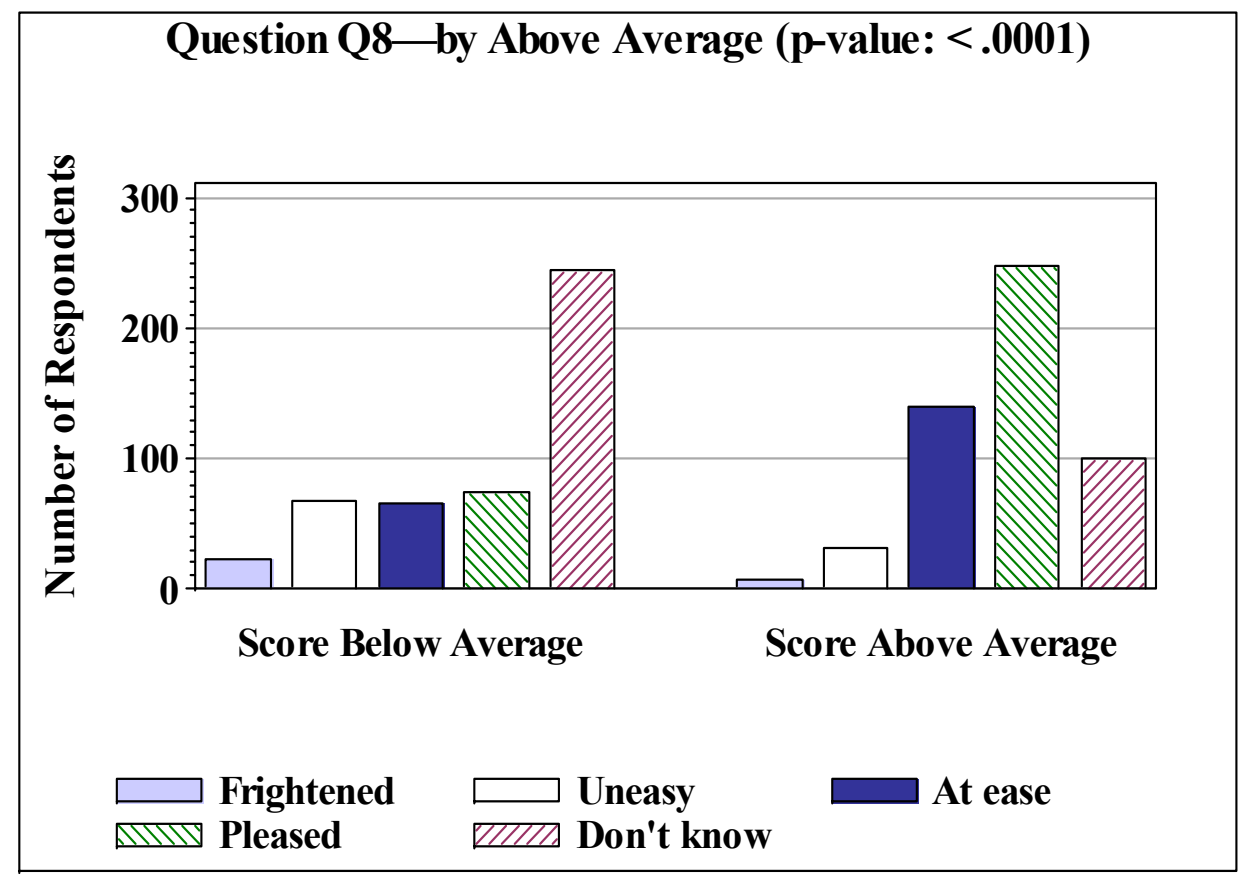

Figure 4.13. Responses by technical score above/below average to Question 8, "How would you feel if your local gas station also sold hydrogen," general public survey.

Another statistically significant finding in the 2008 survey is the relationship between the respondent's score on the technical questions and his/her reaction to the statement "Hydrogen is too dangerous for everyday use by the general public" (Question 9, general public survey). As shown in Figure 4.14, respondents who knew more about hydrogen and fuel cell technologies (as indicated by their technical scores) were much more likely to consider this statement false; that is, they were more comfortable with the idea of everyday use of hydrogen by the general public.

Three comparisons by gender were statistically significant. Males are much more comfortable with hydrogen and fuel cell technologies than females, as shown in Figures 4.15, 4.16, and 4.17. When asked how they would feel if their local gas station also sold hydrogen, females were more likely than males to respond "Frightened," "Uneasy," or "Don't know" (Figure 4.15). When asked how they would feel if a school, hospital, or other building in their neighborhood was powered by a fuel cell located on its property, females again were more likely than males to respond "Frightened," "Uneasy," or "Don't know" (Figure 4.16). Females were also more likely to believe that hydrogen was not as safe as gasoline for vehicle use (Figure 4.17). ${ }^{36}$

\footnotetext{
${ }^{36}$ Gender differences among general public respondents were also observed in 2004 . See, for example, Figure 4.8 of the 2004 report.
} 


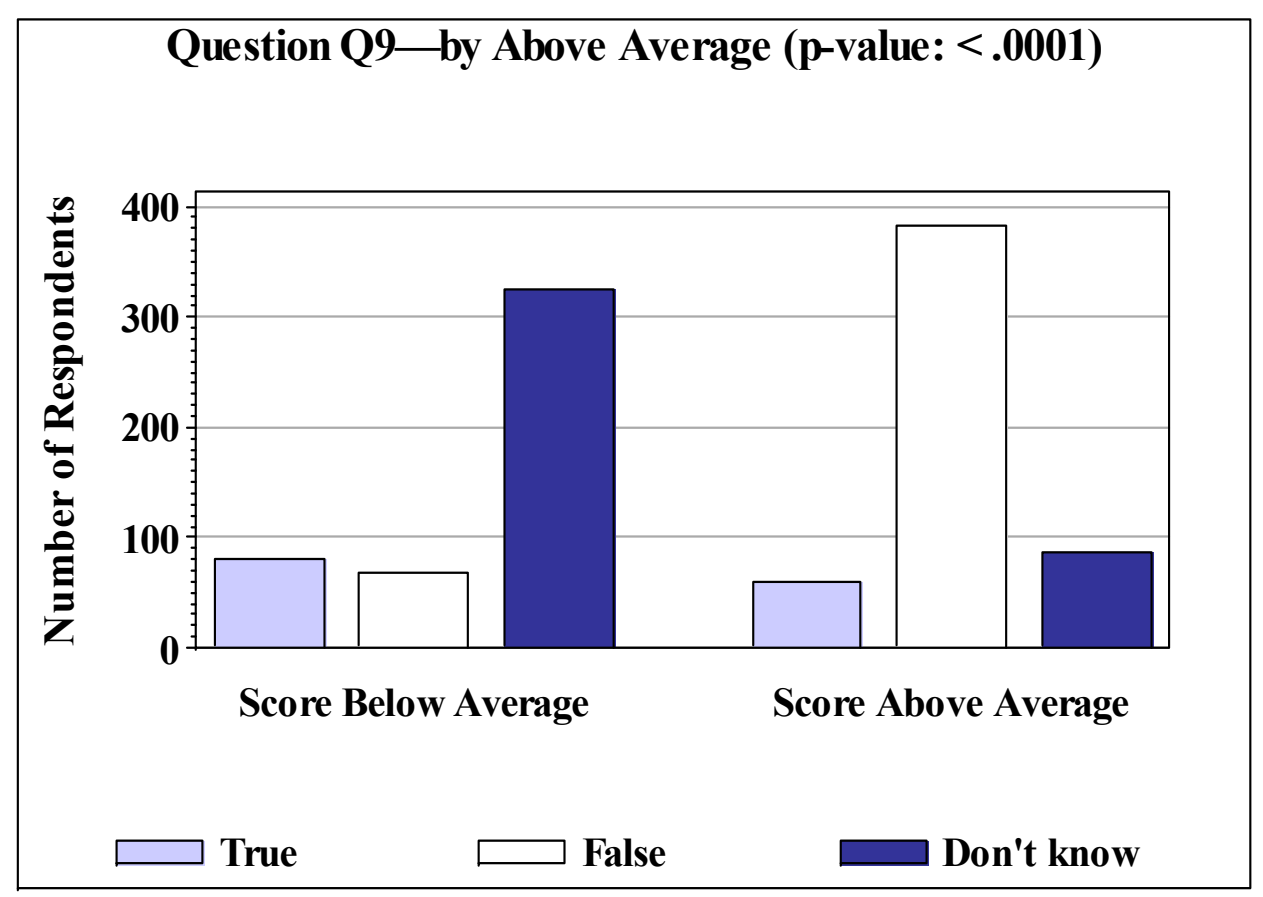

Figure 4.14. Responses by technical score above/below average to Question 9, "Please tell me if the following statement is true, if it is false, or if you don't know: "Hydrogen is too dangerous for everyday use by the general public," general public survey.

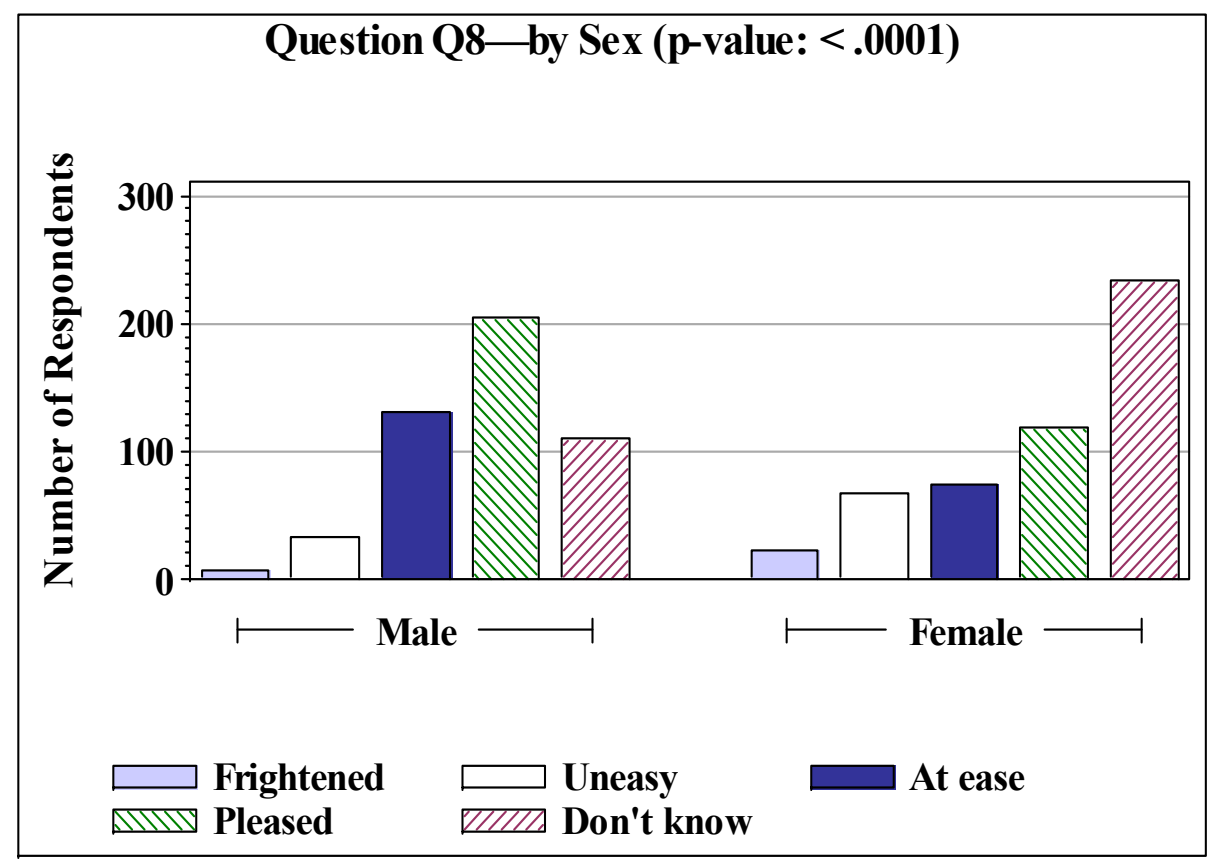

Figure 4.15. Responses by gender to Question 8, "How would you feel if your local gas station also sold hydrogen," general public survey. 


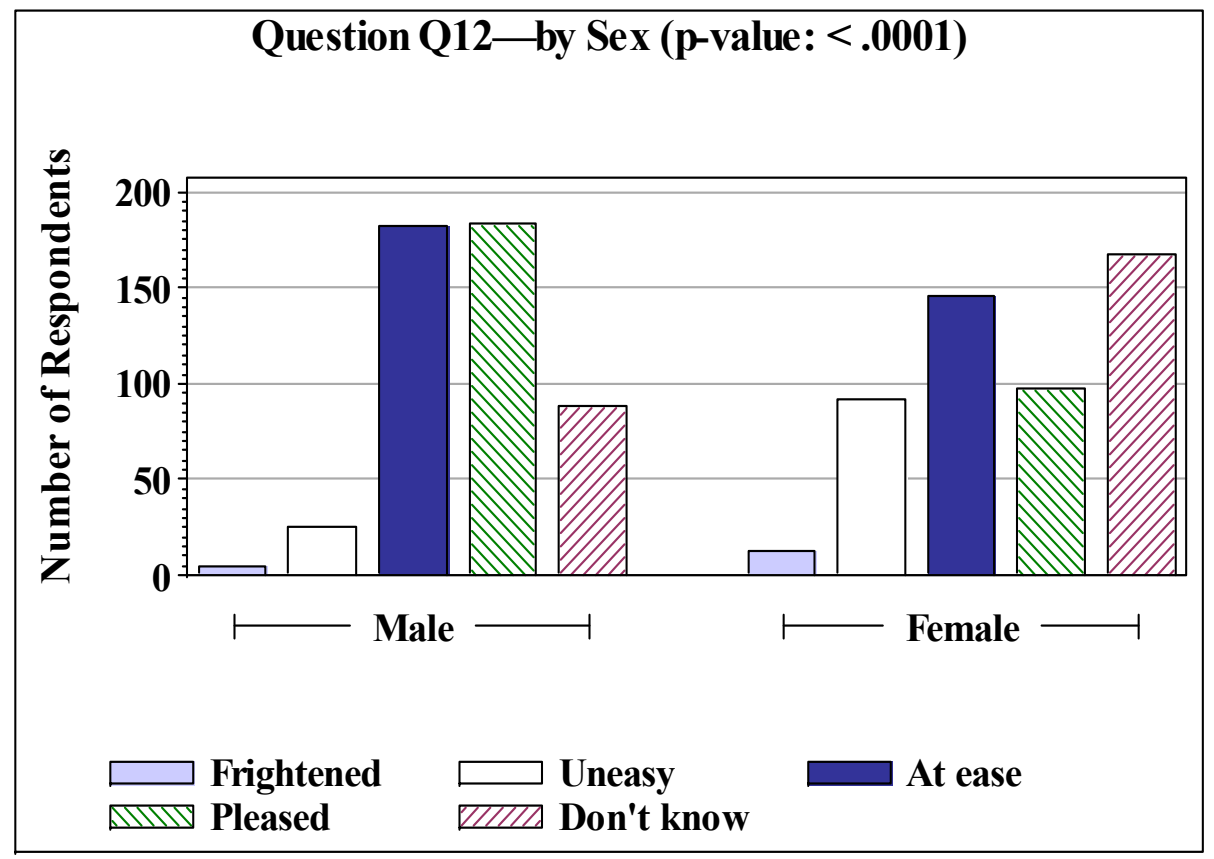

Figure 4.16. Responses by gender to Question 12, "How would you feel if a school, hospital, or other building in your neighborhood was powered by a fuel cell located on its property," general public survey.

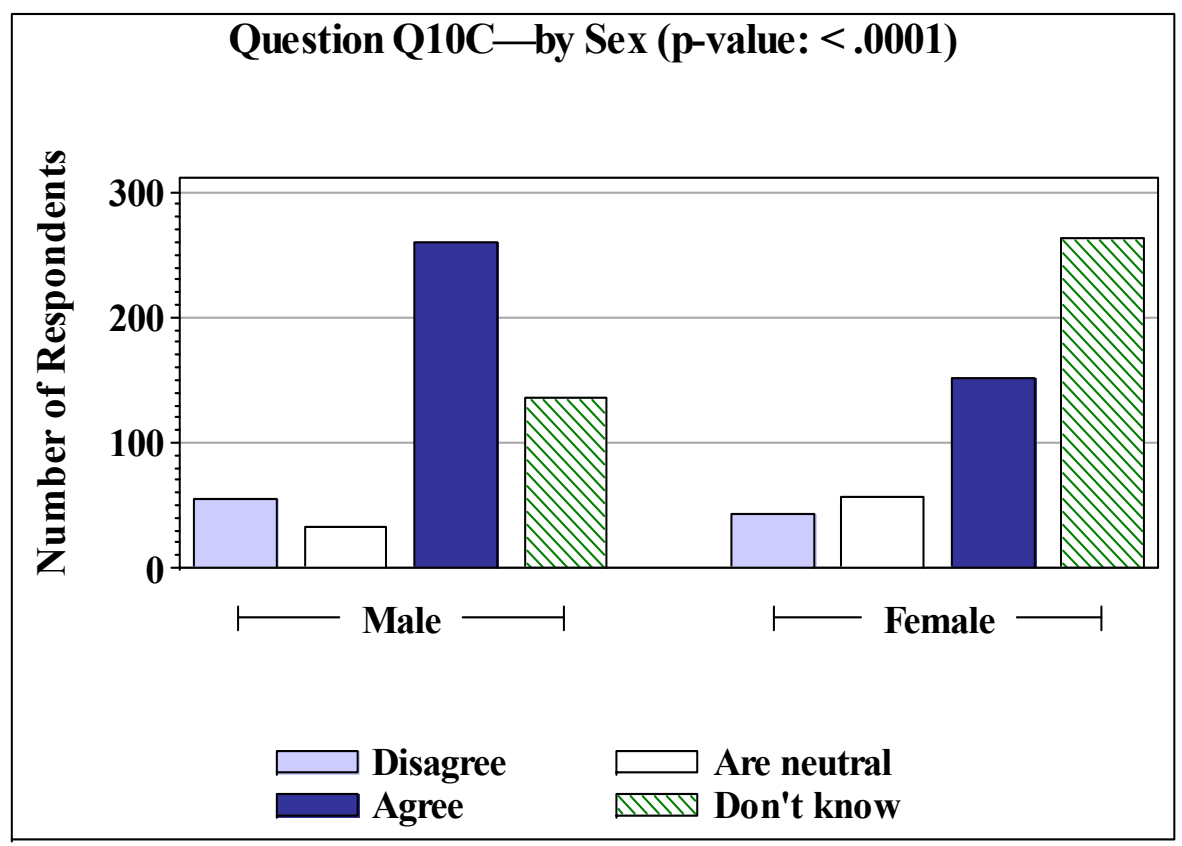

Figure 4.17. Responses by gender to Question 10C, "Hydrogen is as safe to use in my car as gasoline and diesel fuels," general public survey. 
Another statistically significant finding was a comparison of responses to Question 8 by age. Figure 4.18 shows that respondents under age 45 were more likely to indicate that they did not know how they would feel if their local gas station also sold hydrogen; respondents age 45 and over were more likely to be pleased.

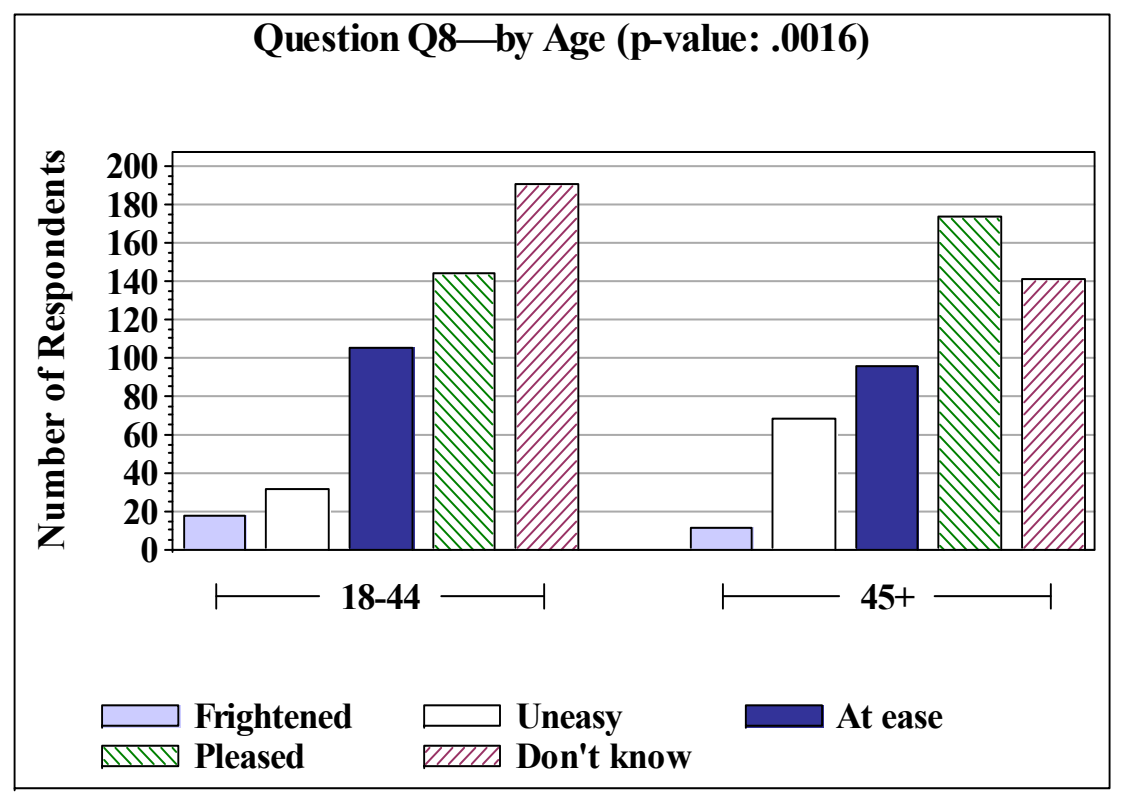

Figure 4.18. Responses by age to Question 8, "How would you feel if your local gas station also sold hydrogen," general public survey.

\subsection{COMPARISON WITH THE 2004 BASELINE}

A primary objective of conducting multiple surveys over time is to compare changes in the survey results. Figure 4.19 shows the differences in the average technical scores for each of the eight technical questions on the survey as well as the difference between 2008 and 2004 in the overall average score. A positive difference indicates improvement in 2008. For example, for the 2008 question 2A, the scores were on average 7 percentage points higher in 2008 than in 2004. Respondents in 2008 had higher average scores on Questions 2A, 2D, 5, and 9; however, they had lower average scores on Questions 2B, 2C, 4, and 6. The general public had an overall average technical score of 35.19\% correct responses in 2008; in 2004 the average percent correct was $32.84 \%$ on eleven technical questions. However, only eight of those eleven questions were used again in 2008. The 2004 average score for the eight questions used in both 2004 and 2008 is 35.18. This is almost identical to the 2008 average. Thus, there is essentially no difference at all between 2004 and 2008 average scores. Error bars on the chart show 95\% confidence ranges for the average score differences. A 95\% error range containing 0 indicates that the corresponding difference is not statistically significant. In addition to showing that the difference in the overall average scores is not statistically significant (which is almost obvious from the nearly exact agreement in the two averages) the error range for the overall average difference (from $-5 \%$ to $+5 \%$ ) shows that the nearly exact agreement is also, at least in part, merely a coincidence. 


\section{8 vs 2004 Baseline Scores}

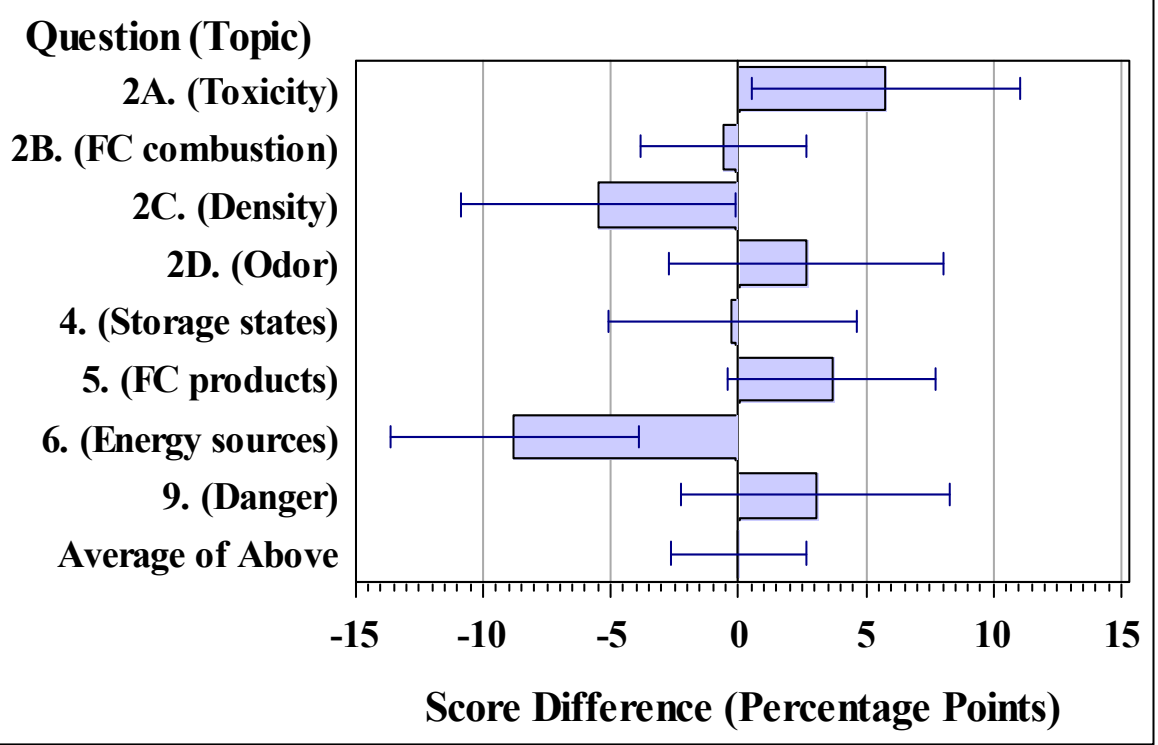

Figure 4.19. Differences between the 2008 and 2004 average percentage correct for each technical question and overall, general public survey. Bars to the right of zero indicate improvement in 2008; bars to the left indicate a decline. The error bars are $95 \%$ confidence intervals for the differences. Confidence limits that span the origin (0) indicate that the change indicated by the corresponding bar is not statistically significant (at the 0.05 level of significance).

In 2004, general public respondents were asked to rank the importance of safety, cost, environment, and convenience when selecting a vehicle fuel or home power supply. The ranking question was also asked in 2008 with the addition of another ranking option, "Performance." Results for the ranking question for the 2008/2009 survey are shown in Figure 4.4; the results of this question for 2004 are shown in Figure 4.20.

Although the "Performance" category was not considered in 2004, the preference ranks for the other four categories are directly comparable. The 2004 and 2008 average rankings for those four categories were in the same order, with one exception: in 2004, safety was considered most important, followed by cost; in 2008 cost was considered most important, followed by safety. As the tight confidence bars in Figures 4.4 and 4.20 suggest, this reversal is statistically significant $(\mathrm{p}<0.0001)$. A likely reason for the public's greater concern about cost in 2008 is the dramatic rise in gasoline costs.

Several questions in the survey concerned safety issues and the use of hydrogen. Changes in the public's perception of hydrogen safety are shown in the next few figures. Figure 4.21 shows that the 2008 percentage (13.9\%) of respondents who believe that hydrogen is too dangerous for everyday use is about half of what it was in $2004(27.5 \%)$. This difference is statistically significant $(\mathrm{p}<0.0001)$. 


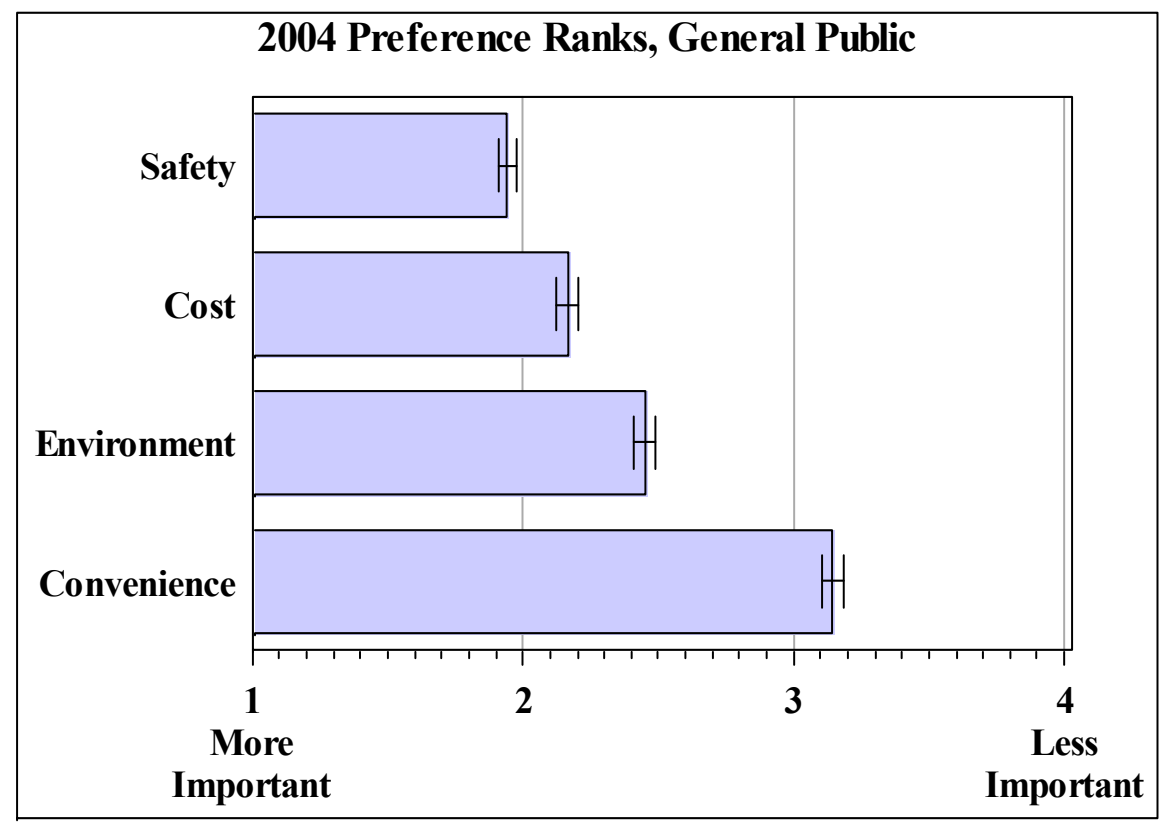

Figure 4.20. Mean of the general public's 2004 preference rankings of cost, safety, environment, and convenience. (Rank $=1$ for first choice, 2 for second choice, etc.) The error bar on each chart bar shows $95 \%$ confidence limits for the mean rank.

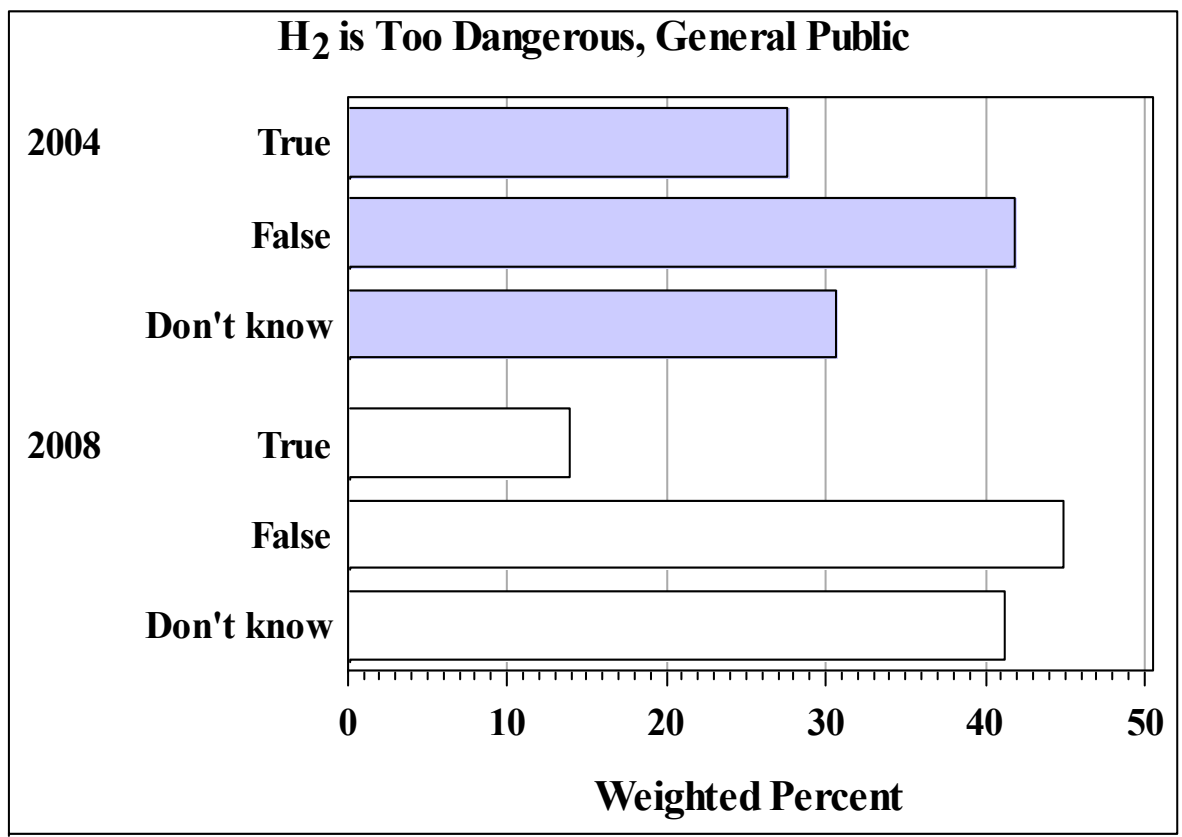

Figure 4.21. Comparison of results of the 2004 and 2008 surveys regarding opinions about the everyday use of hydrogen, Question 9, general public survey. 
Another question concerned the comfort level of the general public with the sale of hydrogen at their local gas station. Figure 4.22 compares the 2004 and 2008 responses to this question. The number of respondents who indicated that they would be frightened or uneasy in $2004(8.0 \%$ and $18.6 \%$ respectively) decreased appreciably in 2008 (to $3.0 \%$ and $9.9 \%$ respectively). Both decreases were statistically significant $(p<0.0001$ in each case).

Another question examined opinions about the safety of hydrogen in vehicles. As shown in Figure 4.23, the percentage of respondents who disagreed with the statement, "Hydrogen is as safe to use in my car as gasoline and diesel fuels" decreased between 2004 and 2008 (from $15.6 \%$ to $9.9 \%)$. The difference is also statistically significant $(\mathrm{p}=0.002)$. The proportion of respondents who agreed with the statement changed only slightly, however $(41.1 \%$ in 2008 ; $39.2 \%$ in 2004).

Although no statistically significant change between the surveys of 2004 and 2008 was observed in the average percentage of correct responses to the technical knowledge questions, the results shown in Figures 4.21 through 4.23 indicate that the general public is nevertheless becoming more aware of and more comfortable with the use of hydrogen technology, and more confident in its safety.

The sources that the general public use to obtain energy information were almost identical to those identified in the 2004 survey.

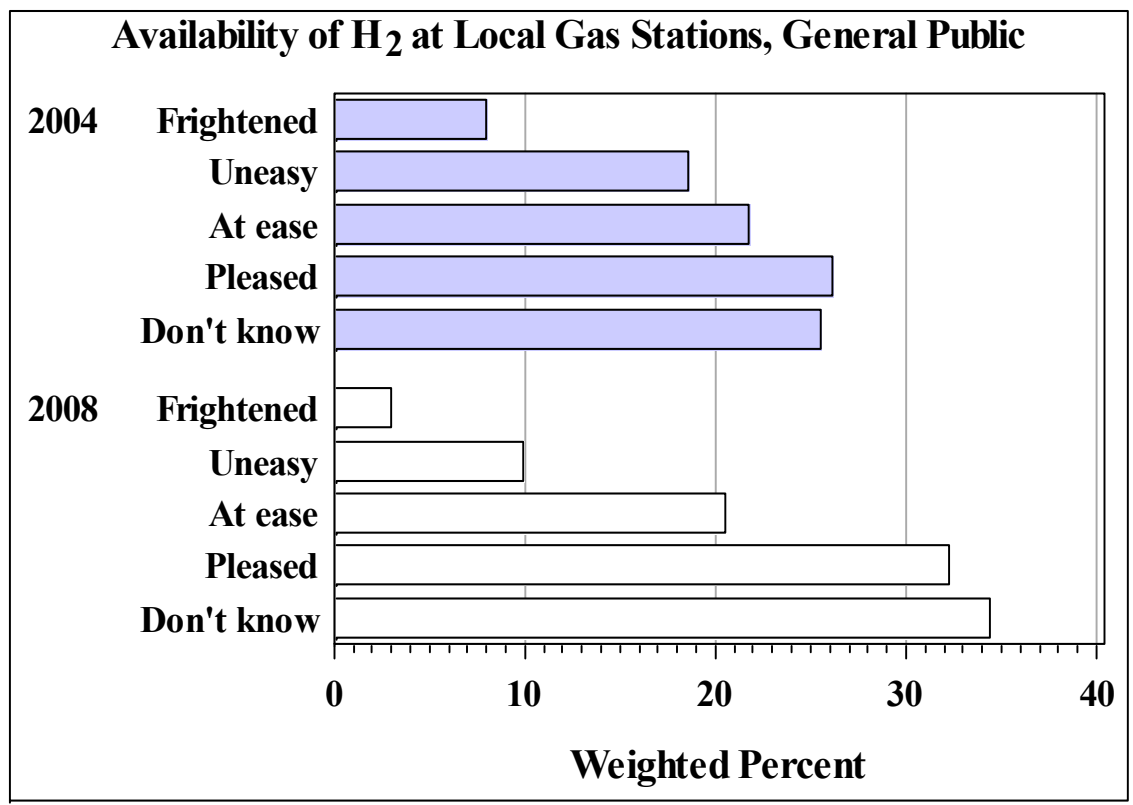

Figure 4.22. Comparison of results of the 2004 and 2008 surveys regarding opinions about the availability of hydrogen at a local gas station, Question 8, general public survey. 


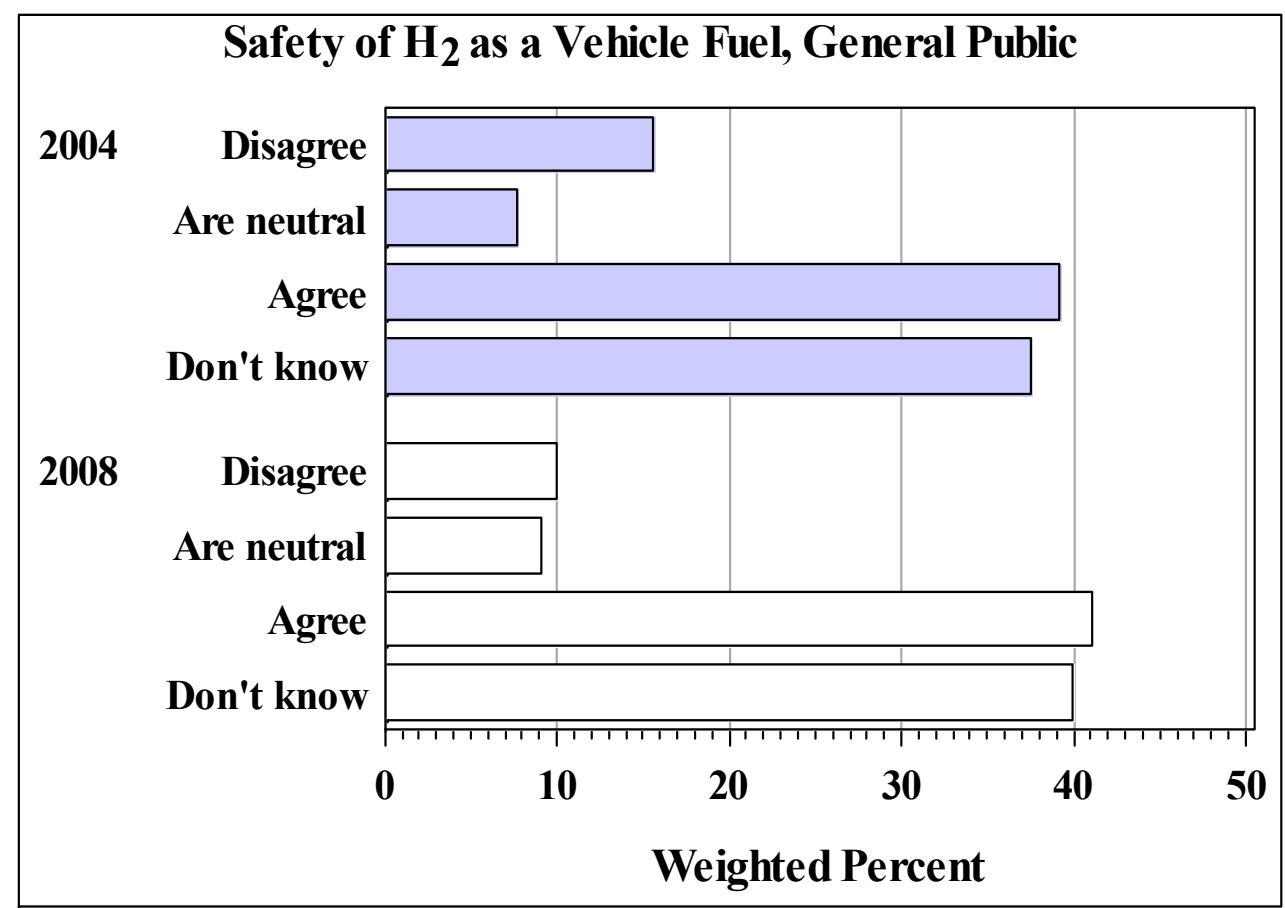

Figure 4.23. Comparison of results of the 2004 and 2008 surveys regarding opinions about the safety of hydrogen as a vehicle fuel, Question 10C, general public survey. 


\section{RESULTS: STUDENT SURVEY}

\subsection{INTRODUCTION}

This section summarizes the results of the student survey. A copy of the survey questionnaire is in Appendix A.2. A total of 1,004 interviews with teens ages 12-17 were completed during the period of June 3 - July 12, 2008. Interviews were conducted via a telephone survey conducted among a national probability sample, which included 503 males and 501 females, living in private households in the continental United States. The total average interview length was 13.9 minutes, broken down into a screening time of 3.4 minutes and a main interview length of 10.4 minutes. A summary of responses to this survey, by question number, is provided in Appendix C.2.

The interview was conducted in Spanish if the person who answered the phone answered in Spanish or if the student requested that the interview be conducted in Spanish. It the person who answered the phone was not proficient in either English or Spanish, the interview was terminated.

Section 5.2 is a general summary of the student responses. Relationships between the response variables are discussed in Section 5.3. Differences between the 2008 and 2004 survey results are discussed in Section 5.4.

For the sake of simplicity, the responses "Don't know," "No opinion," and "Don't know/no opinion" are all be treated equivalently and generally as "Don't know" in this report.

The response rate for the 2008 Student Survey is discussed in Appendix E.2. The response rate is $29.53 \%$. This 2008 rate is actually slightly higher than the rate of .2754 computed for the 2004 survey. It seems unlikely, however, that this is due to a behavioral change in subjects and their tendency to respond. Comparison of Table E.2 with the corresponding table (Table 5.3) in the 2004 report shows that the number of "known ineligible" subjects was much higher in 2008 than in 2004 (122,983 in 2008 and 64,231 in 2004), while the numbers of "known eligible" subjects were proportionately much closer (2,358 in 2008 and 1,984 in 2004). Furthermore the numbers of "eligibility unknown" subjects were nearly the same (55,367 in 2008 and 54,984 in 2004). In turn, the proportion e of eligible households is much smaller for $2008(\mathbf{e}=.01881)$ than for 2004 $(\mathbf{e}=.02996)$, which (because the numbers of "eligibility unknown" subjects are nearly the same) translates to a smaller response rate in 2008.

The AAPOR RR3 response rate used here is premised on the assumption that the proportion of eligible subjects is the same, whether eligibility is determined or not. This is an approximation, however, and it seems likely that the accuracy of the approximation might differ for the 2004 and 2008 vendor-supplied sampling frames, particularly since there were with so many more "known ineligibles" in 2008. The change in response rates thus seems more likely an artifact of the precision of the sampling frames than an increase in the tendency to respond among eligible subjects. 
The teens were asked the last grade of school completed. The responses are shown in Figure 5.1. Most (83\%) of the teens had completed elementary school (i.e., grade 6), but less that $10 \%$ had completed high school or college.

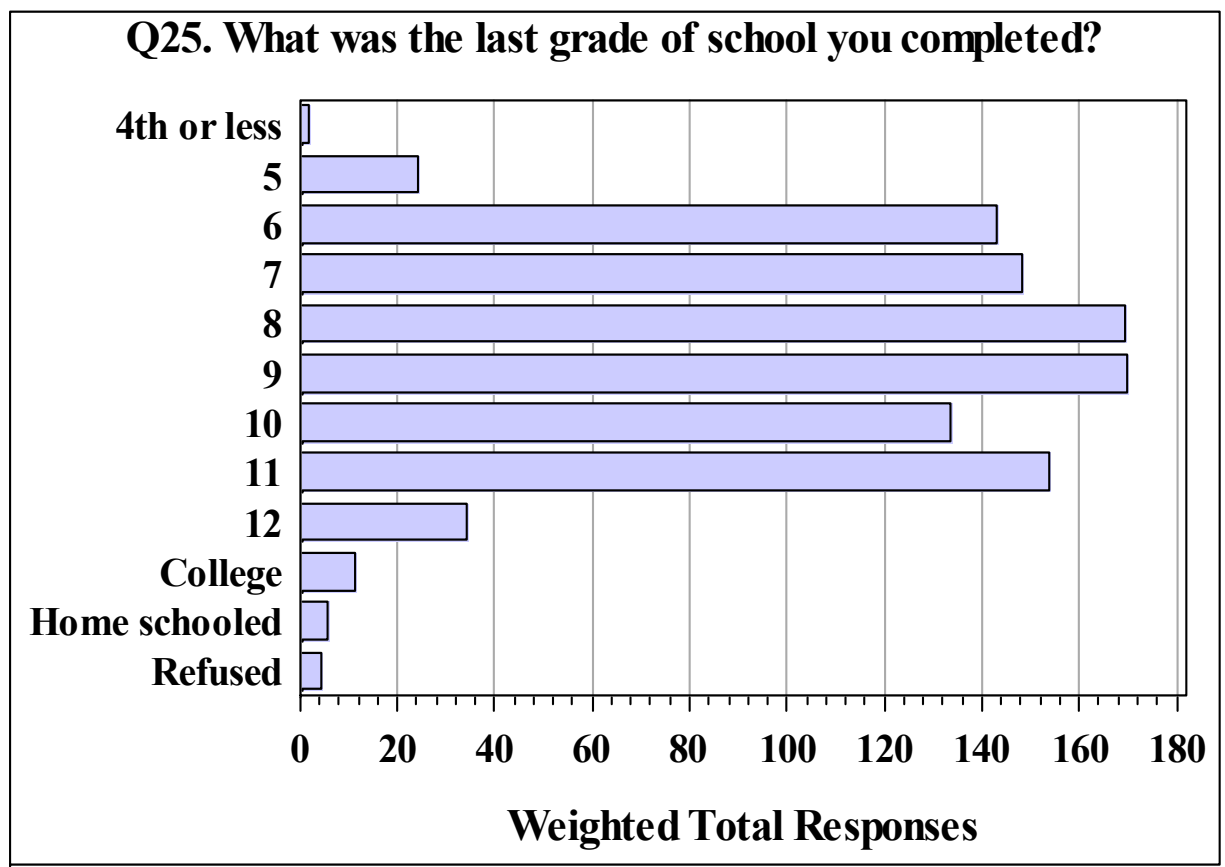

Figure 5.1. Distribution of students by grade level (Question 25, student survey).

\subsection{SUMMARY}

The section summarizes the responses to the individual questions in the student survey. Most of the questions are summarized as proportions of respondents in each of the respective multiple choice categories. Answers to the technical questions are summarized individually and are also compiled into an overall technical score. Relationships between responses to different questions and comparisons with the 2004 survey results are considered in Section 5.3 and 5.4.

Table 5.1 summarizes the technical questions in terms of whether they were answered correctly or incorrectly with "Don't know" treated as an incorrect response. 
Table 5.1. Summary of Results for the Technical Knowledge Questions (correct/incorrect), Students

\begin{tabular}{|l|r|r|r|r|}
\hline \multicolumn{1}{|c|}{ Question } & $\begin{array}{c}\text { Number } \\
\text { of } \\
\text { responses }\end{array}$ & $\begin{array}{c}\text { Weighted } \\
\text { percent } \\
\text { correct }\end{array}$ & $\begin{array}{c}\text { Lower 95\% } \\
\text { confidence } \\
\text { bound }\end{array}$ & $\begin{array}{c}\text { Upper 95\% } \\
\text { confidence } \\
\text { bound }\end{array}$ \\
\hline 2A. Hydrogen gas is toxic (false) & 1,004 & 46.83 & 43.72 & 49.95 \\
\hline $\begin{array}{l}\text { 2B. Fuel cells produce electricity through hydrogen } \\
\text { combustion (false) }\end{array}$ & 1,004 & 16.02 & 13.71 & 18.33 \\
\hline 2C. Hydrogen is lighter than air (true) & 1,004 & 50.87 & 47.77 & 53.97 \\
\hline 2D. Hydrogen has a distinct odor (false) & 1,004 & 56.98 & 53.87 & 60.09 \\
\hline $\begin{array}{l}\text { 4. In which state or condition can hydrogen be } \\
\text { stored? (chemical compound and liquid) }\end{array}$ & 1,004 & 38.93 & 35.88 & 41.98 \\
\hline $\begin{array}{l}\text { 5. When using pure hydrogen, fuel cell vehicles } \\
\text { generate electricity, water, and what else? (heat) }\end{array}$ & 1,004 & 20.55 & 18.01 & 23.08 \\
\hline $\begin{array}{l}\text { 6. Hydrogen can be produced using which of the } \\
\text { following sources of energy? (natural gas, } \\
\text { sunlight, organic matter) }\end{array}$ & 1,004 & 33.74 & 30.78 & 36.71 \\
\hline $\begin{array}{l}\text { 9. Hydrogen is too dangerous for everyday use by } \\
\text { the general public (false) }\end{array}$ & 1,004 & 54.83 & 51.75 & 57.91 \\
\hline Overall Average & 1,004 & 39.8 & 38.51 & 41.18 \\
\hline
\end{tabular}

The greatest percentage of correct responses is $57.0 \%$, for Question 2D (Hydrogen has a distinct odor...), followed by $54.8 \%$ for Question 9 (Hydrogen is too dangerous...). The smallest percentage of correct responses is $16.0 \%$, for Question 2B (Fuel cells produce electricity through...), followed by $20.6 \%$ for Question 5 (When using pure hydrogen, fuel cell vehicles generate...).

The correct/incorrect perspective used in Table 5.1 is conventional, since "Don't know" is generally considered an incorrect response. However, "Don't know" was a very common response to the survey technical questions. Figure 5.2 shows the responses broken down according to type: Correct, Incorrect, and "Don't know." On average, $39.8 \%$ of the technical questions were answered correctly, $35.8 \%$ were answered incorrectly, and $24.4 \%$ were answered with "Don't know."

Figure 5.3 shows the distribution of the number of correct responses. The distribution is more normal (bell-shaped) than the distribution in Figure 4.2 for the general public, but the dispersion about the mean score (39.8\% or 3.2 correct) is again substantial, with the number of correct responses ranging from 0 correct ( $5 \%$ of students) to all 8 correct ( $0.5 \%$ of students).

The first question in the survey asked respondents to gauge their familiarity with hydrogen and fuel cell technologies. Figure 5.4 shows the distribution of responses. A greater number of student respondents considered themselves "Familiar" with hydrogen and fuel cell technologies than did general public respondents. (This and other cross-population comparisons are considered in detail in Section 9.) 


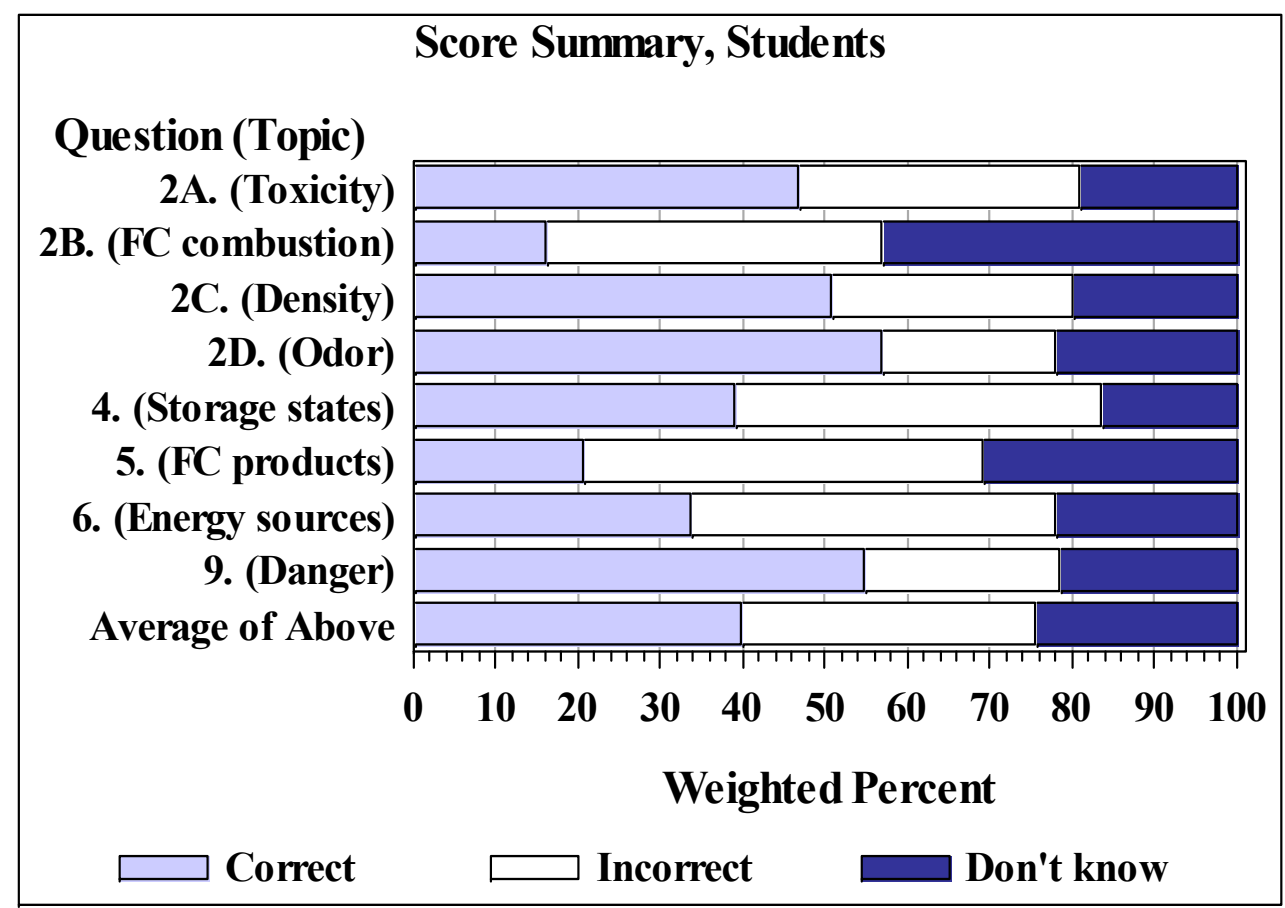

Figure 5.2. Weighted percent of correct, incorrect, and "Don't know" responses for the technical knowledge questions, student survey.

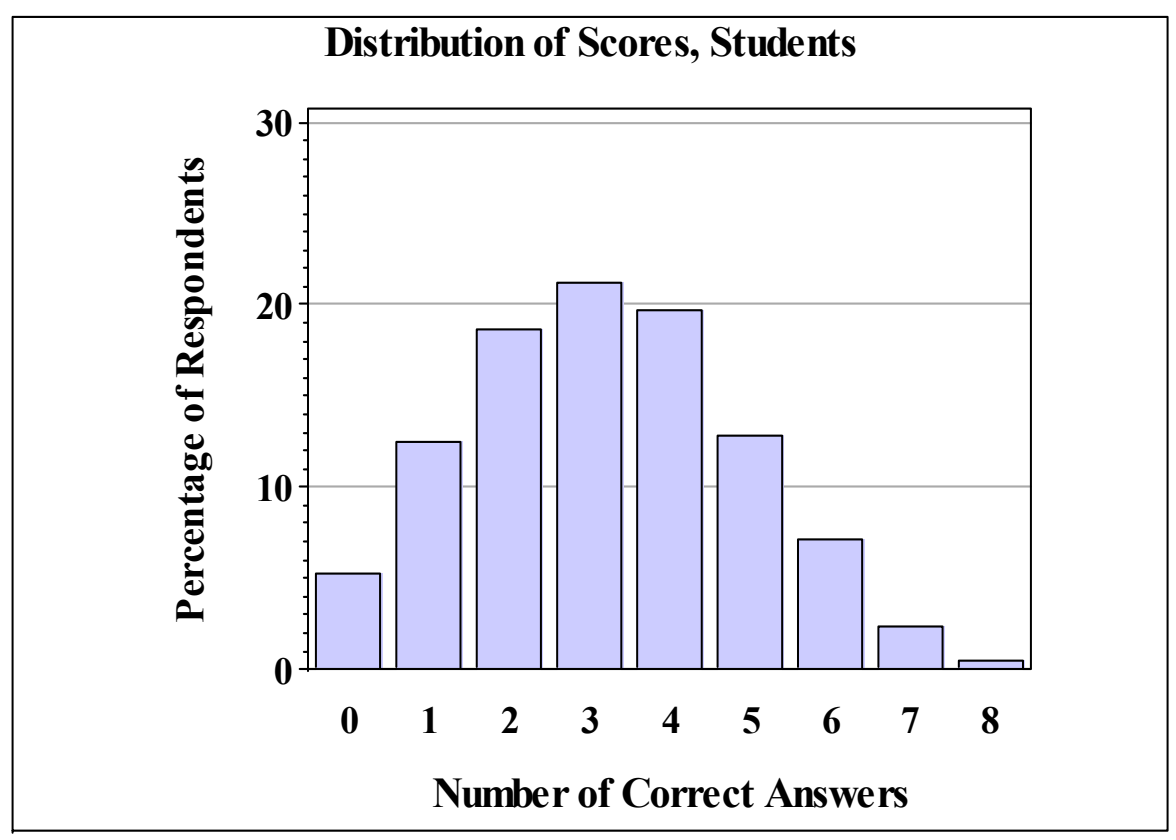

Figure 5.3. Distribution of the number of correct answers to the eight technical knowledge questions, student survey. 


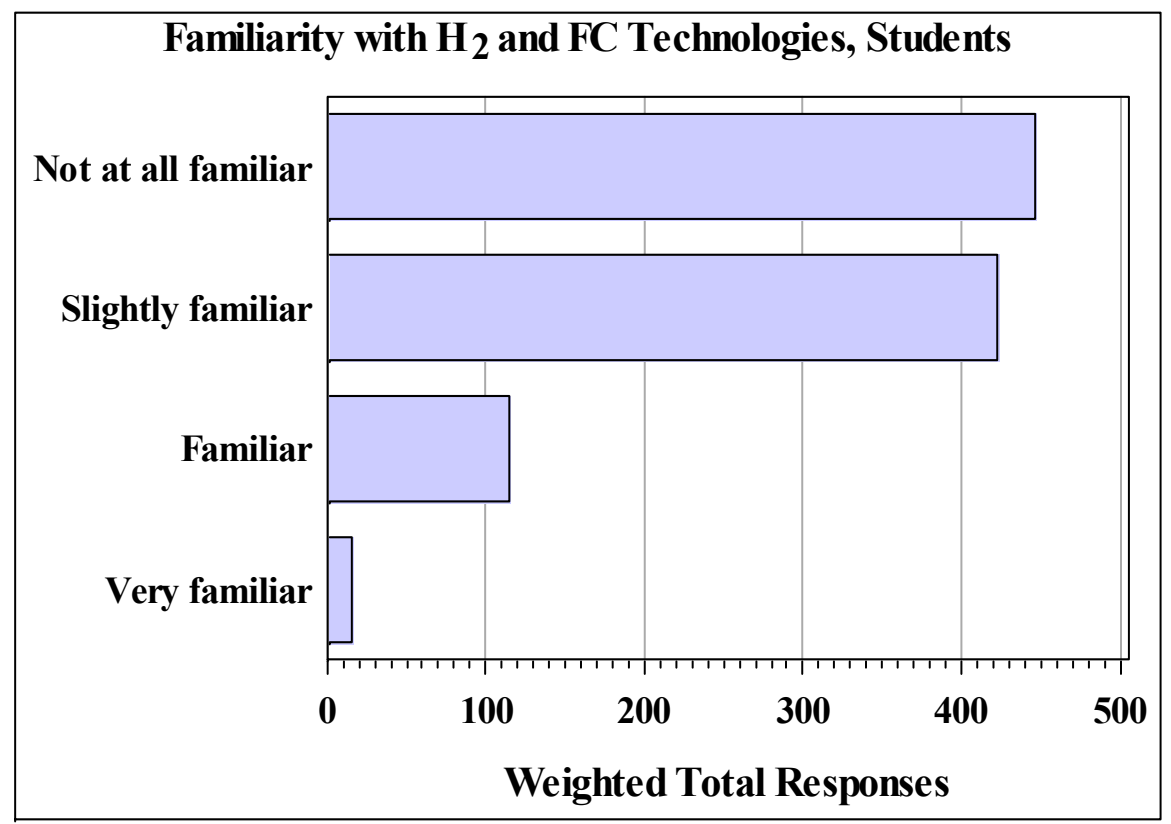

Figure 5.4. Distribution of responses to the question about familiarity with hydrogen and fuel cell technologies, Question 1, student survey.

Each student respondent was asked first to imagine going shopping for a new automobile and then to rank each of six characteristics (cost of vehicle at the point of sale, gas mileage, power and speed, reliability, safety, and impact on the environment or emissions produced) for its importance (responses: not important, neutral, important, no opinion). Figure 5.5 shows the student responses among students who had an opinion. The teens rated "Safety" as the most important characteristic and rated "Power and speed" as the least important characteristic. The teens also rated a vehicle's gas mileage as more important than the purchase price of the vehicle.

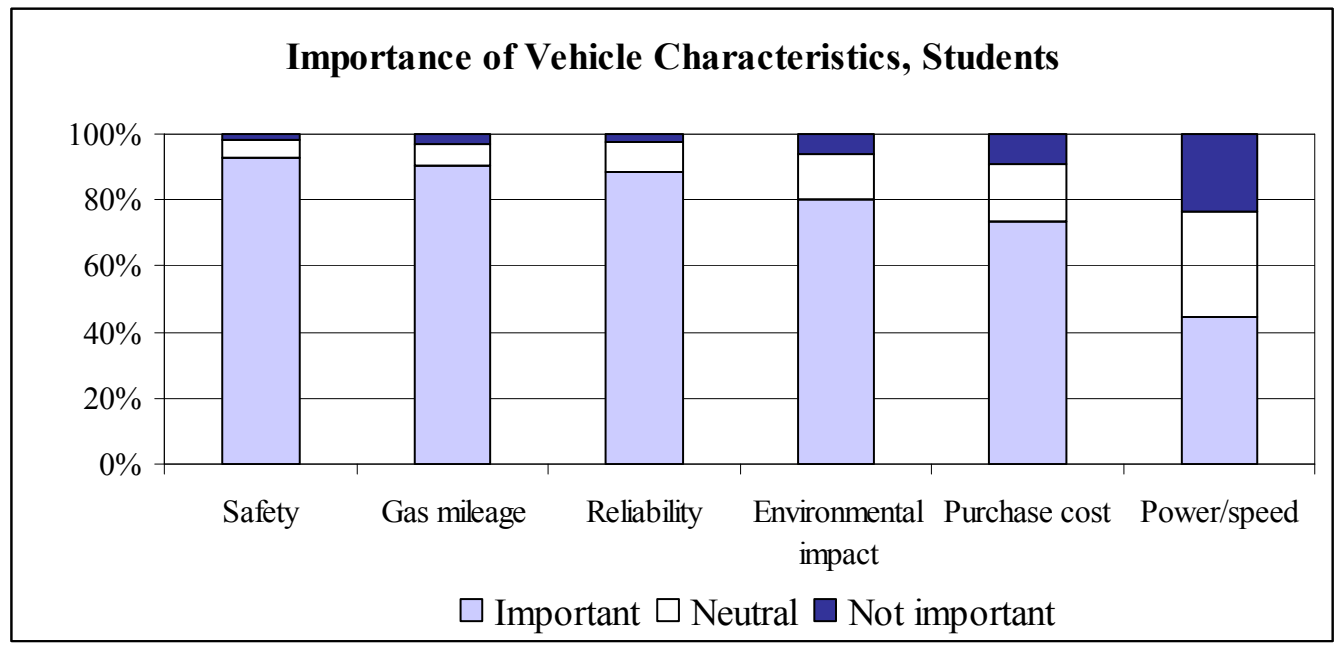

Figure 5.5. Importance of six specific characteristics of a new automobile, Question 20, student survey. 
Two statements were read to students in order to obtain opinions about potential benefits of using hydrogen as a vehicle fuel. Students were asked whether they agreed or disagreed with the statements. Responses (Figure 5.6) indicated that students generally "Agree" that the use of hydrogen will reduce U.S. dependence on foreign oil and will reduce emissions and improve air quality.

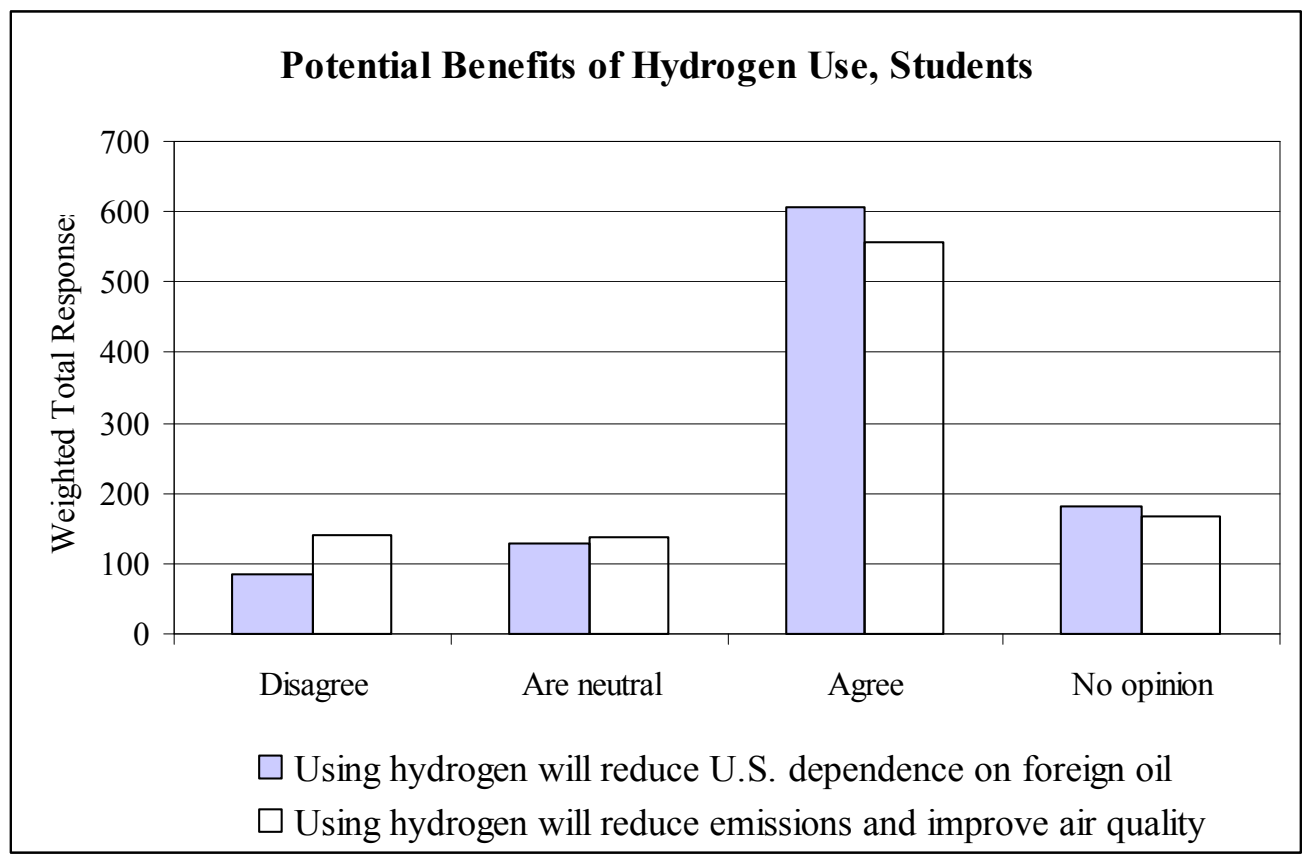

Figure 5.6. Responses to statements about the potential benefits of the use of hydrogen as a vehicle fuel, Questions 10A and 10B, student survey.

Students were also asked about the use of fuel cells for providing power to their home, car, laptop computer, or (the correct response) all of these. Figure 5.7 suggests that students are aware of the potential uses of fuel cells.

Several questions asked students to provide opinions about the safety of fuel cells and hydrogen. Figure 5.8 shows the responses for the survey question about the safety of hydrogen relative to gasoline and diesel (survey Question 10C). The options that were provided to respondents were "Disagree," "Are neutral," "Agree," or "Don’t know." As can be seen in Figure 5.8, most $(43.9 \%)$ students agreed with the statement "Hydrogen is as safe to use in my car as gasoline and diesel fuels," though "Don't know" was also a common a response. 


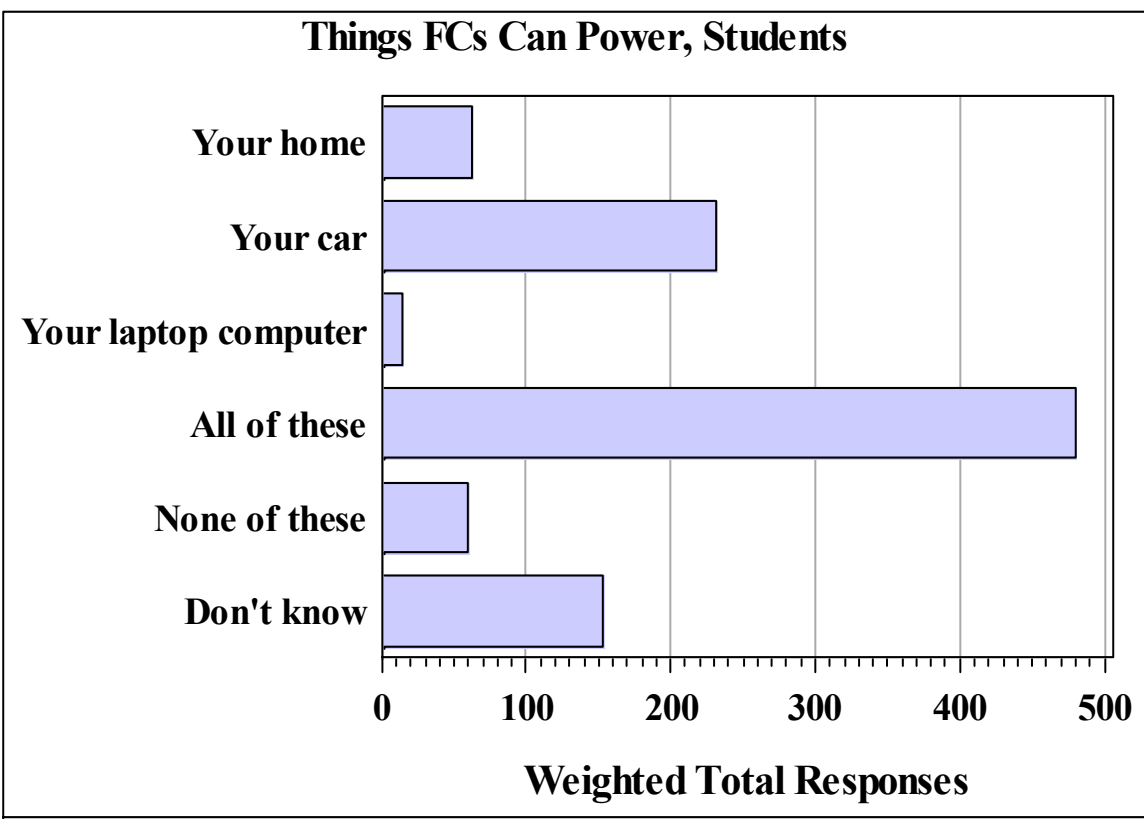

Figure 5.7. Responses to statements about the uses of fuel cells, Question 3, student survey.

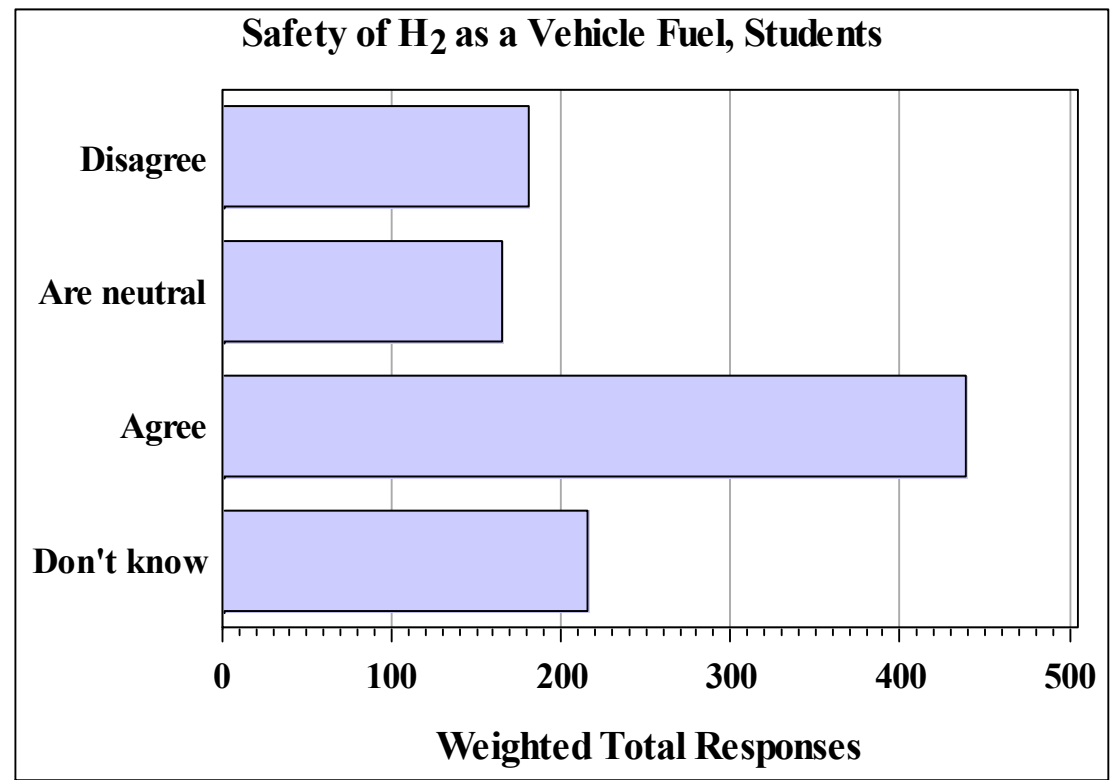

Figure 5.8. Responses to the statement, "Hydrogen is as safe to use in my car as gasoline and diesel fuels," Question 10C, student survey.

Students were asked how they would feel if their local gas station also sold hydrogen (Figure 5.9). More than half of respondents indicated that they would be either "At ease" or "Pleased," and only $18 \%$ said they would be either "Uneasy" or "Frightened." 


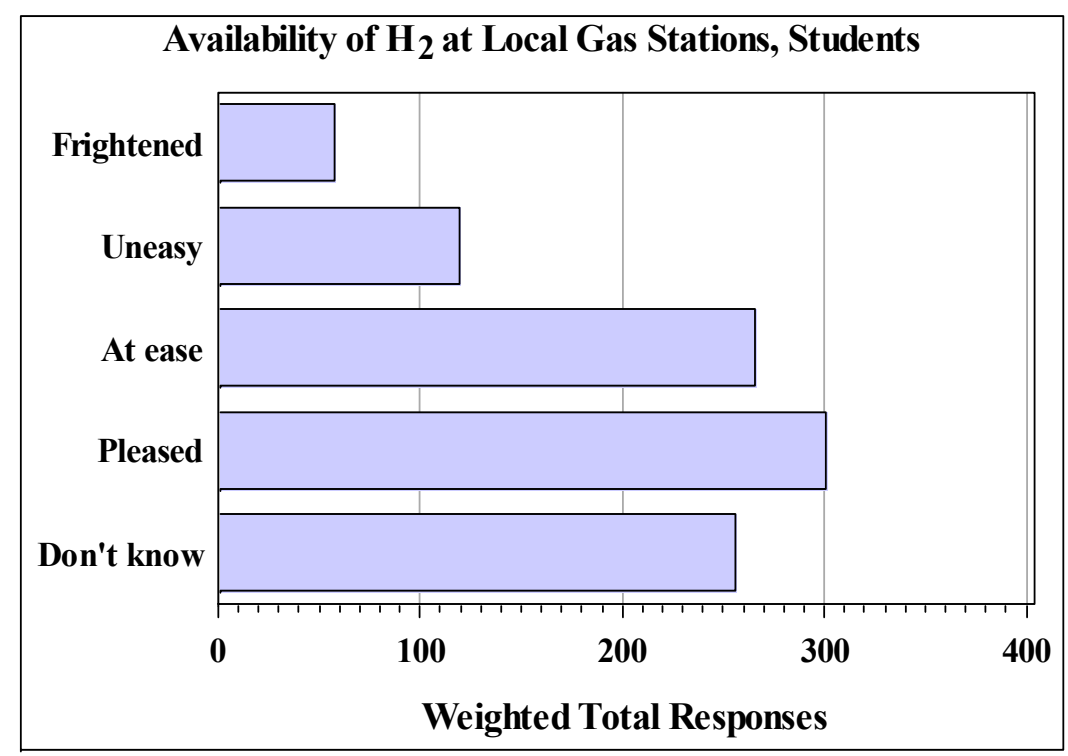

Figure 5.9. Responses to the possibility of sales of hydrogen at a local gas station, Question 8, student survey.

A similar question (Question 8A) asked students how they would feel if their school's electricity and heat were provided by a fuel cell located on school grounds. The students' responses are shown in Figure 5.10. As with Question 8, more than half of the students indicated that they would be either "At ease" or "Pleased."

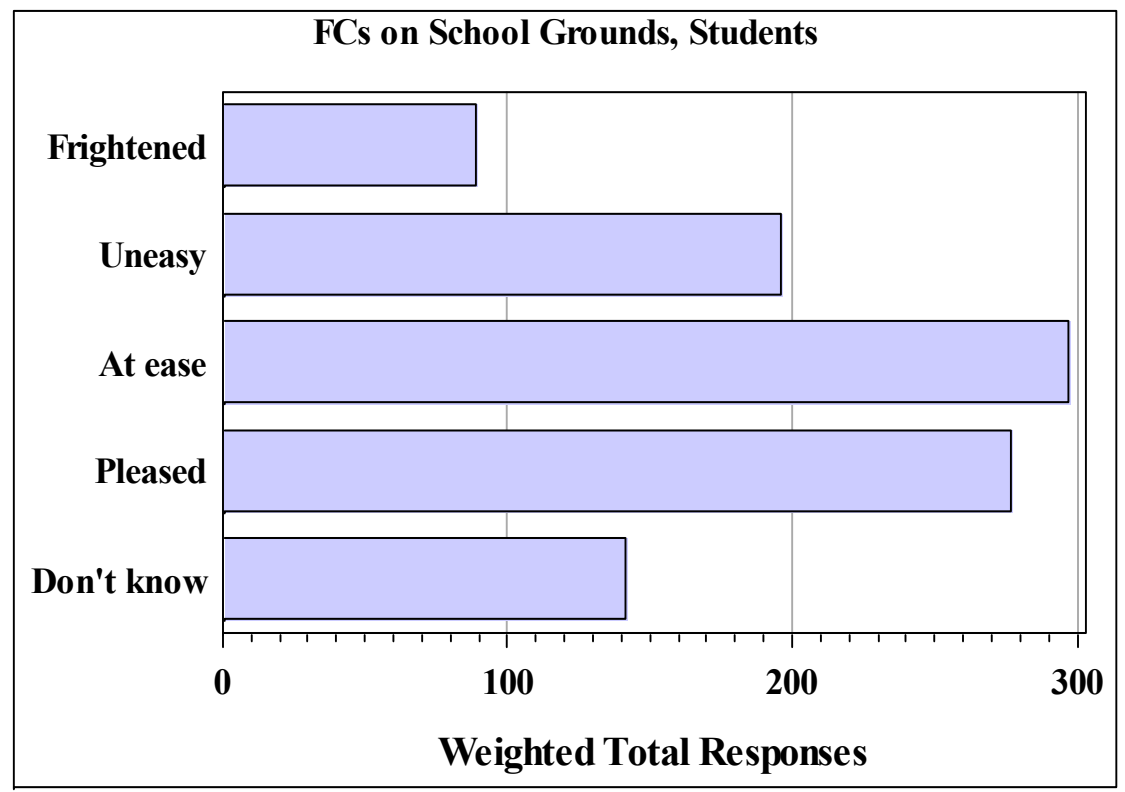

Figure 5.10. Responses to the possibility of using a fuel cell to provide electricity and heat for the respondent's school, Question 8A, student survey.

Question 24 asked students about the frequency of use ("Never," "Sometimes," "Frequently") of mass media sources (television, radio, internet, etc.) they use to obtain energy information. As 
shown in Figure 5.11, respondents indicated that they used television and classroom instruction most frequently for obtaining energy information. Over half the students indicated that they never used the radio to obtain energy information

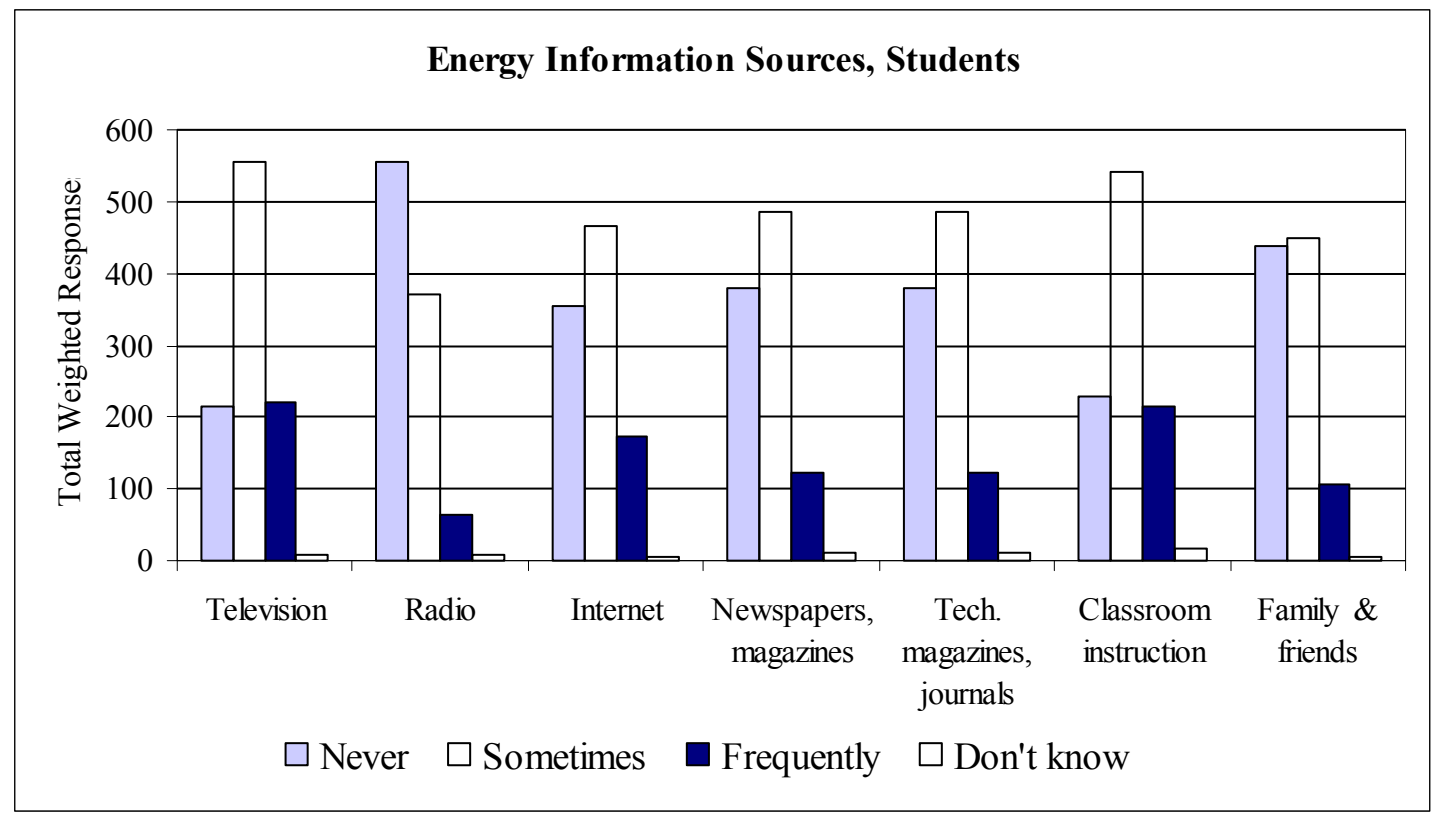

Figure 5.11. Weighted counts of responses regarding the frequency of use of different types of mass media for obtaining energy information, Question 24, student survey.

\subsection{RELATIONSHIPS}

The summary statistics discussed in Section 5.2 are "one-way" statistics in the sense that the response categories are defined in terms of one variable such as sex, region, or response to an opinion question such as "Hydrogen is as safe to use in my car as gasoline and diesel fuels." However, relationships in the responses determined by two or more variables may also be of interest. Although no relationships were of particular interest a priori, a few of the more statistically significant two-way relationships are illustrated in this section. Interactions that were considered were with the survey variables and sex, region, urban/non-urban familiarity with hydrogen technologies, and whether or not the score on the technical questions was above the average for the sample. The statistical significance criterion is the significance level (p) of a chisquare test that accounts for the sampling weights. ${ }^{37}$

As shown in Figure 5.12, respondents who scored below average on the technical questions were more likely to assess their familiarity as "Not at all familiar," and respondents who scored above average were more likely to claim a higher familiarity with hydrogen and fuel cell technologies. Thus, the familiarity self-assessments are consistent with the technical awareness scores.

\footnotetext{
${ }^{37}$ Measures could also be based on odds ratios or combinations of odd ratios and significance levels as well as other metrics. Significance levels alone were used for simplicity and because sample sizes are essentially the same for all survey questions.
} 


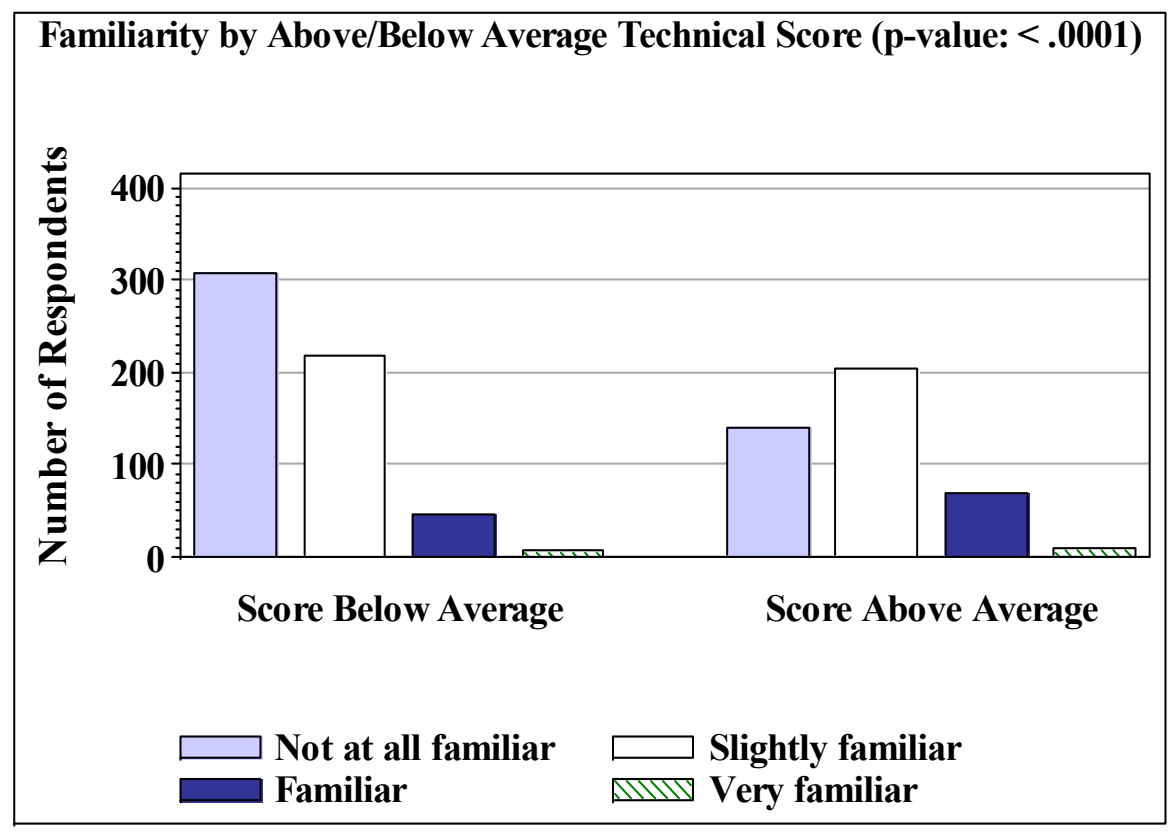

Figure 5.12. Responses by technical score above/below average to Question 1 (familiarity of respondents to hydrogen and fuel cell technologies), student survey.

In the 2004 survey results, an interesting and statistically significant finding was that respondents who did better on the technical knowledge questions were much more likely to say that they would be comfortable with a local hydrogen gas station. This finding was also evident in the 2008 survey of the students, as shown in Figure 5.13.

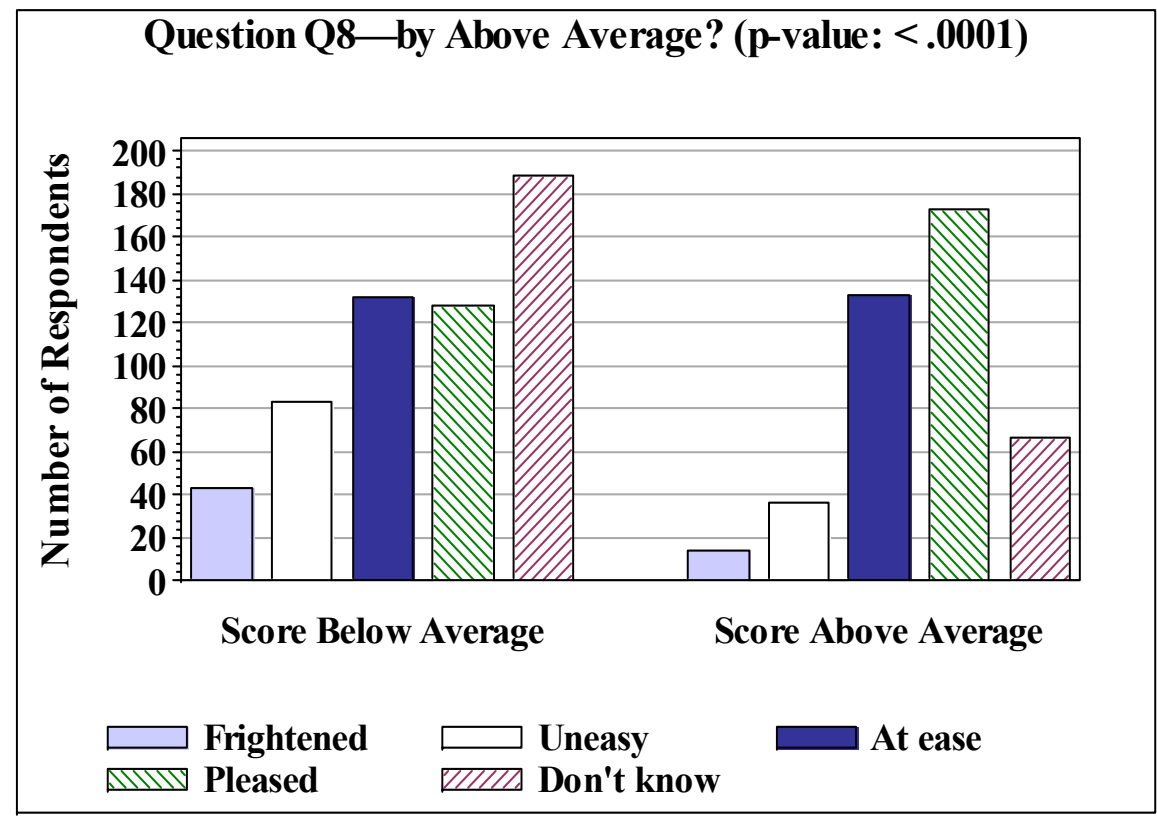

Figure 5.13. Responses by technical score above/below average to Question 8, "How would you feel if your local gas station also sold hydrogen," student survey. 
The relationship of students' responses to Question 8 was also examined in terms of their expression of familiarity with hydrogen and fuel cell technologies. This relationship, shown in Figure 5.14, shows that students who considered themselves "Slightly familiar" or "Familiar" with hydrogen and fuel cell technologies were more likely to be "Pleased" with the idea of a local gas station that also sold hydrogen.

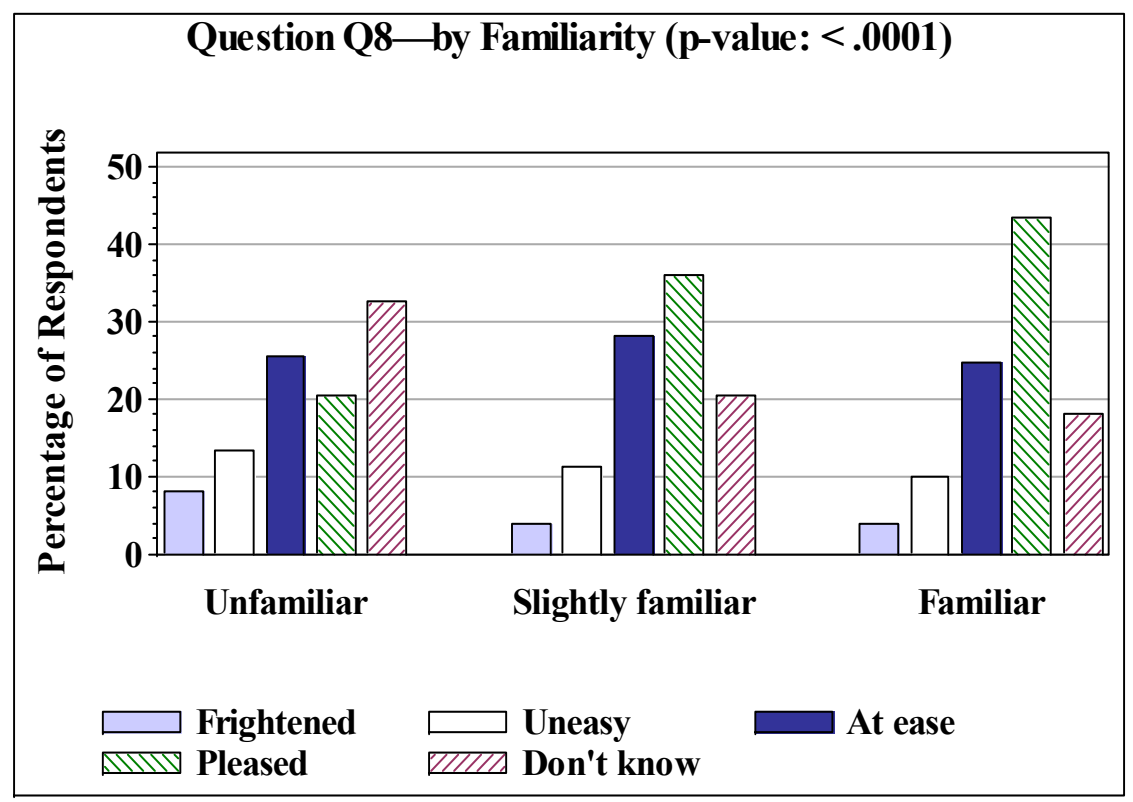

Figure 5.14. Response percentages by familiarity to Question 8, "How would you feel if your local gas station also sold hydrogen," student survey.

The relationship of technical knowledge score and responses to Question 8a was also studied. Question 8a asked students how they would feel if their school's power were provided by a fuel cell located on school grounds. It was found that students with a technical score above average were more comfortable with the idea of a fuel cell being located on the school grounds. In fact, the students with "Above average" scores provided fewer "Don't know" responses, and their most frequent response was "Pleased" (Figure 5.15).

Teens generally agreed with the statement that the use of hydrogen would reduce U.S. dependence on foreign oil (see Figure 5.6). Their responses by degree of familiarity to this statement are shown in Figure 5.16. The more familiar students were with hydrogen and fuel cell technologies, the more likely they were to agree with the statement.

Another statistically significant $(\mathrm{p}<0.0001)$ relationship is between responses to Question $8 \mathrm{~A}$ (feelings about having a fuel cell located on school grounds) and gender. Female students responded more often with "Uneasy" or "Don't know" and less often with "At ease" or "Pleased" (Figure 5.17).

\footnotetext{
${ }^{38}$ Gender differences among students were also observed in 2004. See, for example, Figure 5.8 of the 2004 report.
} 


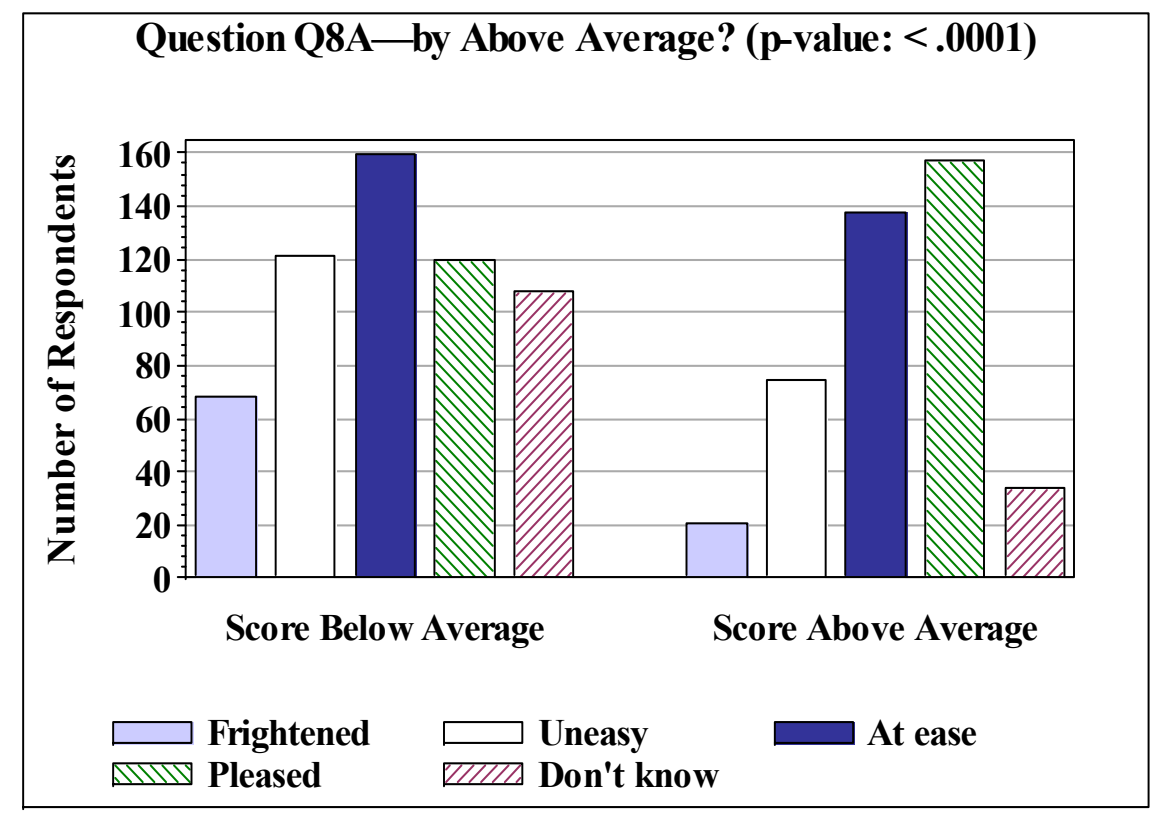

Figure 5.15. Responses by technical score above/below average to Question 8A, "How would you feel if your school's electricity and heat were provided by a fuel cell located on school grounds," student survey.

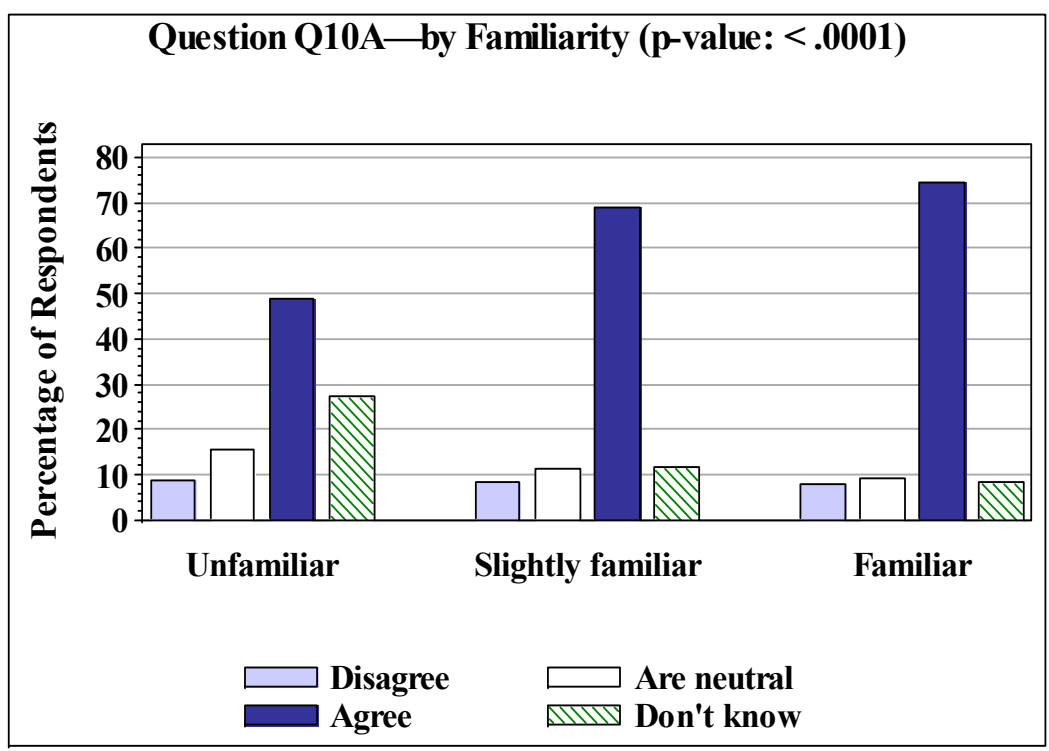

Figure 5.16. Response percentages by familiarity to Question 10A, "Using hydrogen will reduce U.S. dependence on foreign oil," student survey. 


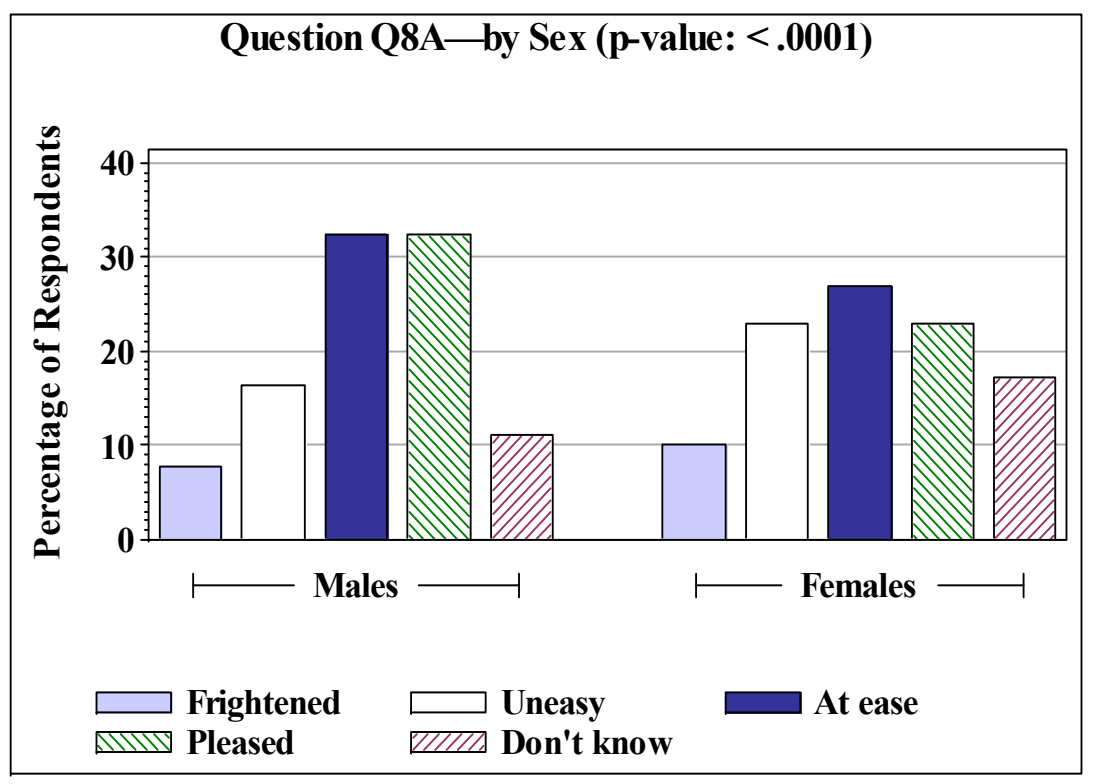

Figure 5.17. Response percentages by gender to Question 8A, "How would you feel if your school's electricity and heat were provided by a fuel cell located on school grounds," student survey.

\subsection{COMPARISON WITH THE 2004 BASELINE}

A primary objective of repeating surveys over time is to compare changes in the survey results. Figure 5.18 shows the differences in the average technical scores for each of the eight technical questions on the survey. The overall average technical score in 2008 was $39.8 \%$ correct responses; in 2004 the average score was $32.2 \%$. This difference is statistically significant $(\mathrm{p}<0.0001)$. As Figure 5.18 indicates, the increase in the overall score was primarily due to increases in the scores for four individual questions: 2A (about toxicity), 2D (about odor), 5 (about fuel cell combustion products), and 9 (about hydrogen safety). The differences for these four questions are all statistically significant (respectively, $\mathrm{p}=0.0001 ; \mathrm{p}<0.0001 ; \mathrm{p}=0.03$; $\mathrm{p}<0.0001)$. For the other questions, the changes, either positive or negative, were not statistically significant.

Several questions in the survey concerned safety issues and the use of hydrogen. Changes in students' perceptions of hydrogen safety are shown in the next few figures. Figure 5.19 shows that student opinions about hydrogen safety have changed slightly. In 2004, for example, 31.5\% of the students felt that hydrogen was too dangerous for everyday use; in $2008,23.7 \%$ of the students thought that hydrogen was too dangerous for everyday use. The difference ( 7.3 percentage points) is statistically significant $(\mathrm{p}=0.0001)$. 


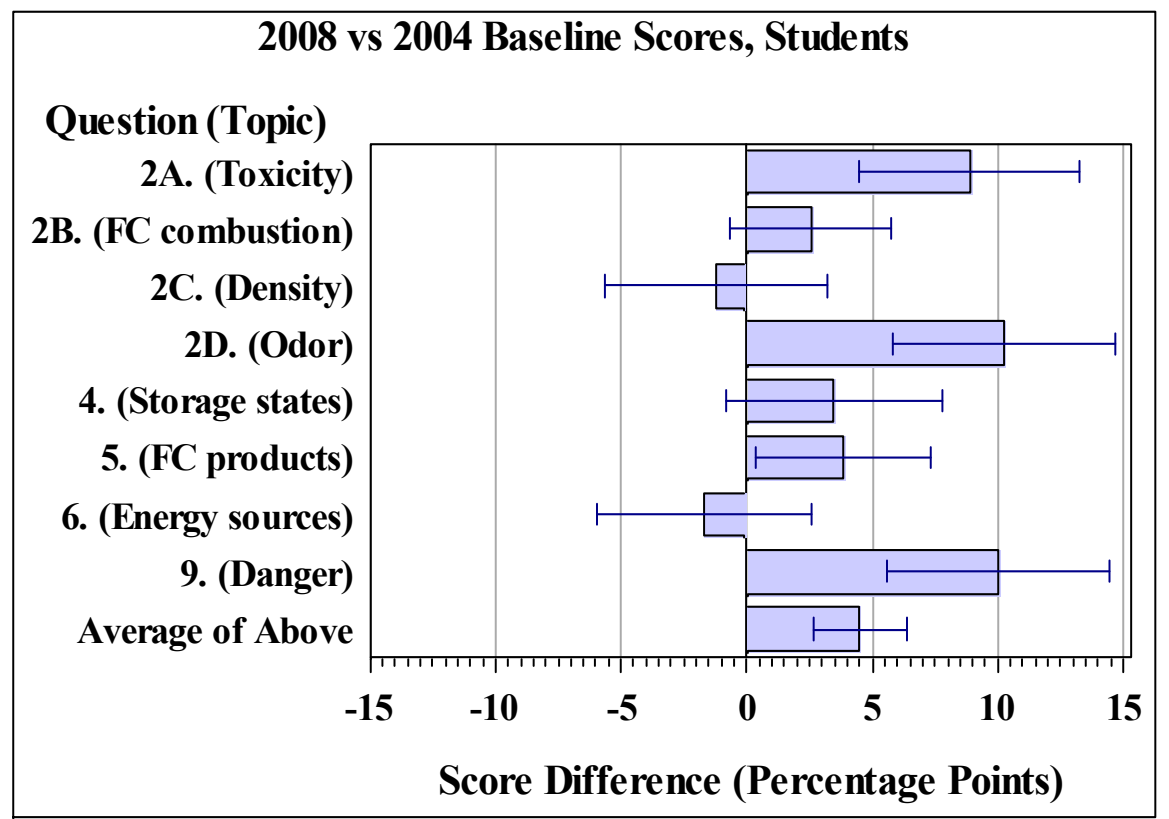

Figure 5.18. Differences between the 2008 and 2004 average percentage correct for each technical question and overall, student survey. Bars to the right of zero show improvement in 2008. The error bars are $95 \%$ confidence intervals for the differences.

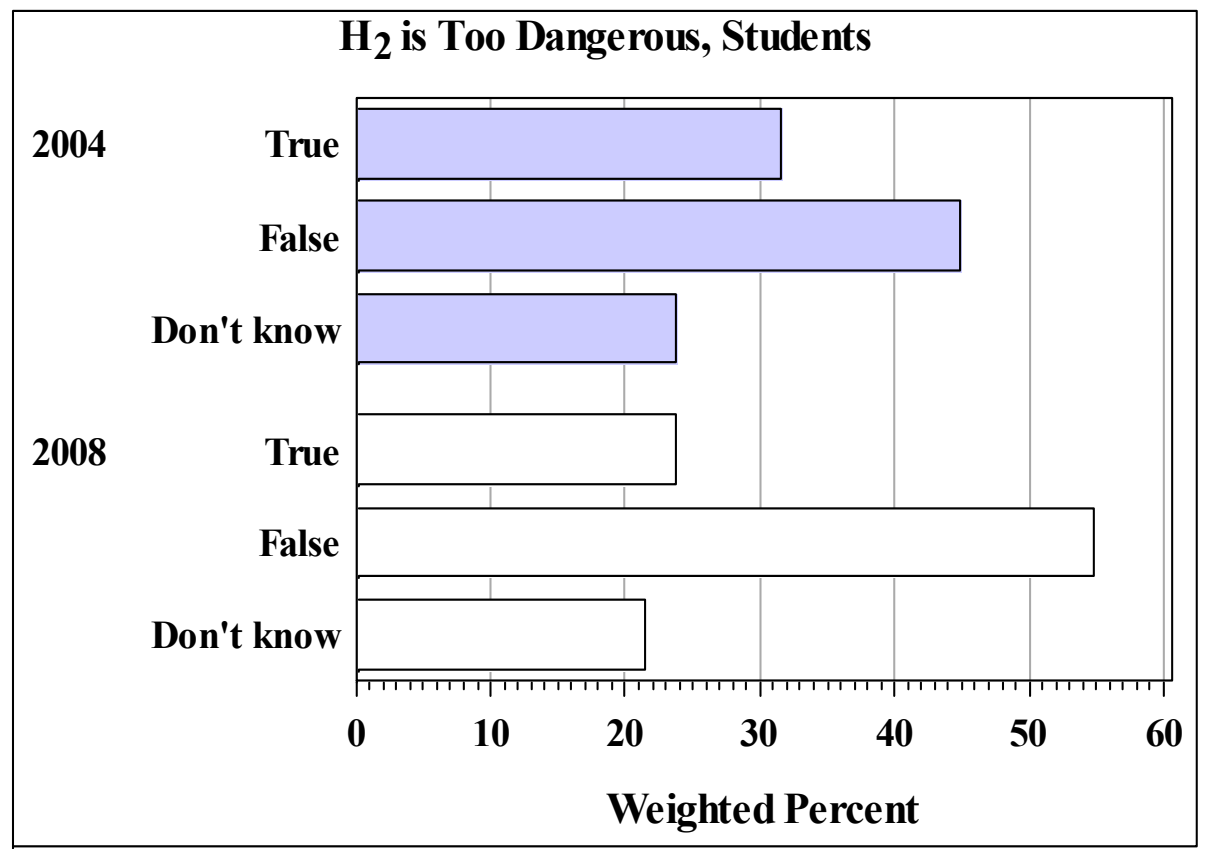

Figure 5.19. Comparison of results of the 2004 and 2008 surveys regarding opinions about the everyday use of hydrogen, Question 9, student survey. 
Another question was about the comfort level of students with the sale of hydrogen at their local gas station. Figure 5.20 compares the results of the 2004 and 2008 surveys to this question. The percentage of respondents who indicated that they would be "Frightened" or "Uneasy" in 2004 (9.1\% and $18.7 \%$ respectively) decreased in 2008 (to $5.6 \%$ and $12.0 \%$ respectively). Both decreases were statistically significant $(\mathrm{p}=0.006$ and $\mathrm{p}<0.0001$ respectively.) In addition, the students who provided a "Don't know" response also decreased significantly from $35.3 \%$ to $25.6 \%(\mathrm{p}<0.0001)$.

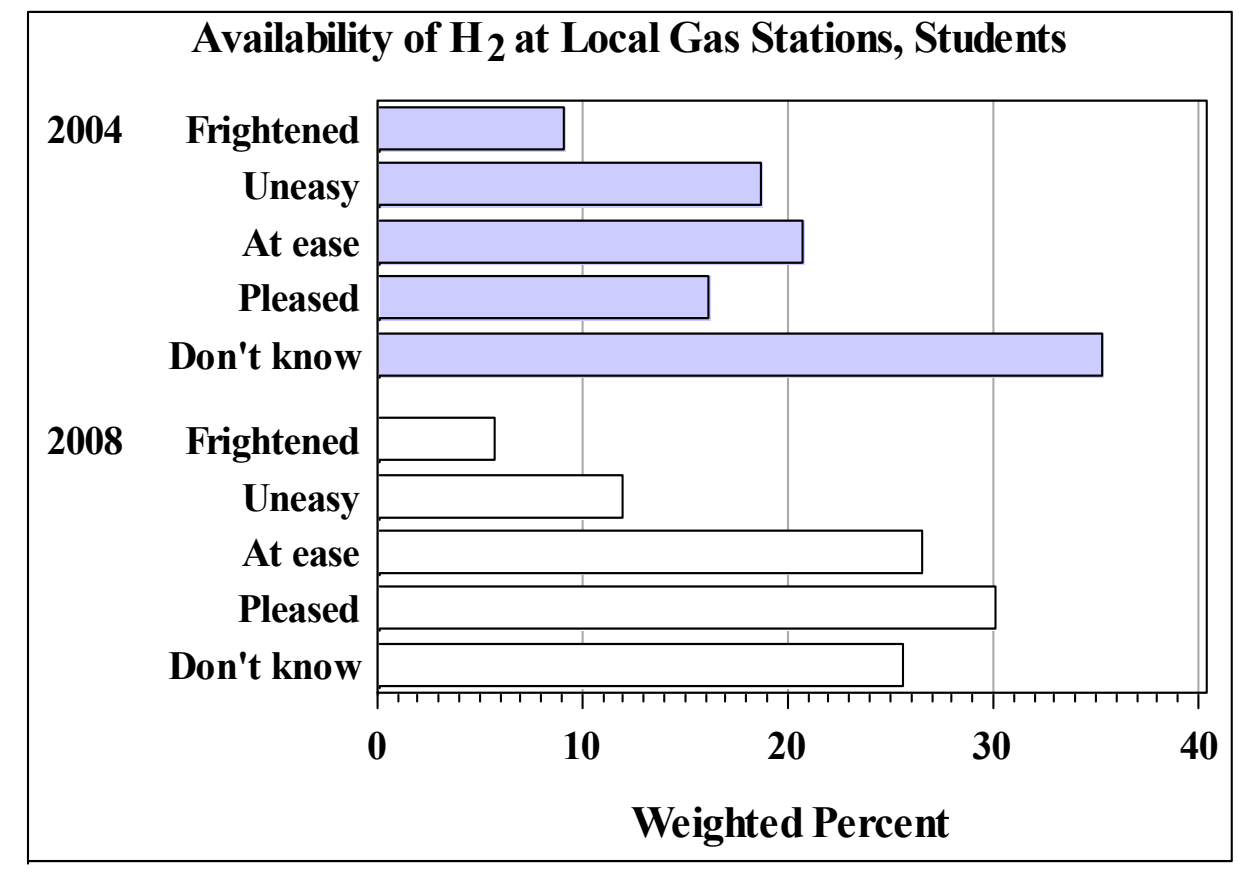

Figure 5.20. Comparison of results of the 2004 and 2008 surveys regarding opinions about the availability of hydrogen at a local gas station, Question 8, student survey.

So, in addition to statistically significant increases in the percentage of correct responses to the technical knowledge questions, the results shown in Figures 5.19 through 5.21 indicate that students are becoming more aware of, more comfortable with, and more confident in the safety of hydrogen technologies.

Sources used by students to obtain energy information showed growth in the use of the Internet since 2004. The number of students indicating that they "Sometimes" use the Internet rose from 361 to 467 . The number of students indicating that they "Sometimes" read technical magazines or journals to obtain energy information also rose slightly.

Response rates for the two student surveys were very similar: 0.2754 for the 2004 survey and 0.2953 for the $2008 / 2009$ survey. 
Another question examined opinions about the safety of hydrogen in vehicles. As shown in Figure 5.21, the percentage of respondents who disagreed with the statement, "Hydrogen is as safe to use in my car as gasoline and diesel fuels" decreased between 2004 and 2008 (27.0\% in 2004 to $18.1 \%$ in 2008). The percentage of respondents who agreed with the statement also increased slightly (36.6\% in 2004 to $43.9 \%$ in 2008).

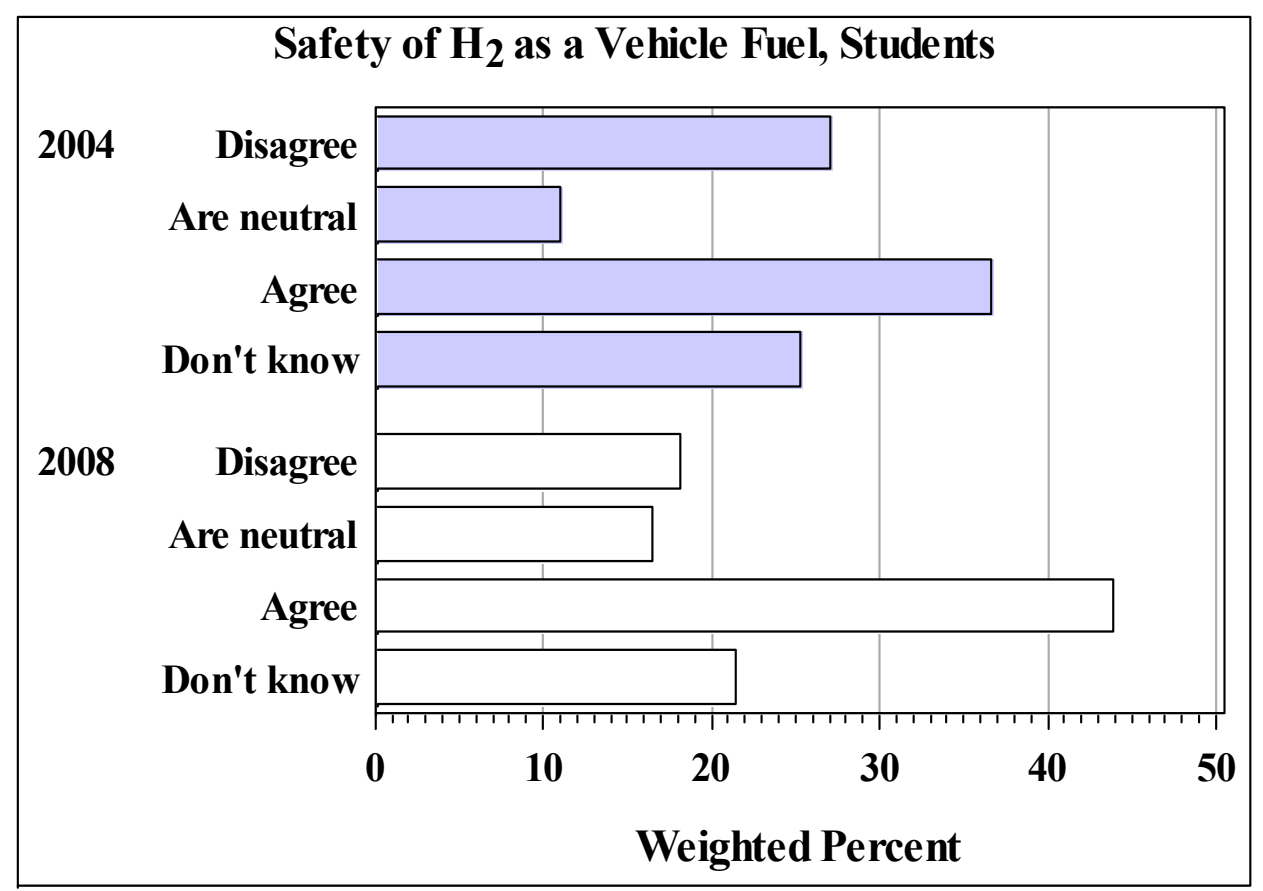

Figure 5.21. Comparison of results of the 2004 and 2008 surveys regarding opinions about the safety of hydrogen as a vehicle fuel, Question 10C, student survey. 


\section{RESULTS: STATE AND LOCAL GOVERNMENT SURVEY}

\subsection{INTRODUCTION}

This section summarizes the results of the survey of state and local governments. A copy of the survey questionnaire is in Appendix A.3. From a master list of 246 potential respondents, a total of 220 interviews were completed during the period of March 12 - May 9, 2008. The total average interview length was 14.3 minutes, broken down into a screening time of slightly under 1.8 minutes and a main survey length of 12.6 minutes. A summary of responses to this survey, by question number, is provided in Appendix C.3.

To improve survey response rates, the DOE FCT Office sent letters to the individuals on the master list telling them about the survey and encouraging their participation. A copy of this letter is provided in Appendix D.1.

Section 6.2 is a general summary of the responses of the state and local officials. Relationships between the response variables are discussed in Section 6.3. Differences between the 2008 and 2004 survey results are discussed in Section 6.4.

For the sake of simplicity, the responses "Don't know," "No opinion," and "Don't know/no opinion" are all treated equivalently and generally as "Don't know" in this report.

The response rate for the 2008 State and Local Government Survey is discussed in Appendix E.3. The response rate is $89.4 \%$. Had the entire target population been sampled $(100 \%$ response), there would be no statistical sampling error in the survey estimates. The response rate is less than perfect, however, and so estimates computed from this data are subject to error. As an approximation, this error is handled as sampling error in the data analysis. Because the sample is nearly complete, finite population correction factors ${ }^{39}$ are applied in the analysis with the SAS surveymeans and surveyfreq procedures. ${ }^{40}$

\subsection{SUMMARY}

The section summarizes the responses to the individual questions in the state and local government survey. Most of the questions are summarized as proportions of respondents in each of the respective multiple choice categories. Preference ranks are summarized as means. Answers to the technical questions are summarized individually and are also compiled into an overall technical score. Relationships between responses to different questions and comparisons with the 2004 survey results are considered in Section 6.3 and 6.4.

Table 6.1 summarizes the technical questions in terms of whether they were answered correctly or incorrectly with "Don't know" treated as an incorrect response. Confidence intervals for the percentages of correct responses reflect statistical error due to nonresponse.

\footnotetext{
${ }^{39}$ Cochran, William G., Sampling Techniques, Third Edition, John Wiley \& Sons, Inc., New York, 1977, p. 24.

${ }^{40}$ SAS Institute, SAS/STAT 9.1 User's Guide, SAS Institute, Inc., Cary, North Carolina, 2004, p. 165.
} 
The greatest percentage of correct responses is $82.3 \%$, for Question 9 (Hydrogen is too dangerous...), followed by $78.1 \%$ for Question 2C (Hydrogen is lighter than air). The smallest percentage of correct responses 43.2\%, for Question 2B (Fuel cells produce electricity through...), followed by $60.5 \%$ for Question 4 (In which state or condition can hydrogen...).

\begin{tabular}{|l|r|r|r|r|}
\hline \multicolumn{1}{|c|}{ Table 6.1. Summary of Results on the Technical Knowledge Questions (correct/incorrect), } \\
State and Local Governments
\end{tabular}

The correct/incorrect perspective used in Table 6.1 is conventional, since "Don't know" is generally considered an incorrect response. However, "Don't know" was a very common response to the survey technical questions. Figure 6.1 shows the responses broken down according to type: Correct, Incorrect, and "Don't know." On average, $66.6 \%$ of the technical questions were answered correctly, $14.8 \%$ were answered incorrectly, and $18.5 \%$ were answered with "Don't know."

Figure 6.2 shows the distribution of the number of correct responses for the state and local government survey. Although there were a few respondents with no correct answers, $68.6 \%$ of respondents had five or more correct answers. Comparison of Figure 6.2 with the corresponding figure for the general public (Figure 4.2) shows that in addition to having a higher mean, the distribution of scores for the government officials is also slightly less dispersed than the distribution for the general public, ${ }^{41}$ as might be expected, given the more varied backgrounds of general public respondents.

\footnotetext{
${ }^{41}$ Mean \pm standard deviation for the two distributions are $5.33 \pm 1.97$ for the government officials and $2.81 \pm 2.07$ for the general public.
} 


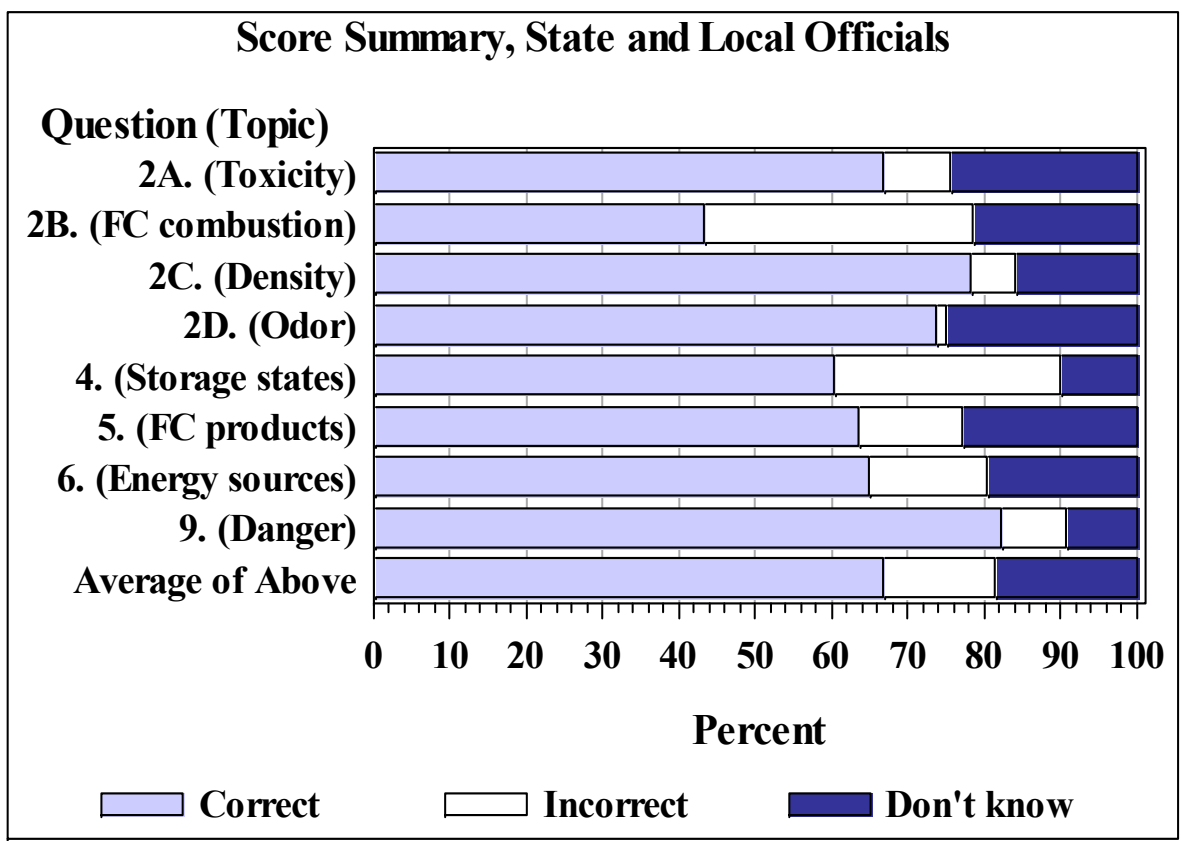

Figure 6.1. Weighted percent of correct, incorrect, and "Don't know" responses for the technical knowledge questions, state and local government agencies.

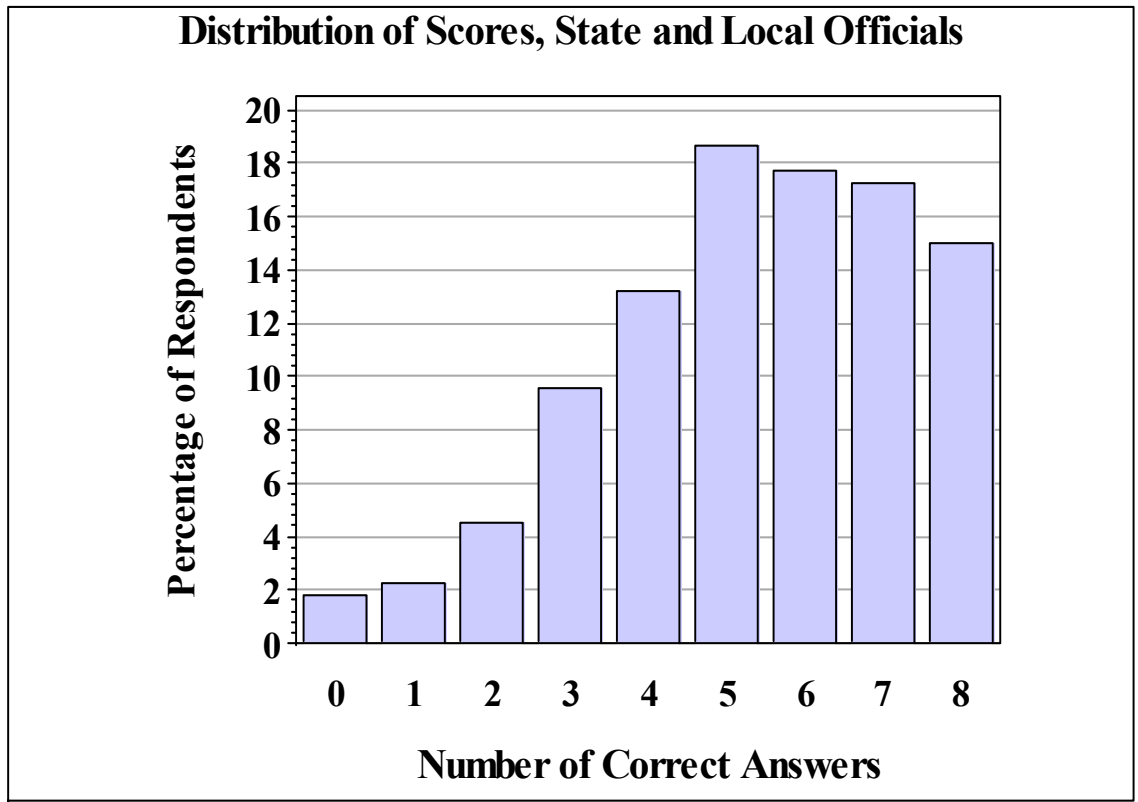

Figure 6.2. Distribution of the number of correct answers to the eight technical knowledge questions, state and local government agencies. 
The first question in the survey asked respondents to gauge their familiarity with hydrogen and fuel cell technologies. Figure 6.3 shows the distribution of responses. Half of all respondents considered themselves "Slightly familiar" with hydrogen and fuel cell technologies, and 8.6\% considered themselves "Very familiar."

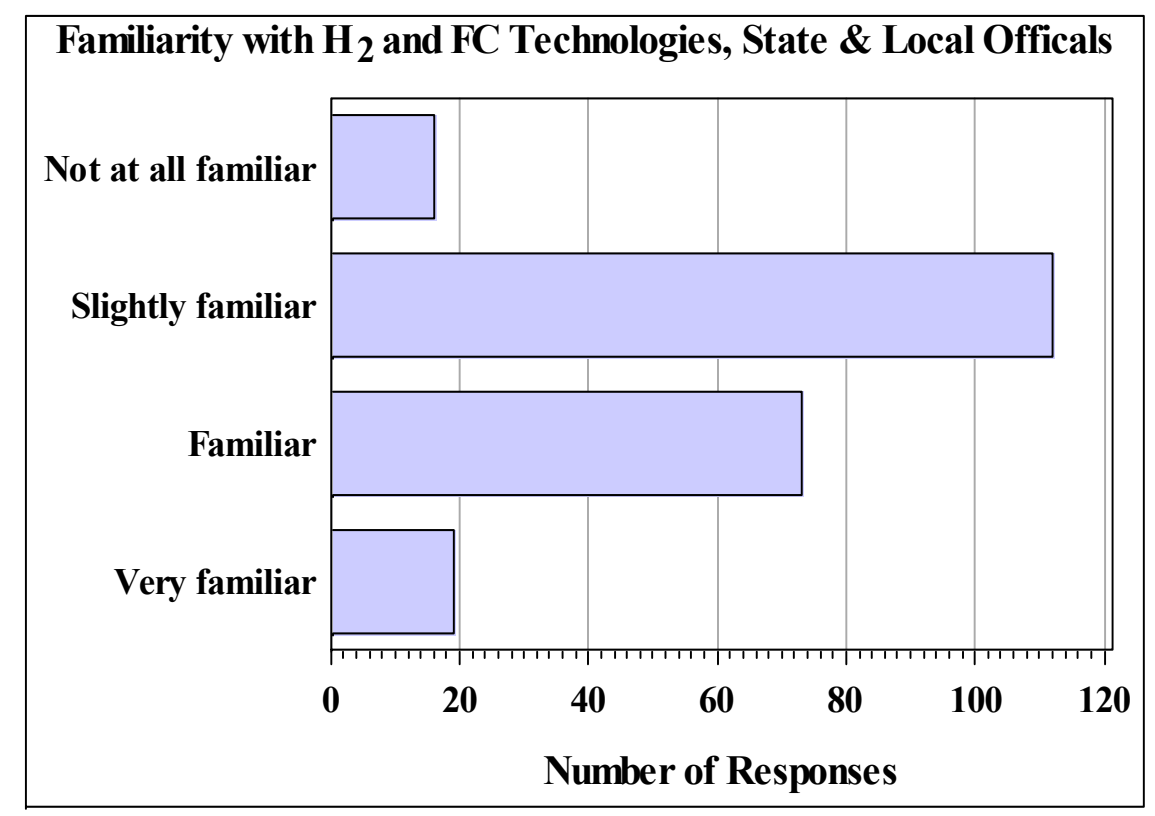

Figure 6.3. Distribution of responses to the question about familiarity with hydrogen and fuel cell technologies, Question 1, state and local government agencies.

The rank scores for the question asking respondents to rank the importance of safety, cost, environment, convenience, and performance (Question 7) are summarized in Table 6.2 as the weighted averages of the ranks (1-5) assigned by each survey subject. In this ranking, "1" ranks as more important than " 2 ," etc. Therefore, the lower the weighted average rank, the more important is the "Value." On average, the rankings were in the order "Cost" is more important than "Safety" is more important than "Environment" is more important than "Performance" is more important than "Convenience." Of course many individuals departed from this exact order.

\begin{tabular}{|l|c|c|c|c|}
\hline \multicolumn{5}{|c|}{ Table 6.2. Summary of Importance Ranking, State and Local Governments } \\
\hline Question & $\begin{array}{c}\text { Number of } \\
\text { responses }\end{array}$ & $\begin{array}{c}\text { Average } \\
\text { rank }\end{array}$ & $\begin{array}{c}\text { Lower 95\% } \\
\text { confidence } \\
\text { bound }\end{array}$ & $\begin{array}{c}\text { Upper 95\% } \\
\text { confidence } \\
\text { bound }\end{array}$ \\
\hline Cost & 218 & 2.43 & 2.37 & 2.48 \\
\hline Safety & 219 & 2.75 & 2.69 & 2.81 \\
\hline Environment & 218 & 2.96 & 2.90 & 3.02 \\
\hline Performance & 217 & 3.38 & 3.32 & 3.43 \\
\hline Convenience & 218 & 3.46 & 3.40 & 3.52 \\
\hline
\end{tabular}


Figure 6.4 illustrates the pattern shown in Table 6.2. The last ten "Value" entries in Appendix C. 3 are for pairwise comparisons based on the safety, cost, environment, convenience, and performance rankings. Each possible pair (e.g., safety and cost) is considered separately.

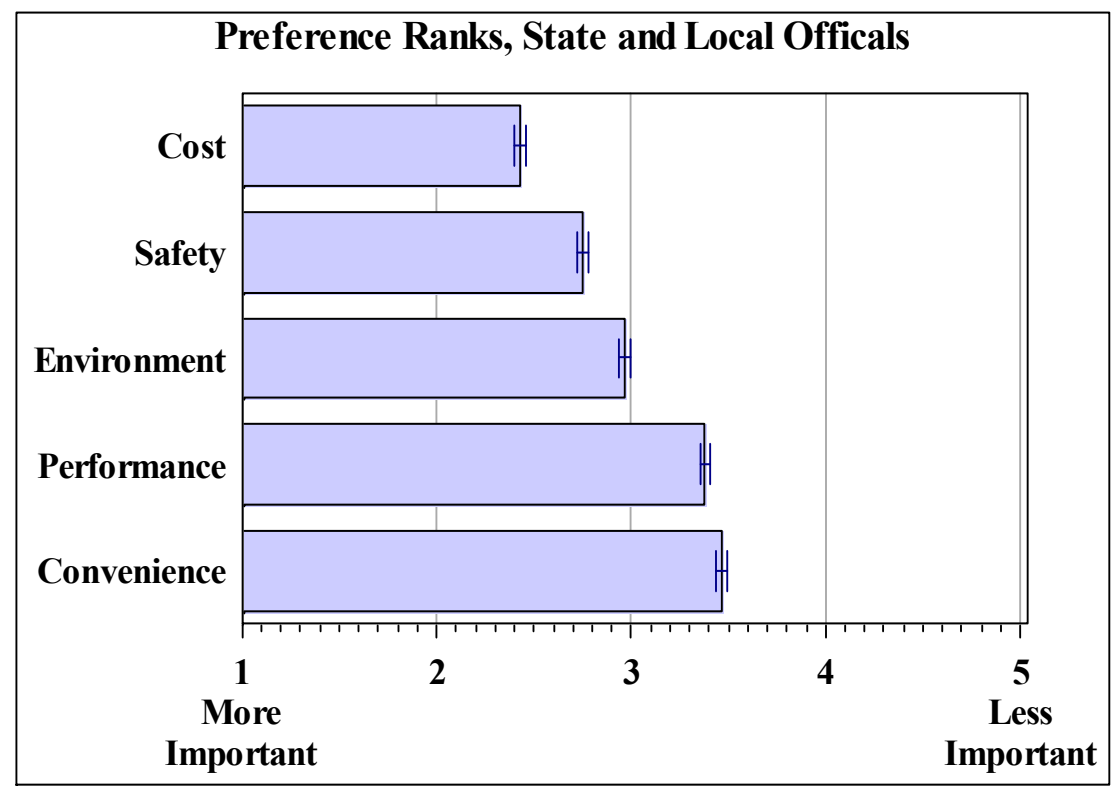

Figure 6.4. Mean of preference rankings of cost, safety, environment, convenience, and performance, Question 7, state and local government agencies. (Rank=1 for first choice, 2 for second choice, etc.) The error bar on each chart bar shows 95\% confidence limits for the mean rank.

Officials with the government agencies were asked whether they would recommend buying or leasing fuel cell vehicles for their organization's vehicle or a stakeholder organization's vehicle fleet if the fuel cell vehicles were available at a cost competitive to gasoline internal combustion engine vehicles. Almost $80 \%$ of the officials responded "Yes." The responses to this question are shown in Figure 6.5.

Officials were also asked whether they would recommend buying a stationary fuel cell to help with the power needs of their facility or a stakeholder organization's facility if the stationary fuel cells were available at a cost competitive to traditional power systems. Over $82 \%$ of the officials responded "Yes." The responses to this question are shown in Figure 6.6. 


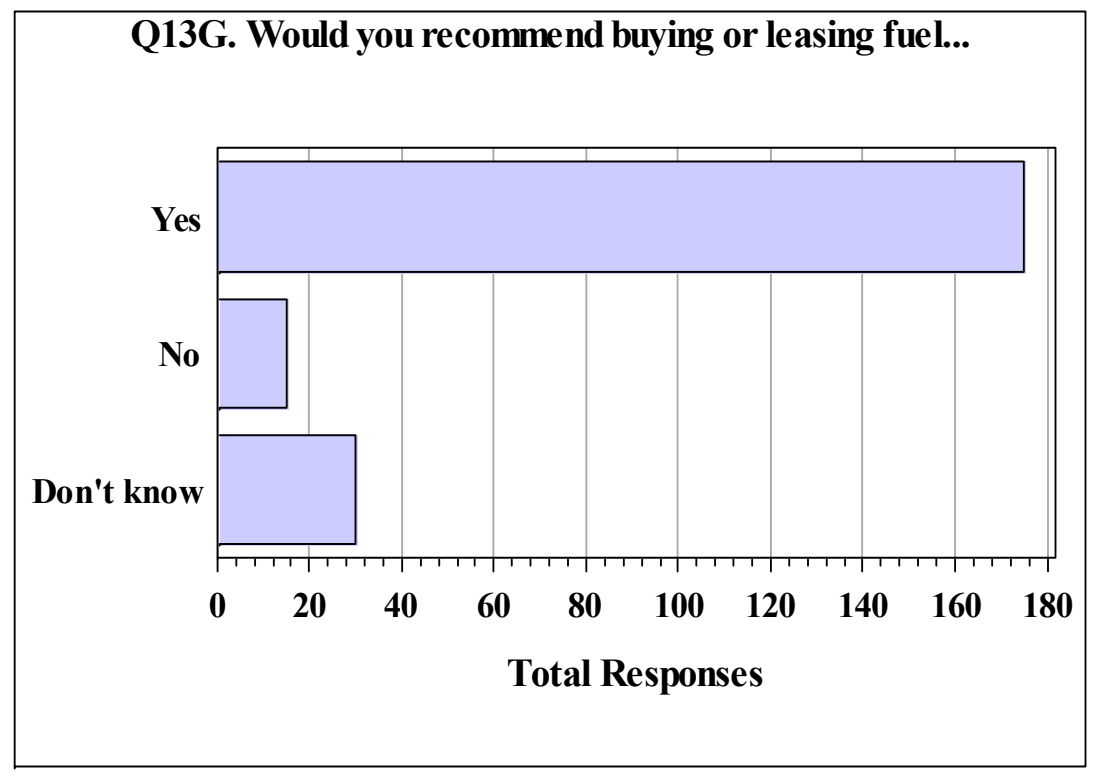

Figure 6.5. Share of respondents who would recommend purchasing a fuel cell vehicle for their organization's vehicle fleet if the cost were comparable to that of a gasoline vehicle, Question 13G, state and local government agencies.

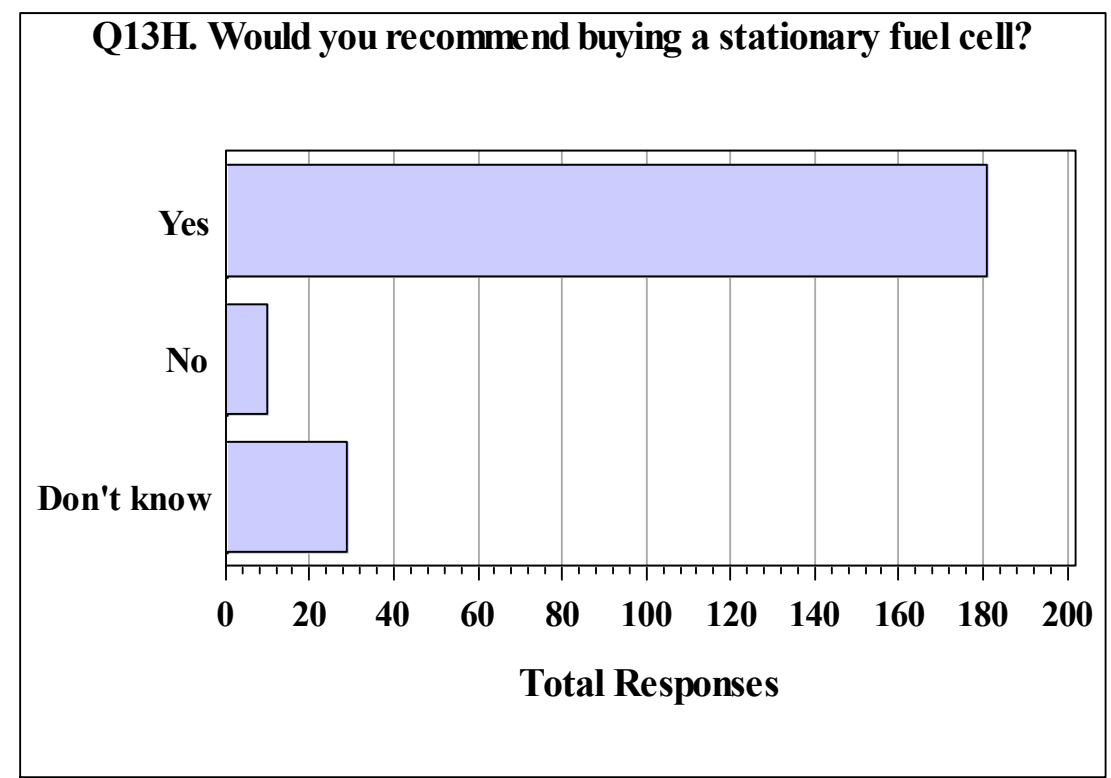

Figure 6.6. Share of respondents who would recommend purchasing a stationary fuel cell to help meet the power needs of their facility if stationary fuel cells were available at a cost comparable to that of traditional power systems, Question $13 \mathrm{H}$, state and local government agencies. 
Government officials were next asked a similar question (Question 13I) about the use of hydrogen and fuel cell technologies to meet their organization's energy needs; in this case, however, the relative costs of traditional technologies were not considered as part of the question. In this case most (47.7\%) officials responded that they plan to wait to see how the market develops (Figure 6.7).

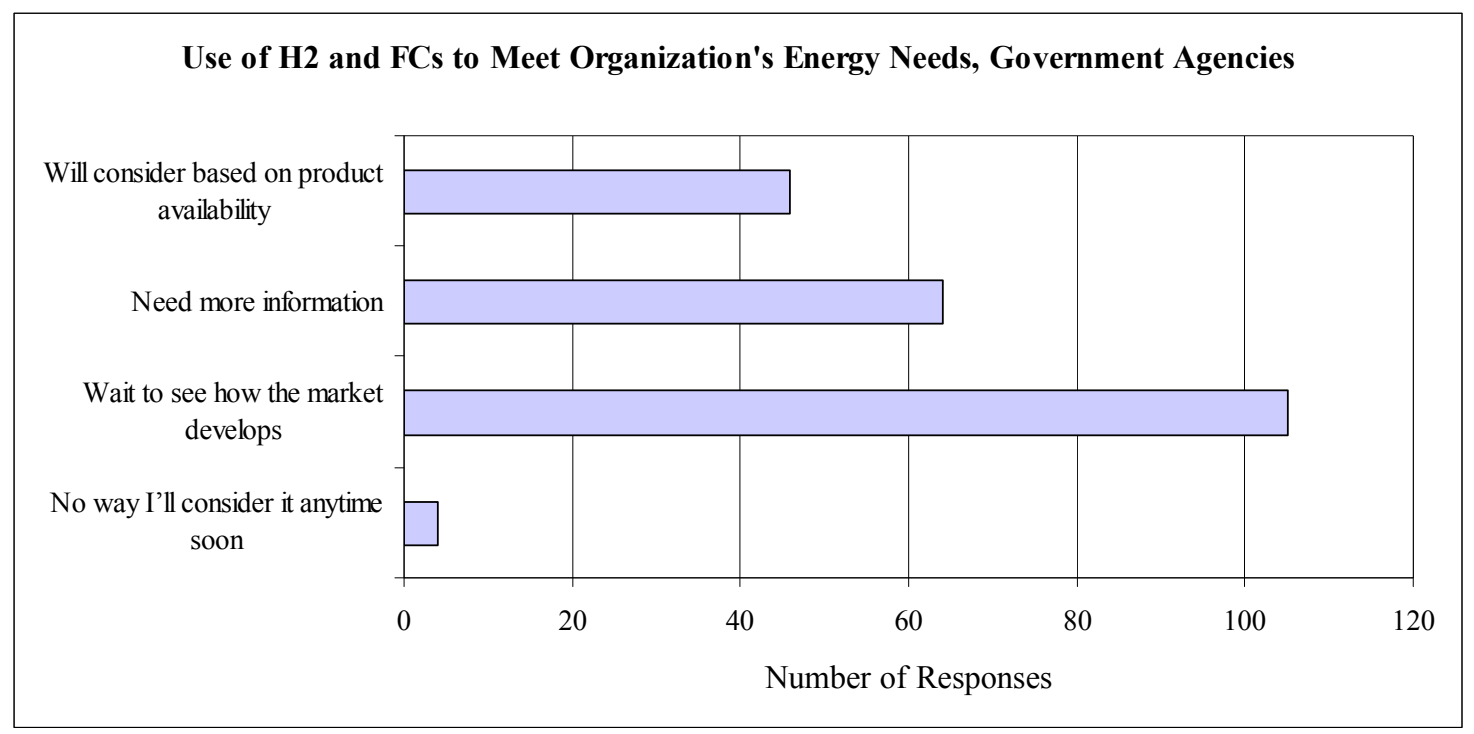

Figure 6.7. Opinions of government officials about using hydrogen and fuel cell technologies to meet their organization's energy needs, Question 13I, state and local government agencies.

Respondents to the survey of government agencies were asked two questions about information sources. Question 14 asked about the frequency of use ("Never," "Sometimes," "Frequently") of information sources to make decisions about energy costs and safety. As shown in Figure 6.8, the sources marked "Frequently" most often were industry or trade associations or non-profit organizations, Federal government, and State government. The sources of information that received the greatest number of "Never" responses were teachers and schools, friends and family members, and local government agencies. These responses were very similar to those recorded in the 2004 survey.

Question 15 also asked about information sources, but from the perspective of media sources, that is, information vectors (television, radio, internet, etc.) for obtaining energy information. As shown in Figure 6.9, respondents indicated that they most frequently used the Internet, science and technology journals, and trade magazines. 


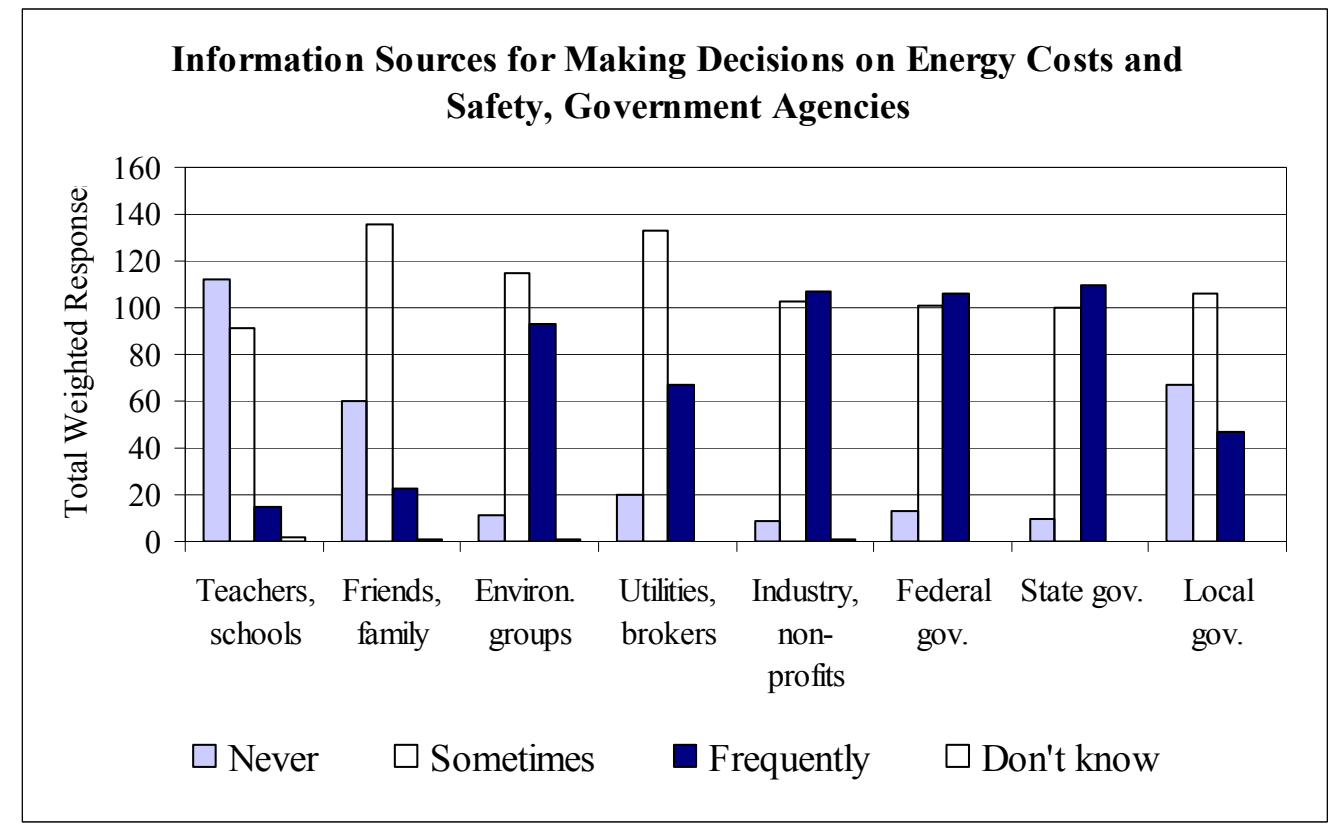

Figure 6.8. Weighted counts of responses regarding the frequency of use of information sources when making decisions about energy costs and safety, Question 14, state and local government agencies.

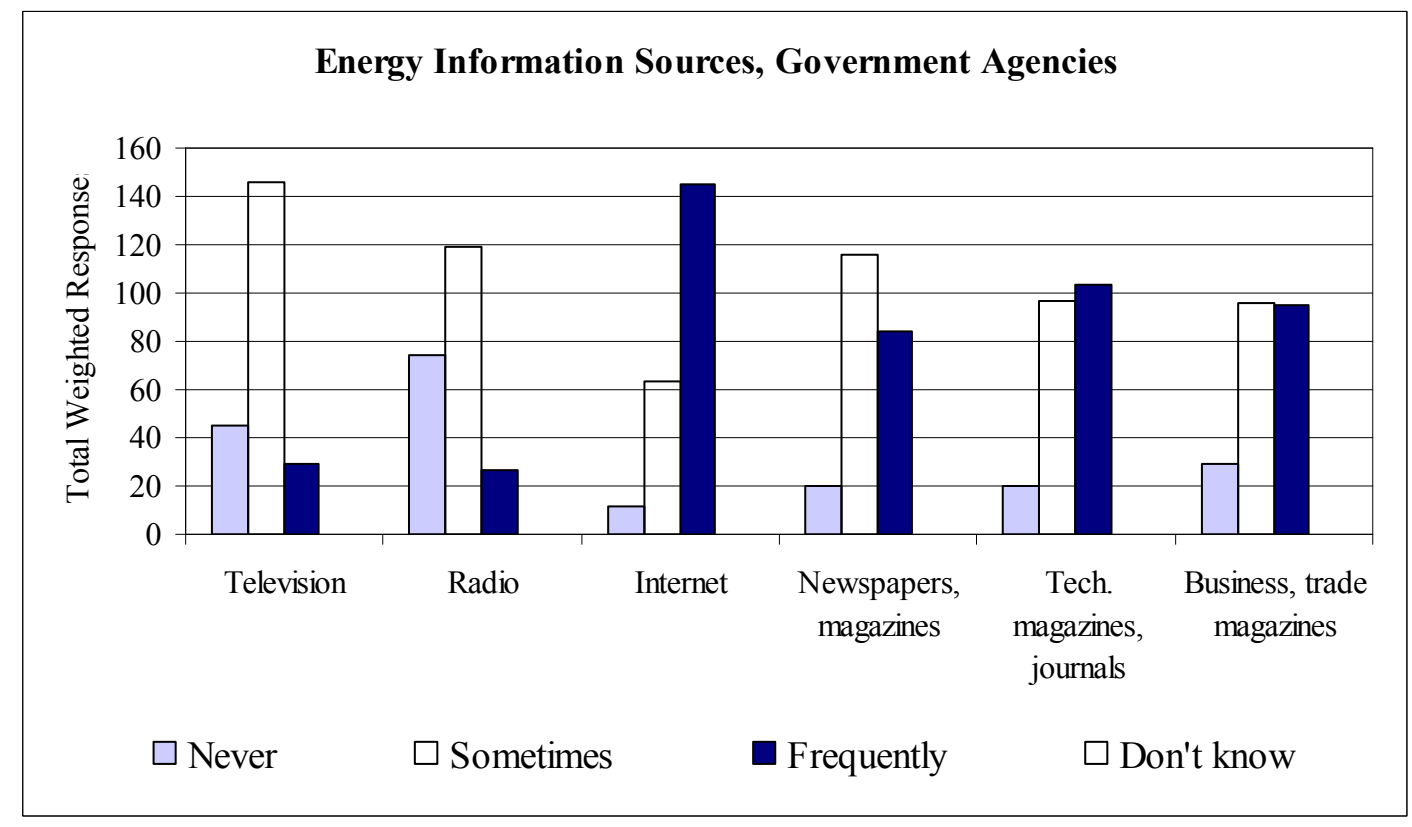

Figure 6.9. Weighted counts of responses regarding the frequency of use of different types of mass media for obtaining energy information, Question 15, state and local government agencies. 
Questions 20-24 were about the respondents' awareness of hydrogen and fuel cell technology penetration. (To read the complete questions, please see Appendix A.3.) Figure 6.10 shows the percentages of state and local officials responding "Yes" to these questions. Only a few respondents indicated that their own agencies had hydrogen vehicles or stationary fuel cells. A greater number of respondents indicated that other agencies in their geographic jurisdiction were using hydrogen-powered vehicles or stationary fuel cells.

Officials were asked if their agencies had plans to use hydrogen and/or fuel cells in the future. Those responding "Yes" were then asked the time frame for implementation. As can be seen in Figure 6.11, almost half of the respondents indicated that their agencies had no plans to use hydrogen or fuel cells in the near future. About $21 \%$ plan to implement hydrogen or fuel cell technologies within the next five years. These percentages are very similar to the findings of the 2004 survey.

Almost $70 \%$ of the government officials indicated that they had received information about hydrogen and fuel cell technologies, which is much higher than the corresponding percentage for $2004(52 \%)$. Less than $20 \%$ of respondents had attended a training class on hydrogen or fuel cells, and almost $70 \%$ indicated that they would like to participate in a class. These responses are shown in Figure 6.12.

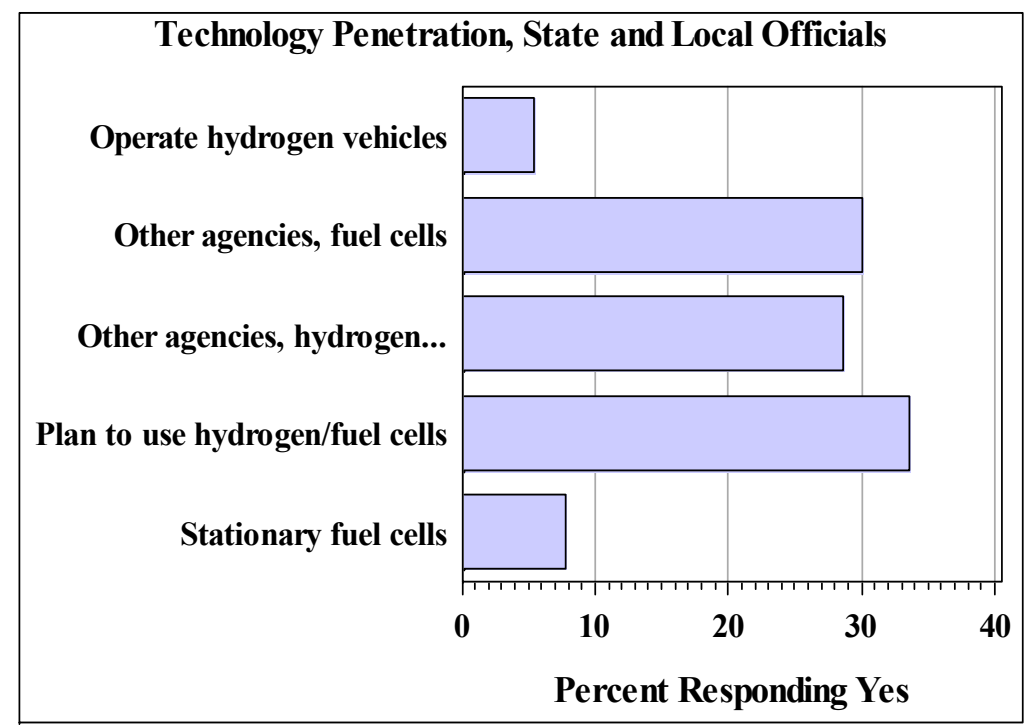

Figure 6.10. Percentages of officials who responded "Yes" to Questions 20-24 about hydrogen and fuel cell technology penetration, state and local government agencies. 


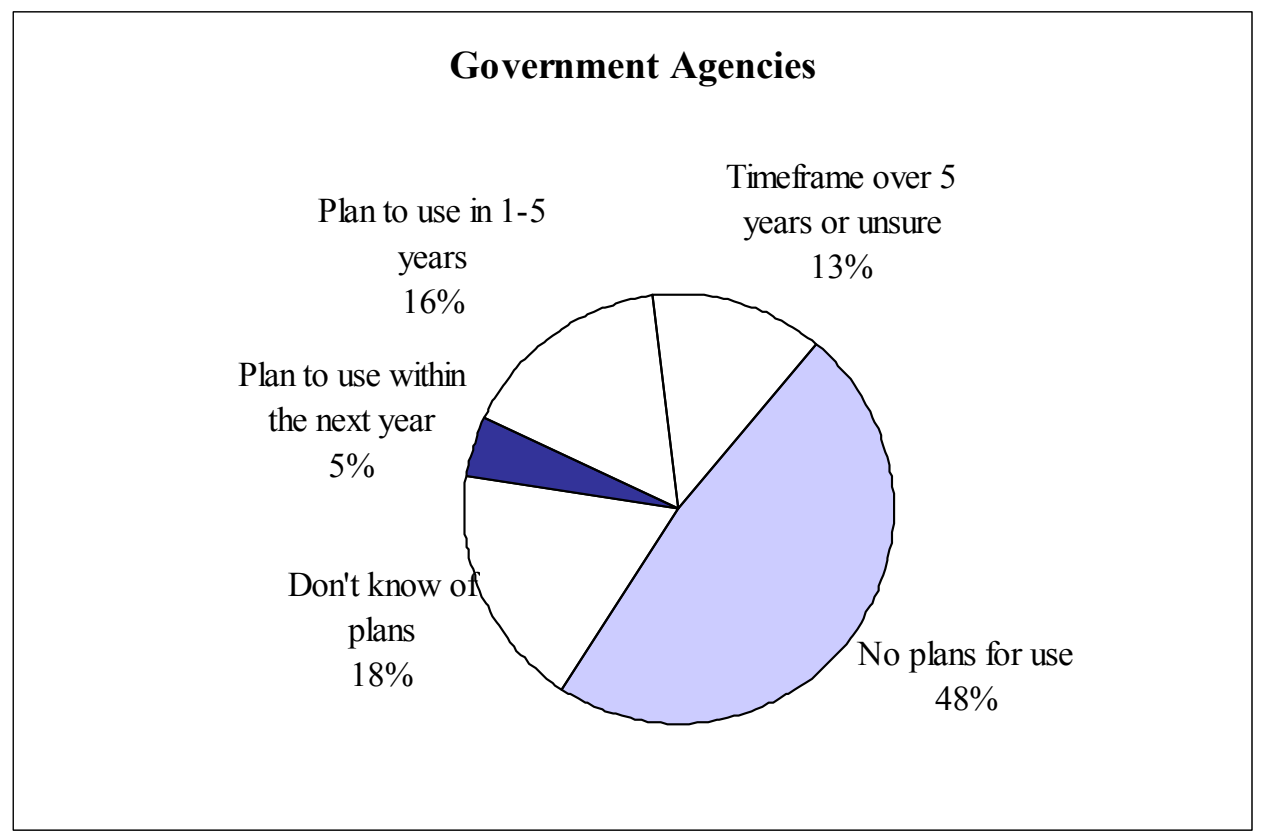

Figure 6.11. Responses to Questions 24-25 concerning plans to use hydrogen and fuel cell technologies, state and local government agencies.

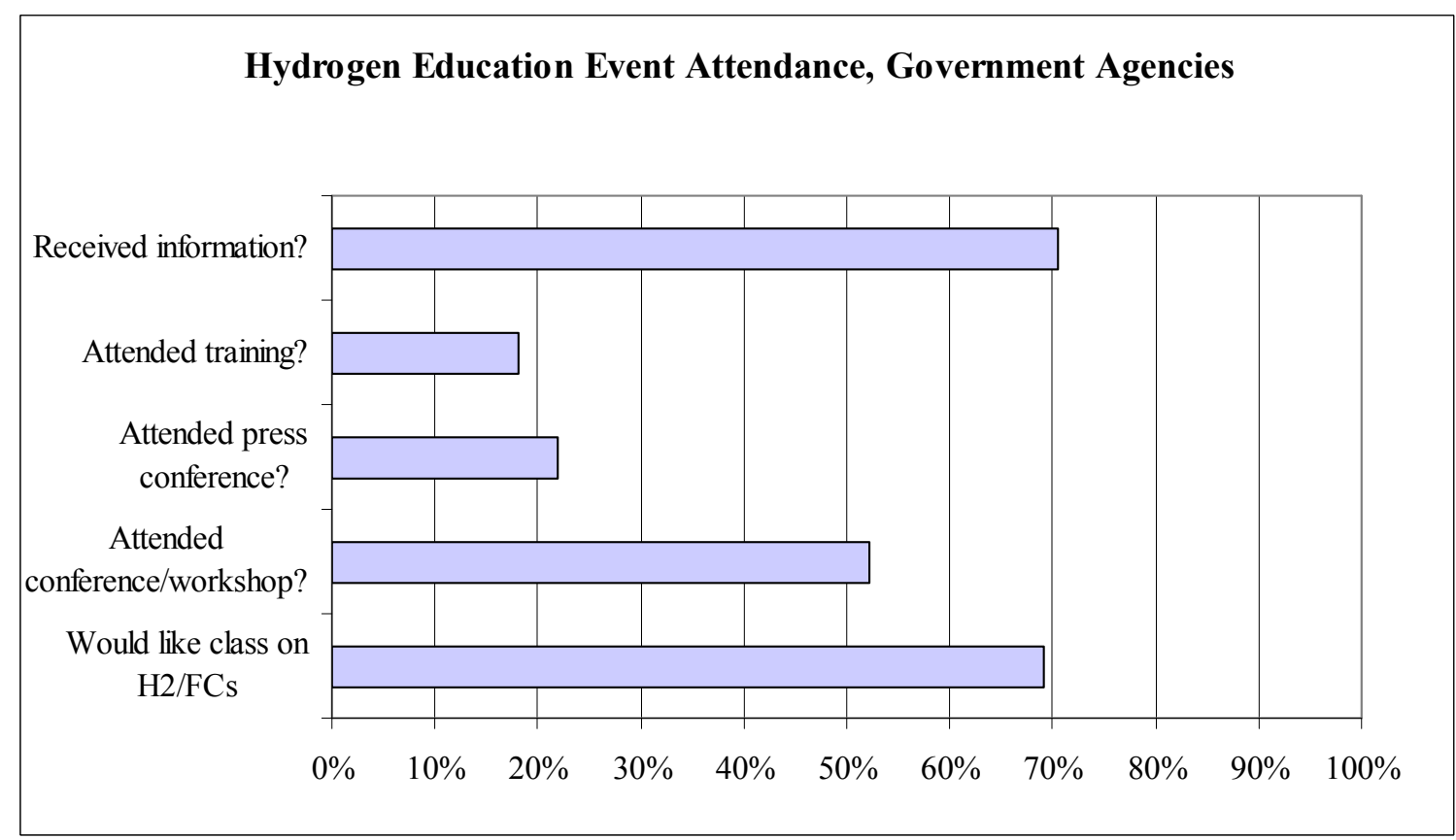

Figure 6.12. Percentages of "Yes" responses concerning possession of information about hydrogen and/or fuel cells and desire to attend a class, Questions 26-29, state and local government agencies. 


\subsection{RELATIONSHIPS}

The summary statistics in Section 6.2 are "one-way" statistics in the sense that the response categories are defined in terms of one variable such as response to an opinion question (e.g., Question 10C, "Hydrogen is as safe to use in my car as gasoline and diesel fuels"). However, relationships in the responses determined by two or more variables may also be of interest. Although no relationships were of particular interest a priori, in this section a few of the more statistically significant ones are illustrated. Interactions that were considered were with the survey variables and region, function (environmental protection, transportation, energy, etc.), familiarity with hydrogen and fuel cell technologies, and whether or not the score on the technical questions was above the average for the sample. The statistical significance criterion is the significance level (p) of a chi-square test. ${ }^{42}$

As shown in Figure 6.13, respondents who scored below average on the technical questions were more likely to assess their familiarity as "Not at all familiar" or "Slightly familiar," and respondents who scored above average were more likely to claim a higher familiarity with hydrogen and fuel cell technologies. Thus, the familiarity self-assessments are consistent with the technical awareness scores.

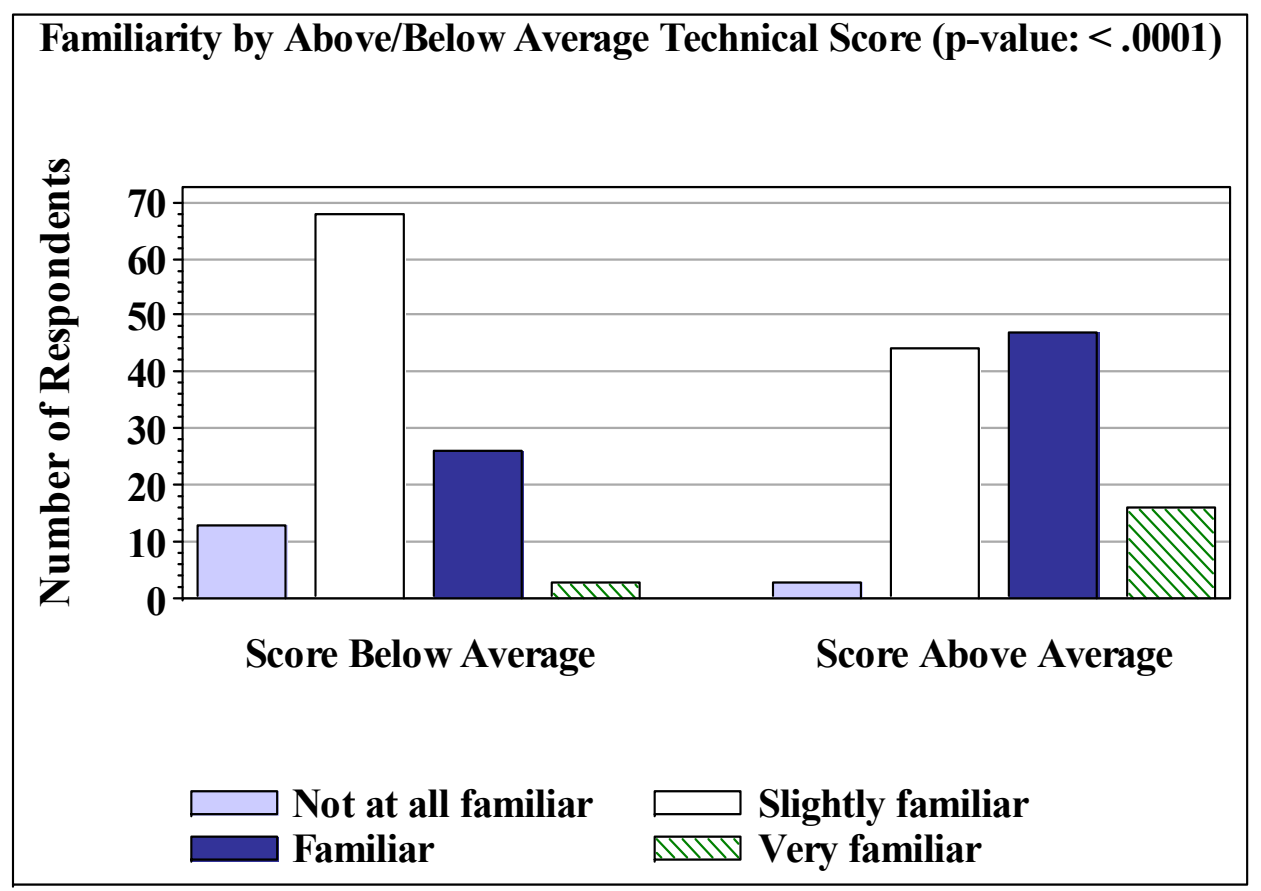

Figure 6.13. Responses by technical score above/below average to Question 1 (familiarity of respondents to hydrogen and fuel cell technologies), state and local government agencies.

\footnotetext{
${ }^{42}$ Measures could also be based on odds ratios or combinations of odd ratios and significance levels as well as other metrics. Significance levels alone were used for simplicity and because sample sizes are essentially the same for all survey questions.
} 
Another interesting relationship was that of responses to the technical questions by functional group. For example, respondents were asked whether the following statement was true or false: "Fuel cells produce electricity through hydrogen combustion." (The statement is false.) Over half of the State Energy Offices and Departments of Environmental Protection answered this question correctly. State Departments of Transportation and city and county offices, however, responded correctly much less frequently.

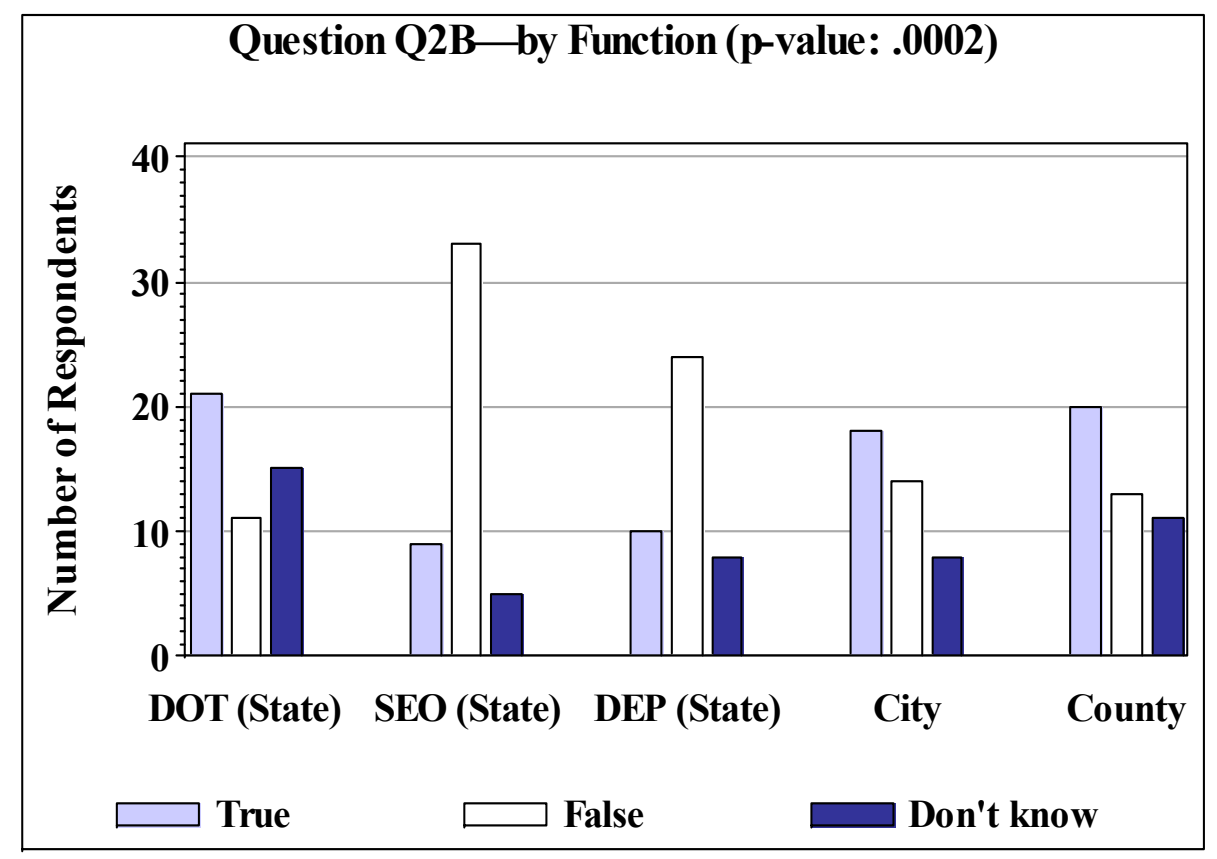

Figure 6.14. Responses by functional group to Question 2B (technical question on fuel cells), state and local government agencies.

\subsection{COMPARISON WITH THE 2004 BASELINE}

A primary objective of conducting multiple surveys over time is to compare survey results.

Figure 6.15 shows the differences in the average technical scores for each of the eight technical questions on the survey. The overall average technical score in 2008 was $66.65 \%$ correct responses; in 2004 the average score was $66.58 \%{ }^{43}$ The difference (.07) is essentially zero. There were statistically significant changes between 2004 and 2008, however, in the percentages correct for some of the individual questions. In particular, respondents did much better on the fuel cell questions, $2 \mathrm{~B}$ and 5 ( $\mathrm{p}<0.0001$ in both cases). This improvement was offset by significantly poorer performance on some of the basic hydrogen questions, for example Questions 2A about toxicity and 2D about odor ( $\mathrm{p}<0.0001$ in both cases).

\footnotetext{
${ }^{43}$ This is the 2004 percentage of correct responses to the eight technical questions asked both in 2004 and 2008. For all eleven of the technical questions that were asked originally in 2004, the percentage correct was $65.8 \%$.
} 


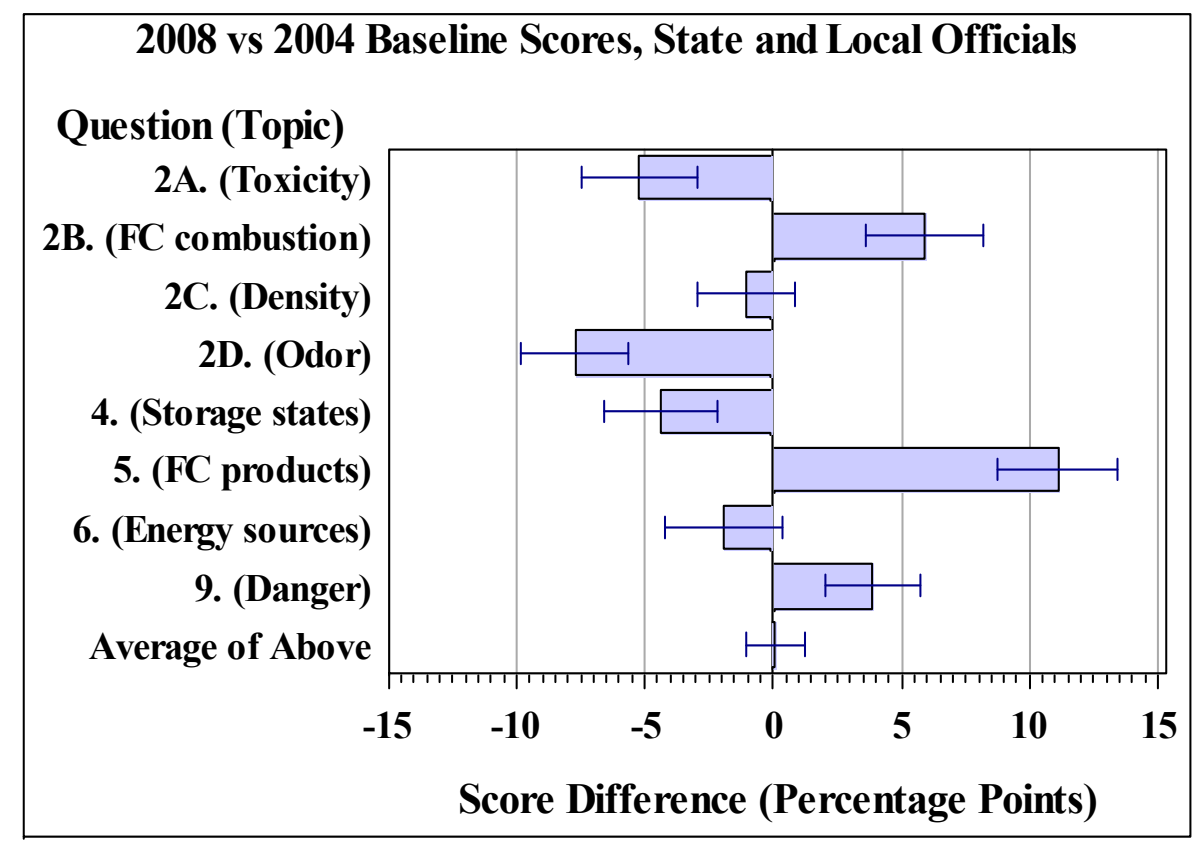

Figure 6.15. Differences between the 2008 and 2004 average percentage correct for each technical question and overall, state and local government agencies. Bars to the right of zero show improvement in 2008. The error bars are 95\% confidence intervals for the differences.

Several questions in the survey concerned safety issues and the use of hydrogen. For many of these, changes in the opinions of government officials toward hydrogen safety are shown in the next few figures. There is much less difference between the 2004 and 2008 perceptions about hydrogen safety for government officials than for the other survey populations. This is likely because in 2004 government officials were already more informed than the other survey populations about hydrogen and fuel cell technologies. Figure 6.16 shows the very slight changes in responses to the statement, "Hydrogen is too dangerous for everyday use by the general public (false)."

On the other hand, for the question (Question 8) about comfort level with the sale of hydrogen at their local gas station, there was a statistically significant change. Figure 6.17 compares the results of the 2004 and 2008 surveys to this question. The number of officials that said they would be "Pleased" increased from $53 \%$ to $67 \%$. This difference is highly significant $(\mathrm{p}<0.0001)$.

Another question examined opinions about the safety of hydrogen in vehicles. The 2004 and 2008 response profiles for this question are shown in Figure 6.18. Although there are some slight differences, the response profiles are quite similar. Again, the slight differences probably reflect the fact that many of the state and local officials were already familiar with hydrogen issues in 2004, as they continue to be in 2008 . 


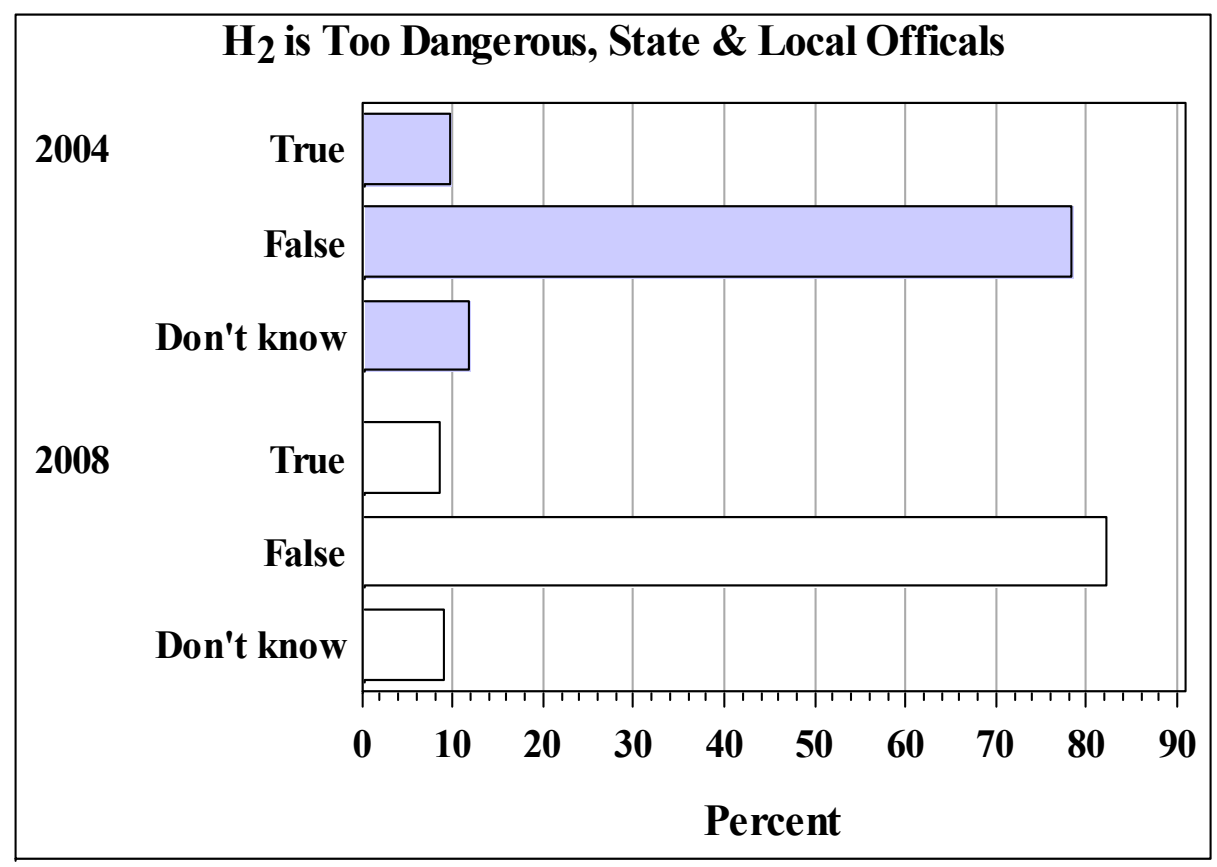

Figure 6.16. Comparison of results of the 2004 and 2008 surveys regarding the statement, "Hydrogen is too dangerous for everyday use by the general public (false)," Question 9, state and local government survey.

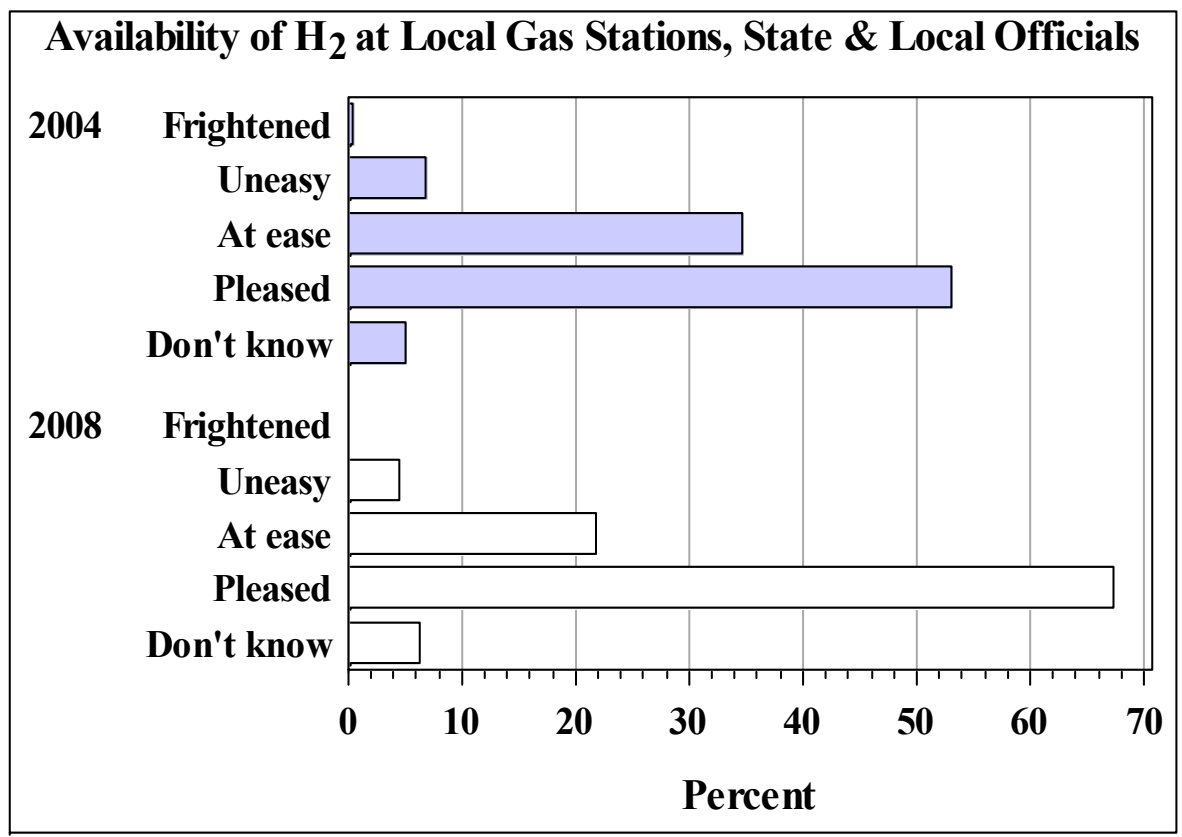

Figure 6.17. Comparison of results of the 2004 and 2008 surveys regarding opinions about the availability of hydrogen at a local gas station, Question 8, state and local government survey. 


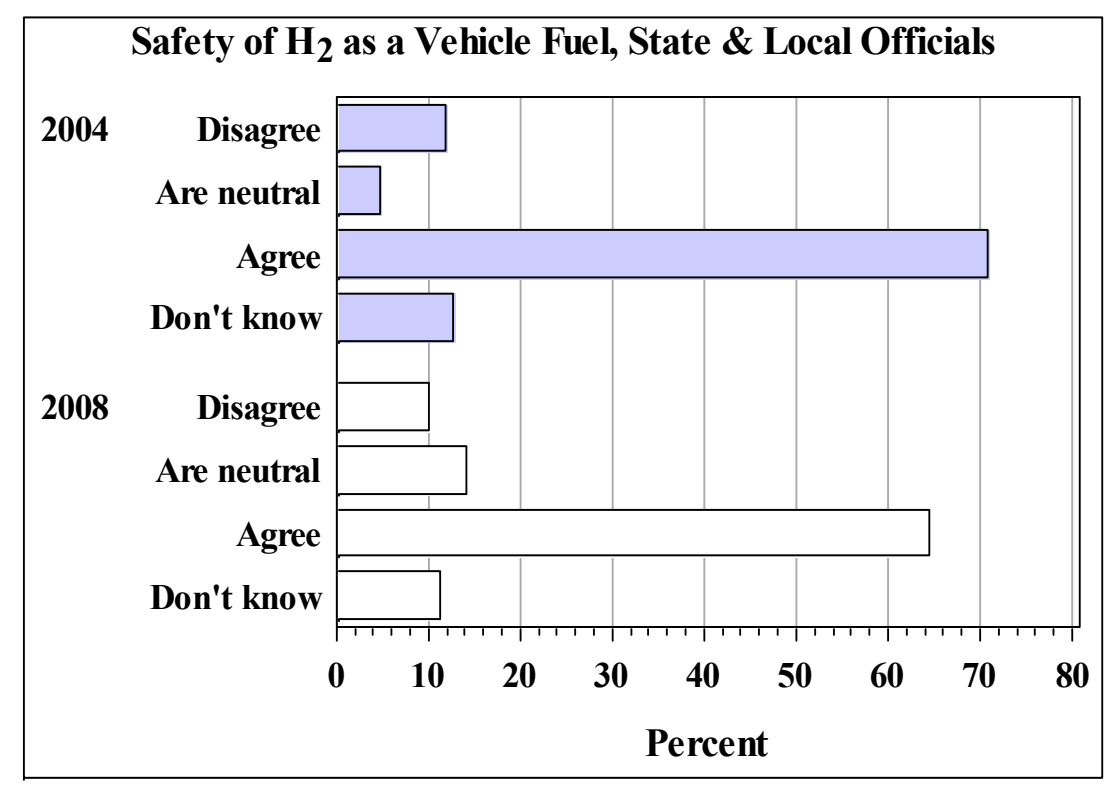

Figure 6.18. Comparison of results of the 2004 and 2008 surveys regarding opinions about the safety of hydrogen as a vehicle fuel, Question 10C (Hydrogen is as safe to use in my car as gasoline and diesel fuels), state and local government survey.

In general, the same sources were used by government personnel to obtain energy information in 2008/2009 as were used in 2004 (see Figure 6.9). A slightly greater percentage of respondents indicated that they used the Internet "Frequently" (58\% in 2004 and 66\% in 2008/2009).

The time frames for implementing hydrogen and fuel cell technologies in the future were relatively unchanged. In 2004, 30\% of respondents indicated that their agency had plans to use hydrogen or fuel cells in the future; in 2008/2009, 34\% indicated such plans. For those respondents with plans for use, Table 6.3 shows the time frames for implementation.

\begin{tabular}{|l|c|c|}
\hline \multicolumn{1}{|c|}{$\begin{array}{c}\text { Table 6.3. Time frames for Implementation for Government Agencies Planning to } \\
\text { Use Hydrogen or Fuel Cells in the Future }\end{array}$} \\
\hline \multicolumn{1}{|c|}{$\mathbf{2 0 0 4}$} & $\mathbf{2 0 0 8}$ \\
\hline Within the next year & 13 & 10 \\
\hline 1-5 years & 33 & 35 \\
\hline Over 5 years & 23 & 26 \\
\hline Don't know & 2 & 3 \\
\hline Total of those with implementation plans & 71 & 74 \\
\hline
\end{tabular}

Finally, response rates were lower for the current survey, down from 0.959 to 0.894 . 


\section{RESULTS: END USER SURVEY}

\subsection{INTRODUCTION}

This section summarizes the results of the survey of end users and potential end users of hydrogen and fuel cell technologies. A copy of the survey questionnaire is in Appendix A.4. A total of 601 interviews with persons in positions of responsibility in business and industry in the United States were completed during the period of May 2-13, 2008. The total average interview length was 14.4 minutes, broken down into a screening time of 2.5 minutes and a main interview length of 11.9 minutes. A summary of responses to this survey, by question number, is provided in Appendix C.4.

The survey was stratified into three sectors of business and industry: transportation, business types for which energy usage is primarily for heating/cooling and uninterrupted power is required, and industrial sectors with large power requirements. Businesses were identified using NAICS (North American Industry Classifications System) codes. Two hundred potential end users were surveyed in each of the three categories. The distribution of survey respondents by subcategory are shown in Figure 7.1.

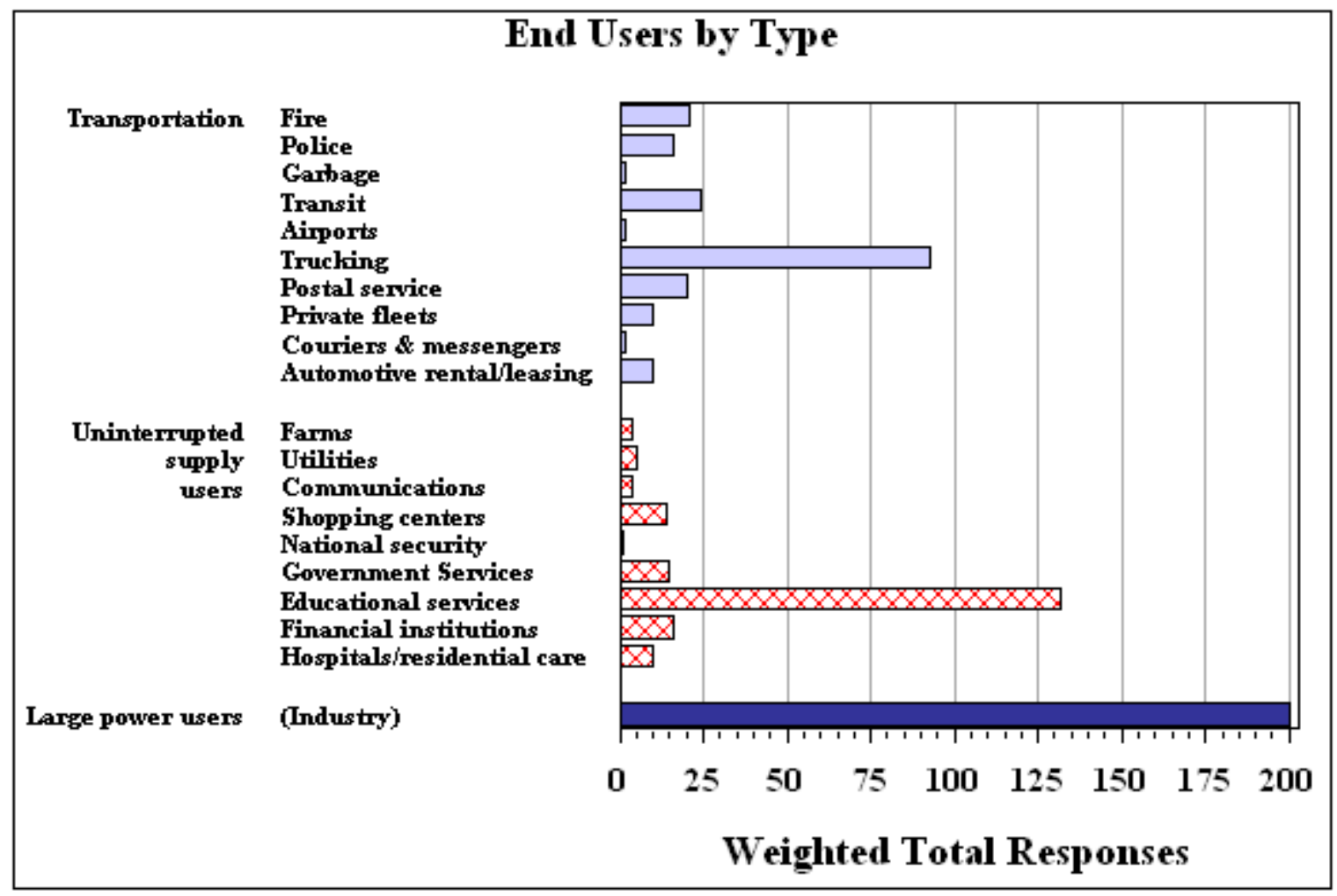

Figure 7.1. Distribution of respondents by business subcategory, end user survey. 
Section 7.2 is a general summary of the responses of the end users. Relationships between the response variables are discussed in Section 7.3. Differences between the 2008 and 2004 survey results are discussed in Section 7.4.

For the sake of simplicity, the responses "Don't know," "No opinion," and "Don't know/no opinion" are all treated equivalently and generally as "Don't know" in this report.

The response rate for the 2008 End User Survey is discussed in Appendix E.4. The response rate is $17.0 \%$. This response rate is considerably lower than the 2004 rate of 0.2914 . The drop in the response rate does not appear related to the response rate among the "known eligible" respondents or to the eligibility rate, which was .6962 in 2004. Rather it is due to a disproportionate increase in the number of unknown eligibility, which was 330 in 2004 but increased to 4,619 in 2008. (Note that 4,619/330 = 14.0, while the 2008 and 2004 surveys were designed to capture 600 and 99 respondents respectively, 600/99=6.1.) As with the student survey this difference is probably at least partly due to the precision of the vendor-supplied sampling frames.

\subsection{SUMMARY}

The section summarizes the responses to the individual questions in the end user survey. Most of the questions are summarized as proportions of respondents in each of the respective multiple choice categories. Answers to the technical questions are summarized individually and are also compiled into an overall technical score. Relationships between responses to different questions and comparisons with the 2004 survey results are considered in Section 7.3 and 7.4.

Table 7.1 summarizes the technical questions in terms of whether they were answered correctly or incorrectly with "Don't know" treated as an incorrect response. The greatest percentage of correct responses is 63.4\%, for Question 5C (Hydrogen is lighter than air), followed by 62,1\% for Question 12 (Hydrogen is too dangerous...). The smallest percentage of correct responses is $22.5 \%$, for Question 5B followed by 31.5\% for Question 8 (When using pure hydrogen...).

The correct/incorrect perspective used in Table 7.1 is conventional, since "Don't know" is generally considered an incorrect response. However, "Don't know" was a very common response to the survey technical questions. Figure 7.2 shows the responses broken down according to type: Correct, Incorrect, and "Don't know." On average, $47.9 \%$ of the technical questions were answered correctly, 15.7\% were answered incorrectly, and 36.4\% were answered with "Don't know." 
Table 7.1. Summary of Results on the Technical Knowledge Questions (correct/incorrect), End Users

\begin{tabular}{|l|r|r|r|r|}
\hline \multicolumn{1}{|c|}{ Question } & $\begin{array}{c}\text { Number } \\
\text { of } \\
\text { responses }\end{array}$ & $\begin{array}{l}\text { Percent } \\
\text { correct }\end{array}$ & $\begin{array}{c}\text { Lower 95\% } \\
\text { confidence } \\
\text { bound }\end{array}$ & $\begin{array}{c}\text { Upper 95\% } \\
\text { confidence } \\
\text { bound }\end{array}$ \\
\hline 5A. Hydrogen gas is toxic (false) & 601 & 55.24 & 51.54 & 58.95 \\
\hline $\begin{array}{l}\text { 5B. Fuel cells produce electricity through } \\
\text { hydrogen combustion (false) }\end{array}$ & 601 & 22.46 & 19.35 & 25.57 \\
\hline 5C. Hydrogen is lighter than air (true) & 601 & 63.39 & 59.79 & 67.00 \\
\hline 5D. Hydrogen has a distinct odor (false) & 601 & 60.07 & 56.42 & 63.71 \\
\hline $\begin{array}{l}\text { 7. In which state or condition can hydrogen be } \\
\text { stored? (chemical compound, liquid) }\end{array}$ & 601 & 45.76 & 42.02 & 49.50 \\
\hline $\begin{array}{l}\text { 8. When using pure hydrogen, fuel cell vehicles } \\
\text { generate electricity, water, and what else? (heat) }\end{array}$ & 601 & 31.45 & 27.96 & 34.93 \\
\hline $\begin{array}{l}\text { 9. Hydrogen can be produced using which of the } \\
\text { following sources of energy? (natural gas, } \\
\text { sunlight, organic matter) }\end{array}$ & 601 & 42.76 & 39.05 & 46.47 \\
\hline $\begin{array}{l}\text { 12. Hydrogen is too dangerous for everyday use } \\
\text { by the general public (false) }\end{array}$ & 601 & 62.06 & 58.42 & 65.70 \\
\hline Overall average & 601 & 47.9 & 45.85 & 49.95 \\
\hline
\end{tabular}

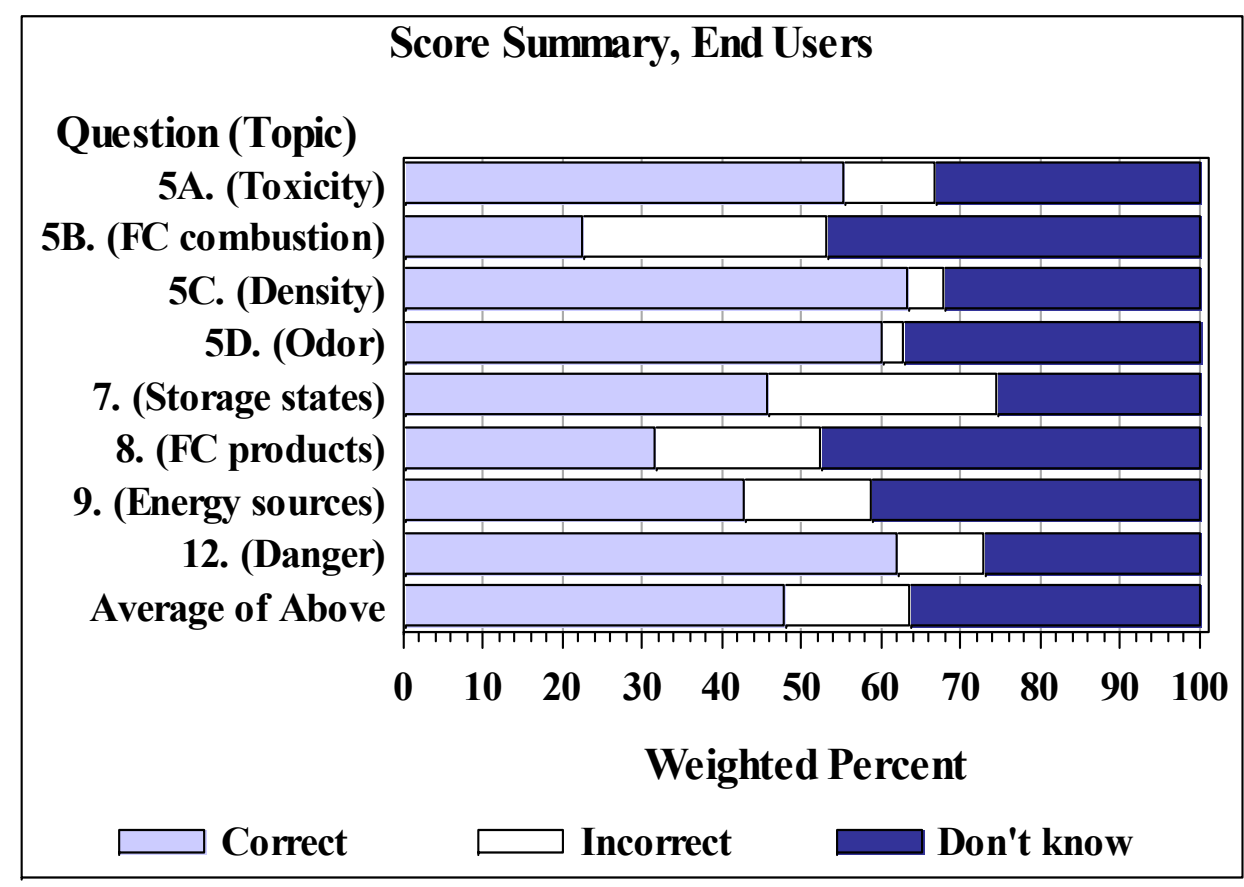

Figure 7.2. Weighted percent of correct, incorrect, and "Don't know" responses for the technical knowledge questions, end user survey. 
Figure 7.3 shows the distribution of the number of correct responses. The distribution mean is 3.83 (47.9\%) correct answers; the standard deviation is 2.2 correct answers.

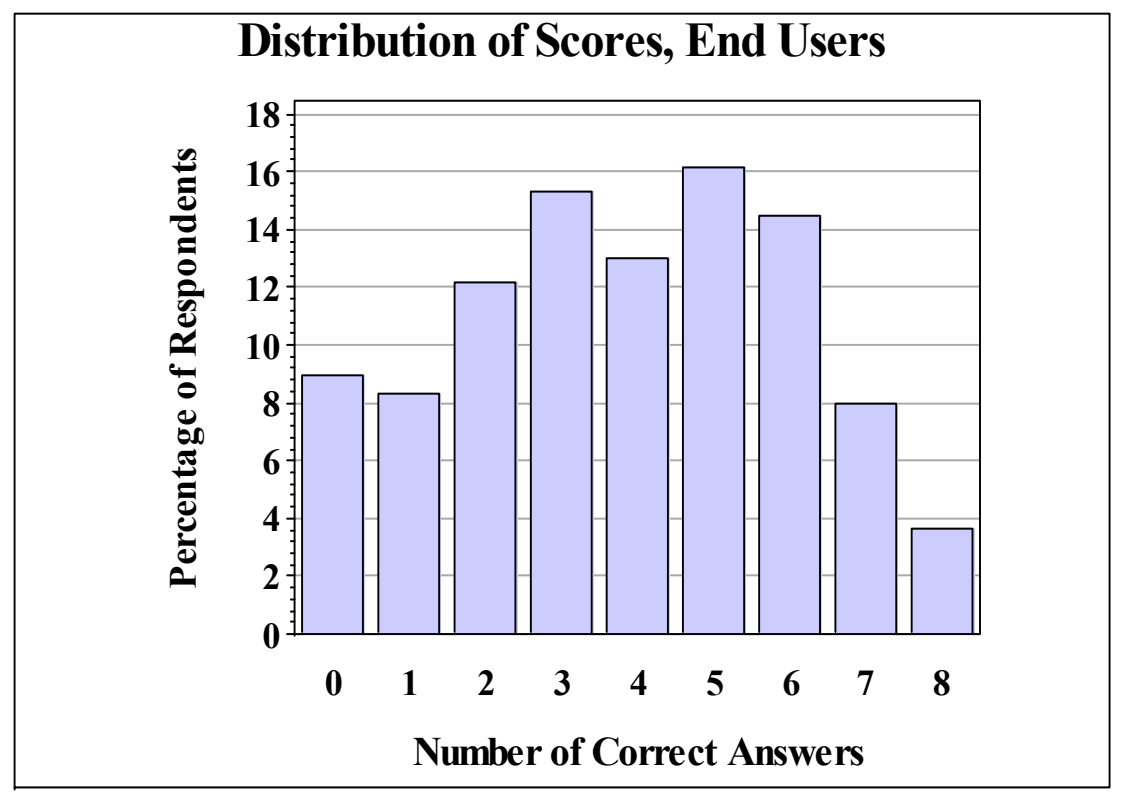

Figure 7.3. Distribution of the number of correct answers to the eight technical knowledge questions, end user survey.

End users with fewer than three correct responses to the eight technical questions did not necessarily have a greater number of incorrect answers. They had a high frequency of "Don't know" responses. The high proportions of "Don't know" responses suggest that these respondents may have been dismissive with the technical questions, for whatever reason, not even wanting to bother with them. Because these respondents represent a substantial and clearly separate subpopulation of end users, an education program might be designed to treat them separately.

The first question in the survey asked respondents to gauge their familiarity with hydrogen and fuel cell technologies. Figure 7.4 shows the distribution of responses. Over half of all respondents considered themselves "Slightly familiar" with hydrogen and fuel cell technologies.

When asked about the importance of specific characteristics of fuels or power supplies, end users responded that all of the itemized characteristics were considered important. End users listed "Safety" and "Dependability" as having the highest importance and "Environmental impact," "Maintenance cost," and "Installation cost" as having the least importance (Figure 7.5). 


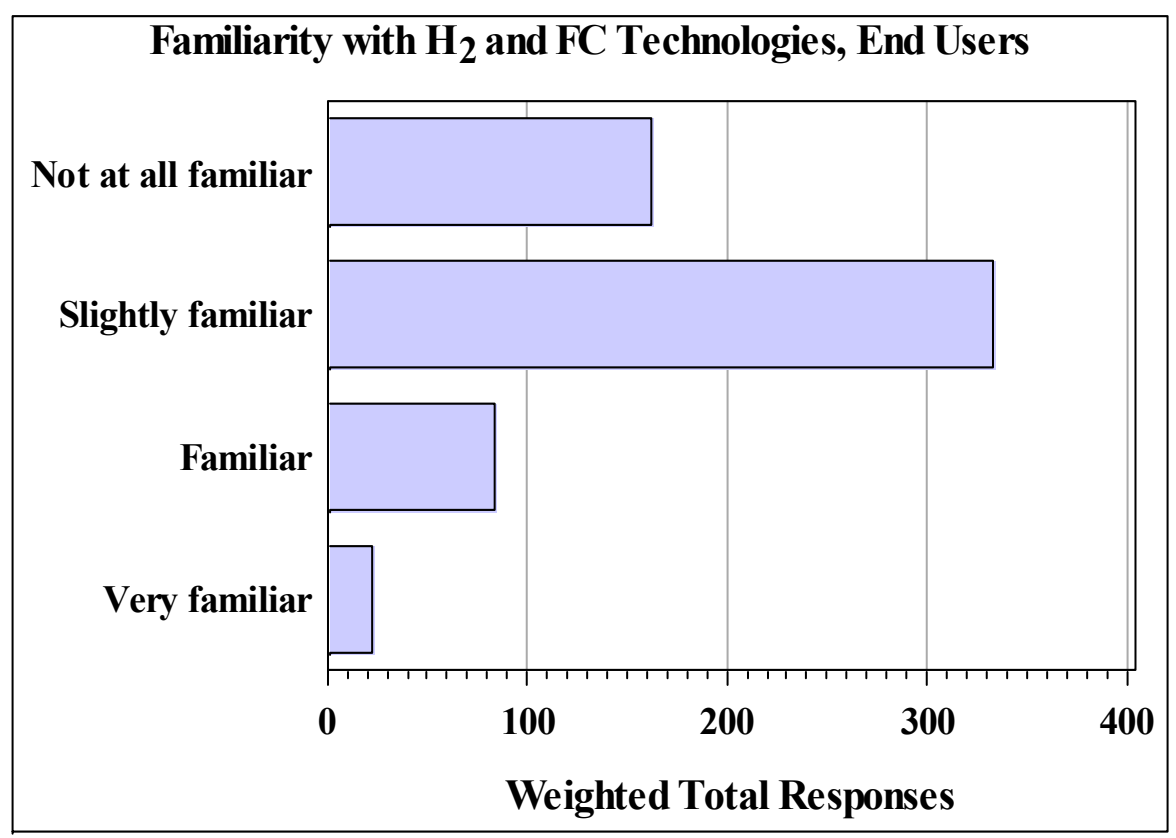

Figure 7.4. Distribution of responses to the question about familiarity with hydrogen and fuel cell technologies, Question 1, end user survey.

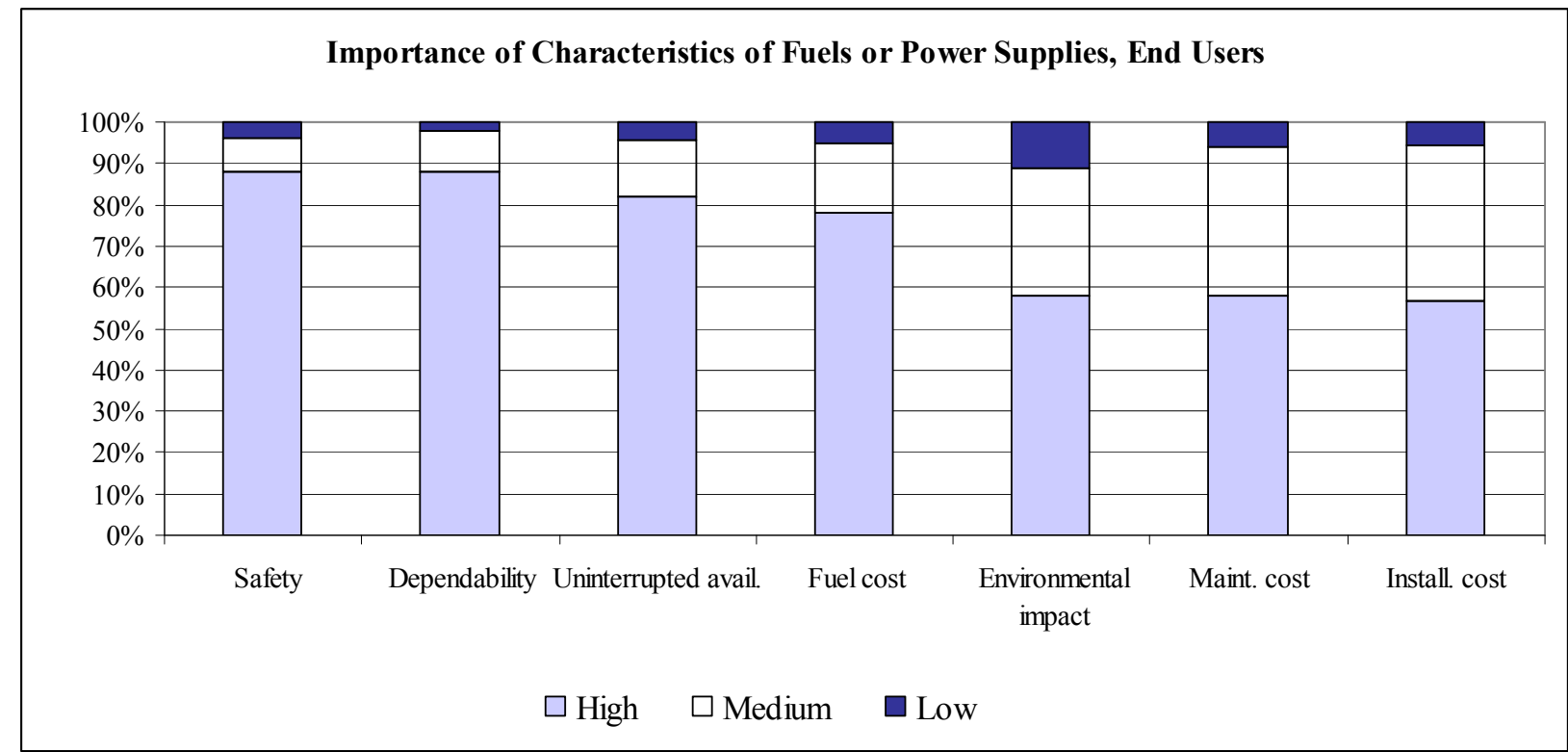

Figure 7.5. Importance of seven specific characteristics of fuels or power supplies, end user survey.

Only 47 end users (less than 8\%) responded that their organization used hydrogen and/or fuel cells for any purpose. Of these respondents, 19 indicated that the usage was to power buses and other vehicles. 
When asked about future plans to use hydrogen and/or fuel cells, 77 respondents (about 14\%) indicated that their organization did have plans for future use. Of these 77 , only four end users indicated that the time frame for future usage was within one year; 29 of the total 77 indicated that usage was planned within 1-5 years. (See Appendix C.3, Q26. Does your organization have plans to use hydrogen and/or fuel cells in the future? And Q27. What is the time frame for plans to use hydrogen and/or fuel cells?)

End users were asked whether they would recommend buying or leasing fuel cell vehicles for their organization's vehicle or a stakeholder organization's vehicle fleet if the fuel cell vehicles were available at a cost competitive to gasoline internal combustion engine vehicles. Over $80 \%$ of the respondents answered "Yes" (Figure 7.6).

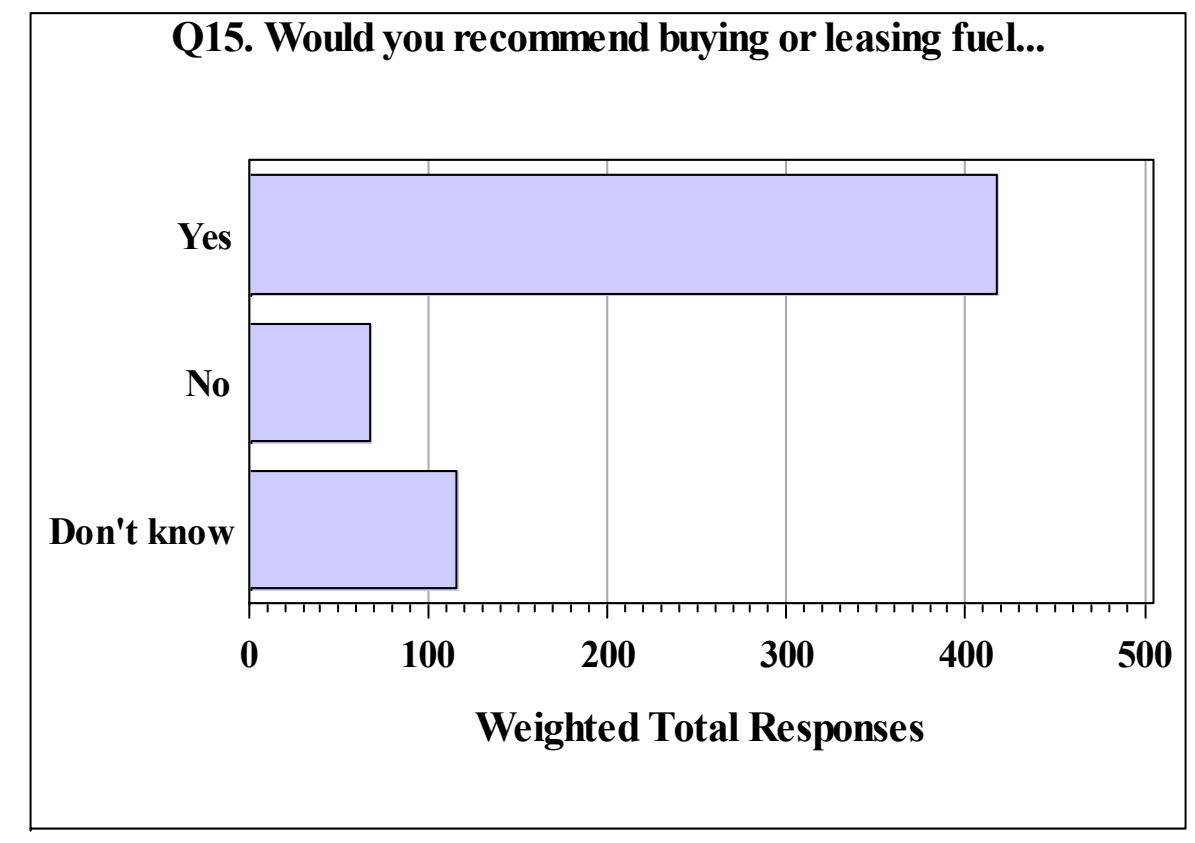

Figure 7.6. Share of respondents who would recommend purchasing a fuel cell vehicle for their organization's vehicle fleet if the cost were comparable to that of a gasoline vehicle, Question 15, end user survey.

End users were also asked whether they would recommend buying a stationary fuel cell to help with the power needs of their facility or a stakeholder organization's facility if the stationary fuel cells were available at a cost competitive to traditional power systems. Over $82 \%$ of the respondents responded "Yes." The responses to this question are shown in Figure 7.7. 


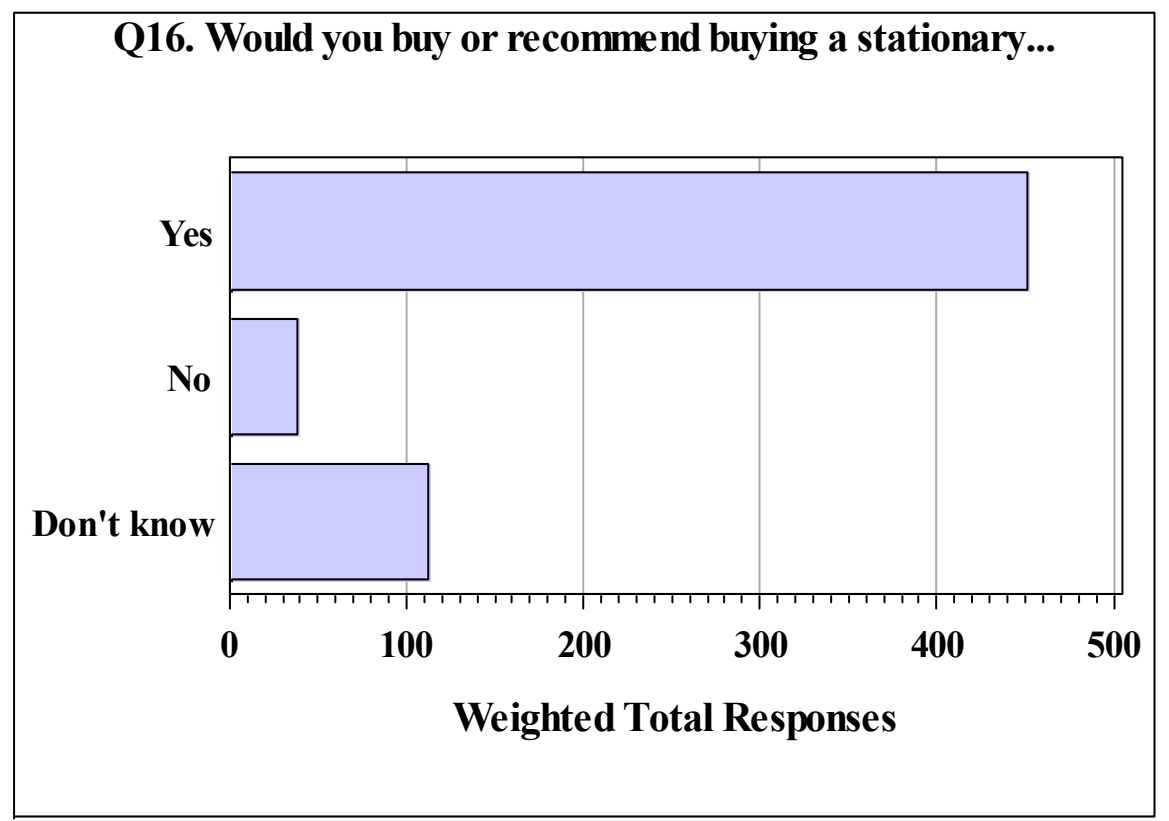

Figure 7.7. Share of respondents who would recommend purchasing a stationary fuel cell to help meet the power needs of their facility if the cost were comparable to that of traditional power systems, Question 16, end user survey.

End users were next asked a similar question (Question 17) about the use of hydrogen and fuel cell technologies to meet their organization's energy needs, though in this case, the relative costs of traditional technologies were not considered as part of the question. In this case the most frequent (47.7\%) response is "wait to see how the market develops" (Figure 7.8).

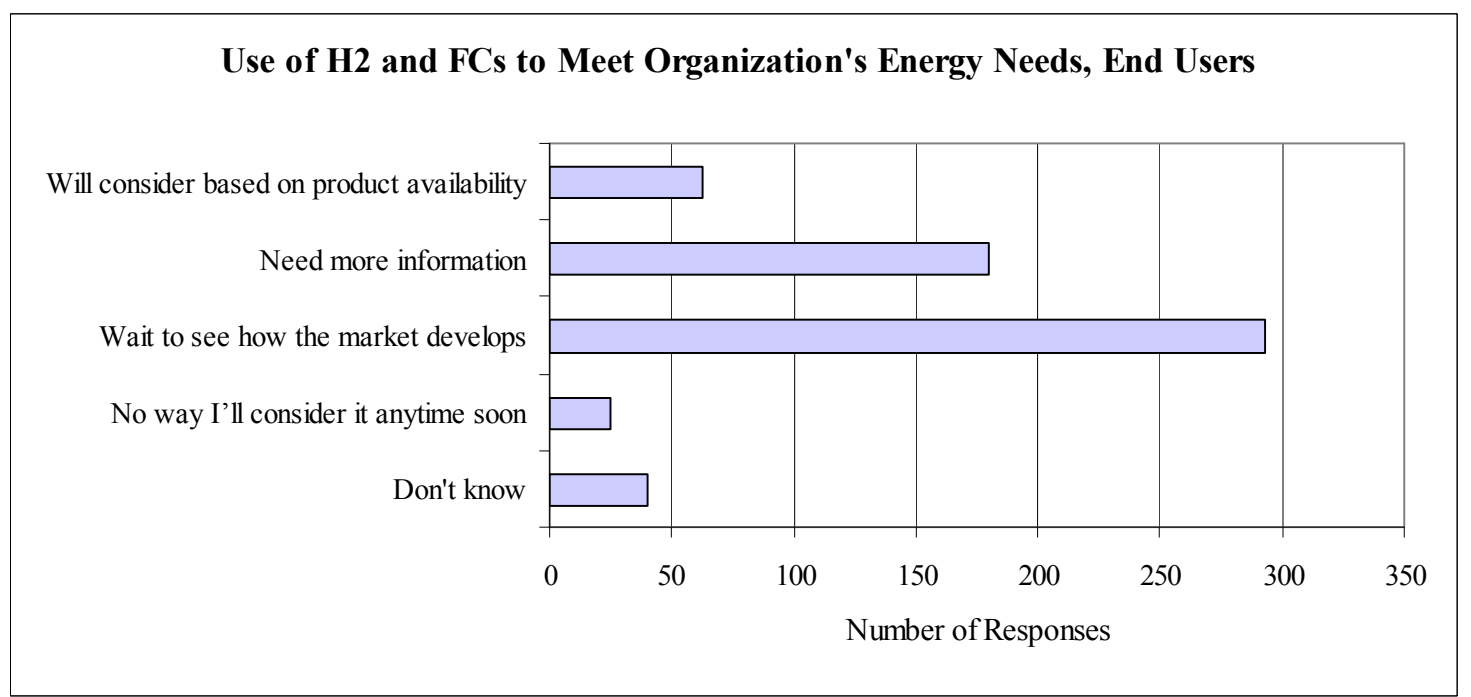

Figure 7.8. Opinions of end users about using hydrogen and fuel cell technologies to meet their organization's energy needs, Question 17, end user survey. 
Two statements were read in order to obtain opinions about potential benefits of using hydrogen as a vehicle fuel. Respondents were asked whether they agreed or disagreed with the statements. Responses (Figure 7.9) indicated that about $80 \%$ of the end users agreed with the two statements about the benefits of hydrogen usage.

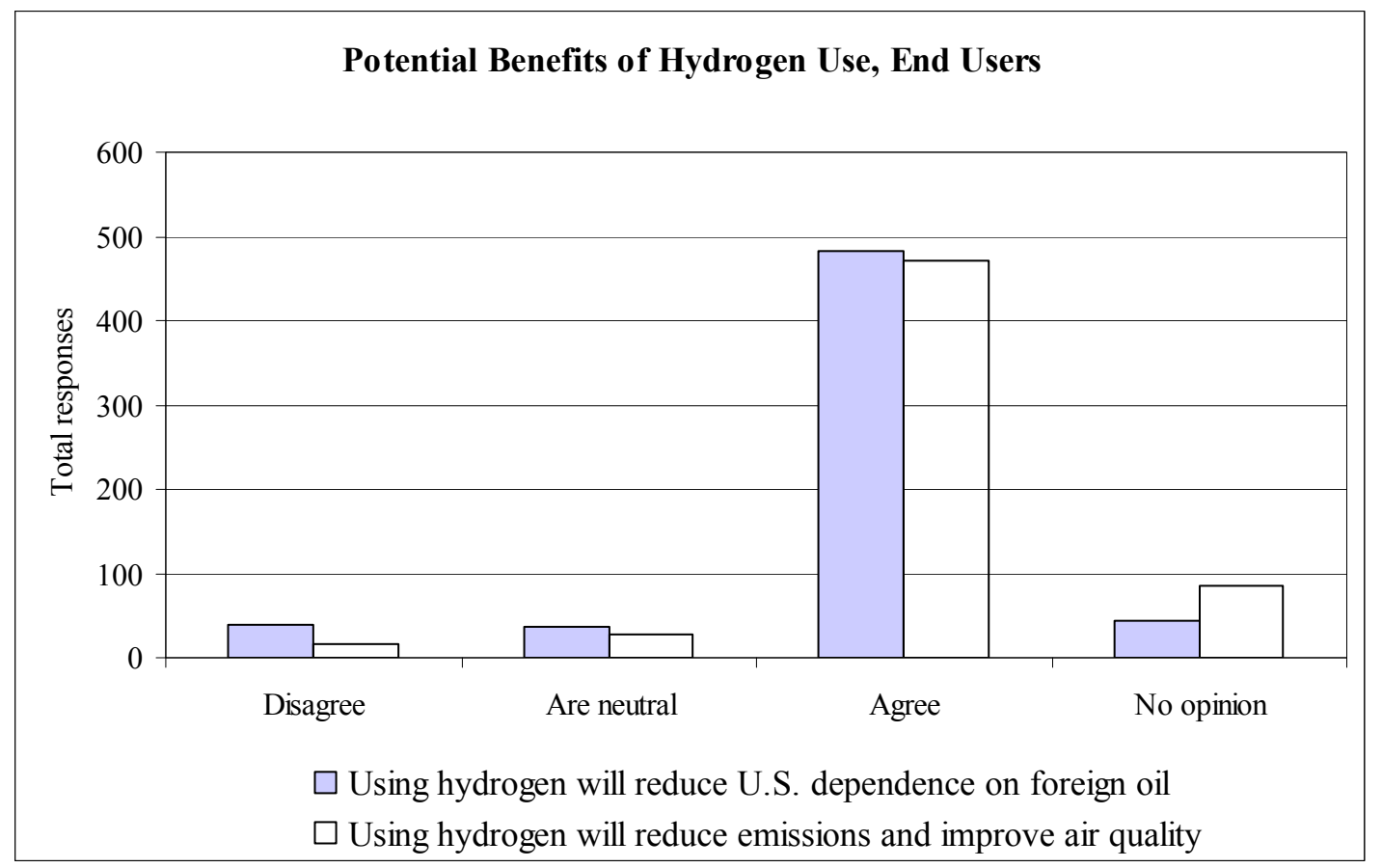

Figure 7.9. Responses to statements about the potential benefits of the use of hydrogen as a vehicle fuel, Questions 13A (Using hydrogen will reduce U.S. dependence on foreign oil) and 13B (Using hydrogen will reduce emissions and improve air quality), end user survey.

Several questions addressed interviewee perceptions regarding the safety of hydrogen and fuel cells. Figure 7.10 shows the responses graphically for the survey question about the safety of hydrogen relative to gasoline and diesel (survey Question 13C). As shown in this figure, over half of all respondents agreed that hydrogen is as safe to use as gasoline and diesel fuels.

Respondents were asked how they would feel if their local gas station also sold hydrogen. Almost half (48.9\%, Appendix C.4) said they would be pleased. Figure 7.11 shows their responses to this question. 


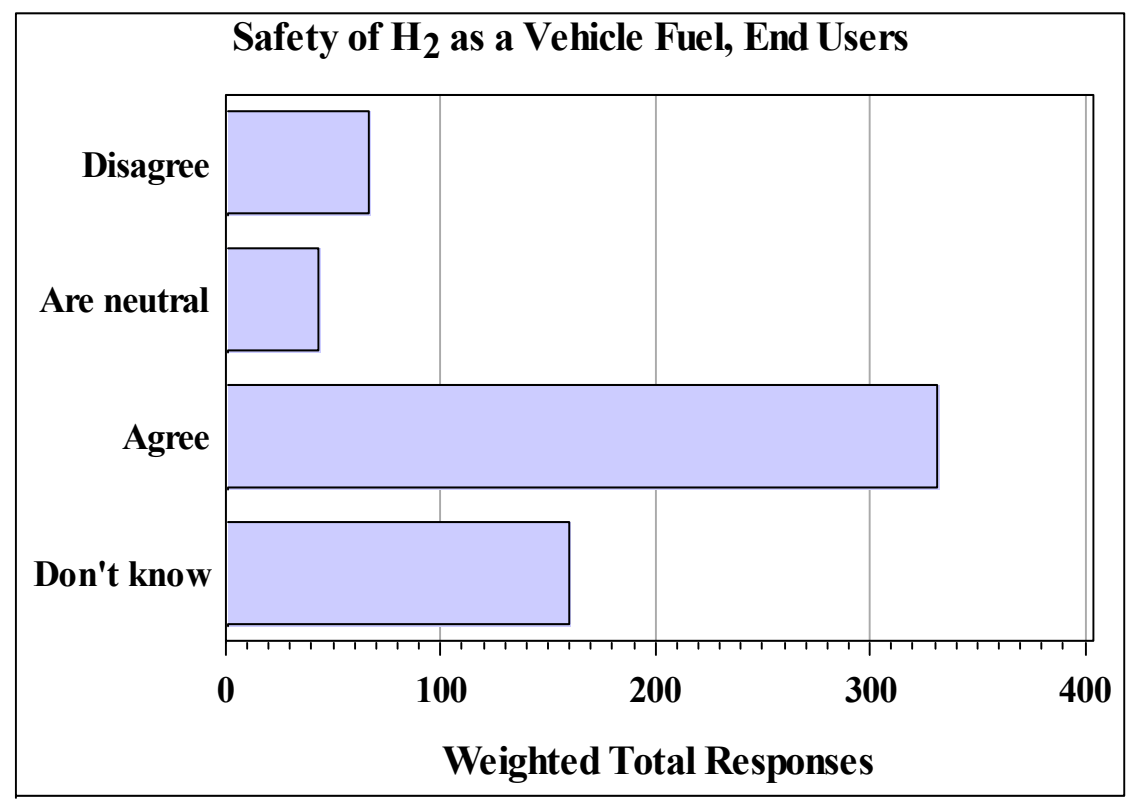

Figure 7.10. Responses to the statement, "Hydrogen is as safe to use in my car as gasoline and diesel fuels," Question 13C, end user survey.

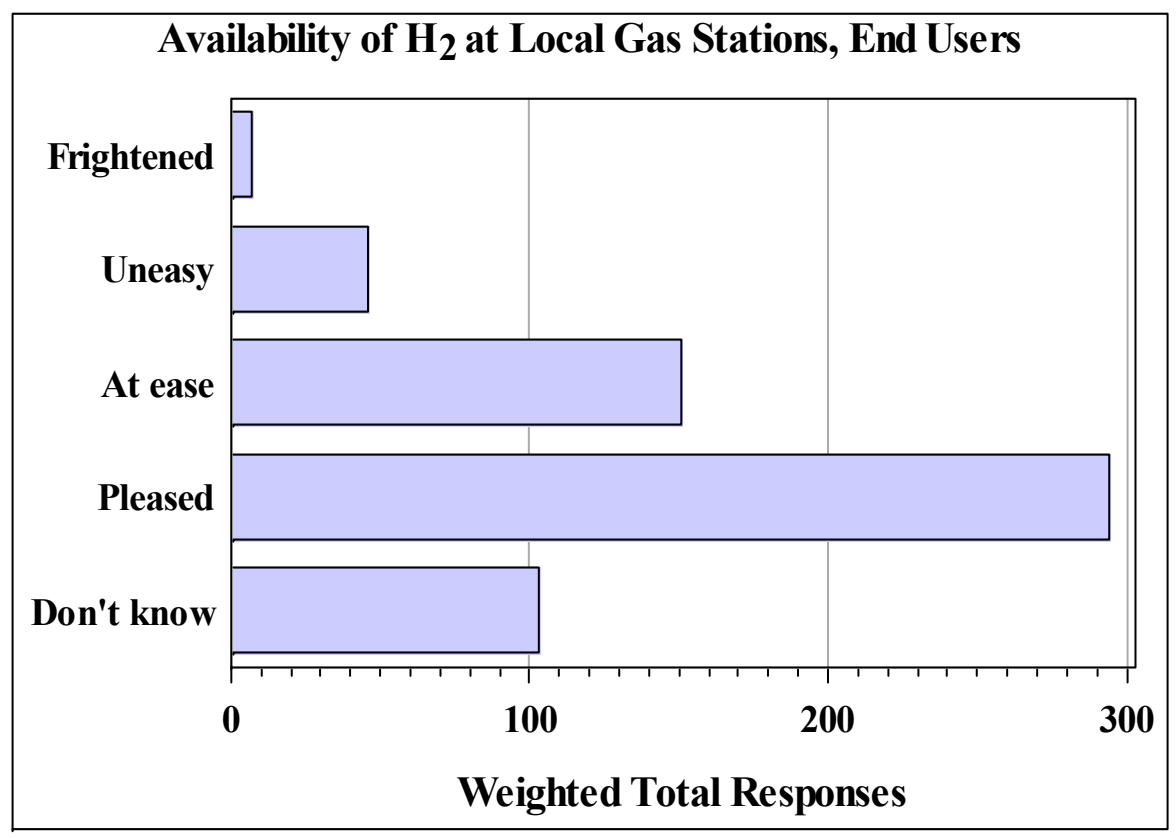

Figure 7.11. Reactions to the possibility of sales of hydrogen at a local gas station, Question 11, end user survey. 
When asked their opinions on the safety of hydrogen for everyday use by the general public, most end users indicated that they thought hydrogen was safe for usage (Figure 7.12).

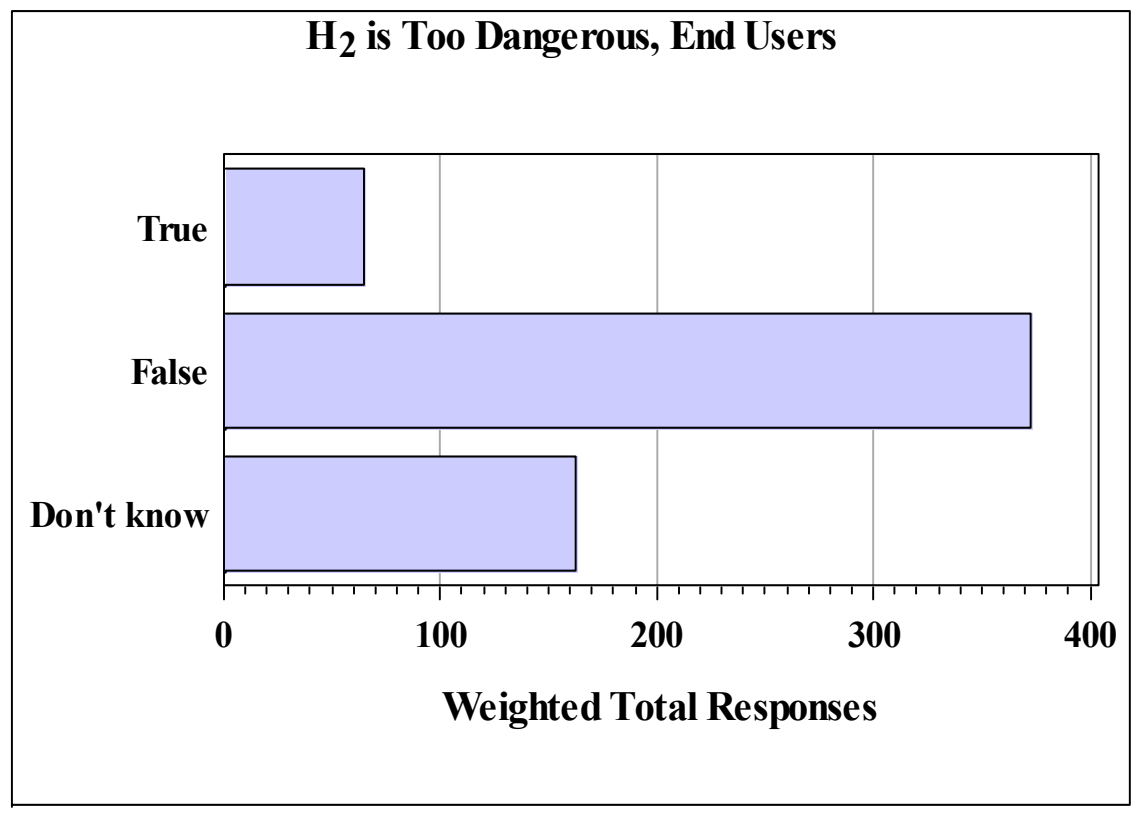

Figure 7.12. Reactions to the statement, "Hydrogen is too dangerous for everyday use by the general public," Question 12, end user survey.

Respondents to the end user survey were asked two questions about information sources. Question 18 asked about the frequency of use ("Never," "Sometimes," "Frequently") of information sources to make decisions about energy costs and safety. As shown in Figure 7.13, the sources marked "Frequently" most often were utility companies or brokers and industry or trade associations or non-profit organizations. Federal and State government sources and environmental groups were noted as "Sometimes" and "Frequently" used by a large percentage of respondents. The sources of information that received the greatest number of "Never" responses were teachers and schools, friends and family members, and local government agencies. These responses were very similar to those recorded in the 2004 survey.

Question 19 also asked about information sources, but from the perspective of media sources, that is, information vectors (television, radio, internet, etc.) for obtaining energy information. As shown in the Figure 7.14, respondents indicated that they rarely used the radio to obtain energy information; their most frequent media sources for obtaining energy information were the Internet and trade magazines. 


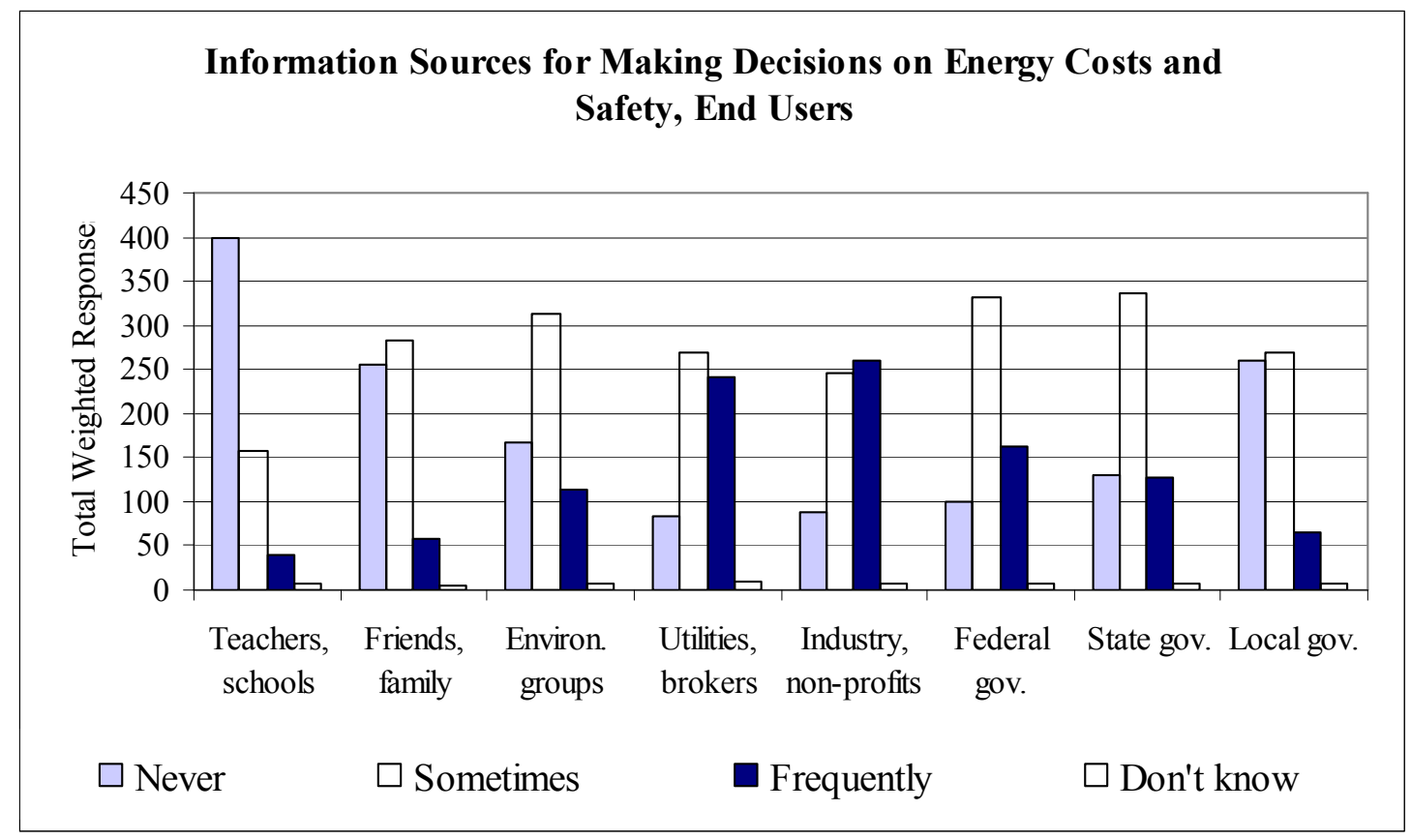

Figure 7.13. Weighted counts of responses regarding the frequency of use of information sources when making decisions about energy costs and safety, Question 18, end user survey.

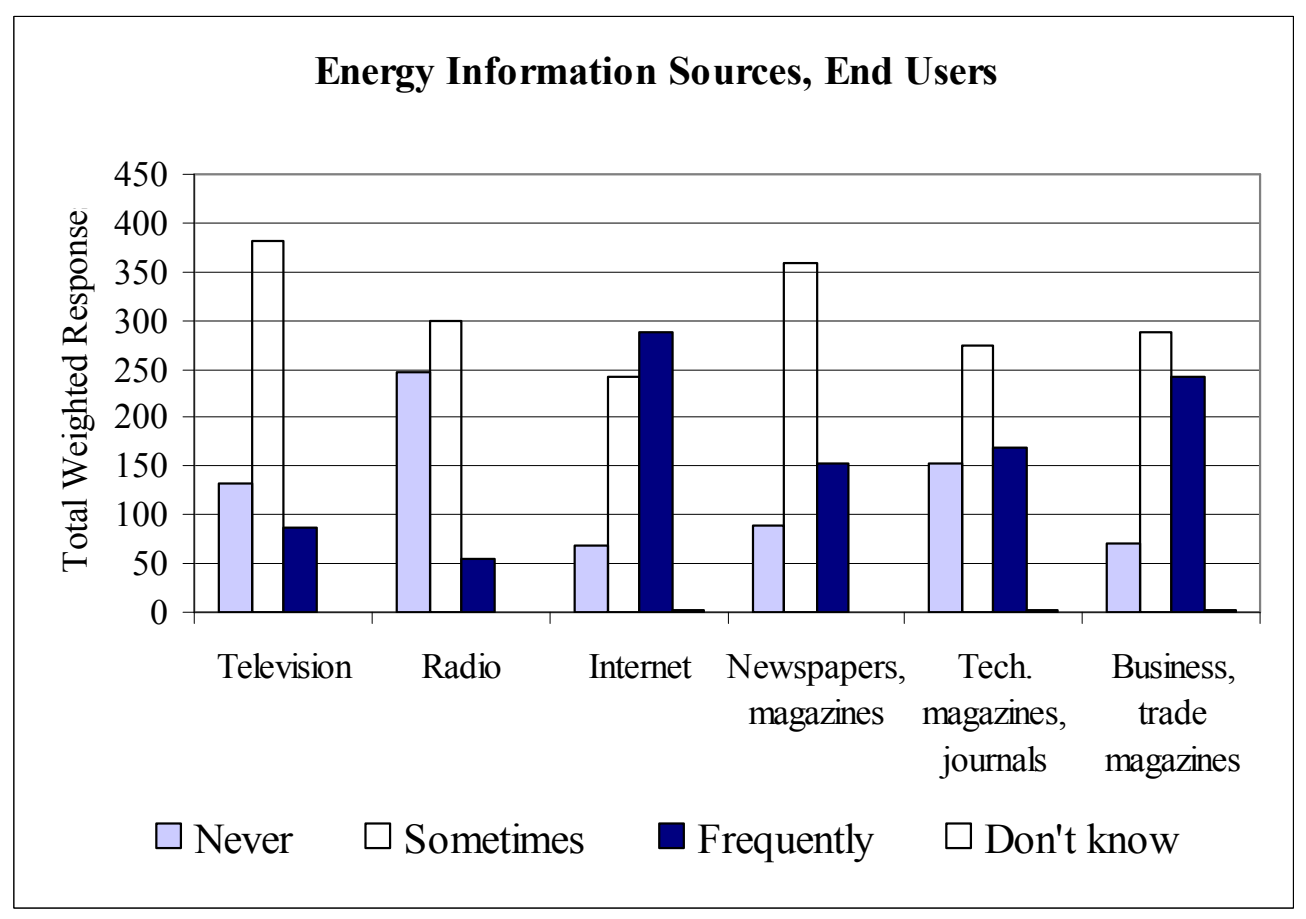

Figure 7.14. Weighted counts of responses regarding the frequency of use of different types of mass media for obtaining energy information, Question 19, end user survey. 
End users were asked several questions on whether they had received specific information or training on hydrogen and/or fuel cell technologies. Figure 7.15 shows the responses to these questions. Only $29.5 \%$ of end user respondents had received information at their workplace, and $70.7 \%$ of the respondents indicated that training would be helpful.

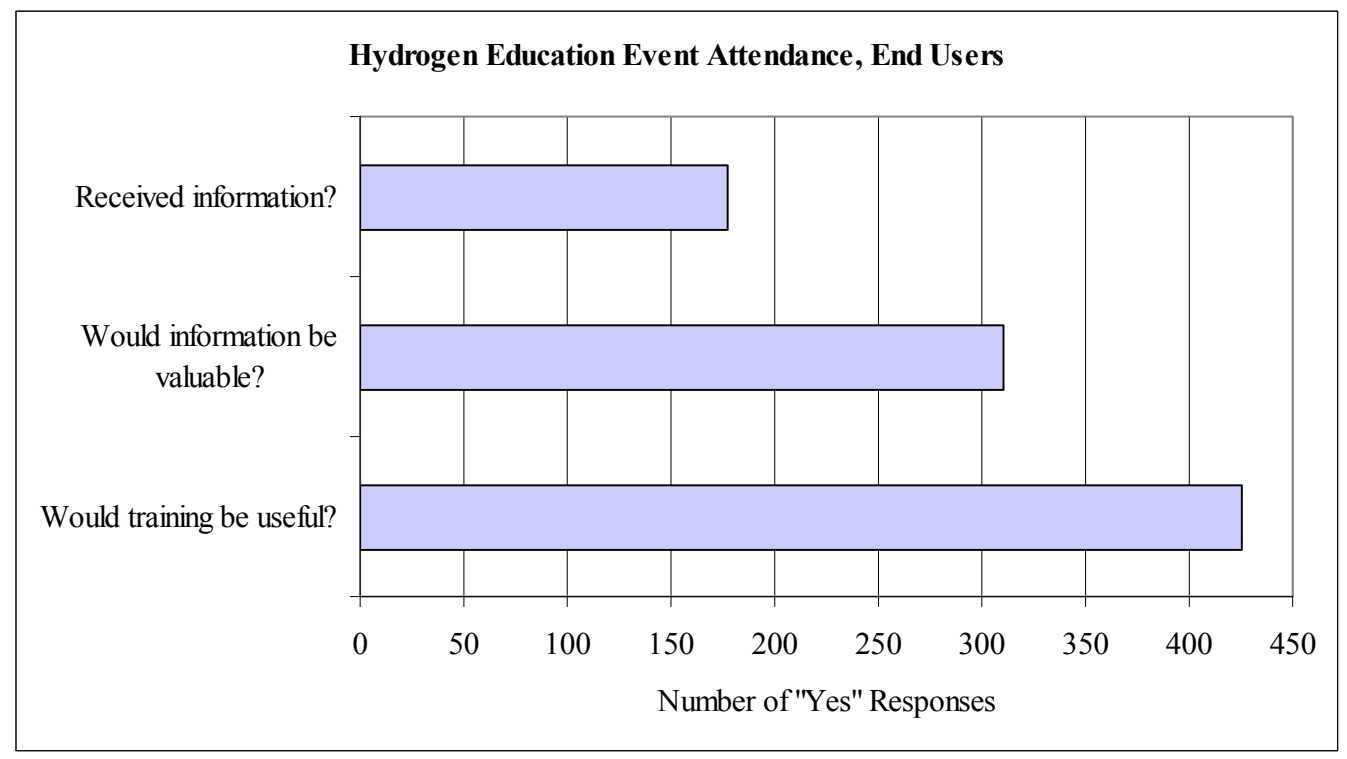

Figure 7.15. Number of "Yes" responses to Questions 20-22 concerning receiving information about hydrogen and/or fuel cells and the desire to attend a class, end user survey.

\subsection{RELATIONSHIPS}

The summary statistics in Section 7.2 are "one-way" statistics in the sense that the response categories are defined in terms of one variable such as response to an opinion question (e.g., Question 13C, "Hydrogen is as safe to use in my car as gasoline and diesel fuels"). However, relationships in the responses determined by two or more variables may also be of interest. Although no relationships were of particular interest a priori, in this section a few of the more statistically significant ones are illustrated. Interactions that were considered were with the survey variables and sex, region, urban/non-urban, familiarity with hydrogen and whether or not the score on the technical questions was above the average for the sample. The statistical significance criterion is the significance level (p) of a chi-square test that accounts for the sampling weights. ${ }^{44}$

As shown in Figure 7.16, respondents who scored below average on the technical questions were more likely to assess their familiarity as "Not at all familiar" or "Slightly familiar," and respondents who scored above average were more likely to claim a higher familiarity with

\footnotetext{
${ }^{44}$ Measures could also be based on odds ratios or combinations of odd ratios and significance levels as well as other metrics. Significance levels alone were used for simplicity and because sample sizes are essentially the same for all survey questions.
} 
hydrogen and fuel cell technologies. Thus, the familiarity self-assessments are consistent with the technical awareness scores.

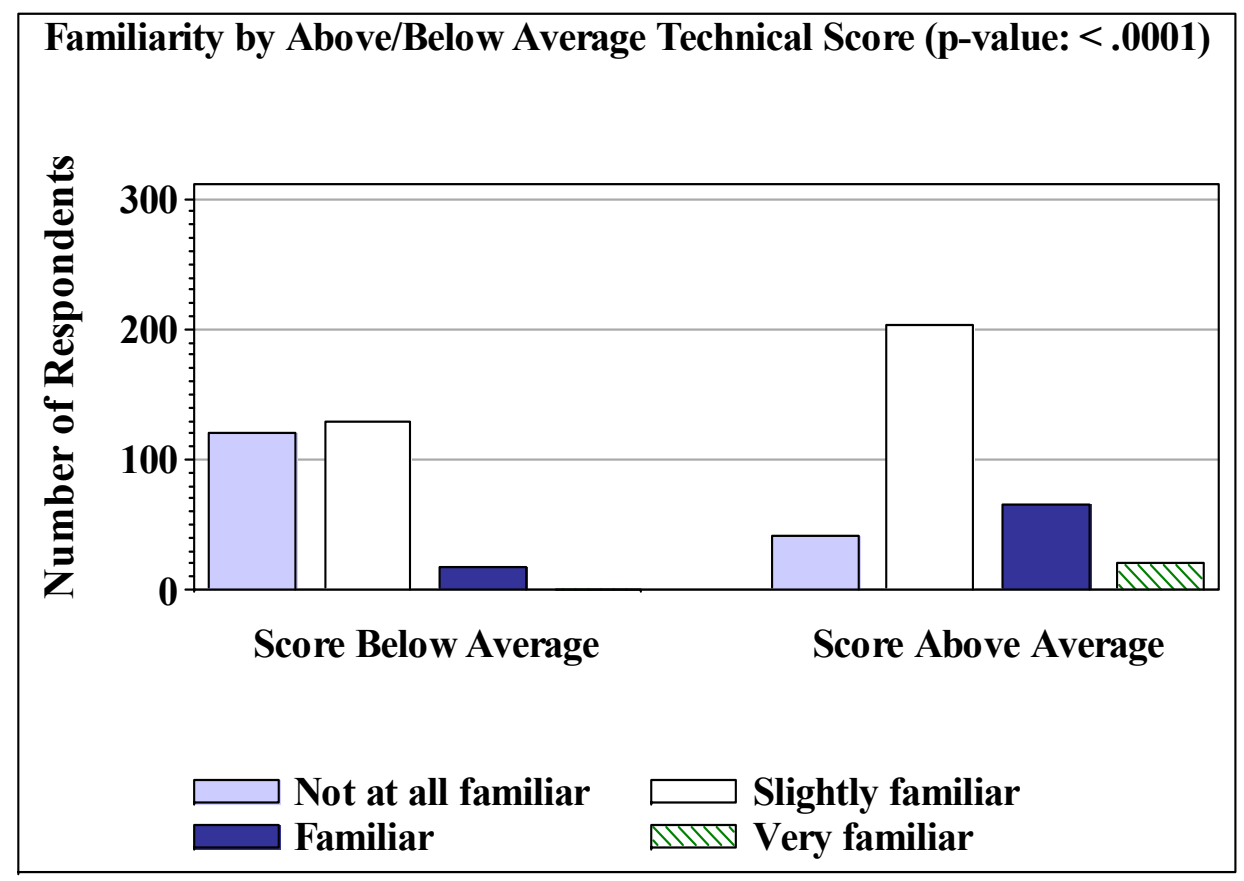

Figure 7.16. Responses by technical score above/below average to Question 1 (familiarity of respondents to hydrogen and fuel cell technologies), end user survey.

Respondents who knew more about hydrogen (i.e., who answered more technical questions correctly) were much more likely to agree with the statement "Hydrogen is as safe to use in my car as gasoline and diesel fuels." As shown in Figure 7.17, respondents with a score below average on the technical questions were most likely to express "No opinion" to this statement.

In the end user survey, males were much more likely to agree with the statement that "Hydrogen is as safe to use in my car as gasoline and diesel fuels." ${ }^{45}$ Figure 7.18 shows that females were more likely to express "No opinion" to this statement.

End users who considered themselves as "Slightly familiar" or "Familiar" with hydrogen and fuel cell technologies were highly likely to believe that hydrogen is safe for everyday use by the general public, as shown in Figure 7.19.

When asked for an opinion about the statement "Using hydrogen will reduce emissions and improve air quality," there was a statistically significant $(p<0.0001)$ difference in the responses of male and female respondents. Male end users were much more likely to agree with the statement; females were more likely to respond "Don't know" (Figure 7.20).

\footnotetext{
${ }^{45}$ Note that the end user survey sample consisted for 519 males and 82 females. Males constituted $86 \%$ of the survey sample.
} 


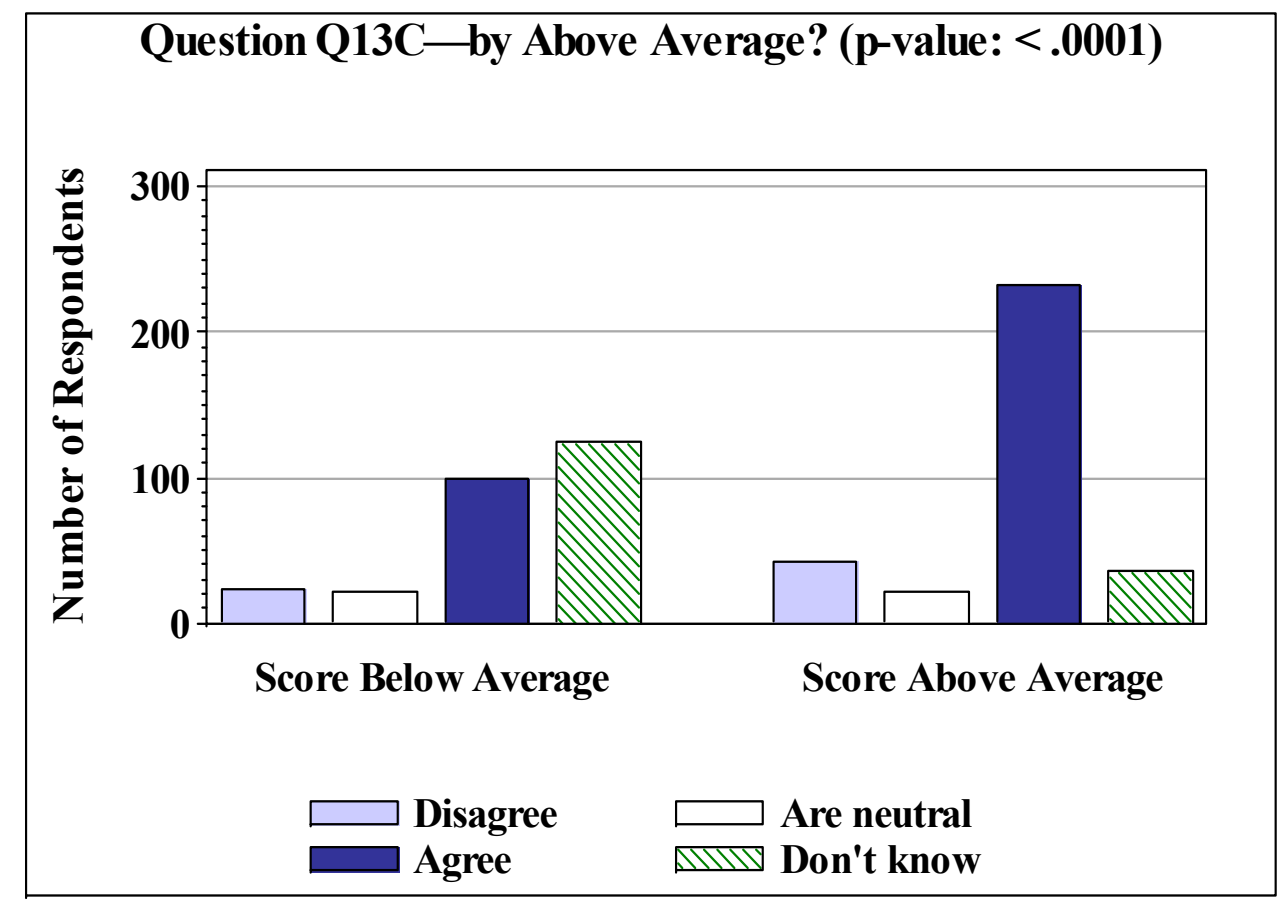

Figure 7.17. Responses by technical score above/below average to Question 13C, "Hydrogen is as safe to use in my car as gasoline and diesel fuels," end user survey.

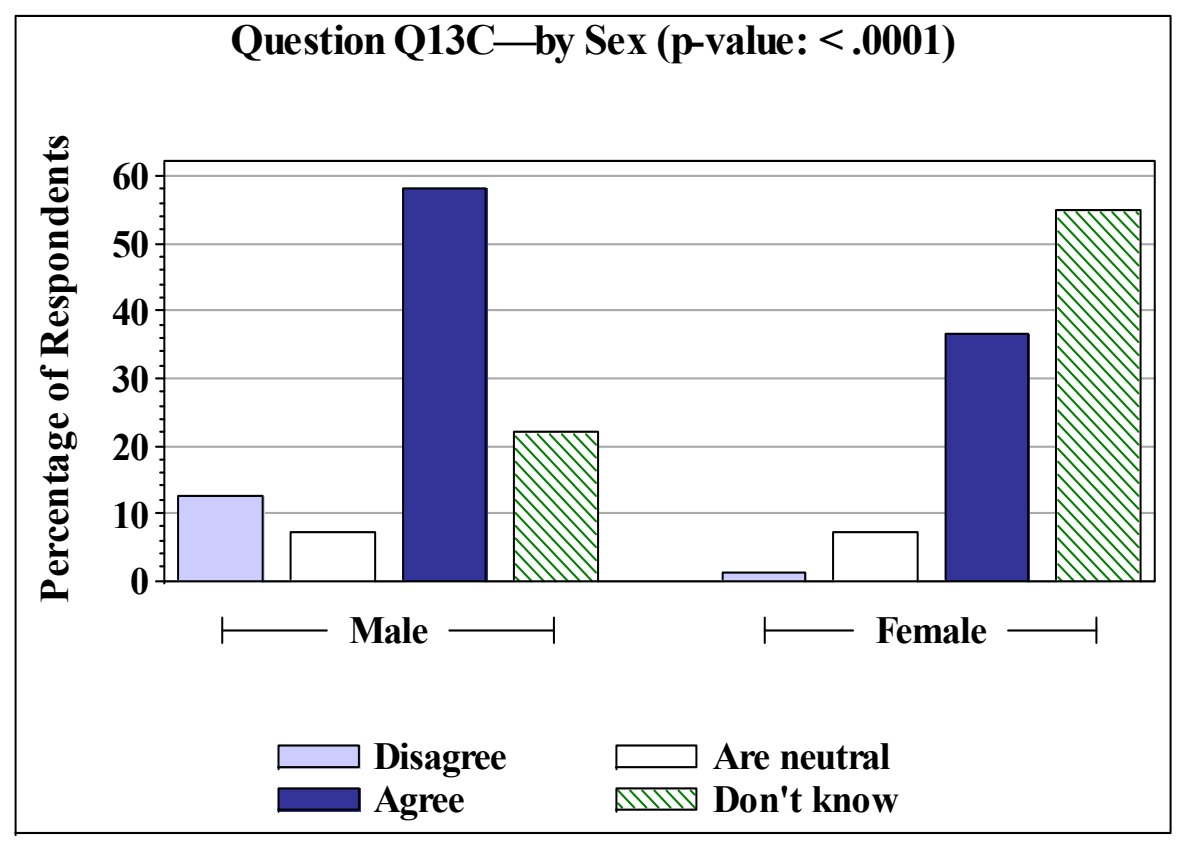

Figure 7.18. Percent of responses by gender to Question 13C, "Hydrogen is as safe to use in my car as gasoline and diesel fuels," end user survey. 


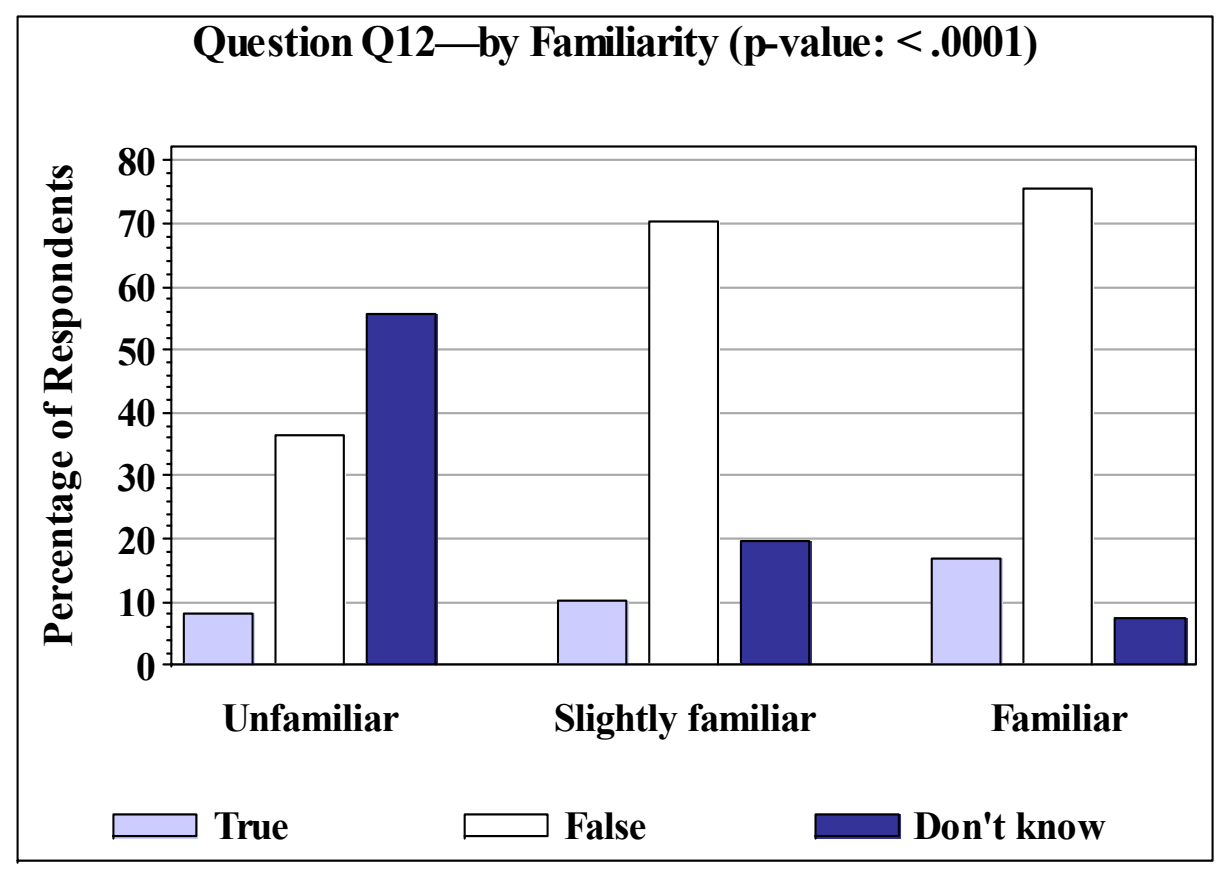

Figure 7.19. Percent of responses by familiarity to Question 12, "Hydrogen is too dangerous for everyday use by the general public," end user survey.

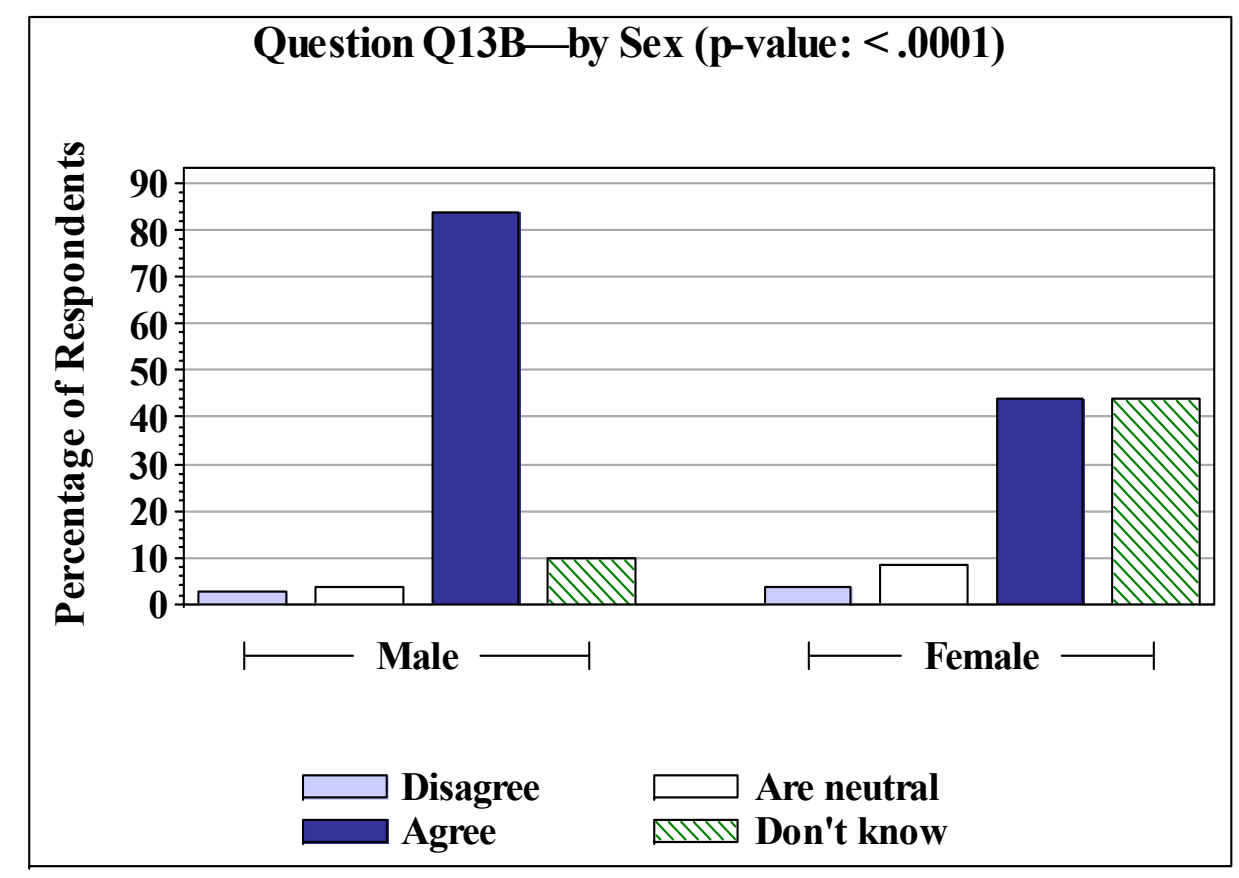

Figure 7.20. Response percentages by gender to Question 13B, "Using hydrogen will reduce emissions and improve air quality," end user survey. 
Figure 7.21 shows the frequencies of business categories (transportation users, users needing an uninterrupted power supply, users with large power requirements) for respondents with fewer than three and with three or more correct answers to the eight technical questions. The distribution of correct/incorrect technical responses over the three sectors is fairly equal except that respondents in the lower scoring group were more likely to be from the transportation sector. In the 2004 survey, lower scores were more likely to be from the uninterrupted supply category.

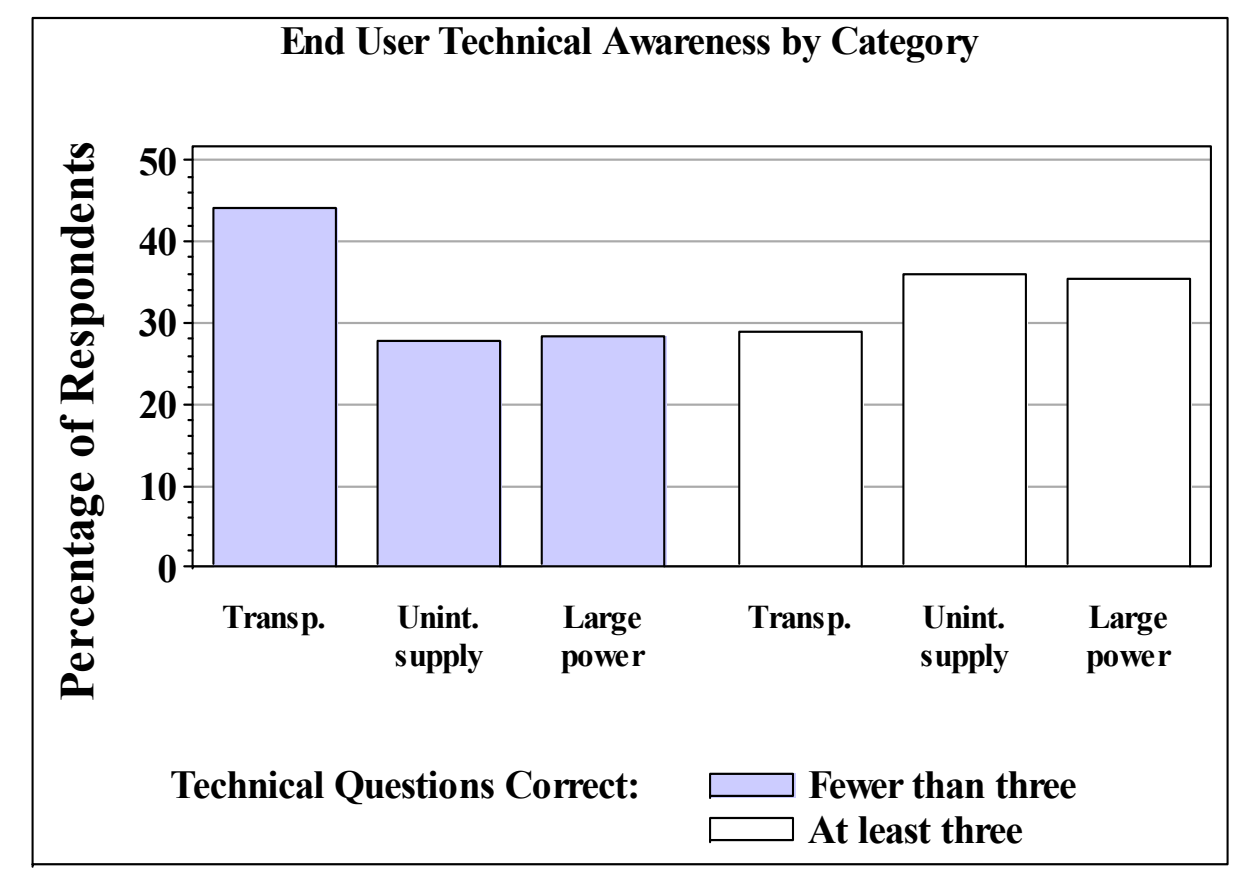

Figure 7.21. Business categories of the end user respondents who correctly answered fewer than three and at least three of the eight technical questions, end user survey.

Figure 7.22 shows responses to "How would you feel if your local gas station also sold hydrogen?" for respondents with fewer than three or at least three correct answers to the technical questions. This chart clearly shows that respondents that answered fewer than three questions correctly were much less likely to be "Pleased" and much more likely to select "Don't know" in response to this question. 


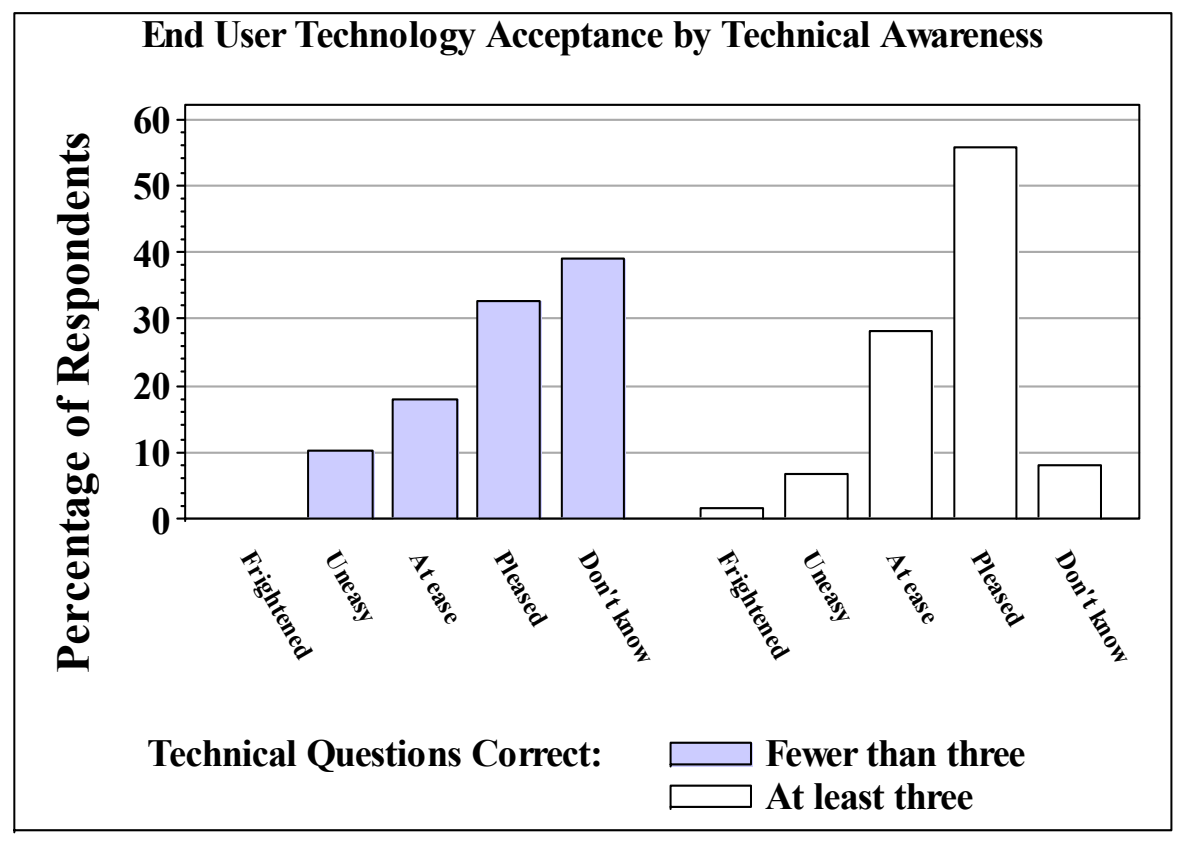

Figure 7.22. Response percentages to "How would you feel if your local gas station also sold hydrogen" by whether or not respondents correctly answered at least three of the eight technical questions, end user survey.

\subsection{COMPARISON WITH THE 2004 BASELINE}

A primary objective of repeating surveys over time is to compare survey results. Figure 7.23 shows the differences in the average technical scores for each of the eight technical questions on the survey. The overall average technical score in 2008 was $47.9 \%$ correct responses; in 2004 the average score was $46.3 \% .{ }^{46}$ Respondents in 2008 had higher average scores overall and on every individual question except Question 7, which concerned states or conditions in which hydrogen could be stored. The differences were generally small, however, and none were statistically significant. ${ }^{47}$

Several questions in the survey concerned safety issues and the use of hydrogen. Changes in the opinions of potential end users toward hydrogen safety are shown in the next three figures. Although the three figures all reflect a trend toward slightly more positive perceptions about hydrogen technology, only the last of the three (Figure 7.26) reflects statistically significant changes since 2004 .

\footnotetext{
${ }^{46}$ This is the 2004 percentage of correct responses to the technical questions asked both in 2004 and 2008. For all eleven of the technical questions that were asked originally in 2004, the percentage correct was $44.4 \%$.

${ }^{47}$ Although the 2008 end user survey had 601 respondents, the 2004 end user survey had only 99 . As the differences here are subject to the statistical error in both surveys, the confidence limits for the differences are much wider than for any of the other survey components.
} 


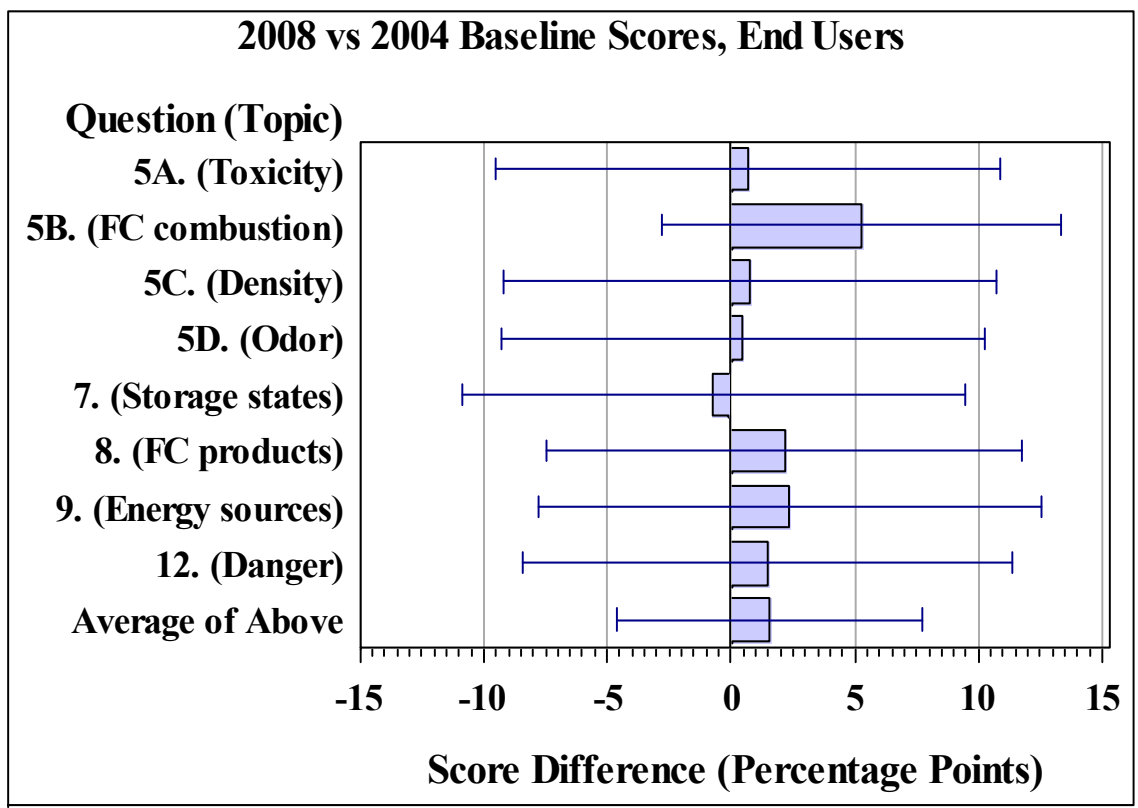

Figure 7.23. Differences between the 2008 and 2004 average percentage correct for each technical question and overall, end user survey. Bars to the right of zero show improvement in 2008. The error bars are $95 \%$ confidence intervals for the differences.

Figure 7.24 shows changes in opinions about the everyday use of hydrogen.

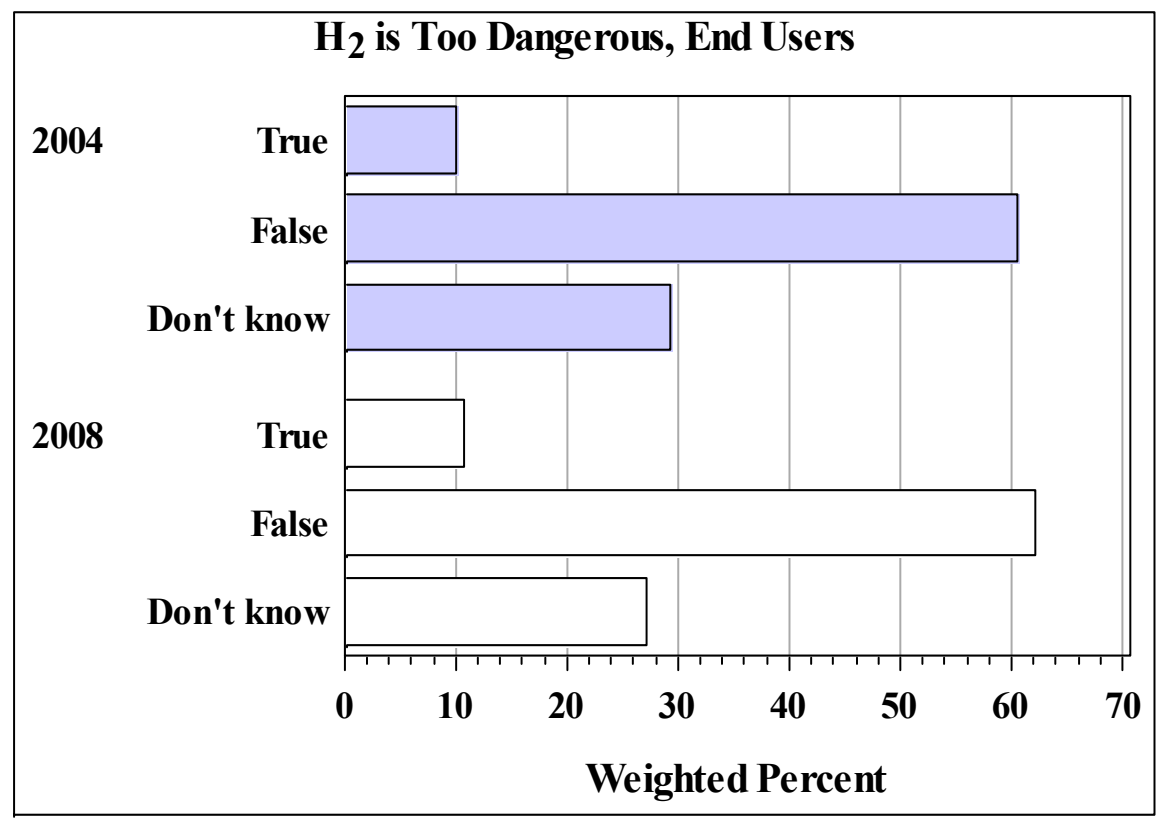

Figure 7.24. Comparisons of results of the 2004 and 2008 surveys regarding the statement, "Hydrogen is too dangerous for everyday use by the general public," Question 12, end user survey. 
Another question examined opinions about the safety of hydrogen in vehicles. As shown in Figure 7.25, opinions about the use of hydrogen as a vehicle fuel changed only slightly between 2004 and 2008. Over 50\% of respondents agreed that the fuel is safe, but about $10 \%$ disagreed.

Another question was about the comfort level of end users with the sale of hydrogen at their local gas station. Figure 7.26 compares the results of the 2004 and 2008 surveys to this question. The number of end users that said they would be "Pleased" increased from $32.3 \%$ to $48.9 \%$. This difference is statistically significant $(p=0.0009)$. (The percentages responding that they were either frightened or uneasy also increased slightly, however.)

The sources used by end users to obtain energy information as recorded by the 2008/2009 survey were similar to those used in 2004, with two exceptions: radio and Internet usage. In 2004, $60 \%$ of end users indicated that they "Never" used the radio to obtain energy information; in the current survey, only $41 \%$ said they "Never" use the radio. In 2004, over a fourth of the respondents indicated that they "Never" used the Internet; however, in 2008/2009, only 11\% indicated they "Never" use the Internet and 48\% indicated that they use it "Frequently." (See entry Q11 in Appendix C.4 and the entry for Question 13e in Appendix C.4 of 2004 report.)

End user plans for using hydrogen and/or fuel cell technologies in the future have changed slightly. In 2004, 8\% indicated their agency had plans for future use, 63\% indicated "No," and $29 \%$ responded "Don't know." In 2008/2009, 14\% had implementation plans, 63\% indicated "No," and 23\% responded "Don't know." In 2004, only 99 end user respondents were interviewed; in 2008/2009, 600 end users were interviewed. Table 7.2 compares the differences in terms of percentage of respondents who indicated their agency had plans for future implementation.

Finally, there was a large drop in the response rates for the end user population - from 0.2914 in 2004 to 0.1701 in $2008 / 2009$.

\begin{tabular}{|l|c|c|}
\hline \multicolumn{3}{|c|}{ Table 7.2. Time frames for Implementation for End Users Planning to Use } \\
Hydrogen or Fuel Cells in the Future
\end{tabular}




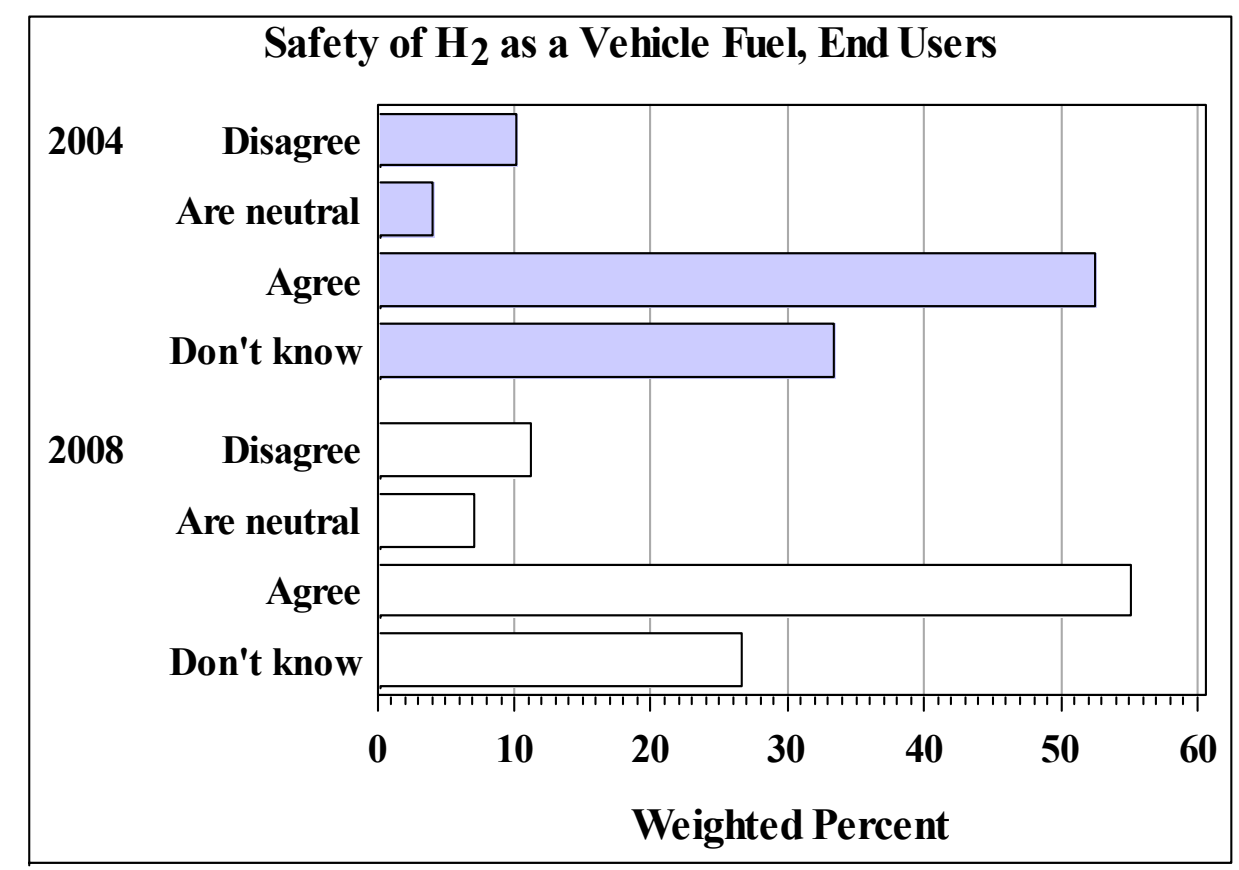

Figure 7.25. Comparisons of results of the 2004 and 2008 surveys regarding opinions about the safety of hydrogen as a vehicle fuel, Question 13C, end user survey.

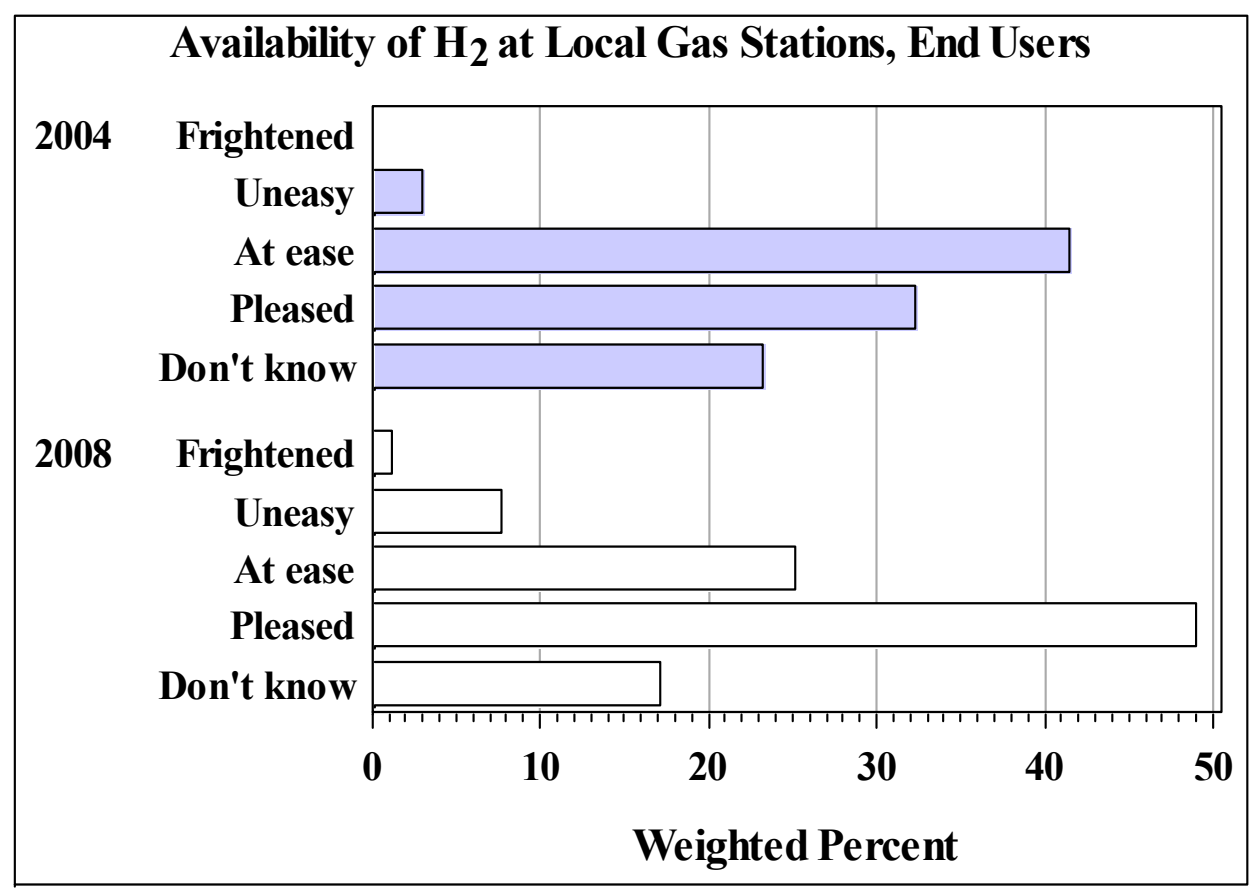

Figure 7.26. Comparisons of results of the 2004 and 2008 surveys regarding opinions about the availability of hydrogen at a local gas station, Question 11, end user survey. 


\section{RESULTS: SAFETY AND CODES OFFICIALS SURVEY}

\subsection{INTRODUCTION}

This section summarizes the results of the survey of safety and codes officials. A copy of the survey questionnaire is in Appendix A.5. A master list of 193 potential respondents was compiled; the master list contained contact information from four groups: International Association of State Fire Chiefs (IAFC), 50 contacts; International Code Council (ICC), 49 contacts; National Association of State Fire Marshalls (NASFM), 50 contacts; and National Fire Protection Association (NFPA), 44 contacts. A total of 149 interviews were completed during the period of May 27-June 26, 2009. The total average interview length was 17 minutes, broken down into a screening time of 3 minutes and a main interview length of 14 minutes. A summary of responses to this survey, by question number, is provided in Appendix C.5.

To improve survey response rates, the DOE FCT office sent letters to the individuals on the master list telling them about the survey and encouraging their participation. A copy of this letter is provided in Appendix D.2.

Section 8.2 is a general summary of the responses of the safety and codes officials. Relationships between the response variables are discussed in Section 8.3. There was no survey of safety and codes officials in 2004; therefore, the 2008/2009 survey results are the baseline for this population.

For the sake of simplicity, the responses "Don't know," "No opinion," and "Don't know/no opinion" are all treated equivalently and generally as "Don't know" in this report.

The response rate for the 2008 End User Survey is discussed in Appendix E.5. The response rate is $77.2 \%$. Had the entire target population been sampled (100\% response), there would be no statistical sampling error in the survey estimates. The response rate is less than perfect, however, and so estimates computed from this data are subject to error. As an approximation, this error is handled as sampling error in the data analysis. Because the sample is nearly complete, finite population correction factors ${ }^{48}$ are applied in the analysis with the SAS surveymeans and surveyfreq procedures. ${ }^{49}$

\subsection{SUMMARY}

The section summarizes the responses to the individual questions in the safety and codes officials survey. Most of the questions are summarized as proportions of respondents in each of the respective multiple choice categories. Preference ranks are summarized as means. Answers to the technical questions are summarized individually and are also compiled into an overall technical score. Relationships between responses to different questions are considered in Section 8.3.

\footnotetext{
${ }^{48}$ Cochran, William G., Sampling Techniques, Third Edition, John Wiley \& Sons, Inc., New York, 1977, p. 24.

${ }^{49}$ SAS Institute, SAS/STAT 9.1 User's Guide, SAS Institute, Inc., Cary, North Carolina, 2004, p. 165.
} 
Table 8.1 summarizes the technical questions in terms of whether they were answered correctly or incorrectly with "Don't know" treated as an incorrect response. Confidence intervals for the percentages of correct responses reflect statistical error due to nonresponse, under the assumption that nonresponse is random.

The greatest percentage of correct responses is 73.8\%, for Question 9 (Hydrogen is too dangerous), followed by $73.2 \%$ for Question 2C (Hydrogen is lighter than air...). The smallest percentage of correct responses is $20.1 \%$, for Question 2B (Fuel cells produce electricity through...) followed by $36.2 \%$ for Question 5 (When using pure hydrogen...).

\begin{tabular}{|l|r|r|r|r|}
\hline \multicolumn{1}{|c|}{ Table 8.1. Summary of Results on the Technical Knowledge Questions (correct/incorrect), } \\
Safety and Codes Officials
\end{tabular}

The correct/incorrect perspective used in Table 8.1 is conventional, since "Don't know" is generally considered an incorrect response. However, "Don't know" was a very common response to the survey technical questions. Figure 8.1 shows the responses broken down according to type: Correct, Incorrect, and "Don't know." On average, 51.5\% of the technical questions were answered correctly, 21.3\% were answered incorrectly, and $27.2 \%$ were answered with "Don't know." 


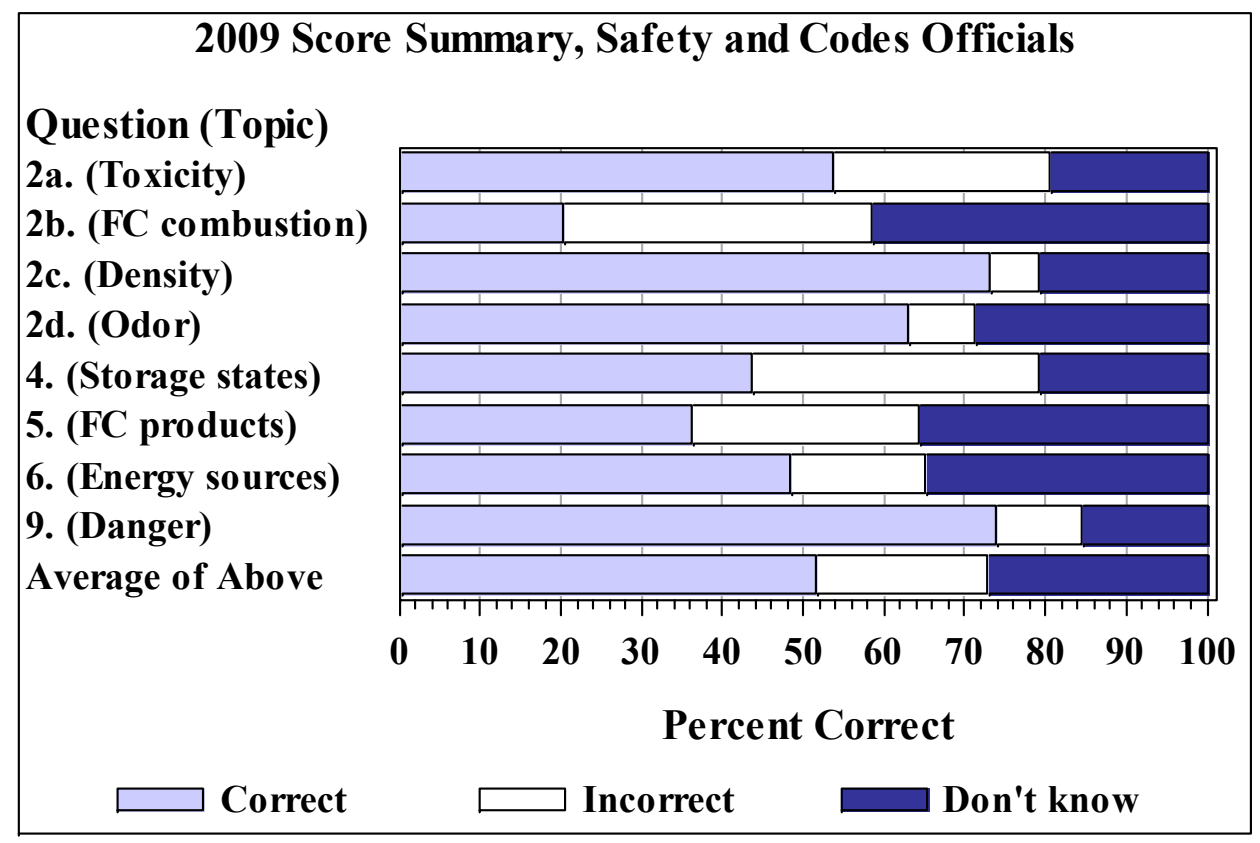

Figure 8.1. Weighted percent of correct, incorrect, and "Don't know" responses for the technical knowledge questions, safety and codes officials.

Figure 8.2 shows the distribution of the number of correct responses for the safety and codes officials survey. There were a few respondents with no correct answers and a few who answered all eight questions correctly. Most respondents answered between three and six questions correctly, and $45.6 \%$ of respondents had five or more correct answers. Comparison of Figure 8.2 with the corresponding figure for state and local government officials (Figure 6.2) shows that the government officials have a higher mean; however, the dispersions (standard deviations) are almost exactly the same. ${ }^{50}$

The first question in the survey asked respondents to gauge their familiarity with hydrogen and fuel cell technologies. Figure 8.3 shows the distribution of responses. Over $62.4 \%$ of all respondents considered themselves "Slightly familiar" with hydrogen and fuel cell technologies, and $22.1 \%$ considered themselves "Familiar."

The rank scores for the question asking respondents to rank the importance of safety, cost, environment, convenience, and performance (Question 7) are summarized in Table 8.2 as the averages of the ranks (1-5) assigned by each survey subject. Note that on the rank scale, 1 is higher (more important) than 2 , which is higher than 3 , etc. Thus, the lower the weighted average rank, the more important is the "Value." On average cost and safety were considered of essentially the same and of greatest importance, followed by convenience, performance, and the environment (with performance and the environment also essentially the same). Of course many individuals departed from this exact order.

\footnotetext{
${ }^{50}$ Mean \pm standard deviation for the two distributions are $5.33 \pm 1.97$ for the government officials and $4.12 \pm 1.95$ for the safety and codes officials.
} 


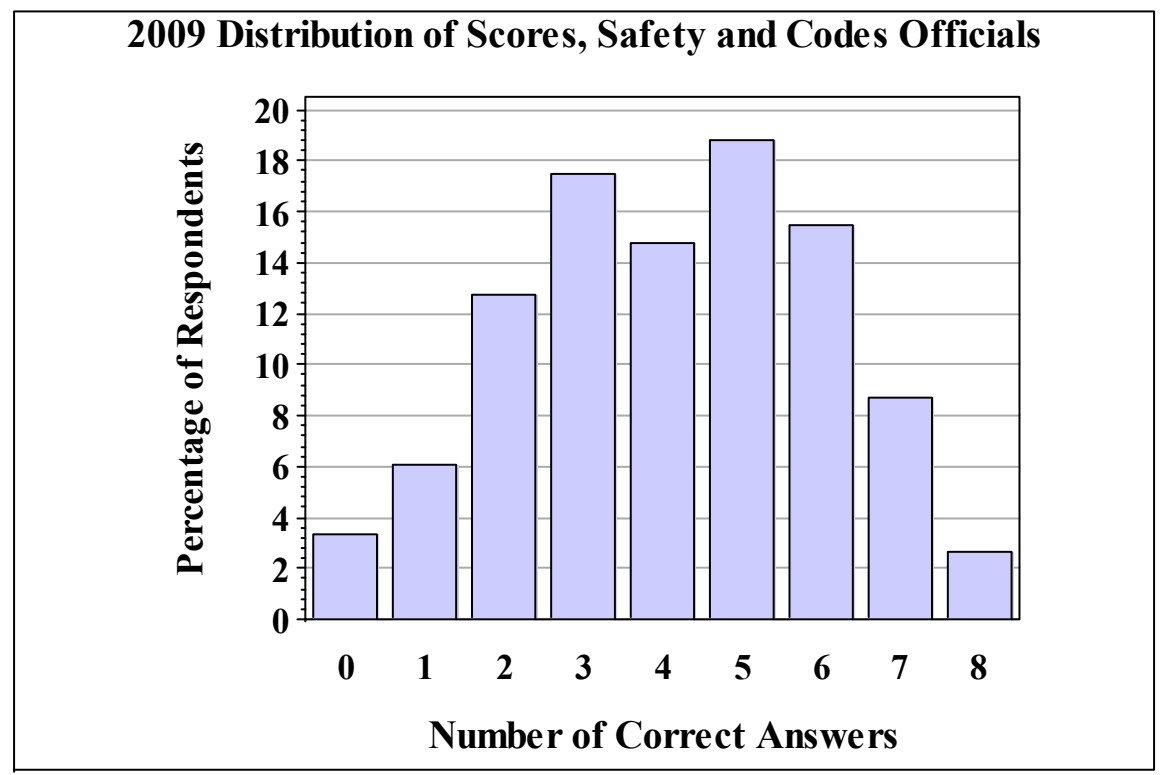

Figure 8.2. Distribution of the number of correct answers to the eight technical knowledge questions, safety and codes officials.

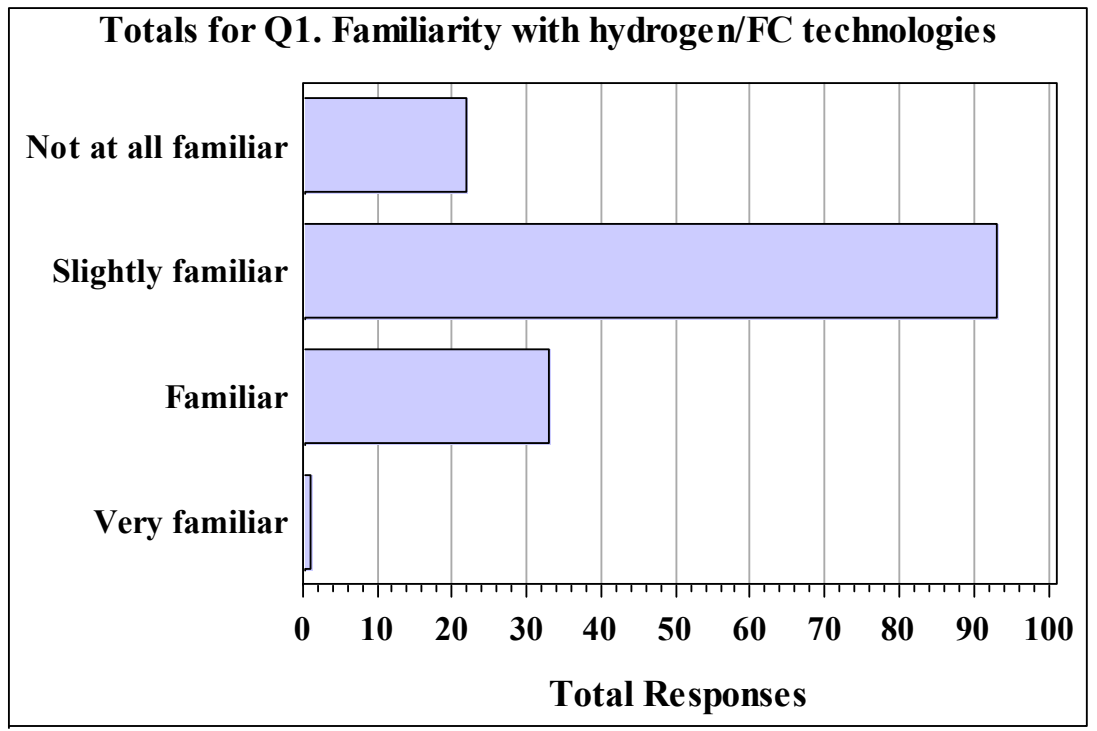

Figure 8.3. Distribution of responses to the question about familiarity with hydrogen and fuel cell technologies, Question 1, safety and codes officials. 


\begin{tabular}{|l|c|c|c|c|}
\hline \multicolumn{5}{|c|}{ Table 8.2. Summary of Importance Ranking, Safety and Codes Officials } \\
\hline Question & $\begin{array}{c}\text { Number of } \\
\text { responses }\end{array}$ & $\begin{array}{c}\text { Average } \\
\text { rank }\end{array}$ & $\begin{array}{c}\text { Lower 95\% } \\
\text { confidence } \\
\text { bound }\end{array}$ & $\begin{array}{c}\text { Upper 95\% } \\
\text { confidence } \\
\text { bound }\end{array}$ \\
\hline Cost & 148 & 2.26 & 2.17 & 2.35 \\
\hline Safety & 148 & 2.26 & 2.17 & 2.35 \\
\hline Environment & 148 & 3.70 & 3.59 & 3.80 \\
\hline Performance & 148 & 3.68 & 3.58 & 3.77 \\
\hline Convenience & 148 & 3.11 & 3.01 & 3.21 \\
\hline
\end{tabular}

Figure 8.4 illustrates the pattern shown in Table 8.2. The last ten "Value" entries in Appendix C.5 are for pairwise comparisons based on the safety, cost, environment, convenience, and performance rankings. Each possible pair (e.g., safety and cost) is considered separately.

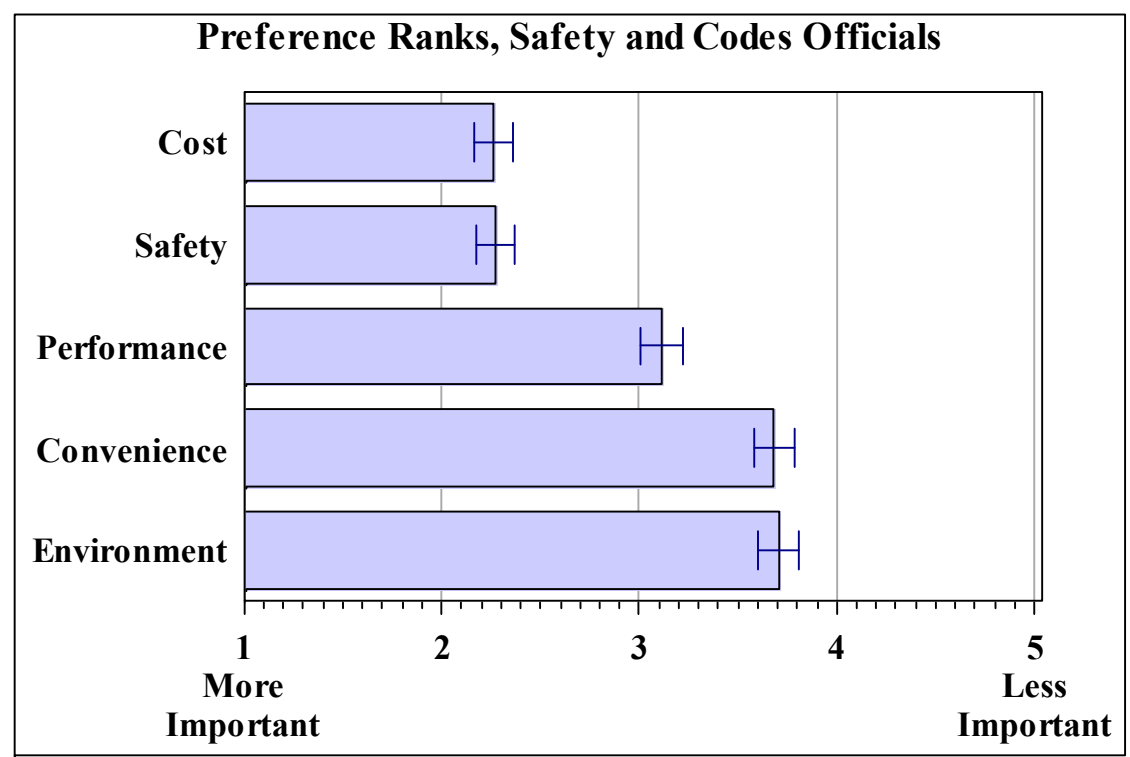

Figure 8.4. Mean of preference rankings of cost, safety, environment, convenience, and performance, Question 7, safety and codes officials. (Rank $=1$ for first choice, 2 for second choice, etc.) The error bar on each chart bar shows $95 \%$ confidence limits for the mean rank.

Respondents were asked about the use of fuel cells for providing power to their home, car, laptop computer, or all of these. Figure 8.5 suggests that safety and codes officials are aware of the potential uses of fuel cells since $57.0 \%$ indicated the correct response (all of these).

Several questions involved respondents' opinions about the safety of fuel cells and hydrogen. Figure 8.6 shows the responses for the survey question about the safety of hydrogen relative to gasoline and diesel (Question 10C). The options that were provided to respondents were "Disagree," "Are neutral," "Agree," or "Don’t know/no opinion." As can be seen in Figure 8.5, over $90 \%$ of the safety and codes officials agreed with the statement "Hydrogen is as safe to use 
in my car as gasoline and diesel fuels," although "Don't know/no opinion" was also a common response.

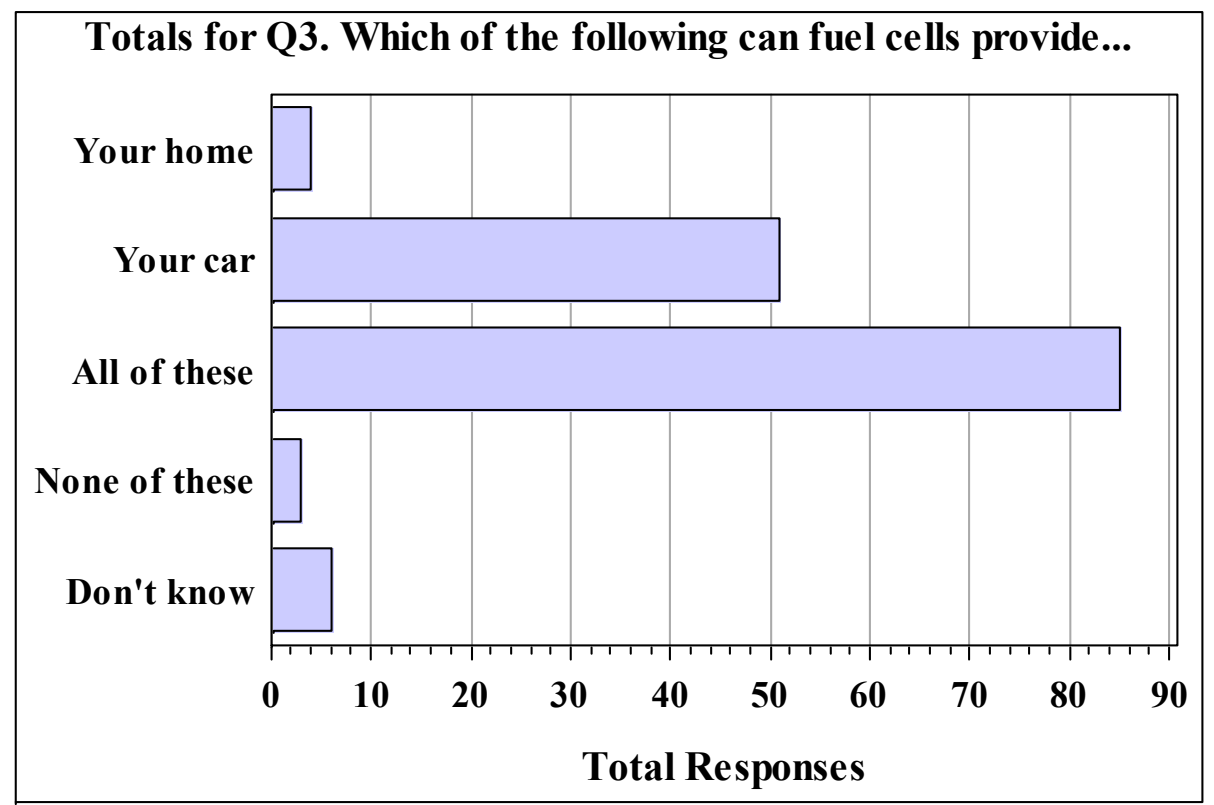

Figure 8.5. Responses to statements about the uses of fuel cells, Question 3 (Which of the following can fuel cells provide power to?), safety and codes officials.

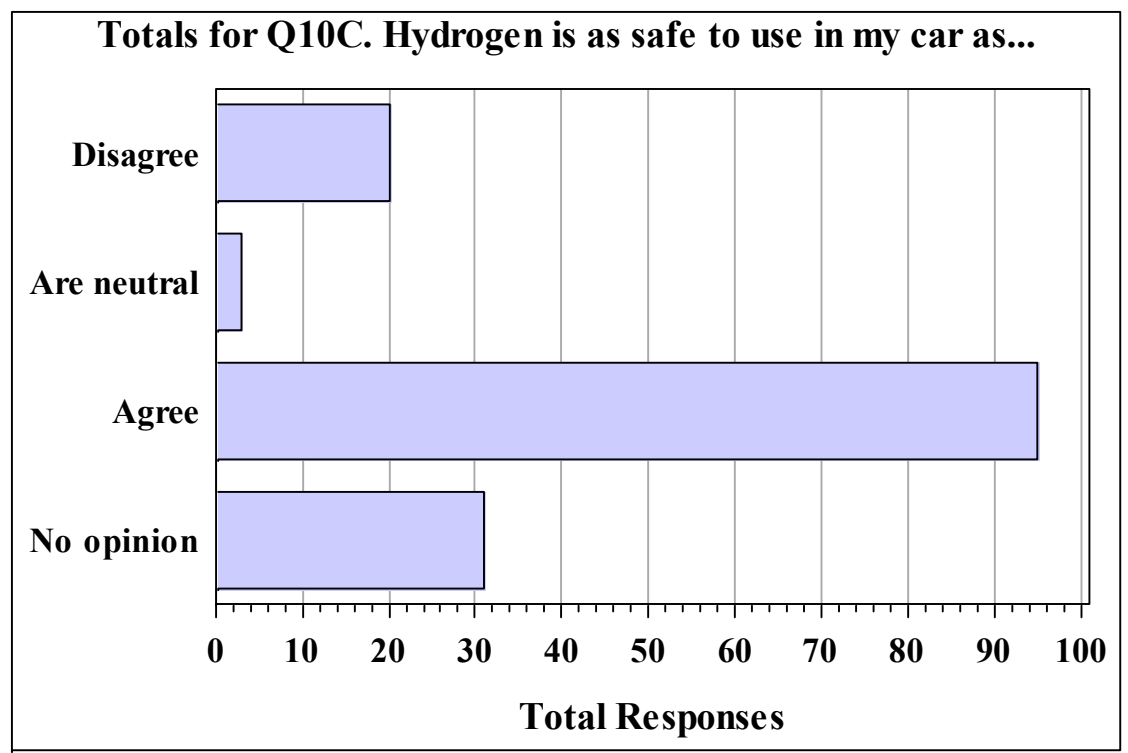

Figure 8.6. Responses to statement, "Hydrogen is as safe to use in my car as gasoline and diesel fuels," Question 10C, safety and codes officials. 
Safety and codes officials were asked how they would feel if their local gas station also sold hydrogen. Figure 8.7 shows their responses to this question. While slightly over $12 \%$ of respondents indicated they would be "Frightened" or "Uneasy," 38.9\% indicated they would be "At ease," and $40.3 \%$ responded that they would be "Pleased."

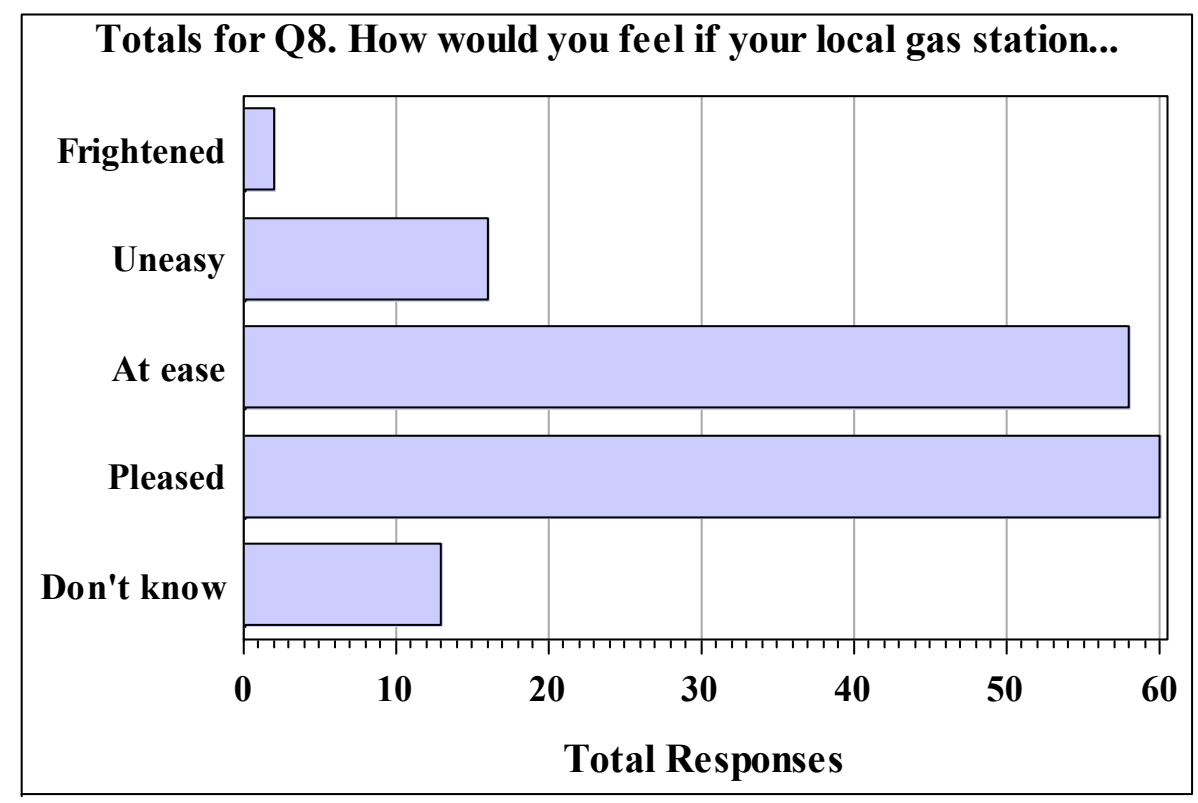

Figure 8.7. Responses to the possibility of sales of hydrogen at a local gas station, Question 8 (How would you feel if your local gas station also sold hydrogen?), safety and codes officials.

When safety and codes officials were asked whether they had ever been involved in permitting a stationary fuel cell installation, hydrogen refueling station, or other hydrogen fuel cell project, $87.3 \%$ of the respondents answered "No." In addition, fewer than one in four respondents $(24.2 \%)$ knew anyone who had been involved in permitting a hydrogen fuel cell project.

Safety and codes officials were asked whether they had the information that they would need if they were asked to review a request for a stationary fuel cell permit. Only $37.6 \%$ responded "Yes," and only $24.8 \%$ of all respondents indicated that they would feel "Comfortable" conducting the review.

Similar questions were asked about reviewing a request for a hydrogen fueling station permit. About $41 \%(40.9 \%)$ of respondents said that they had the information needed to review the permit request, and $26.8 \%$ indicated that they would feel "Comfortable" conducting the review.

It is significant that a large number of safety and codes officials involved in the survey indicated the would feel "Uneasy" conducting the reviews; $40.9 \%$ would feel "Uneasy" conducting a permitting review for a stationary fuel cell, and 38.9\% would feel "Uneasy" reviewing a permit request for a hydrogen fueling station. 
When asked where they would go to obtain information for reviewing an application, only one respondent indicated a complete lack of knowledge on where to seek information. Generally, respondents indicated that they would try all sources, but the source most frequently chosen was industry, followed closely by national organizations. Table 8.3 provides the responses to this question.

\begin{tabular}{|l|c|c|c|}
\hline \multicolumn{4}{|c|}{$\begin{array}{c}\text { Table 8.3. Sources that Would Be Used if Additional Information Were Needed to } \\
\text { Review an Application for a Stationary Fuel Cell or Hydrogen Fueling Station, } \\
\text { Question 35, Safety and Codes Officials }\end{array}$} \\
\hline & Would use & Would not use & Total responses \\
\hline Peers & 108 & 41 & 149 \\
\hline Federal government & 117 & 32 & 149 \\
\hline State government & 118 & 31 & 149 \\
\hline Nonprofit organization & 82 & 67 & 149 \\
\hline Industry source & 138 & 11 & 149 \\
\hline National organization & 136 & 13 & 149 \\
\hline Local agency's regulations & 115 & 34 & 149 \\
\hline Don't know/no opinion & 1 & 148 & 149 \\
\hline
\end{tabular}

Safety and codes officials were asked two questions about information sources. Question 14 asked about the frequency of use ("Never," "Sometimes," "Frequently") of information sources to make decisions about energy costs and safety. As shown in Figure 8.8, the source marked "Frequently" most often was industry, trade associations, or non-profit organizations; this source was followed closely by utilities/brokers and State government. The sources of information that received the greatest number of "Never" responses were teachers and schools, friends and family members, and environmental groups.

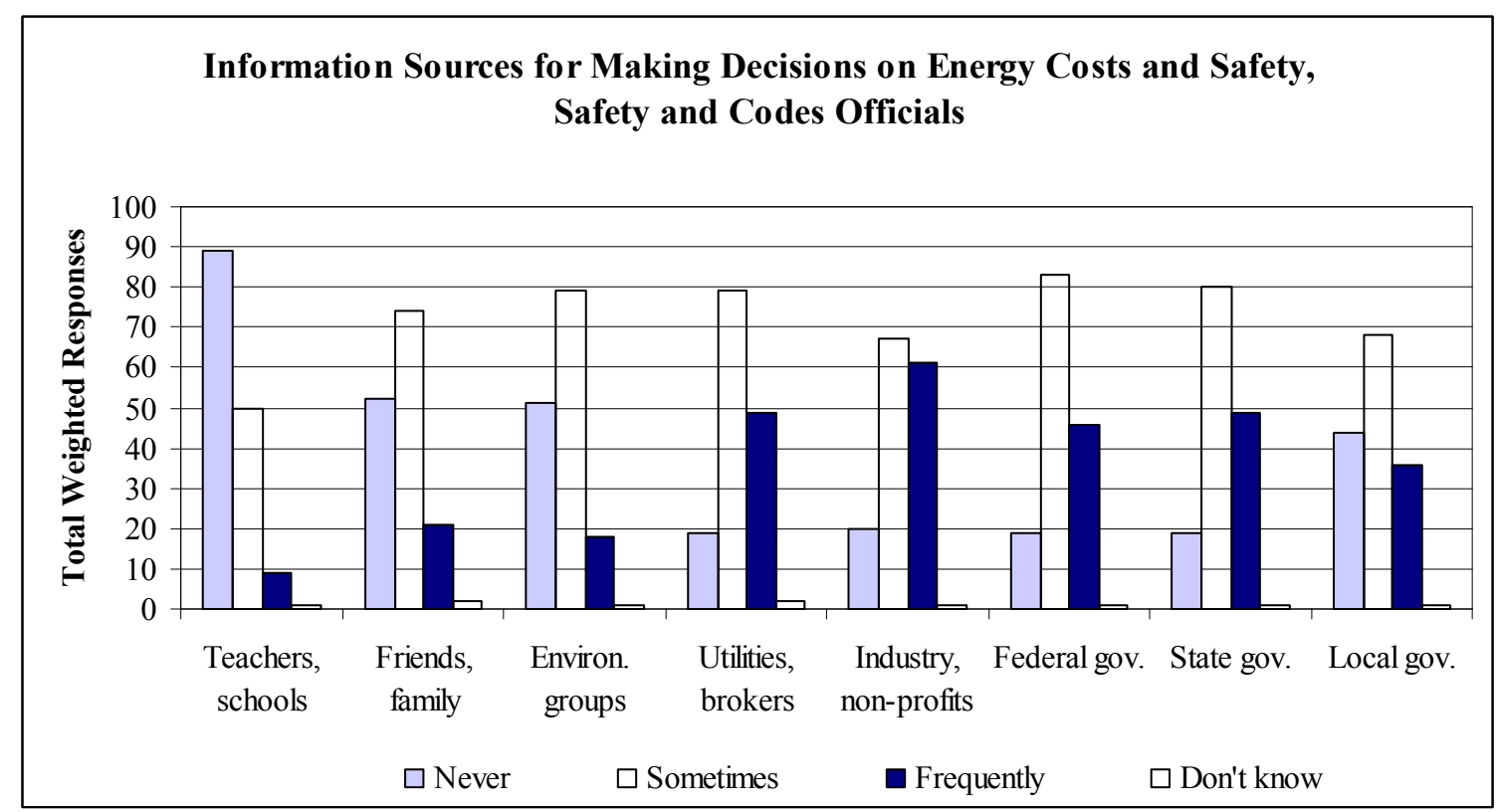

Figure 8.8. Weighted counts of responses regarding the frequency of use of information sources when making decisions about energy costs and safety, Question 14, safety and codes officials. 
Question 15 also asked about information sources, but from the perspective of media sources, that is, information vectors (television, radio, internet, etc.) for obtaining energy information. As shown in Figure 8.9, respondents indicated that their most frequent media source for obtaining energy information was the Internet, followed by business and trade magazines.

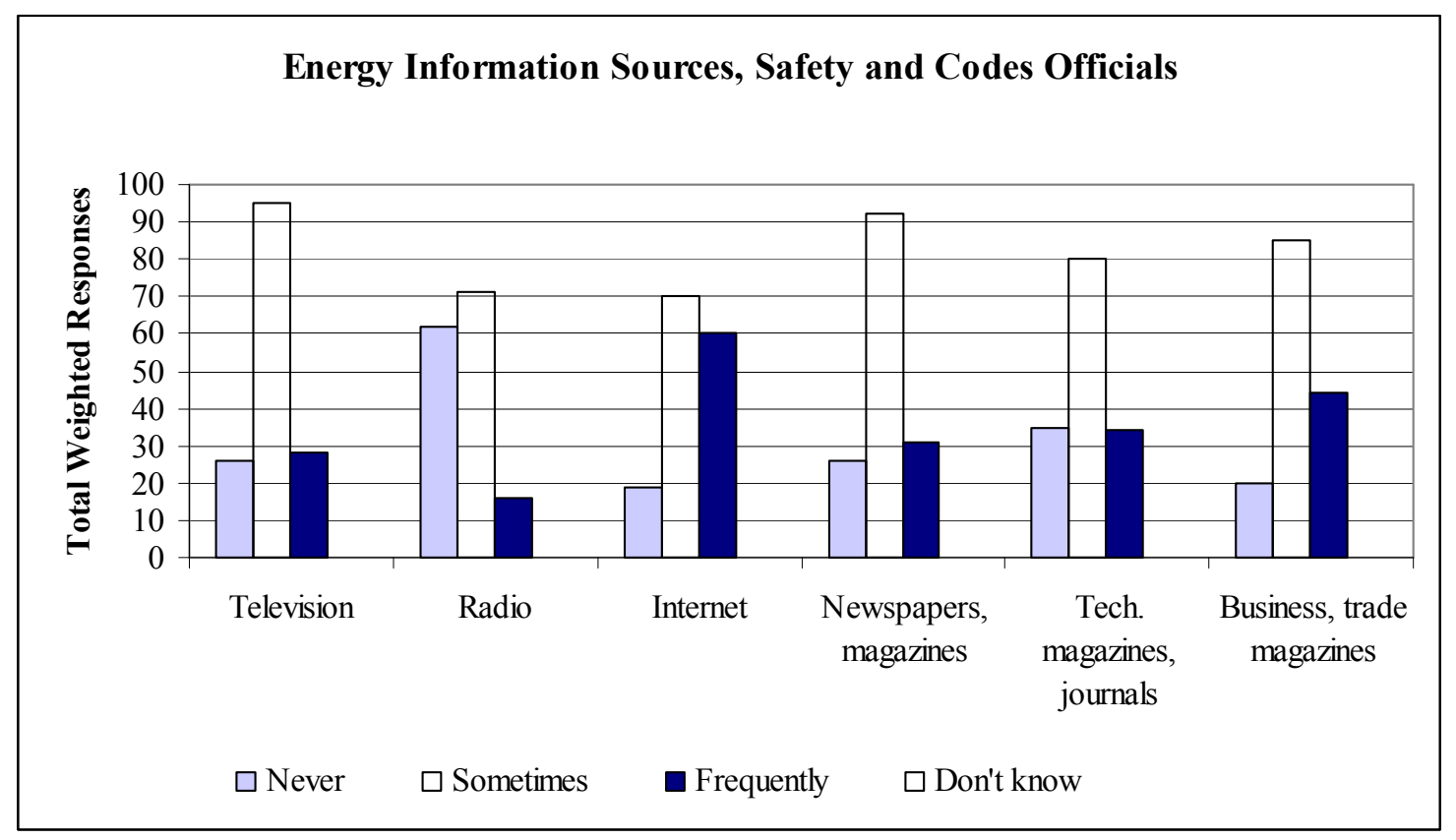

Figure 8.9. Weighted counts of responses regarding the frequency of use of different types of mass media for obtaining energy information, Question 15, safety and codes officials.

Over $65 \%$ of the safety and codes officials indicated that they had received information about hydrogen and fuel cell technologies (Question 26). While only $27.5 \%$ of respondents had participated in a training class on hydrogen or fuel cells, $77.8 \%$ indicated that they would like to participate in a class (Questions 17 and 19). Most respondents (50\%) indicated that an in-person class at a local facility would be the most useful format for a class (Question 20).

\subsection{RELATIONSHIPS}

The summary statistics in Section 8.2 are "one-way" statistics in the sense that the response categories are defined in terms of one variable such as response to an opinion question (e.g., Question 10C, "Hydrogen is as safe to use in my car as gasoline and diesel fuels"). However, relationships in the responses determined by two or more variables may also be of interest. Although no relationships were of particular interest a priori, in this section a few of the more statistically significant ones are illustrated. Interactions that were considered were with the survey variables and familiarity with hydrogen and fuel cell technologies and the whether 
respondent overall technical scores were above average for the sample. The statistical significance criterion is the significance level $(p)$ of a chi-square test. ${ }^{51}$

As shown in Figure 8.10, respondents who scored below average on the technical questions were more likely to assess their familiarity as "Not at all familiar" or "Slightly familiar," and respondents who scored above average were more likely to claim a higher familiarity with hydrogen and fuel cell technologies. Thus, the familiarity self assessments are consistent with the technical awareness scores.

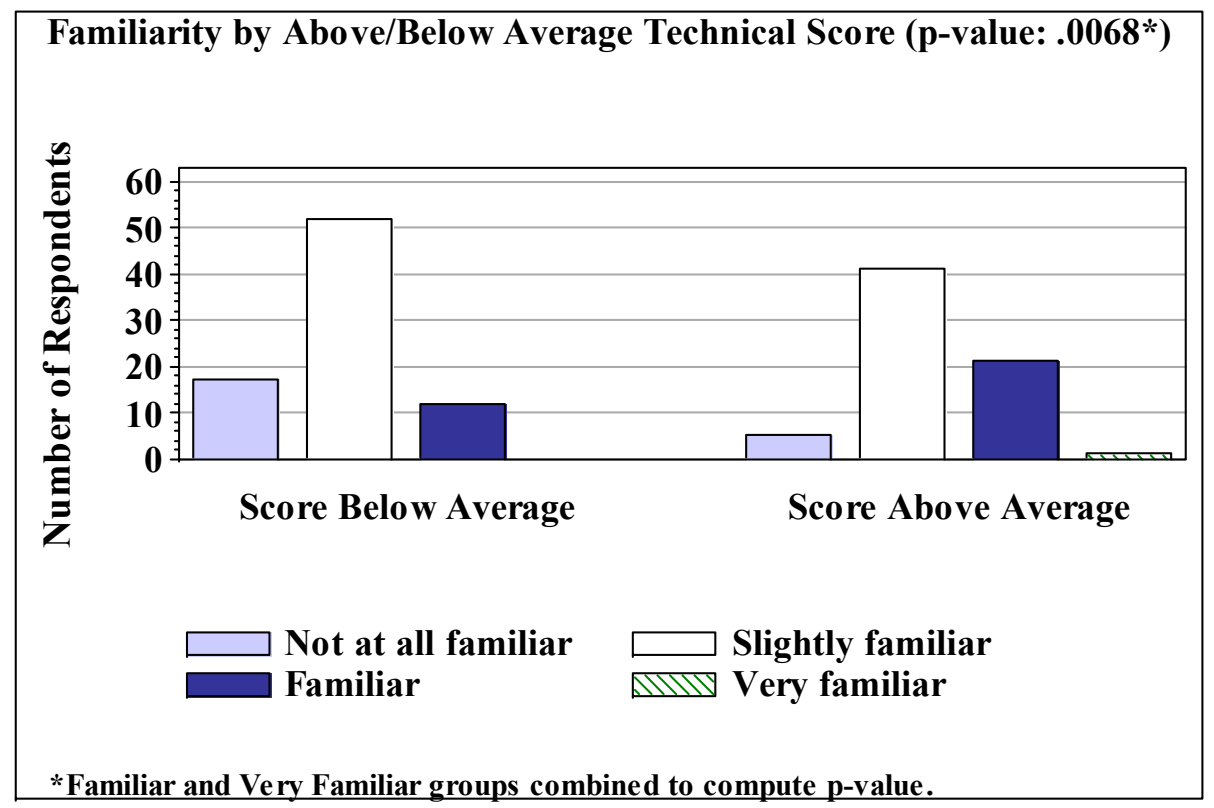

Figure 8.10. Responses by technical score above/below average to Question 1 (familiarity of respondents to hydrogen and fuel cell technologies), safety and codes officials.

Safety and codes officials considered hydrogen and fuel cell technologies as "Equally as safe" or, in many cases, "Safer" than technologies in use today. This opinion was even more pronounced for respondents with above average scores on the technical knowledge questions. Figure 8.11 shows that respondents with below average scores were much more likely to have "No opinion" about the safety of small portable devices such as laptop computers or cell phones; respondents with below average scores were also more likely to think these devices were "Not as safe." Respondents with above average score, on the other hand, were more likely to assert that these devices were "Equally as safe" as technologies in use today.

\footnotetext{
${ }^{51}$ Measures could also be based on odds ratios or combinations of odd ratios and significance levels as well as other metrics. Significance levels alone were used for simplicity and because sample sizes are essentially the same for all survey questions.
} 


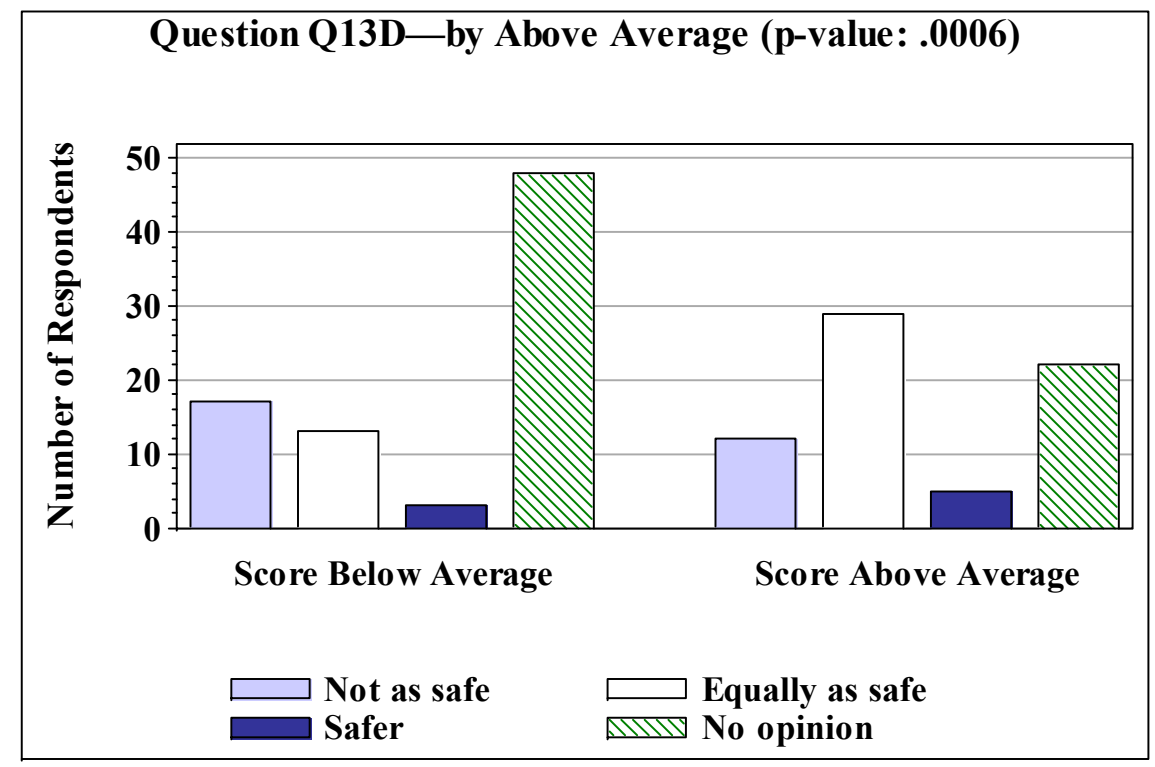

Figure 8.11. Responses by technical score above/below average concerning the safety relative to technology in use today of small portable devices such as laptop computers or cell phones, Question 13D, safety and codes officials. 


\section{COMPARISON OF RESULTS FOR THE FIVE POPULATIONS}

Sections 4-8 summarize the findings of the 2008/2009 surveys of the general public, students, state and local governments, end users, and safety and codes officials, respectively. Some comparisons are also made with the results of the 2004 surveys, to measure changes, but very few comparisons are made among the five component populations. Cross-population comparisons are discussed in this section. It should be stressed, however, that comparisons of the different populations are not the primary purpose of the hydrogen surveys. Each of the populations is different, and each population may require a different approach in the education program. The primary purpose of the surveys is to measure knowledge and opinions and changes in knowledge and opinions in each survey population separately. ${ }^{52}$

Table 9.1 shows numbers of respondents and response rates for the survey populations in 2004 and 2008/2009. Response rates for students and the general public were similar in both survey years. Response rates for government officials and end users declined. In both survey years, response rates for government officials were the highest, although the 2009 response rate for safety and codes officials was also high.

\begin{tabular}{|l|c|c|c|c|c|}
\hline \multicolumn{7}{|c|}{ Table 9.1. Sample Sizes and Response Rates by Population for the 2004 } \\
and 2008/2009 Surveys \\
\hline \multirow{2}{*}{ Population } & \multicolumn{2}{|c|}{ Sample size } & Response rate (\%) & $\begin{array}{c}\text { Response rate } \\
\text { difference } \\
\text { (percentage points) }\end{array}$ \\
\cline { 2 - 5 } & $\mathbf{2 0 0 4}$ & $\mathbf{2 0 0 8 / 9}$ & $\mathbf{2 0 0 4}$ & $\mathbf{2 0 0 8 / 9}$ & -1.8 \\
\hline General public & 889 & 1,000 & 24.8 & 23.0 & +2.0 \\
\hline Students & 1,000 & 1,004 & 27.5 & 29.5 & -6.5 \\
\hline Government agencies & 236 & 220 & 95.9 & 89.4 & -12.1 \\
\hline End users & 99 & 601 & 29.1 & 17.0 & NA \\
\hline Safety and codes officials & NA & 149 & NA & 77.2 & \\
\hline
\end{tabular}

The five different survey populations expressed very different opinions about their familiarity with hydrogen and fuel cell technologies. Figure 9.1 shows that the general public and to a slightly lesser extent students, rated themselves for the most part "Not at all familiar" or "Slightly familiar," while end users rated themselves more familiar, and government officials even more familiar than end users. Safety and codes officials had the highest percentage of "Slightly familiar" responses. This population also had a high percentage of respondents rating themselves as "Familiar" with hydrogen and fuel cell technologies.

Figure 9.2 illustrates the differences in percentages of correct technical responses among the five populations. Students (ages 12-17) performed slightly better than the adult general public. Among the other populations, the state and local officials correctly answered the technical questions most frequently.

\footnotetext{
${ }^{52}$ The population of safety and codes officials was not surveyed in 2004 .
} 


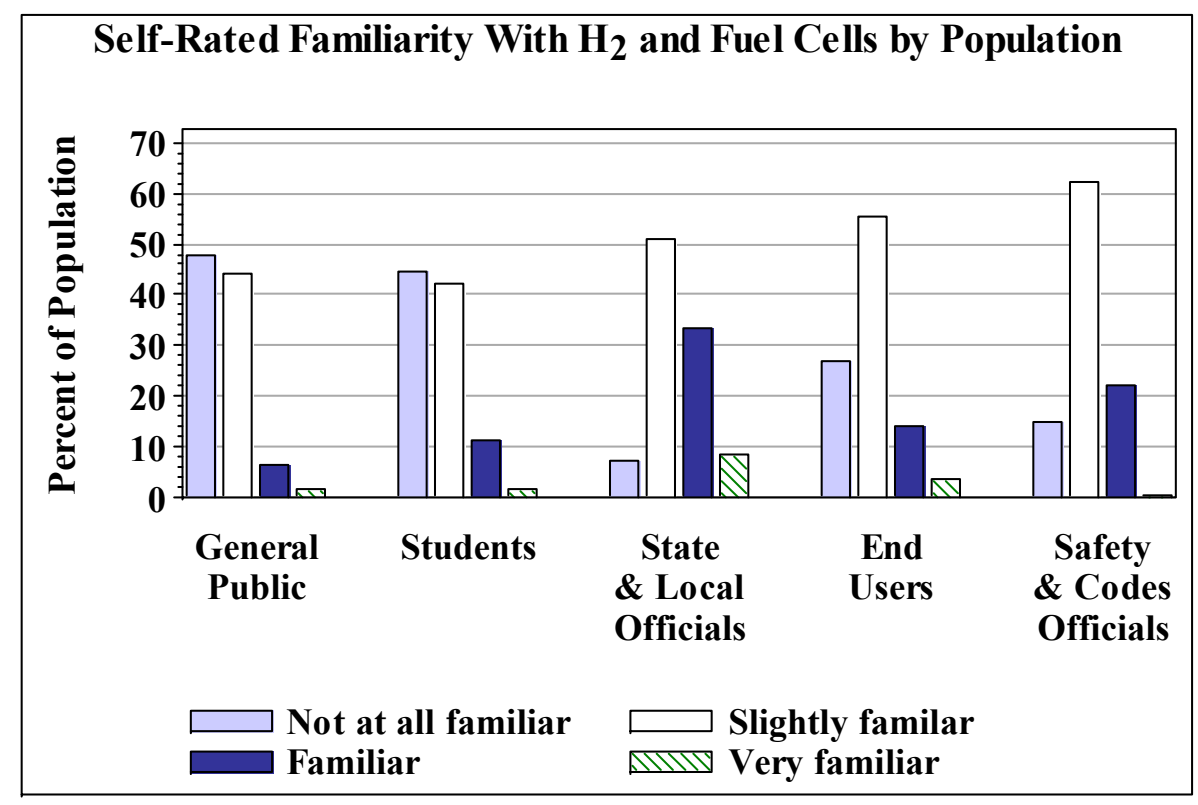

Figure 9.1. The self-rated levels of familiarity with hydrogen and fuel cell technologies for each of the five component populations, 2008/2009 survey.

Figure 9.2 also shows differences between the average percentage of correct scores for technical questions about fuel cell questions (Questions 2B and 5 on the general public survey) and for all eight technical questions together. Because the fuel cell questions were less likely to be answered correctly than the general hydrogen questions, it might be assumed that either (1) knowledge about fuel cells is not as prevalent as general knowledge about hydrogen and the hydrogen economy (particularly so for the general public and students), or (2) the fuel cell questions were more difficult questions.

Another way of looking at the technical scores for the 2008/2009 survey, is to look at the proportion of correct, incorrect, and don't know scores for all populations. As shown in Figure 9.3, the population with the greatest proportion of correct responses and least proportion of incorrect and "Don't know" responses is the state and local government agencies. The general public has the fewest correct responses and greatest proportion of "Don't know" responses.

A comparison of the percentages of "Don't know" responses to the technical questions over time is another indicator of change in knowledge. Figure 9.4 shows percentages of "Don't know" responses to the eight technical questions. In 2008/2009, the population with the highest percentage of "Don't know" responses was the general public $(45.4 \%)$, followed by the end users (36.4\%), the students $(24.4 \%)$ and the state and local officials $(18.5 \%)$. Figure 9.3 shows that these percentages are generally fairly close to the corresponding 2004 percentages (safety and codes officials results for 2009 only). 


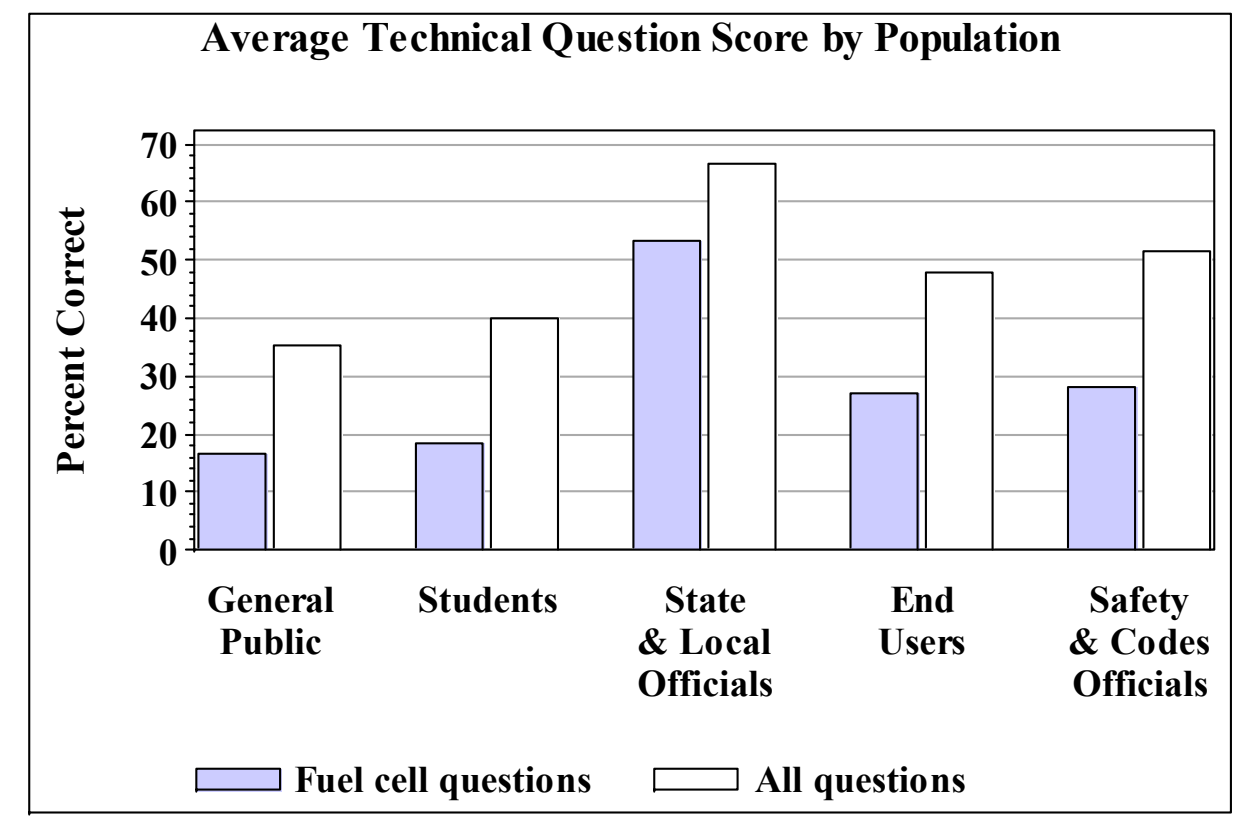

Figure 9.2. Distribution of the average percentage of correct responses to the eight technical questions by population, for fuel cell questions (Questions 2B and 5 on the general public survey) and all eight technical questions, 2008/2009 survey.

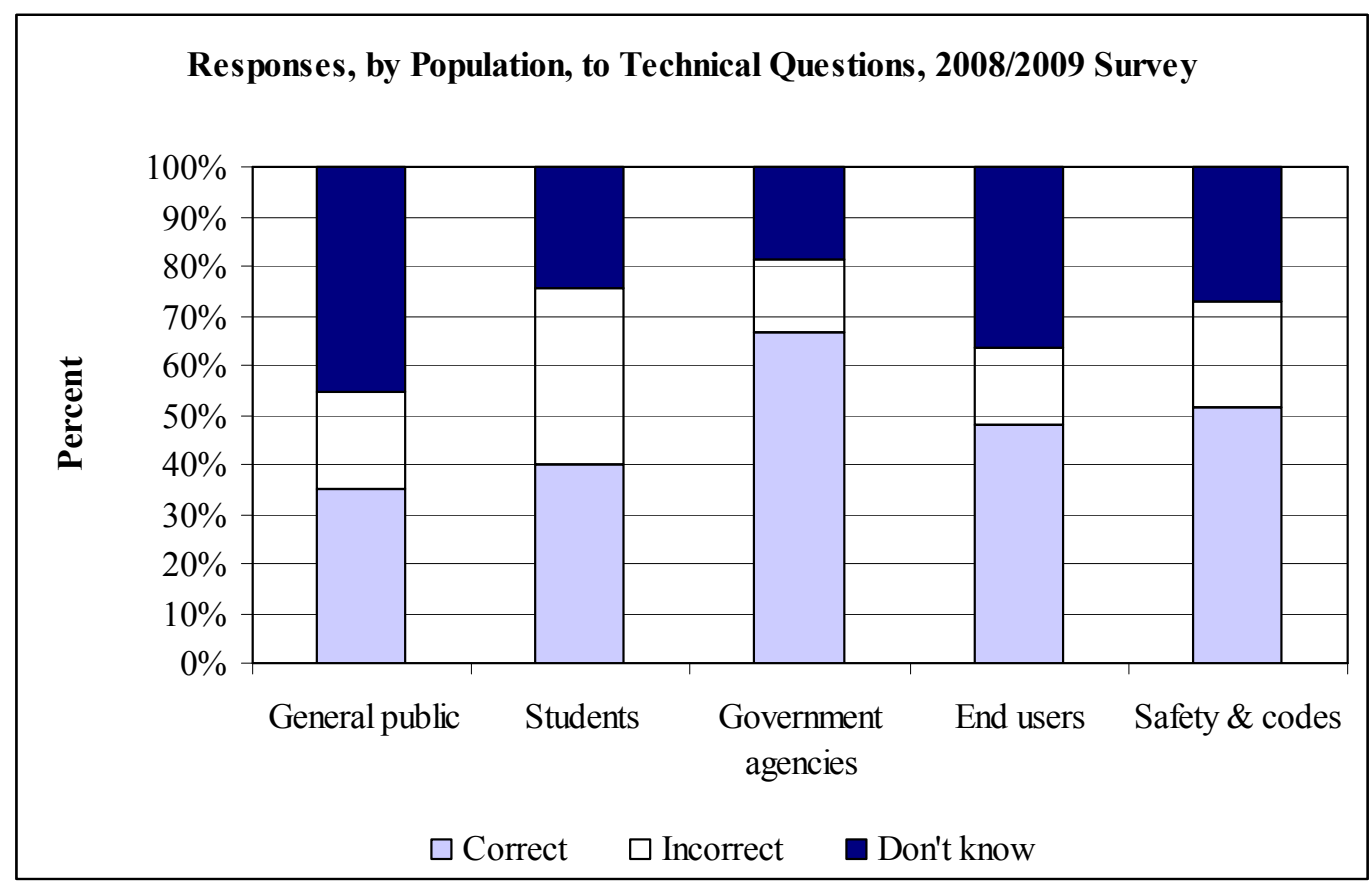

Figure 9.3. Distribution of the average percentage of correct, incorrect, and "Don't know" responses to the eight technical questions by population, 2008/2009 survey. 


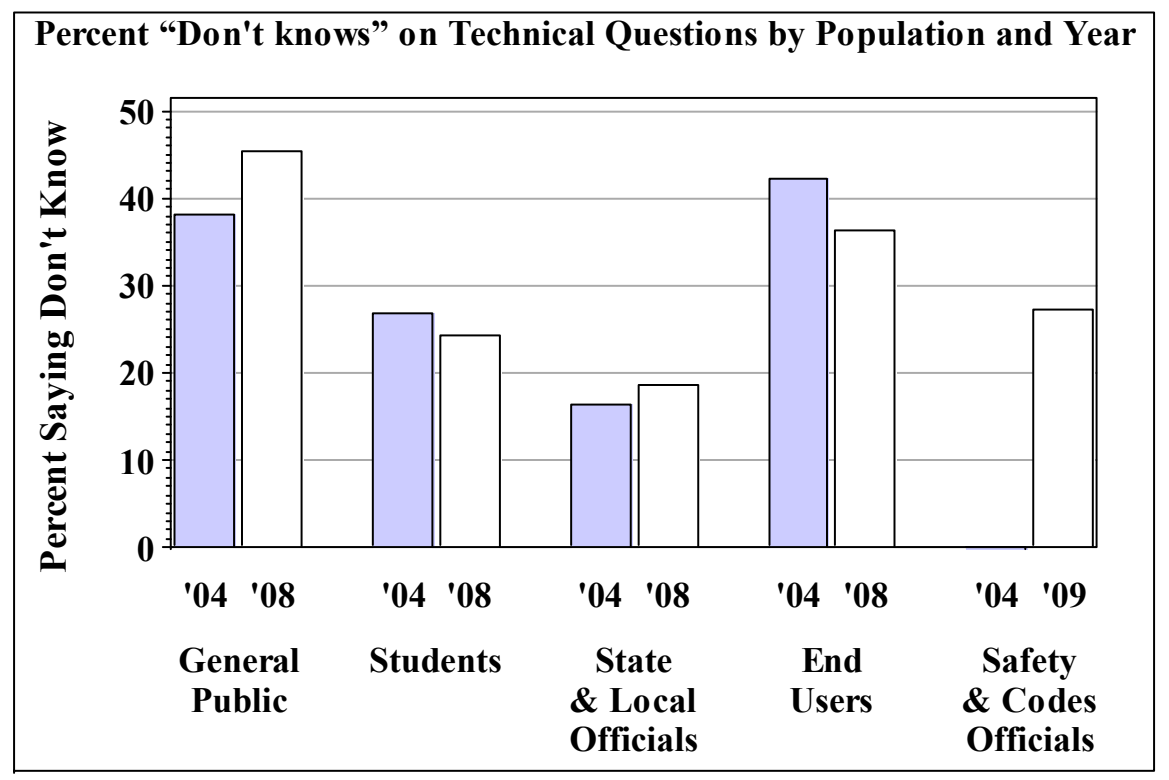

Figure 9.4. Percentage of respondents in each population that answered "Don't know" to the eight technical questions assessing knowledge of hydrogen and fuel cells.

Table 9.2 is similar to Table 9.1 but shows, rather than response rates, average technical question scores (percent correct) for the five populations. The table shows that in 2004 and again in 2008, government agencies were by far the most knowledgeable about hydrogen, according to the survey responses. The 2008 performance for all populations (except safety and codes officials) was as good or slightly better than in 2004. However, only for the students was the increase $(4.5 \%)$ statistically significant $(\mathrm{p}<0.0001)$.

\begin{tabular}{|l|c|c|c|c|c|}
\hline \multicolumn{2}{|c|}{ Table 9.2. Average Technical Scores by Population for the 2004 and 2008/2009 Surveys } \\
\hline \multirow{2}{*}{ Population } & \multicolumn{2}{|c|}{ Sample size } & \multicolumn{2}{c|}{$\begin{array}{c}\text { Technical score } \\
\text { (\% correct) }\end{array}$} & $\begin{array}{c}\text { Score difference } \\
\text { (percentage points) }\end{array}$ \\
\cline { 2 - 5 } & $\mathbf{2 0 0 4}$ & $\mathbf{2 0 0 8 - 0 9}$ & $\mathbf{2 0 0 4}$ & $\mathbf{2 0 0 8 - 0 9}$ & +0.0 \\
\hline General public & 889 & 1,000 & 35.2 & 35.2 & +4.5 \\
\hline Students & 1,000 & 1,004 & 35.3 & 39.8 & +0.1 \\
\hline Government agencies & 236 & 220 & 66.6 & 66.6 & +1.6 \\
\hline End users & 99 & 601 & 46.3 & 47.9 & NA \\
\hline Safety and codes officials & NA & 193 & NA & 51.5 & \\
\hline
\end{tabular}

The general public, state and local officials, and safety and codes officials were asked to rank the importance of safety, cost, environment, convenience, and performance when selecting a vehicle fuel or a power supply for a home or business. Figure 9.5 shows the average preference rankings for each of these population groups. For both the general public and the state and local officials, the rankings were in the order of cost (most important), followed by safety, environment, performance, and convenience. The trend from cost to performance was steeper for the general public than for the state and local officials, however, indicating that preferences for the general 
public were somewhat stronger. The same trend was also seen for the safety and codes officials, with the exception that they considered environmental impact least important.

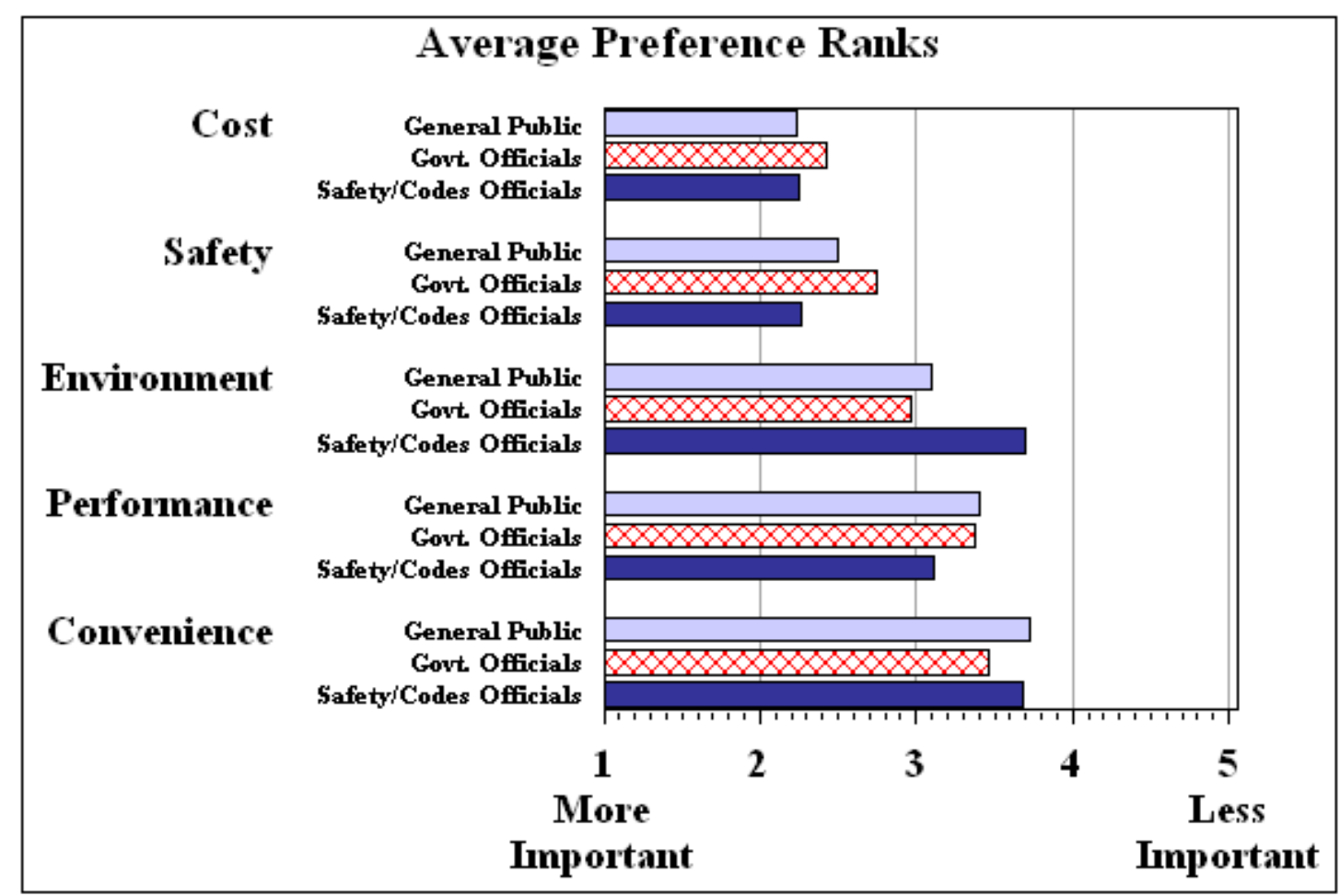

Figure 9.5. Comparison of average preference rankings of cost, safety, environment, convenience, and performance for the general public, government officials, and safety and codes officials, 2008/2009 survey.

Several questions asked for opinions about the safety and advantages of hydrogen as a vehicle fuel. Figure 9.6 shows that in 2008 all five populations tended to believe that hydrogen technologies will reduce emissions and dependence on foreign oil, with government officials the most optimistic of all. In addition, over $60 \%$ of the government officials, over $60 \%$ of the safety and codes officials, and over $50 \%$ of the end user respondents considered hydrogen as safe as gasoline or diesel fuels. (For a comparison of this figure with 2004 results, see Figure 8.3 of the 2004 report.)

Figure 9.7 shows that every 2008 population considered hydrogen as generally safe for use with all specified applications. Students were slightly more positive in their responses than the general public. The applications receiving the most positive reactions were "Personal cars and trucks" and "Commercial vehicles." The application that received the lowest safety rating was "Small portable devices." Again, the safety ratings provided by government officials were higher (more optimistic) than ratings provided by the other populations. (For a comparison of this figure with 2004 results, see Figure 8.5 of the 2004 report.) 


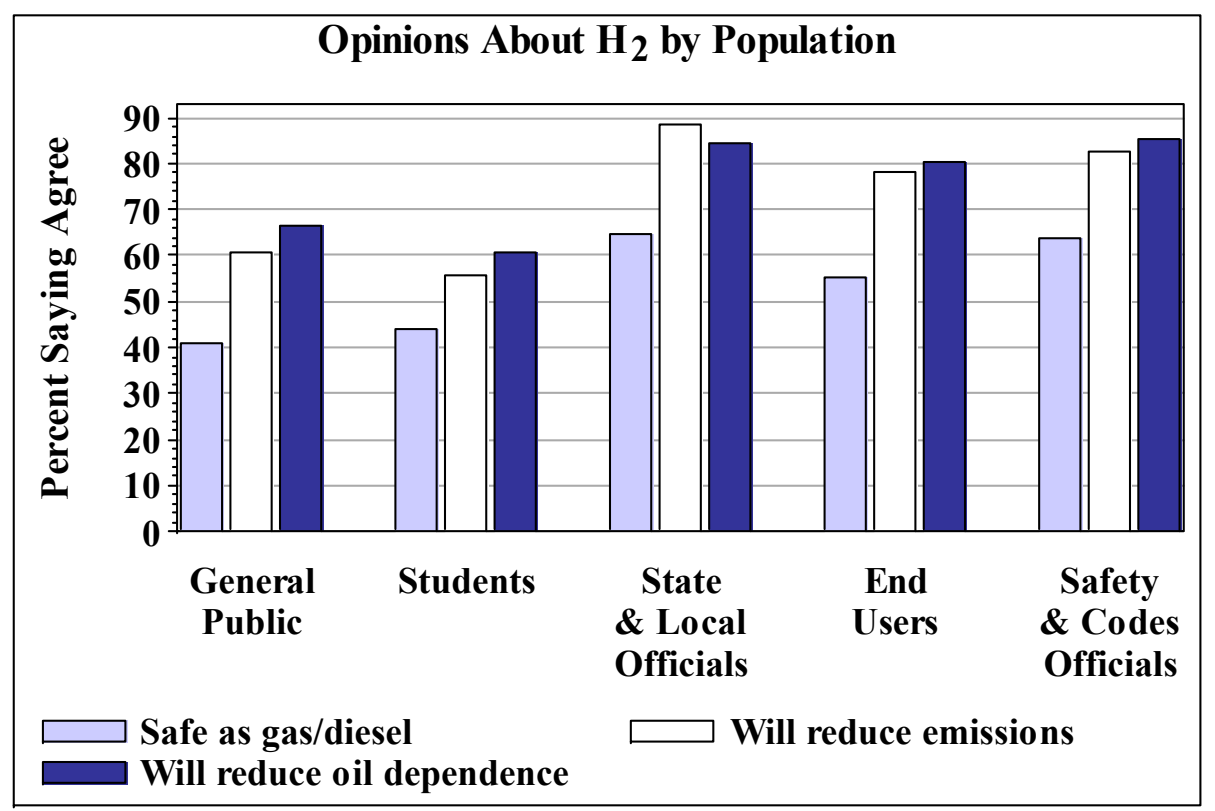

Figure 9.6. Percentage of respondents in each population that agreed with statements about the advantages and safety of hydrogen as a vehicle fuel, 2008/2009 survey.

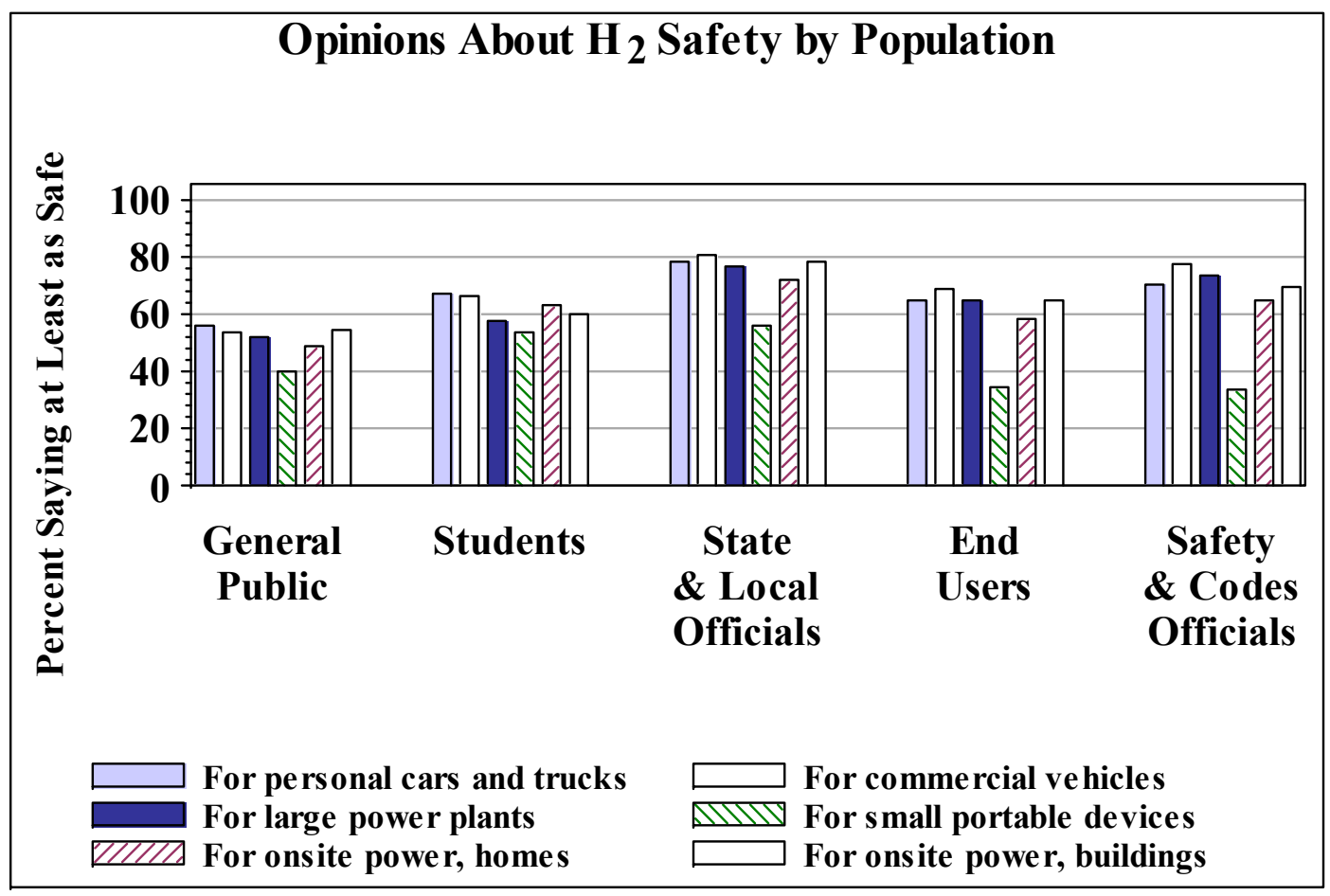

Figure 9.7. For each survey population and for six applications, the percentages of respondents answering that hydrogen and fuel cells are equally as safe as other technologies in use today. 
Figure 9.8 shows that for each of the survey populations, in both 2004 and 2008, the percentage of respondents indicating that hydrogen is "Not too dangerous for everyday use by the general public" was consistently higher than the percentage indicating that hydrogen is "As safe to use in my car as gasoline and diesel fuels." The state and local officials are again the most optimistic. Apparently "Not too dangerous for everyday use" is an easier criterion to meet, in the opinions of respondents, than "As safe as gasoline and diesel fuel." Given our nation's long history with gasoline and diesel fuels but inexperience with hydrogen, this is not surprising.

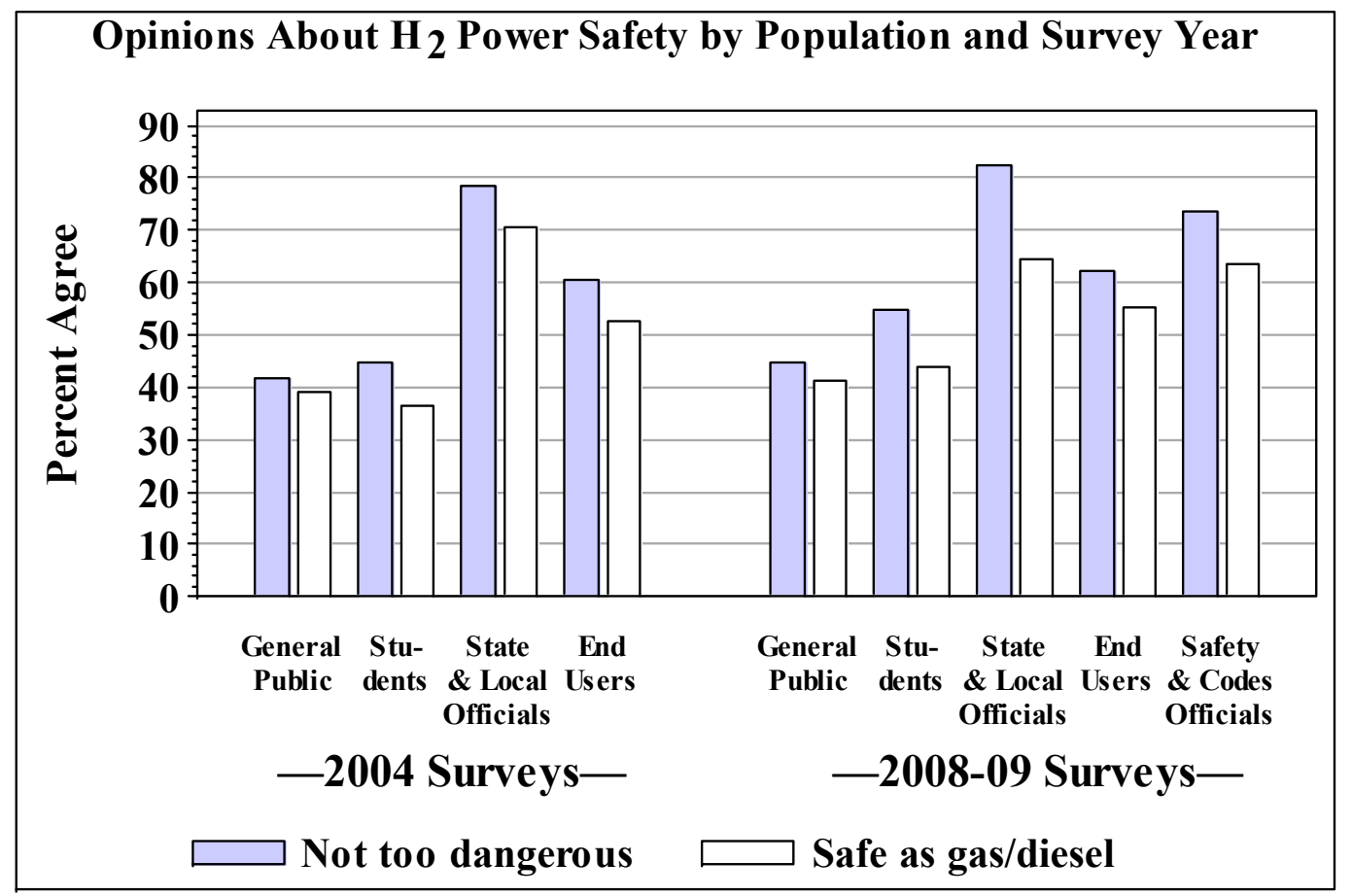

Figure 9.8. Percentages of respondents who disagreed with the statement "Hydrogen is too dangerous for everyday use by the general public" and percentages who agreed with the statement "Hydrogen is as safe to use in my car as gasoline and diesel fuels."

Figure 9.9 shows that the percentages of respondents who would be pleased or at ease with the sales of hydrogen at their local gas station has increased slightly in each population group since the 2004 survey. The greatest increase was for students. In the 2008 survey students were more positive that the general public about a gas station selling hydrogen, whereas they were less positive in $2004 .^{53}$

\footnotetext{
${ }^{53}$ See Figures 4.22, 5.20, 6.17, 7.22, and surrounding discussion for statistical significance levels of comparisons of 2004 and 2008 results for individual populations.
} 


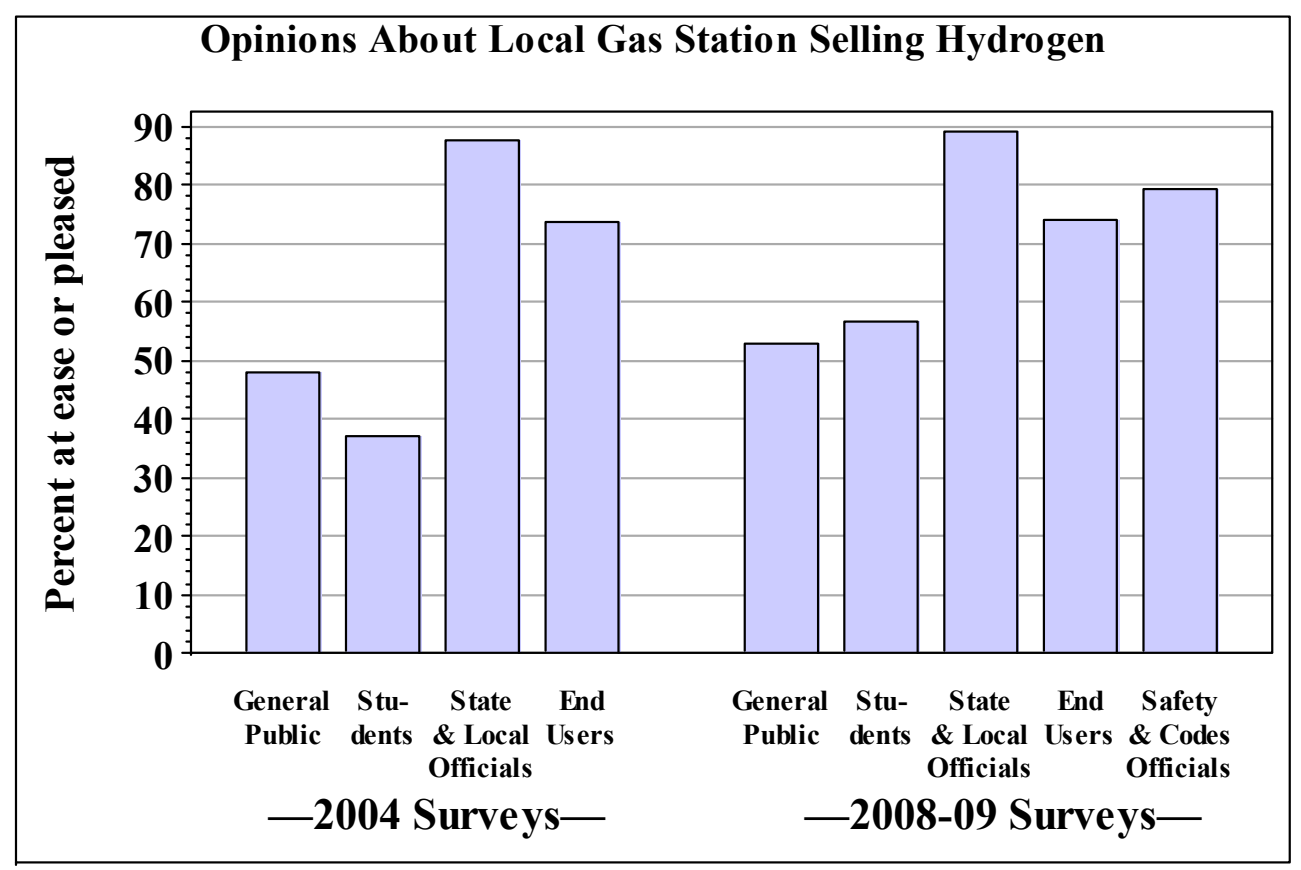

Figure 9.9. Percentage, by population group, of respondents that indicated they would be pleased or at ease with sales of hydrogen at a local gas station, 2004 and 2008 surveys.

Figure 9.10 shows the percentage of respondents from each population that noted frequent use of different types of mass media for obtaining energy information. The figure shows that the Internet is the prime energy information source for government officials, end users, and safety and codes officials. Government officials and end users were also the most likely to refer to science and technology magazines and journals. With the exception of science and technology magazines and journals, the general public indicated a higher usage than students for each media source. The media source used least by all populations for obtaining energy information was the radio. (For a comparison of this figure with 2004 results, see Figure 8.6 of the 2004 report.) 


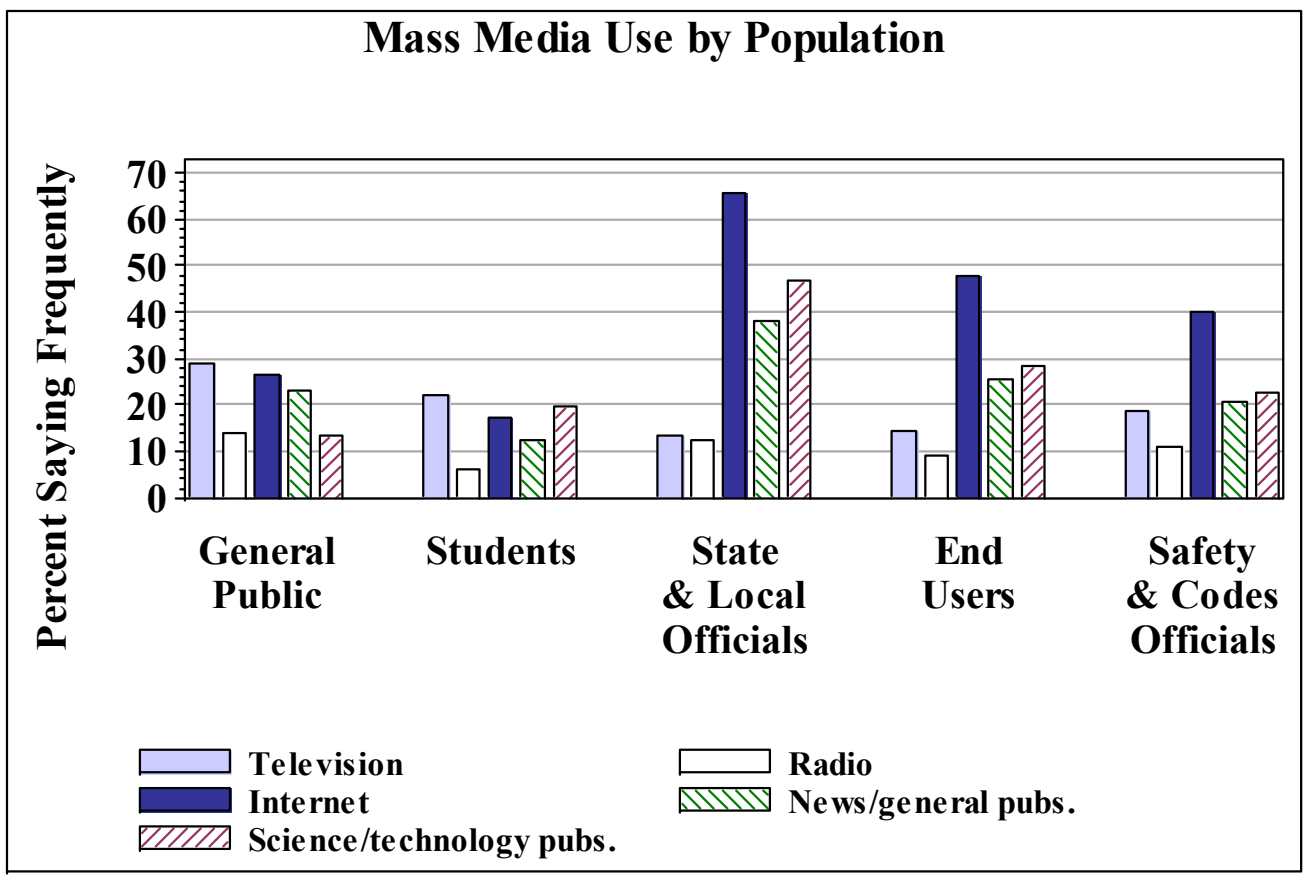

Figure 9.10. Percentages of respondents indicating frequent use of various mass media for obtaining energy information, by population group. 


\section{SUMMARY AND CONCLUSIONS}

\subsection{SUMMARY}

Scientific sampling was used to survey five populations: (1) the general public, ages 18 and over; (2) students, ages 12-17; (3) state and local government officials from state departments of transportation and environmental protection, state energy offices, and functionally similar personnel from cities and counties; (4) potential hydrogen end users in three business categories: transportation, businesses requiring uninterrupted power supplies, and industries with large power requirements; and (5) safety and codes officials in four organizations: International Association of State Fire Chiefs (IAFC), International Code Council (ICC), National Association of State Fire Marshalls (NASFM), and National Fire Protection Association (NFPA). The surveys were designed to obtain 1,000 sample responses from each of the general public and student categories, and to sample 246 state and local officials, 600 large-scale end users, and 200 safety and codes officials.

The survey questions were designed to accomplish specific objectives. Technical questions were posed to measure technical understanding and awareness of hydrogen and fuel cells technologies. Opinion questions measured attitudes about the relative importance of safety, cost, the environment, performance, and convenience for a vehicle fuel or power supply for a home or business. Questions were posed to assess visions about the likelihood of various future applications of hydrogen technology. For most of the questions, "I don't know" or "I have no opinion" were perfectly acceptable answers. Questions about information sources (teachers, friends, government, etc.) and media (radio, Internet, magazines, etc.) were posed to assess how energy technology information is received.

At various stages in their development the survey questionnaires were reviewed by National Hydrogen Association and U.S. Fuel Cell Council personnel and by management at the DOE FCT program office. Federal Register notices were published, and Office of Management and Budget approval to conduct the surveys was obtained, per the Paperwork Reduction Act of 1995.

The general public and student survey samples were selected by random digit dialing. Potential large-scale end users were selected by random sampling. The surveys of state and local government agencies and of safety and codes officials were of their entire target populations (i.e., except for nonresponse, they are complete samples). All five surveys were administered by computer-assisted telephone interviewing (CATI). The General Public and Student Surveys were administered in either English or Spanish, at the option of the respondents. For all populations except the safety and codes officials, the length of the survey was less than 15 minutes, including the introduction, screening process, and general information and demographic questions. The average interview length of safety and codes officials was 17 minutes.

The five surveys were conducted in $2008 / 2009$. This report is essentially a data book, a digest of the survey data collected for the five survey populations. In addition, the report shows changes in 
knowledge and opinions of the four component populations that were surveyed in $2004 .{ }^{54}$ Many conclusions can be made from the survey data. However, the purpose here is not to draw the conclusions, but rather to summarize the data in a way that facilitates drawing them.

\subsection{CONCLUSIONS}

The biggest data quality limitation of the hydrogen survey data is nonresponse bias. Table 10.1 shows 2004 and 2008/2009 response rates (percentages) by survey component population. Response rates were for the most part very slightly lower for the 2008/2009 surveys. This is consistent with trends toward increasing use of caller ID.

\begin{tabular}{|l|c|c|}
\hline \multicolumn{3}{|c|}{$\begin{array}{c}\text { Table 10.1. Response Rates by Population, } \\
\mathbf{2 0 0 4} \text { and 2008/2009 Surveys }\end{array}$} \\
\hline Population & $\mathbf{2 0 0 4}$ & $\mathbf{2 0 0 8 / 2 0 0 9}$ \\
\hline General public & $24.8 \%$ & $23.0 \%$ \\
\hline Students & $27.5 \%$ & $29.5 \%$ \\
\hline Government agencies & $95.9 \%$ & $89.4 \%$ \\
\hline End Users & $29.1 \%$ & $17.0 \%$ \\
\hline Safety and codes officials & NA* & $77.2 \%$ \\
\hline *Safety and codes officials were not surveyed in 2004. \\
\hline
\end{tabular}

We are willing to accept nonresponse bias because it is not severe enough to invalidate the survey, and because all reasonable measures were taken to minimize it. We also expect that changes in response rates will not obscure measurements of changes in knowledge of, awareness of, and attitudes toward hydrogen. An issue involving telephone surveys is the possibility of undercoverage because of cell-phone-only households. While sampling weights provide a partial correction, it is not feasible to fully address the cell-phone-only issue is the 2008/2009 hydrogen surveys.

The primary objective of the data analysis is to estimate the proportions of target population individuals who would respond to the survey questions in the various possible ways. The data analysis incorporates necessary adjustments for the sampling design (sampling probabilities and stratification) and sampling weights, which are used to adjust for a priori unequal sampling probabilities as well as nonresponse. Otherwise the data analysis mostly involves straightforward estimation of proportions of the respondents providing various answers to the questions. However, sample-weight-adjusted contingency table chi-square tests were also computed to further identify differences between demographic groups.

Several of the more significant results of the 2008/2009 hydrogen knowledge and opinions survey are as follows:

- The average technical knowledge scores for each of the populations surveyed in both 2004 and 2008 increased slightly, though, except for students, the increases were not

\footnotetext{
${ }^{54}$ In 2004, surveys of the general public, students, state and local government agencies, and end users were conducted.
} 
statistically significant. For students, the average technical score increased 4.5 percentage points, a difference that is statistically significant $(p<0.0001)$. As in the 2004 survey, state and local officials had the highest average score on the technical knowledge questions. (See Table 9.2.)

- When choosing a vehicle fuel or power source, the general public, on average, consider the following in decreasing order of importance: cost, safety, environmental impact, performance, convenience. State and local officials had exactly the same preference. Safety and codes officials had the same preferences also with the exception that environmental impact was ranked as least important. (Preference ranking questions were not asked to end users or students.)

- As in the 2004 survey, for the general public, students, and end users, hydrogen technology acceptance is strongly associated with hydrogen technical awareness $(\mathrm{p}<0.0001$; see Figures 4.13, 5.13, 7.22). For state and local government officials and safety and codes officials, this relationship was not statistically significant.

- Despite having only small increases in average technical scores, all four populations surveyed in both 2004 and 2008 expressed greater confidence in the safety of hydrogen technologies in 2008 than in 2004. For example, in 2008 fewer students indicated that they would be "Frightened" or "Uneasy" with the availability of hydrogen at a local gas station and more students indicated that they would be "At ease" or "Pleased." Similar trend are evident for the general public, state and local officials, and end users. For state and local officials and end users, the proportions of respondents who indicated they would be "pleased" if hydrogen were available at their local gas station increased by over 15 percentage points. (See Figures 4.22, 5.20, 6.17, 7.22, and surrounding discussion for statistical significance levels of comparisons of 2004 and 2008 results for the individual populations. Safety and codes officials were surveyed in 2008/2009 only.)

- Most respondents in all five survey groups agreed that the use of hydrogen as a vehicle fuel would reduce U.S. dependence on foreign oil and would reduce emissions and improve air quality. (See Figure 9.6.)

- Over $60 \%$ of the government officials, over $60 \%$ of the safety and codes officials and over $50 \%$ of end user respondents believe that hydrogen is as safe as gasoline or diesel fuel. Corresponding percentages for the general public and students, though lower, have increased since 2004. In all five populations, greater proportions feel that hydrogen is not too dangerous for everyday use by the general public. (See Figure 9.8. Also see Figures $4.21,5.19,6.16,7.24$, and surrounding discussion for statistical significance levels of comparisons of 2004 and 2008 results for the individual populations. Safety and codes officials were surveyed in 2008/2009 only.)

- About $21 \%$ of the state and local agencies surveyed in 2008 have plans to use hydrogen and fuel cell technologies within the next five years, which is essentially the same as in 2004. (See Figure 6.11.) 
- When asked about implementing hydrogen and fuel cell technologies to meet their organizations' energy needs, almost half (48.8\%) of end users stated their position as "wait and see how the market develops," and 30\% stated their position as "considering it but need more information." (See Figure 7.8.)

- According to the 2008/2009 surveys, the Internet is an important source for obtaining energy information for state and local officials, end users, and safety and codes officials; television is the primary source of energy information for the general public and students. (See Figure 9.10.) These results are very similar to findings in 2004.

- When asked about training, $69 \%$ of state and local agency officials, $71 \%$ of end users, and $78 \%$ of safety and codes officials said they would like to participate in a class on hydrogen or fuel cell technologies.

- State and local officials were most likely to rate themselves as either "familiar" or "very familiar" with hydrogen and fuel cell technologies, followed closely by safety and codes officials. End users were less likely to rate themselves this way, students and the general public, much less likely.

- State and local officials were most likely to rate themselves as either "Familiar" or "Very familiar" with hydrogen and fuel cell technologies, followed by safety and codes officials (See Figure 9.1.)

- Statistically significance differences between genders were observed in responses to several of the questions about safety and technology acceptance, in the general public, student, and end user populations. (See Figure 4.15-17, 5.12, 7.16.)

- No statistically significant changes since 2004 were observed in respondent concepts (state and local government agencies and end user populations only) of time frames for implementing hydrogen technologies. (See Tables 6.4 and 7.3.) 


\section{REFERENCES}

AAPOR, Standard Definitions: Final Dispositions of Case Codes and Outcome Rates for Surveys, The American Association for Public Opinion Research, Lenexa, Kansas, http://www.aapor.org/uploads/Standard_Definitions_07 08_Final.pdf, revised 2008.

AAPOR, "Best Practices for Survey and Public Opinion Research," http://www.aapor.org/bestpractices .

Associated Press, "More Than One-Sixth of Households Have Only Cell Phones," http://www.ohio.com/business/36313319.html, Posted 01:28 p.m. EST, Dec 17, 2008.

Blumberg, Stephen J., Julian V. Luke, and Marcie L. Cynamon, "Telephone Coverage and Health Survey Estimates: Evaluating the Need for Concern About Wireless Substitution," American Journal of Public Health, 96(5), May 2006.

Blumenthal, Mark, "Cell Phones and Political Surveys: Part I," http://www.pollster.com/blogs/cell phones and political_surv.php, July 3, 2007.

Bureau of Transportation Statistics, "Omnibus Survey, Household Survey Results," http://www.bts.gov/omnibus_surveys/household_survey/general_methodology.html.

Cochran, William G., Sampling Techniques, Third Edition, John Wiley \& Sons, Inc., New York, 1977.

Frankel, Lester R., "The Report of the CASRO Task Force on Response Rates," in: Improving Data Quality in a Sample Survey, edited by Frederick Wiseman, Cambridge, Massachusetts, Marketing Science Institute, 1983.

Keeter, S., C. Kennedy, M. Dimock, J. Best, and P. Craighill, "Gauging the Impact of Growing Nonresponse on Estimates from a National RDD Telephone Survey," Public Opinion Quarterly, 70(5), 759-779, http://poq.oxfordjournals.org/cgi/reprint/70/5/759.pdf, Special Issue, 2006.

Lavrakas, Paul J., Charles D. Shuttles, Charlotte Steeh, and Howard Fienberg, "The State of Surveying Cell Phone Numbers in the United States, 2007 and Beyond," Public Opinion Quarterly, 71(5), 840-854, 2007.

Link, Michael W., et al., "Practicability of Including Cell Phone Numbers in Random Digit Dialed Surveys: Pilot Study Results from the Behavioral Risk Factor Surveillance System," http://www.fcsm.gov/07papers/Link.II-C.pdf, accessed 2008.

Marketing Systems Group, “GENESYS,” http://www.m-s-g.com/genesys/genesyshme.htm. 
McGuckin, Nancy, Mary Ann Keyes, and Susan Liss, "Hang-ups-Looking at Nonresponse in Telephone Surveys," International Conference on Travel Survey Methods, http://www.fhwa.dot.gov/ohim/hang_ups.htm, 2002.

SAS Institute, SAS/STAT 9.1 User's Guide, SAS Institute, Inc., Cary, North Carolina, 2004.

Schmoyer, R. L., Tykey Truett, and Christy Cooper, Results of the 2004 Knowledge and Opinions Surveys for the Baseline Knowledge Assessment of the U.S. Department of Energy Hydrogen Program, ORNL/TM-2006/417, http://cta.ornl.gov/cta/Publications/Reports/ORNL_TM_2006_417.pdf, April 2006.

Schmoyer, R. L., Tykey Truett, and Susan Diegel, Data Collection, Quality Assurance, and Analysis Plan for the 2008/2009 Hydrogen and Fuel Cells Knowledge and Opinions Surveys, ORNL/TM-2008/113, http://cta.ornl.gov/cta/Publications/Reports/ORNL_TM_2008_113.pdf, September 2008.

Truett, Tykey, Literature Review for the Baseline Knowledge Assessment of the Hydrogen, Fuel Cells, and Infrastructure Technologies Program, ORNL/TM-2003/258, http://cta.ornl.gov/cta/Publications/Reports/ORNL TM 2003 258.pdf, October 2003.

Truett, Tykey, Rick Schmoyer, and Christy Cooper. Compendium: Surveys Evaluating Knowledge and Opinions of Hydrogen and Fuel Cell Technologies, ORNL/TM2008/151, http://www-cta.ornl.gov/cta/Publications/Reports/ORNL_TM_2008_151.pdf, October 2008.

U.S. Census Bureau, "Projected Population by Single Year of Age, Sex, Race, and Hispanic Origin for the United States: July 1, 2000 to July 1, 2050," http://www.census.gov/population/www/projections/downloadablefiles.html, released 2008.

ZuWallack, Randal S., "Piloting Data Collection via Cellular Phones: Results, Experiences, and Lessons Learned," Macro International Inc. (white paper), http://www.orcmacro.com/Survey/CellPhone/Cell\%20phone $\% 20$ white $\% 20$ paper.pdf, September 2007. 


\title{
APPENDIX A SURVEY INSTRUMENTS
}

\author{
A.1. GENERAL PUBLIC SURVEY \\ A.2.. STUDENT SURVEY \\ A.3. STATE AND LOCAL GOVERNMENT AGENCIES \\ A.4. END USER SURVEY \\ A.5. SAFETY AND CODE OFFICIALS
}




\section{A.1. GENERAL PUBLIC SURVEY}

OPINION RESEARCH CORPORATION

JANUARY 2008

HYDROGEN-GENERAL PUBLIC

ORC \# 35878

BALLOT \#

TELEPHONE \#

SURVEY \#

CALL

\section{QUOTA CELLS/TARGETS}

1,000 total respondents

TELEPHONE NUMBER: TIME ENDED:

TIME STARTED:

LENGTH: (MINUTES)

DATE:

INTERVIEWER:

I.D.:

INTERVIEWERS: MAKE SURE YOU HAVE THE FOLLOWING TO GIVE TO RESPONDENTS AS NEEDED OR IF REQUESTED:

- OMB CONTROL NUMBER: 1910-5124

- HFCIT WEBSITE URL: http://wwwl.eere.energy.gov/hydrogenandfuelcells/education/

- IF ASKED AT ANY POINT DURING THE SURVEY, THE INTERVIEWER SHOULD

TELL THE RESPONDENT THAT THERE ARE NO TRICK QUESTIONS

Hello, I'm calling from Opinion Research Corporation on behalf of the U.S. Department of Energy. Your household has been randomly selected for an important national research survey about new energy sources. I want to assure you we are not selling any products or services. 
S1 This survey is to be conducted with one adult, 18 years of age or older, who lives in this household. If there is more than one, may I please speak to the adult in this household who had the most recent birthday?

01 YES, SPEAKING

02 YES, SOMEONE ELSE

03 NO, NOT AVAILABLE NOW

04 NO, NOT AVAILABLE UNTIL AFTER FIELD (INSERT LAST DATE OF FIELD)

96 BUSINESS --> THANK AND RECORD AS UNUSABLE; BUSINESS

97 GROUP QUARTERS --> THANK AND RECORD AS UNUSABLE; GROUP QUARTERS

98 OTHER NON-HOUSEHOLD - > THANK AND RECORD AS UNUSABLE; OTHER NON-HOUSEHOLD

99 REFUSED---> THANK, RECORD AS REFUSED AFTER INTRO/HH

\section{IF S1(01), CONTINUE TO S2}

IF S1 (02), CONTINUE

IF S1 (03), SET CALL BACK, RECORD FIRST NAME FOR REFERENCE

IF S1(04), THANK AND RECORD AS UNAVAILABLE TILL AFTER FIELD

\section{WHEN RESPONDENT ON THE PHONE/ON CALLBACK : [READ AS NEEDED]}

Hello, I'm _ calling from Opinion Research Corporation. We're conducting a research survey on behalf of the U.S. Department of Energy about new energy sources. We are not selling any products or services.

S2 The survey takes about 12 minutes to complete. While your responses are voluntary, every response is extremely important because the results to this survey will be used to help design the hydrogen education program for the U.S. Department of Energy. Your responses are confidential and will not be associated with your household in any way.

01 OK TO CONTINUE

02 NOT CONVENIENT, SET CALL BACK APPOINTMENT

99 REFUSED --> RECORD AS REFUSED AFTER INTRO/RESP IDENTIFIED

$\begin{array}{ll}\text { RECORD GENDER } \\ 01 & \text { MALE } \\ 02 & \text { FEMALE }\end{array}$


Before we get started, I want to mention that there are both technical and opinion questions in the survey. Tell me what you think or believe, but keep in mind that "no opinion" or "don't know" are perfectly acceptable responses.

First of all ...

Q1 Please rate your familiarity with hydrogen and fuel cell technologies. Are you... [READ LIST. RECORD ONE ANSWER]

01 Not at all familiar - You know nothing about hydrogen and fuel cell technologies

02 Slightly familiar - You've heard about hydrogen and fuel cell technologies, read an article or watched a television feature about the technology, or participated in a casual conversation about the technology

03 Familiar - You've had limited experience with hydrogen and fuel cell technologies, researched the subjec

$04 \mathrm{t}$ for school, work, or personal interest, or learned about the technology in a class or workshop

05 Very familiar - You consider yourself an expert in hydrogen and fuel cell technologies

Q2 I am going to read several statements. After each one, please tell me if you believe the statement is true, if it is false, or if you don't know. [ROTATE STATEMENTS]

$01 \quad$ True

$02 \quad$ False

99 Don't know/No opinion

A. Hydrogen gas is toxic

B. Fuel cells produce electricity through hydrogen combustion

C. Hydrogen is lighter than air

D. Hydrogen has a distinct odor

Q3 Which of the following can fuel cells provide power to? [READ ENTIRE LIST BEFORE RECORDING ONE ANSWER. ROTATE 01-03]

$01 \quad$ Your home

02 Your car

03 Your laptop computer

04 All of these

05 Or, none of these

99 Don't know/No opinion

Q4 In which state or condition can hydrogen be stored? [READ ENTIRE LIST BEFORE RECORDING ONE ANSWER. ROTATE 01-02]

01 Chemical compound

02 Liquid

03 Both of these

04 Or, neither of these

99 Don't know/No opinion 
Q5 When using pure hydrogen, fuel cell vehicles generate electricity, water, and what else? [READ ENTIRE LIST BEFORE RECORDING ONE ANSWER. ROTATE 01-03]

$01 \quad$ Carbon dioxide

$02 \quad$ Nitrous oxides

03 Heat

04 Or, all of these

99 Don't know/No opinion

Q6 Hydrogen can be produced using which of the following sources of energy? [READ ENTIRE LIST BEFORE RECORDING ONE ANSWER. ROTATE 01-03]

$\begin{array}{ll}01 & \text { Natural gas } \\ 02 & \text { Sunlight } \\ 03 & \text { Organic matter } \\ 04 & \text { Or, all of these } \\ 99 & \text { Don't know/No opinion }\end{array}$

Q7A For the next question, I will ask you to rank five items. It may be easier if you write them down. Do you need a moment to get something to write with?

The factors are: [READ AND ROTATE FACTORS]. Now, please tell me which factor is MOST important to you, personally, when selecting a fuel for your vehicle or power supply for your home or business? [RE-READ ENTIRE LIST AS NEEDED BEFORE RECORDING ONE ANSWER]
01 Safety
02 Low cost
03 Environmental impact
04 Convenience
05 Performance
99 DON'T KNOW/REFUSED/NO RESPONSE

[IF Q7A (01-05) MENTIONED, ASK FOR EACH NOT MENTIONED IN Q7A]

Q7B Now, from the remaining factors, which one of the following is MOST IMPORTANT to you when selecting a fuel for your vehicle or power supply for your home or business? [READ ENTIRE LIST BEFORE RECORDING ONE ANSWER]
$01 \quad$ Safety
02 Low cost
03 Environmental impact
04 Convenience
05 Performance
99 DON'T KNOW/REFUSED/NO RESPONSE 
[IF Q7B (01-05) MENTIONED, ASK FOR EACH NOT MENTIONED IN Q7A AND Q7B]

Q7C Now, from the remaining factors, which one of the following is MOST IMPORTANT to you when selecting a fuel for your vehicle or power supply for your home or business? [READ ENTIRE LIST BEFORE RECORDING ONE ANSWER]

$01 \quad$ Safety

02 Low cost

03 Environmental impact

04 Convenience

05 Performance

99 DON'T KNOW/REFUSED/NO RESPONSE

[IF Q7C (01-05) MENTIONED, ASK FOR EACH NOT MENTIONED IN Q7A, Q7B, AND Q7C]

Q7D Finally, which of the following factors is MORE IMPORTANT to you when selecting a fuel for your vehicle or power supply for your home or business? [READ ENTIRE LIST BEFORE RECORDING ONE ANSWER]

$01 \quad$ Safety

02 Low cost

03 Environmental impact

04 Convenience

05 Performance

99 DON'T KNOW/REFUSED/NO RESPONSE

Q8 How would you feel if your local gas station also sold hydrogen? Would you say ... [READ ENTIRE LIST BEFORE RECORDING ONE ANSWER.]

$\begin{array}{ll}01 & \text { Frightened } \\ 02 & \text { Uneasy } \\ 03 & \text { At ease } \\ 04 & \text { Or, pleased } \\ 99 & \text { Don't know/No opinion }\end{array}$

Q9 Please tell me if you believe the following statement is true, if it is false, or if you don't know. "Hydrogen is too dangerous for everyday use by the general public."

01 TRUE

02 FALSE

99 DON'T KNOW/NO OPINION 
Q10 Next, I am going to read several statements about potential benefits of using hydrogen as a VEHICLE FUEL. For each, tell me if you disagree, are neutral, agree or if you have no opinion? [ROTATE STATEMENTS]

$01 \quad$ Disagree

$02 \quad$ Are neutral

03 Agree

$99 \quad$ No opinion

A. Using hydrogen will reduce U.S. dependence on foreign oil

B. Using hydrogen will reduce emissions and improve air quality

C. Hydrogen is as safe to use in my car as gasoline and diesel fuels

Q11 Imagine you are shopping for a new car. If you could walk into a dealership today and buy a fuel cell vehicle at the same price as a comparable gasoline vehicle model, would you buy it?
$01 \quad$ YES
$02 \quad$ NO
99 DON'T KNOW/NO OPINION

Q12 How would you feel if a school, hospital, or other building in your neighborhood was powered by a fuel cell located on its property? Would you say ... [READ ENTIRE LIST BEFORE RECORDING ONE ANSWER.]

$\begin{array}{ll}01 & \text { Frightened } \\ 02 & \text { Uneasy } \\ 03 & \text { At ease } \\ 04 & \text { Or, pleased } \\ 99 & \text { Don't know/No opinion }\end{array}$

Q13 For the following applications, please rate the safety of using hydrogen and fuel cells, in comparison with technology in use today.

Is it not as safe, equally as safe or safer to use hydrogen and fuel cells for... [ROTATE STATEMENTS]

$01 \quad$ Not as safe

02 Equally as safe

03 Safer

99 No opinion

A. Personal cars and trucks

B. Buses and commercial vehicles

C. Large power plants

D. Small portable devices such as laptop computers or cell phones

E. Onsite power for the home

F. Onsite power for buildings such as hospitals and schools 
Q14 The next question is about your use of information sources that can help you make decisions about energy costs and safety. How often do you use each of the following sources for energy information? Would you say never, sometimes, or frequently? [DO NOT ROTATE STATEMENTS]

$01 \quad$ Never

02 Sometimes

03 Frequently

99 DON'T KNOW
A. Teachers and schools
B. Friends and family members
C. Environmental and conservation groups
D. Utility companies or brokers, for example, gas or electricity providers
E. Industry or trade associations or non-profit organizations
F. Federal government
G. State government
H. Local government

Q15 Finally, how often do you get ENERGY information from different types of mass media? Would you say that you never, sometimes, or frequently get energy information from ... [ROTATE STATEMENTS]

\section{$01 \quad$ Never \\ 02 Sometimes \\ 03 Frequently \\ 99 DON'T KNOW}
A. Television
B. Radio
C. The Internet
D. Newspapers and general interest magazines
E. Science and technology magazines and journals
F. Business or trade magazines 
I have a few questions about you and your household for statistical purposes only.

Q16 What was the last grade in school you completed?

$\begin{array}{ll}01 & \text { 8TH GRADE OR LESS } \\ 02 & \text { HIGH SCHOOL INCOMPLETE [GRADES 9, 10, 11] } \\ 03 & \text { HIGH SCHOOL COMPLETE [GRADE 12] } \\ 04 & \text { SOME COLLEGE, BUT NO DEGREE } \\ 05 & \text { ASSOCIATES DEGREE } \\ 06 & \text { COLLEGE GRADUATE/BACHELORS DEGREE } \\ 07 & \text { POSTGRADUATE DEGREE, SUCH AS MASTER'S, PH.D., MD, JD } \\ 99 & \text { REFUSED/NR }\end{array}$

Q17 What is your age?

$\begin{array}{ll}01 & 18-20 \\ 02 & 21-24 \\ 03 & 25-29 \\ 04 & 30-34 \\ 05 & 35-39 \\ 06 & 40-44 \\ 07 & 45-49 \\ 08 & 50-54 \\ 09 & 55-59 \\ 10 & 60-64 \\ 11 & 65-69 \\ 12 & 70-74 \\ 13 & 75 \text { OR OLDER } \\ 99 & \text { REFUSED/NR }\end{array}$

Q18 Which of the following best describes you? [READ LIST]

$\begin{array}{ll}01 & \text { White/Caucasian } \\ 02 & \text { Black/African-American } \\ 03 & \text { Hispanic } \\ 04 & \text { Asian/Asian-American } \\ 05 & \text { American Indian/Native Alaskan } \\ 06 & \text { Some other race } \\ 99 & \text { REFUSED/NR }\end{array}$


Q19 How many total telephone numbers does your household have that a person can answer? Please do not include extension phones, cell phones or telephone lines that are used only for a fax or a modem.

$\begin{array}{ll}01 & \text { ONE } \\ 02 & \text { TWO } \\ 03 & \text { THREE } \\ 04 & \text { FOUR } \\ 05 & \text { FIVE OR MORE } \\ 99 & \text { DON'T KNOW/REFUSED }\end{array}$

That's all the questions we have today. Thank you very much for your time.

CONFIRM PHONE NUMBER. 


\section{A.2. STUDENT SURVEY}

OPINION RESEARCH CORPORATION

JUNE 2008

HYDROGEN-STUDENTS (TEENS 12-17 YEARS OLD)

ORC \# 36048

BALLOT \#

TELEPHONE \#

SURVEY \#

CALL

1000 TEENS 12-17

INTERVIEWERS: MAKE SURE YOU HAVE THE FOLLOWING TO GIVE TO RESPONDENTS AS NEEDED OR IF REQUESTED:

- OMB CONTROL NUMBER: 1910-5124

- HFCIT WEBSITE URL: http://www1.eere.energy.gov/hydrogenandfuelcells/education/

- IF ASKED AT ANY POINT DURING THE SURVEY, THE INTERVIEWER SHOULD

TELL THE RESPONDENT THAT THERE ARE NO TRICK QUESTIONS

Hello, I'm __ calling from Opinion Research Corporation on behalf of the U.S. Department of Energy. Your household has been randomly selected for an important national research survey about new energy sources. I want to assure you we are not selling any products or services.

S1 May I speak to an adult 18 years old or older who lives in this household?

$\begin{array}{ll}01 & \text { YES } \\ 03 & \text { NO, NOT AVAILABLE NOW -- > SET CALLINUE } \\ 04 & \text { NO, NOT AVAILABLE UNTIL AFTER FIELD--> THANK AND RECORD AS } \\ & \\ 05 & \text { SCHEDULE SPANISH CALLBACK } \\ 96 & \text { BUSINESS --> THANK AND RECORD AS UNUSABLE; BUSINESS } \\ 97 & \text { GROUP QUARTERS --> THANK AND RECORD AS UNUSABLE; GROUP } \\ & \text { QUARTERS } \\ 98 & \text { OTHER NON-HOUSEHOLD -> THANK AND RECORD AS UNUSABLE; OTHER } \\ & \text { NON-HOUSEHOLD } \\ 99 & \text { REFUSED---> THANK, RECORD AS REFUSED AFTER INTRO/HH }\end{array}$




\section{S2A-E OMITTED}

S2F And how many people in this household are 12 to 17 years of age?

$01 \quad$ ONE

02 TWO OR MORE

98 NONE

99 REFUSED

IF TEENS 12-17, S2F [01,02] CONTINUE.

IF NO TEENS, S2F [98], THANK AND RECORD AS INELIGIBLE, NO TEEN (S2F)

IF REFUSED, S2F [99], THANK AND RECORD AS REFUSED AT SCREEN (S2F)

S3 May I please speak to the 12-17 year old who had the most recent birthday? The survey should take about 14 minutes to complete.

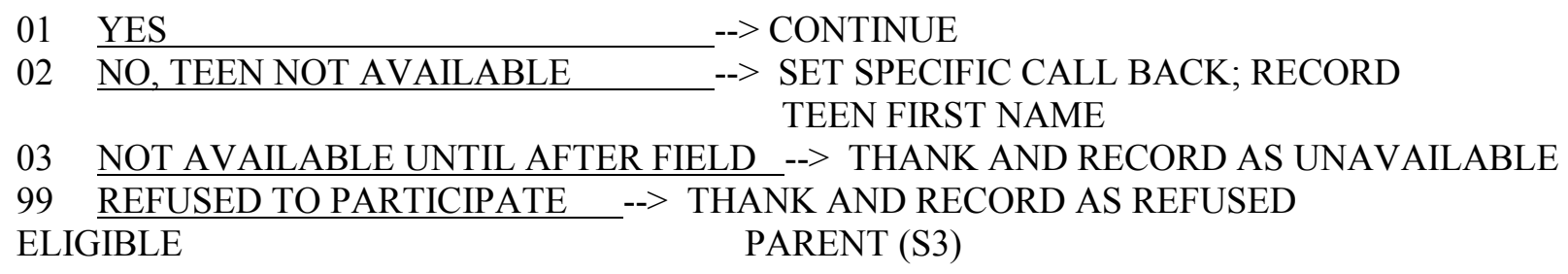

IF THE TEEN 12-17 IS NOT AVAILABLE, SET CALLBACK. WHEN CALL BACK OCCURS, WE SHOULD BE ASKING FOR THE TEEN, SINCE WE ALREADY HAVE THE PARENTAL PERMISSION. 
WHEN TEEN RESPONDENT ON THE PHONE/ON CALLBACK: [READ AS NEEDED] Hello, I'm _ calling from Opinion Research Corporation. We're conducting a research survey on behalf of the U.S. Department of Energy about your knowledge and opinions about hydrogen and fuel cell technologies. Your responses are voluntary; however, every response is extremely important. The survey takes about 14 minutes to complete.

S4 The results to this survey will be used to help design the hydrogen education program for the U.S. Department of Energy. Your answers are confidential and will not be associated with you or your household in any way.

INTERVIEWER RECORD:

01 OK TO CONTINUE

02 NOT CONVENIENT, SET CALL BACK APPOINTMENT; RECORD TEEN FIRST NAME

99 REFUSED --> RECORD AS REFUSED /TEEN IDENTIFIED [S4]

\title{
RECORD GENDER OF TEEN
}

MALE

FEMALE

\begin{tabular}{c} 
CHECK GENDER/REGION QUOTAS. \\
IF FULL, TERMINATE AND RECORD AS INELIGIBLE, QUOTA FILLED \\
NORTHEAST $(\mathbf{N}=\mathbf{1 8 2})-($ MALE $=\mathbf{9 1} /$ FEMALE $=\mathbf{9 1})$ \\
NORTH CENTRAL $(\mathbf{N}=\mathbf{2 1 1})-($ MALE $=\mathbf{1 0 6} /$ FEMALE $=\mathbf{1 0 5})$ \\
SOUTH $(\mathbf{N}=\mathbf{3 6 8})-($ MALE $=\mathbf{1 8 4} /$ FEMALE $=\mathbf{1 8 4})$ \\
WEST $(\mathbf{N}=\mathbf{2 3 9})-($ MALE $=\mathbf{1 1 9} /$ FEMALE $=\mathbf{1 2 0})$ \\
\hline
\end{tabular}

S5 Please tell me, what is your age?
$01 \quad 12$
$02 \quad 13$
$03 \quad 14$
$04 \quad 15$
$05 \quad 16$
$06 \quad 17$
$->$ CONTINUE
99 REFUSED TO PARTICIPATE -> THANK AND RECORD AS REFUSED AT AGE(S5)

\author{
CHECK AGE QUOTAS. \\ Ages 12-14 ( $\mathrm{N}=500)$ \\ Ages 15-17 (N=500)
}

IF FULL, TERMINATE AND RECORD AS INELIGIBLE, QUOTA FILLED 
Before we get started, I want to mention that there are both technical and opinion questions in the survey. Tell me what you think or believe, but keep in mind that "no opinion" or "don't know" are perfectly acceptable responses.

First of all ...

Q1 Please rate your familiarity with hydrogen and fuel cell technologies. Are you... [READ LIST. RECORD ONE ANSWER]

06 Not at all familiar - You know nothing about hydrogen and fuel cell technologies

07 Slightly familiar - You've heard about hydrogen and fuel cell technologies, read an article or watched a television feature about the technology, or participated in a casual conversation about the technology

08 Familiar - You've had limited experience with hydrogen and fuel cell technologies, researched the subject for school, work, or personal interest, or learned about the technology in a class or workshop

09 Very familiar - You consider yourself an expert in hydrogen and fuel cell technologies

Q2 I am going to read several statements. After each one, please tell me if you believe the statement is true, if it is false, or if you don't know.

[ROTATE STATEMENTS]

03 True

$04 \quad$ False

99 Don't know/No opinion

A. Hydrogen gas is toxic

B. Fuel cells produce electricity through hydrogen combustion

C. Hydrogen is lighter than air

D. Hydrogen has a distinct odor

Q3 Which of the following can fuel cells provide power to?

[READ ENTIRE LIST BEFORE RECORDING ONE ANSWER. ROTATE 01-03]

04 Your home

05 Your car

06 Your laptop computer

06 All of these

07 Or, none of these

99 Don't know/No opinion

Q4 In which state or condition can hydrogen be stored?

[READ ENTIRE LIST BEFORE RECORDING ONE ANSWER. ROTATE 01-02]

05 Chemical compound

06 Liquid

07 Both of these

08 Or, neither of these

99 Don't know/No opinion 
Q5 When using pure hydrogen, fuel cell vehicles generate electricity, water, and what else? [READ ENTIRE LIST BEFORE RECORDING ONE ANSWER. ROTATE 01-03]

$05 \quad$ Carbon dioxide

$06 \quad$ Nitrous oxides

$07 \quad$ Heat

08 Or, all of these

99 Don't know/No opinion

Q6 Hydrogen can be produced using which of the following sources of energy?

[READ ENTIRE LIST BEFORE RECORDING ONE ANSWER. ROTATE 01-03]

$05 \quad$ Natural gas

$06 \quad$ Sunlight

$07 \quad$ Organic matter

08 Or, all of these

100 Don't know/No opinion

Q7A-Q7D OMITTED

Q8 How would you feel if your local gas station also sold hydrogen? Would you say ... [READ ENTIRE LIST BEFORE RECORDING ONE ANSWER]

$\begin{array}{cl}05 & \text { Frightened } \\ 06 & \text { Uneasy } \\ 07 & \text { At ease } \\ 08 & \text { Or, pleased } \\ 100 & \text { Don't know/No opinion }\end{array}$

Q8A How would you feel if your school's electricity and heat were provided by a fuel cell located on school grounds? Would you say ...

[READ ENTIRE LIST BEFORE RECORDING ONE ANSWER]

$01 \quad$ Frightened

02 Uneasy

03 At ease

04 Or, pleased

99 Don't know/No opinion 
Q9 Please tell me if you believe the following statement is true, if it is false, or if you don't know.

"Hydrogen is too dangerous for everyday use by the general public."

03 TRUE

04 FALSE

99 DON'T KNOW/NO OPINION

Q10 Next, I am going to read several statements about potential benefits of using hydrogen as a VEHICLE FUEL. For each, please tell me if you disagree, are neutral, agree or if you have no opinion? [ROTATE STATEMENTS]

$04 \quad$ Disagree

$05 \quad$ Are neutral

06 Agree

$100 \quad$ No opinion

A. Using hydrogen will reduce U.S. dependence on foreign oil

B. Using hydrogen will reduce emissions and improve air quality

C. Hydrogen is as safe to use in my car as gasoline and diesel fuels

\section{Q11-Q12 OMITTED}

Q13 For the following applications, please rate the safety of using hydrogen and fuel cells, in comparison with technology in use today.

Is it not as safe, equally as safe or safer to use hydrogen and fuel cells for... [ROTATE STATEMENTS]

$01 \quad$ Not as safe

02 Equally as safe

03 Safer

99 No opinion

A. Personal cars and trucks

B. Buses and commercial vehicles

C. Large power plants

D. Small portable devices such as laptop computers or cell phones

E. Onsite power for the home

F. Onsite power for buildings such as hospitals and schools

Q14-Q19 OMITTED 
Q20 I am going to read several characteristics of new vehicles. Please imagine that you are shopping for an automobile, and rank each of the following characteristics for its importance to you. Would you say it is not important, you are neutral, it is important or you don't have an opinion? [ROTATE STATEMENTS]

$01 \quad$ Not important

02 Neutral

03 Important

99 No opinion

A. Cost of vehicle at the point of sale

B. Gas mileage

C. Power and speed

E. Reliability

F. Safety

G. Impact on the environment, or emissions produced

I am going to ask several questions regarding science topics that you may have learned about at school or home or by some other method, for example, church, scouts, the Internet, etc.

\section{ASK QUESTIONS Q21-Q23 IN SEQUENCE FOR A-G}

Q21 Have you...

[ROTATE STATEMENTS]

$01 \quad$ YES

$02 \quad \mathrm{NO}$

99 DON'T KNOW

A. Received instruction on or otherwise learned about energy use, fuels, and emissions

B. Received instruction on or otherwise learned about hydrogen and fuel cells

C. Ever used a demonstration kit to produce hydrogen

D. Ever used a model fuel cell science kit

E. Ever seen or used a hydrogen fuel cell model car

F. Participated in a fuel cell vehicle design competition

G. Participated in a science bowl or other science competition 
[ASK FOR EACH Q21A-G (01)]

Q22 Did the learning or activity take place at school?

[IF ASKED, INDICATE THAT "AT SCHOOL" INCLUDES HOME-SCHOOLED ACTIVITIES FOR STUDENTS WHO RECEIVE ALL THEIR EDUCATION VIA HOME SCHOOLING]

$01 \quad$ YES

02 NO

99 DON'T KNOW

A. Received instruction on or otherwise learned about energy use, fuels, and emissions

B. Received instruction on or otherwise learned about hydrogen and fuel cells

C. Ever used a demonstration kit to produce hydrogen

D. Ever used a model fuel cell science kit

E. Ever seen or used a hydrogen fuel cell model car

F. Participated in a fuel cell vehicle design competition

G. Participated in a science bowl or other science competition

[ASK FOR EACH Q22A-G (02-99)]

Q23 If not at school, where did the learning take place?

[DO NOT READ LIST. RECORD ONE ANSWER]

$\begin{array}{ll}01 & \text { HOME [FAMILY ACTIVITY, NOT HOME-SCHOOL] } \\ 02 & \text { CHURCH/TEMPLE/RELIGIOUS ORGANIZATION } \\ 03 & \text { SCOUTS } \\ 04 & \text { THE INTERNET } \\ 195 & \text { OTHER [SPECIFY] } \\ 199 & \text { DON'T KNOW }\end{array}$

A. Received instruction on or otherwise learned about energy use, fuels, and emissions

B. Received instruction on or otherwise learned about hydrogen and fuel cells

C. Ever used a demonstration kit to produce hydrogen

D. Ever used a model fuel cell science kit

E. Ever seen or used a hydrogen fuel cell model car

F. Participated in a fuel cell vehicle design competition

G. Participated in a science bowl or other science competition 
Q24 How often do you get ENERGY information from different types of mass media? Would you say that you never, sometimes, or frequently get energy information from ...

[ROTATE STATEMENTS]

$01 \quad$ Never

02 Sometimes

03 Frequently

99 DON'T KNOW
A. Television
B. Radio
C. The Internet
D. Newspapers and general interest magazines
E. Science and technology magazines and journals
F. Classroom instructions
G. General discussions with family and/or friends

I have a few questions about you and your household for statistical purposes only.

Q25 What was the last grade of school you completed?
01 4TH OR LESS
$02 \quad 5$
$03 \quad 6$
$04 \quad 7$
$05 \quad 8$
$06 \quad 9$
$07 \quad 10$
$08 \quad 11$
$09 \quad 12$
10 FIRST YEAR OF COLLEGE OR MORE
11 HOME SCHOOLED
99 REFUSED/NR

Q26 Which of the following best describes you?

[READ LIST. RECORD AS MANY AS APPLY]

$\begin{array}{ll}01 & \text { White/Caucasian } \\ 02 & \text { Black/African-American } \\ 03 & \text { Hispanic } \\ 04 & \text { Asian/Asian-American } \\ 05 & \text { American Indian/Native Alaskan } \\ 06 & \text { Some other race } \\ 99 & \text { REFUSED/NR }\end{array}$


Q27 How many total telephone numbers does your household have that a person can answer? Please do not include extension phones, cell phones or telephone lines that are used only for a fax or a modem.

$\begin{array}{ll}01 & \text { ONE } \\ 02 & \text { TWO } \\ 03 & \text { THREE } \\ 04 & \text { FOUR } \\ 05 & \text { FIVE OR MORE } \\ 99 & \text { DON'T KNOW/REFUSED }\end{array}$

Q28 INTERVIEWER - DO NOT ASK: WAS THIS SURVEY CONDUCTED MOSTLY IN

01 ENGLISH

02 SPANISH

That's all the questions we have today. Thank you very much for your time.

CONFIRM PHONE NUMBER 


\title{
A.3. STATE AND LOCAL GOVERNMENT AGENCIES
}

\author{
OPINION RESEARCH CORPORATION \\ FEBRUARY 2008 \\ HYDROGEN-STATE AND LOCAL GOVERNMENT AGENCIES
}

ORC \# 35948

BALLOT \#

TELEPHONE \#

SURVEY \#

CALL

\section{QUOTA CELLS/TARGETS}

XXX total respondents

TELEPHONE NUMBER: TIME ENDED:

TIME STARTED:

LENGTH: (MINUTES)

DATE:

INTERVIEWER:

I.D.:

INTERVIEWERS: MAKE SURE YOU HAVE THE FOLLOWING TO GIVE TO RESPONDENTS AS NEEDED OR IF REQUESTED:

- OMB CONTROL NUMBER: 1910-5124

- HFCIT WEBSITE URL: http://www1.eere.energy.gov/hydrogenandfuelcells/education/

- IF ASKED AT ANY POINT DURING THE SURVEY, THE INTERVIEWER SHOULD

TELL THE RESPONDENT THAT THERE ARE NO TRICK QUESTIONS

AT INTRO SCREEN, DISPLAY INFO FOR INTERVIEWER: RESPONDENT NAME, TITLE AND AGENCY CONTACTED

SA May I please speak to [INSERT RESPONDENT NAME FROM SAMPLE]?

$\begin{array}{lll}01 & \text { YES } & -->\text { CONTINUE } \\ 02 & \text { NOT AVAILABLE NOW } & -->\text { SCHEDULE CALLBACK } \\ 03 & \text { NO LONGER AT AGENCY } & \text {--> SKIP TO S2 } \\ 99 & \text { REFUSED }\end{array}$


(READ ONCE RESPONDENT IS ON THE PHONE)

Hello, my name is calling from Opinion Research Corporation on behalf of the U.S. Department of Energy. Your agency has been selected for an important national research survey about new energy sources. You have (your office has) been sent a letter from JoAnn Milliken, Program Manager of DOE's Hydrogen Program, which explained the purpose and importance of this survey. The survey takes about 12 minutes to complete.

S1 $01 \quad$ CONTINUE WITH SURVEY -->SKIP TO TEXT BEFORE Q1 02 DID NOT RECEIVE LETTER/N NOT CONVENIENT NOW INFORMATION -->CONTINUE 03 04 99 NOT APPROPRIATE PERSON REFUSED ->SET CALL BACK APPOINTMENT

[ASK IF S1(02)]

S1A The Department of Energy is sponsoring a survey of state and local agencies and your agency has been selected for this important national research about new energy sources. Your responses are confidential and your agency's name will not be associated with the survey results. While your responses are voluntary, every response is extremely important because the results to this survey will be used to guide the development of The Department of Energy's hydrogen education activities.

$\begin{array}{ll}01 & \text { CONTINUE WITH SURVEY } \\ 02 & \text { NOT CONVENIENT NOW -->SKIP TO TEXT BEFORE Q1 } \\ 03 & \text { NOT APPROPRIATE PERSON TO CONDUCT INTERVIEW-->CONTINUE TO S2 } \\ 99 & \text { REFUSED --> THANK AND RECORD AS REFUSED (S1A) }\end{array}$

S2 [IF SA (03) READ] Can you please give me the name, title and telephone number of the person who now fills the position vacated by [INSERT RESPONDENT NAME]?

[IF S1 (04) OR S1A (03) READ] Can you please give me the name, title and telephone number of the person who is best suited to represent your agency for this survey?

01 \begin{tabular}{ll} 
YES & $-->$ CONTINUE \\
\hline NO/REFUSED & $-->$ THANK AND
\end{tabular}

99 --> THANK AND RECORD AS REFUSED (S2) 
FIELDS FOR RECORDING CONTACT INFORMATION

Full Name: 2a- First name, 2b- Last name

Title: 2c

Telephone number: $2 \mathrm{~d}$

S2VER [CONFIRM INFORMATION- READ BACK TO THEM FOR ACCURACY]

01 FIRST NAME INCORRECT/CHANGE

02 LAST NAME INCORRECT/CHANGE

03 TITLE INCORRECT/CHANGE

04 TELEPHONE NUMBER INCORRECT/CHANGE

05 ALL INFORMATION CORRECT

99 REFUSED -->THANK AND RECORD AS REFUSED (S2VER)

\section{INTERVIEWER: IF NEW CONTACT WOULD LIKE TO CONDUCT INTERVIEW NOW, GO BACK TO TEXT BEFORE S1. OTHERWISE, IF PROVIDED NEW CONTACT INFO, S2[1], S2VER[05] SCHEDULE CALLBACK.}

Before we get started, I want to mention that there are both technical and opinion questions in the survey. Tell me what you think or believe, but keep in mind that "no opinion" or "don't know" are perfectly acceptable responses.

First of all ...

Q1 Please rate your familiarity with hydrogen and fuel cell technologies. Are you... [READ LIST. RECORD ONE ANSWER]

10 Not at all familiar - You know nothing about hydrogen and fuel cell technologies

11 Slightly familiar - You've heard about hydrogen and fuel cell technologies, read an article or watched a television feature about the technology, or participated in a casual conversation about the technology

12 Familiar - You've had limited experience with hydrogen and fuel cell technologies, researched the subject for school, work, or personal interest, or learned about the technology in a class or workshop

13 Very familiar - You consider yourself an expert in hydrogen and fuel cell technologies

Q2 I am going to read several statements. After each one, please tell me if you believe the statement is true, if it is false, or if you don't know. [ROTATE STATEMENTS]

05 True

$06 \quad$ False

99 Don't know/No opinion

A. Hydrogen gas is toxic

B. Fuel cells produce electricity through hydrogen combustion

C. Hydrogen is lighter than air

D. Hydrogen has a distinct odor

Q3 Which of the following can fuel cells provide power to? [READ ENTIRE LIST BEFORE RECORDING ONE ANSWER. ROTATE 01-03] 
$07 \quad$ Your home

08 Your car

09 Your laptop computer

08 All of these

09 Or, none of these

99 Don't know/No opinion

Q4 In which state or condition can hydrogen be stored? [READ ENTIRE LIST BEFORE RECORDING ONE ANSWER. ROTATE 01-02]

09 Chemical compound

10 Liquid

11 Both of these

12 Or, neither of these

99 Don't know/No opinion 
Q5 When using pure hydrogen, fuel cell vehicles generate electricity, water, and what else? [READ ENTIRE LIST BEFORE RECORDING ONE ANSWER. ROTATE 01-03]

09 Carbon dioxide

$10 \quad$ Nitrous oxides

11 Heat

12 Or, all of these

99 Don't know/No opinion

Q6 Hydrogen can be produced using which of the following sources of energy? [READ ENTIRE LIST BEFORE RECORDING ONE ANSWER. ROTATE 01-03]

$\begin{array}{cl}09 & \text { Natural gas } \\ 10 & \text { Sunlight } \\ 11 & \text { Organic matter } \\ 12 & \text { Or, all of these } \\ 101 & \text { Don't know/No opinion }\end{array}$

Q7A For the next question, I will ask you to rank five items. It may be easier if you write them down. Do you need a moment to get something to write with?

The factors are: [READ AND ROTATE FACTORS]. Now, please tell me which factor is MOST important to you, personally, when selecting a fuel for your vehicle or power supply for your home or business? [RE-READ ENTIRE LIST AS NEEDED BEFORE RECORDING ONE ANSWER]
01 Safety
02 Low cost
03 Environmental impact
04 Convenience
05 Performance
99 DON'T KNOW/REFUSED/NO RESPONSE

[IF Q7A (01-05) MENTIONED, ASK FOR EACH NOT MENTIONED IN Q7A]

Q7B Now, from the remaining factors, which one of the following is MOST IMPORTANT to you when selecting a fuel for your vehicle or power supply for your home or business? [READ ENTIRE LIST BEFORE RECORDING ONE ANSWER]
$01 \quad$ Safety
02 Low cost
03 Environmental impact
04 Convenience
05 Performance
99 DON'T KNOW/REFUSED/NO RESPONSE 
[IF Q7B (01-05) MENTIONED, ASK FOR EACH NOT MENTIONED IN Q7A AND Q7B]

Q7C Now, from the remaining factors, which one of the following is MOST IMPORTANT to you when selecting a fuel for your vehicle or power supply for your home or business? [READ ENTIRE LIST BEFORE RECORDING ONE ANSWER]

$01 \quad$ Safety

02 Low cost

03 Environmental impact

04 Convenience

05 Performance

99 DON'T KNOW/REFUSED/NO RESPONSE

[IF Q7C (01-05) MENTIONED, ASK FOR EACH NOT MENTIONED IN Q7A, Q7B, AND Q7C]

Q7D Finally, which of the following factors is MORE IMPORTANT to you when selecting a fuel for your vehicle or power supply for your home or business? [READ ENTIRE LIST BEFORE RECORDING ONE ANSWER]

$01 \quad$ Safety

02 Low cost

03 Environmental impact

04 Convenience

05 Performance

99 DON'T KNOW/REFUSED/NO RESPONSE

Q8 How would you feel if your local gas station also sold hydrogen? Would you say ... [READ ENTIRE LIST BEFORE RECORDING ONE ANSWER.]

$\begin{array}{cl}09 & \text { Frightened } \\ 10 & \text { Uneasy } \\ 11 & \text { At ease } \\ 12 & \text { Or, pleased } \\ 101 & \text { Don't know/No opinion }\end{array}$

Q9 Please tell me if you believe the following statement is true, if it is false, or if you don't know. "Hydrogen is too dangerous for everyday use by the general public."

05 TRUE

06 FALSE

99 DON'T KNOW/NO OPINION 
Q10 Next, I am going to read several statements about potential benefits of using hydrogen as a VEHICLE FUEL. For each, tell me if you disagree, are neutral, agree or if you have no opinion? [ROTATE STATEMENTS]

$07 \quad$ Disagree

$08 \quad$ Are neutral

$09 \quad$ Agree

$101 \quad$ No opinion

A. Using hydrogen will reduce U.S. dependence on foreign oil

B. Using hydrogen will reduce emissions and improve air quality

C. Hydrogen is as safe to use in my car as gasoline and diesel fuels

Q11 OMITTED

Q12 OMITTED

Q13 For the following applications, please rate the safety of using hydrogen and fuel cells, in comparison with technology in use today.

Is it not as safe, equally as safe or safer to use hydrogen and fuel cells for... [ROTATE STATEMENTS]

$01 \quad$ Not as safe

02 Equally as safe

03 Safer

99 No opinion
A. Personal cars and trucks
B. Buses and commercial vehicles
C. Large power plants
D. Small portable devices such as laptop computers or cell phones
E. Onsite power for the home
F. Onsite power for buildings such as hospitals and schools

Q13G If fuel cell vehicles were available today at a cost competitive to gasoline internal combustion engine vehicles, would you recommend buying or leasing them for your organization's or a stakeholder's vehicle fleet?

$01 \quad$ YES

02 NO

99 DON'T KNOW/NO OPINION

Q13H If stationary fuel cells were available today at a cost competitive to traditional power systems, would you recommend buying one to help meet the power needs of your facility or a stakeholder's facility?

$01 \quad$ YES

02 NO

99 DON'T KNOW/NO OPINION 
Q13I I am going to read several statements. Please select the ONE that BEST describes how you feel about using hydrogen and fuel cell technology to meet your organization's energy needs. [READ ENTIRE LIST BEFORE RECORDING ONE ANSWER]

$01 \quad$ I know enough to seriously consider it if products are available

02 I am considering it but need more information

03 I am going to wait to see how the market develops

04 There is no way I'll consider it anytime soon

99 DON'T KNOW/NO OPINION

Q14 The next question is about your use of information sources that can help you make decisions about energy costs and safety. How often do you use each of the following sources for energy information? Would you say never, sometimes, or frequently? [DO NOT ROTATE STATEMENTS]

$01 \quad$ Never

02 Sometimes

03 Frequently

99 DON'T KNOW
A. Teachers and schools
B. Friends and family members
C. Environmental and conservation groups
D. Utility companies or brokers, for example, gas or electricity providers
E. Industry or trade associations or non-profit organizations
F. Federal government
G. State government
H. Local government

Q15 How often do you get ENERGY information from different types of mass media? Would you say that you never, sometimes, or frequently get energy information from ... [ROTATE STATEMENTS]
$01 \quad$ Never
02 Sometimes
03 Frequently
99 DON'T KNOW
A. Television
B. Radio
C. The Internet
D. Newspapers and general interest magazines
E. Science and technology magazines and journals
F. Business or trade magazines

Q16-Q19 OMITTED 
Q20 Does your agency operate any hydrogen vehicles?

$\begin{array}{ll}01 & \text { YES } \\ 02 & \text { NO } \\ 99 & \text { DON'T KNOW }\end{array}$

Q21 Do you know of any other organization that operates hydrogen-powered buses or other fleet vehicles in the area covered by your geographic jurisdiction?

$\begin{array}{ll}01 & \text { YES } \\ 02 & \text { NO } \\ 99 & \text { DON'T KNOW }\end{array}$

Q22 Does your agency own or operate any stationary fuel cells?
$01 \quad$ YES
02 NO
99 DON'T KNOW

Q23 Do you know of any other organization that operates stationary fuel cells in the area covered by your geographic jurisdiction?

$01 \quad$ YES

$02 \quad \mathrm{NO}$

99 DON'T KNOW

Q24 Does your agency have plans to use hydrogen or fuel cells in the future?

$\begin{array}{ll}01 & \text { YES } \\ 02 & \text { NO } \\ 99 & \text { DON'T KNOW }\end{array}$

[ASK IF Q24 (01)]

Q25 What is the time frame for plans to use hydrogen or fuel cells? [READ LIST. RECORD ONE ANSWER]

$01 \quad$ Within the next year

$02 \quad 1-5$ years

03 Over 5 years

99 DON'T KNOW

Q26 Have you ever received information about hydrogen and fuel cell technologies?
$01 \quad$ YES
02 NO
99 DON'T KNOW 
[ASK IF Q26 (02-99)]

Q27 Would information about hydrogen and fuel cell technologies be valuable to you?

$01 \quad$ YES

02 NO

99 DON'T KNOW

Q28 Have you attended any of the following events? [ROTATE ITEMS]

$01 \quad$ YES

02 NO

99 DON'T KNOW

A. A training class on hydrogen or fuel cells

B. A press conference concerning the use of hydrogen or fuel cells

C. A conference or workshop that included a session on hydrogen or fuel cells

Q29 Would you like to participate in a class on hydrogen or fuel cells?

$01 \quad$ YES

$02 \quad \mathrm{NO}$

99 DON'T KNOW

[ASK IF Q29(01)]

Q30 Which class format is MOST useful to you? [READ ENTIRE LIST BEFORE RECORDING ONE ANSWER]

$01 \quad$ In-person class at a local facility

02 In-person class in conjunction with a relevant conference or event

03 Web-based class

99 DON'T KNOW/NO OPINION

That's all the questions we have today. Thank you very much for your time.

CONFIRM PHONE NUMBER. 


\section{A.4. END USER SURVEY}

\section{OPINION RESEARCH CORPORATION}

APRIL 2008

HYDROGEN-LARGE SCALE END USERS

ORC \# 36015

BALLOT \#

TELEPHONE \#

SURVEY \#

CALL

\section{QUOTA CELLS/TARGETS}

XXX total respondents

TELEPHONE NUMBER: TIME ENDED:

TIME STARTED:

LENGTH: (MINUTES)

DATE:

INTERVIEWER:

I.D.:

INTERVIEWERS: MAKE SURE YOU HAVE THE FOLLOWING TO GIVE TO RESPONDENTS AS NEEDED OR IF REQUESTED:

- OMB CONTROL NUMBER: 1910-5124

- HFCIT WEBSITE URL: http://www1.eere.energy.gov/hydrogenandfuelcells/education/

- IF ASKED AT ANY POINT DURING THE SURVEY, THE INTERVIEWER SHOULD

TELL THE RESPONDENT THAT THERE ARE NO TRICK QUESTIONS

[AT SWITCHBOARD]

SA May I please speak to the person who is most responsible for energy-related decisions at this location?

$\begin{array}{lll}04 & \text { YES } & \text {-->CONTINUE } \\ 05 & \text { NOT AVAILABLE NOW } & \text {-->SCHEDULE CALLBACK } \\ 100 & \text { REFUSED } & \text {--> THANK AND RECORD AS REFUSED (SA) }\end{array}$


(READ ONCE RESPONDENT IS ON THE PHONE)

Hello, my name is __ calling from Opinion Research Corporation on behalf of the U.S. Department of Energy. The DOE is sponsoring a survey about energy sources with business leaders in your sector. Each company we contact is an important part of the survey process and we urge you or someone within your organization to participate. While your responses are voluntary, every response is valuable in this survey because the results will be used to help design the hydrogen education program for the Department of Energy. Are you the person most responsible for energy related decisions at this location?

S1 $01 \quad$ YES, CONTINUE WITH SURVEY $\quad-->$ SKIP TO TEXT BEFORE Q1 02 NOT CONVENIENT NOW -->SET CALL BACK APPOINTMENT

03 NOT APPROPRIATE PERSON TO CONDUCT INTERVIEW-->CONTINUE TO S2 99 REFUSED -->THANK AND RECORD AS REFUSED

S2 Can you please give me the name, title and telephone number of the person who is best suited to represent your organization for this survey?

$\begin{array}{lll}01 & \text { YES } & -->\text { RECORD INFORMATION AND ARRANGE CALLBACK } \\ 100 & \text { NO/REFUSED }\end{array}$ 
Before we get started, I want to mention that there are both technical and opinion questions in the survey. Tell me what you think or believe, but keep in mind that "no opinion" or "don't know" are perfectly acceptable responses. I would like you to know that your responses are confidential and you and your company name will not be associated with the results. It should take about 12 minutes to complete.

First of all ...

Q1 Please rate your familiarity with hydrogen and fuel cell technologies. Are you... [READ LIST. RECORD ONE ANSWER]

14 Not at all familiar - You know nothing about hydrogen and fuel cell technologies

15 Slightly familiar - You've heard about hydrogen and fuel cell technologies, read an article or watched a television feature about the technology, or participated in a casual conversation about the technology

16 Familiar - You've had limited experience with hydrogen and fuel cell technologies, researched the subject for school, work, or personal interest, or learned about the technology in a class or workshop

17 Very familiar - You consider yourself an expert in hydrogen and fuel cell technologies

Q2 I am going to read several job titles -- please tell me which one applies to you.

[READ LIST. RECORD ONE ANSWER]

$01 \quad$ Fleet manager

02 Plant or facility manager

03 Operations manager

$04 \quad$ Financial manager

05 Energy manager

06 CEO

195 Something else [SPECIFY]

199 DON'T KNOW/REFUSED

Q3 How many years have you held this position?

[READ LIST. RECORD ONE ANSWER]

01 Less than one year

02 Between one and five years

03 Over five years

99 DON'T KNOW/REFUSED

[ASK IF RESPONDENT IS IN “TRANSPORTATION” SECTOR]

Q4A How many vehicles are in the GROUND-BASED fleet operated by your organization or agency? [DO NOT READ LIST. RECORD ONE ANSWER]

01 LESS THAN 100

$02 \quad 100-1,000$

$03 \quad 1,001-10,000$

04 OVER 10,000

99 DON'T KNOW/REFUSED 
[ASK IF RESPONDENT IS IN “NEEDS UNINTERRUPTED POWER” OR “LARGE POWER REQUIREMENTS" SECTOR]

Q4B What is the average annual cost of electrical energy for your organization or agency? [DO NOT READ LIST. RECORD ONE ANSWER]

01 UNDER $\$ 100,000$

$02 \$ 100,000$ TO $\$ 1,000,000$

$03 \$ 1,000,001$ TO $\$ 2,000,000$

04 OVER $\$ 2,000,000$

99 DON'T KNOW/REFUSED

Q5 I am going to read several statements. After each one, please tell me if you believe the statement is true, if it is false, or if you don't know.

[ROTATE STATEMENTS]

$07 \quad$ True

$08 \quad$ False

99 DON'T KNOW/NO OPINION

A. Hydrogen gas is toxic

B. Fuel cells produce electricity through hydrogen combustion

C. Hydrogen is lighter than air

D. Hydrogen has a distinct odor

Q6 Which of the following can fuel cells provide power to?

[READ ENTIRE LIST BEFORE RECORDING ONE ANSWER. ROTATE 01-03]
10 Your home
11 Your car
12 Your laptop computer
10 All of these
11 Or, none of these
99 DON'T KNOW/NO OPINION

Q7 In which state or condition can hydrogen be stored?

[READ ENTIRE LIST BEFORE RECORDING ONE ANSWER. ROTATE 01-02]

13 Chemical compound

14 Liquid

15 Both of these

16 Or, neither of these

99 DON'T KNOW/NO OPINION 
Q8 When using pure hydrogen, fuel cell vehicles generate electricity, water, and what else?

[READ ENTIRE LIST BEFORE RECORDING ONE ANSWER. ROTATE 01-03]

13 Carbon dioxide

$14 \quad$ Nitrous oxides

15 Heat

16 Or, all of these

99 DON'T KNOW/NO OPINION

Q9 Hydrogen can be produced using which of the following sources of energy?

[READ ENTIRE LIST BEFORE RECORDING ONE ANSWER. ROTATE 01-03]

$\begin{array}{cl}13 & \text { Natural gas } \\ 14 & \text { Sunlight } \\ 15 & \text { Organic matter } \\ 16 & \text { Or, all of these } \\ 102 & \text { DON'T KNOW/NO OPINION }\end{array}$

Q10 I am going to read some characteristics of fuels or power supplies. Please rate the importance of each characteristic for your facility, using a scale of low, medium, high or no opinion.

[ROTATE STATEMENTS]

01 Low

02 Medium

03 High

$99 \quad$ NO OPINION

A. System installation cost

B. System maintenance cost

C. Fuel cost

D. Dependability

E. Safety

F. Environmental impact

G. Uninterrupted availability

Q11 How would you feel if your local gas station also sold hydrogen? Would you say ... [READ ENTIRE LIST BEFORE RECORDING ONE ANSWER.]

$\begin{array}{cl}13 & \text { Frightened } \\ 14 & \text { Uneasy } \\ 15 & \text { At ease } \\ 16 & \text { Or, pleased } \\ 102 & \text { DON'T KNOW/NO OPINION }\end{array}$

Q12 Please tell me if you believe the following statement is true, if it is false, or if you don't know.

"Hydrogen is too dangerous for everyday use by the general public."

07 TRUE

08 FALSE

99 DON'T KNOW/NO OPINION

Hydrogen Knowledge and Opinions Surveys A-35

April 21, 2010 
Q13 Next, I am going to read several statements about potential benefits of using hydrogen as a VEHICLE FUEL. For each, tell me if you disagree, are neutral, agree or if you have no opinion? [ROTATE STATEMENTS]

$\begin{array}{cl}10 & \text { Disagree } \\ 11 & \text { Are neutral } \\ 12 & \text { Agree } \\ 102 & \text { NO OPINION }\end{array}$

A. Using hydrogen will reduce U.S. dependence on foreign oil

B. Using hydrogen will reduce emissions and improve air quality

C. Hydrogen is as safe to use in my car as gasoline and diesel fuels

Q14 For the following applications, please rate the safety of using hydrogen and fuel cells, in comparison with technology in use today.

Is it not as safe, equally as safe or safer to use hydrogen and fuel cells for... [ROTATE STATEMENTS]

$01 \quad$ Not as safe

02 Equally as safe

03 Safer

99 NO OPINION
A. Personal cars and trucks
B. Buses and commercial vehicles
C. Large power plants
D. Small portable devices such as laptop computers or cell phones
E. Onsite power for the home
F. Onsite power for buildings such as hospitals and schools

Q15 If fuel cell vehicles were available today at a cost competitive to gasoline internal combustion engine vehicles, would you recommend buying or leasing them for your organization's vehicle fleet?
03 YES
$04 \quad \mathrm{NO}$
99 DON'T KNOW/NO OPINION

Q16 If stationary fuel cells were available today at a cost competitive to traditional power systems, would you buy or recommend buying one to help meet your facility's needs?

$\begin{array}{ll}03 & \text { YES } \\ 04 & \text { NO } \\ 99 & \text { DON'T KNOW/NO OPINION }\end{array}$ 
Q17 I am going to read several statements. Please select the ONE that BEST describes how you feel about using hydrogen and fuel cell technology to meet your organization's energy needs. [READ ENTIRE LIST BEFORE RECORDING ONE ANSWER]

05 I know enough to seriously consider it if products are available

06 I am considering it but need more information

07 I am going to wait and see how the market develops

08 There is no way I'll consider it anytime soon

100 DON'T KNOW/NO OPINION

Q18 The next question is about your use of information sources that can help you make decisions about energy costs and safety. How often do you use each of the following sources for energy information? Would you say never, sometimes, or frequently?

[DO NOT ROTATE STATEMENTS]

$01 \quad$ Never

02 Sometimes

03 Frequently

99 DON'T KNOW
A. Teachers and schools
B. Friends and family members
C. Environmental and conservation groups
D. Utility companies or brokers, for example, gas or electricity providers
E. Industry or trade associations or non-profit organizations
F. Federal government
G. State government
H. Local government

Q19 How often do you get ENERGY information from different types of mass media? Would you say that you never, sometimes, or frequently get energy information from ... [ROTATE STATEMENTS]

$\begin{array}{ll}01 & \text { Never } \\ 02 & \text { Sometimes } \\ 03 & \text { Frequently } \\ 99 & \text { DON'T KNOW }\end{array}$
A. Television
B. Radio
C. The Internet
D. Newspapers and general interest magazines
E. Science and technology magazines and journals
F. Business or trade magazines

Q20 Have you received information at your workplace concerning hydrogen and/or fuel cells?

$\begin{array}{ll}03 & \text { YES } \\ 04 & \text { NO } \\ 100 & \text { DON'T KNOW }\end{array}$


[ASK IF Q20 (02-99)]

Q21 Would information about hydrogen and fuel cell technologies be valuable to you?

03 YES

$04 \quad \mathrm{NO}$

100 DON'T KNOW

Q22 Would a "Hydrogen 101" class, or training at a conference, be of value to you?

$\begin{array}{ll}03 & \text { YES } \\ 04 & \text { NO } \\ 100 & \text { DON'T KNOW }\end{array}$

[ASK IF Q22 (01)]

Q23 Which class format is MOST useful to you?

[READ ENTIRE LIST BEFORE RECORDING ONE ANSWER]

04 In-person class at a local facility

05 In-person class in conjunction with a relevant conference or event

06 Web-based class

100 DON'T KNOW/NO OPINION

Q24 Does your organization use hydrogen and/or fuel cells for any purpose?

$01 \quad$ YES

$02 \quad \mathrm{NO}$

99 DON'T KNOW

[ASK IF Q24 (01)]

Q25 What is the PRIMARY function of the hydrogen and/or fuel cells used by your organization? [READ ENTIRE LIST BEFORE RECORDING ONE ANSWER]

01 To power buses

02 To power vehicles other than buses

03 To provide stationary on-site power

04 To provide power for small portable equipment

05 To provide back-up power

195 OTHER [SPECIFY]

199 DON'T KNOW/REFUSED

[ASK IF Q24 $(02,99)]$

Q26 Does your organization have plans to use hydrogen and/or fuel cells in the future?

$01 \quad$ YES

02 NO

99 DON'T KNOW 
[ASK IF Q26 (01)]

Q27 What is the time frame for plans to use hydrogen and/or fuel cells?

[READ LIST. RECORD ONE ANSWER]

$04 \quad$ Within the next year

$05 \quad 1-5$ years

06 Over 5 years

100 DON'T KNOW

CONFIRM PHONE NUMBER.

That's all the questions we have today. Thank you very much for your time. 


\title{
A.5 SAFETY AND CODES OFFICIALS SURVEY
}

\author{
OPINION RESEARCH CORPORATION
}

MAY 2009

HYDROGEN-SAFETY AND CODES OFFICIALS

ORC \# 36386

BALLOT \#

TELEPHONE \#

SURVEY \#

CALL

\section{QUOTA CELLS/TARGETS}

200 total respondents

TELEPHONE NUMBER: TIME ENDED:

TIME STARTED:

LENGTH: (MINUTES)

DATE:

INTERVIEWER:

I.D.:

INTERVIEWERS: MAKE SURE YOU HAVE THE FOLLOWING TO GIVE TO RESPONDENTS AS NEEDED OR IF REQUESTED:

- OMB CONTROL NUMBER: 1910-5140

- HFCIT WEBSITE URL: http://hydrogenenergy.gov/

- IF ASKED AT ANY POINT DURING THE SURVEY, THE INTERVIEWER SHOULD

TELL THE RESPONDENT THAT THERE ARE NO TRICK QUESTIONS

AT INTRO SCREEN, DISPLAY INFO FOR INTERVIEWER: RESPONDENT NAME, TITLE AND AGENCY CONTACTED

SA May I please speak to [INSERT RESPONDENT NAME FROM SAMPLE]?

$\begin{array}{lll}06 & \text { YES } & -->\text { CONTINUE } \\ 07 & \text { NOT AVAILABLE NOW } & -->\text { SCHEDULE CALLBACK [SIDEBAR] } \\ 08 & \text { NO LONGER AT AGENCY } & \text {-->SKIP TO S2 } \\ 101 & \text { REFUSED } & -->\text { THANK AND RECORD AS REFUSED (SA) }\end{array}$


(READ ONCE RESPONDENT IS ON THE PHONE)

Hello, my name is calling from Opinion Research Corporation on behalf of the U.S. Department of Energy. Your agency has been selected for an important national research survey about new energy sources. You have (your office has) been sent a letter from Sunita Satyapal, Acting Program Manager of the DOE Hydrogen Program, which explained the purpose and importance of this survey. The survey takes about 12 minutes to complete.

S1 $01 \quad$ CONTINUE WITH SURVEY -->SKIP TO TEXT BEFORE Q1

02 DID NOT RECEIVE LETTER/NEED MORE INFORMATION -->CONTINUE

03 NOT CONVENIENT NOW -->SET CALL BACK APPOINTMENT [SIDEBAR]

04 NOT APPROPRIATE PERSON TO CONDUCT INTERVIEW-->SKIP TO S2

99 REFUSED -->THANK AND RECORD AS REFUSED

[ASK IF S1(02)]

S1A The Department of Energy is sponsoring a survey of safety and codes officials and your agency has been selected for this important national research about new energy sources. Your responses are confidential and your agency's name will not be associated with the survey results. While your responses are voluntary, every response is extremely important because the results to this survey will be used to guide the development of The Department of Energy's hydrogen education activities.

01 CONTINUE WITH SURVEY -->SKIP TO TEXT BEFORE Q1

02 NOT CONVENIENT NOW -->SET CALL BACK APPOINTMENT [SIDEBAR]

03 NOT APPROPRIATE PERSON TO CONDUCT INTERVIEW-->CONTINUE TO S2

99 REFUSED -->THANK AND RECORD AS REFUSED (S1A)

S2 [IF SA (03) READ] Can you please give me the name, title and telephone number of the person who now fills the position vacated by [INSERT RESPONDENT NAME]?

[IF S1 (04) OR S1A (03) READ] Can you please give me the name, title and telephone number of the person who is best suited to represent your agency for this survey?

01

YES $-->$ CONTINUE

101

-->THANK AND RECORD AS REFUSED (S2) 
DISPLAY INFORMATION FROM S2 TO VERIFY ACCURACY.

S2VER [CONFIRM INFORMATION- READ BACK TO THEM FOR ACCURACY]

$\begin{array}{lll}06 & \text { CORRECT } & -->\text { CONTINUE } \\ 07 & \text { INCORRECT } & -->\text { RETURN TO S2 } \\ 99 & \text { REFUSED } & -->\text { THANK AND RECORD AS REFUSED (S2VER) }\end{array}$

S3 INTERVIEWER: HOW WILL THE INTERVIEW BE COMPLETED?

01 CONTINUE WITH THE PERSON ON THE PHONE

02 SCHEDULE CALLBACK WITH NEW PERSON 
Before we get started, I want to mention that there are both technical and opinion questions in the survey. Tell me what you think or believe, but keep in mind that "no opinion" or "don't know" are perfectly acceptable responses.

First of all ...

Q1 Please rate your familiarity with hydrogen and fuel cell technologies. Are you... [READ LIST. RECORD ONE ANSWER]

18 Not at all familiar - You know nothing about hydrogen and fuel cell technologies

19 Slightly familiar - You've heard about hydrogen and fuel cell technologies, read an article or watched a television feature about the technology, or participated in a casual conversation about the technology

20 Familiar - You've had limited experience with hydrogen and fuel cell technologies, researched the subject for school, work, or personal interest, or learned about the technology in a class or workshop

21 Very familiar - You consider yourself an expert in hydrogen and fuel cell technologies

Q2 I am going to read several statements. After each one, please tell me if you believe the statement is true, if it is false, or if you don't know. [RANDOMIZE STATEMENTS]

09 TRUE

10 FALSE

99 DON'T KNOW/NO OPINION

A. Hydrogen gas is toxic

B. Fuel cells produce electricity through hydrogen combustion

C. Hydrogen is lighter than air

D. Hydrogen has a distinct odor

Q3 Which of the following can fuel cells provide power to? [READ ENTIRE LIST BEFORE RECORDING ONE ANSWER. RANDOMIZE 01-03]

13 Your home

14 Your car

15 Your laptop computer

12 All of these

13 Or, none of these

99 DON'T KNOW

Q4 In which state or condition can hydrogen be stored? [READ ENTIRE LIST BEFORE RECORDING ONE ANSWER. ROTATE 01-02]

17 Chemical compound

18 Liquid

19 Both of these

20 Or, neither of these

99 DON'T KNOW 
Q5 When using pure hydrogen, fuel cell vehicles generate electricity, water, and what else? [READ ENTIRE LIST BEFORE RECORDING ONE ANSWER. RANDOMIZE 01-03]

17 Carbon dioxide

$18 \quad$ Nitrous oxides

19 Heat

20 Or, all of these

99 DON'T KNOW

Q6 Hydrogen can be produced using which of the following sources of energy? [READ ENTIRE LIST BEFORE RECORDING ONE ANSWER. RANDOMIZE 01-03]

$\begin{array}{cl}17 & \text { Natural gas } \\ 18 & \text { Sunlight } \\ 19 & \text { Organic matter } \\ 20 & \text { Or, all of these } \\ 103 & \text { DON'T KNOW }\end{array}$

Q7A For the next question, I will ask you to rank five items. It may be easier if you write them down. Do you need a moment to get something to write with?

The factors are: [READ AND RANDOMIZE FACTORS]. Now, please tell me which factor is MOST important to you, personally, when selecting a fuel for your vehicle or power supply for your home or business? [RE-READ ENTIRE LIST AS NEEDED BEFORE RECORDING ONE ANSWER]
$01 \quad$ Safety
02 Low cost
03 Environmental impact
04 Convenience
05 Performance
99 DON'T KNOW/NO OPINION

[IF Q7A (01-05) MENTIONED, ASK FOR EACH NOT MENTIONED IN Q7A]

Q7B Now, from the remaining factors, which one of the following is MOST IMPORTANT to you when selecting a fuel for your vehicle or power supply for your home or business? [READ ENTIRE LIST BEFORE RECORDING ONE ANSWER]
$01 \quad$ Safety
02 Low cost
03 Environmental impact
04 Convenience
05 Performance
99 DON'T KNOW/NO OPINION 
[IF Q7B (01-05) MENTIONED, ASK FOR EACH NOT MENTIONED IN Q7A AND Q7B]

Q7C Now, from the remaining factors, which one of the following is MOST IMPORTANT to you when selecting a fuel for your vehicle or power supply for your home or business? [READ ENTIRE LIST BEFORE RECORDING ONE ANSWER]

$01 \quad$ Safety

02 Low cost

03 Environmental impact

04 Convenience

05 Performance

99 DON'T KNOW/NO OPINION

[IF Q7C (01-05) MENTIONED, ASK FOR EACH NOT MENTIONED IN Q7A, Q7B, AND Q7C]

Q7D Finally, which of the following factors is MORE IMPORTANT to you when selecting a fuel for your vehicle or power supply for your home or business? [READ ENTIRE LIST BEFORE RECORDING ONE ANSWER]

$01 \quad$ Safety

02 Low cost

03 Environmental impact

04 Convenience

05 Performance

99 DON'T KNOW/NO OPINION

Q8 How would you feel if your local gas station also sold hydrogen? Would you say ... [READ ENTIRE LIST BEFORE RECORDING ONE ANSWER.]

$\begin{array}{cl}17 & \text { Frightened } \\ 18 & \text { Uneasy } \\ 19 & \text { At ease } \\ 20 & \text { Or, pleased } \\ 103 & \text { DON'T KNOW/NO OPINION }\end{array}$

Q9 Please tell me if you believe the following statement is true, if it is false, or if you don't know. "Hydrogen is too dangerous for everyday use by the general public."

09 TRUE

10 FALSE

99 DON'T KNOW/NO OPINION 
Q10 Next, I am going to read several statements about potential benefits of using hydrogen as a VEHICLE FUEL. For each, tell me if you disagree, are neutral, agree or if you have no opinion? [RANDOMIZE STATEMENTS]

$\begin{array}{cl}13 & \text { DISAGREE } \\ 14 & \text { ARE NEUTRAL } \\ 15 & \text { AGREE } \\ 103 & \text { NO OPINION }\end{array}$

A. Using hydrogen will reduce U.S. dependence on foreign oil

B. Using hydrogen will reduce emissions and improve air quality

C. Hydrogen is as safe to use in my car as gasoline and diesel fuels

Q11 OMITTED

Q12 OMITTED

Q13 For the following applications, please rate the safety of using hydrogen and fuel cells, in comparison with technology in use today.

Is it not as safe, equally as safe or safer to use hydrogen and fuel cells for... [RANDOMIZE STATEMENTS]

$\begin{array}{ll}01 & \text { NOT AS SAFE } \\ 02 & \text { EQUALLY AS SAFE } \\ 03 & \text { SAFER } \\ 99 & \text { NO OPINION }\end{array}$
A. Personal cars and trucks
B. Buses and commercial vehicles
C. Large power plants
D. Small portable devices such as laptop computers or cell phones
E. Onsite power for the home
F. Onsite power for buildings such as hospitals and schools

Q13G, H, I OMITTED 
Q14 The next question is about your use of information sources that can help you make decisions about energy costs and safety. How often do you use each of the following sources for energy information? Would you say never, sometimes, or frequently? [DO NOT ROTATE STATEMENTS]

$01 \quad$ NEVER

02 SOMETIMES

03 FREQUENTLY

99 DON'T KNOW
A. Teachers and schools
B. Friends and family members
C. Environmental and conservation groups
D. Utility companies or brokers, for example, gas or electricity providers
E. Industry or trade associations or non-profit organizations
F. Federal government
G. State government
H. Local government

Q15 How often do you get ENERGY information from different types of mass media? Would you say that you never, sometimes, or frequently get energy information from ... [RANDOMIZE

STATEMENTS]

$\begin{array}{ll}01 & \text { NEVER } \\ 02 & \text { SOMETIMES } \\ 03 & \text { FREQUENTLY } \\ 99 & \text { DON'T KNOW }\end{array}$
A. Television
B. Radio
C. The Internet
D. Newspapers and general interest magazines
E. Science and technology magazines and journals
F. Business or trade magazines

Q16-19 OMITTED

Q20-25 OMITTED

Q25A Have you ever been involved in permitting a stationary fuel cell installation, hydrogen fueling station, or other hydrogen fuel cell project?
$01 \quad$ YES
02 NO
99 DON'T KNOW 
Q25B Do you know anyone or have any of your colleagues or peers been involved in permitting a stationary fuel cell, hydrogen fueling station, or other hydrogen fuel cell project?

$01 \quad$ YES

$02 \quad \mathrm{NO}$

99 DON'T KNOW

Q26 Have you ever received information about hydrogen and fuel cell technologies?

$05 \quad$ YES

$06 \quad \mathrm{NO}$

101 DON'T KNOW

Q27-28 OMITTED

Q28A Have you ever participated in a training class about hydrogen and fuel cell technologies?

$01 \quad$ YES

02 NO

a. DON'T KNOW

[ASK IF Q28A (01)]

Q28B Was the class useful?

$01 \quad$ YES

02 NO

99 DON'T KNOW/NO OPINION

[ASK IF Q28A $(02,99)]$

Q29 Would you like to participate in a class on hydrogen or fuel cells?

$05 \quad$ YES

06 NO

101 DON'T KNOW/NO OPINION

[ASK IF Q29 (01)]

Q30 Which class format is MOST useful to you? [READ ENTIRE LIST BEFORE RECORDING ONE ANSWER]

07 In-person class at a local facility

08 In-person class in conjunction with a relevant conference or event

09 Web-based class

101 DON'T KNOW/NO OPINION

Q31 If you were asked to review a request for a stationary fuel cell permit, would you have the information to do so?

$01 \quad$ YES

02 NO

99 DON'T KNOW/NO OPINION 
Q32 If you were asked to review a request for a stationary fuel cell permit, how would you feel about conducting the review? [READ ENTIRE LIST BEFORE RECORDING ONE ANSWER.]

01 Uneasy

02 Curious

03 Or, comfortable

99 DON'T KNOW/NO OPINION

Q33 If you were asked to review a request for a hydrogen fueling station permit, would you have the information to do so?

$01 \quad$ YES

$02 \quad \mathrm{NO}$

99 DON'T KNOW

Q34 If you were asked to review a request for a hydrogen fueling station permit, how would you feel about conducting the review? [READ ENTIRE LIST BEFORE RECORDING ONE ANSWER.]
01 Uneasy
02 Curious
03 Or, comfortable
99 DON'T KNOW/NO OPINION

Q35 If you need information about hydrogen and fuel cell technologies in order to review an application for a stationary fuel cell or hydrogen fueling station, where would you seek that information?

[READ LIST. RECORD AS MANY AS APPLY. WAIT FOR YES OR NO FOR EACH]

$\begin{array}{ll}01 & \text { Peers } \\ 02 & \text { Federal government } \\ 03 & \text { State government } \\ 04 & \text { Nonprofit organization } \\ 05 & \text { Industry source } \\ 06 & \text { National organization } \\ 07 & \text { Local agency's regulations } \\ 99 & \text { DON'T KNOW/NO OPINION }\end{array}$

That's all the questions we have today. Thank you very much for your time. 


\section{APPENDIX B FEDERAL REGISTER NOTICES}

General Public, Students, Government Agencies, and End Users

B.1. Sixty-day Federal Register Notice. Federal Register, Vol. 71, No. 222, Friday, November 17, 2006, page 66943 (http://www.access.gpo.gov/su docs/fedreg/a061117c.html)

B.2. Thirty-day Federal Register Notice. Federal Register, Vol. 72, No. 50, Thursday, March 15, 2007, page 12169 (http://www.access.gpo.gov/su docs/fedreg/a070315c.html)

\section{$\underline{\text { Safety and Codes Officials }}$}

B.3. Sixty-day Federal Register Notice. Federal Register, Vol. 73, No. 2, Thursday, January 3, 2008, page 482 (http://www.access.gpo.gov/su docs/fedreg/a080103c.html)

B.4. Thirty-day Federal Register Notice. Federal Register, Vol. 73, No. 84, Wednesday, April 30, 2008, pages 23453-23454

(http://www.access.gpo.gov/su docs/fedreg/a080430c.html) 


\section{B.1 FEDERAL REGISTER, NOVEMBER 17, 2006}

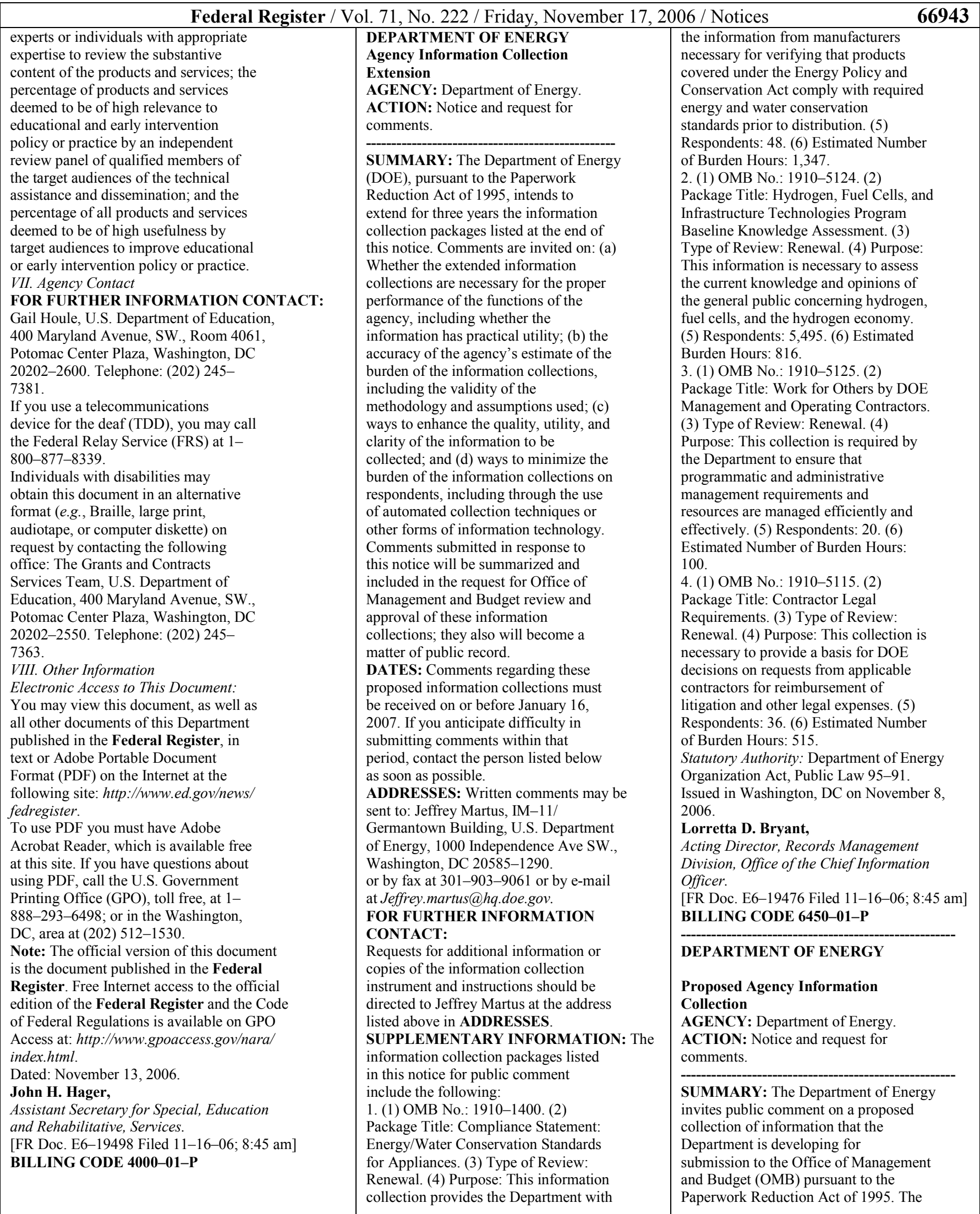




\section{B.2 FEDERAL REGISTER, MARCH 15, 2007}

\begin{tabular}{|c|c|c|}
\hline Feder & Vol. 72, No. 50 / Thursday, March & 007 / Notices \\
\hline 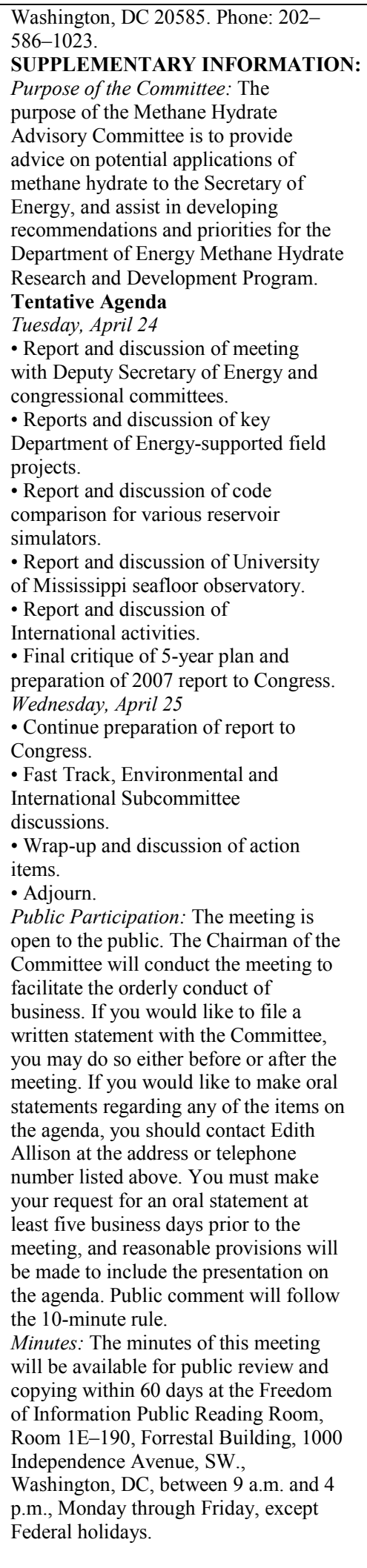 & 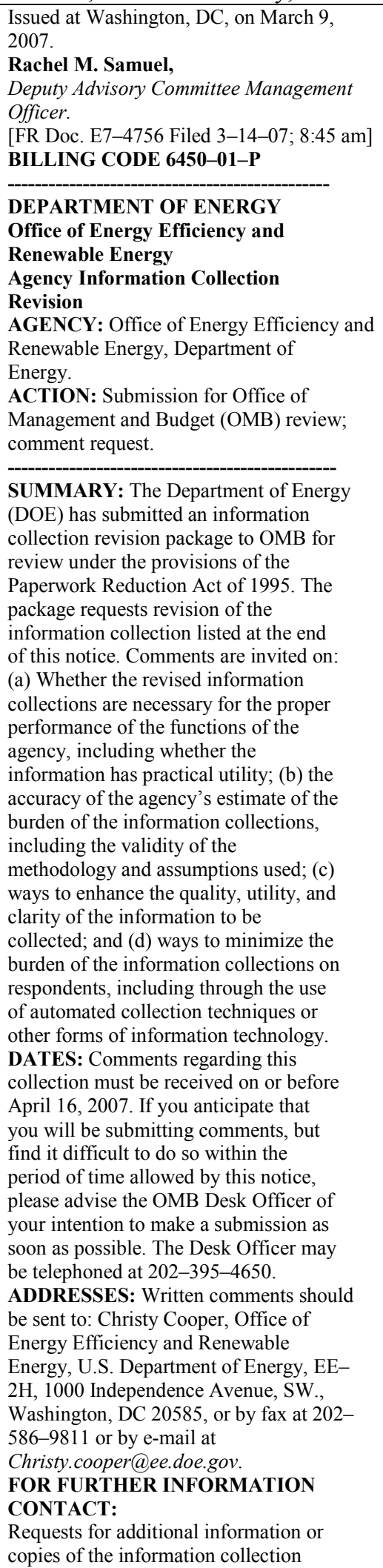 & 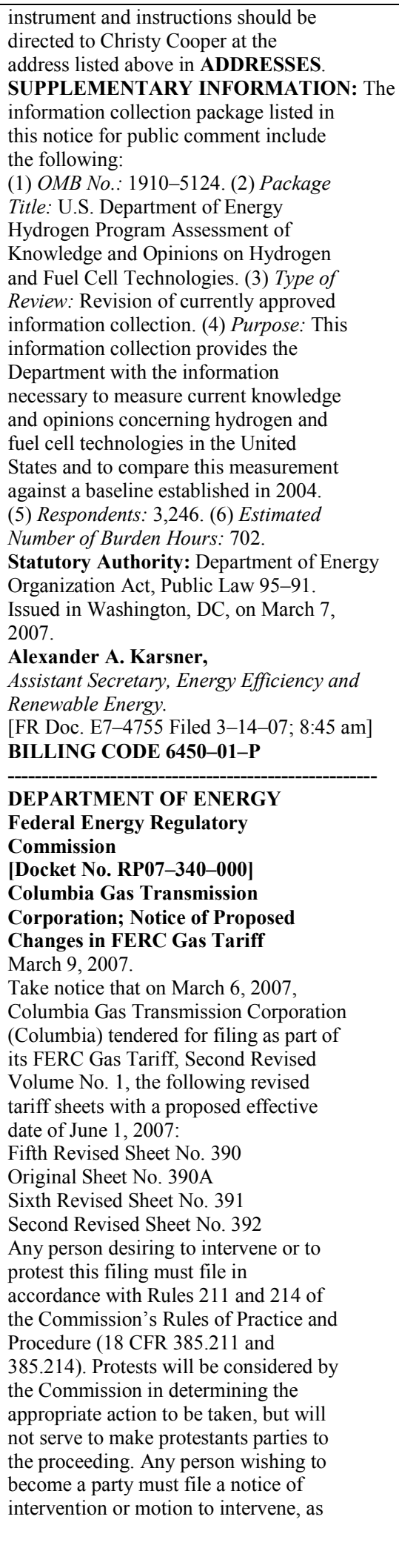 \\
\hline
\end{tabular}




\section{B.3 FEDERAL REGISTER, JANUARY 3, 2008}

\begin{tabular}{|c|c|c|}
\hline \multirow[b]{2}{*}{ 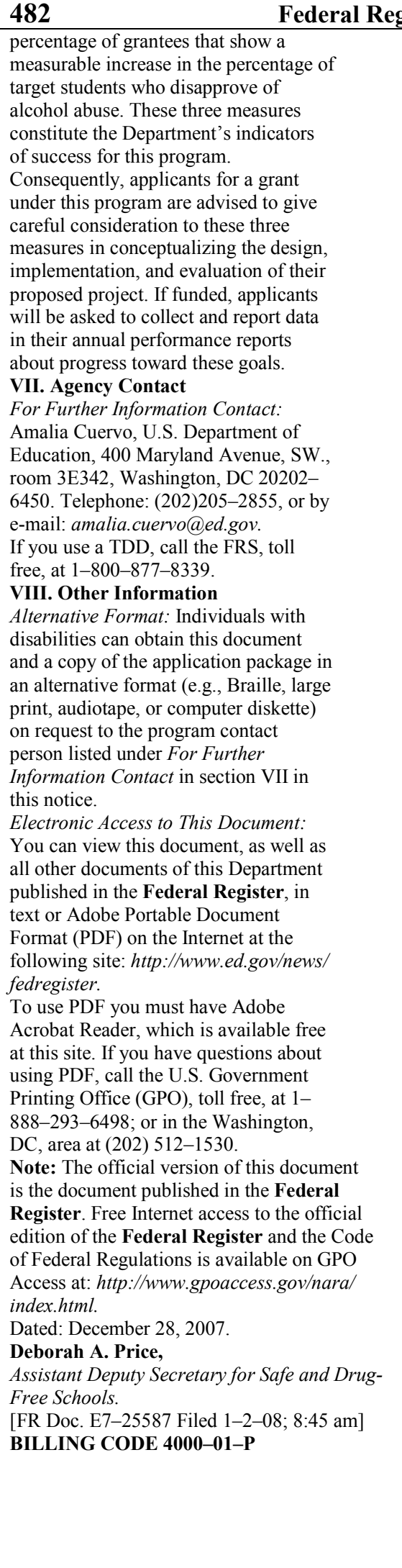 } & \multirow[b]{2}{*}{ 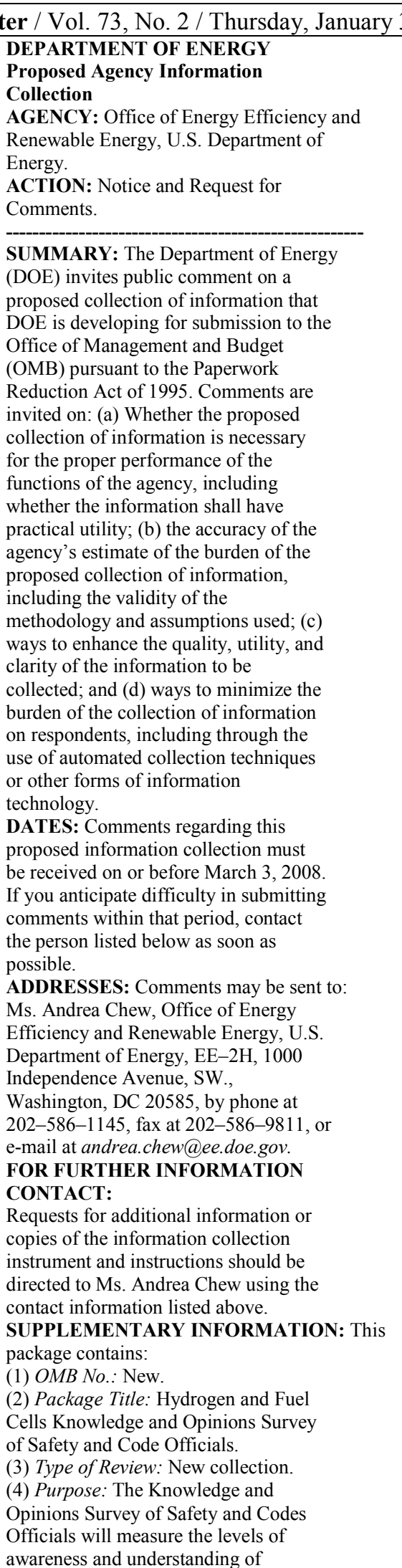 } & \\
\hline & & $\begin{array}{l}\text { Organization Act, Public Law 95-91. } \\
\text { Issued in Washington, DC, on December } \\
\text { 18, 2007. } \\
\text { Alexander A. Karsner, } \\
\text { Assistant Secretary, Energy Efficiency and } \\
\text { Renewable Energy. } \\
\text { [FR Doc. E7-25567 Filed 1-2-08; 8:45 am] } \\
\text { BILLING CODE 6450-01-P } \\
\text { DEPARTMENT OF ENERGY } \\
\text { Federal Energy Regulatory } \\
\text { Commission } \\
\text { Combined Notice of Filings \#1 } \\
\text { December 27, 2007. } \\
\text { Take notice that the Commission } \\
\text { received the following electric rate } \\
\text { filings: } \\
\text { Docket Numbers: ER94-389-027; } \\
\text { ER02-2509-006; ER00-840-007; ER01- } \\
\text { 137-005; ER98-1767-010; ER99-2992- } \\
\text { 007; ER99-3165-007; ER02-1942-006; } \\
\text { ER01-596-005; ER01-2690-009; ER02- } \\
\text { 77-009; ER00-1780-007; ER99-415- } \\
\text { 014; ER01-389-007; ER01-2641-011; } \\
\text { ER01-558-010; ER01-557-010; ER01- } \\
\text { 560-010; ER01-559-010; ER02-24-009; } \\
\text { ER02-26-008; ER02-25-008; ER05-- } \\
\text { 524-003; ER02-963-008. } \\
\text { Applicants: Tenaska Power Services } \\
\text { Co.; Kiowa Power Partners, LLC; } \\
\text { Tenaska Alabama Partners, L.P.; }\end{array}$ \\
\hline
\end{tabular}




\section{B.4 FEDERAL REGISTER, APRIL 30, 2008}

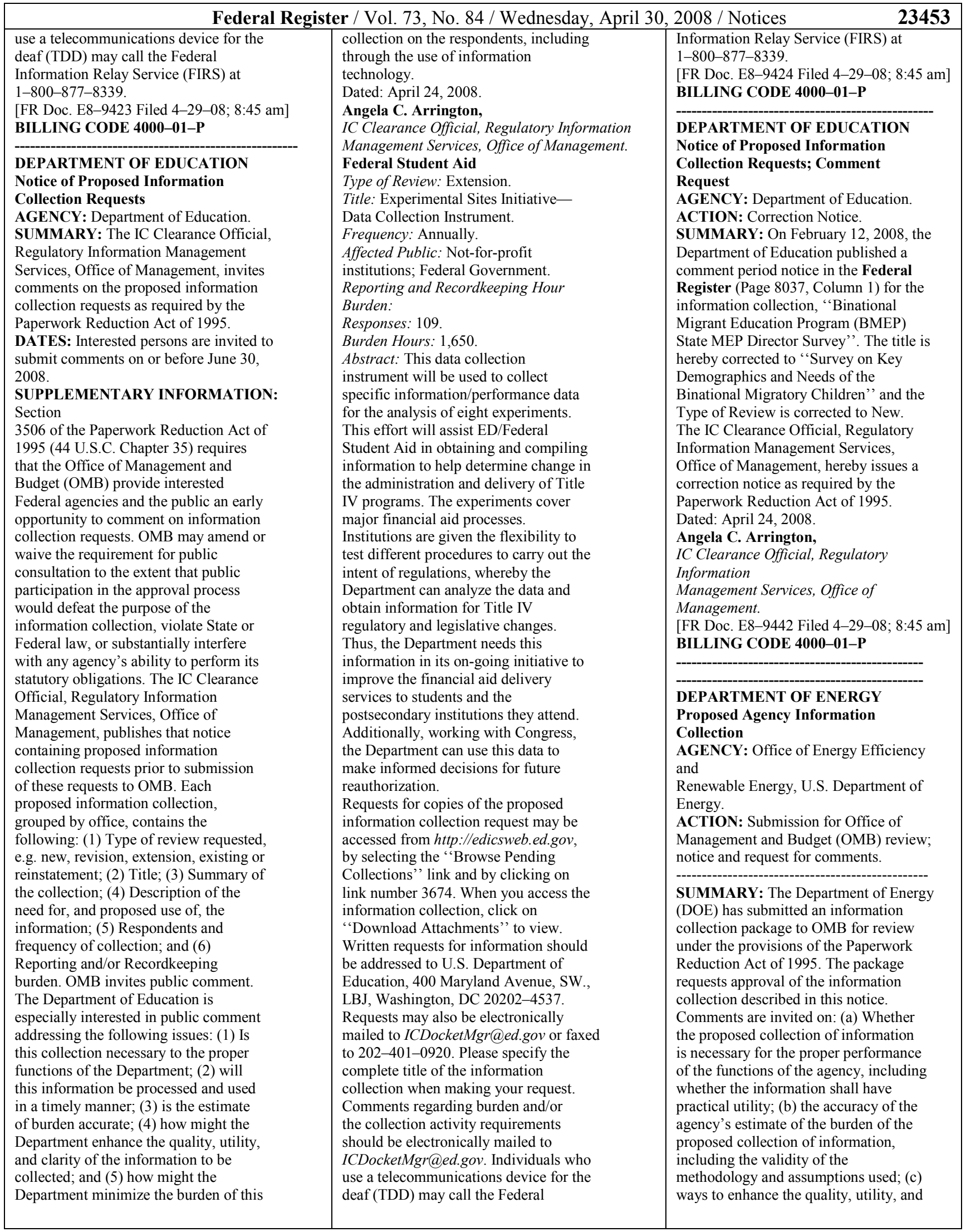


clarity of the information to be

collected; and (d) ways to minimize the burden of the collection of information on respondents, including through the use of automated collection techniques or other forms of information technology.

DATES: Comments regarding this proposed information collection must be received on or before May 30, 2008. If you anticipate difficulty in submitting comments within the period of time allowed by this notice, please advise the OMB Desk Officer of your intention to make a submission as soon as possible. The Desk Officer may be telephoned at 202-395-4650.

ADDRESSES: Comments may be sent to: DOE Desk Officer, Office of

Management and Budget, New

Executive Office Building, Room 10102, 735 17th Street, NW., Washington, DC

20503,

and to

Ms. Christy Cooper, Office of Energy

Efficiency and Renewable Energy, U.S.

Department of Energy, EE-2H, 1000

Independence Avenue, SW.,

Washington, DC 20585,

by phone at $202-586-1885$, fax at

202-586-9811, or e-mail at

christy.cooper@ee.doe.gov.

\section{FOR FURTHER INFORMATION}

\section{CONTACT:}

Requests for additional information or copies of the information collection instrument and instructions should be directed to Ms. Christy Cooper using the contact information listed above.

SUPPLEMENTARY INFORMATION: The information collection package listed in this notice for public comment include the following:

(1) $O M B$ No.: New.

(2) Package Title: Hydrogen and Fuel

Cells Knowledge and Opinions Survey of Safety and Code Officials.

(3) Type of Review: New collection.

(4) Purpose: The Knowledge and Opinions Survey of Safety and Codes Officials will measure the levels of awareness and understanding of hydrogen and fuel cell technologies within this population. Information gathered in this assessment will assist DOE's Hydrogen Education Program in formulating an overall education plan for hydrogen technologies. Changes in knowledge levels will be determined when, after three years, the population will be surveyed again using the same survey instrument and methodology. (5) Respondents: Interviews with 200 total officials will be conducted using computer-assisted telephone interview technology. Lists of persons responsible for safety and codes will be compiled from the following universe: agencies responsible for developing codes related to hydrogen and fuel cell technologies, including members of the International Code Council and the National Fire Protection Association; and safety officials responsible for adopting, enacting, and/or enforcing codes related to buildings and fire safety, including members of the National Association of State Fire Marshals, who are responsible for fire prevention, and the International Association of Fire Chiefs, who are responsible for fire protection.

(6) Estimated Number of Burden Hours: 40 hours (12 minutes per interview times 200 respondents). Statutory Authority: Department of Energy Organization Act, Public Law 95-91. Issued in Washington, DC, on April 22, 2008.

John Mizroch,

Principal Deputy Assistant Secretary, Energy Efficiency and Renewable Energy.

[FR Doc. E8-9468 Filed 4-29-08; 8:45 am] BILLING CODE 6450-01-P

\section{DEPARTMENT OF ENERGY}

Federal Energy Regulatory

Commission

[Docket No. CP08-151-000]

Stingray Pipeline Company, L.L.C.; Notice of Application

April 23, 2008

Take notice that on April 14, 2008,

Stingray Pipeline Company, L.L.C.

(Stingray), 1100 Louisiana, Suite 3300, Houston, Texas 77002, filed in Docket No. CP08-151-000, an application under section 7 of the Natural Gas Act (NGA) and Part 157 of the Federal Energy Regulatory Commission's (Commission) regulations for a certificate of public convenience and necessity authorizing the abandonment of eight compressor units at Stingray Compressor Stations 701 and 702. Stingray's proposal is more fully described as set forth in the application that is on file with the Commission and open to public inspection. The instant filing may be also viewed on the Web at $h t t p: / / w w w$.ferc.gov using the

" "eLibrary" link. Enter the docket number excluding the last three digits in the docket number field to access the document. For assistance, call (866) 208-3676 or TTY, (202) 502-8659. Any questions regarding the application should be directed to: Cynthia A. Corcoran, Vice PresidentRegulatory Affairs, Stingray Pipeline Company, L.L.C., 1100 Louisiana, Suite 3300 , Houston, Texas 77002 at (713) $821-2265$ or by fax at (713) 353-1742.
Pursuant to section 157.9 of the Commission's rules, 18 CFR 157.9, within 90 days of this Notice the Commission staff will either: Complete its environmental assessment (EA) and place it into the Commission's public record (eLibrary) for this proceeding, or issue a Notice of Schedule for Environmental Review. If a Notice of Schedule for Environmental Review is issued, it will indicate, among other milestones, the anticipated date for the Commission staff's issuance of the final environmental impact statement (FEIS) or EA for this proposal. The filing of the EA in the Commission's public record for this proceeding or the issuance of a Notice of Schedule for Environmental Review will serve to notify federal and state agencies of the timing for the completion of all necessary reviews, and the subsequent need to complete all federal authorizations within 90 days of the date of issuance of the Commission staff's FEIS or EA.

There are two ways to become involved in the Commission's review of this project. First, any person wishing to obtain legal status by becoming a party to the proceedings for this project should, on or before the below listed comment date, file with the Federal Energy Regulatory Commission, 888 First Street, NE., Washington, DC 20426, a motion to intervene in accordance with the requirements of the Commission's Rules of Practice and Procedure (18 CFR 385.214 or 385.211 ) and the Regulations under the NGA (18 CFR 157.10). A person obtaining party status will be placed on the service list maintained by the Secretary of the Commission and will receive copies of all documents filed by the applicant and by all other parties. A party must submit 14 copies of filings made with the Commission and must mail a copy to the applicant and to every other party in the proceeding. Only parties to the proceeding can ask for court review of Commission orders in the proceeding. However, a person does not have to intervene in order to have comments considered. The second way to participate is by filing with the Secretary of the Commission, as soon as possible, an original and two copies of comments in support of or in opposition to this project. The Commission will consider these comments in determining the appropriate action to be taken, but the filing of a comment alone will not serve to make the filer a party to the proceeding. The Commission's rules require that persons filing comments in opposition to the project provide copies of their protests only to the party or parties directly involved in the protest. 


\title{
APPENDIX C \\ TOTAL COUNTS FOR EACH SURVEY QUESTION WITH WEIGHTS AND STANDARD ERRORS
}

\author{
C.1 SUMMARY OF RESPONSES TO THE GENERAL PUBLIC SURVEY \\ C.2 SUMMARY OF RESPONSES TO THE STUDENT SURVEY \\ C.3 SUMMARY OF RESPONSES TO THE STATE AND LOCAL GOVERNMENT \\ SURVEY \\ C.4 SUMMARY OF RESPONSES TO THE END USER SURVEY \\ C.5 SUMMARY OF RESPONSES TO THE SAFETY AND CODES OFFICIALS \\ SURVEY
}




\section{C.1. SUMMARY OF RESPONSES TO THE GENERAL PUBLIC SURVEY}

\begin{tabular}{|c|c|c|c|c|c|}
\hline Question/Metric & $\begin{array}{l}\text { Unweighted } \\
\text { Frequency }\end{array}$ & $\begin{array}{l}\text { Weighted } \\
\text { Frequency }\end{array}$ & $\begin{array}{c}\text { Standard } \\
\text { Deviation } \\
\text { of Weighted } \\
\text { Frequency }\end{array}$ & $\begin{array}{l}\text { Weighted } \\
\text { Percent }\end{array}$ & $\begin{array}{c}\text { Standard } \\
\text { Error of } \\
\text { Weighted } \\
\text { Percent }\end{array}$ \\
\hline \multicolumn{6}{|l|}{ Sex } \\
\hline Male & 500 & 484.1 & 23.7 & 48.4 & 2.03 \\
\hline Female & 500 & 515.9 & 24.2 & 51.6 & 2.03 \\
\hline Total for Sex & 1,000 & 999.9 & 25.3 & 100 & 0.00 \\
\hline \multicolumn{6}{|l|}{ Age } \\
\hline $18-44$ & 309 & 487.6 & 31.0 & 49.8 & 2.04 \\
\hline $45+$ & 668 & 490.7 & 12.4 & 50.2 & 2.04 \\
\hline Total for Age & 977 & 978.2 & 25.1 & 100 & 0.00 \\
\hline \multicolumn{6}{|l|}{ Region } \\
\hline Northeast & 187 & 187.4 & 8.9 & 18.7 & 0.85 \\
\hline Midwest & 223 & 223.1 & 8.5 & 22.3 & 0.85 \\
\hline South & 365 & 364.8 & 17.0 & 36.5 & 1.28 \\
\hline West & 225 & 224.7 & 14.1 & 22.5 & 1.19 \\
\hline Total for Region & 1,000 & 999.9 & 25.3 & 100 & 0.00 \\
\hline \multicolumn{6}{|l|}{ Degree } \\
\hline No degree & 507 & 539.5 & 27.1 & 54.6 & 1.99 \\
\hline Degree & 481 & 447.7 & 19.7 & 45.4 & 1.99 \\
\hline Total for Degree & 988 & 987.2 & 25.2 & 100 & 0.00 \\
\hline \multicolumn{6}{|l|}{ Education } \\
\hline 8th grade or less & 22 & 18.8 & 4.8 & 1.88 & 0.48 \\
\hline High school incomplete & 42 & 58.4 & 12.5 & 5.84 & 1.21 \\
\hline
\end{tabular}




\begin{tabular}{|l|c|c|c|c|c|}
\hline \multicolumn{1}{|c|}{ Question/Metric } & $\begin{array}{c}\text { Unweighted } \\
\text { Frequency }\end{array}$ & $\begin{array}{c}\text { Standard } \\
\text { Weighted } \\
\text { Frequency }\end{array}$ & $\begin{array}{c}\text { Seviation } \\
\text { of Weighted } \\
\text { Frequency }\end{array}$ & $\begin{array}{c}\text { Weighted } \\
\text { Percent }\end{array}$ & $\begin{array}{c}\text { Error of } \\
\text { Weighted } \\
\text { Percent }\end{array}$ \\
\hline High school complete & 279 & 286.6 & 20.8 & 28.7 & 1.88 \\
\hline Some college, no degree & 164 & 175.7 & 17.4 & 17.6 & 1.64 \\
\hline Associates degree & 67 & 69.7 & 11.9 & 6.97 & 1.15 \\
\hline Bachelors degree & 247 & 235.7 & 15.2 & 23.6 & 1.56 \\
\hline Postgraduate degree & 167 & 142.3 & 11.9 & 14.2 & 1.23 \\
\hline Refused & 12 & 12.7 & 4.3 & 1.27 & 0.43 \\
\hline Total for Education & 1,000 & 999.9 & 25.3 & 100 & 0.00 \\
\hline
\end{tabular}

\begin{tabular}{|l|c|c|c|c|c|}
\hline Above Average? \\
\hline Score Below Average & 458 & 472.7 & 25.8 & 47.3 & 2.04 \\
\hline Score Above Average & 542 & 527.2 & 22.0 & 52.7 & 2.04 \\
\hline Total for Above Average? & 1,000 & 999.9 & 25.3 & 100 & 0.00 \\
\hline
\end{tabular}

\section{Q1. Familiarity with hydrogen/FC technologies}

\begin{tabular}{|l|c|c|c|c|c|}
\hline Not at all familiar & 461 & 476.7 & 24.7 & 47.7 & 2.03 \\
\hline Slightly familiar & 446 & 441.2 & 22.8 & 44.1 & 2.01 \\
\hline Familiar & 73 & 64.2 & 8.2 & 6.42 & 0.83 \\
\hline Very familiar & 20 & 17.8 & 4.4 & 1.78 & 0.45 \\
\hline Total for Q1 & 1,000 & 999.9 & 25.3 & 100 & 0.00 \\
\hline
\end{tabular}

\section{Q2A. Hydrogen gas is toxic}

\begin{tabular}{|l|c|c|c|c|c|}
\hline True & 182 & 204.7 & 19.7 & 20.5 & 1.80 \\
\hline False & 432 & 428.7 & 22.2 & 42.9 & 2.01 \\
\hline Don't know & 386 & 366.5 & 20.3 & 36.7 & 1.93 \\
\hline Total for Q2A & 1,000 & 999.9 & 25.3 & 100 & 0.00 \\
\hline
\end{tabular}




\begin{tabular}{|c|c|c|c|c|c|}
\hline Question/Metric & $\begin{array}{l}\text { Unweighted } \\
\text { Frequency }\end{array}$ & $\begin{array}{l}\text { Weighted } \\
\text { Frequency }\end{array}$ & $\begin{array}{c}\text { Standard } \\
\text { Deviation } \\
\text { of Weighted } \\
\text { Frequency }\end{array}$ & $\begin{array}{l}\text { Weighted } \\
\text { Percent }\end{array}$ & $\begin{array}{c}\text { Standard } \\
\text { Error of } \\
\text { Weighted } \\
\text { Percent }\end{array}$ \\
\hline \multicolumn{6}{|c|}{ Q2B. Fuel cells produce electricity through hydrogen combustion } \\
\hline True & 300 & 294.3 & 18.4 & 29.4 & 1.78 \\
\hline False & 129 & 112.5 & 11.0 & 11.2 & 1.12 \\
\hline Don't know & 571 & 593.1 & 26.9 & 59.3 & 1.92 \\
\hline Total for Q2B & 1,000 & 999.9 & 25.3 & 100 & 0.00 \\
\hline \multicolumn{6}{|c|}{ Q2C. Hydrogen is lighter than air } \\
\hline True & 539 & 518.3 & 22.4 & 51.8 & 2.04 \\
\hline False & 81 & 82.9 & 10.6 & 8.29 & 1.05 \\
\hline Don't know & 380 & 398.7 & 24.4 & 39.9 & 2.04 \\
\hline Total for Q2C & 1,000 & 999.9 & 25.3 & 100 & 0.00 \\
\hline \multicolumn{6}{|c|}{ Q2D. Hydrogen has a distinct odor } \\
\hline True & 80 & 80.8 & 10.4 & 8.08 & 1.04 \\
\hline False & 514 & 496.1 & 21.6 & 49.6 & 2.04 \\
\hline Don't know & 406 & 423.0 & 25.5 & 42.3 & 2.07 \\
\hline Total for Q2D & 1,000 & 999.9 & 25.3 & 100 & 0.00 \\
\hline \multicolumn{6}{|c|}{ Q3. Which of the following can fuel cells provide power to? } \\
\hline Your home & 44 & 55.9 & 13.5 & 5.59 & 1.30 \\
\hline Your car & 184 & 187.0 & 17.7 & 18.7 & 1.66 \\
\hline Your laptop computer & 5 & 3.5 & 1.6 & 0.35 & 0.16 \\
\hline All of these & 475 & 462.4 & 19.6 & 46.2 & 1.98 \\
\hline None of these & 50 & 48.2 & 8.1 & 4.82 & 0.81 \\
\hline Don't know & 242 & 242.8 & 19.3 & 24.3 & 1.78 \\
\hline Total for Q3 & 1,000 & 999.9 & 25.3 & 100 & 0.00 \\
\hline
\end{tabular}




\begin{tabular}{|l|c|c|c|c|c|}
\hline \multicolumn{1}{|c|}{ Question/Metric } & $\begin{array}{c}\text { Unweighted } \\
\text { Frequency }\end{array}$ & $\begin{array}{c}\text { Standard } \\
\text { Weviation } \\
\text { Frequency }\end{array}$ & $\begin{array}{c}\text { St Weighted } \\
\text { Frequency }\end{array}$ & $\begin{array}{c}\text { Weighted } \\
\text { Percent }\end{array}$ & $\begin{array}{c}\text { Weighted } \\
\text { Error of } \\
\text { Percent }\end{array}$ \\
\hline \multicolumn{7}{|l|}{ Q4. In which state or condition can hydrogen be stored? } & 6.3 & 2.66 & 0.62 \\
\hline Chemical compound & 24 & 26.6 & 17.3 & 24.6 & 1.68 \\
\hline Liquid & 262 & 245.6 & 19.3 & 29.2 & 1.82 \\
\hline Both of these & 288 & 292.0 & 8.6 & 5.31 & 0.85 \\
\hline Neither of these & 50 & 53.1 & 23.7 & 38.3 & 2.01 \\
\hline Don't know & 376 & 382.6 & 25.3 & 100 & 0.00 \\
\hline Total for Q4 & 1,000 & 999.9 & & & \\
\hline
\end{tabular}

Q5. When using pure hydrogen, fuel cell vehicles generate electricity, water, and what else?

\begin{tabular}{|l|c|c|c|c|c|}
\hline Carbon dioxide & 74 & 77.0 & 10.2 & 7.70 & 1.01 \\
\hline Nitrous oxides & 30 & 30.4 & 6.3 & 3.05 & 0.63 \\
\hline Heat & 230 & 221.3 & 15.7 & 22.1 & 1.56 \\
\hline All of these & 117 & 117.7 & 11.9 & 11.8 & 1.19 \\
\hline Don't know & 549 & 553.4 & 27.2 & 55.3 & 1.98 \\
\hline Total for Q5 & 1,000 & 999.9 & 25.3 & 100 & 0.00 \\
\hline
\end{tabular}

Q6. Hydrogen can be produced using which of the following sources of energy?

\begin{tabular}{|l|c|c|c|c|c|}
\hline Natural gas & 63 & 60.7 & 9.7 & 6.07 & 0.96 \\
\hline Sunlight & 40 & 49.2 & 9.6 & 4.92 & 0.95 \\
\hline Organic matter & 93 & 92.5 & 10.6 & 9.25 & 1.06 \\
\hline All of these & 312 & 296.4 & 17.2 & 29.6 & 1.74 \\
\hline Don't know & 492 & 501.1 & 26.5 & 50.1 & 2.04 \\
\hline Total for Q6 & 1,000 & 999.9 & 25.3 & 100 & 0.00 \\
\hline
\end{tabular}

\section{Q7A. First}




\begin{tabular}{|l|c|c|c|c|c|}
\hline \multicolumn{1}{|c|}{ Question/Metric } & $\begin{array}{c}\text { Unweighted } \\
\text { Frequency }\end{array}$ & $\begin{array}{c}\text { Standard } \\
\text { Weighted } \\
\text { Frequency }\end{array}$ & $\begin{array}{c}\text { Standard } \\
\text { of Weighted } \\
\text { Frequency }\end{array}$ & $\begin{array}{c}\text { Weighted } \\
\text { Percent }\end{array}$ & $\begin{array}{c}\text { Error of } \\
\text { Weighted } \\
\text { Percent }\end{array}$ \\
\hline Safety & 282 & 287.6 & 20.0 & 28.8 & 1.85 \\
\hline Low cost & 366 & 377.0 & 23.6 & 37.7 & 2.03 \\
\hline Environmental impact & 161 & 150.4 & 12.9 & 15.0 & 1.31 \\
\hline Convenience & 76 & 74.0 & 9.5 & 7.40 & 0.95 \\
\hline Performance & 100 & 96.9 & 12.6 & 9.69 & 1.23 \\
\hline Don't know & 15 & 14.1 & 4.0 & 1.41 & 0.40 \\
\hline Total for Q7A & 1,000 & 999.9 & 25.3 & 100 & 0.00 \\
\hline
\end{tabular}

\section{Q7B. Second}

\begin{tabular}{|l|c|c|c|c|c|}
\hline Safety & 212 & 221.7 & 19.3 & 22.5 & 1.80 \\
\hline Low cost & 268 & 270.8 & 19.9 & 27.5 & 1.86 \\
\hline Environmental impact & 214 & 212.1 & 16.5 & 21.5 & 1.63 \\
\hline Convenience & 134 & 135.1 & 13.0 & 13.7 & 1.31 \\
\hline Performance & 154 & 141.4 & 14.1 & 14.3 & 1.40 \\
\hline Don't know & 3 & 4.7 & 3.5 & 0.47 & 0.35 \\
\hline Total for Q7B & 985 & 985.8 & 25.2 & 100 & 0.00 \\
\hline
\end{tabular}

\section{Q7C. Third}

\begin{tabular}{|l|c|c|c|c|c|}
\hline Safety & 242 & 230.7 & 17.5 & 23.5 & 1.71 \\
\hline Low cost & 158 & 153.2 & 13.6 & 15.6 & 1.39 \\
\hline Environmental impact & 189 & 202.9 & 19.4 & 20.7 & 1.81 \\
\hline Convenience & 156 & 152.7 & 15.2 & 15.6 & 1.50 \\
\hline Performance & 226 & 233.6 & 17.9 & 23.8 & 1.74 \\
\hline Don't know & 11 & 8.1 & 2.6 & 0.82 & 0.26 \\
\hline Total for Q7C & 982 & 981.1 & 25.1 & 100 & 0.00 \\
\hline
\end{tabular}




\begin{tabular}{|c|c|c|c|c|c|}
\hline Question/Metric & $\begin{array}{l}\text { Unweighted } \\
\text { Frequency }\end{array}$ & $\begin{array}{l}\text { Weighted } \\
\text { Frequency }\end{array}$ & $\begin{array}{c}\text { Standard } \\
\text { Deviation } \\
\text { of Weighted } \\
\text { Frequency }\end{array}$ & $\begin{array}{l}\text { Weighted } \\
\text { Percent }\end{array}$ & $\begin{array}{c}\text { Standard } \\
\text { Error of } \\
\text { Weighted } \\
\text { Percent }\end{array}$ \\
\hline \multicolumn{6}{|l|}{ Q7D. Fourth } \\
\hline Safety & 177 & 171.3 & 15.3 & 17.6 & 1.54 \\
\hline Low cost & 114 & 98.4 & 10.0 & 10.1 & 1.05 \\
\hline Environmental impact & 182 & 189.4 & 17.3 & 19.5 & 1.68 \\
\hline Convenience & 214 & 227.9 & 19.0 & 23.4 & 1.80 \\
\hline Performance & 279 & 278.6 & 19.6 & 28.6 & 1.87 \\
\hline Don't know & 5 & 7.4 & 4.9 & 0.76 & 0.50 \\
\hline Total for Q7D & 971 & 973.1 & 25.1 & 100 & 0.00 \\
\hline \multicolumn{6}{|l|}{ Q7E. Fifth } \\
\hline Safety & 65 & 66.1 & 9.4 & 6.85 & 0.97 \\
\hline Low cost & 76 & 84.4 & 11.6 & 8.74 & 1.18 \\
\hline Environmental impact & 220 & 210.8 & 16.7 & 21.8 & 1.67 \\
\hline Convenience & 391 & 379.5 & 22.1 & 39.3 & 2.03 \\
\hline Performance & 214 & 224.9 & 18.3 & 23.3 & 1.77 \\
\hline Total for Q7E & 966 & 965.7 & 24.8 & 100 & 0.00 \\
\hline
\end{tabular}

Q8. How would you feel if your local gas station also sold hydrogen?

\begin{tabular}{|l|c|c|c|c|c|}
\hline Frightened & 27 & 29.8 & 7.3 & 2.98 & 0.72 \\
\hline Uneasy & 110 & 99.0 & 10.3 & 9.90 & 1.04 \\
\hline At ease & 212 & 204.9 & 15.4 & 20.5 & 1.53 \\
\hline Pleased & 352 & 322.4 & 16.7 & 32.2 & 1.75 \\
\hline Don't know & 299 & 343.8 & 26.3 & 34.4 & 2.12 \\
\hline Total for Q8 & 1,000 & 999.9 & 25.3 & 100 & 0.00 \\
\hline
\end{tabular}

Q9. Hydrogen is too dangerous for everyday use by the general public 


\begin{tabular}{|l|c|c|c|c|c|}
\hline \multicolumn{1}{|c|}{ Question/Metric } & $\begin{array}{c}\text { Unweighted } \\
\text { Frequency }\end{array}$ & $\begin{array}{c}\text { Standard } \\
\text { Weighted } \\
\text { Frequency }\end{array}$ & $\begin{array}{c}\text { Seviation } \\
\text { of Weighted } \\
\text { Frequency }\end{array}$ & $\begin{array}{c}\text { Weighted } \\
\text { Percent }\end{array}$ & $\begin{array}{c}\text { Wrror of } \\
\text { Weighted } \\
\text { Percent }\end{array}$ \\
\hline True & 155 & 139.0 & 12.3 & 13.9 & 1.25 \\
\hline False & 464 & 449.5 & 20.8 & 45.0 & 1.99 \\
\hline Don't know & 381 & 411.4 & 25.8 & 41.1 & 2.06 \\
\hline Total for Q9 & 1,000 & 999.9 & 25.3 & 100 & 0.00 \\
\hline
\end{tabular}

Q10A. Using hydrogen will reduce U.S. dependence on foreign oil

\begin{tabular}{|l|c|c|c|c|c|}
\hline Disagree & 52 & 52.0 & 8.2 & 5.20 & 0.82 \\
\hline Are neutral & 52 & 66.5 & 14.0 & 6.65 & 1.34 \\
\hline Agree & 712 & 664.6 & 20.2 & 66.5 & 2.10 \\
\hline Don't know & 184 & 216.8 & 21.7 & 21.7 & 1.92 \\
\hline Total for Q10A & 1,000 & 999.9 & 25.3 & 100 & 0.00 \\
\hline
\end{tabular}

Q10B. Using hydrogen will reduce emissions and improve air quality

\begin{tabular}{|l|c|c|c|c|c|}
\hline Disagree & 27 & 33.2 & 7.2 & 3.32 & 0.72 \\
\hline Are neutral & 67 & 72.7 & 12.1 & 7.27 & 1.18 \\
\hline Agree & 623 & 604.5 & 22.4 & 60.5 & 2.05 \\
\hline Don't know & 283 & 289.4 & 22.1 & 28.9 & 1.95 \\
\hline Total for Q10B & 1,000 & 999.9 & 25.3 & 100 & 0.00 \\
\hline
\end{tabular}

\section{Q10C. Hydrogen is as safe to use in my car as gasoline and diesel fuels}

\begin{tabular}{|l|c|c|c|c|c|}
\hline Disagree & 98 & 99.3 & 12.3 & 9.93 & 1.21 \\
\hline Are neutral & 79 & 90.9 & 13.8 & 9.09 & 1.33 \\
\hline Agree & 429 & 410.6 & 20.2 & 41.1 & 1.96 \\
\hline Don't know & 394 & 399.1 & 23.5 & 39.9 & 2.01 \\
\hline Total for Q10C & 1,000 & 999.9 & 25.3 & 100 & 0.00 \\
\hline
\end{tabular}




\begin{tabular}{|l|c|c|c|c|c|}
\hline \multicolumn{1}{|c|}{ Question/Metric } & $\begin{array}{c}\text { Unweighted } \\
\text { Frequency }\end{array}$ & $\begin{array}{c}\text { Weighted } \\
\text { Frequency }\end{array}$ & $\begin{array}{c}\text { Standard } \\
\text { Deviation } \\
\text { of Weighted } \\
\text { Frequency }\end{array}$ & $\begin{array}{c}\text { Weighted } \\
\text { Percent }\end{array}$ & $\begin{array}{c}\text { Standard } \\
\text { Error of } \\
\text { Weighted } \\
\text { Percent }\end{array}$ \\
\hline Q11. Shopping for a new car...buy a fuel cell vehicle at the same price, would you? \\
\hline Yes & 610 & 623.0 & 25.3 & 62.3 & 1.96 \\
\hline No & 205 & 185.0 & 15.2 & 18.5 & 1.49 \\
\hline Don't know & 185 & 191.9 & 17.5 & 19.2 & 1.65 \\
\hline Total for Q11 & 1,000 & 999.9 & 25.3 & 100 & 0.00 \\
\hline \multicolumn{7}{|c|}{} & & & & \\
\hline Q12. How would you feel if a school, hospital, or other building in your neighborhood was \\
powered by a fuel cell located
\end{tabular}

\section{Q13A. Personal cars and trucks}

\begin{tabular}{|l|c|c|c|c|c|}
\hline Not as safe & 106 & 94.9 & 10.8 & 9.49 & 1.08 \\
\hline Equally as safe & 418 & 412.7 & 22.4 & 41.3 & 1.99 \\
\hline Safer & 135 & 144.6 & 13.9 & 14.5 & 1.37 \\
\hline Don't know & 341 & 347.7 & 22.5 & 34.8 & 1.97 \\
\hline Total for Q13A & 1,000 & 999.9 & 25.3 & 100 & 0.00 \\
\hline
\end{tabular}

\section{Q13B. Buses and commercial vehicles}

\begin{tabular}{|l|c|c|c|c|c|}
\hline Not as safe & 93 & 95.8 & 13.4 & 9.58 & 1.29 \\
\hline Equally as safe & 420 & 395.7 & 19.8 & 39.6 & 1.94 \\
\hline Safer & 127 & 137.2 & 13.7 & 13.7 & 1.35 \\
\hline Don't know & 360 & 371.3 & 23.8 & 37.1 & 2.03 \\
\hline
\end{tabular}




\begin{tabular}{|l|c|c|c|c|c|}
\hline \multicolumn{1}{|c|}{ Question/Metric } & $\begin{array}{c}\text { Unweighted } \\
\text { Frequency }\end{array}$ & $\begin{array}{c}\text { Weighted } \\
\text { Frequency }\end{array}$ & $\begin{array}{c}\text { Standard } \\
\text { Deviation } \\
\text { of Weighted } \\
\text { Frequency }\end{array}$ & $\begin{array}{c}\text { Weighted } \\
\text { Percent }\end{array}$ & $\begin{array}{c}\text { Standard } \\
\text { Error of } \\
\text { Weighted } \\
\text { Percent }\end{array}$ \\
\hline Total for Q13B & 1,000 & 999.9 & 25.3 & 100 & 0.00 \\
\hline \multicolumn{7}{|l|}{} & & & & \\
\hline Q13C. Large power plants & & 96.1 & 13.8 & 9.61 & 1.33 \\
\hline Not as safe & 87 & 358.4 & 18.3 & 35.8 & 1.86 \\
\hline Equally as safe & 383 & 163.7 & 16.2 & 16.4 & 1.54 \\
\hline Safer & 154 & 381.7 & 23.4 & 38.2 & 2.01 \\
\hline Don't know & 376 & 999.9 & 25.3 & 100 & 0.00 \\
\hline Total for Q13C & 1,000 & & & & \\
\hline
\end{tabular}

Q13D. Small portable devices such as laptop computers or cell phones

\begin{tabular}{|l|c|c|c|c|c|}
\hline Not as safe & 133 & 137.7 & 16.1 & 13.8 & 1.52 \\
\hline Equally as safe & 284 & 295.5 & 20.8 & 29.6 & 1.89 \\
\hline Safer & 90 & 101.8 & 12.4 & 10.2 & 1.22 \\
\hline Don't know & 493 & 464.9 & 21.4 & 46.5 & 2.00 \\
\hline Total for Q13D & 1,000 & 999.9 & 25.3 & 100 & 0.00 \\
\hline
\end{tabular}

Q13E. Onsite power for the home

\begin{tabular}{|l|c|c|c|c|c|}
\hline Not as safe & 115 & 113.8 & 12.2 & 11.4 & 1.21 \\
\hline Equally as safe & 383 & 367.7 & 19.5 & 36.8 & 1.90 \\
\hline Safer & 110 & 117.8 & 12.8 & 11.8 & 1.26 \\
\hline Don't know & 392 & 400.5 & 25.0 & 40.1 & 2.05 \\
\hline Total for Q13E & 1,000 & 999.9 & 25.3 & 100 & 0.00 \\
\hline
\end{tabular}

\section{Q13F. Onsite power for buildings such as hospitals and schools}

\begin{tabular}{|l|c|c|c|c|c|}
\hline Not as safe & 92 & 87.6 & 10.8 & 8.76 & 1.07 \\
\hline Equally as safe & 416 & 406.9 & 21.6 & 40.7 & 1.98 \\
\hline
\end{tabular}




\begin{tabular}{|l|c|c|c|c|c|}
\hline \multicolumn{1}{|c|}{ Question/Metric } & $\begin{array}{c}\text { Unweighted } \\
\text { Frequency }\end{array}$ & $\begin{array}{c}\text { Weighted } \\
\text { Frequency }\end{array}$ & $\begin{array}{c}\text { Standard } \\
\text { Deviation } \\
\text { of Weighted } \\
\text { Frequency }\end{array}$ & $\begin{array}{c}\text { Weighted } \\
\text { Percent }\end{array}$ & $\begin{array}{c}\text { Standard } \\
\text { Error of } \\
\text { Weighted } \\
\text { Percent }\end{array}$ \\
\hline Safer & 126 & 132.9 & 14.8 & 13.3 & 1.43 \\
\hline Don't know & 366 & 372.6 & 22.9 & 37.3 & 2.00 \\
\hline Total for Q13F & 1,000 & 999.9 & 25.3 & 100 & 0.00 \\
\hline
\end{tabular}

Q14A. Teachers and schools

\begin{tabular}{|l|c|c|c|c|c|}
\hline Never & 673 & 630.4 & 21.9 & 63.0 & 2.06 \\
\hline Sometimes & 221 & 248.1 & 21.4 & 24.8 & 1.90 \\
\hline Frequently & 80 & 98.2 & 14.3 & 9.82 & 1.38 \\
\hline Don't know & 26 & 23.3 & 5.5 & 2.33 & 0.55 \\
\hline Total for Q14A & 1,000 & 999.9 & 25.3 & 100 & 0.00 \\
\hline
\end{tabular}

Q14B. Friends and family members

\begin{tabular}{|l|c|c|c|c|c|}
\hline Never & 277 & 277.0 & 19.4 & 27.7 & 1.81 \\
\hline Sometimes & 497 & 484.8 & 23.7 & 48.5 & 2.04 \\
\hline Frequently & 207 & 223.4 & 18.3 & 22.3 & 1.71 \\
\hline Don't know & 19 & 14.7 & 3.8 & 1.47 & 0.38 \\
\hline Total for Q14B & 1,000 & 999.9 & 25.3 & 100 & 0.00 \\
\hline
\end{tabular}

Q14C. Environmental and conservation groups

\begin{tabular}{|l|c|c|c|c|c|}
\hline Never & 458 & 503.2 & 27.1 & 50.3 & 2.03 \\
\hline Sometimes & 377 & 346.2 & 18.2 & 34.6 & 1.84 \\
\hline Frequently & 140 & 132.1 & 13.1 & 13.2 & 1.29 \\
\hline Don't know & 25 & 18.4 & 4.0 & 1.84 & 0.41 \\
\hline Total for Q14C & 1,000 & 999.9 & 25.3 & 100 & 0.00 \\
\hline
\end{tabular}

Q14D. Utility companies or brokers, for example, gas or electricity providers 


\begin{tabular}{|c|c|c|c|c|c|}
\hline Question/Metric & $\begin{array}{l}\text { Unweighted } \\
\text { Frequency }\end{array}$ & $\begin{array}{l}\text { Weighted } \\
\text { Frequency }\end{array}$ & $\begin{array}{c}\text { Standard } \\
\text { Deviation } \\
\text { of Weighted } \\
\text { Frequency }\end{array}$ & $\begin{array}{l}\text { Weighted } \\
\text { Percent }\end{array}$ & $\begin{array}{c}\text { Standard } \\
\text { Error of } \\
\text { Weighted } \\
\text { Percent }\end{array}$ \\
\hline Never & 365 & 373.1 & 23.5 & 37.3 & 2.01 \\
\hline Sometimes & 483 & 483.5 & 22.9 & 48.4 & 2.03 \\
\hline Frequently & 142 & 135.6 & 12.9 & 13.6 & 1.28 \\
\hline Don't know & 10 & 7.8 & 2.6 & 0.78 & 0.26 \\
\hline Total for Q14D & 1,000 & 999.9 & 25.3 & 100 & 0.00 \\
\hline \multicolumn{6}{|c|}{ Q14E. Industry or trade associations or non-profit organizations } \\
\hline Never & 487 & 523.9 & 26.5 & 52.4 & 2.00 \\
\hline Sometimes & 375 & 358.2 & 20.2 & 35.8 & 1.90 \\
\hline Frequently & 112 & 97.9 & 9.7 & 9.79 & 0.99 \\
\hline Don't know & 26 & 19.8 & 4.1 & 1.99 & 0.41 \\
\hline Total for Q14E & 1,000 & 999.9 & 25.3 & 100 & 0.00 \\
\hline \multicolumn{6}{|c|}{ Q14F. Federal government } \\
\hline Never & 440 & 478.2 & 26.3 & 47.8 & 2.04 \\
\hline Sometimes & 430 & 401.9 & 19.8 & 40.2 & 1.93 \\
\hline Frequently & 111 & 105.7 & 12.0 & 10.6 & 1.19 \\
\hline Don't know & 19 & 14.1 & 3.3 & 1.41 & 0.34 \\
\hline Total for Q14F & 1,000 & 999.9 & 25.3 & 100 & 0.00 \\
\hline \multicolumn{6}{|c|}{ Q14G. State government } \\
\hline Never & 448 & 485.9 & 26.3 & 48.6 & 2.04 \\
\hline Sometimes & 437 & 405.4 & 19.9 & 40.5 & 1.94 \\
\hline Frequently & 92 & 90.1 & 11.5 & 9.01 & 1.14 \\
\hline Don't know & 23 & 18.5 & 4.2 & 1.85 & 0.42 \\
\hline Total for Q14G & 1,000 & 999.9 & 25.3 & 100 & 0.00 \\
\hline
\end{tabular}




\begin{tabular}{|c|c|c|c|c|c|}
\hline Question/Metric & $\begin{array}{l}\text { Unweighted } \\
\text { Frequency }\end{array}$ & $\begin{array}{l}\text { Weighted } \\
\text { Frequency }\end{array}$ & $\begin{array}{c}\text { Standard } \\
\text { Deviation } \\
\text { of Weighted } \\
\text { Frequency }\end{array}$ & $\begin{array}{l}\text { Weighted } \\
\text { Percent }\end{array}$ & $\begin{array}{c}\text { Standard } \\
\text { Error of } \\
\text { Weighted } \\
\text { Percent }\end{array}$ \\
\hline \multicolumn{6}{|c|}{ Q14H. Local government } \\
\hline Never & 491 & 518.3 & 26.4 & 51.8 & 2.03 \\
\hline Sometimes & 402 & 368.8 & 18.2 & 36.9 & 1.87 \\
\hline Frequently & 86 & 95.5 & 13.8 & 9.55 & 1.33 \\
\hline Don't know & 21 & 17.3 & 4.1 & 1.73 & 0.41 \\
\hline Total for Q14H & 1,000 & 999.9 & 25.3 & 100 & 0.00 \\
\hline \multicolumn{6}{|l|}{ Q15A. Television } \\
\hline Never & 148 & 165.3 & 19.1 & 16.5 & 1.75 \\
\hline Sometimes & 554 & 541.2 & 22.8 & 54.1 & 2.03 \\
\hline Frequently & 288 & 286.9 & 18.6 & 28.7 & 1.78 \\
\hline Don't know & 10 & 6.6 & 2.1 & 0.66 & 0.21 \\
\hline Total for Q15A & 1,000 & 999.9 & 25.3 & 100 & 0.00 \\
\hline \multicolumn{6}{|l|}{ Q15B. Radio } \\
\hline Never & 377 & 381.4 & 24.1 & 38.1 & 2.04 \\
\hline Sometimes & 472 & 474.4 & 22.6 & 47.4 & 2.03 \\
\hline Frequently & 146 & 140.6 & 12.8 & 14.1 & 1.28 \\
\hline Don't know & 5 & 3.5 & 1.6 & 0.35 & 0.16 \\
\hline Total for Q15B & 1,000 & 999.9 & 25.3 & 100 & 0.00 \\
\hline \multicolumn{6}{|l|}{ Q15C. The Internet } \\
\hline Never & 397 & 353.1 & 20.2 & 35.3 & 1.88 \\
\hline Sometimes & 346 & 378.9 & 21.8 & 37.9 & 1.96 \\
\hline Frequently & 250 & 262.8 & 20.0 & 26.3 & 1.84 \\
\hline
\end{tabular}




\begin{tabular}{|c|c|c|c|c|c|}
\hline Question/Metric & $\begin{array}{l}\text { Unweighted } \\
\text { Frequency }\end{array}$ & $\begin{array}{l}\text { Weighted } \\
\text { Frequency }\end{array}$ & $\begin{array}{c}\text { Standard } \\
\text { Deviation } \\
\text { of Weighted } \\
\text { Frequency }\end{array}$ & $\begin{array}{c}\text { Weighted } \\
\text { Percent }\end{array}$ & $\begin{array}{c}\text { Standard } \\
\text { Error of } \\
\text { Weighted } \\
\text { Percent }\end{array}$ \\
\hline Don't know & 7 & 5.0 & 1.9 & 0.50 & 0.19 \\
\hline Total for Q15C & 1,000 & 999.9 & 25.3 & 100 & 0.00 \\
\hline \multicolumn{6}{|c|}{ Q15D. Newspapers and general interest magazines } \\
\hline Never & 221 & 235.0 & 20.2 & 23.5 & 1.83 \\
\hline Sometimes & 524 & 529.5 & 24.5 & 53.0 & 2.03 \\
\hline Frequently & 248 & 230.5 & 15.7 & 23.0 & 1.58 \\
\hline Don't know & 7 & 5.0 & 1.9 & 0.50 & 0.19 \\
\hline Total for Q15D & 1,000 & 999.9 & 25.3 & 100 & 0.00 \\
\hline \multicolumn{6}{|c|}{ Q15E. Science and technology magazines and journals } \\
\hline Never & 530 & 548.0 & 26.4 & 54.8 & 1.99 \\
\hline Sometimes & 328 & 311.7 & 18.6 & 31.2 & 1.80 \\
\hline Frequently & 134 & 133.0 & 13.0 & 13.3 & 1.29 \\
\hline Don't know & 8 & 7.3 & 2.8 & 0.73 & 0.28 \\
\hline Total for Q15E & 1,000 & 999.9 & 25.3 & 100 & 0.00 \\
\hline \multicolumn{6}{|c|}{ Q15F. Business or trade magazines } \\
\hline Never & 553 & 580.7 & 27.8 & 58.1 & 1.94 \\
\hline Sometimes & 328 & 318.8 & 18.1 & 31.9 & 1.80 \\
\hline Frequently & 111 & 94.8 & 9.6 & 9.48 & 0.98 \\
\hline Don't know & 8 & 5.6 & 2.0 & 0.56 & 0.20 \\
\hline Total for Q15F & 1,000 & 999.9 & 25.3 & 100 & 0.00 \\
\hline \multicolumn{6}{|l|}{ Safety } \\
\hline 1 & 282 & 287.6 & 19.9 & 29.4 & 1.89 \\
\hline
\end{tabular}




\begin{tabular}{|c|c|c|c|c|c|}
\hline Question/Metric & $\begin{array}{l}\text { Unweighted } \\
\text { Frequency }\end{array}$ & $\begin{array}{l}\text { Weighted } \\
\text { Frequency }\end{array}$ & $\begin{array}{c}\text { Standard } \\
\text { Deviation } \\
\text { of Weighted } \\
\text { Frequency }\end{array}$ & $\begin{array}{l}\text { Weighted } \\
\text { Percent }\end{array}$ & $\begin{array}{c}\text { Standard } \\
\text { Error of } \\
\text { Weighted } \\
\text { Percent }\end{array}$ \\
\hline 2 & 212 & 221.7 & 19.3 & 22.7 & 1.81 \\
\hline 3 & 242 & 230.7 & 17.5 & 23.6 & 1.72 \\
\hline 4 & 177 & 171.3 & 15.3 & 17.5 & 1.53 \\
\hline 5 & 65 & 66.1 & 9.4 & 6.76 & 0.95 \\
\hline Total for Safety & 978 & 977.3 & 25.1 & 100 & 0.00 \\
\hline \multicolumn{6}{|l|}{ Cost } \\
\hline 1 & 366 & 377.0 & 23.6 & 38.3 & 2.05 \\
\hline 2 & 268 & 270.8 & 19.9 & 27.5 & 1.86 \\
\hline 3 & 158 & 153.2 & 13.6 & 15.6 & 1.38 \\
\hline 4 & 114 & 98.4 & 10.0 & 10.0 & 1.04 \\
\hline 5 & 76 & 84.4 & 11.6 & 8.58 & 1.16 \\
\hline Total for Cost & 982 & 983.7 & 25.2 & 100 & 0.00 \\
\hline \multicolumn{6}{|l|}{ Environment } \\
\hline 1 & 161 & 150.4 & 12.9 & 15.6 & 1.35 \\
\hline 2 & 214 & 212.1 & 16.5 & 22.0 & 1.66 \\
\hline 3 & 189 & 202.9 & 19.4 & 21.0 & 1.84 \\
\hline 4 & 182 & 189.4 & 17.3 & 19.6 & 1.69 \\
\hline 5 & 220 & 210.8 & 16.7 & 21.8 & 1.67 \\
\hline Total for Environment & 966 & 965.7 & 24.8 & 100 & 0.00 \\
\hline \multicolumn{6}{|l|}{ Convenience } \\
\hline 1 & 76 & 74.0 & 9.5 & 7.63 & 0.98 \\
\hline 2 & 134 & 135.1 & 13.0 & 13.9 & 1.33 \\
\hline 3 & 156 & 152.7 & 15.2 & 15.8 & 1.51 \\
\hline
\end{tabular}




\begin{tabular}{|l|c|c|c|c|c|}
\hline & Question/Metric & $\begin{array}{c}\text { Standard } \\
\text { Frequency }\end{array}$ & $\begin{array}{c}\text { Weighted } \\
\text { Frequency }\end{array}$ & $\begin{array}{c}\text { Standard } \\
\text { of Weighted } \\
\text { Frequency }\end{array}$ & $\begin{array}{c}\text { Weighted } \\
\text { Percent } \\
\text { Error of } \\
\text { Weighted } \\
\text { Percent }\end{array}$ \\
\hline 4 & 214 & 227.9 & 19.0 & 23.5 & 1.81 \\
\hline 5 & 391 & 379.5 & 22.2 & 39.2 & 2.03 \\
\hline Total for Convenience & 971 & 969.3 & 24.8 & 100 & 0.00 \\
\hline
\end{tabular}

\section{Performance}

\begin{tabular}{|l|c|c|c|c|c|}
\hline 1 & 100 & 96.9 & 12.6 & 9.93 & 1.26 \\
\hline 2 & 154 & 141.4 & 14.1 & 14.5 & 1.42 \\
\hline 3 & 226 & 233.6 & 17.9 & 23.9 & 1.75 \\
\hline 4 & 279 & 278.6 & 19.6 & 28.6 & 1.87 \\
\hline 5 & 214 & 224.9 & 18.3 & 23.1 & 1.76 \\
\hline Total for Performance & 973 & 975.3 & 25.1 & 100 & 0.00 \\
\hline
\end{tabular}

\section{Partial}

\begin{tabular}{|l|c|c|c|c|c|}
\hline Complete & 966 & 965.7 & 25.5 & 96.6 & 0.76 \\
\hline Partial & 34 & 34.2 & 7.7 & 3.42 & 0.76 \\
\hline Total for Partial & 1,000 & 999.9 & 25.3 & 100 & 0.00 \\
\hline
\end{tabular}

\section{Safety $>$ Cost?}

\begin{tabular}{|l|c|c|c|c|c|}
\hline No & 565 & 565.1 & 25.5 & 56.5 & 2.01 \\
\hline Yes & 435 & 434.8 & 22.1 & 43.5 & 2.01 \\
\hline Total for Safety > Cost? & 1,000 & 999.9 & 25.3 & 100 & 0.00 \\
\hline
\end{tabular}

\section{Safety $>$ Environment?}

\begin{tabular}{|l|c|c|c|c|c|}
\hline No & 409 & 398.8 & 19.9 & 39.9 & 1.93 \\
\hline Yes & 591 & 601.1 & 26.9 & 60.1 & 1.93 \\
\hline $\begin{array}{l}\text { Total for Safety } \\
\text { Environment? }\end{array}$ & 1,000 & 999.9 & 25.3 & 100 & 0.00 \\
\hline
\end{tabular}




\begin{tabular}{|l|c|c|c|c|c|}
\hline \multicolumn{1}{|c|}{ Question/Metric } & $\begin{array}{c}\text { Unweighted } \\
\text { Frequency }\end{array}$ & $\begin{array}{c}\text { Standard } \\
\text { Weighted } \\
\text { Frequency }\end{array}$ & $\begin{array}{c}\text { Seviation } \\
\text { of Weighted } \\
\text { Frequency }\end{array}$ & $\begin{array}{c}\text { Weighted } \\
\text { Percent }\end{array}$ & $\begin{array}{c}\text { Error of } \\
\text { Weighted } \\
\text { Percent }\end{array}$ \\
\hline \multicolumn{2}{|l|}{} & & & \\
\hline Safety $>$ Convenience? & 293 & 290.6 & 18.9 & 29.1 & 1.80 \\
\hline No & 707 & 709.4 & 26.3 & 70.9 & 1.80 \\
\hline Yes & 1,000 & 999.9 & 25.3 & 100 & 0.00 \\
\hline $\begin{array}{l}\text { Total for Safety } \\
\text { Convenience? }\end{array}$ & & & & \\
\hline
\end{tabular}

\section{Safety $>$ Performance?}

\begin{tabular}{|l|c|c|c|c|c|}
\hline No & 328 & 312.4 & 19.9 & 31.2 & 1.86 \\
\hline Yes & 672 & 687.5 & 26.0 & 68.8 & 1.86 \\
\hline $\begin{array}{l}\text { Total for Safety }> \\
\text { Performance? }\end{array}$ & 1,000 & 999.9 & 25.3 & 100 & 0.00 \\
\hline
\end{tabular}

\section{Cost $>$ Environment?}

\begin{tabular}{|l|c|c|c|c|c|}
\hline No & 364 & 351.8 & 18.9 & 35.2 & 1.86 \\
\hline Yes & 636 & 648.1 & 27.1 & 64.8 & 1.86 \\
\hline $\begin{array}{l}\text { Total for Cost }> \\
\text { Environment? }\end{array}$ & 1,000 & 999.9 & 25.3 & 100 & 0.00 \\
\hline
\end{tabular}

\section{Cost $>$ Convenience?}

\begin{tabular}{|l|c|c|c|c|c|}
\hline No & 220 & 225.8 & 17.1 & 22.6 & 1.65 \\
\hline Yes & 780 & 774.2 & 26.4 & 77.4 & 1.65 \\
\hline $\begin{array}{l}\text { Total for Cost }> \\
\text { Convenience? }\end{array}$ & 1,000 & 999.9 & 25.3 & 100 & 0.00 \\
\hline
\end{tabular}

\section{Cost $>$ Performance?}

\begin{tabular}{|l|l|l|l|l|l|}
\hline No & 307 & 294.8 & 19.0 & 29.5 & 1.82 \\
\hline Yes & 693 & 705.1 & 26.6 & 70.5 & 1.82 \\
\hline
\end{tabular}




\begin{tabular}{|l|c|c|c|c|c|}
\hline \multicolumn{1}{|c|}{ Question/Metric } & $\begin{array}{c}\text { Unweighted } \\
\text { Frequency }\end{array}$ & $\begin{array}{c}\text { Standard } \\
\text { Weighted } \\
\text { Frequency }\end{array}$ & $\begin{array}{c}\text { Sevian } \\
\text { of Weighted } \\
\text { Frequency }\end{array}$ & $\begin{array}{c}\text { Weighted } \\
\text { Percent }\end{array}$ & $\begin{array}{c}\text { Standard } \\
\text { Error of } \\
\text { Weighted } \\
\text { Percent }\end{array}$ \\
\hline $\begin{array}{l}\text { Total for Cost }> \\
\text { Performance? }\end{array}$ & 1,000 & 999.9 & 25.3 & 100 & 0.00 \\
\hline
\end{tabular}

\section{Environment $>$ Convenience?}

\begin{tabular}{|l|c|c|c|c|c|}
\hline No & 395 & 393.7 & 21.2 & 39.4 & 1.96 \\
\hline Yes & 605 & 606.2 & 25.9 & 60.6 & 1.96 \\
\hline $\begin{array}{l}\text { Total for Environment }> \\
\text { Convenience? }\end{array}$ & 1,000 & 999.9 & 25.3 & 100 & 0.00 \\
\hline
\end{tabular}

\section{Environment $>$ Performance?}

\begin{tabular}{|l|c|c|c|c|c|}
\hline No & 452 & 441.8 & 22.6 & 44.2 & 2.02 \\
\hline Yes & 548 & 558.1 & 25.1 & 55.8 & 2.02 \\
\hline $\begin{array}{l}\text { Total for Environment }> \\
\text { Performance? }\end{array}$ & 1,000 & 999.9 & 25.3 & 100 & 0.00 \\
\hline
\end{tabular}

\section{Convenience $>$ Performance?}

\begin{tabular}{|l|c|c|c|c|c|}
\hline No & 597 & 584.6 & 25.2 & 58.5 & 2.00 \\
\hline Yes & 403 & 415.3 & 22.3 & 41.5 & 2.00 \\
\hline $\begin{array}{l}\text { Total for Convenience }> \\
\text { Performance? }\end{array}$ & 1,000 & 999.9 & 25.3 & 100 & 0.00 \\
\hline
\end{tabular}




\section{General Public Survey Technical Question Summary}

\begin{tabular}{|l|r|r|r|r|}
\hline & $\begin{array}{r}\text { Number } \\
\text { of } \\
\text { Question }\end{array}$ & $\begin{array}{c}\text { Weighted } \\
\text { Percent } \\
\text { Correct }\end{array}$ & $\begin{array}{c}\text { Lower } \\
\text { 95\% } \\
\text { Confidence } \\
\text { Bound }\end{array}$ & $\begin{array}{c}\text { Upper } \\
\text { 95\% } \\
\text { Confidence } \\
\text { Bound }\end{array}$ \\
\hline 2A. Hydrogen gas is toxic (false) & 1,000 & 42.87 & 38.92 & 46.82 \\
\hline $\begin{array}{l}\text { 2B. Fuel cells produce electricity through hydrogen } \\
\text { combustion (false) }\end{array}$ & 1,000 & 11.25 & 9.05 & 13.45 \\
\hline 2C. Hydrogen is lighter than air (true) & 1,000 & 51.83 & 47.83 & 55.83 \\
\hline 2D. Hydrogen has a distinct odor (false) & 1,000 & 49.62 & 45.61 & 53.63 \\
\hline $\begin{array}{l}\text { 4. In which state or condition can hydrogen be } \\
\text { stored? (chemical compound, liquid) }\end{array}$ & 1,000 & 29.20 & 25.64 & 32.77 \\
\hline $\begin{array}{l}\text { 5. When using pure hydrogen, fuel cell vehicles } \\
\text { generate electricity, water, and what else? (heat) }\end{array}$ & 1,000 & 22.13 & 19.07 & 25.20 \\
\hline $\begin{array}{l}\text { 6. Hydrogen can be produced using which of the } \\
\text { following sources of energy? (natural gas, sunlight, } \\
\text { organic matter) }\end{array}$ & 1,000 & 29.65 & 26.23 & 33.06 \\
\hline $\begin{array}{l}\text { 9. Hydrogen is too dangerous for everyday use by the } \\
\text { general public (false) }\end{array}$ & 1,000 & 44.95 & 41.05 & \\
\hline Overall Average & 1,000 & 35.19 & 33.17 & 37.21 \\
\hline
\end{tabular}

General Public Survey Summary of Importance Ranking

\begin{tabular}{|l|r|r|r|r|}
\hline Question & $\begin{array}{r}\text { Number } \\
\text { of }\end{array}$ & $\begin{array}{r}\text { Weighted } \\
\text { Average } \\
\text { Rank }\end{array}$ & $\begin{array}{c}\text { Lower } \\
\mathbf{9 5 \%} \\
\text { Confidence } \\
\text { Bound }\end{array}$ & $\begin{array}{c}\text { Upper } \\
\mathbf{9 5 \%} \\
\text { Confidence } \\
\text { Bound }\end{array}$ \\
\hline Safety & 978 & 2.50 & 2.40 & 2.59 \\
\hline Cost & 982 & 2.23 & 2.13 & 2.33 \\
\hline Environment & 966 & 3.10 & 3.00 & 3.21 \\
\hline Convenience & 971 & 3.73 & 3.63 & 3.83 \\
\hline Performance & 973 & 3.40 & 3.30 & 3.51 \\
\hline
\end{tabular}




\section{C.2. SUMMARY OF RESPONSES TO THE STUDENT SURVEY}

\begin{tabular}{|c|c|c|c|c|c|}
\hline Question/Metric & $\begin{array}{l}\text { Unweighted } \\
\text { Frequency }\end{array}$ & $\begin{array}{l}\text { Weighted } \\
\text { Frequency }\end{array}$ & $\begin{array}{c}\text { Standard } \\
\text { Deviation } \\
\text { of Weighted } \\
\text { Frequency }\end{array}$ & $\begin{array}{c}\text { Weighted } \\
\text { Percent }\end{array}$ & $\begin{array}{c}\text { Standard } \\
\text { Error of } \\
\text { Weighted } \\
\text { Percent }\end{array}$ \\
\hline \multicolumn{6}{|l|}{ Sex } \\
\hline Males & 503 & 509.3 & 16.3 & 50.9 & 1.59 \\
\hline Females & 501 & 490.7 & 15.8 & 49.1 & 1.59 \\
\hline Total for Sex & 1,004 & 999.9 & 4.7 & 100 & 0.00 \\
\hline \multicolumn{6}{|l|}{ Region } \\
\hline Northeast & 186 & 181.6 & 2.1 & 18.2 & 0.19 \\
\hline Midwest & 215 & 211.5 & 2.0 & 21.1 & 0.18 \\
\hline South & 356 & 368.0 & 2.7 & 36.8 & 0.22 \\
\hline West & 247 & 238.9 & 2.6 & 23.9 & 0.22 \\
\hline Total for Region & 1,004 & 999.9 & 4.7 & 100 & 0.00 \\
\hline \multicolumn{6}{|l|}{ Urban/Non-Urban } \\
\hline Urban & 493 & 486.9 & 3.4 & 48.7 & 0.24 \\
\hline Non-Urban & 511 & 513.0 & 3.3 & 51.3 & 0.24 \\
\hline $\begin{array}{l}\text { Total for Urban/Non- } \\
\text { Urban }\end{array}$ & 1,004 & 999.9 & 4.7 & 100 & 0.00 \\
\hline \multicolumn{6}{|l|}{ Above Average? } \\
\hline Score Below Average & 581 & 576.2 & 15.9 & 57.6 & 1.57 \\
\hline Score Above Average & 423 & 423.7 & 15.9 & 42.4 & 1.57 \\
\hline $\begin{array}{l}\text { Total for Above } \\
\text { Average? }\end{array}$ & 1,004 & 999.9 & 4.7 & 100 & 0.00 \\
\hline \multicolumn{6}{|c|}{ Q1. Familiarity with hydrogen/FC technologies } \\
\hline Not at all familiar & 452 & 446.6 & 15.8 & 44.7 & 1.57 \\
\hline
\end{tabular}




\begin{tabular}{|c|c|c|c|c|c|}
\hline Question/Metric & $\begin{array}{l}\text { Unweighted } \\
\text { Frequency }\end{array}$ & $\begin{array}{l}\text { Weighted } \\
\text { Frequency }\end{array}$ & $\begin{array}{c}\text { Standard } \\
\text { Deviation } \\
\text { of Weighted } \\
\text { Frequency }\end{array}$ & $\begin{array}{c}\text { Weighted } \\
\text { Percent }\end{array}$ & $\begin{array}{c}\text { Standard } \\
\text { Error of } \\
\text { Weighted } \\
\text { Percent }\end{array}$ \\
\hline Slightly familiar & 424 & 422.9 & 15.8 & 42.3 & 1.57 \\
\hline Familiar & 113 & 114.9 & 10.3 & 11.5 & 1.03 \\
\hline Very familiar & 15 & 15.5 & 4.0 & 1.55 & 0.40 \\
\hline Total for Q1 & 1,004 & 999.9 & 4.7 & 100 & 0.00 \\
\hline \multicolumn{6}{|c|}{ Q2A. Hydrogen gas is toxic } \\
\hline True & 343 & 339.6 & 15.0 & 34.0 & 1.49 \\
\hline False & 469 & 468.3 & 16.0 & 46.8 & 1.59 \\
\hline Don't know & 192 & 192.0 & 12.7 & 19.2 & 1.26 \\
\hline Total for Q2A & 1,004 & 999.9 & 4.7 & 100 & 0.00 \\
\hline \multicolumn{6}{|c|}{ Q2B. Fuel cells produce electricity through hydrogen combustion } \\
\hline True & 408 & 408.1 & 15.8 & 40.8 & 1.56 \\
\hline False & 158 & 160.2 & 11.9 & 16.0 & 1.18 \\
\hline Don't know & 438 & 431.6 & 15.7 & 43.2 & 1.57 \\
\hline Total for Q2B & 1,004 & 999.9 & 4.7 & 100 & 0.00 \\
\hline \multicolumn{6}{|c|}{ Q2C. Hydrogen is lighter than air } \\
\hline True & 508 & 508.7 & 16.0 & 50.9 & 1.58 \\
\hline False & 296 & 293.1 & 14.5 & 29.3 & 1.45 \\
\hline Don't know & 200 & 198.1 & 12.7 & 19.8 & 1.27 \\
\hline Total for Q2C & 1,004 & 999.9 & 4.7 & 100 & 0.00 \\
\hline \multicolumn{6}{|c|}{ Q2D. Hydrogen has a distinct odor } \\
\hline True & 212 & 209.0 & 12.9 & 20.9 & 1.29 \\
\hline False & 569 & 569.7 & 16.1 & 57.0 & 1.58 \\
\hline
\end{tabular}




\begin{tabular}{|c|c|c|c|c|c|}
\hline Question/Metric & $\begin{array}{l}\text { Unweighted } \\
\text { Frequency }\end{array}$ & $\begin{array}{l}\text { Weighted } \\
\text { Frequency }\end{array}$ & $\begin{array}{c}\text { Standard } \\
\text { Deviation } \\
\text { of Weighted } \\
\text { Frequency }\end{array}$ & $\begin{array}{l}\text { Weighted } \\
\text { Percent }\end{array}$ & $\begin{array}{c}\text { Standard } \\
\text { Error of } \\
\text { Weighted } \\
\text { Percent }\end{array}$ \\
\hline Don't know & 223 & 221.2 & 13.3 & 22.1 & 1.33 \\
\hline Total for Q2D & 1,004 & 999.9 & 4.7 & 100 & 0.00 \\
\hline \multicolumn{6}{|c|}{ Q3. Which of the following can fuel cells provide power to? } \\
\hline Your home & 64 & 62.1 & 7.5 & 6.22 & 0.75 \\
\hline Your car & 233 & 231.1 & 13.4 & 23.1 & 1.34 \\
\hline Your laptop computer & 15 & 14.4 & 3.7 & 1.44 & 0.38 \\
\hline All of these & 481 & 479.6 & 16.2 & 48.0 & 1.59 \\
\hline None of these & 60 & 60.2 & 7.7 & 6.02 & 0.77 \\
\hline Don't know & 151 & 152.5 & 11.5 & 15.2 & 1.15 \\
\hline Total for Q3 & 1,004 & 999.9 & 4.7 & 100 & 0.00 \\
\hline \multicolumn{6}{|c|}{ Q4. In which state or condition can hydrogen be stored? } \\
\hline Chemical compound & 199 & 197.4 & 12.6 & 19.7 & 1.26 \\
\hline Liquid & 141 & 143.7 & 11.4 & 14.4 & 1.13 \\
\hline Both of these & 390 & 389.3 & 15.7 & 38.9 & 1.56 \\
\hline Neither of these & 109 & 106.5 & 9.7 & 10.7 & 0.97 \\
\hline Don't know & 165 & 163.0 & 11.8 & 16.3 & 1.18 \\
\hline Total for Q4 & 1,004 & 999.9 & 4.7 & 100 & 0.00 \\
\hline \multicolumn{6}{|c|}{ Q5. When using pure hydrogen, fuel cell vehicles generate electricity, water, and what else? } \\
\hline Carbon dioxide & 203 & 201.1 & 12.9 & 20.1 & 1.28 \\
\hline Nitrous oxides & 44 & 43.6 & 6.4 & 4.36 & 0.64 \\
\hline Heat & 202 & 205.4 & 13.0 & 20.5 & 1.29 \\
\hline All of these & 243 & 241.7 & 13.6 & 24.2 & 1.36 \\
\hline Don't know & 312 & 308.1 & 14.6 & 30.8 & 1.46 \\
\hline
\end{tabular}




\begin{tabular}{|c|c|c|c|c|c|}
\hline Question/Metric & $\begin{array}{l}\text { Unweighted } \\
\text { Frequency }\end{array}$ & $\begin{array}{l}\text { Weighted } \\
\text { Frequency }\end{array}$ & $\begin{array}{c}\text { Standard } \\
\text { Deviation } \\
\text { of Weighted } \\
\text { Frequency }\end{array}$ & $\begin{array}{l}\text { Weighted } \\
\text { Percent }\end{array}$ & $\begin{array}{c}\text { Standard } \\
\text { Error of } \\
\text { Weighted } \\
\text { Percent }\end{array}$ \\
\hline Total for Q5 & 1,004 & 999.9 & 4.7 & 100 & 0.00 \\
\hline \multicolumn{6}{|c|}{ Q6. Hydrogen can be produced using which of the following sources of energy? } \\
\hline Natural gas & 229 & 227.0 & 13.4 & 22.7 & 1.34 \\
\hline Sunlight & 117 & 116.4 & 10.3 & 11.6 & 1.03 \\
\hline Organic matter & 100 & 97.8 & 9.4 & 9.78 & 0.94 \\
\hline All of these & 339 & 337.4 & 15.1 & 33.7 & 1.51 \\
\hline Don't know & 219 & 221.3 & 13.5 & 22.1 & 1.34 \\
\hline Total for Q6 & 1,004 & 999.9 & 4.7 & 100 & 0.00 \\
\hline \multicolumn{6}{|c|}{ Q8. How would you feel if your local gas station also sold hydrogen? } \\
\hline Frightened & 58 & 57.5 & 7.5 & 5.75 & 0.75 \\
\hline Uneasy & 120 & 119.9 & 10.5 & 12.0 & 1.05 \\
\hline At ease & 266 & 265.5 & 14.1 & 26.6 & 1.40 \\
\hline Pleased & 300 & 301.1 & 14.6 & 30.1 & 1.45 \\
\hline Don't know & 260 & 255.9 & 13.9 & 25.6 & 1.39 \\
\hline Total for Q8 & 1,004 & 999.9 & 4.7 & 100 & 0.00 \\
\hline \multicolumn{6}{|c|}{$\begin{array}{l}\text { Q8A. How would you feel if your school's electricity and heat were provided by a fuel cell } \\
\text { located on school grounds? }\end{array}$} \\
\hline Frightened & 90 & 89.1 & 9.2 & 8.92 & 0.91 \\
\hline Uneasy & 197 & 196.0 & 12.6 & 19.6 & 1.26 \\
\hline At ease & 300 & 296.8 & 14.4 & 29.7 & 1.45 \\
\hline Pleased & 274 & 276.8 & 14.4 & 27.7 & 1.43 \\
\hline Don't know & 143 & 141.2 & 11.1 & 14.1 & 1.11 \\
\hline Total for Q8A & 1,004 & 999.9 & 4.7 & 100 & 0.00 \\
\hline
\end{tabular}




\begin{tabular}{|c|c|c|c|c|c|}
\hline Question/Metric & $\begin{array}{c}\text { Unweighted } \\
\text { Frequency }\end{array}$ & $\begin{array}{l}\text { Weighted } \\
\text { Frequency }\end{array}$ & $\begin{array}{c}\text { Standard } \\
\text { Deviation } \\
\text { of Weighted } \\
\text { Frequency }\end{array}$ & $\begin{array}{c}\text { Weighted } \\
\text { Percent }\end{array}$ & $\begin{array}{c}\text { Standard } \\
\text { Error of } \\
\text { Weighted } \\
\text { Percent }\end{array}$ \\
\hline \multicolumn{6}{|c|}{ Q9. Hydrogen is too dangerous for everyday use by the general public. } \\
\hline True & 240 & 237.1 & 13.6 & 23.7 & 1.35 \\
\hline False & 546 & 548.2 & 16.1 & 54.8 & 1.57 \\
\hline Don't know & 218 & 214.6 & 13.0 & 21.5 & 1.30 \\
\hline Total for Q9 & 1,004 & 999.9 & 4.7 & 100 & 0.00 \\
\hline \multicolumn{6}{|c|}{ Q10A. Using hydrogen will reduce U.S. dependence on foreign oil } \\
\hline Disagree & 84 & 83.8 & 8.9 & 8.38 & 0.89 \\
\hline Are neutral & 130 & 128.0 & 10.6 & 12.8 & 1.06 \\
\hline Agree & 605 & 606.5 & 16.0 & 60.7 & 1.55 \\
\hline Don't know & 185 & 181.7 & 12.2 & 18.2 & 1.22 \\
\hline Total for Q10A & 1,004 & 999.9 & 4.7 & 100 & 0.00 \\
\hline \multicolumn{6}{|c|}{ Q10B. Using hydrogen will reduce emissions and improve air quality } \\
\hline Disagree & 143 & 139.2 & 10.9 & 13.9 & 1.09 \\
\hline Are neutral & 137 & 137.9 & 11.1 & 13.8 & 1.11 \\
\hline Agree & 555 & 556.4 & 16.2 & 55.6 & 1.58 \\
\hline Don't know & 169 & 166.4 & 11.9 & 16.6 & 1.19 \\
\hline Total for Q10B & 1,004 & 999.9 & 4.7 & 100 & 0.00 \\
\hline \multicolumn{6}{|c|}{ Q10C. Hydrogen is as safe to use in my car as gasoline and diesel fuels } \\
\hline Disagree & 183 & 180.8 & 12.1 & 18.1 & 1.21 \\
\hline Are neutral & 168 & 165.3 & 11.8 & 16.5 & 1.18 \\
\hline Agree & 436 & 438.7 & 15.9 & 43.9 & 1.57 \\
\hline Don't know & 217 & 215.1 & 13.1 & 21.5 & 1.31 \\
\hline Total for Q10C & 1,004 & 999.9 & 4.7 & 100 & 0.00 \\
\hline
\end{tabular}




\begin{tabular}{|c|c|c|c|c|c|}
\hline Question/Metric & $\begin{array}{l}\text { Unweighted } \\
\text { Frequency }\end{array}$ & $\begin{array}{l}\text { Weighted } \\
\text { Frequency }\end{array}$ & $\begin{array}{c}\text { Standard } \\
\text { Deviation } \\
\text { of Weighted } \\
\text { Frequency }\end{array}$ & $\begin{array}{c}\text { Weighted } \\
\text { Percent }\end{array}$ & $\begin{array}{c}\text { Standard } \\
\text { Error of } \\
\text { Weighted } \\
\text { Percent }\end{array}$ \\
\hline \multicolumn{6}{|c|}{ Q13A. Personal cars and trucks } \\
\hline Not as safe & 170 & 167.6 & 11.9 & 16.8 & 1.19 \\
\hline Equally as safe & 369 & 367.4 & 15.4 & 36.7 & 1.53 \\
\hline Safer & 300 & 300.0 & 14.7 & 30.0 & 1.46 \\
\hline Don't know & 165 & 165.0 & 11.9 & 16.5 & 1.18 \\
\hline Total for Q13A & 1,004 & 999.9 & 4.7 & 100 & 0.00 \\
\hline \multicolumn{6}{|c|}{ Q13B. Buses and commercial vehicles } \\
\hline Not as safe & 174 & 171.1 & 12.1 & 17.1 & 1.21 \\
\hline Equally as safe & 343 & 344.3 & 15.4 & 34.4 & 1.52 \\
\hline Safer & 323 & 322.1 & 15.1 & 32.2 & 1.50 \\
\hline Don't know & 164 & 162.3 & 11.7 & 16.2 & 1.17 \\
\hline Total for Q13B & 1,004 & 999.9 & 4.7 & 100 & 0.00 \\
\hline \multicolumn{6}{|c|}{ Q13C. Large power plants } \\
\hline Not as safe & 230 & 229.4 & 13.5 & 22.9 & 1.35 \\
\hline Equally as safe & 266 & 262.8 & 13.8 & 26.3 & 1.38 \\
\hline Safer & 312 & 312.5 & 15.0 & 31.3 & 1.49 \\
\hline Don't know & 196 & 195.2 & 12.6 & 19.5 & 1.26 \\
\hline Total for Q13C & 1,004 & 999.9 & 4.7 & 100 & 0.00 \\
\hline \multicolumn{6}{|c|}{ Q13D. Small portable devices such as laptop computers or cell phones } \\
\hline Not as safe & 275 & 273.2 & 14.3 & 27.3 & 1.43 \\
\hline Equally as safe & 345 & 342.3 & 15.1 & 34.2 & 1.51 \\
\hline Safer & 189 & 190.0 & 12.6 & 19.0 & 1.25 \\
\hline
\end{tabular}




\begin{tabular}{|c|c|c|c|c|c|}
\hline Question/Metric & $\begin{array}{c}\text { Unweighted } \\
\text { Frequency }\end{array}$ & $\begin{array}{l}\text { Weighted } \\
\text { Frequency }\end{array}$ & $\begin{array}{c}\text { Standard } \\
\text { Deviation } \\
\text { of Weighted } \\
\text { Frequency }\end{array}$ & $\begin{array}{c}\text { Weighted } \\
\text { Percent }\end{array}$ & $\begin{array}{c}\text { Standard } \\
\text { Error of } \\
\text { Weighted } \\
\text { Percent }\end{array}$ \\
\hline Don't know & 195 & 194.5 & 12.6 & 19.4 & 1.26 \\
\hline Total for Q13D & 1,004 & 999.9 & 4.7 & 100 & 0.00 \\
\hline \multicolumn{6}{|c|}{ Q13E. Onsite power for the home } \\
\hline Not as safe & 203 & 201.4 & 12.8 & 20.1 & 1.27 \\
\hline Equally as safe & 342 & 342.8 & 15.3 & 34.3 & 1.52 \\
\hline Safer & 290 & 286.7 & 14.3 & 28.7 & 1.43 \\
\hline Don't know & 169 & 169.0 & 11.9 & 16.9 & 1.19 \\
\hline Total for Q13E & 1,004 & 999.9 & 4.7 & 100 & 0.00 \\
\hline \multicolumn{6}{|c|}{ Q13F. Onsite power for buildings such as hospitals and schools } \\
\hline Not as safe & 240 & 234.5 & 13.4 & 23.5 & 1.34 \\
\hline Equally as safe & 311 & 313.2 & 15.0 & 31.3 & 1.49 \\
\hline Safer & 283 & 283.1 & 14.6 & 28.3 & 1.45 \\
\hline Don't know & 170 & 169.2 & 11.9 & 16.9 & 1.19 \\
\hline Total for Q13F & 1,004 & 999.9 & 4.7 & 100 & 0.00 \\
\hline \multicolumn{6}{|c|}{ Q20A. Cost of vehicle at the point of sale } \\
\hline Not important & 87 & 86.4 & 9.0 & 8.64 & 0.89 \\
\hline Neutral & 162 & 160.7 & 11.7 & 16.1 & 1.17 \\
\hline Important & 690 & 687.3 & 15.0 & 68.7 & 1.47 \\
\hline Don't know & 65 & 65.5 & 7.9 & 6.55 & 0.79 \\
\hline Total for Q20A & 1,004 & 999.9 & 4.7 & 100 & 0.00 \\
\hline \multicolumn{6}{|l|}{ Q20B. Gas mileage } \\
\hline Not important & 28 & 28.1 & 5.3 & 2.81 & 0.53 \\
\hline
\end{tabular}




\begin{tabular}{|c|c|c|c|c|c|}
\hline Question/Metric & $\begin{array}{c}\text { Unweighted } \\
\text { Frequency }\end{array}$ & $\begin{array}{l}\text { Weighted } \\
\text { Frequency }\end{array}$ & $\begin{array}{c}\text { Standard } \\
\text { Deviation } \\
\text { of Weighted } \\
\text { Frequency }\end{array}$ & $\begin{array}{l}\text { Weighted } \\
\text { Percent }\end{array}$ & $\begin{array}{c}\text { Standard } \\
\text { Error of } \\
\text { Weighted } \\
\text { Percent }\end{array}$ \\
\hline Neutral & 63 & 61.8 & 7.6 & 6.18 & 0.76 \\
\hline Important & 872 & 867.2 & 11.4 & 86.7 & 1.10 \\
\hline Don't know & 41 & 42.8 & 6.7 & 4.28 & 0.67 \\
\hline Total for Q20B & 1,004 & 999.9 & 4.7 & 100 & 0.00 \\
\hline \multicolumn{6}{|c|}{ Q20C. Power and speed } \\
\hline Not important & 226 & 222.9 & 13.1 & 22.3 & 1.32 \\
\hline Neutral & 304 & 303.5 & 14.7 & 30.3 & 1.46 \\
\hline Important & 424 & 423.1 & 16.1 & 42.3 & 1.59 \\
\hline Don't know & 50 & 50.5 & 7.0 & 5.05 & 0.70 \\
\hline Total for Q20C & 1,004 & 999.9 & 4.7 & 100 & 0.00 \\
\hline \multicolumn{6}{|l|}{ Q20E. Reliability } \\
\hline Not important & 23 & 23.9 & 5.1 & 2.39 & 0.51 \\
\hline Neutral & 86 & 85.9 & 9.0 & 8.59 & 0.90 \\
\hline Important & 836 & 831.7 & 12.5 & 83.2 & 1.21 \\
\hline Don't know & 59 & 58.3 & 7.5 & 5.83 & 0.75 \\
\hline Total for Q20E & 1,004 & 999.9 & 4.7 & 100 & 0.00 \\
\hline \multicolumn{6}{|l|}{ Q20F. Safety } \\
\hline Not important & 15 & 15.2 & 3.9 & 1.52 & 0.39 \\
\hline Neutral & 52 & 52.4 & 7.1 & 5.24 & 0.71 \\
\hline Important & 906 & 900.9 & 10.3 & 90.1 & 0.95 \\
\hline Don't know & 31 & 31.4 & 5.7 & 3.14 & 0.57 \\
\hline Total for Q20F & 1,004 & 999.9 & 4.7 & 100 & 0.00 \\
\hline
\end{tabular}




\begin{tabular}{|c|c|c|c|c|c|}
\hline Question/Metric & $\begin{array}{c}\text { Unweighted } \\
\text { Frequency }\end{array}$ & $\begin{array}{l}\text { Weighted } \\
\text { Frequency }\end{array}$ & $\begin{array}{c}\text { Standard } \\
\text { Deviation } \\
\text { of Weighted } \\
\text { Frequency }\end{array}$ & $\begin{array}{c}\text { Weighted } \\
\text { Percent }\end{array}$ & $\begin{array}{c}\text { Standard } \\
\text { Error of } \\
\text { Weighted } \\
\text { Percent }\end{array}$ \\
\hline \multicolumn{6}{|c|}{ Q20G. Impact on the environment, or emissions produced } \\
\hline Not important & 55 & 56.4 & 7.5 & 5.64 & 0.75 \\
\hline Neutral & 134 & 132.4 & 10.7 & 13.2 & 1.07 \\
\hline Important & 753 & 749.7 & 14.2 & 75.0 & 1.38 \\
\hline Don't know & 62 & 61.4 & 7.6 & 6.14 & 0.76 \\
\hline Total for Q20G & 1,004 & 999.9 & 4.7 & 100 & 0.00 \\
\hline \multicolumn{6}{|c|}{ Q21A. Received instruction on or otherwise learned about energy use, fuels, and emissions } \\
\hline Yes & 664 & 660.7 & 15.3 & 66.1 & 1.51 \\
\hline No & 316 & 316.8 & 15.1 & 31.7 & 1.49 \\
\hline Don't know & 24 & 22.4 & 4.5 & 2.24 & 0.46 \\
\hline Total for Q21A & 1,004 & 999.9 & 4.7 & 100 & 0.00 \\
\hline \multicolumn{6}{|c|}{ Q21B. Received instruction on or otherwise learned about hydrogen and fuel cells } \\
\hline Yes & 487 & 484.6 & 16.1 & 48.5 & 1.60 \\
\hline No & 498 & 496.7 & 16.2 & 49.7 & 1.60 \\
\hline Don't know & 19 & 18.6 & 4.2 & 1.86 & 0.42 \\
\hline Total for Q21B & 1,004 & 999.9 & 4.7 & 100 & 0.00 \\
\hline \multicolumn{6}{|c|}{ Q21C. Ever used a demonstration kit to produce hydrogen } \\
\hline Yes & 97 & 97.3 & 9.5 & 9.73 & 0.94 \\
\hline No & 880 & 875.8 & 11.1 & 87.6 & 1.05 \\
\hline Don't know & 27 & 26.8 & 5.2 & 2.68 & 0.52 \\
\hline Total for Q21C & 1,004 & 999.9 & 4.7 & 100 & 0.00 \\
\hline
\end{tabular}




\begin{tabular}{|c|c|c|c|c|c|}
\hline Question/Metric & $\begin{array}{l}\text { Unweighted } \\
\text { Frequency }\end{array}$ & $\begin{array}{l}\text { Weighted } \\
\text { Frequency }\end{array}$ & $\begin{array}{c}\text { Standard } \\
\text { Deviation } \\
\text { of Weighted } \\
\text { Frequency }\end{array}$ & $\begin{array}{l}\text { Weighted } \\
\text { Percent }\end{array}$ & $\begin{array}{c}\text { Standard } \\
\text { Error of } \\
\text { Weighted } \\
\text { Percent }\end{array}$ \\
\hline Yes & 64 & 64.3 & 8.0 & 6.43 & 0.80 \\
\hline No & 909 & 904.9 & 10.3 & 90.5 & 0.95 \\
\hline Don't know & 31 & 30.7 & 5.5 & 3.07 & 0.55 \\
\hline Total for Q21D & 1,004 & 999.9 & 4.7 & 100 & 0.00 \\
\hline \multicolumn{6}{|c|}{ Q21E. Ever seen or used a hydrogen fuel cell model car } \\
\hline Yes & 134 & 136.8 & 11.2 & 13.7 & 1.12 \\
\hline No & 844 & 838.5 & 12.2 & 83.9 & 1.19 \\
\hline Don't know & 26 & 24.6 & 4.8 & 2.46 & 0.48 \\
\hline Total for Q21E & 1,004 & 999.9 & 4.7 & 100 & 0.00 \\
\hline \multicolumn{6}{|c|}{ Q21F. Participated in a fuel cell vehicle design competition } \\
\hline Yes & 26 & 25.7 & 5.0 & 2.57 & 0.50 \\
\hline No & 970 & 966.7 & 7.3 & 96.7 & 0.56 \\
\hline Don't know & 8 & 7.5 & 2.7 & 0.75 & 0.27 \\
\hline Total for Q21F & 1,004 & 999.9 & 4.7 & 100 & 0.00 \\
\hline \multicolumn{6}{|c|}{ Q21G. Participated in a science bowl or other science competition } \\
\hline Yes & 356 & 356.3 & 15.4 & 35.6 & 1.53 \\
\hline No & 644 & 639.5 & 15.5 & 64.0 & 1.53 \\
\hline Don't know & 4 & 4.0 & 2.0 & 0.40 & 0.20 \\
\hline Total for Q21G & 1,004 & 999.9 & 4.7 & 100 & 0.00 \\
\hline \multicolumn{6}{|c|}{ Q22A. Received instruction on or otherwise learned about energy use, fuels, and emissions } \\
\hline Yes & 606 & 603.0 & 7.9 & 91.3 & 1.10 \\
\hline No & 54 & 53.4 & 7.0 & 8.08 & 1.06 \\
\hline
\end{tabular}




\begin{tabular}{|c|c|c|c|c|c|}
\hline Question/Metric & $\begin{array}{l}\text { Unweighted } \\
\text { Frequency }\end{array}$ & $\begin{array}{l}\text { Weighted } \\
\text { Frequency }\end{array}$ & $\begin{array}{c}\text { Standard } \\
\text { Deviation } \\
\text { of Weighted } \\
\text { Frequency }\end{array}$ & $\begin{array}{c}\text { Weighted } \\
\text { Percent }\end{array}$ & $\begin{array}{c}\text { Standard } \\
\text { Error of } \\
\text { Weighted } \\
\text { Percent }\end{array}$ \\
\hline Don't know & 4 & 4.3 & 2.2 & 0.66 & 0.33 \\
\hline Total for Q22A & 664 & 660.7 & 3.6 & 100 & 0.00 \\
\hline \multicolumn{6}{|c|}{ Q22B. Received instruction on or otherwise learned about hydrogen and fuel cells } \\
\hline Yes & 428 & 426.3 & 7.9 & 88.0 & 1.50 \\
\hline No & 52 & 51.8 & 6.9 & 10.7 & 1.43 \\
\hline Don't know & 7 & 6.5 & 2.5 & 1.35 & 0.51 \\
\hline Total for Q22B & 487 & 484.6 & 3.3 & 100 & 0.00 \\
\hline \multicolumn{6}{|c|}{ Q22C. Ever used a demonstration kit to produce hydrogen } \\
\hline Yes & 94 & 94.0 & 2.3 & 96.6 & 1.99 \\
\hline No & 2 & 2.4 & 1.7 & 2.43 & 1.76 \\
\hline Don't know & 1 & 0.9 & 0.9 & 0.94 & 0.94 \\
\hline Total for Q22C & 97 & 97.3 & 1.5 & 100 & 0.00 \\
\hline \multicolumn{6}{|c|}{ Q22D. Ever used a model fuel cell science kit } \\
\hline Yes & 56 & 56.8 & 3.0 & 88.3 & 4.18 \\
\hline No & 7 & 6.5 & 2.5 & 10.2 & 3.88 \\
\hline Don't know & 1 & 1.0 & 1.0 & 1.52 & 1.52 \\
\hline Total for Q22D & 64 & 64.3 & 1.2 & 100 & 0.00 \\
\hline \multicolumn{6}{|c|}{ Q22E. Ever seen or used a hydrogen fuel cell model car } \\
\hline Yes & 58 & 57.4 & 5.5 & 42.0 & 4.14 \\
\hline No & 74 & 77.4 & 6.0 & 56.6 & 4.10 \\
\hline Don't know & 2 & 1.9 & 1.3 & 1.37 & 0.97 \\
\hline Total for Q22E & 134 & 136.8 & 2.0 & 100 & 0.00 \\
\hline
\end{tabular}




\begin{tabular}{|c|c|c|c|c|c|}
\hline Question/Metric & $\begin{array}{l}\text { Unweighted } \\
\text { Frequency }\end{array}$ & $\begin{array}{l}\text { Weighted } \\
\text { Frequency }\end{array}$ & $\begin{array}{c}\text { Standard } \\
\text { Deviation } \\
\text { of Weighted } \\
\text { Frequency }\end{array}$ & $\begin{array}{c}\text { Weighted } \\
\text { Percent }\end{array}$ & $\begin{array}{c}\text { Standard } \\
\text { Error of } \\
\text { Weighted } \\
\text { Percent }\end{array}$ \\
\hline \multicolumn{6}{|c|}{ Q22F. Participated in a fuel cell vehicle design competition } \\
\hline Yes & 17 & 16.5 & 1.7 & 64.4 & 6.65 \\
\hline No & 9 & 9.2 & 1.7 & 35.6 & 6.65 \\
\hline Total for Q22F & 26 & 25.7 & 0.1 & 100 & 0.00 \\
\hline \multicolumn{6}{|c|}{ Q22G. Participated in a science bowl or other science competition } \\
\hline Yes & 348 & 348.3 & 4.0 & 97.7 & 0.81 \\
\hline No & 7 & 7.0 & 2.7 & 1.97 & 0.75 \\
\hline Don't know & 1 & 1.0 & 1.0 & 0.29 & 0.29 \\
\hline Total for Q22G & 356 & 356.3 & 2.9 & 100 & 0.00 \\
\hline \multicolumn{6}{|c|}{ Q23A. Received instruction on or otherwise learned about energy use, fuels, and emissions } \\
\hline Home & 22 & 22.4 & 3.8 & 38.9 & 6.44 \\
\hline Scouts & 3 & 2.9 & 1.7 & 5.03 & 2.91 \\
\hline The internet & 12 & 11.5 & 3.0 & 19.9 & 5.21 \\
\hline Other & 14 & 13.9 & 3.4 & 24.2 & 5.80 \\
\hline Don't know & 7 & 7.0 & 2.5 & 12.1 & 4.36 \\
\hline Total for Q23A & 58 & 57.7 & 1.1 & 100 & 0.00 \\
\hline \multicolumn{6}{|c|}{ Q23B. Received instruction on or otherwise learned about hydrogen and fuel cells } \\
\hline Home & 22 & 22.0 & 2.7 & 37.6 & 4.74 \\
\hline Scouts & 3 & 3.0 & 1.7 & 5.09 & 2.95 \\
\hline The internet & 17 & 16.4 & 2.5 & 28.1 & 4.39 \\
\hline Other & 9 & 9.5 & 2.8 & 16.3 & 4.76 \\
\hline Don't know & 8 & 7.5 & 2.3 & 12.9 & 3.92 \\
\hline
\end{tabular}




\begin{tabular}{|c|c|c|c|c|c|}
\hline Question/Metric & $\begin{array}{l}\text { Unweighted } \\
\text { Frequency }\end{array}$ & $\begin{array}{l}\text { Weighted } \\
\text { Frequency }\end{array}$ & $\begin{array}{c}\text { Standard } \\
\text { Deviation } \\
\text { of Weighted } \\
\text { Frequency }\end{array}$ & $\begin{array}{c}\text { Weighted } \\
\text { Percent }\end{array}$ & $\begin{array}{c}\text { Standard } \\
\text { Error of } \\
\text { Weighted } \\
\text { Percent }\end{array}$ \\
\hline Total for Q23B & 59 & 58.3 & 0.6 & 100 & 0.00 \\
\hline \multicolumn{6}{|c|}{ Q23C. Ever used a demonstration kit to produce hydrogen } \\
\hline Home & 1 & 1.5 & & 44.4 & \\
\hline The internet & 2 & 1.8 & & 55.6 & \\
\hline Total for Q23C & 3 & 3.3 & & 100 & 0.00 \\
\hline \multicolumn{6}{|c|}{ Q23D. Ever used a model fuel cell science kit } \\
\hline Home & 4 & 3.9 & & 52.3 & \\
\hline Scouts & 1 & 1.0 & & 12.9 & \\
\hline The internet & 1 & 0.8 & & 10.6 & \\
\hline Other & 1 & 1.0 & & 13.0 & \\
\hline Don't know & 1 & 0.8 & & 11.3 & \\
\hline Total for Q23D & 8 & 7.5 & & 100 & 0.00 \\
\hline \multicolumn{6}{|c|}{ Q23E. Ever seen or used a hydrogen fuel cell model car } \\
\hline Home & 23 & 24.0 & 4.0 & 30.3 & 5.01 \\
\hline Church & 1 & 1.0 & 1.0 & 1.22 & 1.22 \\
\hline The internet & 13 & 13.8 & 3.4 & 17.5 & 4.34 \\
\hline Other & 34 & 35.1 & 4.1 & 44.3 & 5.13 \\
\hline Don't know & 5 & 5.3 & 2.4 & 6.71 & 3.04 \\
\hline Total for Q23E & 76 & 79.3 & 1.7 & 100 & 0.00 \\
\hline \multicolumn{6}{|c|}{ Q23F. Participated in a fuel cell vehicle design competition } \\
\hline Home & 2 & 1.9 & 1.1 & 21.2 & 12.3 \\
\hline Scouts & 2 & 2.4 & 0.0 & 26.3 & 0.18 \\
\hline
\end{tabular}




\begin{tabular}{|c|c|c|c|c|c|}
\hline Question/Metric & $\begin{array}{l}\text { Unweighted } \\
\text { Frequency }\end{array}$ & $\begin{array}{l}\text { Weighted } \\
\text { Frequency }\end{array}$ & $\begin{array}{c}\text { Standard } \\
\text { Deviation } \\
\text { of Weighted } \\
\text { Frequency }\end{array}$ & $\begin{array}{c}\text { Weighted } \\
\text { Percent }\end{array}$ & $\begin{array}{c}\text { Standard } \\
\text { Error of } \\
\text { Weighted } \\
\text { Percent }\end{array}$ \\
\hline Other & 4 & 4.0 & 1.2 & 43.2 & 12.5 \\
\hline Don't know & 1 & 0.8 & 0.0 & 9.24 & 0.06 \\
\hline Total for Q23F & 9 & 9.2 & 0.1 & 100 & 0.00 \\
\hline \multicolumn{6}{|c|}{ Q23G. Participated in a science bowl or other science competition } \\
\hline Home & 3 & 3.5 & 0.0 & 43.3 & 0.58 \\
\hline The internet & 1 & 1.0 & 0.0 & 12.0 & 0.16 \\
\hline Don't know & 4 & 3.6 & 0.1 & 44.7 & 0.74 \\
\hline Total for Q23G & 8 & 8.0 & 0.1 & 100 & 0.00 \\
\hline \multicolumn{6}{|l|}{ Q24A. Television } \\
\hline Never & 217 & 216.2 & 13.2 & 21.6 & 1.32 \\
\hline Sometimes & 560 & 555.5 & 16.0 & 55.6 & 1.58 \\
\hline Frequently & 219 & 220.6 & 13.4 & 22.1 & 1.33 \\
\hline Don't know & 8 & 7.6 & 2.7 & 0.76 & 0.27 \\
\hline Total for Q24A & 1,004 & 999.9 & 4.7 & 100 & 0.00 \\
\hline \multicolumn{6}{|l|}{ Q24B. Radio } \\
\hline Never & 563 & 556.1 & 16.0 & 55.6 & 1.60 \\
\hline Sometimes & 370 & 371.0 & 15.6 & 37.1 & 1.55 \\
\hline Frequently & 61 & 63.3 & 8.0 & 6.33 & 0.80 \\
\hline Don't know & 10 & 9.5 & 3.0 & 0.95 & 0.30 \\
\hline Total for Q24B & 1,004 & 999.9 & 4.7 & 100 & 0.00 \\
\hline \multicolumn{6}{|l|}{ Q24C. The Internet } \\
\hline Never & 356 & 354.1 & 15.3 & 35.4 & 1.52 \\
\hline
\end{tabular}




\begin{tabular}{|c|c|c|c|c|c|}
\hline Question/Metric & $\begin{array}{c}\text { Unweighted } \\
\text { Frequency }\end{array}$ & $\begin{array}{l}\text { Weighted } \\
\text { Frequency }\end{array}$ & $\begin{array}{c}\text { Standard } \\
\text { Deviation } \\
\text { of Weighted } \\
\text { Frequency }\end{array}$ & $\begin{array}{l}\text { Weighted } \\
\text { Percent }\end{array}$ & $\begin{array}{c}\text { Standard } \\
\text { Error of } \\
\text { Weighted } \\
\text { Percent }\end{array}$ \\
\hline Sometimes & 467 & 466.7 & 16.1 & 46.7 & 1.59 \\
\hline Frequently & 175 & 173.5 & 11.9 & 17.4 & 1.19 \\
\hline Don't know & 6 & 5.6 & 2.3 & 0.56 & 0.23 \\
\hline Total for Q24C & 1,004 & 999.9 & 4.7 & 100 & 0.00 \\
\hline \multicolumn{6}{|c|}{ Q24D. Newspapers and general interest magazines } \\
\hline Never & 385 & 379.3 & 15.3 & 37.9 & 1.53 \\
\hline Sometimes & 484 & 486.7 & 16.1 & 48.7 & 1.58 \\
\hline Frequently & 123 & 122.8 & 10.4 & 12.3 & 1.04 \\
\hline Don't know & 12 & 11.1 & 3.2 & 1.11 & 0.32 \\
\hline Total for Q24D & 1,004 & 999.9 & 4.7 & 100 & 0.00 \\
\hline \multicolumn{6}{|c|}{ Q24E. Science and technology magazines and journals } \\
\hline Never & 422 & 420.3 & 15.8 & 42.0 & 1.57 \\
\hline Sometimes & 364 & 364.4 & 15.4 & 36.4 & 1.53 \\
\hline Frequently & 201 & 199.0 & 12.6 & 19.9 & 1.25 \\
\hline Don't know & 17 & 16.2 & 3.9 & 1.62 & 0.39 \\
\hline Total for Q24E & 1,004 & 999.9 & 4.7 & 100 & 0.00 \\
\hline \multicolumn{6}{|c|}{ Q24F. Classroom instructions } \\
\hline Never & 226 & 227.9 & 13.5 & 22.8 & 1.34 \\
\hline Sometimes & 546 & 541.8 & 16.0 & 54.2 & 1.59 \\
\hline Frequently & 215 & 213.7 & 13.2 & 21.4 & 1.32 \\
\hline Don't know & 17 & 16.5 & 4.0 & 1.65 & 0.40 \\
\hline Total for Q24F & 1,004 & 999.9 & 4.7 & 100 & 0.00 \\
\hline
\end{tabular}




\begin{tabular}{|c|c|c|c|c|c|}
\hline Question/Metric & $\begin{array}{l}\text { Unweighted } \\
\text { Frequency }\end{array}$ & $\begin{array}{l}\text { Weighted } \\
\text { Frequency }\end{array}$ & $\begin{array}{c}\text { Standard } \\
\text { Deviation } \\
\text { of Weighted } \\
\text { Frequency }\end{array}$ & $\begin{array}{l}\text { Weighted } \\
\text { Percent }\end{array}$ & $\begin{array}{c}\text { Standard } \\
\text { Error of } \\
\text { Weighted } \\
\text { Percent }\end{array}$ \\
\hline \multicolumn{6}{|c|}{ Q24G. General discussions with family and/or friends } \\
\hline Never & 443 & 437.4 & 15.8 & 43.7 & 1.58 \\
\hline Sometimes & 448 & 448.7 & 16.2 & 44.9 & 1.60 \\
\hline Frequently & 106 & 107.1 & 9.9 & 10.7 & 0.99 \\
\hline Don't know & 7 & 6.7 & 2.5 & 0.67 & 0.25 \\
\hline Total for Q24G & 1,004 & 999.9 & 4.7 & 100 & 0.00 \\
\hline \multicolumn{6}{|c|}{ Q25. What was the last grade of school you completed? } \\
\hline 4th or less & 2 & 1.8 & 1.3 & 0.18 & 0.13 \\
\hline 5 & 24 & 24.4 & 5.0 & 2.44 & 0.50 \\
\hline 6 & 144 & 143.0 & 11.3 & 14.3 & 1.12 \\
\hline 7 & 153 & 148.2 & 11.1 & 14.8 & 1.11 \\
\hline 8 & 175 & 169.3 & 11.8 & 16.9 & 1.18 \\
\hline 9 & 170 & 169.9 & 11.9 & 17.0 & 1.19 \\
\hline 10 & 130 & 133.7 & 11.0 & 13.4 & 1.09 \\
\hline 11 & 149 & 153.9 & 11.8 & 15.4 & 1.17 \\
\hline 12 & 35 & 34.2 & 5.8 & 3.42 & 0.58 \\
\hline College & 12 & 11.5 & 3.3 & 1.15 & 0.33 \\
\hline Home schooled & 5 & 5.6 & 2.5 & 0.56 & 0.25 \\
\hline Refused & 5 & 4.5 & 2.0 & 0.45 & 0.20 \\
\hline Total for Q25 & 1,004 & 999.9 & 4.7 & 100 & 0.00 \\
\hline
\end{tabular}




\section{Student Survey Technical Question Summary}

\begin{tabular}{|l|r|r|r|r|}
\hline & $\begin{array}{r}\text { Number } \\
\text { Question }\end{array}$ & $\begin{array}{c}\text { Weighted } \\
\text { Percent } \\
\text { Responses }\end{array}$ & $\begin{array}{c}\text { Lower } \\
\text { C5\% } \\
\text { Confidence } \\
\text { Bound }\end{array}$ & $\begin{array}{c}\text { Upper } \\
\text { 95\% } \\
\text { Confidence } \\
\text { Bound }\end{array}$ \\
\hline 2A. Hydrogen gas is toxic (false) & 1,004 & 46.83 & 43.72 & 49.95 \\
\hline $\begin{array}{l}\text { 2B. Fuel cells produce electricity through hydrogen } \\
\text { combustion (false) }\end{array}$ & 1,004 & 16.02 & 13.71 & 18.33 \\
\hline 2C. Hydrogen is lighter than air (true) & 1,004 & 50.87 & 47.77 & 53.97 \\
\hline 2D. Hydrogen has a distinct odor (false) & 1,004 & 56.98 & 53.87 & 60.09 \\
\hline $\begin{array}{l}\text { 4. In which state or condition can hydrogen be } \\
\text { stored? (chemical compound, liquid) }\end{array}$ & 1,004 & 38.93 & 35.88 & 41.98 \\
\hline $\begin{array}{l}\text { 5. When using pure hydrogen, fuel cell vehicles } \\
\text { generate electricity, water, and what else? (heat) }\end{array}$ & 1,004 & 20.55 & 18.01 & 23.08 \\
\hline $\begin{array}{l}\text { 6. Hydrogen can be produced using which of the } \\
\text { following sources of energy? (natural gas, sunlight, } \\
\text { organic matter) }\end{array}$ & 1,004 & 33.74 & 30.78 & 36.71 \\
\hline $\begin{array}{l}\text { 9. Hydrogen is too dangerous for everyday use by the } \\
\text { general public (false) }\end{array}$ & 1,004 & 54.83 & 51.75 & \\
\hline Overall Average & 1,004 & 39.84 & 38.51 & 41.18 \\
\hline
\end{tabular}




\section{C.3. SUMMARY OF RESPONSES TO THE STATE AND LOCAL GOVERNMENT AGENCIES SURVEY}

\begin{tabular}{|l|c|c|c|c|}
\hline \multicolumn{1}{|c|}{ Question/Metric } & Frequency & $\begin{array}{c}\text { Standard } \\
\text { Deviation of } \\
\text { Frequency }\end{array}$ & Percent & $\begin{array}{c}\text { Standard } \\
\text { Error of } \\
\text { Percent }\end{array}$ \\
\hline Function & 47 & 6.1 & 21.4 & 2.77 \\
\hline DOT (State) & 47 & 6.1 & 21.4 & 2.77 \\
\hline SEO (State) & 42 & 5.8 & 19.1 & 2.66 \\
\hline DEP (State) & 40 & 5.7 & 18.2 & 2.61 \\
\hline City & 44 & 5.9 & 20.0 & 2.70 \\
\hline County & 220 & 0.0 & 100 & 0.00 \\
\hline Total for Function & & \multicolumn{4}{|l|}{} \\
\hline
\end{tabular}

\begin{tabular}{|c|c|c|c|c|}
\hline \multicolumn{5}{|l|}{ Above Average? } \\
\hline Score Below Average & 110 & 2.3 & 50.0 & 1.02 \\
\hline Score Above Average & 110 & 2.3 & 50.0 & 1.02 \\
\hline Total for Above Average? & 220 & 0.0 & 100 & 0.00 \\
\hline \multicolumn{5}{|c|}{ Q1. Please rate your familiarity with hydrogen and fuel cell technologies. } \\
\hline Not at all familiar & 16 & 1.2 & 7.27 & 0.54 \\
\hline Slightly familiar & 112 & 2.4 & 50.9 & 1.07 \\
\hline Familiar & 73 & 2.2 & 33.2 & 1.02 \\
\hline Very familiar & 19 & 1.3 & 8.64 & 0.60 \\
\hline Total for Q1 & 220 & 0.0 & 100 & 0.00 \\
\hline \multicolumn{5}{|l|}{ Q2A. Hydrogen gas is toxic } \\
\hline True & 19 & 1.4 & 8.64 & 0.62 \\
\hline False & 147 & 2.3 & 66.8 & 1.04 \\
\hline Don't know & 54 & 2.1 & 24.5 & 0.95 \\
\hline Total for Q2A & 220 & 0.0 & 100 & 0.00 \\
\hline
\end{tabular}




\begin{tabular}{|c|c|c|c|c|}
\hline Question/Metric & Frequency & $\begin{array}{c}\text { Standard } \\
\text { Deviation of } \\
\text { Frequency }\end{array}$ & Percent & $\begin{array}{c}\text { Standard } \\
\text { Error of } \\
\text { Percent }\end{array}$ \\
\hline \multicolumn{5}{|c|}{ Q2B. Fuel cells produce electricity through hydrogen combustion } \\
\hline True & 78 & 2.2 & 35.5 & 1.02 \\
\hline False & 95 & 2.3 & 43.2 & 1.03 \\
\hline Don't know & 47 & 1.9 & 21.4 & 0.88 \\
\hline Total for Q2B & 220 & 0.0 & 100 & 0.00 \\
\hline \multicolumn{5}{|c|}{ Q2C. Hydrogen is lighter than air } \\
\hline True & 172 & 1.9 & 78.2 & 0.87 \\
\hline False & 13 & 1.1 & 5.91 & 0.51 \\
\hline Don't know & 35 & 1.7 & 15.9 & 0.76 \\
\hline Total for Q2C & 220 & 0.0 & 100 & 0.00 \\
\hline \multicolumn{5}{|c|}{ Q2D. Hydrogen has a distinct odor } \\
\hline True & 3 & 0.6 & 1.36 & 0.25 \\
\hline False & 162 & 2.1 & 73.6 & 0.95 \\
\hline Don't know & 55 & 2.1 & 25.0 & 0.94 \\
\hline Total for Q2D & 220 & 0.0 & 100 & 0.00 \\
\hline \multicolumn{5}{|c|}{ Q3. Which of the following can fuel cells provide power to? } \\
\hline Your home & 4 & 0.5 & 1.82 & 0.22 \\
\hline Your car & 29 & 1.5 & 13.2 & 0.69 \\
\hline Your laptop computer & 2 & 0.6 & 0.91 & 0.26 \\
\hline All of these & 175 & 1.8 & 79.5 & 0.82 \\
\hline None of these & 5 & 0.5 & 2.27 & 0.24 \\
\hline Don't know & 5 & 0.7 & 2.27 & 0.30 \\
\hline Total for Q3 & 220 & 0.0 & 100 & 0.00 \\
\hline
\end{tabular}




\begin{tabular}{|c|c|c|c|c|}
\hline Question/Metric & Frequency & $\begin{array}{c}\text { Standard } \\
\text { Deviation of } \\
\text { Frequency }\end{array}$ & Percent & $\begin{array}{c}\text { Standard } \\
\text { Error of } \\
\text { Percent }\end{array}$ \\
\hline \multicolumn{5}{|c|}{ Q4. In which state or condition can hydrogen be stored? } \\
\hline Chemical compound & 5 & 0.6 & 2.27 & 0.26 \\
\hline Liquid & 50 & 2.0 & 22.7 & 0.91 \\
\hline Both of these & 133 & 2.2 & 60.5 & 1.02 \\
\hline Neither of these & 10 & 0.8 & 4.55 & 0.38 \\
\hline Don't know & 22 & 1.3 & 10.0 & 0.61 \\
\hline Total for Q4 & 220 & 0.0 & 100 & 0.00 \\
\hline
\end{tabular}

Q5. When using pure hydrogen, fuel cell vehicles generate electricity, water, and what el se?

\begin{tabular}{|l|c|c|c|c|}
\hline Carbon dioxide & 16 & 1.3 & 7.27 & 0.61 \\
\hline Nitrous oxides & 5 & 0.7 & 2.27 & 0.33 \\
\hline Heat & 140 & 2.3 & 63.6 & 1.04 \\
\hline All of these & 9 & 0.9 & 4.09 & 0.43 \\
\hline Don't know & 50 & 1.9 & 22.7 & 0.87 \\
\hline Total for Q5 & 220 & 0.0 & 100 & 0.00 \\
\hline
\end{tabular}

Q6. Hydrogen can be produced using which of the following sources of energy?

\begin{tabular}{|l|c|c|c|c|}
\hline Natural gas & 19 & 1.4 & 8.64 & 0.62 \\
\hline Sunlight & 3 & 0.6 & 1.36 & 0.26 \\
\hline Organic matter & 12 & 1.1 & 5.45 & 0.51 \\
\hline All of these & 143 & 2.2 & 65.0 & 1.02 \\
\hline Don't know & 43 & 1.8 & 19.5 & 0.83 \\
\hline Total for Q6 & 220 & 0.0 & 100 & 0.00 \\
\hline
\end{tabular}

\section{Q7A. First}




\begin{tabular}{|l|c|c|c|c|}
\hline \multicolumn{1}{|c|}{ Question/Metric } & Frequency & $\begin{array}{c}\text { Standard } \\
\text { Deviation of } \\
\text { Frequency }\end{array}$ & Percent & $\begin{array}{c}\text { Standard } \\
\text { Error of } \\
\text { Percent }\end{array}$ \\
\hline Safety & 58 & 2.2 & 26.4 & 0.98 \\
\hline Cost & 70 & 2.2 & 31.8 & 1.00 \\
\hline Environment & 43 & 1.9 & 19.5 & 0.88 \\
\hline Convenience & 26 & 1.5 & 11.8 & 0.69 \\
\hline Performance & 22 & 1.3 & 10.0 & 0.60 \\
\hline Don't know & 1 & 0.2 & 0.45 & 0.11 \\
\hline Total for Q7A & 220 & 0.0 & 100 & 0.00 \\
\hline
\end{tabular}

\begin{tabular}{|l|c|c|c|c|}
\hline Q7B. Second & \multicolumn{1}{|l|}{} \\
\hline Safety & 40 & 1.9 & 18.3 & 0.86 \\
\hline Cost & 55 & 2.1 & 25.1 & 0.95 \\
\hline Environment & 46 & 1.9 & 21.0 & 0.88 \\
\hline Convenience & 38 & 1.7 & 17.4 & 0.79 \\
\hline Performance & 40 & 1.9 & 18.3 & 0.86 \\
\hline Total for Q7B & 219 & 0.0 & 100 & 0.00 \\
\hline
\end{tabular}

\begin{tabular}{|l|c|c|c|c|}
\hline Q7C. Third & 49 & 2.0 & 22.4 & 0.92 \\
\hline Safety & 44 & 1.9 & 20.1 & 0.87 \\
\hline Cost & 43 & 2.0 & 19.6 & 0.89 \\
\hline Environment & 37 & 1.7 & 16.9 & 0.80 \\
\hline Convenience & 44 & 1.9 & 20.1 & 0.87 \\
\hline Performance & 2 & 0.4 & 0.91 & 0.17 \\
\hline Don't know & 219 & 0.0 & 100 & 0.00 \\
\hline Total for Q7C & & & & \\
\hline & & & & \\
\hline Q7D. Fourth & 43 & 1.8 & 19.7 & 0.81 \\
\hline Safety & & & \\
\hline
\end{tabular}




\begin{tabular}{|l|c|c|c|c|}
\hline \multicolumn{1}{|c|}{ Question/Metric } & Frequency & $\begin{array}{c}\text { Standard } \\
\text { Deviation of } \\
\text { Frequency }\end{array}$ & Percent & $\begin{array}{c}\text { Standard } \\
\text { Error of } \\
\text { Percent }\end{array}$ \\
\hline Cost & 28 & 1.6 & 12.8 & 0.74 \\
\hline Environment & 48 & 2.0 & 22.0 & 0.90 \\
\hline Convenience & 43 & 1.9 & 19.7 & 0.89 \\
\hline Performance & 56 & 2.1 & 25.7 & 0.98 \\
\hline Total for Q7D & 218 & 0.0 & 100 & 0.00 \\
\hline
\end{tabular}

Q8. How would you feel if your local gas station also sold hydrogen?

\begin{tabular}{|l|c|c|c|c|}
\hline Uneasy & 10 & 1.0 & 4.55 & 0.46 \\
\hline At ease & 48 & 1.9 & 21.8 & 0.89 \\
\hline Pleased & 148 & 2.2 & 67.3 & 1.02 \\
\hline Don't know & 14 & 1.2 & 6.36 & 0.56 \\
\hline Total for Q8 & 220 & 0.0 & 100 & 0.00 \\
\hline
\end{tabular}

Q9. Hydrogen is too dangerous for everyday use by the general public.

\begin{tabular}{|l|c|c|c|c|}
\hline True & 19 & 1.3 & 8.64 & 0.58 \\
\hline False & 181 & 1.8 & 82.3 & 0.83 \\
\hline Don't know & 20 & 1.4 & 9.09 & 0.66 \\
\hline Total for Q9 & 220 & 0.0 & 100 & 0.00 \\
\hline
\end{tabular}

Q10A. Using hydrogen will reduce U.S. dependence on foreign oil

\begin{tabular}{|l|c|c|c|c|}
\hline Disagree & 9 & 0.9 & 4.09 & 0.39 \\
\hline Are neutral & 17 & 1.4 & 7.73 & 0.62 \\
\hline Agree & 186 & 1.8 & 84.5 & 0.81 \\
\hline Don't know & 8 & 1.0 & 3.64 & 0.45 \\
\hline Total for Q10A & 220 & 0.0 & 100 & 0.00 \\
\hline
\end{tabular}

Q10B. Using hydrogen will reduce emissions and improve air quality 


\begin{tabular}{|l|c|c|c|c|}
\hline \multicolumn{1}{|c|}{ Question/Metric } & Frequency & $\begin{array}{c}\text { Standard } \\
\text { Deviation of } \\
\text { Frequency }\end{array}$ & Percent & $\begin{array}{c}\text { Standard } \\
\text { Error of } \\
\text { Percent }\end{array}$ \\
\hline Disagree & 7 & 0.8 & 3.18 & 0.38 \\
\hline Are neutral & 8 & 1.0 & 3.64 & 0.45 \\
\hline Agree & 195 & 1.6 & 88.6 & 0.72 \\
\hline Don't know & 10 & 1.1 & 4.55 & 0.48 \\
\hline Total for Q10B & 220 & 0.0 & 100 & 0.00 \\
\hline
\end{tabular}

Q10C. Hydrogen is as safe to use in my car as gasoline and diesel fuels

\begin{tabular}{|l|c|c|c|c|}
\hline Disagree & 22 & 1.4 & 10.0 & 0.63 \\
\hline Are neutral & 31 & 1.7 & 14.1 & 0.78 \\
\hline Agree & 142 & 2.3 & 64.5 & 1.04 \\
\hline Don't know & 25 & 1.6 & 11.4 & 0.72 \\
\hline Total for Q10C & 220 & 0.0 & 100 & 0.00 \\
\hline
\end{tabular}

\section{Q13A. Personal cars and trucks}

\begin{tabular}{|l|c|c|c|c|}
\hline Not as safe & 19 & 1.3 & 8.64 & 0.58 \\
\hline Equally as safe & 143 & 2.3 & 65.0 & 1.05 \\
\hline Safer & 30 & 1.7 & 13.6 & 0.77 \\
\hline Don't know & 28 & 1.7 & 12.7 & 0.78 \\
\hline Total for Q13A & 220 & 0.0 & 100 & 0.00 \\
\hline
\end{tabular}

\section{Q13B. Buses and commercial vehicles}

\begin{tabular}{|l|c|c|c|c|}
\hline Not as safe & 14 & 1.1 & 6.36 & 0.50 \\
\hline Equally as safe & 148 & 2.3 & 67.3 & 1.04 \\
\hline Safer & 30 & 1.7 & 13.6 & 0.77 \\
\hline Don't know & 28 & 1.7 & 12.7 & 0.78 \\
\hline Total for Q13B & 220 & 0.0 & 100 & 0.00 \\
\hline
\end{tabular}




\begin{tabular}{|l|c|c|c|c|}
\hline \multicolumn{1}{|c|}{ Question/Metric } & Frequency & $\begin{array}{c}\text { Standard } \\
\text { Deviation of } \\
\text { Frequency }\end{array}$ & Percent & $\begin{array}{c}\text { Standard } \\
\text { Error of } \\
\text { Percent }\end{array}$ \\
\hline Q13C. Large power plants & 13 & 1.1 & 5.91 & 0.51 \\
\hline Not as safe & 126 & 2.4 & 57.3 & 1.07 \\
\hline Equally as safe & 42 & 1.9 & 19.1 & 0.85 \\
\hline Safer & 39 & 1.9 & 17.7 & 0.87 \\
\hline Don't know & 220 & 0.0 & 100 & 0.00 \\
\hline Total for Q13C & & & \\
\hline
\end{tabular}

Q13D. Small portable devices such as laptop computers or cell phones

\begin{tabular}{|l|c|c|c|c|}
\hline Not as safe & 38 & 1.8 & 17.3 & 0.83 \\
\hline Equally as safe & 113 & 2.4 & 51.4 & 1.08 \\
\hline Safer & 10 & 1.0 & 4.55 & 0.44 \\
\hline Don't know & 59 & 2.1 & 26.8 & 0.97 \\
\hline Total for Q13D & 220 & 0.0 & 100 & 0.00 \\
\hline
\end{tabular}

Q13E. Onsite power for the home

\begin{tabular}{|l|c|c|c|c|}
\hline Not as safe & 28 & 1.5 & 12.7 & 0.69 \\
\hline Equally as safe & 142 & 2.3 & 64.5 & 1.05 \\
\hline Safer & 16 & 1.4 & 7.27 & 0.63 \\
\hline Don't know & 34 & 1.8 & 15.5 & 0.83 \\
\hline Total for Q13E & 220 & 0.0 & 100 & 0.00 \\
\hline
\end{tabular}

Q13F. Onsite power for buildings such as hospitals and schools

\begin{tabular}{|l|c|c|c|c|}
\hline Not as safe & 15 & 1.1 & 6.82 & 0.50 \\
\hline Equally as safe & 146 & 2.3 & 66.4 & 1.04 \\
\hline Safer & 26 & 1.6 & 11.8 & 0.72 \\
\hline Don't know & 33 & 1.8 & 15.0 & 0.83 \\
\hline Total for Q13F & 220 & 0.0 & 100 & 0.00 \\
\hline
\end{tabular}




\begin{tabular}{|l|c|c|c|c|}
\hline \multicolumn{1}{|c|}{ Question/Metric } & Frequency & $\begin{array}{c}\text { Standard } \\
\text { Deviation of } \\
\text { Frequency }\end{array}$ & Percent & $\begin{array}{c}\text { Standard } \\
\text { Error of } \\
\text { Percent }\end{array}$ \\
\hline \multicolumn{5}{|c|}{} \\
\hline Q13G. Would you recommend buying or leasing fuel cells for a vehicle fleet? \\
\hline Yes & 175 & 1.9 & 79.5 & 0.88 \\
\hline No & 15 & 1.1 & 6.82 & 0.52 \\
\hline Don't know & 30 & 1.7 & 13.6 & 0.77 \\
\hline Total for Q13G & 220 & 0.0 & 100 & 0.00 \\
\hline & & & & \\
\hline Q13H. Would you recommend buying a stationary fuel cell? & & 0.84 \\
\hline Yes & 181 & 1.9 & 82.3 & 0.41 \\
\hline No & 10 & 0.9 & 4.55 & 0.77 \\
\hline Don't know & 29 & 1.7 & 13.2 & 0.00 \\
\hline Total for Q13H & 220 & 0.0 & 100 & \\
\hline
\end{tabular}

Q13I. How you feel about hydrogen and fuel cells to meet your organization's energy ne eds.

\begin{tabular}{|l|c|c|c|c|}
\hline $\begin{array}{l}\text { I know enough to seriously } \\
\text { consider it if products are } \\
\text { available }\end{array}$ & 46 & 1.9 & 20.9 & 0.89 \\
\hline $\begin{array}{l}\text { I am considering it but need } \\
\text { more information }\end{array}$ & 64 & 2.2 & 29.1 & 1.00 \\
\hline $\begin{array}{l}\text { I am going to wait to see how the } \\
\text { market develops }\end{array}$ & 105 & 2.4 & 47.7 & 0.27 \\
\hline $\begin{array}{l}\text { There is no way I'll consider it } \\
\text { anytime soon }\end{array}$ & 4 & 0.6 & 1.82 & 0.13 \\
\hline & 1 & 0.3 & 0.45 & 0.00 \\
\hline Total for Q13I & 112 & 220 & 0.0 & 100 \\
\hline
\end{tabular}




\begin{tabular}{|l|c|c|c|c|}
\hline \multicolumn{1}{|c|}{ Question/Metric } & Frequency & $\begin{array}{c}\text { Standard } \\
\text { Deviation of } \\
\text { Frequency }\end{array}$ & Percent & $\begin{array}{c}\text { Standard } \\
\text { Error of } \\
\text { Percent }\end{array}$ \\
\hline Sometimes & 91 & 2.4 & 41.4 & 1.07 \\
\hline Frequently & 15 & 1.1 & 6.82 & 0.51 \\
\hline Don't know & 2 & 0.5 & 0.91 & 0.21 \\
\hline Total for Q14A & 220 & 0.0 & 100 & 0.00 \\
\hline
\end{tabular}

Q14B. Friends and family members

\begin{tabular}{|l|c|c|c|c|}
\hline Never & 60 & 2.2 & 27.3 & 0.98 \\
\hline Sometimes & 136 & 2.3 & 61.8 & 1.05 \\
\hline Frequently & 23 & 1.3 & 10.5 & 0.60 \\
\hline Don't know & 1 & 0.2 & 0.45 & 0.11 \\
\hline Total for Q14B & 220 & 0.0 & 100 & 0.00 \\
\hline
\end{tabular}

\section{Q14C. Environmental and conservation groups}

\begin{tabular}{|l|c|c|c|c|}
\hline Never & 11 & 0.9 & 5.00 & 0.42 \\
\hline Sometimes & 115 & 2.3 & 52.3 & 1.04 \\
\hline Frequently & 93 & 2.3 & 42.3 & 1.03 \\
\hline Don't know & 1 & 0.3 & 0.45 & 0.13 \\
\hline Total for Q14C & 220 & 0.0 & 100 & 0.00 \\
\hline
\end{tabular}

Q14D. Utility companies or brokers, for example, gas or electricity providers

\begin{tabular}{|l|c|c|c|c|}
\hline Never & 20 & 1.2 & 9.09 & 0.56 \\
\hline Sometimes & 133 & 2.3 & 60.5 & 1.04 \\
\hline Frequently & 67 & 2.2 & 30.5 & 0.99 \\
\hline Total for Q14D & 220 & 0.0 & 100 & 0.00 \\
\hline
\end{tabular}

\section{Q14E. Industry or trade associations or non-profit organizations}

\begin{tabular}{|l|l|l|l|l|}
\hline Never & 9 & 1.0 & 4.09 & 0.46 \\
\hline
\end{tabular}




\begin{tabular}{|l|c|c|c|c|}
\hline \multicolumn{1}{|c|}{ Question/Metric } & Frequency & $\begin{array}{c}\text { Standard } \\
\text { Deviation of } \\
\text { Frequency }\end{array}$ & Percent & $\begin{array}{c}\text { Standard } \\
\text { Error of } \\
\text { Percent }\end{array}$ \\
\hline Sometimes & 103 & 2.3 & 46.8 & 1.06 \\
\hline Frequently & 107 & 2.3 & 48.6 & 1.05 \\
\hline Don't know & 1 & 0.2 & 0.45 & 0.11 \\
\hline Total for Q14E & 220 & 0.0 & 100 & 0.00 \\
\hline
\end{tabular}

\section{Q14F. Federal government}

\begin{tabular}{|l|c|c|c|c|}
\hline Never & 13 & 1.2 & 5.91 & 0.53 \\
\hline Sometimes & 101 & 2.4 & 45.9 & 1.07 \\
\hline Frequently & 106 & 2.3 & 48.2 & 1.07 \\
\hline Total for Q14F & 220 & 0.0 & 100 & 0.00 \\
\hline
\end{tabular}

\section{Q14G. State government}

\begin{tabular}{|l|c|c|c|c|}
\hline Never & 10 & 1.0 & 4.55 & 0.45 \\
\hline Sometimes & 100 & 2.4 & 45.5 & 1.08 \\
\hline Frequently & 110 & 2.4 & 50.0 & 1.07 \\
\hline Total for Q14G & 220 & 0.0 & 100 & 0.00 \\
\hline
\end{tabular}

\section{Q14H. Local government}

\begin{tabular}{|l|c|c|c|c|}
\hline Never & 67 & 2.1 & 30.5 & 0.94 \\
\hline Sometimes & 106 & 2.4 & 48.2 & 1.08 \\
\hline Frequently & 47 & 1.9 & 21.4 & 0.85 \\
\hline Total for Q14H & 220 & 0.0 & 100 & 0.00 \\
\hline
\end{tabular}

\section{Q15A. Television}

\begin{tabular}{|l|c|c|c|c|}
\hline Never & 45 & 1.9 & 20.5 & 0.86 \\
\hline Sometimes & 146 & 2.2 & 66.4 & 1.01 \\
\hline Frequently & 29 & 1.6 & 13.2 & 0.70 \\
\hline
\end{tabular}




\begin{tabular}{|c|c|c|c|c|}
\hline Question/Metric & Frequency & $\begin{array}{l}\text { Standard } \\
\text { Deviation of } \\
\text { Frequency }\end{array}$ & Percent & $\begin{array}{c}\text { Standard } \\
\text { Error of } \\
\text { Percent }\end{array}$ \\
\hline Total for Q15A & 220 & 0.0 & 100 & 0.00 \\
\hline \multicolumn{5}{|l|}{ Q15B. Radio } \\
\hline Never & 74 & 2.3 & 33.6 & 1.03 \\
\hline Sometimes & 119 & 2.4 & 54.1 & 1.09 \\
\hline Frequently & 27 & 1.6 & 12.3 & 0.74 \\
\hline Total for Q15B & 220 & 0.0 & 100 & 0.00 \\
\hline \multicolumn{5}{|l|}{ Q15C. The Internet } \\
\hline Never & 12 & 1.1 & 5.45 & 0.50 \\
\hline Sometimes & 63 & 2.1 & 28.6 & 0.96 \\
\hline Frequently & 145 & 2.2 & 65.9 & 1.00 \\
\hline Total for Q15C & 220 & 0.0 & 100 & 0.00 \\
\hline \multicolumn{5}{|c|}{ Q15D. Newspapers and general interest magazines } \\
\hline Never & 20 & 1.4 & 9.09 & 0.66 \\
\hline Sometimes & 116 & 2.4 & 52.7 & 1.09 \\
\hline Frequently & 84 & 2.3 & 38.2 & 1.07 \\
\hline Total for Q15D & 220 & 0.0 & 100 & 0.00 \\
\hline \multicolumn{5}{|c|}{ Q15E. Science and technology magazines and journals } \\
\hline Never & 20 & 1.4 & 9.09 & 0.64 \\
\hline Sometimes & 97 & 2.4 & 44.1 & 1.07 \\
\hline Frequently & 103 & 2.4 & 46.8 & 1.07 \\
\hline Total for Q15E & 220 & 0.0 & 100 & 0.00 \\
\hline
\end{tabular}




\begin{tabular}{|l|c|c|c|c|}
\hline \multicolumn{1}{|c|}{ Question/Metric } & Frequency & $\begin{array}{c}\text { Standard } \\
\text { Deviation of } \\
\text { Frequency }\end{array}$ & Percent & $\begin{array}{c}\text { Standard } \\
\text { Error of } \\
\text { Percent }\end{array}$ \\
\hline Never & 29 & 1.7 & 13.2 & 0.78 \\
\hline Sometimes & 96 & 2.4 & 43.6 & 1.08 \\
\hline Frequently & 95 & 2.3 & 43.2 & 1.06 \\
\hline Total for Q15F & 220 & 0.0 & 100 & 0.00 \\
\hline
\end{tabular}

Q20. Does your agency operate any hydrogen vehicles?

\begin{tabular}{|l|c|c|c|c|}
\hline Yes & 12 & 1.1 & 5.45 & 0.49 \\
\hline No & 197 & 1.5 & 89.5 & 0.69 \\
\hline Don't know & 11 & 1.2 & 5.00 & 0.52 \\
\hline Total for Q20 & 220 & 0.0 & 100 & 0.00 \\
\hline
\end{tabular}

Q21. Any other organization that operates hydrogen-powered buses or other fleet vehicles in the area covered by your geo

\begin{tabular}{|l|c|c|c|c|}
\hline Yes & 63 & 2.2 & 28.6 & 0.98 \\
\hline No & 142 & 2.3 & 64.5 & 1.04 \\
\hline Don't know & 15 & 1.2 & 6.82 & 0.55 \\
\hline Total for Q21 & 220 & 0.0 & 100 & 0.00 \\
\hline
\end{tabular}

Q22. Does your agency own or operate any stationary fuel cells?

\begin{tabular}{|l|c|c|c|c|}
\hline Yes & 17 & 1.2 & 7.73 & 0.56 \\
\hline No & 184 & 1.8 & 83.6 & 0.81 \\
\hline Don't know & 19 & 1.4 & 8.64 & 0.64 \\
\hline Total for Q22 & 220 & 0.0 & 100 & 0.00 \\
\hline
\end{tabular}

Q23. Any other organization that operates stationary fuel cells in the area covered by your geographic jurisdiction?

\begin{tabular}{|l|c|c|c|c|}
\hline Yes & 66 & 2.1 & 30.0 & 0.97 \\
\hline No & 138 & 2.3 & 62.7 & 1.04 \\
\hline
\end{tabular}




\begin{tabular}{|l|c|c|c|c|}
\hline \multicolumn{1}{|c|}{ Question/Metric } & Frequency & $\begin{array}{c}\text { Standard } \\
\text { Deviation of } \\
\text { Frequency }\end{array}$ & Percent & $\begin{array}{c}\text { Standard } \\
\text { Error of } \\
\text { Percent }\end{array}$ \\
\hline Don't know & 16 & 1.2 & 7.27 & 0.56 \\
\hline Total for Q23 & 220 & 0.0 & 100 & 0.00 \\
\hline
\end{tabular}

Q24. Does your agency have plans to use hydrogen or fuel cells in the future?

\begin{tabular}{|l|c|c|c|c|}
\hline Yes & 74 & 2.2 & 33.6 & 0.99 \\
\hline No & 106 & 2.4 & 48.2 & 1.07 \\
\hline Don't know & 40 & 1.9 & 18.2 & 0.86 \\
\hline Total for Q24 & 220 & 0.0 & 100 & 0.00 \\
\hline
\end{tabular}

Q25. What is the time frame for plans to use hydrogen or fuel cells?

\begin{tabular}{|l|c|c|c|c|}
\hline Within the next year & 10 & 1.0 & 13.5 & 1.36 \\
\hline $1-5$ years & 35 & 1.4 & 47.3 & 1.85 \\
\hline Over 5 years & 26 & 1.3 & 35.1 & 1.72 \\
\hline Don't know & 3 & 0.6 & 4.05 & 0.74 \\
\hline Total for Q25 & 74 & 0.0 & 100 & 0.00 \\
\hline
\end{tabular}

Q26. Have you ever received information about hydrogen and fuel cell technologies?

\begin{tabular}{|l|c|c|c|c|}
\hline Yes & 155 & 2.1 & 70.5 & 0.98 \\
\hline No & 64 & 2.1 & 29.1 & 0.97 \\
\hline Don't know & 1 & 0.4 & 0.45 & 0.19 \\
\hline Total for Q26 & 220 & 0.0 & 100 & 0.00 \\
\hline
\end{tabular}

Q27. Would information about hydrogen and fuel cell technologies be valuable to you?

\begin{tabular}{|l|c|c|c|c|}
\hline Yes & 59 & 0.8 & 90.8 & 1.25 \\
\hline No & 4 & 0.6 & 6.15 & 0.93 \\
\hline Don't know & 2 & 0.5 & 3.08 & 0.84 \\
\hline Total for Q27 & 65 & 0.0 & 100 & 0.00 \\
\hline
\end{tabular}




\begin{tabular}{|c|c|c|c|c|}
\hline Question/Metric & Frequency & $\begin{array}{c}\text { Standard } \\
\text { Deviation of } \\
\text { Frequency }\end{array}$ & Percent & $\begin{array}{c}\text { Standard } \\
\text { Error of } \\
\text { Percent }\end{array}$ \\
\hline \multicolumn{5}{|c|}{ Q28A. A training class on hydrogen or fuel cells } \\
\hline Yes & 40 & 1.7 & 18.2 & 0.79 \\
\hline No & 178 & 1.8 & 80.9 & 0.81 \\
\hline Don't know & 2 & 0.5 & 0.91 & 0.23 \\
\hline Total for Q28A & 220 & 0.0 & 100 & 0.00 \\
\hline \multicolumn{5}{|c|}{ Q28B. A press conference concerning the use of hydrogen or fuel cells } \\
\hline Yes & 48 & 1.9 & 21.8 & 0.88 \\
\hline No & 172 & 1.9 & 78.2 & 0.88 \\
\hline Total for Q28B & 220 & 0.0 & 100 & 0.00 \\
\hline \multicolumn{5}{|c|}{ Q28C. A conference or workshop that included a session on hydrogen or fuel cells } \\
\hline Yes & 115 & 2.3 & 52.3 & 1.06 \\
\hline No & 104 & 2.3 & 47.3 & 1.06 \\
\hline Don't know & 1 & 0.4 & 0.45 & 0.19 \\
\hline Total for Q28C & 220 & 0.0 & 100 & 0.00 \\
\hline \multicolumn{5}{|c|}{ Q29. Would you like to participate in a class on hydrogen or fuel cells? } \\
\hline Yes & 152 & 2.2 & 69.1 & 1.02 \\
\hline No & 61 & 2.2 & 27.7 & 0.99 \\
\hline Don't know & 7 & 0.9 & 3.18 & 0.42 \\
\hline Total for Q29 & 220 & 0.0 & 100 & 0.00 \\
\hline \multicolumn{5}{|c|}{ Q30. Which class format is MOST useful to you? } \\
\hline In-person & 35 & 1.6 & 23.0 & 1.08 \\
\hline
\end{tabular}




\begin{tabular}{|l|c|c|c|c|}
\hline \multicolumn{1}{|c|}{ Question/Metric } & Frequency & $\begin{array}{c}\text { Standard } \\
\text { Deviation of } \\
\text { Frequency }\end{array}$ & Percent & $\begin{array}{c}\text { Standard } \\
\text { Error of } \\
\text { Percent }\end{array}$ \\
\hline $\begin{array}{l}\text { In-person class in conjunction } \\
\text { with a re }\end{array}$ & 64 & 1.9 & 42.1 & 1.26 \\
\hline & 50 & 1.8 & 32.9 & 1.20 \\
\hline & 3 & 0.5 & 1.97 & 0.31 \\
\hline Total for Q30 & 152 & 0.0 & 100 & 0.00 \\
\hline
\end{tabular}

\begin{tabular}{|l|c|c|c|c|}
\hline Sex \\
\hline Males & 172 & 2.0 & 78.2 & 0.89 \\
\hline Females & 48 & 2.0 & 21.8 & 0.89 \\
\hline Total for Sex & 220 & 0.0 & 100 & 0.00 \\
\hline
\end{tabular}




\section{State and Local Officials Survey Technical Question Summary}

\begin{tabular}{|c|c|c|c|c|}
\hline Question & $\begin{array}{c}\text { Number } \\
\text { of } \\
\text { Responses }\end{array}$ & $\begin{array}{l}\text { Percent } \\
\text { Correct }\end{array}$ & $\begin{array}{l}\text { Lower } 95 \% \\
\text { Confidence } \\
\text { Bound }\end{array}$ & $\begin{array}{l}\text { Upper } 95 \% \\
\text { Confidence } \\
\text { Bound }\end{array}$ \\
\hline 2A. Hydrogen gas is toxic (false) & 220 & 66.82 & 64.77 & 68.86 \\
\hline $\begin{array}{l}\text { 2B. Fuel cells produce electricity through hydrogen } \\
\text { combustion (false) }\end{array}$ & 220 & 43.18 & 41.15 & 45.21 \\
\hline 2C. Hydrogen is lighter than air (true) & 220 & 78.18 & 76.46 & 79.91 \\
\hline 2D. Hydrogen has a distinct odor (false) & 220 & 73.64 & 71.76 & 75.51 \\
\hline $\begin{array}{l}\text { 4. In which state or condition can hydrogen be stored? } \\
\text { (chemical compound, liquid) }\end{array}$ & 220 & 60.45 & 58.45 & 62.46 \\
\hline $\begin{array}{l}\text { 5. When using pure hydrogen, fuel cell vehicles } \\
\text { generate electricity, water, and what else? (heat) }\end{array}$ & 220 & 63.64 & 61.59 & 65.68 \\
\hline $\begin{array}{l}\text { 6. Hydrogen can be produced using which of the } \\
\text { following sources of energy? (natural gas, sunlight, } \\
\text { organic matter) }\end{array}$ & 220 & 65.00 & 62.99 & 67.01 \\
\hline $\begin{array}{l}\text { 9. Hydrogen is too dangerous for everyday use by the } \\
\text { general public (false) }\end{array}$ & 220 & 82.27 & 80.63 & 83.92 \\
\hline Overall Average & 220 & 66.65 & 65.60 & 67.69 \\
\hline
\end{tabular}

State and Local Officials Survey Summary of Importance Ranking

\begin{tabular}{|c|c|c|c|c|}
\hline Question & $\begin{array}{r}\text { Number } \\
\text { of } \\
\text { Responses }\end{array}$ & $\begin{array}{c}\text { Average } \\
\text { Rank }\end{array}$ & $\begin{array}{l}\text { Lower } \\
95 \% \\
\text { Confidence } \\
\text { Bound }\end{array}$ & $\begin{array}{c}\text { Upper } \\
95 \% \\
\text { Confidence } \\
\text { Bound }\end{array}$ \\
\hline Safety & 219 & 2.75 & 2.69 & 2.81 \\
\hline Cost & 218 & 2.43 & 2.37 & 2.48 \\
\hline Environment & 218 & 2.96 & 2.90 & 3.02 \\
\hline Convenience & 218 & 3.46 & 3.40 & 3.52 \\
\hline Performance & 217 & 3.38 & 3.32 & 3.43 \\
\hline
\end{tabular}




\section{C.4. SUMMARY OF RESPONSES TO THE END USER SURVEY}

\begin{tabular}{|l|c|c|c|c|}
\hline \multicolumn{1}{|c|}{ Question/Metric } & Frequency & $\begin{array}{c}\text { Standard } \\
\text { Deviation of } \\
\text { Frequency }\end{array}$ & Percent & $\begin{array}{c}\text { Standard Error of } \\
\text { Percent }\end{array}$ \\
\hline Category & 200 & 11.6 & 33.3 & 1.92 \\
\hline Transportation & 201 & 11.6 & 33.4 & 1.93 \\
\hline Uninterrupted supply users & 200 & 11.6 & 33.3 & 1.92 \\
\hline Large power users & 601 & 0.0 & 100 & 0.00 \\
\hline Total for Category & & & & \\
\hline
\end{tabular}

\section{Subcategory}

\begin{tabular}{|l|c|c|c|c|}
\hline Trucking & 93 & 6.3 & 15.5 & 1.05 \\
\hline Transit & 24 & 4.1 & 3.99 & 0.69 \\
\hline Postal service & 20 & 3.8 & 3.33 & 0.63 \\
\hline Couriers \& messengers & 2 & 1.3 & 0.33 & 0.21 \\
\hline Automotive rental/leasing & 10 & 2.8 & 1.66 & 0.46 \\
\hline Police & 16 & 3.4 & 2.66 & 0.57 \\
\hline Fire & 21 & 3.9 & 3.49 & 0.65 \\
\hline Garbage & 2 & 1.3 & 0.33 & 0.21 \\
\hline Private fleets & 10 & 2.8 & 1.66 & 0.46 \\
\hline Airports & 2 & 1.3 & 0.33 & 0.21 \\
\hline Farms & 4 & 1.9 & 0.67 & 0.32 \\
\hline Financial institutions & 16 & 3.7 & 2.66 & 0.62 \\
\hline Educational services & 132 & 6.5 & 22.0 & 1.08 \\
\hline Hospitals/residential care & 10 & 3.0 & 1.66 & 0.49 \\
\hline Communications & 4 & 1.9 & 0.67 & 0.32 \\
\hline National security & 15 & 1.0 & 0.17 & 0.16 \\
\hline Utilities & 2.1 & 0.83 & 0.35 \\
\hline Shopping centers & 3.5 & 2.33 & 0.58 \\
\hline Government Services & 3.6 & 2.50 & 0.60 \\
\hline & 14 & & & \\
\hline
\end{tabular}




\begin{tabular}{|l|c|c|c|c|}
\hline \multicolumn{1}{|c|}{ Question/Metric } & Frequency & $\begin{array}{c}\text { Standard } \\
\text { Deviation of } \\
\text { Frequency }\end{array}$ & Percent & $\begin{array}{c}\text { Standard Error of } \\
\text { Percent }\end{array}$ \\
\hline Industry & 200 & 0.0 & 33.3 & 0.00 \\
\hline Total for Subcategory & 601 & 0.0 & 100 & 0.00 \\
\hline
\end{tabular}

\section{Region}

\begin{tabular}{|l|c|c|c|c|}
\hline Northeast & 109 & 8.8 & 18.1 & 1.46 \\
\hline Midwest & 177 & 10.4 & 29.5 & 1.72 \\
\hline South & 200 & 10.7 & 33.3 & 1.79 \\
\hline West & 115 & 9.0 & 19.1 & 1.50 \\
\hline Total for Region & 601 & 0.0 & 100 & 0.00 \\
\hline
\end{tabular}

\section{Sex}

\begin{tabular}{|l|c|c|c|c|}
\hline Male & 519 & 7.9 & 86.4 & 1.31 \\
\hline Female & 82 & 7.9 & 13.6 & 1.31 \\
\hline Total for Sex & 601 & 0.0 & 100 & 0.00 \\
\hline
\end{tabular}

\section{Above Average?}

\begin{tabular}{|l|c|c|c|c|}
\hline Score Below Average & 269 & 11.3 & 44.8 & 1.88 \\
\hline Score Above Average & 332 & 11.3 & 55.2 & 1.88 \\
\hline Total for Above Average? & 601 & 0.0 & 100 & 0.00 \\
\hline
\end{tabular}

Q1. Please rate your familiarity with hydrogen and fuel cell technologies

\begin{tabular}{|l|c|c|c|c|}
\hline Not at all familiar & 162 & 10.2 & 27.0 & 1.69 \\
\hline Slightly familiar & 333 & 11.4 & 55.4 & 1.90 \\
\hline Familiar & 84 & 8.0 & 14.0 & 1.32 \\
\hline Very familiar & 22 & 4.4 & 3.66 & 0.72 \\
\hline Total for Q1 & 601 & 0.0 & 100 & 0.00 \\
\hline
\end{tabular}




\begin{tabular}{|l|c|c|c|c|}
\hline \multicolumn{1}{|c|}{ Question/Metric } & \multicolumn{2}{c|}{$\begin{array}{c}\text { Standard } \\
\text { Deviation of } \\
\text { Frequency }\end{array}$} & Frequency & $\begin{array}{c}\text { Ptandard Error of } \\
\text { Percent }\end{array}$ \\
\hline Q2. Job title & \multicolumn{3}{|l|}{} \\
\hline Fleet manager & 46 & 5.9 & 7.65 & 0.97 \\
\hline Plant or facility manager & 129 & 9.4 & 21.5 & 1.56 \\
\hline Operations manager & 55 & 6.5 & 9.15 & 1.09 \\
\hline Financial manager & 19 & 4.0 & 3.16 & 0.67 \\
\hline Energy manager & 110 & 8.7 & 18.3 & 1.44 \\
\hline CEO & 35 & 5.3 & 5.82 & 0.88 \\
\hline Other & 207 & 10.8 & 34.4 & 1.81 \\
\hline Total for Q2 & 601 & 0.0 & 100 & 0.00 \\
\hline
\end{tabular}

\section{Q3. Years you held this position?}

\begin{tabular}{|l|c|c|c|c|}
\hline Less than one year & 48 & 6.2 & 7.99 & 1.04 \\
\hline Between one and five years & 190 & 10.7 & 31.6 & 1.77 \\
\hline Over five years & 363 & 11.2 & 60.4 & 1.86 \\
\hline Total for Q3 & 601 & 0.0 & 100 & 0.00 \\
\hline
\end{tabular}

Q4A. How many vehicles are in the GROUND-

BASED fleet operated by your organization or agency?

\begin{tabular}{|l|c|c|c|c|}
\hline Less than 100 & 64 & 5.9 & 32.0 & 2.96 \\
\hline $100-1,000$ & 96 & 6.3 & 48.0 & 3.17 \\
\hline $1,001-10,000$ & 23 & 4.0 & 11.5 & 2.02 \\
\hline Over 10,000 & 8 & 2.5 & 4.00 & 1.24 \\
\hline Don't know/refused & 9 & 2.6 & 4.50 & 1.31 \\
\hline Total for Q4A & 200 & 0.0 & 100 & 0.00 \\
\hline
\end{tabular}

Q4B. What is the average annual cost of electrical energy for your organization or agency?

\begin{tabular}{|l|l|l|l|l|}
\hline Under $\$ 100,000$ & 22 & 4.4 & 5.49 & 1.09 \\
\hline
\end{tabular}

$\begin{array}{lll}\text { Hydrogen Knowledge and Opinions Surveys } & \text { C-55 April 21, } 2010\end{array}$ 


\begin{tabular}{|l|c|c|c|c|}
\hline \multicolumn{1}{|c|}{ Question/Metric } & Frequency & $\begin{array}{c}\text { Standard } \\
\text { Deviation of } \\
\text { Frequency }\end{array}$ & Percent & $\begin{array}{c}\text { Standard Error of } \\
\text { Percent }\end{array}$ \\
\hline$\$ 100,000$ to $\$ 1,000,000$ & 72 & 7.3 & 18.0 & 1.82 \\
\hline$\$ 1,000,001$ to $\$ 2,000,000$ & 48 & 6.2 & 12.0 & 1.55 \\
\hline Over $\$ 2,000,000$ & 148 & 9.2 & 36.9 & 2.29 \\
\hline Don't know/refused & 111 & 8.6 & 27.7 & 2.14 \\
\hline Total for Q4B & 401 & 0.0 & 100 & 0.00 \\
\hline
\end{tabular}

\section{Q5A. Hydrogen gas is toxic}

\begin{tabular}{|l|c|c|c|c|}
\hline True & 69 & 7.2 & 11.5 & 1.21 \\
\hline False & 332 & 11.3 & 55.2 & 1.89 \\
\hline Don't know & 200 & 10.8 & 33.3 & 1.80 \\
\hline Total for Q5A & 601 & 0.0 & 100 & 0.00 \\
\hline
\end{tabular}

\section{Q5B. Fuel cells produce electricity through hydrogen combustion}

\begin{tabular}{|l|c|c|c|c|}
\hline True & 184 & 10.6 & 30.6 & 1.76 \\
\hline False & 135 & 9.5 & 22.5 & 1.58 \\
\hline Don't know & 282 & 11.3 & 46.9 & 1.89 \\
\hline Total for Q5B & 601 & 0.0 & 100 & 0.00 \\
\hline
\end{tabular}

\section{Q5C. Hydrogen is lighter than air}

\begin{tabular}{|l|c|c|c|c|}
\hline True & 381 & 11.0 & 63.4 & 1.83 \\
\hline False & 27 & 4.8 & 4.49 & 0.79 \\
\hline Don't know & 193 & 10.7 & 32.1 & 1.78 \\
\hline Total for Q5C & 601 & 0.0 & 100 & 0.00 \\
\hline
\end{tabular}

\section{Q5D. Hydrogen has a distinct odor}

\begin{tabular}{|l|c|c|c|c|}
\hline True & 16 & 3.7 & 2.66 & 0.62 \\
\hline False & 361 & 11.1 & 60.1 & 1.85 \\
\hline
\end{tabular}




\begin{tabular}{|l|c|c|c|c|}
\hline \multicolumn{1}{|c|}{ Question/Metric } & Frequency & $\begin{array}{c}\text { Standard } \\
\text { Deviation of } \\
\text { Frequency }\end{array}$ & Percent & $\begin{array}{c}\text { Standard Error of } \\
\text { Percent }\end{array}$ \\
\hline Don't know & 224 & 11.0 & 37.3 & 1.83 \\
\hline Total for Q5D & 601 & 0.0 & 100 & 0.00 \\
\hline
\end{tabular}

\section{Q6. Which of the following can fuel cells provide power to?}

\begin{tabular}{|l|c|c|c|c|}
\hline Your home & 7 & 2.5 & 1.16 & 0.41 \\
\hline Your car & 100 & 8.5 & 16.6 & 1.41 \\
\hline Your laptop computer & 3 & 1.6 & 0.50 & 0.27 \\
\hline All of these & 416 & 10.5 & 69.2 & 1.75 \\
\hline None of these & 13 & 3.4 & 2.16 & 0.56 \\
\hline Don't know & 62 & 6.9 & 10.3 & 1.15 \\
\hline Total for Q6 & 601 & 0.0 & 100 & 0.00 \\
\hline
\end{tabular}

\section{Q7. In which state or condition can hydrogen be stored?}

\begin{tabular}{|l|c|c|c|c|}
\hline Chemical compound & 12 & 3.3 & 2.00 & 0.54 \\
\hline Liquid & 145 & 9.8 & 24.1 & 1.64 \\
\hline Both of these & 275 & 11.4 & 45.8 & 1.90 \\
\hline Neither of these & 16 & 3.7 & 2.66 & 0.62 \\
\hline Don't know & 153 & 9.9 & 25.5 & 1.65 \\
\hline Total for Q7 & 601 & 0.0 & 100 & 0.00 \\
\hline
\end{tabular}

Q8. When using pure hydrogen, fuel cell vehicles generate electricity, water, and what else?

\begin{tabular}{|l|c|c|c|c|}
\hline Carbon dioxide & 50 & 6.4 & 8.32 & 1.06 \\
\hline Nitrous oxides & 15 & 3.6 & 2.50 & 0.60 \\
\hline Heat & 189 & 10.7 & 31.4 & 1.78 \\
\hline All of these & 61 & 7.0 & 10.1 & 1.16 \\
\hline Don't know & 286 & 11.4 & 47.6 & 1.90 \\
\hline Total for Q8 & 601 & 0.0 & 100 & 0.00 \\
\hline
\end{tabular}




\begin{tabular}{|c|c|c|c|c|}
\hline Question/Metric & Frequency & $\begin{array}{l}\text { Standard } \\
\text { Deviation of } \\
\text { Frequency }\end{array}$ & Percent & $\begin{array}{c}\text { Standard Error of } \\
\text { Percent }\end{array}$ \\
\hline \multicolumn{5}{|c|}{ Q9. Hydrogen can be produced using which of the following sources of energy? } \\
\hline Natural gas & 50 & 6.4 & 8.32 & 1.06 \\
\hline Sunlight & 13 & 3.3 & 2.16 & 0.55 \\
\hline Organic matter & 33 & 5.2 & 5.49 & 0.87 \\
\hline All of these & 257 & 11.3 & 42.8 & 1.89 \\
\hline Don't know & 248 & 11.2 & 41.3 & 1.87 \\
\hline Total for Q9 & 601 & 0.0 & 100 & 0.00 \\
\hline
\end{tabular}

\section{Q10A. System installation cost}

\begin{tabular}{|l|c|c|c|c|}
\hline Low & 30 & 5.0 & 4.99 & 0.83 \\
\hline Medium & 207 & 10.9 & 34.4 & 1.81 \\
\hline High & 308 & 11.4 & 51.2 & 1.90 \\
\hline Don't know & 56 & 6.6 & 9.32 & 1.10 \\
\hline Total for Q10A & 601 & 0.0 & 100 & 0.00 \\
\hline
\end{tabular}

\section{Q10B. System maintenance cost}

\begin{tabular}{|l|c|c|c|c|}
\hline Low & 32 & 5.2 & 5.32 & 0.86 \\
\hline Medium & 197 & 10.7 & 32.8 & 1.79 \\
\hline High & 317 & 11.4 & 52.7 & 1.90 \\
\hline Don't know & 55 & 6.6 & 9.15 & 1.10 \\
\hline Total for Q10B & 601 & 0.0 & 100 & 0.00 \\
\hline
\end{tabular}

\section{Q10C. Fuel cost}

\begin{tabular}{|l|c|c|c|c|}
\hline Low & 28 & 4.8 & 4.66 & 0.80 \\
\hline Medium & 96 & 8.4 & 16.0 & 1.40 \\
\hline High & 440 & 10.2 & 73.2 & 1.69 \\
\hline
\end{tabular}




\begin{tabular}{|l|c|c|c|c|}
\hline \multicolumn{1}{|c|}{ Question/Metric } & Frequency & $\begin{array}{c}\text { Standard } \\
\text { Deviation of } \\
\text { Frequency }\end{array}$ & Percent & $\begin{array}{c}\text { Standard Error of } \\
\text { Percent }\end{array}$ \\
\hline Don't know & 37 & 5.5 & 6.16 & 0.91 \\
\hline Total for Q10C & 601 & 0.0 & 100 & 0.00 \\
\hline
\end{tabular}

\section{Q10D. Dependability}

\begin{tabular}{|l|c|c|c|c|}
\hline Low & 12 & 3.2 & 2.00 & 0.53 \\
\hline Medium & 54 & 6.6 & 8.99 & 1.09 \\
\hline High & 492 & 8.8 & 81.9 & 1.47 \\
\hline Don't know & 43 & 5.9 & 7.15 & 0.98 \\
\hline Total for Q10D & 601 & 0.0 & 100 & 0.00 \\
\hline
\end{tabular}

\section{Q10E. Safety}

\begin{tabular}{|l|c|c|c|c|}
\hline Low & 21 & 4.2 & 3.49 & 0.70 \\
\hline Medium & 47 & 6.1 & 7.82 & 1.02 \\
\hline High & 497 & 8.6 & 82.7 & 1.44 \\
\hline Don't know & 36 & 5.4 & 5.99 & 0.90 \\
\hline Total for Q10E & 601 & 0.0 & 100 & 0.00 \\
\hline
\end{tabular}

\section{Q10F. Environmental impact}

\begin{tabular}{|l|c|c|c|c|}
\hline Low & 63 & 7.0 & 10.5 & 1.17 \\
\hline Medium & 175 & 10.4 & 29.1 & 1.73 \\
\hline High & 329 & 11.3 & 54.7 & 1.89 \\
\hline Don't know & 34 & 5.3 & 5.66 & 0.88 \\
\hline Total for Q10F & 601 & 0.0 & 100 & 0.00 \\
\hline
\end{tabular}

\section{Q10G. Uninterrupted availability}

\begin{tabular}{|l|c|c|c|c|}
\hline Low & 23 & 4.4 & 3.83 & 0.74 \\
\hline Medium & 77 & 7.7 & 12.8 & 1.28 \\
\hline
\end{tabular}




\begin{tabular}{|l|c|c|c|c|}
\hline \multicolumn{1}{|c|}{ Question/Metric } & Frequency & $\begin{array}{c}\text { Standard } \\
\text { Deviation of } \\
\text { Frequency }\end{array}$ & Percent & $\begin{array}{c}\text { Standard Error of } \\
\text { Percent }\end{array}$ \\
\hline High & 453 & 9.9 & 75.4 & 1.65 \\
\hline Don't know & 48 & 6.2 & 7.99 & 1.03 \\
\hline Total for Q10G & 601 & 0.0 & 100 & 0.00 \\
\hline
\end{tabular}

\section{Q11. How would you feel if your local gas station also sold hydrogen?}

\begin{tabular}{|l|c|c|c|c|}
\hline Frightened & 7 & 2.4 & 1.16 & 0.41 \\
\hline Uneasy & 46 & 6.1 & 7.65 & 1.02 \\
\hline At ease & 151 & 10.0 & 25.1 & 1.66 \\
\hline Pleased & 294 & 11.5 & 48.9 & 1.91 \\
\hline Don't know & 103 & 8.6 & 17.1 & 1.43 \\
\hline Total for Q11 & 601 & 0.0 & 100 & 0.00 \\
\hline
\end{tabular}

Q12. Hydrogen is too dangerous for everyday use by the general public.

\begin{tabular}{|l|c|c|c|c|}
\hline True & 65 & 7.1 & 10.8 & 1.18 \\
\hline False & 373 & 11.1 & 62.1 & 1.85 \\
\hline Don't know & 163 & 10.1 & 27.1 & 1.69 \\
\hline Total for Q12 & 601 & 0.0 & 100 & 0.00 \\
\hline
\end{tabular}

\section{Q13A. Using hydrogen will reduce U.S. dependence on foreign oil}

\begin{tabular}{|l|c|c|c|c|}
\hline Disagree & 39 & 5.7 & 6.49 & 0.94 \\
\hline Are neutral & 36 & 5.5 & 5.99 & 0.91 \\
\hline Agree & 483 & 9.1 & 80.4 & 1.52 \\
\hline Don't know & 43 & 5.9 & 7.15 & 0.99 \\
\hline Total for Q13A & 601 & 0.0 & 100 & 0.00 \\
\hline
\end{tabular}

Q13B. Using hydrogen will reduce emissions and improve air quality

\begin{tabular}{|l|l|l|l|l|}
\hline Disagree & 17 & 3.8 & 2.83 & 0.64 \\
\hline
\end{tabular}




\begin{tabular}{|l|c|c|c|c|}
\hline \multicolumn{1}{|c|}{ Question/Metric } & Frequency & $\begin{array}{c}\text { Standard } \\
\text { Deviation of } \\
\text { Frequency }\end{array}$ & Percent & $\begin{array}{c}\text { Standard Error of } \\
\text { Percent }\end{array}$ \\
\hline Are neutral & 27 & 4.7 & 4.49 & 0.79 \\
\hline Agree & 471 & 9.5 & 78.4 & 1.57 \\
\hline Don't know & 86 & 8.0 & 14.3 & 1.34 \\
\hline Total for Q13B & 601 & 0.0 & 100 & 0.00 \\
\hline
\end{tabular}

Q13C. Hydrogen is as safe to use in my car as gasoline and diesel fuels

\begin{tabular}{|l|c|c|c|c|}
\hline Disagree & 67 & 7.2 & 11.1 & 1.20 \\
\hline Are neutral & 43 & 5.9 & 7.15 & 0.99 \\
\hline Agree & 331 & 11.4 & 55.1 & 1.90 \\
\hline Don't know & 160 & 10.1 & 26.6 & 1.68 \\
\hline Total for Q13C & 601 & 0.0 & 100 & 0.00 \\
\hline
\end{tabular}

\section{Q14A. Personal cars and trucks}

\begin{tabular}{|l|c|c|c|c|}
\hline Not as safe & 61 & 6.9 & 10.1 & 1.16 \\
\hline Equally as safe & 315 & 11.5 & 52.4 & 1.91 \\
\hline Safer & 76 & 7.6 & 12.6 & 1.27 \\
\hline Don't know & 149 & 9.9 & 24.8 & 1.64 \\
\hline Total for Q14A & 601 & 0.0 & 100 & 0.00 \\
\hline
\end{tabular}

\section{Q14B. Buses and commercial vehicles}

\begin{tabular}{|l|c|c|c|c|}
\hline Not as safe & 45 & 6.0 & 7.49 & 1.00 \\
\hline Equally as safe & 321 & 11.5 & 53.4 & 1.91 \\
\hline Safer & 90 & 8.2 & 15.0 & 1.37 \\
\hline Don't know & 145 & 9.8 & 24.1 & 1.62 \\
\hline Total for Q14B & 601 & 0.0 & 100 & 0.00 \\
\hline
\end{tabular}

\section{Q14C. Large power plants}




\begin{tabular}{|l|c|c|c|c|}
\hline \multicolumn{1}{|c|}{ Question/Metric } & Frequency & $\begin{array}{c}\text { Standard } \\
\text { Deviation of } \\
\text { Frequency }\end{array}$ & Percent & $\begin{array}{c}\text { Standard Error of } \\
\text { Percent }\end{array}$ \\
\hline Not as safe & 21 & 4.2 & 3.49 & 0.70 \\
\hline Equally as safe & 297 & 11.5 & 49.4 & 1.91 \\
\hline Safer & 90 & 8.2 & 15.0 & 1.37 \\
\hline Don't know & 193 & 10.7 & 32.1 & 1.78 \\
\hline Total for Q14C & 601 & 0.0 & 100 & 0.00 \\
\hline
\end{tabular}

Q14D. Small portable devices such as laptop computers or cell phones

\begin{tabular}{|l|c|c|c|c|}
\hline Not as safe & 112 & 9.0 & 18.6 & 1.49 \\
\hline Equally as safe & 174 & 10.4 & 29.0 & 1.73 \\
\hline Safer & 32 & 5.1 & 5.32 & 0.86 \\
\hline Don't know & 283 & 11.5 & 47.1 & 1.91 \\
\hline Total for Q14D & 601 & 0.0 & 100 & 0.00 \\
\hline
\end{tabular}

\section{Q14E. Onsite power for the home}

\begin{tabular}{|l|c|c|c|c|}
\hline Not as safe & 72 & 7.5 & 12.0 & 1.24 \\
\hline Equally as safe & 283 & 11.5 & 47.1 & 1.91 \\
\hline Safer & 67 & 7.2 & 11.1 & 1.20 \\
\hline Don't know & 179 & 10.4 & 29.8 & 1.74 \\
\hline Total for Q14E & 601 & 0.0 & 100 & 0.00 \\
\hline
\end{tabular}

\section{Q14F. Onsite power for buildings such as hospitals and schools}

\begin{tabular}{|l|c|c|c|c|}
\hline Not as safe & 43 & 5.9 & 7.15 & 0.98 \\
\hline Equally as safe & 312 & 11.5 & 51.9 & 1.91 \\
\hline Safer & 77 & 7.7 & 12.8 & 1.27 \\
\hline Don't know & 169 & 10.3 & 28.1 & 1.71 \\
\hline Total for Q14F & 601 & 0.0 & 100 & 0.00 \\
\hline
\end{tabular}




\begin{tabular}{|l|c|c|c|c|}
\hline \multicolumn{1}{|c|}{ Question/Metric } & Frequency & $\begin{array}{c}\text { Standard } \\
\text { Deviation of } \\
\text { Frequency }\end{array}$ & Percent & $\begin{array}{c}\text { Standard Error of } \\
\text { Percent }\end{array}$ \\
\hline Q15. Would you recommend buying or leasing fuel cells for your organization's vehicle fleet? \\
\hline Yes & 417 & 10.6 & 69.4 & 1.76 \\
\hline No & 68 & 7.3 & 11.3 & 1.21 \\
\hline Don't know & 116 & 9.0 & 19.3 & 1.50 \\
\hline Total for Q15 & 601 & 0.0 & 100 & 0.00 \\
\hline
\end{tabular}

Q16. Would you buy or recommend buying a stationary fuel cell to help meet your facility's ne eds?

\begin{tabular}{|l|c|c|c|c|}
\hline Yes & 451 & 9.9 & 75.0 & 1.65 \\
\hline No & 38 & 5.6 & 6.32 & 0.94 \\
\hline Don't know & 112 & 8.9 & 18.6 & 1.48 \\
\hline Total for Q16 & 601 & 0.0 & 100 & 0.00 \\
\hline
\end{tabular}

Q17. How you feel about using hydrogen and fuel cell technology to meet your organization's energy needs.

\begin{tabular}{|l|c|c|c|c|}
\hline $\begin{array}{l}\text { I know enough to seriously } \\
\text { consider it if products are } \\
\text { available }\end{array}$ & 63 & 7.0 & 10.5 & 1.17 \\
\hline $\begin{array}{l}\text { I am considering it but need more } \\
\text { information }\end{array}$ & 180 & 10.5 & 30.0 & 1.75 \\
\hline $\begin{array}{l}\text { I am going to wait and see how the } \\
\text { market develops }\end{array}$ & 293 & 11.5 & 48.8 & 0.76 \\
\hline $\begin{array}{l}\text { There is no way I'll consider it any } \\
\text { time soon }\end{array}$ & 25 & 4.6 & 4.16 & 0.94 \\
\hline Don't know & 40 & 5.6 & 6.66 & 0.00 \\
\hline Total for Q17 & 601 & 0.0 & 100 & \\
\hline
\end{tabular}

Q18A. Teachers and schools

\begin{tabular}{|l|c|c|c|c|}
\hline Never & 398 & 10.6 & 66.2 & 1.77 \\
\hline Sometimes & 158 & 10.1 & 26.3 & 1.68 \\
\hline
\end{tabular}




\begin{tabular}{|l|c|c|c|c|}
\hline \multicolumn{1}{|c|}{ Question/Metric } & Frequency & $\begin{array}{c}\text { Standard } \\
\text { Deviation of } \\
\text { Frequency }\end{array}$ & Percent & $\begin{array}{c}\text { Standard Error of } \\
\text { Percent }\end{array}$ \\
\hline Frequently & 39 & 5.6 & 6.49 & 0.93 \\
\hline Don't know & 6 & 2.3 & 1.00 & 0.38 \\
\hline Total for Q18A & 601 & 0.0 & 100 & 0.00 \\
\hline
\end{tabular}

\section{Q18B. Friends and family members}

\begin{tabular}{|l|c|c|c|c|}
\hline Never & 256 & 11.3 & 42.6 & 1.88 \\
\hline Sometimes & 283 & 11.4 & 47.1 & 1.90 \\
\hline Frequently & 57 & 6.7 & 9.48 & 1.11 \\
\hline Don't know & 5 & 2.1 & 0.83 & 0.35 \\
\hline Total for Q18B & 601 & 0.0 & 100 & 0.00 \\
\hline
\end{tabular}

\section{Q18C. Environmental and conservation groups}

\begin{tabular}{|l|c|c|c|c|}
\hline Never & 168 & 10.3 & 28.0 & 1.71 \\
\hline Sometimes & 312 & 11.5 & 51.9 & 1.91 \\
\hline Frequently & 114 & 9.0 & 19.0 & 1.50 \\
\hline Don't know & 7 & 2.4 & 1.16 & 0.40 \\
\hline Total for Q18C & 601 & 0.0 & 100 & 0.00 \\
\hline
\end{tabular}

Q18D. Utility companies or brokers, for example, gas or electricity providers

\begin{tabular}{|l|c|c|c|c|}
\hline Never & 83 & 7.7 & 13.8 & 1.29 \\
\hline Sometimes & 268 & 11.3 & 44.6 & 1.87 \\
\hline Frequently & 241 & 10.8 & 40.1 & 1.80 \\
\hline Don't know & 9 & 2.7 & 1.50 & 0.46 \\
\hline Total for Q18D & 601 & 0.0 & 100 & 0.00 \\
\hline
\end{tabular}

Q18E. Industry or trade associations or non-profit organizations

\begin{tabular}{|l|l|l|l|l|}
\hline Never & 88 & 8.0 & 14.6 & 1.34 \\
\hline
\end{tabular}




\begin{tabular}{|l|c|c|c|c|}
\hline \multicolumn{1}{|c|}{ Question/Metric } & Frequency & $\begin{array}{c}\text { Standard } \\
\text { Deviation of } \\
\text { Frequency }\end{array}$ & Percent & $\begin{array}{c}\text { Standard Error of } \\
\text { Percent }\end{array}$ \\
\hline Sometimes & 246 & 11.3 & 40.9 & 1.88 \\
\hline Frequently & 259 & 11.4 & 43.1 & 1.89 \\
\hline Don't know & 8 & 2.6 & 1.33 & 0.44 \\
\hline Total for Q18E & 601 & 0.0 & 100 & 0.00 \\
\hline
\end{tabular}

\section{Q18F. Federal government}

\begin{tabular}{|l|c|c|c|c|}
\hline Never & 100 & 8.6 & 16.6 & 1.42 \\
\hline Sometimes & 331 & 11.4 & 55.1 & 1.90 \\
\hline Frequently & 162 & 10.2 & 27.0 & 1.69 \\
\hline Don't know & 8 & 2.6 & 1.33 & 0.44 \\
\hline Total for Q18F & 601 & 0.0 & 100 & 0.00 \\
\hline
\end{tabular}

\section{Q18G. State government}

\begin{tabular}{|l|c|c|c|c|}
\hline Never & 131 & 9.4 & 21.8 & 1.57 \\
\hline Sometimes & 336 & 11.4 & 55.9 & 1.90 \\
\hline Frequently & 127 & 9.4 & 21.1 & 1.56 \\
\hline Don't know & 7 & 2.5 & 1.16 & 0.41 \\
\hline Total for Q18G & 601 & 0.0 & 100 & 0.00 \\
\hline
\end{tabular}

\section{Q18H. Local government}

\begin{tabular}{|l|c|c|c|c|}
\hline Never & 260 & 11.2 & 43.3 & 1.87 \\
\hline Sometimes & 268 & 11.4 & 44.6 & 1.89 \\
\hline Frequently & 65 & 7.1 & 10.8 & 1.18 \\
\hline Don't know & 8 & 2.6 & 1.33 & 0.44 \\
\hline Total for Q18H & 601 & 0.0 & 100 & 0.00 \\
\hline
\end{tabular}

\section{Q19A. Television}




\begin{tabular}{|l|c|c|c|c|}
\hline \multicolumn{1}{|c|}{ Question/Metric } & Frequency & $\begin{array}{c}\text { Standard } \\
\text { Deviation of } \\
\text { Frequency }\end{array}$ & Percent & $\begin{array}{c}\text { Standard Error of } \\
\text { Percent }\end{array}$ \\
\hline Never & 133 & 9.5 & 22.1 & 1.59 \\
\hline Sometimes & 381 & 11.1 & 63.4 & 1.84 \\
\hline Frequently & 86 & 8.0 & 14.3 & 1.33 \\
\hline Don't know & 1 & 0.9 & 0.17 & 0.15 \\
\hline Total for Q19A & 601 & 0.0 & 100 & 0.00 \\
\hline
\end{tabular}

\section{Q19B. Radio}

\begin{tabular}{|l|c|c|c|c|}
\hline Never & 247 & 11.3 & 41.1 & 1.88 \\
\hline Sometimes & 299 & 11.5 & 49.8 & 1.91 \\
\hline Frequently & 54 & 6.6 & 8.99 & 1.09 \\
\hline Don't know & 1 & 0.9 & 0.17 & 0.15 \\
\hline Total for Q19B & 601 & 0.0 & 100 & 0.00 \\
\hline
\end{tabular}

\section{Q19C. The Internet}

\begin{tabular}{|l|c|c|c|c|}
\hline Never & 68 & 7.2 & 11.3 & 1.20 \\
\hline Sometimes & 243 & 11.2 & 40.4 & 1.87 \\
\hline Frequently & 288 & 11.4 & 47.9 & 1.89 \\
\hline Don't know & 2 & 1.3 & 0.33 & 0.22 \\
\hline Total for Q19C & 601 & 0.0 & 100 & 0.00 \\
\hline
\end{tabular}

\section{Q19D. Newspapers and general interest magazines}

\begin{tabular}{|l|c|c|c|c|}
\hline Never & 88 & 8.1 & 14.6 & 1.35 \\
\hline Sometimes & 358 & 11.3 & 59.6 & 1.88 \\
\hline Frequently & 154 & 10.0 & 25.6 & 1.67 \\
\hline Don't know & 1 & 0.9 & 0.17 & 0.15 \\
\hline Total for Q19D & 601 & 0.0 & 100 & 0.00 \\
\hline
\end{tabular}




\begin{tabular}{|l|c|c|c|c|}
\hline \multicolumn{1}{|c|}{ Question/Metric } & \multicolumn{1}{c|}{$\begin{array}{c}\text { Standard } \\
\text { Deviation of } \\
\text { Frequency }\end{array}$} & Percent & $\begin{array}{c}\text { Standard Error of } \\
\text { Percent }\end{array}$ \\
\hline Q19E. Science and technology magazines and journals & Frequency & \multicolumn{2}{|c|}{} \\
\hline Never & 153 & 9.6 & 25.5 & 1.60 \\
\hline Sometimes & 275 & 11.4 & 45.8 & 1.90 \\
\hline Frequently & 170 & 10.3 & 28.3 & 1.71 \\
\hline Don't know & 3 & 1.6 & 0.50 & 0.27 \\
\hline Total for Q19E & 601 & 0.0 & 100 & 0.00 \\
\hline & & & & \\
\hline Q19F. Business or trade magazines & & & & 1.21 \\
\hline Never & 70 & 7.3 & 1.6 & 1.91 \\
\hline Sometimes & 288 & 11.5 & 47.9 & 1.87 \\
\hline Frequently & 241 & 11.3 & 40.1 & 0.21 \\
\hline Don't know & 2 & 1.3 & 0.33 & 0.00 \\
\hline Total for Q19F & 601 & 0.0 & 100 & \\
\hline & & & & \\
\hline
\end{tabular}

Q20. Have you received information at your workplace concerning hydrogen/fuel cells?

\begin{tabular}{|l|c|c|c|c|}
\hline Yes & 177 & 10.5 & 29.5 & 1.74 \\
\hline No & 410 & 10.7 & 68.2 & 1.78 \\
\hline Don't know & 14 & 3.5 & 2.33 & 0.58 \\
\hline Total for Q20 & 601 & 0.0 & 100 & 0.00 \\
\hline
\end{tabular}

Q21. Would information about hydrogen and fuel cell technologies be valuable to you?

\begin{tabular}{|l|c|c|c|c|}
\hline Yes & 310 & 8.5 & 73.1 & 2.02 \\
\hline No & 83 & 7.6 & 19.6 & 1.80 \\
\hline Don't know & 31 & 5.0 & 7.31 & 1.18 \\
\hline Total for Q21 & 424 & 0.0 & 100 & 0.00 \\
\hline
\end{tabular}

Q22. Would a "Hydrogen 101" class, or training at a conference, be of value to you?

$\begin{array}{lll}\text { Hydrogen Knowledge and Opinions Surveys } & \text { C-67 April 21, } 2010\end{array}$ 


\begin{tabular}{|l|c|c|c|c|}
\hline \multicolumn{1}{|c|}{ Question/Metric } & Frequency & $\begin{array}{c}\text { Standard } \\
\text { Deviation of } \\
\text { Frequency }\end{array}$ & Percent & $\begin{array}{c}\text { Standard Error of } \\
\text { Percent }\end{array}$ \\
\hline Yes & 425 & 10.4 & 70.7 & 1.73 \\
\hline No & 148 & 9.9 & 24.6 & 1.64 \\
\hline Don't know & 28 & 4.8 & 4.66 & 0.80 \\
\hline Total for Q22 & 601 & 0.0 & 100 & 0.00 \\
\hline
\end{tabular}

\section{Q23. Which class format is MOST useful to you?}

\begin{tabular}{|l|c|c|c|c|}
\hline In-person class at a local facility & 129 & 8.9 & 30.4 & 2.08 \\
\hline $\begin{array}{l}\text { In-person class in conjunction with } \\
\text { a relevant conference or event }\end{array}$ & 134 & 9.0 & 31.5 & 2.12 \\
\hline Web-based class & 142 & 9.0 & 33.4 & 2.11 \\
\hline Don't know & 20 & 4.1 & 4.71 & 0.96 \\
\hline Total for Q23 & 425 & 0.0 & 100 & 0.00 \\
\hline
\end{tabular}

Q24. Does your organization use hydrogen and/or fuel cells for any purpose?

\begin{tabular}{|l|c|c|c|c|}
\hline Yes & 47 & 6.2 & 7.82 & 1.03 \\
\hline No & 521 & 7.8 & 86.7 & 1.30 \\
\hline Don't know & 33 & 5.2 & 5.49 & 0.87 \\
\hline Total for Q24 & 601 & 0.0 & 100 & 0.00 \\
\hline
\end{tabular}

Q25. What is the PRIMARY function of the hydrogen and/or fuel cells used by your organizat ion?

\begin{tabular}{|l|c|c|c|c|}
\hline To power buses & 3 & 1.5 & 6.38 & 3.30 \\
\hline $\begin{array}{l}\text { To power vehicles other than } \\
\text { buses }\end{array}$ & 16 & 3.0 & 34.0 & 6.29 \\
\hline $\begin{array}{l}\text { To provide stationary on-site } \\
\text { power }\end{array}$ & 7 & 2.3 & 14.9 & 4.89 \\
\hline $\begin{array}{l}\text { To provide power for small } \\
\text { portable equipment }\end{array}$ & 2 & 1.3 & 4.26 & 2.79 \\
\hline To provide back-up power & 1 & 0.9 & 2.13 & 1.90 \\
\hline
\end{tabular}




\begin{tabular}{|l|c|c|c|c|}
\hline \multicolumn{1}{|c|}{ Question/Metric } & Frequency & $\begin{array}{c}\text { Standard } \\
\text { Deviation of } \\
\text { Frequency }\end{array}$ & Percent & $\begin{array}{c}\text { Standard Error of } \\
\text { Percent }\end{array}$ \\
\hline Other & 15 & 2.7 & 31.9 & 5.64 \\
\hline Don't know/refused & 3 & 1.6 & 6.38 & 3.45 \\
\hline Total for Q25 & 47 & 0.0 & 100 & 0.00 \\
\hline
\end{tabular}

Q26. Does your organization have plans to use hydrogen and/or fuel cells in the future?

\begin{tabular}{|l|c|c|c|c|}
\hline Yes & 77 & 7.5 & 13.9 & 1.36 \\
\hline No & 350 & 10.6 & 63.2 & 1.91 \\
\hline Don't know & 127 & 9.3 & 22.9 & 1.67 \\
\hline Total for Q26 & 554 & 0.0 & 100 & 0.00 \\
\hline
\end{tabular}

Q27. What is the time frame for plans to use hydrogen and/or fuel cells?

\begin{tabular}{|l|c|c|c|c|}
\hline Within the next year & 4 & 1.8 & 5.19 & 2.31 \\
\hline $1-5$ years & 29 & 4.0 & 37.7 & 5.13 \\
\hline Over 5 years & 21 & 3.7 & 27.3 & 4.80 \\
\hline Don't know & 23 & 3.7 & 29.9 & 4.77 \\
\hline Total for Q27 & 77 & 0.0 & 100 & 0.00 \\
\hline
\end{tabular}




\section{End User Survey Technical Question Summary}

\begin{tabular}{|c|c|c|c|c|}
\hline Question & $\begin{array}{c}\text { Number } \\
\text { of } \\
\text { Responses }\end{array}$ & $\begin{array}{l}\text { Percent } \\
\text { Correct }\end{array}$ & $\begin{array}{l}\text { Lower } 95 \% \\
\text { Confidence } \\
\text { Bound }\end{array}$ & $\begin{array}{l}\text { Upper } 95 \% \\
\text { Confidence } \\
\text { Bound }\end{array}$ \\
\hline 5A. Hydrogen gas is toxic (false) & 601 & 55.24 & 51.54 & 58.95 \\
\hline $\begin{array}{l}\text { 5B. Fuel cells produce electricity through hydrogen } \\
\text { combustion (false) }\end{array}$ & 601 & 22.46 & 19.35 & 25.57 \\
\hline 5C. Hydrogen is lighter than air (true) & 601 & 63.39 & 59.79 & 67.00 \\
\hline 5D. Hydrogen has a distinct odor (false) & 601 & 60.07 & 56.42 & 63.71 \\
\hline $\begin{array}{l}\text { 7. In which state or condition can hydrogen be stored? } \\
\text { (chemical compound, liquid) }\end{array}$ & 601 & 45.76 & 42.02 & 49.50 \\
\hline $\begin{array}{l}\text { 8. When using pure hydrogen, fuel cell vehicles } \\
\text { generate electricity, water, and what else? (heat) }\end{array}$ & 601 & 31.45 & 27.96 & 34.93 \\
\hline $\begin{array}{l}\text { 9. Hydrogen can be produced using which of the } \\
\text { following sources of energy? (natural gas, sunlight, } \\
\text { organic matter) }\end{array}$ & 601 & 42.76 & 39.05 & 46.47 \\
\hline $\begin{array}{l}\text { 12. Hydrogen is too dangerous for everyday use by the } \\
\text { general public (false) }\end{array}$ & 601 & 62.06 & 58.42 & 65.70 \\
\hline Overall Average & 601 & 47.90 & 45.85 & 49.95 \\
\hline
\end{tabular}




\section{C.5. SUMMARY OF RESPONSES TO THE SAFETY AND CODES OFFICIALS SURVEY}

\begin{tabular}{|c|c|c|c|c|}
\hline Question/Metric & Frequency & $\begin{array}{c}\text { Standard } \\
\text { Deviation } \\
\text { of Frequency }\end{array}$ & Percent & $\begin{array}{c}\text { Standard } \\
\text { Error of } \\
\text { Percent }\end{array}$ \\
\hline \multicolumn{5}{|l|}{ Above Average? } \\
\hline Score Below Average & 81 & 2.9 & 54.4 & 1.95 \\
\hline Score Above Average & 68 & 2.9 & 45.6 & 1.95 \\
\hline Total for Above Average? & 149 & 0.0 & 100 & 0.00 \\
\hline \multicolumn{5}{|c|}{ Q1. Familiarity with hydrogen/FC technologies } \\
\hline Not at all familiar & 22 & 2.0 & 14.8 & 1.33 \\
\hline Slightly familiar & 93 & 2.7 & 62.4 & 1.83 \\
\hline Familiar & 33 & 2.4 & 22.1 & 1.58 \\
\hline Very familiar & 1 & 0.5 & 0.67 & 0.34 \\
\hline Total for Q1 & 149 & 0.0 & 100 & 0.00 \\
\hline \multicolumn{5}{|l|}{ Q2A. Hydrogen gas is toxic } \\
\hline True & 40 & 2.6 & 26.8 & 1.74 \\
\hline False & 80 & 2.9 & 53.7 & 1.93 \\
\hline Don't know & 29 & 2.3 & 19.5 & 1.52 \\
\hline Total for Q2A & 149 & 0.0 & 100 & 0.00 \\
\hline \multicolumn{5}{|c|}{ Q2B. Fuel cells produce electricity through hydrogen combustion } \\
\hline True & 57 & 2.8 & 38.3 & 1.86 \\
\hline False & 30 & 2.3 & 20.1 & 1.55 \\
\hline Don't know & 62 & 2.8 & 41.6 & 1.88 \\
\hline Total for Q2B & 149 & 0.0 & 100 & 0.00 \\
\hline
\end{tabular}




\begin{tabular}{|c|c|c|c|c|}
\hline Question/Metric & Frequency & $\begin{array}{c}\text { Standard } \\
\text { Deviation } \\
\text { of Frequency }\end{array}$ & Percent & $\begin{array}{c}\text { Standard } \\
\text { Error of } \\
\text { Percent }\end{array}$ \\
\hline True & 109 & 2.5 & 73.2 & 1.70 \\
\hline False & 9 & 1.4 & 6.04 & 0.91 \\
\hline Don't know & 31 & 2.3 & 20.8 & 1.55 \\
\hline Total for Q2C & 149 & 0.0 & 100 & 0.00 \\
\hline \multicolumn{5}{|c|}{ Q2D. Hydrogen has a distinct odor } \\
\hline True & 12 & 1.6 & 8.05 & 1.04 \\
\hline False & 94 & 2.8 & 63.1 & 1.86 \\
\hline Don't know & 43 & 2.6 & 28.9 & 1.74 \\
\hline Total for Q2D & 149 & 0.0 & 100 & 0.00 \\
\hline \multicolumn{5}{|c|}{ Q3. Which of the following can fuel cells provide power to? } \\
\hline Your home & 4 & 1.0 & 2.68 & 0.67 \\
\hline Your car & 51 & 2.8 & 34.2 & 1.86 \\
\hline All of these & 85 & 2.9 & 57.0 & 1.93 \\
\hline None of these & 3 & 0.9 & 2.01 & 0.58 \\
\hline Don't know & 6 & 1.2 & 4.03 & 0.78 \\
\hline Total for Q3 & 149 & 0.0 & 100 & 0.00 \\
\hline \multicolumn{5}{|c|}{ Q4. In which state or condition can hydrogen be stored? } \\
\hline Chemical compound & 4 & 1.0 & 2.68 & 0.67 \\
\hline Liquid & 42 & 2.6 & 28.2 & 1.73 \\
\hline Both of these & 65 & 2.9 & 43.6 & 1.93 \\
\hline Neither of these & 7 & 1.2 & 4.70 & 0.81 \\
\hline Don't know & 31 & 2.3 & 20.8 & 1.56 \\
\hline Total for Q4 & 149 & 0.0 & 100 & 0.00 \\
\hline
\end{tabular}




\begin{tabular}{|c|c|c|c|c|}
\hline Question/Metric & Frequency & $\begin{array}{c}\text { Standard } \\
\text { Deviation } \\
\text { of Frequency }\end{array}$ & Percent & $\begin{array}{c}\text { Standard } \\
\text { Error of } \\
\text { Percent }\end{array}$ \\
\hline \multicolumn{5}{|c|}{ Q5. When using pure hydrogen, fuel cell vehicles generate electricity, water, and what else? } \\
\hline Carbon dioxide & 18 & 1.9 & 12.1 & 1.28 \\
\hline Nitrous oxides & 1 & 0.5 & 0.67 & 0.34 \\
\hline Heat & 54 & 2.8 & 36.2 & 1.89 \\
\hline All of these & 23 & 2.1 & 15.4 & 1.43 \\
\hline Don't know & 53 & 2.8 & 35.6 & 1.87 \\
\hline Total for Q5 & 149 & 0.0 & 100 & 0.00 \\
\hline \multicolumn{5}{|c|}{ Q6. Hydrogen can be produced using which of the following sources of energy? } \\
\hline Natural gas & 10 & 1.5 & 6.71 & 1.00 \\
\hline Sunlight & 2 & 0.7 & 1.34 & 0.45 \\
\hline Organic matter & 13 & 1.6 & 8.72 & 1.07 \\
\hline All of these & 72 & 2.9 & 48.3 & 1.93 \\
\hline Don't know & 52 & 2.8 & 34.9 & 1.87 \\
\hline Total for Q6 & 149 & 0.0 & 100 & 0.00 \\
\hline \multicolumn{5}{|l|}{ Q7A. First } \\
\hline Safety & 55 & 2.8 & 36.9 & 1.88 \\
\hline Low cost & 51 & 2.7 & 34.2 & 1.80 \\
\hline Environmental impact & 11 & 1.5 & 7.38 & 1.00 \\
\hline Convenience & 10 & 1.5 & 6.71 & 0.97 \\
\hline Performance & 21 & 2.0 & 14.1 & 1.36 \\
\hline Don't know & 1 & 0.4 & 0.67 & 0.27 \\
\hline Total for Q7A & 149 & 0.0 & 100 & 0.00 \\
\hline \multicolumn{5}{|l|}{ Q7B. Second } \\
\hline Safety & 38 & 2.5 & 25.7 & 1.70 \\
\hline
\end{tabular}




\begin{tabular}{|c|c|c|c|c|}
\hline Question/Metric & Frequency & $\begin{array}{c}\text { Standard } \\
\text { Deviation } \\
\text { of Frequency }\end{array}$ & Percent & $\begin{array}{c}\text { Standard } \\
\text { Error of } \\
\text { Percent }\end{array}$ \\
\hline Low cost & 40 & 2.6 & 27.0 & 1.73 \\
\hline Environmental impact & 24 & 2.1 & 16.2 & 1.44 \\
\hline Convenience & 17 & 1.9 & 11.5 & 1.28 \\
\hline Performance & 29 & 2.3 & 19.6 & 1.58 \\
\hline Total for Q7B & 148 & 0.0 & 100 & 0.00 \\
\hline \multicolumn{5}{|l|}{ Q7C. Third } \\
\hline Safety & 26 & 2.2 & 17.6 & 1.49 \\
\hline Low cost & 33 & 2.4 & 22.3 & 1.63 \\
\hline Environmental impact & 19 & 2.0 & 12.8 & 1.34 \\
\hline Convenience & 32 & 2.4 & 21.6 & 1.59 \\
\hline Performance & 38 & 2.5 & 25.7 & 1.68 \\
\hline Total for Q7C & 148 & 0.0 & 100 & 0.00 \\
\hline \multicolumn{5}{|l|}{ Q7D. Fourth } \\
\hline Safety & 19 & 1.8 & 12.8 & 1.24 \\
\hline Low cost & 16 & 1.9 & 10.8 & 1.25 \\
\hline Environmental impact & 39 & 2.5 & 26.4 & 1.69 \\
\hline Convenience & 41 & 2.6 & 27.7 & 1.78 \\
\hline Performance & 33 & 2.4 & 22.3 & 1.65 \\
\hline Total for Q7D & 148 & 0.0 & 100 & 0.00 \\
\hline \multicolumn{5}{|c|}{ Q8. How would you feel if your local gas station also sold hydrogen? } \\
\hline Frightened & 2 & 0.6 & 1.34 & 0.41 \\
\hline Uneasy & 16 & 1.8 & 10.7 & 1.19 \\
\hline At ease & 58 & 2.9 & 38.9 & 1.92 \\
\hline Pleased & 60 & 2.8 & 40.3 & 1.90 \\
\hline
\end{tabular}




\begin{tabular}{|c|c|c|c|c|}
\hline Question/Metric & Frequency & $\begin{array}{c}\text { Standard } \\
\text { Deviation } \\
\text { of Frequency }\end{array}$ & Percent & $\begin{array}{c}\text { Standard } \\
\text { Error of } \\
\text { Percent }\end{array}$ \\
\hline Don't know & 13 & 1.7 & 8.72 & 1.15 \\
\hline Total for Q8 & 149 & 0.0 & 100 & 0.00 \\
\hline \multicolumn{5}{|c|}{ Q9. Hydrogen is too dangerous for everyday use by the general public? } \\
\hline True & 16 & 1.8 & 10.7 & 1.22 \\
\hline False & 110 & 2.5 & 73.8 & 1.69 \\
\hline Don't know & 23 & 2.0 & 15.4 & 1.37 \\
\hline Total for Q9 & 149 & 0.0 & 100 & 0.00 \\
\hline \multicolumn{5}{|c|}{ Q10A. Using hydrogen will reduce U.S. dependence on foreign oil } \\
\hline Disagree & 8 & 1.4 & 5.37 & 0.91 \\
\hline Are neutral & 6 & 1.1 & 4.03 & 0.77 \\
\hline Agree & 127 & 2.1 & 85.2 & 1.38 \\
\hline No opinion & 8 & 1.3 & 5.37 & 0.85 \\
\hline Total for Q10A & 149 & 0.0 & 100 & 0.00 \\
\hline \multicolumn{5}{|c|}{ Q10B. Using hydrogen will reduce emissions and improve air quality } \\
\hline Disagree & 5 & 1.0 & 3.36 & 0.69 \\
\hline Are neutral & 5 & 1.0 & 3.36 & 0.69 \\
\hline Agree & 123 & 2.2 & 82.6 & 1.50 \\
\hline No opinion & 16 & 1.8 & 10.7 & 1.23 \\
\hline Total for Q10B & 149 & 0.0 & 100 & 0.00 \\
\hline \multicolumn{5}{|c|}{ Q10C. Hydrogen is as safe to use in my car as gasoline and diesel fuels } \\
\hline Disagree & 20 & 2.0 & 13.4 & 1.36 \\
\hline Are neutral & 3 & 0.9 & 2.01 & 0.58 \\
\hline Agree & 95 & 2.8 & 63.8 & 1.87 \\
\hline
\end{tabular}




\begin{tabular}{|c|c|c|c|c|}
\hline Question/Metric & Frequency & $\begin{array}{c}\text { Standard } \\
\text { Deviation } \\
\text { of Frequency }\end{array}$ & Percent & $\begin{array}{c}\text { Standard } \\
\text { Error of } \\
\text { Percent }\end{array}$ \\
\hline No opinion & 31 & 2.3 & 20.8 & 1.55 \\
\hline Total for Q10C & 149 & 0.0 & 100 & 0.00 \\
\hline \multicolumn{5}{|c|}{ Q13A. Personal cars and trucks } \\
\hline Not as safe & 23 & 2.1 & 15.4 & 1.43 \\
\hline Equally as safe & 89 & 2.9 & 59.7 & 1.93 \\
\hline Safer & 16 & 1.8 & 10.7 & 1.20 \\
\hline No opinion & 21 & 2.0 & 14.1 & 1.37 \\
\hline Total for Q13A & 149 & 0.0 & 100 & 0.00 \\
\hline \multicolumn{5}{|c|}{ Q13B. Buses and commercial vehicles } \\
\hline Not as safe & 14 & 1.7 & 9.40 & 1.17 \\
\hline Equally as safe & 103 & 2.7 & 69.1 & 1.82 \\
\hline Safer & 13 & 1.6 & 8.72 & 1.07 \\
\hline No opinion & 19 & 1.9 & 12.8 & 1.31 \\
\hline Total for Q13B & 149 & 0.0 & 100 & 0.00 \\
\hline \multicolumn{5}{|l|}{ Q13C. Large power plants } \\
\hline Not as safe & 5 & 1.1 & 3.36 & 0.75 \\
\hline Equally as safe & 85 & 2.9 & 57.0 & 1.93 \\
\hline Safer & 25 & 2.2 & 16.8 & 1.46 \\
\hline No opinion & 34 & 2.4 & 22.8 & 1.62 \\
\hline Total for Q13C & 149 & 0.0 & 100 & 0.00 \\
\hline \multicolumn{5}{|c|}{ Q13D. Small portable devices such as laptop computers or cell phones } \\
\hline Not as safe & 29 & 2.3 & 19.5 & 1.57 \\
\hline Equally as safe & 42 & 2.6 & 28.2 & 1.77 \\
\hline
\end{tabular}




\begin{tabular}{|c|c|c|c|c|}
\hline Question/Metric & Frequency & $\begin{array}{c}\text { Standard } \\
\text { Deviation } \\
\text { of Frequency }\end{array}$ & Percent & $\begin{array}{c}\text { Standard } \\
\text { Error of } \\
\text { Percent }\end{array}$ \\
\hline Safer & 8 & 1.3 & 5.37 & 0.85 \\
\hline No opinion & 70 & 2.9 & 47.0 & 1.94 \\
\hline Total for Q13D & 149 & 0.0 & 100 & 0.00 \\
\hline \multicolumn{5}{|c|}{ Q13E. Onsite power for the home } \\
\hline Not as safe & 19 & 1.9 & 12.8 & 1.31 \\
\hline Equally as safe & 84 & 2.9 & 56.4 & 1.95 \\
\hline Safer & 13 & 1.6 & 8.72 & 1.10 \\
\hline No opinion & 33 & 2.4 & 22.1 & 1.63 \\
\hline Total for Q13E & 149 & 0.0 & 100 & 0.00 \\
\hline \multicolumn{5}{|c|}{ Q13F. Onsite power for buildings such as hospitals and schools } \\
\hline Not as safe & 12 & 1.6 & 8.05 & 1.09 \\
\hline Equally as safe & 88 & 2.9 & 59.1 & 1.94 \\
\hline Safer & 15 & 1.8 & 10.1 & 1.18 \\
\hline No opinion & 34 & 2.5 & 22.8 & 1.65 \\
\hline Total for Q13F & 149 & 0.0 & 100 & 0.00 \\
\hline \multicolumn{5}{|c|}{ Q14A. Teachers and schools } \\
\hline Never & 89 & 2.9 & 59.7 & 1.93 \\
\hline Sometimes & 50 & 2.8 & 33.6 & 1.86 \\
\hline Frequently & 9 & 1.4 & 6.04 & 0.91 \\
\hline Don't know & 1 & 0.4 & 0.67 & 0.27 \\
\hline Total for Q14A & 149 & 0.0 & 100 & 0.00 \\
\hline \multicolumn{5}{|c|}{ Q14B. Friends and family members } \\
\hline Never & 52 & 2.8 & 34.9 & 1.86 \\
\hline
\end{tabular}




\begin{tabular}{|c|c|c|c|c|}
\hline Question/Metric & Frequency & $\begin{array}{c}\text { Standard } \\
\text { Deviation } \\
\text { of Frequency }\end{array}$ & Percent & $\begin{array}{c}\text { Standard } \\
\text { Error of } \\
\text { Percent }\end{array}$ \\
\hline Sometimes & 74 & 2.9 & 49.7 & 1.95 \\
\hline Frequently & 21 & 2.0 & 14.1 & 1.36 \\
\hline Don't know & 2 & 0.6 & 1.34 & 0.41 \\
\hline Total for Q14B & 149 & 0.0 & 100 & 0.00 \\
\hline \multicolumn{5}{|c|}{ Q14C. Environmental and conservation groups } \\
\hline Never & 51 & 2.8 & 34.2 & 1.85 \\
\hline Sometimes & 79 & 2.9 & 53.0 & 1.97 \\
\hline Frequently & 18 & 1.9 & 12.1 & 1.27 \\
\hline Don't know & 1 & 0.5 & 0.67 & 0.30 \\
\hline Total for Q14C & 149 & 0.0 & 100 & 0.00 \\
\hline \multicolumn{5}{|c|}{ Q14D. Utility companies or brokers, for example, gas or electricity providers } \\
\hline Never & 19 & 1.9 & 12.8 & 1.26 \\
\hline Sometimes & 79 & 2.9 & 53.0 & 1.95 \\
\hline Frequently & 49 & 2.7 & 32.9 & 1.83 \\
\hline Don't know & 2 & 0.6 & 1.34 & 0.41 \\
\hline Total for Q14D & 149 & 0.0 & 100 & 0.00 \\
\hline \multicolumn{5}{|c|}{ Q14E. Industry or trade associations or non-profit organizations } \\
\hline Never & 20 & 1.9 & 13.4 & 1.30 \\
\hline Sometimes & 67 & 2.9 & 45.0 & 1.95 \\
\hline Frequently & 61 & 2.9 & 40.9 & 1.92 \\
\hline Don't know & 1 & 0.5 & 0.67 & 0.30 \\
\hline Total for Q14E & 149 & 0.0 & 100 & 0.00 \\
\hline
\end{tabular}




\begin{tabular}{|c|c|c|c|c|}
\hline Question/Metric & Frequency & $\begin{array}{c}\text { Standard } \\
\text { Deviation } \\
\text { of Frequency }\end{array}$ & Percent & $\begin{array}{c}\text { Standard } \\
\text { Error of } \\
\text { Percent }\end{array}$ \\
\hline Never & 19 & 2.0 & 12.8 & 1.31 \\
\hline Sometimes & 83 & 2.9 & 55.7 & 1.94 \\
\hline Frequently & 46 & 2.7 & 30.9 & 1.80 \\
\hline Don't know & 1 & 0.5 & 0.67 & 0.30 \\
\hline Total for Q14F & 149 & 0.0 & 100 & 0.00 \\
\hline \multicolumn{5}{|l|}{ Q14G. State government } \\
\hline Never & 19 & 2.0 & 12.8 & 1.31 \\
\hline Sometimes & 80 & 2.9 & 53.7 & 1.96 \\
\hline Frequently & 49 & 2.7 & 32.9 & 1.83 \\
\hline Don't know & 1 & 0.5 & 0.67 & 0.30 \\
\hline Total for Q14G & 149 & 0.0 & 100 & 0.00 \\
\hline \multicolumn{5}{|l|}{ Q14H. Local government } \\
\hline Never & 44 & 2.7 & 29.5 & 1.80 \\
\hline Sometimes & 68 & 2.9 & 45.6 & 1.95 \\
\hline Frequently & 36 & 2.5 & 24.2 & 1.67 \\
\hline Don't know & 1 & 0.5 & 0.67 & 0.30 \\
\hline Total for Q14H & 149 & 0.0 & 100 & 0.00 \\
\hline \multicolumn{5}{|l|}{ Q15A. Television } \\
\hline Never & 26 & 2.2 & 17.4 & 1.46 \\
\hline Sometimes & 95 & 2.8 & 63.8 & 1.88 \\
\hline Frequently & 28 & 2.3 & 18.8 & 1.53 \\
\hline Total for Q15A & 149 & 0.0 & 100 & 0.00 \\
\hline
\end{tabular}




\begin{tabular}{|c|c|c|c|c|}
\hline Question/Metric & Frequency & $\begin{array}{c}\text { Standard } \\
\text { Deviation } \\
\text { of Frequency }\end{array}$ & Percent & $\begin{array}{c}\text { Standard } \\
\text { Error of } \\
\text { Percent }\end{array}$ \\
\hline Never & 62 & 2.8 & 41.6 & 1.89 \\
\hline Sometimes & 71 & 2.8 & 47.7 & 1.89 \\
\hline Frequently & 16 & 1.8 & 10.7 & 1.18 \\
\hline Total for Q15B & 149 & 0.0 & 100 & 0.00 \\
\hline \multicolumn{5}{|l|}{ Q15C. The Internet } \\
\hline Never & 19 & 1.9 & 12.8 & 1.30 \\
\hline Sometimes & 70 & 2.9 & 47.0 & 1.95 \\
\hline Frequently & 60 & 2.9 & 40.3 & 1.91 \\
\hline Total for Q15C & 149 & 0.0 & 100 & 0.00 \\
\hline \multicolumn{5}{|c|}{ Q15D. Newspapers and general interest magazines } \\
\hline Never & 26 & 2.2 & 17.4 & 1.47 \\
\hline Sometimes & 92 & 2.8 & 61.7 & 1.89 \\
\hline Frequently & 31 & 2.4 & 20.8 & 1.60 \\
\hline Total for Q15D & 149 & 0.0 & 100 & 0.00 \\
\hline \multicolumn{5}{|c|}{ Q15E. Science and technology magazines and journals } \\
\hline Never & 35 & 2.5 & 23.5 & 1.66 \\
\hline Sometimes & 80 & 2.9 & 53.7 & 1.96 \\
\hline Frequently & 34 & 2.4 & 22.8 & 1.61 \\
\hline Total for Q15E & 149 & 0.0 & 100 & 0.00 \\
\hline \multicolumn{5}{|c|}{ Q15F. Business or trade magazines } \\
\hline Never & 20 & 2.0 & 13.4 & 1.36 \\
\hline Sometimes & 85 & 2.9 & 57.0 & 1.95 \\
\hline Frequently & 44 & 2.7 & 29.5 & 1.79 \\
\hline
\end{tabular}




\begin{tabular}{|c|c|c|c|c|}
\hline Question/Metric & Frequency & $\begin{array}{c}\text { Standard } \\
\text { Deviation } \\
\text { of Frequency }\end{array}$ & Percent & $\begin{array}{l}\text { Standard } \\
\text { Error of } \\
\text { Percent }\end{array}$ \\
\hline Total for Q15F & 149 & 0.0 & 100 & 0.00 \\
\hline \multicolumn{5}{|c|}{ Q25A. Have you ever been involved in permitting a...hydrogen fuel cell project? } \\
\hline Yes & 19 & 1.9 & 12.8 & 1.28 \\
\hline No & 130 & 1.9 & 87.2 & 1.28 \\
\hline Total for Q25A & 149 & 0.0 & 100 & 0.00 \\
\hline \multicolumn{5}{|c|}{ Q25B. Do you know anyone...involved in permitting a...hydrogen fuel cell project? } \\
\hline Yes & 36 & 2.4 & 24.2 & 1.62 \\
\hline No & 107 & 2.5 & 71.8 & 1.67 \\
\hline Don't know & 6 & 1.1 & 4.03 & 0.71 \\
\hline Total for Q25B & 149 & 0.0 & 100 & 0.00 \\
\hline \multicolumn{5}{|c|}{ Q26. Have you ever received information about hydrogen and fuel cell technologies? } \\
\hline Yes & 97 & 2.6 & 65.1 & 1.76 \\
\hline No & 48 & 2.6 & 32.2 & 1.77 \\
\hline Don't know & 4 & 1.0 & 2.68 & 0.66 \\
\hline Total for Q26 & 149 & 0.0 & 100 & 0.00 \\
\hline \multicolumn{5}{|c|}{ Q28A. Have you ever participated in a training class about hydrogen and fuel cell technologies? } \\
\hline Yes & 41 & 2.5 & 27.5 & 1.65 \\
\hline No & 108 & 2.5 & 72.5 & 1.65 \\
\hline Total for Q28A & 149 & 0.0 & 100 & 0.00 \\
\hline \multicolumn{5}{|c|}{ Q28B. Was the class useful? } \\
\hline Yes & 40 & 0.4 & 97.6 & 0.99 \\
\hline Don't know & 1 & 0.4 & 2.44 & 0.99 \\
\hline
\end{tabular}




\begin{tabular}{|c|c|c|c|c|}
\hline Question/Metric & Frequency & $\begin{array}{c}\text { Standard } \\
\text { Deviation } \\
\text { of Frequency }\end{array}$ & Percent & $\begin{array}{c}\text { Standard } \\
\text { Error of } \\
\text { Percent }\end{array}$ \\
\hline Total for Q28B & 41 & 0.0 & 100 & 0.00 \\
\hline \multicolumn{5}{|c|}{ Q29. Would you like to participate in a class on hydrogen or fuel cells? } \\
\hline Yes & 84 & 2.0 & 77.8 & 1.84 \\
\hline No & 21 & 1.9 & 19.4 & 1.76 \\
\hline Don't know & 3 & 0.8 & 2.78 & 0.78 \\
\hline Total for Q29 & 108 & 0.0 & 100 & 0.00 \\
\hline \multicolumn{5}{|c|}{ Q30. Which class format is most useful to you? } \\
\hline In-person class at a local facility & 42 & 2.1 & 50.0 & 2.52 \\
\hline $\begin{array}{l}\text { In-person class together with } \\
\text { conference }\end{array}$ & 20 & 1.9 & 23.8 & 2.24 \\
\hline Web-based class & 22 & 1.9 & 26.2 & 2.30 \\
\hline Total for Q30 & 84 & 0.0 & 100 & 0.00 \\
\hline \multicolumn{5}{|c|}{$\begin{array}{l}\text { Q31. Asked to review a request for a stationary fuel cell permit, would you have the information } \\
\text { to do so? }\end{array}$} \\
\hline Yes & 56 & 2.7 & 37.6 & 1.83 \\
\hline No & 91 & 2.7 & 61.1 & 1.84 \\
\hline Don't know & 2 & 0.7 & 1.34 & 0.48 \\
\hline Total for Q31 & 149 & 0.0 & 100 & 0.00 \\
\hline \multicolumn{5}{|c|}{$\begin{array}{l}\text { Q32. Asked to review a request for a stationary fuel cell permit, how would you feel about } \\
\text { conducting the review? }\end{array}$} \\
\hline Uneasy & 61 & 2.7 & 40.9 & 1.80 \\
\hline Curious & 49 & 2.7 & 32.9 & 1.83 \\
\hline Comfortable & 37 & 2.4 & 24.8 & 1.63 \\
\hline Don't know & 2 & 0.7 & 1.34 & 0.48 \\
\hline
\end{tabular}




\begin{tabular}{|c|c|c|c|c|}
\hline Question/Metric & Frequency & $\begin{array}{c}\text { Standard } \\
\text { Deviation } \\
\text { of Frequency }\end{array}$ & Percent & $\begin{array}{l}\text { Standard } \\
\text { Error of } \\
\text { Percent }\end{array}$ \\
\hline Total for Q32 & 149 & 0.0 & 100 & 0.00 \\
\hline \multicolumn{5}{|c|}{$\begin{array}{l}\text { Q33. Asked to review a request for a hydrogen fueling station permit, would you have the } \\
\text { information to do so? }\end{array}$} \\
\hline Yes & 61 & 2.8 & 40.9 & 1.88 \\
\hline No & 83 & 2.8 & 55.7 & 1.90 \\
\hline Don't know & 5 & 1.1 & 3.36 & 0.72 \\
\hline Total for Q33 & 149 & 0.0 & 100 & 0.00 \\
\hline \multicolumn{5}{|c|}{$\begin{array}{l}\text { Q34. Asked to review a request for a hydrogen fueling station permit, how would you feel about } \\
\text { conducting the review? }\end{array}$} \\
\hline Uneasy & 58 & 2.7 & 38.9 & 1.84 \\
\hline Curious & 50 & 2.7 & 33.6 & 1.84 \\
\hline Comfortable & 40 & 2.6 & 26.8 & 1.71 \\
\hline Don't know & 1 & 0.5 & 0.67 & 0.34 \\
\hline Total for Q34 & 149 & 0.0 & 100 & 0.00 \\
\hline \multicolumn{5}{|c|}{ Q351. Seek information from peers } \\
\hline No & 41 & 2.6 & 27.5 & 1.76 \\
\hline Yes & 108 & 2.6 & 72.5 & 1.76 \\
\hline Total for Q351 & 149 & 0.0 & 100 & 0.00 \\
\hline \multicolumn{5}{|c|}{ Q352. Seek information from federal government } \\
\hline No & 32 & 2.4 & 21.5 & 1.62 \\
\hline Yes & 117 & 2.4 & 78.5 & 1.62 \\
\hline Total for Q352 & 149 & 0.0 & 100 & 0.00 \\
\hline
\end{tabular}




\begin{tabular}{|c|c|c|c|c|}
\hline Question/Metric & Frequency & $\begin{array}{c}\text { Standard } \\
\text { Deviation } \\
\text { of Frequency }\end{array}$ & Percent & $\begin{array}{c}\text { Standard } \\
\text { Error of } \\
\text { Percent }\end{array}$ \\
\hline No & 31 & 2.4 & 20.8 & 1.59 \\
\hline Yes & 118 & 2.4 & 79.2 & 1.59 \\
\hline Total for Q353 & 149 & 0.0 & 100 & 0.00 \\
\hline \multicolumn{5}{|c|}{ Q354. Seek information from nonprofit organization } \\
\hline No & 67 & 2.9 & 45.0 & 1.96 \\
\hline Yes & 82 & 2.9 & 55.0 & 1.96 \\
\hline Total for Q354 & 149 & 0.0 & 100 & 0.00 \\
\hline \multicolumn{5}{|c|}{ Q355. Seek information from industry source } \\
\hline No & 11 & 1.5 & 7.38 & 1.04 \\
\hline Yes & 138 & 1.5 & 92.6 & 1.04 \\
\hline Total for Q355 & 149 & 0.0 & 100 & 0.00 \\
\hline \multicolumn{5}{|c|}{ Q356. Seek information from national organization } \\
\hline No & 13 & 1.7 & 8.72 & 1.11 \\
\hline Yes & 136 & 1.7 & 91.3 & 1.11 \\
\hline Total for Q356 & 149 & 0.0 & 100 & 0.00 \\
\hline \multicolumn{5}{|c|}{ Q357. Seek information from local agency's regulations } \\
\hline No & 34 & 2.4 & 22.8 & 1.62 \\
\hline Yes & 115 & 2.4 & 77.2 & 1.62 \\
\hline Total for Q357 & 149 & 0.0 & 100 & 0.00 \\
\hline \multicolumn{5}{|c|}{ Q358. Seek information--Don't know } \\
\hline No & 148 & 0.5 & 99.3 & 0.34 \\
\hline Yes & 1 & 0.5 & 0.67 & 0.34 \\
\hline
\end{tabular}




\begin{tabular}{|c|c|c|c|c|}
\hline Question/Metric & Frequency & $\begin{array}{c}\text { Standard } \\
\text { Deviation } \\
\text { of Frequency }\end{array}$ & Percent & $\begin{array}{c}\text { Standard } \\
\text { Error of } \\
\text { Percent }\end{array}$ \\
\hline Total for Q358 & 149 & 0.0 & 100 & 0.00 \\
\hline \multicolumn{5}{|l|}{ Safety } \\
\hline 1 & 55 & 2.8 & 37.2 & 1.89 \\
\hline 2 & 38 & 2.5 & 25.7 & 1.70 \\
\hline 3 & 26 & 2.2 & 17.6 & 1.49 \\
\hline 4 & 19 & 1.8 & 12.8 & 1.24 \\
\hline 5 & 10 & 1.3 & 6.76 & 0.86 \\
\hline Total for Safety & 148 & 0.0 & 100 & 0.00 \\
\hline \multicolumn{5}{|l|}{ Cost } \\
\hline 1 & 51 & 2.7 & 34.5 & 1.81 \\
\hline 2 & 40 & 2.6 & 27.0 & 1.73 \\
\hline 3 & 33 & 2.4 & 22.3 & 1.63 \\
\hline 4 & 16 & 1.9 & 10.8 & 1.25 \\
\hline 5 & 8 & 1.3 & 5.41 & 0.87 \\
\hline Total for Cost & 148 & 0.0 & 100 & 0.00 \\
\hline \multicolumn{5}{|l|}{ Environment } \\
\hline 1 & 11 & 1.5 & 7.43 & 1.01 \\
\hline 2 & 24 & 2.1 & 16.2 & 1.44 \\
\hline 3 & 19 & 2.0 & 12.8 & 1.34 \\
\hline 4 & 39 & 2.5 & 26.4 & 1.69 \\
\hline 5 & 55 & 2.8 & 37.2 & 1.90 \\
\hline Total for Environment & 148 & 0.0 & 100 & 0.00 \\
\hline
\end{tabular}




\begin{tabular}{|c|c|c|c|c|}
\hline Question/Metric & Frequency & $\begin{array}{c}\text { Standard } \\
\text { Deviation } \\
\text { of Frequency }\end{array}$ & Percent & $\begin{array}{c}\text { Standard } \\
\text { Error of } \\
\text { Percent }\end{array}$ \\
\hline 1 & 10 & 1.5 & 6.76 & 0.98 \\
\hline 2 & 17 & 1.9 & 11.5 & 1.28 \\
\hline 3 & 32 & 2.4 & 21.6 & 1.59 \\
\hline 4 & 41 & 2.6 & 27.7 & 1.78 \\
\hline 5 & 48 & 2.7 & 32.4 & 1.85 \\
\hline Total for Convenience & 148 & 0.0 & 100 & 0.00 \\
\hline \multicolumn{5}{|l|}{ Performance } \\
\hline 1 & 21 & 2.0 & 14.2 & 1.37 \\
\hline 2 & 29 & 2.3 & 19.6 & 1.58 \\
\hline 3 & 38 & 2.5 & 25.7 & 1.68 \\
\hline 4 & 33 & 2.4 & 22.3 & 1.65 \\
\hline 5 & 27 & 2.2 & 18.2 & 1.51 \\
\hline Total for Performance & 148 & 0.0 & 100 & 0.00 \\
\hline \multicolumn{5}{|l|}{ Partial } \\
\hline Complete & 148 & 0.4 & 99.3 & 0.27 \\
\hline Partial & 1 & 0.4 & 0.67 & 0.27 \\
\hline Total for Partial & 149 & 0.0 & 100 & 0.00 \\
\hline \multicolumn{5}{|l|}{ Safety $>$ Cost? } \\
\hline No & 75 & 2.9 & 50.3 & 1.92 \\
\hline Yes & 74 & 2.9 & 49.7 & 1.92 \\
\hline Total for Safety $>$ Cost? & 149 & 0.0 & 100 & 0.00 \\
\hline \multicolumn{5}{|l|}{ Safety > Environment? } \\
\hline No & 33 & 2.2 & 22.1 & 1.50 \\
\hline
\end{tabular}




\begin{tabular}{|c|c|c|c|c|}
\hline Question/Metric & Frequency & $\begin{array}{c}\text { Standard } \\
\text { Deviation } \\
\text { of Frequency }\end{array}$ & Percent & $\begin{array}{c}\text { Standard } \\
\text { Error of } \\
\text { Percent }\end{array}$ \\
\hline Yes & 116 & 2.2 & 77.9 & 1.50 \\
\hline Total for Safety > Environment? & 149 & 0.0 & 100 & 0.00 \\
\hline \multicolumn{5}{|l|}{ Safety $>$ Convenience? } \\
\hline No & 37 & 2.4 & 24.8 & 1.62 \\
\hline Yes & 112 & 2.4 & 75.2 & 1.62 \\
\hline Total for Safety > Convenience? & 149 & 0.0 & 100 & 0.00 \\
\hline \multicolumn{5}{|l|}{ Safety $>$ Performance? } \\
\hline No & 46 & 2.6 & 30.9 & 1.75 \\
\hline Yes & 103 & 2.6 & 69.1 & 1.75 \\
\hline Total for Safety > Performance? & 149 & 0.0 & 100 & 0.00 \\
\hline \multicolumn{5}{|l|}{ Cost $>$ Environment? } \\
\hline No & 34 & 2.5 & 22.8 & 1.66 \\
\hline Yes & 115 & 2.5 & 77.2 & 1.66 \\
\hline Total for Cost $>$ Environment? & 149 & 0.0 & 100 & 0.00 \\
\hline \multicolumn{5}{|l|}{ Cost $>$ Convenience? } \\
\hline No & 31 & 2.3 & 20.8 & 1.56 \\
\hline Yes & 118 & 2.3 & 79.2 & 1.56 \\
\hline Total for Cost $>$ Convenience? & 149 & 0.0 & 100 & 0.00 \\
\hline \multicolumn{5}{|l|}{ Cost $>$ Performance? } \\
\hline No & 50 & 2.8 & 33.6 & 1.85 \\
\hline Yes & 99 & 2.8 & 66.4 & 1.85 \\
\hline Total for Cost $>$ Performance? & 149 & 0.0 & 100 & 0.00 \\
\hline
\end{tabular}




\begin{tabular}{|c|c|c|c|c|}
\hline Question/Metric & Frequency & $\begin{array}{c}\text { Standard } \\
\text { Deviation } \\
\text { of Frequency }\end{array}$ & Percent & $\begin{array}{c}\text { Standard } \\
\text { Error of } \\
\text { Percent }\end{array}$ \\
\hline \multicolumn{5}{|c|}{ Environment $>$ Convenience? } \\
\hline No & 80 & 2.9 & 53.7 & 1.96 \\
\hline Yes & 69 & 2.9 & 46.3 & 1.96 \\
\hline $\begin{array}{l}\text { Total for Environment }> \\
\text { Convenience? }\end{array}$ & 149 & 0.0 & 100 & 0.00 \\
\hline \multicolumn{5}{|c|}{ Environment > Performance? } \\
\hline No & 90 & 2.9 & 60.4 & 1.92 \\
\hline Yes & 59 & 2.9 & 39.6 & 1.92 \\
\hline $\begin{array}{l}\text { Total for Environment }> \\
\text { Performance? }\end{array}$ & 149 & 0.0 & 100 & 0.00 \\
\hline \multicolumn{5}{|c|}{ Convenience $>$ Performance? } \\
\hline No & 98 & 2.8 & 65.8 & 1.86 \\
\hline Yes & 51 & 2.8 & 34.2 & 1.86 \\
\hline $\begin{array}{l}\text { Total for Convenience }> \\
\text { Performance? }\end{array}$ & 149 & 0.0 & 100 & 0.00 \\
\hline
\end{tabular}




\section{Safety and Codes Officials Survey Technical Question Summary}

\begin{tabular}{|c|c|c|c|c|}
\hline Question & $\begin{array}{l}\text { Number } \\
\text { of } \\
\text { Responses }\end{array}$ & $\begin{array}{l}\text { Percent } \\
\text { Correct }\end{array}$ & $\begin{array}{l}\text { Lower } \\
95 \% \\
\text { Confidence } \\
\text { Bound }\end{array}$ & $\begin{array}{l}\text { Upper } \\
95 \% \\
\text { Confidence } \\
\text { Bound }\end{array}$ \\
\hline 2A. Hydrogen gas is toxic (false) & 149 & 53.69 & 49.87 & 57.51 \\
\hline $\begin{array}{l}\text { 2B. Fuel cells produce electricity through hydrogen } \\
\text { combustion (false) }\end{array}$ & 149 & 20.13 & 17.06 & 23.21 \\
\hline 2C. Hydrogen is lighter than air (true) & 149 & 73.15 & 69.79 & 76.52 \\
\hline 2D. Hydrogen has a distinct odor (false) & 149 & 63.09 & 59.40 & 66.77 \\
\hline $\begin{array}{l}\text { 4. In which state or condition can hydrogen be stored? } \\
\text { (chemical compound, liquid) }\end{array}$ & 149 & 43.62 & 39.82 & 47.43 \\
\hline $\begin{array}{l}\text { 5. When using pure hydrogen, fuel cell vehicles } \\
\text { generate electricity, water, and what else? (heat) }\end{array}$ & 149 & 36.24 & 32.50 & 39.98 \\
\hline $\begin{array}{l}\text { 6. Hydrogen can be produced using which of the } \\
\text { following sources of energy? (natural gas, sunlight, } \\
\text { organic matter) }\end{array}$ & 149 & 48.32 & 44.51 & 52.14 \\
\hline $\begin{array}{l}\text { 9. Hydrogen is too dangerous for everyday use by the } \\
\text { general public? (false) }\end{array}$ & 149 & 73.83 & 70.48 & 77.17 \\
\hline Overall Average & 149 & 51.51 & 49.68 & 53.34 \\
\hline
\end{tabular}

Safety and Codes Officials Survey Summary of Importance Ranking

\begin{tabular}{|l|r|r|r|r|}
\hline Question & $\begin{array}{r}\text { Number } \\
\text { of }\end{array}$ & $\begin{array}{r}\text { Lower } \\
\text { Average } \\
\text { Rank }\end{array}$ & $\begin{array}{c}\text { Upper } \\
\text { Confidence } \\
\text { Bound }\end{array}$ & $\begin{array}{c}\text { 95\% } \\
\text { Confidence } \\
\text { Bound }\end{array}$ \\
\hline Safety & 148 & 2.26 & 2.17 & 2.35 \\
\hline Cost & 148 & 2.26 & 2.17 & 2.35 \\
\hline Environment & 148 & 3.70 & 3.59 & 3.80 \\
\hline Convenience & 148 & 3.68 & 3.58 & 3.77 \\
\hline Performance & 148 & 3.11 & 3.01 & 3.21 \\
\hline
\end{tabular}




\section{APPENDIX D NOTIFICATION LETTERS}

\section{D.1. STATE AND LOCAL GOVERNMENT AGENCIES \\ D.2. SAFETY AND CODES OFFICIALS}




\title{
D.1. STATE AND LOCAL GOVERNMENT AGENCIES
}

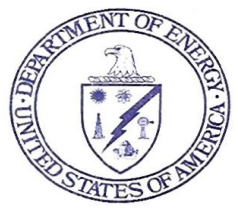

\author{
Department of Energy \\ Washington, DC 20585
}

«Title» «First_Name» «Last_Name»

«Company_Name»

«Address_Line_1»

«Address_Line_2»

«City», «State» «ZIP_Code»

Dear «Title» «Last_Name»:

In support of its efforts to educate key target audiences about hydrogen and fuel cells, the U.S.

Department of Energy (DOE) Hydrogen Program is conducting a survey to assess current levels of awareness of hydrogen and fuel cell technology and applications. Survey audiences include state and local government representatives, safety and code officials, potential end users, students, and the public. Data collected through the survey will inform and guide the development of DOE hydrogen education activities, as well as help to measure changes in knowledge over time. This survey effort follows a baseline survey conducted in 2004 (see www.hydrogenandfuelcells.energy.gov/hydrogen_publications.html for more information).

In the next few weeks, you, in your capacity as state agency representative, will be contacted by Opinion Research Corporation, an independent public opinion research firm located in Princeton, New Jersey, with a request for your input to the DOE survey. We encourage and appreciate your participation. The survey will be conducted over the phone and take approximately 10 minutes. Your responses are voluntary; however, every response is important. None of the responses will be associated with you or your office in any way, and the survey will be treated as confidential. There will be both knowledge and opinion questions; responses of "no opinion" or "don't know" are perfectly acceptable.

Notices of the surveys appeared in the Federal Register on November 17, 2006, and March 15, 2007. For more information about DOE's hydrogen and fuel cell activities, please visit www.hydrogenandfuelcells.energy.gov. If you have any questions, please contact Christy Cooper of my staff, at 202-586-1885 or Christy.Cooper@ee.doe.gov.

If you need to assign someone in your office to take the survey as the agency representative, please contact Janet Ulrich, Opinion Research Corporation, at 800-999-0213, ext. 5464 or by email at Janet.Ulrich@opinionresearch.com, and provide the name, title, and phone number of the person who will take the survey in your place. Thank you in advance for your participation in this extremely important effort.

Sincerely,

JoAnn Milliken

Program Manager

Hydrogen Knowledge and Opinions Surveys

D-2

April 21, 2010 
DOE Hydrogen Program

\title{
D.2. SAFETY AND CODES OFFICIALS
}

\author{
$<<$ Date $>>$ \\ «First_Name» «Last_Name», «Title» \\ «Company_Name» \\ «Address_Line_1» \\ «Address_Line_2» \\ «City», «State» «ZIP_Code» \\ Dear «First_Name» «Last_Name»:
}

In support of its efforts to educate key target audiences about hydrogen and fuel cells, the U.S.

Department of Energy (DOE) Hydrogen Program is conducting a survey to assess current levels of awareness of hydrogen and fuel cell technology and applications. Survey audiences include safety and code officials, state and local government representatives, potential end users, students, and the public. Data collected through the survey will inform and guide the development of DOE hydrogen education activities, as well as help to measure changes in knowledge over time. This survey effort follows a baseline survey conducted in 2004 (for more information, see http://www1.eere.energy.gov/hydrogenandfuelcells/hydrogen_publications.html\#h2 general).

In the next few weeks, you will be contacted by Opinion Research Corporation, an independent public opinion research firm located in Princeton, New Jersey, with a request for your input to the DOE survey. We encourage and appreciate your participation. The survey will be conducted over the phone and take approximately 10 minutes. Your responses are voluntary; however, every response is important. None of the responses will be associated with you or your office in any way. (Confidentiality of individual respondents will be maintained by deleting information identifying respondents and the organizations they work for, once each survey interview is completed.) There will be both knowledge and opinion questions; responses of "no opinion" or "don't know" are perfectly acceptable.

Notices of the surveys appeared in the Federal Register on January 3, 2008, and April 30, 2008. For more information about DOE's hydrogen and fuel cell activities, please visit http://hydrogen.energy.gov/. If you have any questions, please contact Andrea Chew of my staff, at 202-586-1145 or Andrea.Chew@ee.doe.gov.

If you need to assign someone in your office to take the survey as the agency representative, please contact Janet Ulrich, Opinion Research Corporation, at 800-999-0213, ext. 25464 or by email at SafetyCodeOfficialStudy@opinonresearch.com, and provide the name, title, and phone number of the person who will take the survey in your place. Thank you in advance for your participation in this extremely important effort.

Sincerely,

Sunita Satyapal

Acting Program Manager

DOE Hydrogen Program 


\section{APPENDIX E OUTCOME RATES}

E.1. GENERAL PUBLIC SURVEY OUTCOME RATES

E.2. STUDENT SURVEY OUTCOME RATES

E.3. STATE AND LOCAL GOVERNMENT SURVEY OUTCOME RATES

E.4. END USER SURVEY OUTCOME RATES

E.5. SAFETY AND CODES OFFICIALS SURVEY OUTCOME RATES 


\section{E.1. GENERAL PUBLIC SURVEY OUTCOME RATES}

The AAPOR RR3 response rate is estimated from the general public survey outcome frequencies in Table E.1.

\begin{tabular}{|c|c|}
\hline \multicolumn{2}{|c|}{ Table E.1. Outcome Frequencies for the General Public Survey } \\
\hline Outcome type & Frequency \\
\hline Complete interviews (I) & 1,000 \\
\hline Partial interviews $(\mathrm{P})$ & 5 \\
\hline Refusals and break offs (R) & 1,232 \\
\hline Non-contacts (NC) & 279 \\
\hline Other eligible, non-interviews $(\mathrm{O})^{*}$ & 1,048 \\
\hline Known eligible & 3,564 \\
\hline Unknown households (UH) & 2,819 \\
\hline Unknown others (UO) & 0 \\
\hline Eligibility unknown & 2,819 \\
\hline Known ineligible & 9,279 \\
\hline Total phone numbers used & 15,662 \\
\hline
\end{tabular}

The eligibility rate is estimated as

$$
\mathrm{e}=\text { Known eligible / (Known eligible }+ \text { Known ineligible). }
$$

This eligibility rate estimate e was applied to cases of unknown eligibility to estimate the number of those cases that were actually eligible. The AAPOR RR3 response rate is thus estimated as

$$
\text { Response rate }=\mathbf{I} /(\mathbf{I}+\mathbf{P}+\mathbf{R}+\mathrm{NC}+\mathbf{O}+\mathbf{e} \times(\mathbf{U H}+\mathbf{U O})) .
$$

For the general public survey

$$
\mathrm{e}=3,564 /(3,564+9,279)=.2775
$$

and the response rate estimate is

$$
1,000 /(1,000+5+1,232+279+1,048+.2775 \times(2,819+0))=.2301
$$




\section{E.2. STUDENT SURVEY OUTCOME RATES}

The AAPOR RR3 response rate is estimated from the student survey outcome frequencies in Table E.2.

\begin{tabular}{|c|c|}
\hline Outcome Type & Frequency \\
\hline Complete interviews (I) & 1,004 \\
\hline Partial interviews $(\mathrm{P})$ & 136 \\
\hline Refusals and break offs $(\mathrm{R})$ & 902 \\
\hline Non-contacts (NC) & 316 \\
\hline Other eligible, non-interviews $(\mathrm{O})^{*}$ & 0 \\
\hline Known eligible & 2,358 \\
\hline Unknown households (UH) & 51,021 \\
\hline Unknown others (UO) & 4,346 \\
\hline Eligibility unknown & 55,367 \\
\hline Known ineligible & 122,983 \\
\hline Total phone numbers used & 180,708 \\
\hline
\end{tabular}

The eligibility rate is estimated as

$$
\mathrm{e}=\text { Known eligible / (Known eligible }+ \text { Known ineligible). }
$$

The eligibility rate estimate e was applied to cases of unknown eligibility to estimate the number of those cases that were actually eligible. The AAPOR RR3 response rate was then estimated as

$$
\text { Response rate }=\mathbf{I} /(\mathbf{I}+\mathbf{P}+\mathbf{R}+\mathbf{N C}+\mathbf{O}+\mathbf{e} \times(\mathbf{U H}+\mathbf{U O})) .
$$

For the student survey

$$
\mathrm{e}=2,358 /(2,358+122,983)=.0188,
$$

and the response rate estimate is

$$
1,004 /(1,004+136+902+316+.0188 \times(51,021+4,346))=.2953
$$




\section{E.3. STATE AND LOCAL GOVERNMENT SURVEY OUTCOME RATES}

The survey of state and local government agencies differs from other survey components ${ }^{55}$ in that attempts were made to sample the entire target population. That is, an attempt was made to contact fifty SEOs, fifty state DOTs, fifty state DEPs, and the twelve largest cities and twelve largest counties in each of the four Census Regions. As Table E.3 shows, that attempt came fairly close to succeeding.

\begin{tabular}{|l|c|c|c|}
\hline \multicolumn{4}{|c|}{$\begin{array}{c}\text { Table E.3. Outcome Frequencies for the } \\
\text { State and Local Government Survey }\end{array}$} \\
\hline $\begin{array}{c}\text { Government } \\
\text { function }\end{array}$ & $\begin{array}{c}\text { Number } \\
\text { targeted }\end{array}$ & $\begin{array}{c}\text { Number } \\
\text { sampled }\end{array}$ & $\begin{array}{c}\text { Response } \\
\text { rate (\%) }\end{array}$ \\
\hline Cities & 48 & 40 & 83.3 \\
\hline Counties & 48 & 44 & 91.7 \\
\hline DEP & 50 & 42 & 84.0 \\
\hline DOT & 50 & 47 & 94.0 \\
\hline SEO & 50 & 47 & 94.0 \\
\hline Total & $\mathbf{2 4 6}$ & $\mathbf{2 2 0}$ & $\mathbf{8 9 . 4}$ \\
\hline
\end{tabular}

\section{E.4. END USER SURVEY OUTCOME RATES}

The AAPOR RR3 response rate is estimated from the End User Survey outcome frequencies in Table E.4. The eligibility rate can be estimated as

$$
\mathrm{e}=\text { Known eligible / (Known eligible }+ \text { Known ineligible). }
$$

The eligibility rate estimate e can be applied to cases of unknown eligibility to estimate the number of those cases that were actually eligible. The response rate can then be estimated (there are other ways) as

$$
\text { Response rate }=\mathbf{I} /(\mathbf{I}+\mathbf{P}+\mathbf{R}+\mathbf{N C}+\mathbf{O}+\mathbf{e} \times(\mathbf{U B}+\mathbf{U O})) .
$$

For the end user survey

$$
\mathrm{e}=617 /(617+360)=.6315
$$

and the response rate estimate is

$$
601 /(601+16+0+0+0+.6315 \times(1,140+3,479))=.1701
$$

\footnotetext{
${ }^{55}$ A similar process was used for the safety and code officials.
} 


\begin{tabular}{|c|c|}
\hline \multicolumn{2}{|c|}{ Table E.4. Outcome Frequencies for the End User Survey } \\
\hline Outcome Type & Frequency \\
\hline Complete interviews (I) & 601 \\
\hline Partial interviews $(\mathrm{P})$ & 16 \\
\hline Refusals and break offs (R) & 0 \\
\hline Non-contacts (NC) & 0 \\
\hline Other eligible, non-interviews $(\mathrm{O})^{*}$ & 0 \\
\hline Known eligible & 617 \\
\hline Unknown user (UH) & 1,140 \\
\hline Unknown other (UO) & 3,479 \\
\hline Eligibility unknown (non-contact) & 4,619 \\
\hline Quota Filled (QF)** & 290 \\
\hline Other known ineligible (UO) & 70 \\
\hline Known ineligible & 360 \\
\hline Total phone numbers used & 5,596 \\
\hline $\begin{array}{l}\text { *This category is a catchall for various kinds of eligible non-inte } \\
(2008 \text {, page } 45) \text { for a complete listing of outcome categories. } \\
\text { **After } 200 \text { respondents were obtained for any strata, further pot } \\
\text { that strata were regarded as ineligible. }\end{array}$ & $\begin{array}{l}\text { ws. See AAPOR } \\
\text { al respondents in }\end{array}$ \\
\hline
\end{tabular}

\section{E.5. SAFETY AND CODES OFFICIALS SURVEY OUTCOME RATES}

The survey of safety and codes officials targeted four different codes organizations - the IAFC, ICC, NASFM, and the NFPA. Table E.5 shows that the response rate for surveying these organizations was very high.

\begin{tabular}{|l|c|c|c|}
\hline \multicolumn{4}{|c|}{$\begin{array}{c}\text { Table E.5. Outcome Frequencies for the } \\
\text { Survey of Safety and Codes Officials }\end{array}$} \\
\hline Organization & $\begin{array}{c}\text { Number } \\
\text { targeted }\end{array}$ & $\begin{array}{c}\text { Number } \\
\text { sampled }\end{array}$ & $\begin{array}{c}\text { Response } \\
\text { rate (\%) }\end{array}$ \\
\hline IAFC & 50 & 36 & 72.0 \\
\hline ICC & 49 & 41 & 83.7 \\
\hline NASFM & 50 & 37 & 74.0 \\
\hline NFPA & 44 & 35 & 79.5 \\
\hline Total & 193 & 149 & 77.2 \\
\hline
\end{tabular}

